\title{
Forest Products,
}

Livelihoods and

\section{Conservation}

Case Studies of Non-Timber Forest Product Systems

VOLUME 2 - AFRICA

Editors

Terry Sunderland and Ousseynou Ndoye

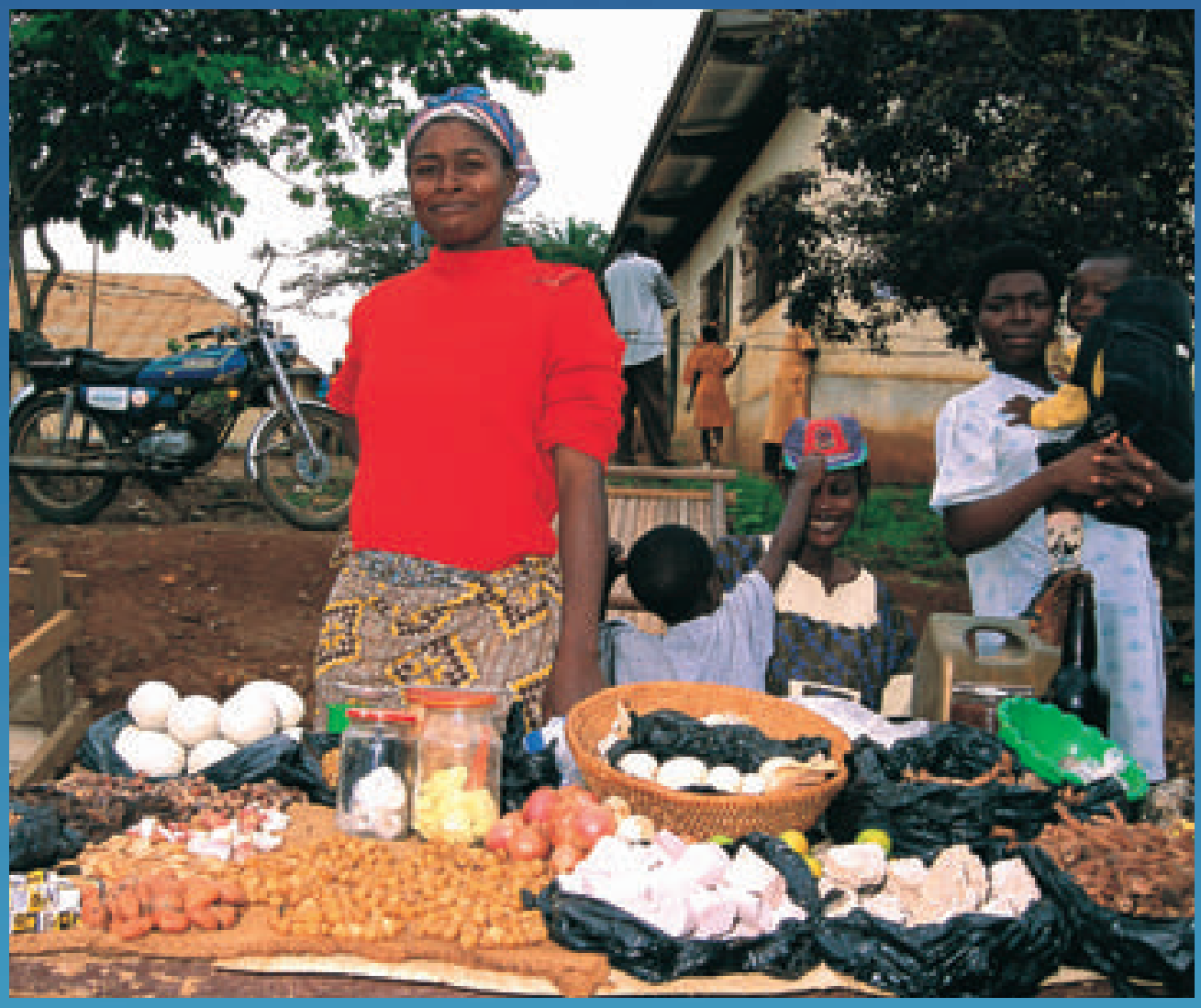




\section{Forest Products, Livelihoods and Conservation}

Case Studies of Non-Timber Forest Product Systems

VOLUME 2 - AFRICA

Editors

Terry Sunderland and Ousseynou Ndoye 
(c) 2004 by CIFOR

All rights reserved. Published in 2004

Printed by Indonesia Printer

Cover photo by Brian Belcher

ISBN 979-3361-25-5

ISBN 979-3361-23-9 (Volumes 1-3)

Copy-editing: Henning Pape-Santos

Illustrations: Iskak Syamsudin and Lucy Smith

Design: Gideon Suharyanto, Yoeli Setiawan and Eko Prianto

Maps: Andy Darmawan

National Library of Indonesia Cataloging-in-Publication Data

Forest Products, Livelihoods and Conservation. Case Studies of Non-Timber Forest Product Systems. Volume 2 - Africa / edited by Terry Sunderland and Ousseynou Ndoye

p.cm.

ISBN 979-3361-25-5

1. Non-timber forest products 2. Livelihoods 3. Conservation 4. Case studies

5. Africa

Published by

Center for International Forestry Research

Mailing address: P.O. Box 6596 JKPWB, Jakarta 10065, Indonesia

Office address: Jl. CIFOR, Situ Gede, Sindang Barang,

Bogor Barat 16680, Indonesia

Tel: $+62(251) 622622$

Fax: $+62(251) 622100$

E-mail: cifor@cgiar.org

Web site: http://www.cifor.cgiar.org 


\section{Contents}

Contributors vi

$\begin{array}{ll}\text { Acknowledgements } & \text { ix }\end{array}$

Foreword by His Excellency, Henri Djombo x

Foreword by J.E. Michael Arnold xii

Chapter 1

Commercialisation of non-timber forest products in Africa:

history, context and prospects

Terry C.H. Sunderland, Susan T. Harrison and Ousseynou Ndoye

\section{MEDICINAL, HYGIENE AND COSMETIC PLANTS}

\section{Chapter 2}

Dental hygiene and livelihoods: a case of chewing sticks in Ghana

Dominic Blay

\section{Chapter 3}

'Chop, but no broke pot': the case of Prunus africana on

Mount Cameroon

Nouhou Ndam and Mahop Tonye Marcelin

\section{Chapter 4}

Achieving a fair and sustainable trade in devil's claw (Harpagophytum spp.)

Rachel Wynberg

\section{Chapter 5}

The informal trade of Cassipourea flanaganii

as a cosmetic in South Africa 


\section{FRUITS AND OILS}

\section{Chapter 6}

The contribution of shea butter (Vitellaria paradoxa C.F. Gaertner) to local livelihoods in Benin

Kathrin Schreckenberg

\section{Chapter 7}

A case study of Garcinia kola nut production-to-consumption system in J4 area of Omo forest reserve, South-west Nigeria Atilade Akanmu Adebisi

\section{Chapter 8}

Potential for development and conservation of Dacryodes edulis in Sakpoba Forest Reserve, Edo State, in the Niger Delta area of Nigeria

Hassan Gbadebo Adewusi

\section{WOODCARVING AND WOOD PRODUCTS}

\section{Chapter 9}

The woodcarving industry in Kenya

Simon Kosgei Choge

\section{Chapter 10}

Carved wooden drums and trade in Mpigi district, Uganda

Patrick Omeja, Joseph Obua and Anthony B. Cunningham

\section{Chapter 11}

Trading forest products in South-Eastern Zimbabwe: ecology, economics and politics of woodcarving Wavell Standa-Gunda and Oliver Braedt

\section{Chapter 12}

The Pterocarpus angolensis DC. based woodcraft industry in the Bushbuckridge district, South Africa

Sheona E. Shackleton and Charlie M. Shackleton

\section{Chapter 13}

Fuelwood in the Maroua area of the Far North Province 


\section{FIBRES AND WEAVING MATERIALS}

\section{Chapter 14}

Palm utilisation for basketry in Xini Ward, Sengwe communal areas, Zimbabwe

Phosiso Sola

\section{Chapter 15}

The rattan industry in the Ashanti and western regions of Ghana

Charles Adu-Anning

\section{Chapter 16}

The rattan sector of Rio Muni, Equatorial Guinea

\section{Chapter 17}

Rattan exploitation in the Yaoundé Region of Cameroon

Louis Defo

\section{ANIMAL PRODUCTS}

\section{Chapter 18}

Sport hunting of elephant in Zimbabwe: a case study of Kanyurira Ward in Guruve district

Dale Doré and Ivan Bond 


\section{Contributors}

\author{
Atilade Akanmu Adebisi \\ CENRAD \\ P.M.B. 5052 \\ 5 Akinola Maja Street \\ Jericho Hills, Ibadan \\ Nigeria \\ E-mail: cenrad@mail.skannet.com; \\ cenrad@ibadan.skannet.com

\section{Hassan Gbadebo Adewusi} \\ Department of Forest Resources \\ Management \\ University of Ibadan \\ Nigeria \\ E-mail: ajilete@hotmail.com

\section{Charles Adu-Anning} \\ Department of Agroforestry \\ Institute of Renewable Natural \\ Resources \\ Kwame Nkrumah University of \\ Science and Technology \\ Kumasi \\ Ghana \\ E-mail: canning@forig.org; \\ canning_01@yahoo.com
}

\section{Michael B. Balinga}

African Rattan Research Programme

c/o Limbe Botanic Garden

P.O. Box 437, Limbe

Cameroon

E-mail: mpbalinga@yahoo.fr

\section{Dominic Blay}

Forestry Research Institute of Ghana University Box 63, Kumasi

Ghana

E-mail: dblay@forig.org

\section{Ivan Bond}

World Wide Fund for Nature

(Southern Africa Region

Programme Office)

Almond Tree Cottage

Long Wittenham Road

North Moreton, Nr Didcot

Oxon OX11 9AZ

United Kingdom

E-mail:

leebee@atcottage.freeserve.co.uk

\section{Oliver Braedt}

Federal Research Centre for

Forestry and Forest Products (BFH)

Leuschnerstrasse 91

D-21031, Hamburg

Germany

E-mail: braedt@holz.uni-hamburg.de

\section{Simon Kosgei Choge}

Kenya Forestry Research Institute

PO. Box 20412, Nairobi

Kenya

E-mail: skchoge2002@yahoo.com;

kefri@arcc.or.ke 
Michelle Cocks

Institute of Social \& Economic

Research, Rhodes University

P.O. Box 94, Grahamstown 6140

South Africa

E-mail: M.Cocks@ru.ac.za

Anthony B. Cunningham

People and Plants Initiative

84 Watkins Street

White Gum Valley, Fremantle

Australia

E-mail: peopleplants@bigpond.com

\section{Louis Defo}

University of Leiden, WOTRO Ph.D

fellowship programme

P.O. Box 8297 Yaounde

Cameroon

E-mail: defotls@yahoo.fr

Mercy A. Dione

University of Buea

SW Province

Cameroon

\section{Tony Dold}

Selmar Schonland Herbarium

Rhodes University

P.O. Box 94, Grahamstown 6140

South Africa

E-mail: T.Dold@ru.ac.za

Dale Doré

SHANDUKO: Centre for Agrarian and

Environmental Research

195 Fife Avenue, Harare

Zimbabwe

E-mail: daledore@zol.co.zw

\section{Susan Tarka Harrison}

Department of Botany

Natural History Museum, London

Cromwell Road

London SW7 5BD

United Kingdom

E-mail: tarkaharrison@yahoo.com
Tata Precillia ljang

Ministry of Scientific and Technical

Research in Cameroon

Institute of Agricultural Research

for Development, Dschang

c/o Presbyterian Church Dschang

P.O.Box 353 Dschang

Cameroon

E-mail: ijang2001@yahoo.fr

Nouhou Ndam

Limbe Botanic Garden

P.O. Box 437, Limbe

Cameroon

E-mail: Lbg@bifunde.com;

Lbgmcp@camnet.cm

Ousseynou Ndoye

CIFOR Cameroon

c/ o IITA Humid Forest Station

B.P. 2008, Yaounde

Cameroon

E-mail: o.ndoye@cgiar.org

Joseph Obua

Department of Forest Biology and

Ecosystems Management

Faculty of Forestry and Nature

Conservation, Makerere University

P.O.Box 7062, Kampala

Uganda

E-mail: obua@forest.mak.ac.ug

\section{Patrick Omeja}

Faculty of Forestry \& Nature

Conservation

Makeree University

PO. Box 7062, Kampala

Uganda

E-mail: omejap@hotmail.com

\section{Kathrin Schreckenberg}

Forest Policy and Environment

Group, Overseas Development

Institute (ODI)

111 Westminster Bridge Road

London SE1 7JD

United Kingdom

E-mail: k.schreckenberg@odi.org.uk 
viii

Charlie M. Shackleton

Environmental Science Department

Rhodes University

Grahamstown, 6140

South Africa

E-mail: c.shackleton@ru.ac.za

Sheona Elizabeth Shackleton

Environmental Science Department

Rhodes University

Grahamstown 6140

South Africa

E-mail: s.shackleton@ru.ac.za

\section{Phosiso Sola}

SAFIRE

10 Lawson Ave, Milton Park

Box BE 398 Belverdere, Harare

Zimbabwe

E-mail: afpc2a@bangor.ac.uk;

sola@safire.co.zW

\section{Wavell Standa Gunda}

Center for International Forestry

Research

Regional Office for Eastern \&

Southern Africa

73 Harare Drive

Mt. Pleasant, Harare

Zimbabwe

E-mail: w.standa@cgiar.org

Terry C.H. Sunderland

African Rattan Research Programme

c/o Limbe Botanic Garden

P.O. Box 437, Limbe

Cameroon

E-mail: afrirattan@aol.com;

TCHSunderland@aol.com
Mahop Tonye Marcelin

PhD student Queen Mary College

University of London

E-mail: tonyemah@yahoo.com

\section{Rachel Wynberg}

Graduate School of Environmental

Studies

University of Strathclyde

P.O. Box 83, Kalk Bay 7990

South Africa

E-mail: rachel@iafrica.com 


\section{Acknowledgements}

We express our thanks to all people who contributed to the content and production of this book, including: Manuel Ruiz-Pérez, Brian Belcher, Bruce Campbell, Julius Tieguhong Chupezi, Laurie Clark, James Acworth, Tony Cunningham, Ramadhani Achdiawan, Koen Kusters, Jeff Sayer, Eyebe Antoine, Citlalli Lopez, Mike Arnold, Titin Suhartini and Munoh Florence. We thank Michelle Cocks and Sheona Shackleton for organising a regional workshop. The work was supported by the UK Department for International Development (DFID) and CIFOR core funding. 


\title{
Foreword
}

\author{
His Excellency, Henri Djombo \\ Minister of Forest Economy \\ and the Environment of the Republic of Congo \\ President of the Conference of Ministers in Charge of Forests of \\ Central Africa (COMIFAC)
}

Several authors have highlighted the importance of Non-Timber Forest Products (NTFPs) in the livelihoods of forest dwellers in Africa. These products, namely fruits, nuts, leaves, barks, cane and bushmeat in particular, have been used for centuries as food and medication by African forest dwellers.

The collection and sale of NTFPs is mainly the activity of poor populations and small traders. As a result, any action aimed at developing the NTFP sector will contribute to poverty alleviation in the same way as it does to the development of the agricultural sector.

The economic crisis of the 1980s in Africa, which resulted in the decline in the profitability of cocoa and coffee production on the international market, prompted the majority of farmers to diversify their sources of income by collecting and selling NTFPs in order to minimize the risks related to agriculture. The economic potential of NTFPs for poverty alleviation is very high compared to traditional cash crops such as coffee and cocoa. Research by the Center for International Forestry Research (CIFOR) has shown that the prices of certain NTFPs could compete with those of cocoa and coffee.

The lack of harmonization of the methodological approaches used in the past did not allow for a comparison of the case studies carried out on NTFPs in various parts of the continent and between Africa and other continents. CIFOR took an unprecedented step by initiating the project on World Comparison of NTFPs, financed by DFID. This project is based on 61 case studies, including 17 in Africa. The lessons learnt from the project were very beneficial to the researchers involved, and put their case studies in a global perspective. It is certain that in Africa, researchers who work on NTFPs do so in isolation. This does not enable them to exchange or learn from other researchers in the same field. The CIFOR project allowed various researchers 
involved to interact for the first time, especially during workshops organized on each continent, and through the web sites created for this purpose.

There is no doubt that this volume, which is devoted to Africa, will help in guiding investments and decision making on NTFPs in the continent for years to come. This volume highlights the important role of NTFPs in the well being of millions of Africans, and it is also the basis of a plea to African governments to work together towards securing the access and property rights of populations. It also indicates the need to improve the performance of markets with a view to intensifying and diversifying viable local economies that have strong bases in national and regional networks. This will contribute to the emergence of a situation where forest resources will be preserved and the livelihoods of populations will be improved (a win-win situation). In my opinion, this intensification and diversification would be attainable in a sustainable way if the domestication of NTFPs were carried out at the same time and on a large scale, thus allowing rural communities to integrate trees into their farming systems.

The publication of this volume is very timely as COMIFAC, CEFDHAC and other sub-regional organizations plan to organize important meetings in 2004. 


\title{
Foreword
}

\author{
J.E. Michael Arnold
}

Products other than timber and other industrial roundwood have always constituted a large part of the forest economy in developing countries. Individual products provide inputs and income directly to huge numbers of rural and urban households. In many countries the aggregate of non-timber forest products (NTFPs) contributes as much, if not more, to national product as industrial roundwood. However, their designation as 'minor' forest products reflects their relative neglect until quite recently. Produced and consumed largely outside the monetary economy, they attracted only limited attention and even less in the way of measurement and research.

The recent increase in interest in NTFPs has been a consequence of a number of shifts in developmental focus. With the evolution in thinking about the importance of rural development and poverty alleviation has come growing interest in how forests and forest products contribute to households' food and livelihood security. Within this framework forest product activities have begun to attract particular attention as being often one of the larger income-generating components of the non-farm part of the rural economy. In recent years this interest has been reinforced by shifts in development policy and strategy towards more market driven activity within this part of the economy.

At the same time, concerns that development activities be consistent with environmental integrity, and not prejudice the future potential of forest and land resources, have highlighted arguments that managing them for NTFPs might be less environmentally damaging than alternative uses of forests. In addition, the policy shifts that encourage devolution of control and management away from central governments to local institutions have drawn more attention to NTFPs as a potentially important incentive to local forest management.

However, the state of knowledge about these aspects of NTFP activities has not kept pace with this emerging and evolving perception of their 
increased importance. Though quite a lot is known about the characteristics of many individual products, much less is known about their commercial performance and developmental linkages. Consequently, we are still at a quite early stage in the process of establishing general patterns of NTFP activity that could help us understand the factors that determine the circumstances in which they are or are not likely to be commercially successful and appropriate.

This knowledge is so rudimentary not only because of the low priority attached to NTFPs in the past, but also because of the complexities of researching and understanding such a highly diverse group of products, produced in such a wide range of different ecological and socioeconomic situations. Some are generated within predominantly subsistence livelihood systems, in order to generate the limited amounts of cash income needed to fill seasonal gaps or tide households over hard times. Others form part of livelihoods that are integrated into the market economy, and can form important and growing sources of household income and improvement. Many NTFPs are goods that fall out of use as incomes rise, or that can no longer compete when more efficiently produced alternatives become available in their markets. Others, in contrast, face expanding markets and generate attractive returns. Consequently greater exposure to market forces may disrupt or even overwhelm some NTFP trades, while offering new or expanded opportunities for others. It is therefore important to understand more precisely the factors that shape such possibilities and threats, in order to be able to identify what types of intervention might encourage the one, or help avert or alleviate the other.

There are also different scenarios to be considered on the supply side. Some NTFPs are extracted from existing 'wild' resources, others are produced from forest resources under some form of management, while still others are outputs of cultivated tree resources within a predominantly agricultural environment. Issues that we may need to know more about include how different forms of management relate to the different roles particular NTFPs play in the associated livelihood and socioeconomic system; the extent to which different NTFP production systems conform to conservation objectives and concerns; and the capacity of existing governance mechanisms to effect desired outcomes.

These three volumes represent one output from a substantial pioneering exercise designed to help fill some of these gaps in our present knowledge base. The study set out to determine what patterns of interaction between factors such as those mentioned above can be discerned from existing information, based on comparative analysis across a substantial number of different products in different situations in Africa, Asia and Latin America. This is not a random, or necessarily representative, sample of case studies. Their choice reflects the availability of the needed information, but the selection covers a wide range of product, circumstance and situation.

The analysis of information provided by this body of work has shown that important patterns can be identified. These are summarised in the introduction chapter of Volume 1. Each volume complements this comparative 
xiv

analysis by providing a descriptive account of each case study that was contributed from a particular geographical region, prepared by the researchers involved. Together they provide a wealth of information about individual NTFPs and the situations in which they are being produced and traded, and indicate the extent of the research base drawn upon in the course of this important exercise. It is to be hoped that it will provide a starting point for further research and analysis to continue the process of improving understanding of the potentials for NTFP activities to contribute successfully to livelihood enhancement and sustainable forest use. 


\title{
Chapter 1
}

\section{Commercialisation of non-timber forest products in Africa: history, context and prospects}

\author{
Terry C.H. Sunderland, Susan T. Harrison \\ and Ousseynou Ndoye
}

\section{INTRODUCTION}

Since the 1970s, non-timber forest products (NTFPs) have emerged to take their place among the many aspects of forest use that guide natural resource decision-makers. In the early 1990s, NTFPs were mooted as a potential alternative to deforestation and land conversion activities (Falconer 1990; Plotkin and Famolare 1992). Some NTFPs have strong market value and it was postulated that the long-term value accruing from the harvest of these products could override the short-term gain of converting that forest or individual trees to other uses such as timber, agriculture, or plantations (Peters et al. 1989; Godoy and Bawa 1993). The attention of both the conservation and the social development communities was captured, and it was put forward that through the harvest of NTFPs, the often marginalised forest peoples of the world might capture valuable income and social benefits, whilst the aim of conserving of natural forests was achieved. If this were indeed the case, then the development and formalisation of the NTFP sector could at once meet the often-contradictory goals of development and conservation.

This optimism, however, was based on exaggerated claims of economic potential which were often over-simplistic assessments of 'value' (Southgate et al. 1996) and a limited evaluation of the complexity of economic, social and market oriented issues surrounding the NTFP category (Lawrence 2003). The advocating of increased commercialisation of forest products for rural livelihoods has also been questioned, and it is argued that many households barely cover the opportunity costs of collection, even for high-value forest products (Southgate et al. 1996) with the majority of the income accruing to those who transform the product or local élites who control the market (Dove 1993).

Despite these concerns NTFPs can form an integral part in conservation and development strategies (Ogle 1996), but this can only be undertaken with the full knowledge of a range of interlinked issues and requiring a multidisciplinary approach which incorporates social, economic, cultural, ecological and policy 
contexts, so often missing in integrated conservation and development projects (Lawrence 2003). To date, and despite massive investment in the NTFP sector, a number of basic conceptual issues remain unresolved in order to better position NTFPs within conservation and development strategies (Ruiz-Pérez and Arnold 1996; Arnold and Ruiz-Pérez 1998).

To that end the Centre for International Forestry Research (CIFOR) developed the project 'Assessment of the potential for non-timber forest products-based development', which is an attempt to address this problem and to improve our understanding of NTFP systems through a comparative and formal analysis of a wide range of case studies of forest product development (Ruiz-Pérez and Byron 1999; Belcher and Ruiz-Pérez 2001). A standardised set of descriptors was developed to capture the key ecological, technological, socio-economic and institutional aspects of forest resource production, processing and trade.

The goal of this NTFP Case Comparison project is to:

- Create typologies of cases

- Identify conditions associated with particular kinds of development and conservation

- Develop and test hypotheses about forest product development

Collaborators from 27 countries, representing 47 institutions in Africa, Asia and Latin America were identified and recruited, contributing a total of 62 case studies to the analysis. The criteria for selecting individual cases included:

- That the forest product has demonstrably significant commercial and trade value (i.e. it is traded in the cash economy)

- That the production, processing and marketing system has been subject to prior research, with data available on at least $70 \%$ of the variables

- The presence of an individual or team of researchers willing to collect additional data to complete the case study documentation and to participate in the comparative analysis

- The need to include an adequate representation of a wide range of cases

This chapter discusses the multidimensional issues surrounding NTFPs in Africa through a summary of the 17 cases undertaken by researchers across the continent as part of the Case Comparison project, which are presented in this book. The subsequent chapters are grouped according to the end use of the particular NTFP: (i) medicinal, hygiene and cosmetic plants; (ii) fruits and oils; (iii) woodcarving and wood products; (iv) fibres and weaving products; and (v) animal products. The location of each case is presented in Figure 1. The most important characteristics of each case are presented in Table 1.

\section{Background to the Case Comparison project in Africa}

Seventeen case studies were performed in 10 different African countries on NTFPs with a range of production, processing and marketing characteristics. Each of the 17 NTFPs chosen has been commercially traded for at least half a century or, in the case of chewsticks (Garcinia spp.) and shea butter (Vittelaria paradoxa), for hundreds of years, and each product reveals strong annual sales figures, often in the US\$ millions. 
The life forms represented by the case studies are as follows. Twelve are trees (including one arboreal palm), three are climbing palms (rattans), one is a perennial herb and the last is an animal (elephant) product. With only one exception (Dacryodes edulis) the majority of the cases originate in the wild or are managed in a wild situation (Vitellaria paradoxa and, in certain instances, Garcinia kola).

However, as in Latin America (Alexiades and Shanley 2004) and Asia (Belcher and Kusters 2004), the availability of comprehensive information on high-value NTFPs in Africa is somewhat scanty and selection of the cases was undoubtedly subject to bias, particularly product-oriented and geographical. It is clear that often more information is available for widely commercialised species and this disparity may have led to bias on the selection of the product type. For example, six of the case studies presented are of wood products-four of woodcarving and one each of chewing sticks and fuelwood-meaning that over one third of the NTFPs cases presented rely on the felling and removal of the entire individual as in timber exploitation. In this instance, this selection may imply that the perceived NTFP paradigm of 'sustainable harvest' is not necessarily represented by these cases and the destructive harvesting techniques employed are probably not wholly representative of the African NTFP sector, which focuses on a much wider range of products than those that are wood-based.

In addition, geographical bias is evident in the selection of the cases presented in this volume, since over $80 \%$ of the studies originated from central, southern and eastern Africa. Undoubtedly this reflects the long history of forest and woodland resource research and the advanced nature of our knowledge of the forestry sector within each region. Despite this bias, with the inclusion of a number of varied products from a wider geographic range, the 17 cases present a diversity of products, management practices and trade regimes that are relatively representative of the African NTFP sector.

Devil's claw (Harpagophytum sp.) highlights quality control and cultivation in relation to NTFPs, particularly for medicinal use where strict regulatory measures are increasingly imposed for exported devil's claw roots. The Sengwe palm (Hyphaene petersiana) was chosen because of its long history of use and coordination of studies completed on the palm use in the basket trade since 1993. While scarcity of NTFPs is not prevalent in all our case studies, it is of major concern for resources such as chewsticks in Ghana (Garcinia spp.) and Pterocarpus angolensis, which are facing scarcity issues. Prunus africana, which is internationally recognised by the Convention on the International Trade in Endangered Species of Flora and Fauna as an endangered species because of overexploitation, is probably the most endangered species in this study.

\section{THE HISTORICAL TRADE OF NTFPS IN AFRICA}

Trade patterns are historically deep rooted in Africa and have heavily influenced the economic development of the continent. The conquest of North Africa by Arab peoples in the seventh century led to the development of many trade links (Townson 1992). These included the extensive trade routes across the Sahara and those along the East African coast, where the seasonal shifts in monsoon winds determined the movement of small sailing vessels that carried people 


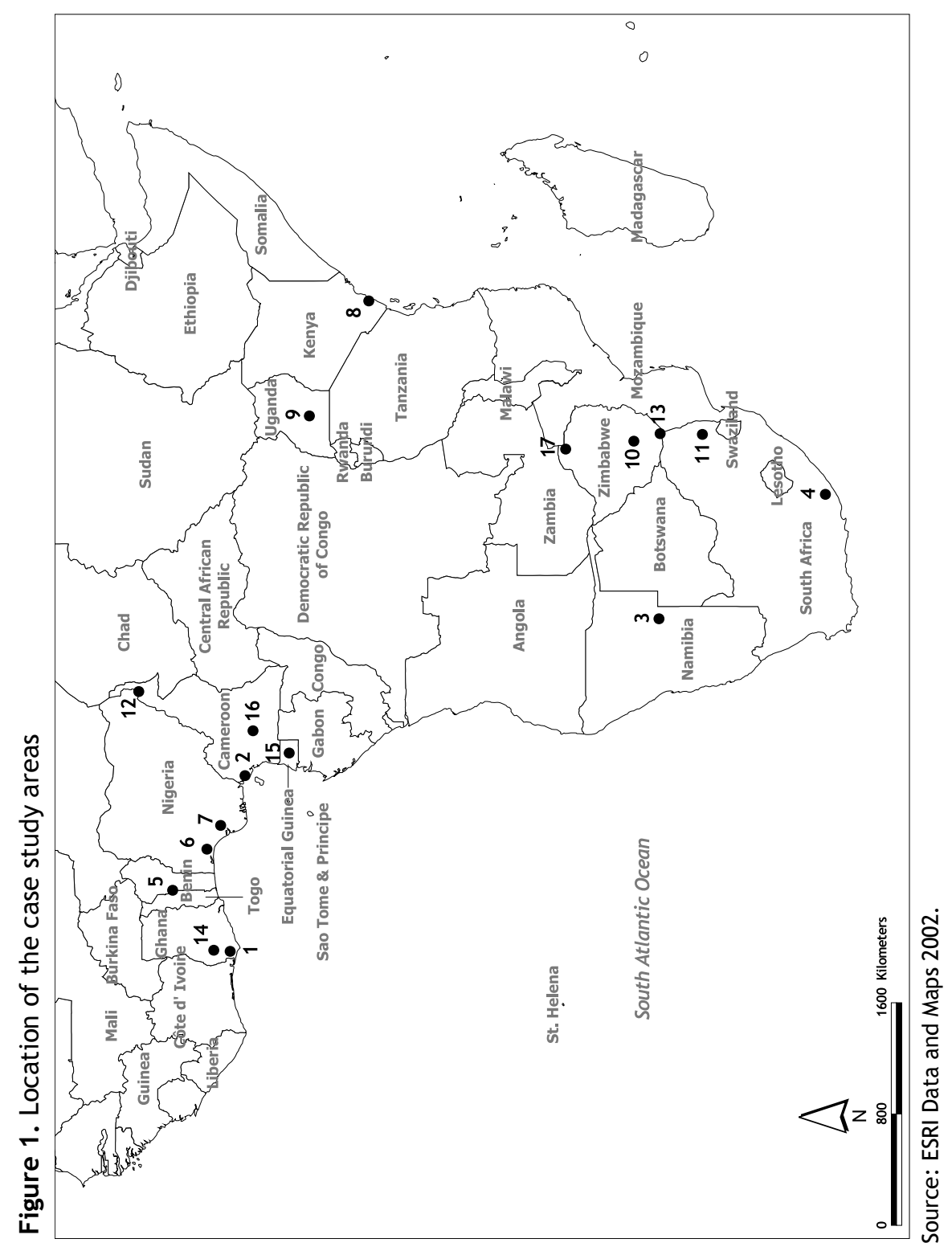




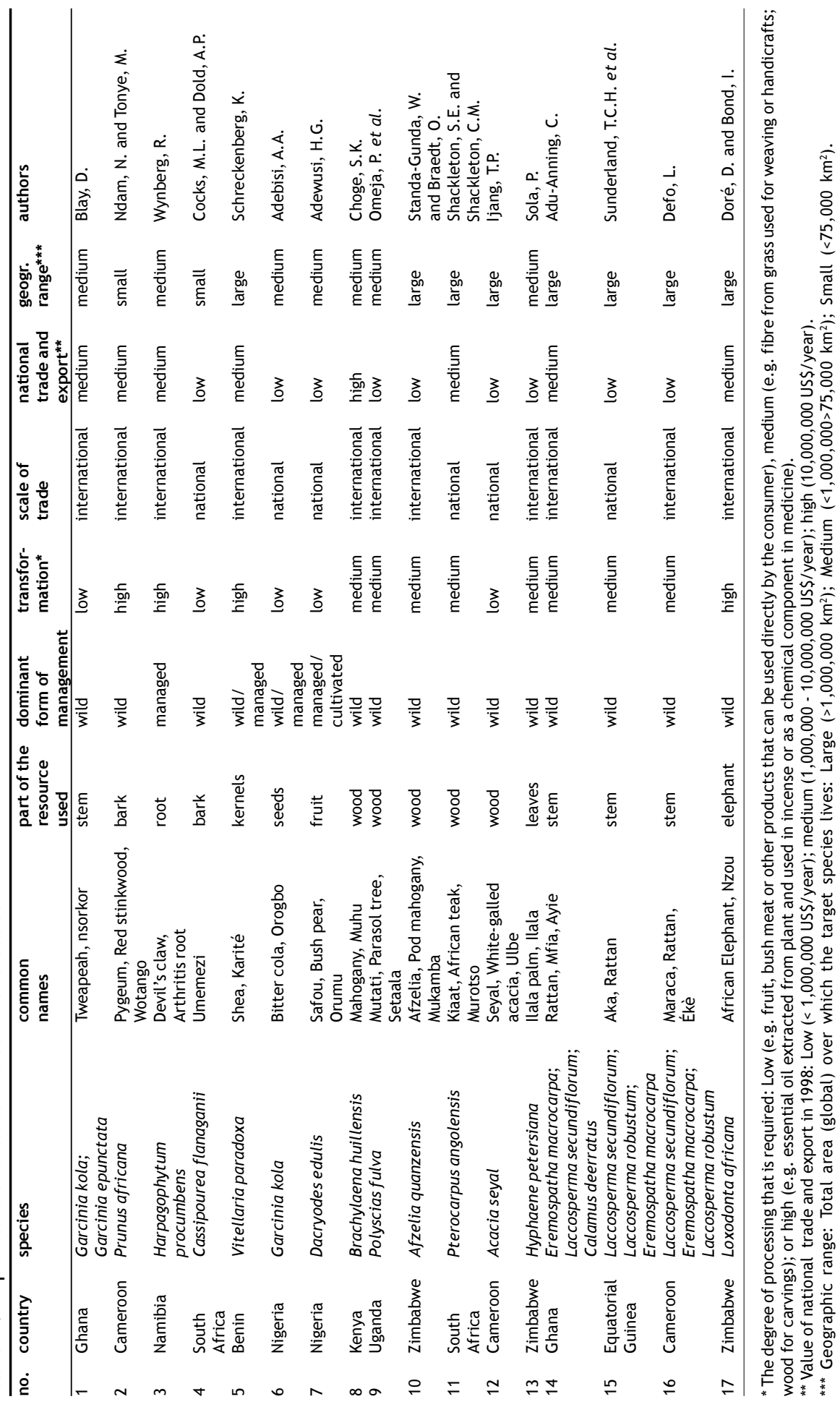


and trade goods to and from the Persian Gulf, the Indian subcontinent and South East Asia (lliffe, 1995).

During this period, a number of high-value products were transported from the forested regions of sub-Saharan Africa for consumption and sale in North Africa, Europe and the Persian Gulf region. For example, aside from palm oil and ivory, pepper (Piper guineense) and kola nuts (Cola acuminata and C. nitida) in particular were traded extensively from the Guinea and Akan (Ghana) forests to the sub-Saharan Sudanic belt (Oliver 1999). Shea butter (Vitellaria paradoxa) was also an important commodity traded from the region since the fourteenth century (Chapter 6 ). In the early mediaeval period, another forest product, melegueta pepper or 'grains of paradise' (Aframomum sp.) began to be transported to Europe for use as a spice and condiment (van Harten 1967). Its recorded use in Europe as early as 1214, long before direct European trade, is testament to the influence and extent of these trans-Saharan and Arabian trade routes (ibid.).

During the sixteenth and seventeenth centuries, Europeans began to explore the African coastlines, both east and west and, aside from their involvement in the lucrative slave trade, realised there was also considerable potential for further 'legitimate' trade (Isichei 1997). An extensive network of trading stations was established at strategic points along the coast, and iron goods, cloth and weapons were transported from Europe and exchanged for spices and condiments, palm oil and ivory (Oliver 1999).

The established trading stations provided steppingstones to colonial expansion and many European powers used their trading influence to annex considerable areas of land during the 'scramble for Africa' from 1870 to 1910 (Packenham 1991; Iliffe 1995). The colonial period was characterised by the trade of non-timber plant resources such as tea, coffee, cocoa and rubber between the continents (Hobhouse 1999), the commercialisation of which led to the conversion of large tracts of forest lands to plantation agriculture, particularly in the humid tropics, where they have become important contributors to many countries' GDP today.

A number of indigenous forest products became increasingly important during the colonial period and these included rattan cane from West and Central Africa being exported to Europe and other colonies for furniture manufacture (Hédin 1929) along with large quantities of shea butter (Vitellaria paradoxa) for the production of margarine and candles (Chapter 6). This latter product became so valuable, that it became a principal component in the agroforestry parklands of Benin described in Chapter 6. In addition, prior to the supply of Brazil rubber (Hevea brasiliensis) from plantations, wild sources of rubber for tyre manufacture were highly valued and the exploitation of native African rubber (Funtumia elastica) from the Congo Free State led to a brutal and exploitative policy of enforced collection for the brief period the activity was economically viable (Hochschild 1998).

More recently, high-value international markets for a number of NTFPs have developed from migrations of people from Africa, such as in areas of Western Europe and North America which have dense, often prosperous, African populations. These people are prepared to pay a premium for genuine African products, often paying up to $500 \%$ more than the local sales price (Clark and 
Sunderland in press). Such high-value resources include chewsticks (Garcinia spp.) (Chapter 2 ) and a wide range of other products, particularly spices, condiments and foodstuffs (Tabuna 1999), including bush plum (Dacryodes edulis) (Chapter 8). In addition to the supply of NTFPs to the African diaspora in the West, a corresponding increase in tourism to the African continent over the past 20 years has led to increased demand for art and craft items, particularly baskets and woodcarvings-hence the relative importance of the woodcarving and weaving industries as presented in this volume (Chapters $9,10,11,12,13,14,15,16$ and 17). At the upper end of this tourist market, safari hunting based on the premise that local communities share the proceeds of the industry has led to the conservation of the wild elephant resource in Zimbabwe (Chapter 18). In addition, the formalisation of the herbal and cosmetic markets has led to a massive increase in the trade volumes of products such as pygeum (Prunus africana) (Chapter 3 ) and devil's claw (Harpagophytum app.) (Chapter 4), together worth some US\$320 million annually.

\section{ECOLOGICAL ISSUES}

\section{Is NTFP harvest sustainable?}

In many respects, and depending on the plant part harvested, the exploitation of wild-sourced NTFPs can be sustainable. However, this requires an understanding of the plant's growth and reproductive characteristics and the application of harvesting practices that permit adequate reproduction or regeneration of the individual organism. Unfortunately even this basic information is woefully incomplete for most taxa. As is evident in nearly all of the case studies presented in this book, growing demand will ultimately intensify the pressure on wild populations. As with any wild plant or animal, if harvesting and mortality exceed annual production, the resource will progressively be depleted and become locally extinct (Cunningham 2000). When the value of an NTFP and the intensity of exploitation are low, human impacts on that species are likely to be minimal. When the value of an NTFP and the intensity of its use are extremely high, however, it is likely that the resource is being overexploited and supplies may become exhausted. For endemic taxa, or those with a limited geographical range, this has serious consequences for the species itself (Cunningham 1999). This is particularly the case with pygeum (Prunus africana), which is restricted to montane forest 'islands' across Africa and Madagascar (Chapter 3 ) and umemezi (Cassipourea flanaganii) which is endemic to the Eastern Cape (Chapter 5). In addition, species that are slowgrowing, such as the ilala palm (Hyphaene petersiana) in southern Africa (Chapter 14) or take many years to become reproductively mature, such as the elephant (Chapter 18) and shea (Vitellaria paradoxa) (Chapter 6), are also more susceptible to population decline when overharvested.

In the majority of cases presented in this book it is important to recognise that threats to wild populations of NTFP species predominantly stem from overharvesting pressures and the lack of effective management of the individual NTFP populations, rather than the loss of habitat through logging or conversion to agriculture or accompanying burning ${ }^{1}$. In fact, logging and other forest 
disturbances (for example, shifting and mixed agriculture) are not necessarily inimical to NTFP production (Laird 1999). Some NTFPs are found in primary forests, but many, particularly rattan canes, respond extremely well to disturbance and are a common component of secondary forest regrowth (Chapters 15, 16 and 17).

Peters (1994) asserts that harvesting seeds and fruits only adds to what is normally high seed mortality and may not adversely impact plant regeneration ${ }^{2}$. The 'fruits and oils' case studies presented in this book support this theory (Chapters 6, 7 and 8). NTFPs prized for their wood, roots or bark, however, are particularly prone to unsustainable use as harvesting either seriously damages or kills the parent plant. For example, the harvesting practices that partially or wholly strip bark from live trees such as pygeum (Prunus africana) and umemezi (Cassipourea flanaganii) expose them to ring-barking and exposure to stemboring insects that can result in considerable postharvest tree mortality (Chapters 3 and 5). Likewise the use of wood products for carving, chewsticks or fuelwood also results in the immediate death of the individual organism (Chapters 2, 9, 10, 11, 12 and 13), as does the sport hunting of elephant (Chapter 18).

\section{Responses to scarcity}

As discussed above, higher demand increases pressure on the resource and as resources become depleted three main strategies are employed to militate against shortfalls in supply: (i) to travel further to find supplies, (ii) simply to substitute the particular forest product with a similar product or (iii) to develop more intensive or cultivated sources of supply (Cunningham 2000).

Increased harvesting range. A typical first response to resource scarcity is to increase the harvest range (Cunningham 2000). For example, in all of the rattan case studies presented in this book, it is reported that the first response to scarcity is to travel further into the forest to find adequate supplies of cane to feed the rural and urban markets (Chapters 15, 16 and 17). However, it is commonly found that local harvesters do not factor in the increased opportunity costs of the additional labour needed to collect these resources from a greater distance and that the "payment received by households [for NTFPs] barely covers the opportunity cost of labour employed in harvesting' (Southgate et al. 1996: 1). As the demand for rattan products continues to grow in West and Central Africa, this response will undoubtedly lead to further scarcity and local extirpation ${ }^{3}$.

Substitution. In a number of instances, when a preferred species becomes scarce, a similar product is utilised in its place. For example, in the case of chewsticks in Ghana, the preferred Garcinia species, G. kola and G. epunctata, are often replaced with other, less desirable chewstick species (Chapter 2). The same occurs in the case of woodcarving, where indigenous species that have become overexploited are being replaced with fast-growing indigenous or, latterly, exotic species, particularly to supply the thriving Kenyan and Zimbabwean woodcarving industries (Chapters 9 and 10). Indeed, substitution of Pterocarpus angolensis with appropriate exotic species is being advocated to militate against the increasing overexploitation of this resource (Chapter 12).

Intensification: is cultivation the answer? Unlike the NTFP resource base in Latin America (Alexiades and Shanley 2004) or Asia (Belcher and Kusters 2004), 
the majority of NTFPs in Africa are predominantly wild-sourced. This is further illustrated by the case studies presented in this book, in that only one species, Dacryodes edulis, is actually 'domesticated' ${ }^{4}$ in the true sense and is widely cultivated in compound gardens throughout Central Africa (Chapter 8). Although shea (Vitellaria paradoxa) occurs on agroforestry parklands in Benin, where it is retained within agricultural systems along with other utilitarian species, it is not intensively planted (Chapter 6). Despite the current lack of intensification in the African NTFP sector, many of the case studies presented in this book advocate the encouraging of cultivation to militate against the increasing overharvesting of these products (Chapters 2, 3, 4, 5, 7, 9, 15 and 17). This is often a secondary response to overharvesting (Cunningham 2000). Indeed Homma (1992) suggests that increased demand of a product leads to increased harvest from the wild resulting in the loss of economic viability of the wild resource and encouraging the process of domestication. It appears, however, that the socio-economic and marketing conditions prevalent in the African natural resource sector discourage the transition from wild harvesting to the provision of cultivated sources of supply for a number of reasons elaborated on later in this chapter.

Better management of the wild resource? Without doubt the best prospects for the sustainability of many wild resources are to develop sustainable harvesting regimes grounded in good ecological science coupled with holistic forest management systems compatible with the notion of 'extractivism' (Boot and Gullison 1995). For example, Peters (1994) outlines the necessary six components for the 'sustainable exploitation' of commercially traded NTFPs:

- Species selection

- Forest inventory

- Yield studies

- Regeneration surveys

- Harvest regime assessments

- Harvest adjustments

This model stresses the importance of a constant flow of information about the ecological response of a species to varying degrees of exploitation and that without continuous adjustment sustainable harvesting fluctuates (Peters 1994). The investment in basic research needed to implement such a regime, however, is often too great to be economically rewarding and, as can be seen from the cases presented in this book, such basic knowledge is often missing or incomplete. This is the case not just in the African context but is also prevalent for species that have been harvested and traded commercially for hundreds of years such as Brazil nut (Boot and Gullison 1995). In short, huge investment in long-term ecological research is required to develop sustainable harvesting models of high-value NTFPs from wild populations; research that is notoriously 'unsexy' to donors. This situation, coupled with the need for integrated community-based monitoring systems (Cunningham 2000), examples of which are few and far between, suggests that such a model is almost impossible to implement. 


\section{SOCIO-ECONOMIC ISSUES}

\section{Household strategies}

During the wider analysis of the Case Comparison project, Belcher et al. (2003) identified a typology of livelihood strategies for NTFPs and noted clear differences among the three continents in the reliance on forest products by rural and urban households and the importance of such products to them. In our case studies from Africa, the majority of the products (14 out of 17) contribute less than $50 \%$ to household incomes and in nine cases, less than $25 \%$. In only three cases did the particular NTFP contribute significantly (more than $70 \%$ ) to the household incomes. Nevertheless, in many cases this contribution to household income is particularly important at times of economic need, such as the payment of school fees (Chapters 16 and 17), or provides seasonal income when agricultural labour needs are low, particularly in the rainy season (Chapters 7 and 8 ). There are then stark contrasts in the case studies outlined in this book in that some NTFPs are used predominantly at the subsistence level while others are highly integrated into the cash economy. For example, cases characterised by a 'coping strategy' (that is, integration into the cash economy of less than $50 \%$ ) are predominantly preoccupied with other agricultural or other natural resource-based activities. Forest products are extracted predominantly from the wild, often in unmanaged, open-access situations; together with agricultural products they provide the main access to the cash economy. These products also provide an important economic safety net through product diversification, and in the context of Homma's model (Homma 1992) these products represent the 'expansion phase' of NTFP economic development.

The three 'specialised' cases are characterised by the respective products providing the greatest contribution to the household economy in the context of a relatively high integration to the cash economy. It is unsurprising that these cases focus on the predominantly urban production of craft materials such as wood carvings (Chapter 12) and rattan baskets and furniture (Chapter 16) and also on the fabrication of specialized hygiene products with a large, well-organised market, such as chewsticks (Chapter 2). However, in light of our case studies, these specialised cases seem to be more of an exception to the rule, and the NTFP sector in Africa is characterised by the prevalence of 'coping strategies'.

Interestingly examples of the 'diversified strategies' identified by Belcher et al. (2003) are rare in the African context, as evidenced by the case studies presented here. This may be due to the predominant lack of product intensification of NTFPs on the continent through cultivation or domestication or the relatively low value of wild harvested NTFPs in comparison to other income generating activities such as agriculture.

\section{Tenure issues and product intensification}

Sustainable NTFP management or forest conservation plans will need to begin with a clear understanding of local land and resource tenure and access rights. For example, research conducted in Cameroon concludes that even for 
economically valuable NTFPs few management techniques are applied under traditional harvest practices (Malleson 1999; van den Berg et al. 2001). The case studies in this book serve to emphasize this situation. Overlapping layers of class, education, elite and statutory 'rights' overlying basic traditional tenure systems will affect how innovations and management options are implemented, and together these relationships will play a direct role in management successes or failures.

In many of the case studies described in this book the lack of management regimes is precipitated by the fact that the resources are considered 'openaccess', for which there is no customary control on harvesting. Destructive harvesting techniques that increase as market pressure begins to build are often a direct result of situations where property rights are poorly defined or not at all (Dove 1993). Similarly, such insecure tenure discourages the investment in intensification through cultivation and this is particularly characteristic of the African NTFP sector, which is heavily reliant on wildsourced forest products. It has been argued that even if the open-access problems that lead to destructive harvesting were resolved, increases in the value of NTFPs might not benefit the conservation of tropical forests or the livelihoods of their inhabitants (Southgate et al. 1996). The reason given for this partly historical observation is that as an extractive commodity becomes scarce, cultivation outside the natural ecosystem has been a characteristic response. However, often such intensification efforts exclude the original resource users with the majority of resultant profits accruing to local élites or commercial concerns (Dove 1993). In addition, removal of an economically valuable product from the forest economy reduces the value of the standing forest leading to more lucrative, often destructive land-use alternatives (Homma 1992). This situation is particularly highlighted by the devil's claw (Harpagophytum spp.) case study where Rachel Wynberg articulately describes the inequity caused by intensification:

'[With the issue of cultivation] two trends are worth noting. First, there is a high level of competition among projects, evidenced by a complete shroud of secrecy (often formalised through confidentiality provisions in contracts), an astonishing absence of collaboration and a distinct lack of published information about the technical aspects of the disparate projects. A second and related trend concerns the increasing involvement of the pharmaceutical industry and private sector in sponsoring and initiating cultivation projects, a development that reflects the vested interests of the industry to secure long-term supplies of the drug and to ensure a high quality product. With a few notable exceptions this is associated with the virtual exclusion of local research institutions from participation in the technical work required and negligible involvement of rural communities in the establishment and ongoing maintenance of projects. Instead, most cultivation initiatives to date draw upon foreign scientists and are located on the lands of commercial white 
farmers in South Africa or Namibia. In all likelihood these patterns do not reflect any technical constraints associated with the difficulties of cultivation, but rather a preference on the part of industry to follow paths of greatest ease.' (Chapter 4)

The HIV/AIDS pandemic has had an enormous impact on the workforce. This is particularly the case in southern Africa where the highest global instance of infection exists; one in five adults is HIV positive and 4.2 million new cases are reported per year. While the instance of infection is decreasing in some countries, such as Uganda, there is a notable increase in others, such as Kenya (Kiai et al. 2002). While health issues were not discussed in great detail in our Case Comparison studies, the great loss of life in Africa has had a strong effect on land tenure and reform issues. This is particularly relevant to land transfer problems facing survivors, especially orphans and single mothers struggling for supplemental income generation for survival.

\section{Gender issues}

The gender differentiation surrounding NTFPs in Africa is particularly interesting and the case studies presented in this book highlight the increasingly important role of forest products in rural livelihoods, particularly for women. Although some industries are entirely male dominated, for example woodcarving (Chapters 9, 10, 11 and 12), rattan furniture production (Chapters 15, 16 and 17), bark harvesting of Prunus africana (Chapter 3 ) and sport hunting of elephant (Chapter 18), women play a dominant role in the marketing and final sale of many products. For example, $85 \%$ of the chewstick trade in Ghana is coordinated by women who organise themselves in a hierarchical trading system (Chapter 2). This level of organisation among female traders of forest products and foodstuffs, often led by market 'Queens', is a common occurrence in the large urban markets of Ghana (Clark 1994). The harvest and sale of fruits and nuts also seems to be a predominantly female economic activity as indicated by the studies of Garcinia kola (Chapter 7), Dacryodes edulis (Chapter 8) and shea (Vitellaria paradoxa), with the trade of this latter product being controlled exclusively by women (Chapter 6). The elderly population is also very much involved with shea, which is seen as a relatively 'simple' activity for them to manage.

Likewise, the local collection and sale of fuelwood in Cameroon is also dominated by women, often assisted by adolescent children (Chapter 13). Interestingly in the last case presented, the involvement of men in fuelwood collection has been to the detriment of the resource; women are more involved with collecting fallen branches and otherwise naturally dry material, whereas the involvement of male harvesters has precipitated significant felling of individual trees which are left to dry before being split and traded. Another male-female dichotomy is also described in the case of umemezi (Cassipourea flanaganii) where, although over $80 \%$ of the harvest and trade is undertaken by women, the few male traders are those that are willing to travel further to sell the bark and hence accrue the greatest revenues from the trade (Chapter 5). 


\section{Equity issues}

Issues of NTFP commercialisation undoubtedly underpin issues of equitable distribution of benefits (Neumann and Hirsch 2000). Browder (1992) draws on available research from the Amazon and suggests that collecting NTFPs does not necessarily greatly benefit rural livelihoods and that the living standards of households that rely on forest products compare poorly with even the meager socio-economic norms of the rural Amazon. Southgate et al. (1996) suggest that, even for highly commercialized products, the greatest share of the profits is normally realised at the processing level, that is, at the top of the domestic marketing trade. This is a view also shared by Dove (1993: 18), who suggests that 'The more successful the [resource] development, the more likely it is that external political and economic forces will become involved, and the less likely it is that local people will be able to retain control.'

In this same vein, a number of the case studies presented in this book exhibit clear and characteristic issues of inequity in the distribution of benefits, particularly for rural harvesters. Most notably, these instances often occur with high-value products that undergo moderate to high levels of transformation and are sold in international markets. The tangible lack of benefits for most NTFP producers seems particularly to affect those involved in the sector as a coping strategy, as discussed above. In contrast, households involved in NTFPs as a specialized strategy attain the greatest level of benefits as they are often involved in both the production and transformation aspects of the system.

Another issue regarding equity is benefit sharing, which is specified in the Convention on Biological Diversity (CBD Article 1) as 'the fair and equitable sharing of the benefits arising out of the utilisation of genetic resources, including by appropriate access to genetic resources and by appropriate transfer of relevant technologies, taking into account all rights over those resources and to technologies, and by appropriate funding' (Glowka et al. 1994: 15).

This is particularly relevant to medicinal plants for pharmaceutical research and drug discovery and incorporates technology transfer as a component to supply benefits back to local people who supply extractable resources. This issue is particularly relevant for devil's claw (Harpagophytum spp.), a traditional medicinal plant that now forms the basis of a US\$100 million per year industry in which the benefits accrue almost entirely to the processing and transformation actors along the marketing chain while a very low proportion of the international trade value benefits the domestic producers. Since the commercialisation of the product resulted from ethnobotanical studies, it represents a classic example of 'biopiracy'.

\section{Cultural issues}

NTFPs are valued not only for their market value; cultural, social and spiritual attributes also add to the value of the products. Though not easily quantified, these characteristics may in some cases be as important to people as the economic value (Davidson-Hunt et al. 2001), an issue that is often overlooked. This is particularly germane to the case comparison studies where the products have been traded for decades. For example, one researcher noted under 'study limitations' the way to 'meet a chief is to introduce yourself with a gift of at 
least 10 cola nuts. These procedures were followed so as to gain the villager's cooperation and to be seen as showing respect'. This ended up facilitating discussions with the villagers as to the kind of research being conducted (Gakou and Force no date).

The case study of devil's claw (Harpagophytum spp.) in Namibia (Chapter 4) describes how the harvesting methodology of these medicinal roots has contributed to Africa's long 'story' of persecution of ethnic groups, particularly the Omakeke San, the primary harvesters. Even though it is pointed out that there are no anthropological studies in relation to the trade of devil's claw, groups such as the Omakeke San have a complex history tied closely to the sociopolitical structure in Namibia. Postindependence resettlement placed them on government-owned farms with other ethnic groups in an area that is one of the most arid and marginal for agricultural production. Facing limited options for work, the Omakeke San are not unlike the people of neighbouring countries where extreme poverty and lack of education define the harvesting of devil's claw as a 'low status' activity. A similar situation exists for chewing sticks in Ghana, where harvesting is labeled a 'menial' activity (Chapter 2).

Further discussed in Chapter 14 is the link between cultural practice and commercialisation: cultural tradition controls the Sengwe (Hyphaene petersiana) harvesting in Zimbabwe, which begins with a 'kraal head has its own designated tapping fields and so the leaf harvesting areas. The chiefs, working through headmen, have overall control of palm utilisation. To date they have managed to stop the transportation and sale of unprocessed palm leaves. So far, the impact of traditional rules has been generally positive as it has resulted in the palm being conserved whilst everyone in the designated area has access to the palm for leaf harvesting'.

\section{MARKET AND TRADE ISSUES}

\section{Trade perspective and history}

The chapters of this volume show the importance of NTFP markets and their role in improving the livelihoods of farmers and traders involved in commercialisation of these products. Like other agricultural commodities, NTFP markets follow the law of supply and demand. The supply of NTFPs is a function of the amount of product harvested as well as the quantity stored. because of the seasonal nature of NTFP production, storage becomes important to insure availability throughout the year. The demand for NTFPs is a function of the quantities buyers are willing and able to purchase, which depends on the amount of capital they have at their disposal and the signal of scarcity in local, national, regional and international markets (Ndoye et al. 1997).

One feature that NTFP markets in Africa have is that they are thin, meaning that a small change in production (supply) has a large effect on the quantity marketed (Ndoye et al. 1999). This changes the role of the markets in assembling and distributing forest products from year to year. For example, the past five years have statistically shown a three- to sixfold increase in the amount of devil's claw (Harpagophytum sp.) traded (Chapter 4). While local trade of this product is centuries old, the international trade history dates 
back just 50 years when Western pharmaceutical companies took interest in the product for medicinal research and pharmaceutical profit.

Local markets for NTFPs. Local markets contribute to the well-being of rural households by enabling farmers to sell their forest products. In these markets, the process of price setting between harvester (farmer or seller) and trader (buyer) involves bargaining (haggling) to reach an equilibrium price somewhere between the lowest price the seller is willing to accept and the highest price the buyer is willing to pay (Ndoye et al. 1997). Haggling is common in African markets and is highlighted in Chapters 9, 12 and 15. Accessibility of and proximity to the markets are important variables that affect farmers' willingness to market their forest products (Chapters 8 and 12). Local markets are affected by many inefficiencies caused by regulatory enforcement officials (police, gendarmerie, forestry officials, municipal authorities), which increase transaction costs. This is particularly the case for rattan (Chapters 14, 15, 16 and 17). One immediate consequence of such practices is the increase of the level of extraction or harvest to meet these costs. Woodcarvers in South Africa face particular difficulties when dealing with regional trade for crafts as opposed to more locally consumed furniture (Chapters 9, 10, 11 and 12).

Adding value. Because there are many players involved in adding value from harvest to market, trade data is often fragmented and unavailable for the entire process as monitoring and seasonality are inconsistent. In the case study of woodcarvings from Pterocarpus angolensis, Shackleton and Shackleton conclude that specialized market studies are needed to further the understanding of this century-old trade (Chapter 12). Urban markets involve migration and people who bring their rural cultural preferences and uses of NTFPs with them.

What is often overlooked in the value chain is the role of intermediaries: (1) intermediary traders who buy from primary producers and sell to larger volume traders, processors, exporters or retailers; (2) export processing services, which facilitate links between producers and commercial buyers and (3) intermediary marketing organisations, which identify market linkages between producers and appropriate buyers and are paid a commission for each deal facilitated (Belcher and Schreckenberg unpublished draft).

Postharvesting handling of NTFPs is vital to product marketability. Consistent storage and transportation, however, are unpredictable in Africa where infrastructure continues to be weak in most areas. This issue could be particularly detrimental in relation to medical plants, which on the open market demand a high level of quality control. Another related issue is scale-up. With demand fluctuating and issues such as fad or niche markets in the U.S. and elsewhere, technical issues such as product scale-up are difficult to judge. This is significant for large internationally marketed products such as shea which is processed in a variety of ways (Chapter 6).

Regional and international markets. Many authors have highlighted the importance of international trade in NTFPs in West and Central Africa, both between neighbouring countries and with countries outside Africa (Falconer 1990; Tabuna 1999). Several reasons explain this importance. 
(a) Eco-physiological: The production of some NTFPs is highly seasonal. For example, Dacryodes edulis production is from June to November in countries like Cameroon and Nigeria and from November to April in Angola, Congo, Democratic Republic of Congo and Gabon. This seasonal variation through the region stimulates trade among countries.

(b) Linguistic and cultural: It is common to find close ethnic groups living on both sides of a given frontier, consuming similar products and with significant trade among them (Ruiz-Pérez et al. 2000).

(c) Migration patterns: Many countries in Europe and North America have important communities of migrants from Africa. For example, NTFPs such as Dacryodes edulis, Gnetum spp., Ricinodendron heudelotii and Irvingia spp. are found in shops specializing in tropical products in Brussels, Lisbon, London and Paris (Tabuna 1999).

(d) Trade value and volume: The majority of NTFPs treated in this volume $(65 \%)$ are traded in international markets. The value of trade is medium (US\$1 million to US\$10 million per year) for $41 \%$ of the cases. Only one NTFP, Bachylaena huillensis, used in woodcarving in Kenya, has a high value of trade (more than US\$10 million per year). Shea butter is intricately linked to other large-scale NTFP exports such as cocoa and cashews. As pricing fluctuates for one market, the other follows suit or acts as a substitute. However, export figures vary from company, government and agency (FAO) statistics-for shea from 7,870 tonnes to 13,000 tonnes of kernels in just one year (Chapter 6).

\section{Trade Organisation and Development}

Fair trade. 'Fair Trade' organisations promote 'eco-harvested' products with an emphasis on rainforest products (Shanley et al. 2002). Fair trade organisations work with producer co-operatives that use democratic principles to ensure that working conditions are safe and dignified and that producers have a say in how their products are created and sold. Co-operatives are encouraged to provide benefits such as health care, child care and access to loans. They encourage producers to reinvest their profits into their communities (www.fairtrade.org).

Fair trade initiatives are hindered, however, by a number of social and institutional constraints. At the local level, these include a lack of tenure security, insufficient monitoring capacity, poor business and management skills and low levels of organisation. Inadequate quality and resource management also present major hurdles. At the international level, monopoly control severely compromises the ability of local producers and range states to receive optimum benefits and prevents range states from adding full value to their resources. Cultivation efforts represent a further threat to ensuring a reliable stream of benefits for harvesting communities.

Some fair trade organisations work to shift processing and packaging activities to the developing world, so that as much work as possible will remain in the producer country. Often, such activities are performed abroad, depriving 
the neediest countries of the opportunity to boost their incomes. With concepts such as these being adopted into practice in an equitable manner, solutions are possible (www.fairtrade.org). Again, Dove (1993) points out the need to recognise that this is not often the case where plantation and NTFP enterprise 'owners' are the most likely to gain. Likewise on the consumer side: 'The responsible consumer is only slightly more enlightened; they are willing to make their contribution, but they are naive about the many complex issues' (Wilkins 1999).

The Fair Trade Federation 2003 report (www.fairtrade.org) details a 37\% increase in North America and the Pacific Rim for fair trade products. Sales reached US\$250 million. However, most trade continues to be skewed to international trade agreements, such as the North American Free Trade Agreement and the General Agreement on Tariffs and Trade, which reduce barriers to trade and investment for firms. As a result, the gap between producers (the poor) and investors (the rich in the 'north') continues to widen. In addition, it must be remembered that consumers are often more interested in protecting ecosystems, not necessarily the people who live in them (Clay 1993). Therefore, it is up to in-country managers to promote fair trade issues and justify the reason behind the subsequent increase in price.

Impact of commercialisation. The income obtained from the sale of NTFPs enables farmers to meet their basic needs and those of their families (purchase of medicinal products, kerosene, soap and clothes; construction of houses; payment of dowry and school fees) (Chapters 3, 12, 13 and 17). The income farmers get from selling NTFPs enables them to finance other lucrative activities such as purchase of pesticide for cocoa plantation (Chapter 17). Income received from the sale of NTFPs can also help rural communities invest in water and electrification projects. This is particularly so in the case of Prunus africana in Cameroon (Chapter 3).

Training producers to commercialise their products, as in the case of the Sengwe palm in South Africa, is assisting them by researching the sales opportunities in distant markets. In addition, training is provided to analyse and capitalise on market trends. Yet again, without a sustainable supply and equitable benefit sharing of Sengwe or the many other NTFPs analysed here and elsewhere, the marketability declines (Chapter 14). In order to improve the market position of NTFPs, one must analyse the commodity 'value chain' in much greater detail. Several strategies can be used to increase returns, such as vertical integration (e.g. packaging), improved quality and efficiency, horizontal integration (e.g. co-operation with other small enterprises) and targeted marketing (Belcher 1998).

\section{POLICY AND DEVELOPMENT}

The global Case Comparison project provides useful examples of success stories, and failures, in relation to NTFPs. There are many government agencies working closely with non-governmental agencies such as CIFOR in organising a vision for NTFPs. Because of variability in NTFPs from wild harvested species such as devil's claw (Chapter 4 ) to field and fallow parkland harvested species such as shea butter (Chapter 6), it is difficult to assess where government policies can 
assist local producers in the form of organisation, sustainable harvesting strategies and forestry reserves support. Clearly, a synergy must exist for a product to move from harvesting into the commercial sector and continue to provide a sustainable yield, economic benefits, and a low ecological impact. But is lumping NTFPs into the forestry sector, in itself, adequate protection?

An example of a foreign ministry working well with other governmental agencies is an extensive study underway in Zimbabwe for which CIFOR has teamed up with the U.S. Agency for International Development's CAMPFIRE programme to study the impacts of the wood carving industry. A potential answer to its success is likely the incorporation of local people in the decision process recognising the potential negative impact on the forest as a resource for production of wood carvings (www.cifor.cigiar.org). The Shackleton and Shackleton study on woodcarving observed that organisation of local producers was a key constraint in the analysis (Chapter 12). Poor business and organisational skills could be issues taken up by government agencies such as the trade ministry. However, with expertise drawn from other institutions, such as CAMPFIRE, alternative strategies can prove useful to both industry and local people.

\section{THE WAY FORWARD}

NTFP case analyses such as those presented here continue to facilitate a sound understanding of NTFP markets and their potential to further enhance livelihood strategies of people in Africa. At the same time, scientists, politicians, nongovernmental organisations and research institutions race to study the various components of domestication of wild species of NTFPs as a possible solution to sustainability. The third, and perhaps most critical, component is the fact that ease of penetrating distant markets with NTFPs while still sustaining local use markets is a delicate balance. The international marketing of biodiversity products brings together at least two starkly different cultures and economies. To succeed, projects must be carefully designed to accommodate the distinct needs of these disparate worlds, and good communication among all parties is a must.

In the case of devil's claw, recent regulations such as permitting created strict harvesting periods for an NTFP traditionally being harvested year-round in an arid region where livelihood options are limited. Because it is now endangered, international support for harvesting monitoring is enforced by the Convention on the International Trade in Endangered Species of Flora and Fauna on an international level. But does this adequately assess the local consumption of devil's claw? The financial benefits to the harvesters rarely exceed $0.85 \%$ of the retail price. Surely a more equitable policy structure is the key to long-term sustainability, on both an economic and an ecological level for this high-in-demand medicinal plant. How can we continue to develop a link between foresters, scientists and government agencies and economists, social workers, village leaders and the artisans and producers of NTFPs?

According to Dove (1993) the 'widely accepted explanation of tropical deforestation attributes it to the poverty of its native inhabitants'. His contrary view is that the poverty of forest dwellers is an outcome of the exploitation of 
forest resources by powerful outsiders. One aspect of this argument is the suggestion that NTFPs are unlikely to be a solution to poverty, as any product that is valuable and for which commercial exploitation is viable, will be taken over by such outsiders. While this theory has been disputed in terms of having universal or even wide applicability, it does have plausibility and, if true, really calls into question the whole notion of conscious attempts to alleviate poverty through forest enterprises (Southgate et al. 1996).

The lessons learned from the case studies are as variable as the products themselves, but there is a resounding complaint of lack of organisation among workers and lack of access to administrative assistance such as credit organisations. In addition, a main conclusion was the need for further studies, whether to assess the urban markets in more detail or to look deeper in the pricing of NTFPs at a subsistence level.

What we can learn from case comparison studies such as these is a cohesive strategy which (1) includes structured policy to promote NTFPs, (2) promotes knowledge of and safe and sustainable access to resources, (3) responds to needs for legislation and regulations and assesses and improves technologies, (4) organises producers, (5) builds capacity and promotes human resources, (6) continues research into domestication, (7) supports technical and marketing strategies and (8) looks to trade history of existing NTFPs and assess market potential prior to introduction of new NTFPs.

Monitoring international trade of NTFPs can be impeded by lack of demand, inconsistency of data from local processing facilities through the market chain and sustainable supply. In turn, these factors are linked to lack of investment. Private capital lacks the will and interest, while state capital lacks the focus, planning and knowledge. A potential role for researchers to help maintain interest in NTFPs by investors and consumers will depend on modernisation of NTFP production. For woodcarvers in Africa, this is a particularly crucial step as they face moving from local sales to tourists into the wholesale market (Chapters 9, 10, 11 and 12).

NTFP commercialisation should start with products already on the market. Introducing new products can take up to five years for foods, 10 for personalcare products and 20 for pharmaceuticals (Clay 1992). All case studies included here are already considered to be infiltrated into trade. The key now is to learn from case comparisons, such as those presented here, as to how NTFPs in Africa can remain a sustainable industry and actually increase the economic position of the local people while also tackling modernisation.

\section{CONCLUSION}

For products such as shea, a commodity heavily within the local and international trade, the options for market sustainability and growth are interdependent on other traded commodities such as cocoa and cashews (Chapter 6). On the other hand, to achieve a fair and sustainable trade base for medicinal plants, such as for devil's claw (Chapter 4), there is a strong need to recognise market constraints of this single product, such as lack of tenure security, poor monitoring, a dwindling resource base and lack of business skills. The differences between these two studies and the remaining 15 are 
inherent to NTFPs-they vary widely in material composition (from wood to elephants), use (medicinals to drumming) and market potential.

The following case studies, spanning 17 NTFPs, reveal an ancient system of resources moving through space and time, resources which further enable African people to benefit from their marketing capacity locally. As our case studies show, establishing or strengthening markets for NTFPs can help to encourage renewable resource conservation and can contribute significantly to rural livelihoods. However, for NTFP extraction to 'save' large tracts of forests and woodlands, the problem of attenuated land and property rights will have to be resolved, just as it must be resolved if eco-tourism, selective logging or any other economic activity is to be conducted in an environmentally sound manner. In addition, attempts to raise the market value of NTFPs, and therefore rural incomes, could be self-defeating if agricultural production of these products originally harvested from the wild is the result. In addition, understanding the political economy is crucial in addressing the economic, social and institutional contexts in which NTFPs are harvested and traded.

\section{ENDNOTES}

1. However, land conversion to agriculture in Benin is affecting the regeneration of Vitellaria paradoxa (Chapter 6).

2. But Philips (1993) suggests that fruit production from tropical forest is far less than most conservationists assume.

3. Fortunately, the commercial species of rattan favoured by artisans are geographically widespread throughout the lowland forest regions of Africa (Sunderland 2001).

4. Domesticated in the sense that the desirable traits of the species have been selected over generations so that the cultivated resource is genetically different from its wild relative. Often such species are only able to be reproduced clonally, of through the use of first generation (or F1) seeds.

\section{REFERENCES}

Alexiades, M. \& Shanley, P. 2004 Productos forestales, medios de subsistencia y conservación: Estudios de caso sobre sistemas de manejo de productos forestales no maderables. In: Alexiades, M. \& Shanley P. (eds.) Productos forestales, medios de subsistencia y conservación: Estudios de caso sobre sistemas de manejo de productos forestales no maderables. Volumen 3 America Latina. Center for International Forestry Research, Bogor.

Arnold, J.E.M. and Ruiz-Pérez, M. 1998 The role of non-timber forest products in conservation and development. In: Wollenberg, E. and Ingles, A. (eds.) Incomes from the forest: methods for the conservation of forest products for local communities, 17-42. CIFOR, Bogor.

Belcher, B. 1998. A production-to-consumption systems approach: lessons from the bamboo and rattan sectors in Asia. In: Wollenberg, E. and Ingles, A. (eds.) Incomes from the forest: methods for the conservation of forest products for local communities, 57-84. CIFOR, Bogor. 
Belcher, B. and Ruiz Pérez, M. 2001 An international comparison of cases of forest product development: overview, description and data requirements. Working paper no. 23. CIFOR, Bogor.

Belcher, B., Ruiz-Pérez, M., and Achdiawan, R. 2003 Global patterns and trends in NTFP development. Paper presented at the International Conference on Rural Livelihoods, Forests and Biodiversity. Bonn, Germany, 19-23 May 2003. CIFOR, Bogor, Indonesia. At: http://www.cifor.cgiar.org/publications/ corporate/cd-roms/bonn_results/index.html

Belcher, B. and Kusters, K. 2004. Non-timber forest product commercialisation: development and conservation lessons. In: Kusters, K. \& Belcher, B. (eds.) Forest products, livelihoods and conservation: Case studies of non-timber forest product systems. Volume 1 - Asia. Center for International Forestry Research, Bogor.

Boot, R.G.A. and Gullison, R.E. 1995 Approaches to developing sustainable extraction systems for tropical forest products. Ecological Applications 5(4): 896-903.

Browder, J.O. 1992 Social and economic constraints on the development of market-oriented extractive reserves in Amazon rain forests. Advances in Economic Botany 9: 33-41.

Clark, G. 1994 Onions are my husband: survival and accumulation by West African market women. University of Chicago Press. 464p.

Clark, L. and Sunderland, T.C.H. In press. CARPE: Building knowledge of the non-timber forest product sector in Central Africa. In: Sunderland, T.C.H. and Clark, L.E. (eds.) The key non-timber forest products of Central Africa: a state of the knowledge. University of Missouri Press.

Clay, J. 1992. Some general principles and strategies for developing markets in North America and Europe for non-timber forest products: lessons from Cultural Survival Enterprises, 1989-1990. Advances in Economic Botany. 9: 101-106.

Cunningham, A.B. 1999. The management of non-wood forest products in protected areas: lessons from a case study of multiple-use in Bwindi Impenetrable National Park, Uganda. In: Sunderland, T.C.H., Clark, L.E. and Vantomme P. (eds.) Non-wood forest products of Central Africa: Current Research Issues and Prospects for Conservation and Development, 143160. Food and Agriculture Organisation, Rome.

Cunningham, A.B. 2000 Applied ethnobotany: people, wild plant use and conservation. Earthscan, London. 300p.

Davidson-Hunt, I., Duchesne, L. and Zasada, J. 2001 Non-timber forest products: local livelihoods and integrated forest management. In: DavidsonHunt, I., Duchesne, L. and Zasada, J. (eds.) Forest communities in the third millenium: linking research, business, and policy toward a sustainable non-timber forest product sector, 1-12. USDA Forest Service North Central Research Station, USA.

Dove, M. 1993 A revisionist view of tropical deforestation and development. Environmental Conservation 20(1): 17-24.

Falconer, J. 1990. The major significance of 'minor' forest products, 47-92. FAO, Rome. 
Gakou, M. and J.E. Force. no date. Learning with farmers for policy changes in natural resource management, In: Forests, Trees and People Newsletter 31. www-trees.slu.ne

Glowka, L., Burhenne-Guilmin, F., Synge, H., McNeely, J.A. and L. Günding. A guide to the Convention on Biological Diversity. IUCN Gland and Cambridge. $161 \mathrm{p}$.

Godoy, R.A. and Bawa, K.S. 1993 The economic value and sustainable harvest of plants and animals from the tropical forest: assumptions, hypotheses and methods. Economic Botany 47: 215-219.

Hédin, L. 1929 Les rotins au Cameroun. Rev. Bot. Appl. 9: 502-507.

Hobhouse, H. 1999 Seeds of change: six plants that transformed mankind. Papermac Press. 381p.

Hochschild, A. 1998. King Leopold's ghost: a story of greed, terror and heroism in colonial Africa, 150-167. Macmillan, London.

Homma, A.K.O. 1992 The dynamics of extraction in Amazonia: a historical perspective. Advances in Economic Botany 9: 23-31.

Iliffe, J. 1995 Africans: the history of a continent, 81-90. Cambridge University Press.

Isichei, E. 1997 A history of African societies to 1870, 349-350. Cambridge University Press.

Kiai, W., Mwangi, W. and Bosire, E. 2002 The impact of HIV/AIDS on the land issues in Kenya. Forest Action Network, Nairobi, Kenya. http:// www.sarpn.org.za/documents/d0000162/P148_Kenya_Report.pdf

Laird, S.A. 1999 The management of forests for timber and non-wood forest products in Central Africa. In: Sunderland, T.C.H., Clark, L.E. and Vantomme, P. (eds.) Non-wood forest products of Central Africa: current research issues and prospects for conservation and development, 51-60. Food and Agriculture Organisation, Rome.

Lawrence, A. 2003 No forest without timber? International Forestry Review 5(2): 87-94.

Malleson, R. 1999 Community management of non-wood forest resources: a case study from the Korup Forest, Cameroon. In: T.C.H. Sunderland, L.E. Clark and P. Vantomme (eds.) Sunderland, T.C.H., Clark, L.E. and Vantomme, P. (eds.) Non-wood forest products of Central Africa: current research issues and prospects for conservation and development, 117-122. Food and Agriculture Organisation, Rome.

Ndoye, O., Ruiz-Perez, M. and Eyebe, A. 1997 The markets of non-timber forest products in the Humid Forest Zone of Cameroon. Rural Development Forestry Network, Network Paper 22c. ODI, London.

Ndoye, O., Ruiz-Perez, M. and Eyebe, A. 1999 Non-wood forest products markets and potential degradation of the forest resource in Central Africa: the role of research in providing a balance between welfare improvement and forest conservation. In: Sunderland, T.C.H., Clark, L.E. and Vantomme, P. (eds.) Non-wood forest products of Central Africa: current research issues and prospects for conservation and development, 183-206. Food and Agriculture Organisation, Rome.

Neumann, R. P. and Hirsch, E. 2000. Commercialisation of non-timber forest products: review and analysis of research. CIFOR, Bogor. 176p. 
Ogle, B. 1996. People's dependency on forests for food security: some lessons learned from a programme of case studies. In: Ruiz-Pérez, M. and Arnold, J.E.M. (eds.) Current issues in non-timber forest products research, 219242. CIFOR, Bogor.

Oliver, R. 1999. The African experience, 97-100. Wiedenfield \& Nicolson, London.

Packenham, T. 1991 The scramble for Africa, 1876-1912. Abacus Press. 738p.

Perez, M.R. and Byron, N. (eds.) 1999 A methodology to analyze divergent case studies of non-timber forest products and their development potential. Forest Science 45(1): 1-14.

Peters, C.M. 1994 Sustainable harvest of non-timber plant resources in tropical moist forest: an ecological primer. Biodiversity Support Program c/o World Wildlife Fund, Washington, D.C. 45p.

Peters, C.M., Gentry, A. and Mendelsohn, R.O. 1989 Valuation of an Amazonian rainforest. Nature 339: 655-656.

Phillips, 0. 1993 The potential for harvesting fruits in tropical rainforests: new data from Amazonian Peru. Biodiversity and Conservation 2: 18-38.

Pierce, A.R. \& Laird, S.A. 2003. In search of comprehensive standards for nontimber

forest products in the botanicals trade. International Forestry Review 5(2): 138-147.

Plotkin, M. and Famolare, L. (eds.) 1992 Sustainable harvest and marketing of rain forest products. Conservation International. Island Press, Washington, D.C. $323 p$.

Ruiz-Pérez, M. and Arnold, J.E.M. (eds.) 1996. Current issues in non-timber forest products research. CIFOR, Bogor. 264p.

Ruiz-Perez, O. Ndoye, A. Eyebe \& A. Puntodewo. 2000. Spatial characterisation of non-timber forests markets in the humid forest zone of Cameroon. International Forestry Review. 2(2): 71-83.

Shanley, P., Laird, S.A., Pierce, A.R. and Guillen, A. (eds.) 2002 Tapping the green market: certification and management of non-timber forest products. Earthscan, London. 456p.

Southgate, D., Ritchie, M.C. and Canelos, P.S. 1996 Can tropical forests be saved by harvesting non-timber forest products? CSERGE Working Paper GEC 96-02. 19p.

Sunderland, T.C.H. 2001. Rattan resources and use in West and Central Africa. Unasylva 52(205): 18-26.

Tabuna, H. 1999 The markets for Central African non-wood forest products in Europe. In: Sunderland, T.C.H., Clark, L.E. and Vantomme, P. (eds.) The non-wood forest products of Central Africa: current research issues and prospects for conservation and development, 251-264. Food and Agriculture Organisation, Rome.

Townson, I. 1992 Exhaustion, Abandonment, and Sustainability: The Dynamics of Forest Product Use in West Africa, with Particular Reference to the Export Trade. M.Sc. Thesis, University of Oxford, Oxford Forestry Institute, UK. $62 p$. 
Van den Berg, J., van Dijk, H., Dkamela, G.P., Ebene, Y. and Ntenwu, T. 2001 The role and dynamics of community institutions in the management of NTFP resources in Cameroon. In: Clark, L. (ed.) Non-timber forest products in central Africa: research results Workshop for the Central African Regional Program for the Environment, 54-59. USAID/CARPE. Van Harten, A.M. 1967 Melegueta pepper. Economic Botany 24(2): 208-216. Wilkins, L. 1999. The new millennium: linking environmental and social issues in fair trade. Networks (Spring). 


\title{
Chapter 2
}

\section{Dental hygiene and livelihoods: a case of chewing sticks in Ghana}

\author{
Dominic Blay ${ }^{1}$
}

\begin{tabular}{llllll}
\hline Common names & $\begin{array}{l}\text { Part of the } \\
\text { resource used }\end{array}$ & Management & $\begin{array}{l}\text { Degree of } \\
\text { transformation }\end{array}$ & $\begin{array}{l}\text { Scale of } \\
\text { trade }\end{array}$ & $\begin{array}{l}\text { Geographic } \\
\text { range }\end{array}$ \\
\hline $\begin{array}{l}\text { Tweapeah, } \\
\text { Nsorkor }\end{array}$ & Stem & Wild & Low & International & Medium \\
\hline
\end{tabular}

\begin{abstract}
This chapter provides an overview of the chewing stick trade in Ghana. Chewing sticks are one of the most important non-timber forest products of the Western Region (Falconer 1990; Falconer 1992) and have provided the primary form of dental care for millennia. The production, trading and marketing of chewing sticks also provides the main source of income for many men and women in rural communities, many of whom are economically marginal. The trade in chewing sticks also contributes significantly to the local, regional and national economies (Tabi-Gyansah 2001). However, as with other resources, the Garcinia spp. exploited for chewing sticks are becoming increasingly scarce, particularly outside of forest reserves (Wong 1997).
\end{abstract}

\section{INTRODUCTION}

The excellent condition of people's teeth in West Africa is common knowledge (Isawumi 1978). Many authors claim that chewing sticks, which many West Africans (Isawumi 1978) and as many as $90 \%$ of the people of southern Ghana utilise, are the major contributory factor for the good condition of people's teeth (Adu-Tutu et al. 1979; Abbiw 1990). Because of the long and widespread use of chewing sticks in the region, there is a wide trade network, which involves a large number of people, both from rural and urban settings. It is estimated there is an average of 250 women in the two main markets in Kumasi alone involved in processing of chewing sticks (Falconer 1992).

The contribution made by chewing sticks to the economy of the Ashanti region of Ghana is estimated at around US\$203,000 (Blay unpublished notes). Thus, in addition to the provision of dental care, chewing sticks contribute to 
the income of many Ghanaians and at the same time contribute to local, regional and national economies. Notwithstanding the medical and economic importance to the nation, the resource base is gradually dwindling because of overexploitation. Yet there are no policies or management strategies in place either to ensure sustainable production of the species concerned or to improve trade and marketing.

\section{METHODOLOGY}

The study on the production-to-consumption system for chewing sticks, the findings of which are presented in this chapter, was undertaken in three villages in the Western Region of Ghana-Banso, Betinasi and Nkwanta-where the majority of chewing stick logs are harvested (Figure 1). Regional markets in Accra and Kumasi and some additional weekly markets in the Western Region of Ghana were also studied. The study used direct observations as well as participatory rural appraisal and 'focus group' survey methodologies (Malleson 2001).

\section{THE RESOURCE BASE}

\section{Introduction}

Chewing sticks are made from the split stems of a number of tree species. Although Isawumi (1978) and Abbiw (1990) mention that over 70 species of woody plants are used in West Africa as chewing sticks, only three species account for the commercial trade-Garcinia epunctata, G. afzelii (both referred to as nsorkor) and G. kola (or tweapeh) (Adu-Tutu et al. 1979; Falconer 1992; Tabi-Gyansah 2001). These species comprise over $90 \%$ of the chewing sticks sold in Ghana (Falconer 1992). The three species of Garcinia are mostly found in the south-western area of Ghana, particularly in the moist evergreen and moist semideciduous forests of the Western Region (Foggie 1941; Hall and Swaine 1976).

\section{Harvesting}

Although historically harvested in the Western Region from both primary and secondary forests, because of overexploitation the harvesting of the species of Garcinia concerned has extended as far as Côte d'Ivoire and Liberia (Holbech 2000). The species are harvested exclusively from the wild. However, recent efforts aimed at production intensification have focussed on planting of Garcinia spp. in agroforestry systems. The nongovernmental organisation Cooperative for American Relief Everywhere International and the local logging company Samartex have undertaken this effort in collaboration with local communities.

Harvesting occurs during six to nine months of the year. It rests in the rainy period because of the poor quality of the roads in the area and because the chewing stick gatherers prefer to work in the dry season (October to March). The majority of harvesting is undertaken in forest reserves owned by the government or, less commonly, in 'off-reserves' owned by families or clans 
Figure 1. Location of the study area
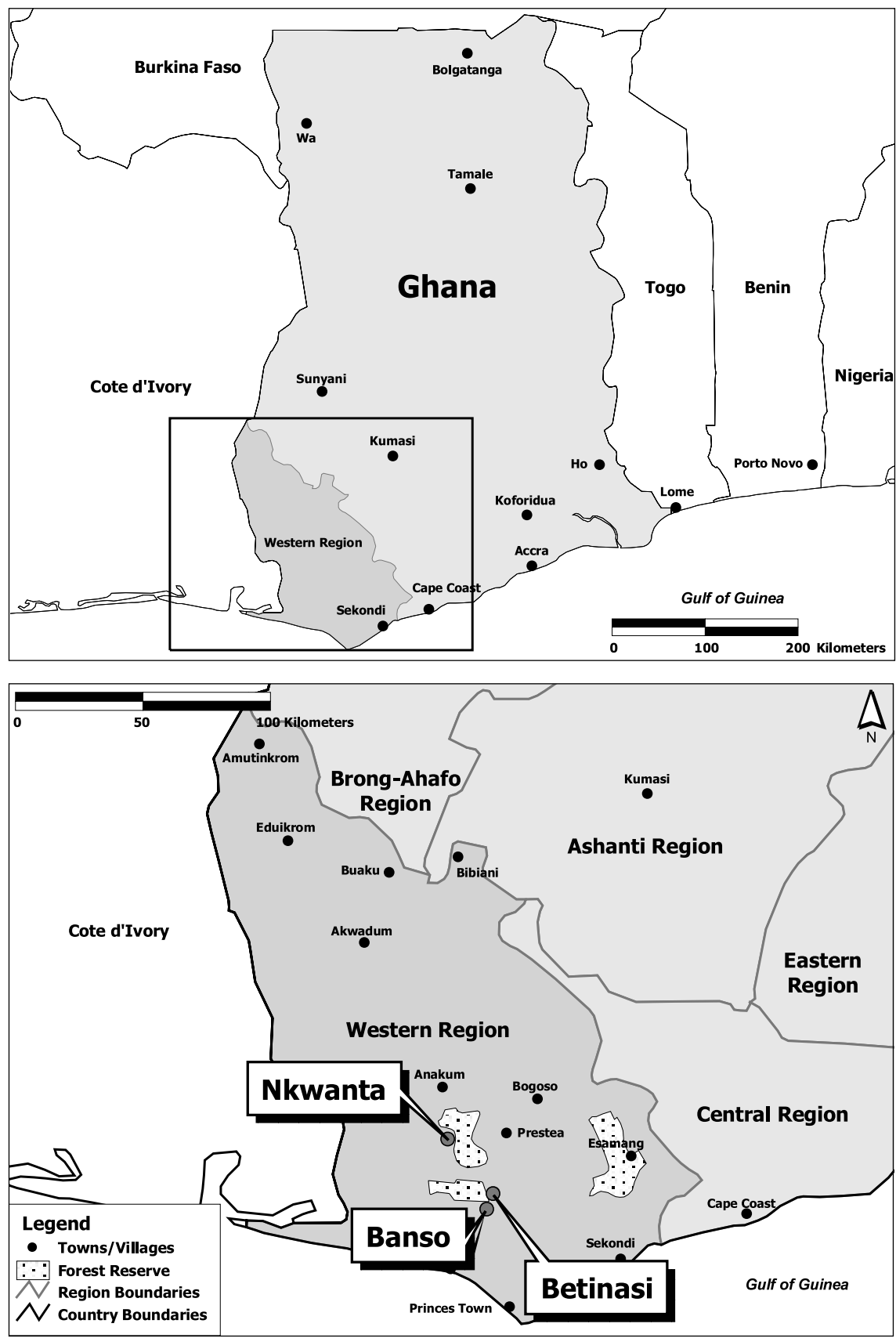

Source: ESRI Data and Maps 2002. 


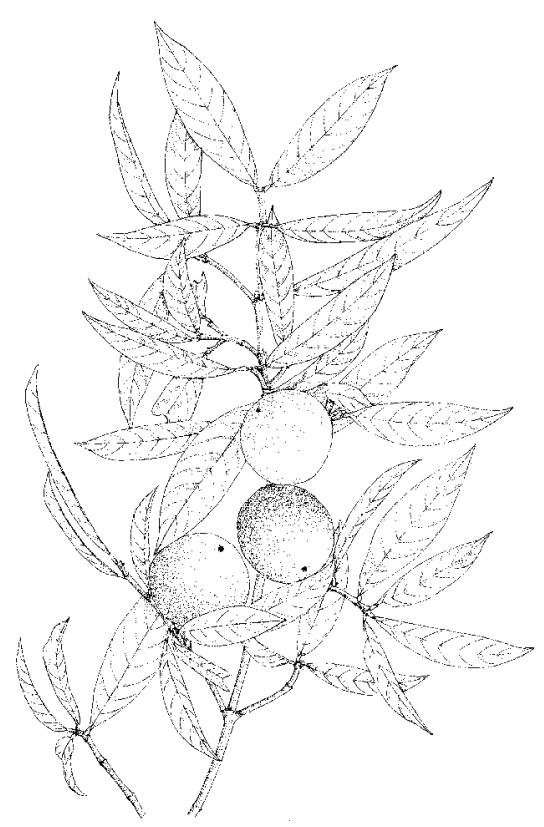

(Garcinia kola)

(Holbech 2000). Since almost all the individuals of the desired species have been destroyed either as a result of persistent farming or from direct exploitation, the remaining harvestable stems are small to medium sized, 12 $\mathrm{cm}$ to $25 \mathrm{~cm}$ diameter at breast height (Wong 1997). Therefore the cutlass (or machete) is the main harvesting tool. However, some more organised individuals, especially urban gatherers, occasionally use chainsaws to fell the trees. The harvesting is extremely destructive as the entire bole is removed for processing. The gatherers operate in teams, usually numbering between three and five men, and at times are hired by a single trader. Harvested logs are carried to a point that is accessible to vehicles. This operation is normally undertaken by men, but women occasionally take part in carrying logs, particularly when in need of immediate additional income. The logs are then loaded and transported to urban centres, where they are taken over by middlemen for distribution. Studies in Ghana have shown that a full truckload contains about 200 logs (Amponsah 1978). The cost of a log depends on its length and size as well as the relative costs of transportation.

\section{RAW MATERIAL PRODUCERS AND SOCIO-ECONOMIC CONTEXT}

\section{Raw material production area}

The logs of Garcinia spp. harvested for the production of chewing sticks are mostly obtained from the villages of Banso, Betinasi and Nkwanta in the southwestern part of Ghana. The geographical and socio-economic characteristics of each settlement are briefly described below. 
Photo 1. Raw logs of Garcinia spp. prior to cutting into billets (Photo by D. Blay)

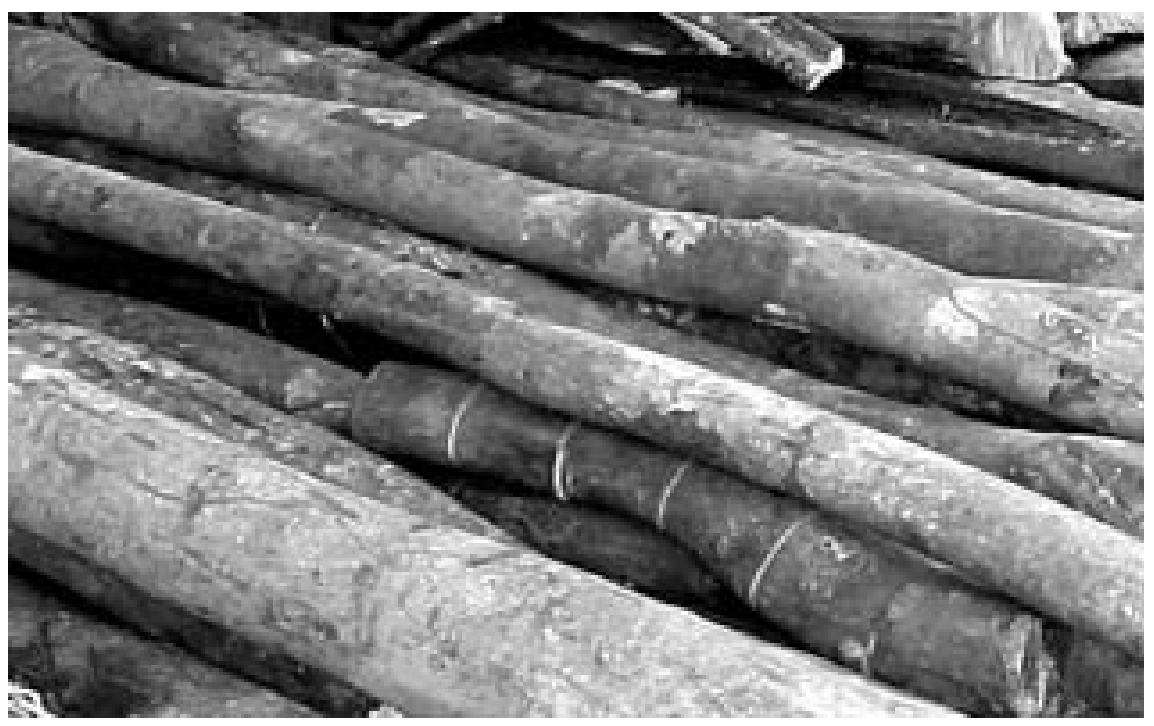

\section{Banso}

Banso is a large village with a population of about 2,000 far up the Ankobra River about 10 miles from Draw River Forest Reserve. Access to Banso is poor, as the only road is impassable for large parts of the year. The river is the only other means of transport. A motorised boat plies it at least once a week and many villagers have their own canoes. The main economic activities are subsistence farming, coconut and palm fruit production and the distilling of akpeteshie (local gin), which occupies many men full time. Farming is primarily a woman's task, men being responsible only for land clearing.

\section{Betinasi}

Betinasi, also with a population of around 2,000 people, is located further up the Ankobra River north of Banso and borders the Draw River Forest Reserve. The village is extremely isolated. It is two hours from Banso by river with canoe as the main means of transport. There are no basic services in the village such as a school or health post. Most people are subsistence farmers and rely heavily on the forest for subsistence goods.

\section{Nkwanta}

Nkwanta is a growing village located to the west of Prestea, a thriving mining town and the nearest urban market, and a few miles from the Fure River Forest Reserve. The settlement has a population of around 3,000 people. Access to market is fairly good and the road is passable during all but the worst of the rainy season. Although the natives of Nkwanta are Wassas, in the last 10 years the population has become more cosmopolitan so that outsiders now outnumber natives. The main economic activities are food crop and cocoa farming, cane 
basket weaving, cane and chewing stick log collection and hunting. Traders come from Accra and Kumasi as well as nearby markets for food and nontimber forest products.

\section{Harvesting and trade}

The average household size in the raw material production area is five to six people. Around $90 \%$ of the households of the region are involved in the harvesting of logs and within these households, almost all the able bodied young men take part in the harvesting of chewing sticks. Thus while the age group involved in harvesting ranges from 10 to 50 years, the active group is between 20 and 40 years. The collection process does not require any particular skill or high level of education and most of the collectors have attained only a basic school education. The average daily wage for harvesting is US\$0.90 and the average annual income from harvesting ranges from US\$300 to US\$400, with $80 \%$ earning between US\$300 and US\$390. Thus the income level of the majority of harvesters is around the average national annual income of US\$390.

Households engaged in harvesting do not earn any other income from forest products. Hence the degree to which the product contributes to household forest product income is 100 percent. However, all of the harvesters engage in subsistence farming and this provides around $20 \%$ of total household income. The income of many harvesters has been steadily declining because of overexploitation, which has resulted in decreased density of the species as well as a reduction in large individuals. Many people in the local and urban communities regard the harvesting of chewing sticks as a 'menial activity', in common with most forest-related activities, and therefore generally hold the workers in low esteem.

\section{Processing}

The processing of raw logs into chewing sticks basically consists of peeling the bark off the logs and cutting them into billets of about $30 \mathrm{~cm}$. Each billet is then split into pieces of about $2 \mathrm{~cm}$ to $5 \mathrm{~cm}$ and put into small bundles of about 20 to 30 pieces, the number depending on the amount the bundle will be sold for. Hence, the processing of the logs into the final product requires very little transformation and the value of the forest product in the finished product is around $95 \%$.

There are two categories of chewing stick processors. First order processors process the cut stems and branches into round logs while second order processors split the round logs into small shards for consumption. The first order processors are male and they comprise around $15 \%$ of the total number of processors. The second order processors make up the remaining $85 \%$ of the total number of processors and these are mostly females. First order processors can earn between US\$300 and US\$800 annually, second order processors, between US\$200 and US\$500.

In Kumasi, nsokor logs are purchased daily at wholesale stations located near production sites in markets and certain designated areas. First order processors, normally working in two-man teams, cut the logs into billets that 
are, on average, $30 \mathrm{~cm}$ long. Second order processors then split these billets with knife and mallet into chewing sticks. Most women process the equivalent of one or two logs a day. Larger chewing sticks prepared for the wholesale market are stored for several weeks and are then split into smaller sizes for sale. These are later split into yet smaller dimensions for the retail market and immediate consumption. The number of chewing sticks produced per log varies considerably depending on the diameter at breast height of the individual tree. On average, between 230 and 1,665 bundles of chewing-sticks are produced per log; thus an approximate mean of 750 chewing sticks bundles are produced per log. Branches are never used in the trade because the cost of transportation is too high to warrant their exploitation and they are considered too small in size to facilitate splitting.

Labour is paid on commission basis, i.e., by the number of logs cut into pieces or number of pieces split. In this regard, processors prefer working alone. Other processors are also involved in the collection and trade of logs from Western Region. These processors have established relationships with village gatherers and visit the village to collect harvested logs. In some cases they pay for the logs in advance and return the following month to collect them. Their profits are higher than those of processors who purchase logs at Kumasi's Central Market because the outside processors are involved in the entire chain of the chewing stick trade from paying forest gatherers in the village for whole raw logs to peddling bundles of chewing sticks in the streets of Kumasi.

Photo 2. Splitting and shaping of chew sticks prior to sale (Photo by T.C.H. Sunderland)

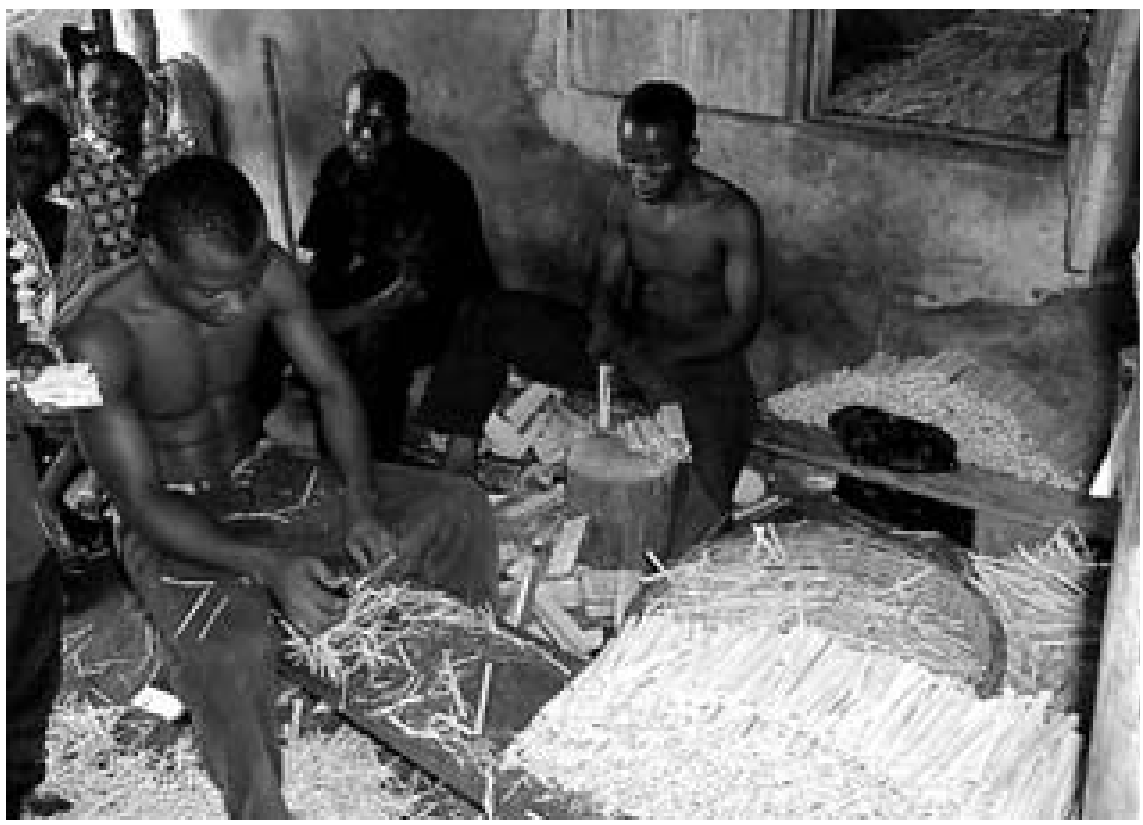


About six years prior to this writing processors established an organisation which regulates their activities, particularly the rates at which they purchase raw materials. This organisation also serves as sociocultural association since members are required to help fellow members during funerals, births and other social functions. Hence there is a relatively high degree of organisation among processors and all members participate highly in the organisation. Nevertheless the organisation is ineffective as far as production is concerned because many members disregard the regulations of the organisation. In spite of the high level of organisation, there is no barrier to entry into the organisation. All one needs is to get a space in the market where the processors are located and the initial capital to purchase logs and processing materials and pay for the processing. Thus, although there is an investment in the processing, this investment is minimal. All these activities are in the private sector with no state intervention except ensuring that all the processors pay their taxes.

\section{CHARACTERISTICS OF TRADE AND MARKETING}

There are two main categories of chewing stick traders-those that trade in chewing stick logs and those that deal in processed logs. Those trading in logs are subdivided into first and second order traders. First order traders sponsor the harvesters directly to bring the logs from the production site to the urban markets. These traders have total control over the truckload (they own it) and then sell the logs to other interested traders. This category of traders constitutes around 30\% of all traders. Second order traders make up $25 \%$ of traders. They buy logs directly from first order traders and sell them to processors. Some of these traders sometimes also act like processors when they process some of the chewing sticks for sale.

The remaining $45 \%$ are the processors and retailers who sell the finished product to the general public. Chewing sticks are sold in all the markets studied in Ashanti, both rural and 'regional' ones, but are absent from smaller markets in Western Region, where an alternative product, the chewing sponge (Acacia kamerunensis), is available. There is a great spectrum in the retail trade ranging from those who sell a few chewing sticks along with household goods to those who specialise in the sale of chewing sticks exclusively. Chewing sticks are commonly sold by those selling plant medicines as well as by traders who sell a multitude of small household wares (e.g., batteries, catapults and soaps). The majority of retail traders, however, do not rely solely on chewing sticks because profits are usually small. A diagram of the trade network appears in Figure 2.

The processors in Kumasi supply chewing sticks to traders throughout the entire region. Even chewing sticks sold in the larger Western Region markets were generally purchased in Kumasi or Accra. For retail traders, returns range from several hundred to 76,000 cedis (up to US\$12) a week. The size of business varies greatly from those who sell a few bundles to those who sell more than 100 bundles a day. Because they are so widely sold, the price of chewing stick bundles is basically uniform across the entire region. Traders may alter the size of the bundle somewhat, but to do so radically would be risky because of competition. Based on our field surveys we estimated the total contribution of chewing sticks production to the regional economy to be about US\$203,000. 
Figure 2. Chewing sticks trade network in Ghana

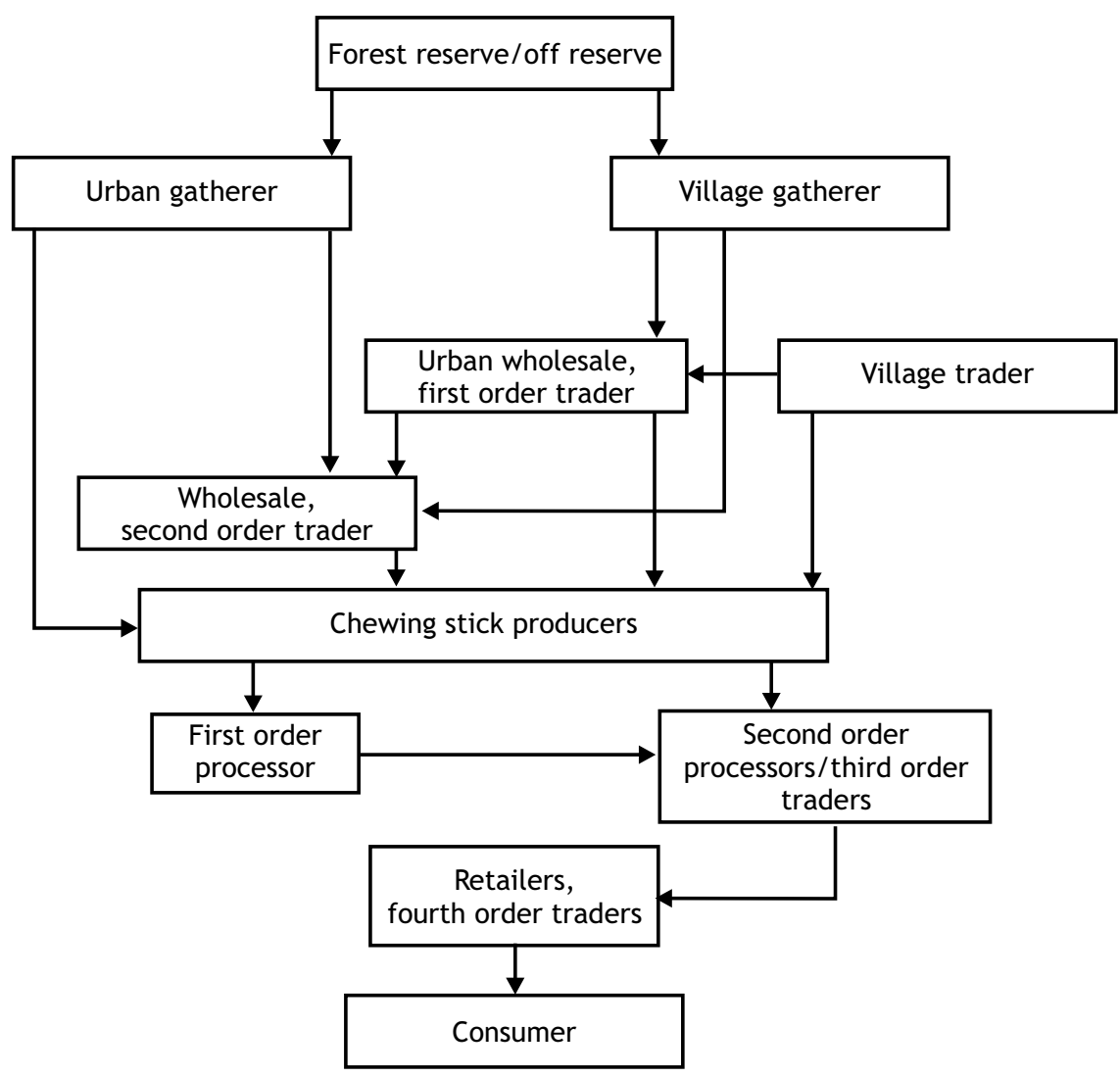

This figure assumes a monthly production of over 14 million chewing stick bundles.

Most traders are aged between 30 and 39 years, only a small minority being 60 years or older. About 15\% are male. Chewing stick trading is the major occupation of $85 \%$ of the traders interviewed while only $15 \%$ consider it as a minor, or secondary, occupation. Chewing stick logs are transported over $300 \mathrm{~km}$ on mostly lateritic roads to Kumasi and Accra, hence the traders incur heavy transportation costs. In addition to the direct costs of transportation, the traders also pay for the cost of loading and off loading.

Traders that double as processors generally employ people to work with them. The income obtained from chewing sticks was said to be decreasing because of the shortage of logs. Almost all traders market their wares at the Kokomba and Aghophloshie markets in Accra and at the Central Market in Kumasi. These markets are well noted in the country for the trade of chewing sticks, both processed and raw. In addition to these main markets, bundles of chewing sticks are retailed in all markets and garages. Processed chewing sticks are also transported to Togo for sale. From our surveys we estimate that about $15 \%$ of the total product is exported to Togo. 
Because of the low level of transformation the product goes through from raw material to finished product, the product cannot be adulterated and it is always in prime condition, except of course when the desired species are not used. Also because of the little transformation, there is no vertical integration. Most of the traders belong to associations that were established in the early 1990s. The main objective of these associations is to regulate the activities of the business and to help one another in times of crises or need. As in the case of the processors, the traders' association is an economic and a sociocultural one. While there are no social, technical or regulatory barriers to second level traders joining any of the associations, there are economic barriers, because one needs some capital before becoming a second order trader.

While there are no corrupt practices financially, there is currently a trend of some traders using alternative species for the genuine Garcinia spp., which are becoming increasingly scarce. Nevertheless there are no national or local government regulations that directly relate to the chewing stick trade apart from the payment of taxes on the produce. There is also no incentive or direct investment from the government. In the absence of government support, the nongovernmental organisation Sinapi Aba has recently stepped in to offer support in the form of soft loans to traders and processors to enable them to increase their working capital. This sponsorship is expected to continue if traders continue to repay their loans.

\section{POLICY ENVIRONMENT}

\section{Legislative framework}

The Forest Services Division of the Forestry Commission, which is the governmental agency responsible for the management of forest resources, has regulations on harvesting of chewing sticks. These regulations however apply only to harvesting in designated Forest Reserves. Here the gatherer must first obtain a permit to enter the reserve. Gatherers who enter Forest Reserves without permit are arrested and at times prosecuted; their logs are seized. The permit system is meant to check excessive exploitation and illegal harvesting, but it has failed to achieve these objectives because the Forest Service does not ensure strict monitoring of harvesting operations. This laxness has led to abuses by both gatherers and Forest Commission staff, which has culminated in depletion of the resource.

After gathering, a specific levy is put on each tree or log before the logs are trucked to the urban market. These taxes or levies are only meant to generate revenue to the national and local governments (the latter called District Assemblies) and are not meant in any way to influence the raw material production.

\section{Traditional Laws}

Traditional laws governing chewing sticks gathering and trade are informal and differ from place to place. Usually these customary regulations cover trees found in off-forest reserves. Here the gatherer pays a token fee together with drinks before he enters the land. Sanctions are instituted against people who 
trespass and the network is such that it is difficult for people to evade payment. However, trees gathered from private lands also require permits before they can be transported to marketing centres.

\section{TRENDS AND ISSUES}

The resource base for chewing sticks in Ghana has seriously declined as a result of considerable overexploitation. As a direct result, currently a lot of harvesting of Garcinia spp. for chewing stick production takes place in Liberia and Côte d'Ivoire (Holbech 2000). This harvesting outside Ghana is affecting the livelihoods of harvesters that cannot afford to go to neighbouring countries to harvest the logs. The decrease in the availability of the Garcinia spp. locally has also led to the hike in price of chewing sticks and to a situation where some traders sell any species that can be used as a chewing stick as Garcinia spp.

\section{Key issues/problems}

The fast depletion of the resource base as result of overexploitation came about because of the lack of appropriate policies and management strategies including adequate monitoring to regulate the remaining resource and to put in place strategies to regenerate the species concerned-the highly organised network of collectors, processors and traders notwithstanding. This network, which spans from the rural communities to the urban areas, provides income to many marginal men and women and therefore contributes significantly to the local and regional economies. The product also has considerable potential for export not only to neighbouring countries but also to Ghanaians in Europe and America who still cherish the use of chewing sticks. Despite the decreased local availability of the desired species there are still considerable levels of processing and trade in chewing sticks as imported logs from Côte d'Ivoire and Liberia supplement domestic stocks. In spite of the importance of the species economically and for health care, the Forest Services Division has paid little attention to the species concerned. There has thus far been no government intervention so as to promote either the regeneration of the species or the development of the market.

\section{Conversation and development lessons}

It is estimated that about 4,700 trees are harvested a month to meet the demands of Kumasi and the Ashanti region alone. Thus about 12,000 to 19,000 logs are processed into chewing sticks monthly for the region. Meanwhile there are equally important processing centres in Accra and Takoradi. Given this market pressure, Garcinia spp. is now seriously threatened in Ghana (Wong 1997).

There is virtually no management system for chewing sticks because there is no information on the current level of stocking or the current rate of exploitation. Although there are regular inventories of timber trees, chewing sticks trees are not inventoried because they are understorey trees. In addition, there is also no information on the regenerative capacity of the species or its rate of growth. Currently the only levels of control of chewing stick exploitation are the high transportation costs and the gatherers' dislike for small logs. However, 
more recently even small logs are harvested since most gatherers are not from the areas they operate within and therefore rarely return to the same forest. In contrast with non-indigenous gatherers, locals allow time for smaller diameter trees to develop since most of these local communities are dependent on the gathering of chewing sticks. Thus the value of the trade in itself does not provide incentives for degradation of the resource base. The resource base has been degraded because of the lack of appropriate policies and management. There is an urgent need to develop a sustainable resource base through the adoption of sound management practices based on scientific data. To achieve that goal, the following information is needed: current level of Garcinia spp. stocking and rate of exploitation. This knowledge should lead to a standardisation of amounts extracted. Current efforts to establish plantations of Garcinia spp. need to be increased.

\section{ENDNOTES}

1. Forestry Research Institute of Ghana University, Box 63 Kumasi, Ghana. E-mail: dblay@forig.org

\section{REFERENCES}

Abbiw, D. 1990 Useful plants of Ghana. Intermediate Technology Publications, London. 337p.

Adu-Tutu, M., Afful, Y., Asante-Appiah, K., Lieberman, D., Hall, J.B. and ElivinLewis, A. 1979 Chewing stick usage in southern Ghana. Economic Botany 33(3): 320-328.

Amponsah, S. 1978 Survey into the chewstick industry at Kejetia Lorry Station. B.Sc Thesis, Institute of Renewable Natural Resources, University of Science and Technology, Kumasi.

Falconer, J. 1990. The local use and value of forests in the West African humid forest zone. In: Koppell, C.R.S. (ed.) The major significance of "minor" forest products, 47-92. Food and Agriculture Organisation, Rome.

Falconer, J. 1992. Non-timber forest products in Southern Ghana: summary report. Forestry Department of Ghana/Overseas Development Administration. 23p.

Foggie, A. 1941. Some ecological observations on a tropical forest in the Gold Coast. Journal of Ecology 34(1): 88-106.

Hall, J.B. and Swaine, M.D. 1976 Classification and ecology of closed canopy forest in Ghana. Journal of Ecology 64: 913-951.

Holbech, L.H. 2000. Non-timber forest products survey: market survey and trade route assessment around the Ankasa Protected area. (Unpubl.) report for the Protected Area Development Programme, Western Region, Ghana. 36pp.

Isawumi, M.A. 1978 Nigerian chewing sticks. Nigerian Field 43(2): 50-58.

Malleson, R. 2001 Development of African rattans: socio-economic studies fieldwork and survey manual for Ghana. African Rattan Research Programme \& University of London. 58p.

Tabi-Gyansah, E. 2001 Analysis of the spatial distribution of NTFPs in the tropical forest of Ghana. ETFRN News 32: 21-22.

Wong, J. 1997. The state of Ghana's forests 1986-1997: non-timber forest products. (Unpubl.) report to ODA/FRR. 52pp. 


\title{
Chapter 3
}

\section{'Chop, but no broke pot': the case of Prunus africana on Mount Cameroon'}

Nouhou Ndam² and Mahop Tonye Marcelin ${ }^{3}$

\begin{tabular}{llllll}
\hline Common names & $\begin{array}{l}\text { Part of the } \\
\text { resource used }\end{array}$ & Management & $\begin{array}{l}\text { Degree of } \\
\text { transformation }\end{array}$ & $\begin{array}{l}\text { Scale of } \\
\text { trade }\end{array}$ & $\begin{array}{l}\text { Geographic } \\
\text { range }\end{array}$ \\
\hline $\begin{array}{l}\text { Pygeum, } \\
\begin{array}{l}\text { Red stinkwood, } \\
\text { Wotango }\end{array}\end{array}$ & Bark & Wild & High & International & Medium \\
\hline
\end{tabular}

\begin{abstract}
P. africana is a tree occurring in some montane regions of Africa. The bark is used by local peoples to treat many diseases and is known internationally as a remedy to prostate disorder. It is exported to developed countries from a number of African countries where it contributes to the economic and social well-being of peoples of this continent. In the Mount Cameroon area where this case study is based, initiatives have been made to sustain its use while increasing its benefit to local communities. This paper outlines the ecological and socio-economic context of the species focusing on its distribution, harvesting, processing, marketing, and policy environment for sustainable use and equity in benefit sharing. Lessons learnt from conservation and development efforts are drawn from the case study.
\end{abstract}

\section{INTRODUCTION}

Prunus africana (Hook.f.) Kalkman, formerly known as Pygeum africana (Hook.f), is a tree belonging to the Rosaceae family distributed in montane forest regions across Africa. Traditionally, it is used to treat malaria, stomach ache, fever, urinary problems, sexually transmitted diseases, wounds, chest pain and heartburn (Carter 1992; Tonye et al.1999). It is a purgative for cattle and its fruits are consumed and disbursed by many birds and insects (Sunderland and Nkefor 1997). Its bark is used in modern medicine to treat prostate disorder that leads to uncontrolled urine release in elderly men (Bombardelli and Morazzoni 1997). It is exported to developed countries from a number of countries where it contributes to the economic and social wellbeing of African peoples. Aside from medicinal use, it is also a source of timber for export or 
building materials, of firewood and of wood for making tools and carvings (Hall et al. 2000).

In the Mount Cameroon region, the species is not only exported to Europe as a medicinal plant product, but the bark is also widely used traditionally as local medicine and the wood for hoe handles and timber. The species is distributed on the main forest massif in patches ranging from $700 \mathrm{~m}$ to 3,000 $\mathrm{m}$ altitude (Achoundong 1995; ONADEF unpublished report). The area has 300,000 inhabitants distributed in 51 villages with an annual population growth rate of $3 \%$ to $6 \%$. These communities have been aware of the commercial value of $P$. africana since the early 1970s. Since then, the benefit from the species has gradually become the driving force for rural development of the region and livelihoods improvement (Ndam and Ewusi 2000).

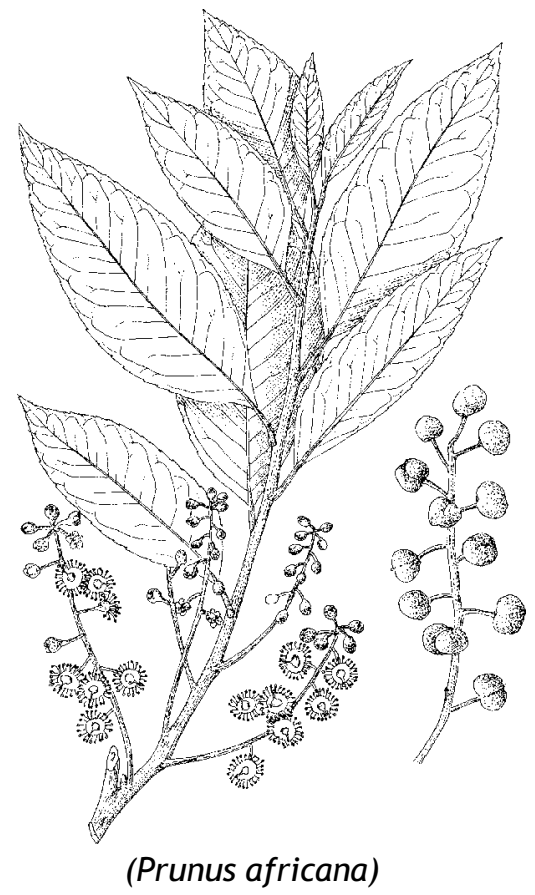

According to an unpublished report to the World Wildlife Fund-Cameroon, the benefit sharing system put in place after the formation of the Mapanja Prunus Harvesters Union has been a good promoter for the sustainable community based organisation. For example, income following nine months of the union's functioning in 1998 amounted to US\$35,700 (25 million CFA), of which US\$2,260 (1.58 million CFA) went to the village development fund, US\$1,530 (1.07 million CFA) covered the group's running costs and the balance of US\$32,925 (22.35 million CFA) was shared among the 60 harvesters according to their output (Ndam and Ewusi 2000). The impact of the income improvement through Prunus activities can easily be noted by the contribution of the village to certain pending development projects like water and electrification projects. In addition, there have been significant individual livelihood improvements, notably in increased house construction in the village, a surge in formal marriages and a greater 
proportion of children being sent to school. As the commercial value of $P$. africana in the international trade continues to increase-it currently stands at US\$220 million annually, representing roughly 3,600 tonnes of raw material (Cunningham et al. 1997)-owing to the gradual inclusion of the plant's products in the U.S. health care system as a dietary supplement, the population of the Mount Cameroon area community based organisations are becoming more organised to secure more benefit for themselves and future generations.

\section{THE PRODUCTION-TO-CONSUMPTION SYSTEM}

\section{The resource base}

Three major forest types are reported to occur in the Mount Cameroon area, namely agricultural fallow (15\%), secondary forest (35\%) and closed-canopy primary forest (50\%) (Ndam 1998). P. africana is an evergreen species occurring in montane areas at a minimum elevation of approximately $900 \mathrm{~m}$ (Hutchinson and Dalziel 1958). In the Mount Cameroon region, the raw material production area represents $2,000 \mathrm{~km}^{2}$ with mixed distribution patterns of isolated and clustered individuals (ONADEF unpublished report). The distribution of the species

Figure 1. Concentration of Prunus africana on lava flows

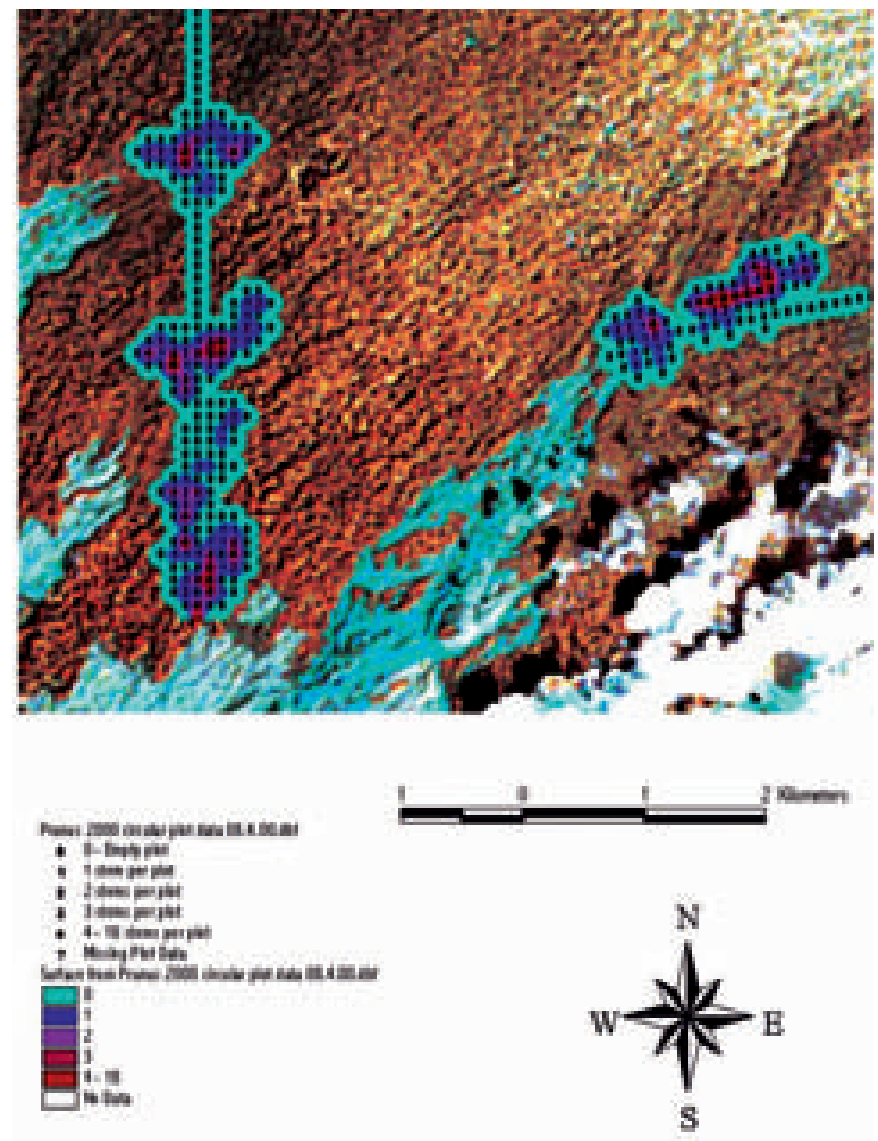


is also closely associated with mean annual temperatures of $11^{\circ} \mathrm{C}$ to $19^{\circ} \mathrm{C}$ in the coolest months and $17^{\circ} \mathrm{C}$ to $23^{\circ} \mathrm{C}$ in the warmest (Fraser et al. unpublished report). It is also evident on Mount Cameroon that $P$. africana thrives in dense stands in areas recently disturbed by volcanic activity, being one of the first species to colonise and form a forest canopy on recent lava flows. Figure 1 illustrates how Prunus africana is heavily concentrated (density represented by colours and numbers) on recent incursions of lava into montane forest areas and disappears completely from the climax (undisturbed) montane forest, as on the north-western flank, which has for the most part not been affected by lava flows for some centuries. Figure 2 shows the main area of $P$. africana occurrence in the study area. The mean density of $P$. africana individuals on Mount Cameroon with a diameter at breast height (DBH) of greater than $20 \mathrm{~cm}$ is estimated at 5.5 trees/ha (ONADEF unpublished report).

The soil in the Mount Cameroon area is volcanic based and such recent laval soils with their associated pyroclastic ash are highly useful for commercial agricultural purposes (FAO-UNESCO 1977). The land use system in the raw material producing area is not in particular conflict with the sustainability of the resource in the wild because much of this intensive agriculture occurs at altitudes below the altitudinal range of $P$. africana.

There is growing interest on the part of the communities, as well as research and environmental institutions, in the domestication of $P$. africana. Basic requirements of $P$. africana seed production and nursery have been studied by Sunderland and Nkefor (1997) and, more recently, by the International Centre for Research in Agroforestry (ICRAF) for vegetative multiplication (Tchoundjeu et al. 2002). Sunderland and Nkefor (1997) reported that, if basic cleaning and storage requirements of Prunus seeds are satisfied, Prunus seeds maintain

Photo 1. Measuring dbh of large individual of $P$. africana (Photo by T.C.H. Sunderland)

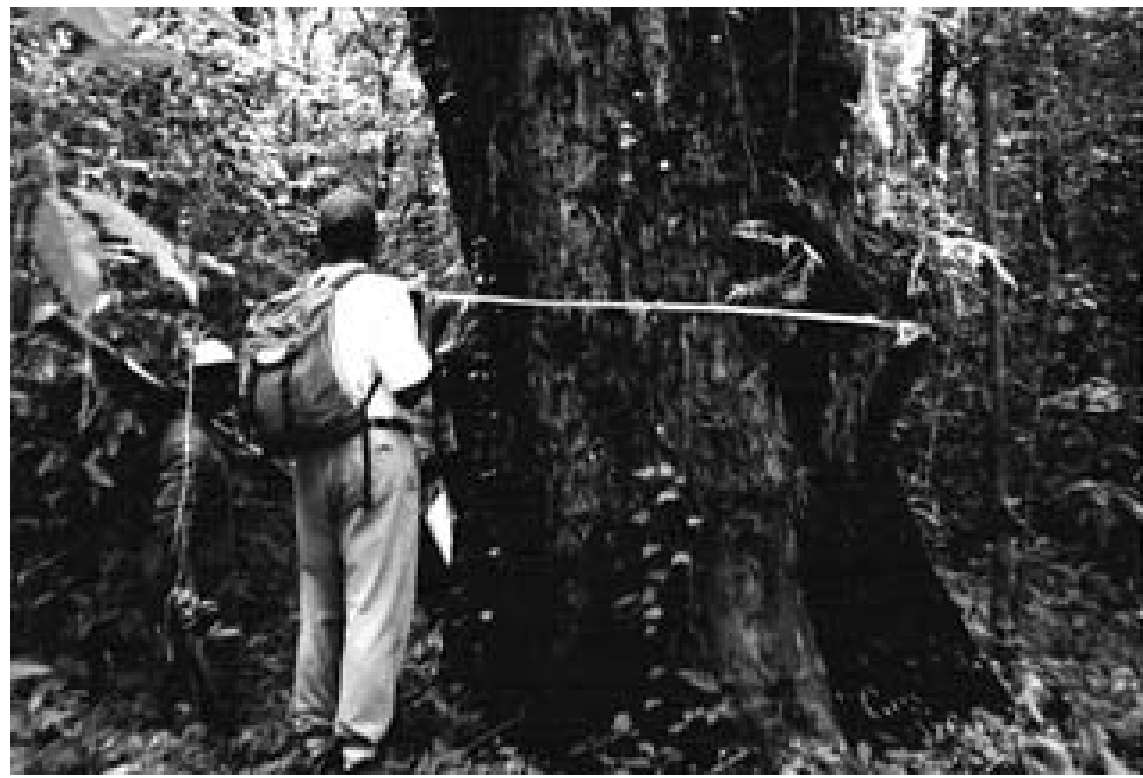


Figure 2. Main area of $P$. africana occurrence on Mount Cameroon

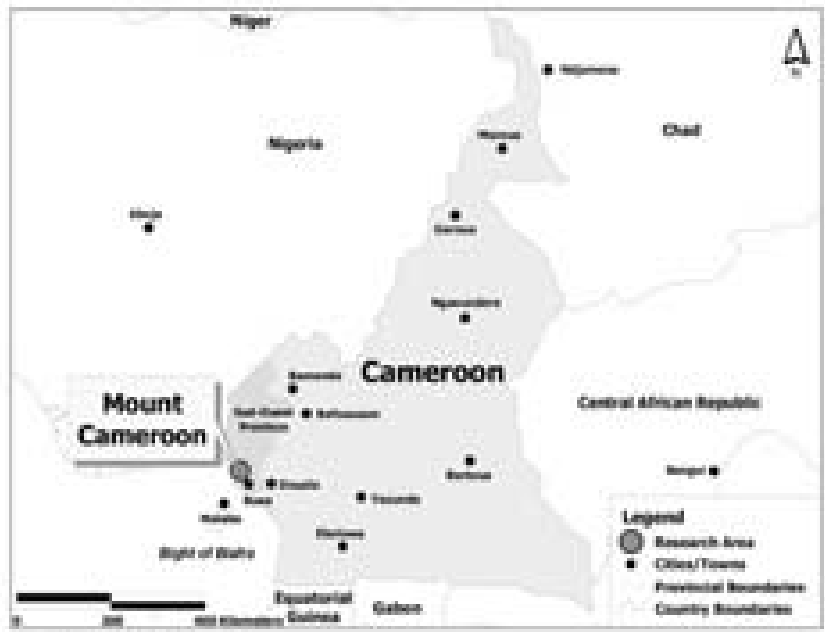

Source: ESRI Data and Maps 2002.
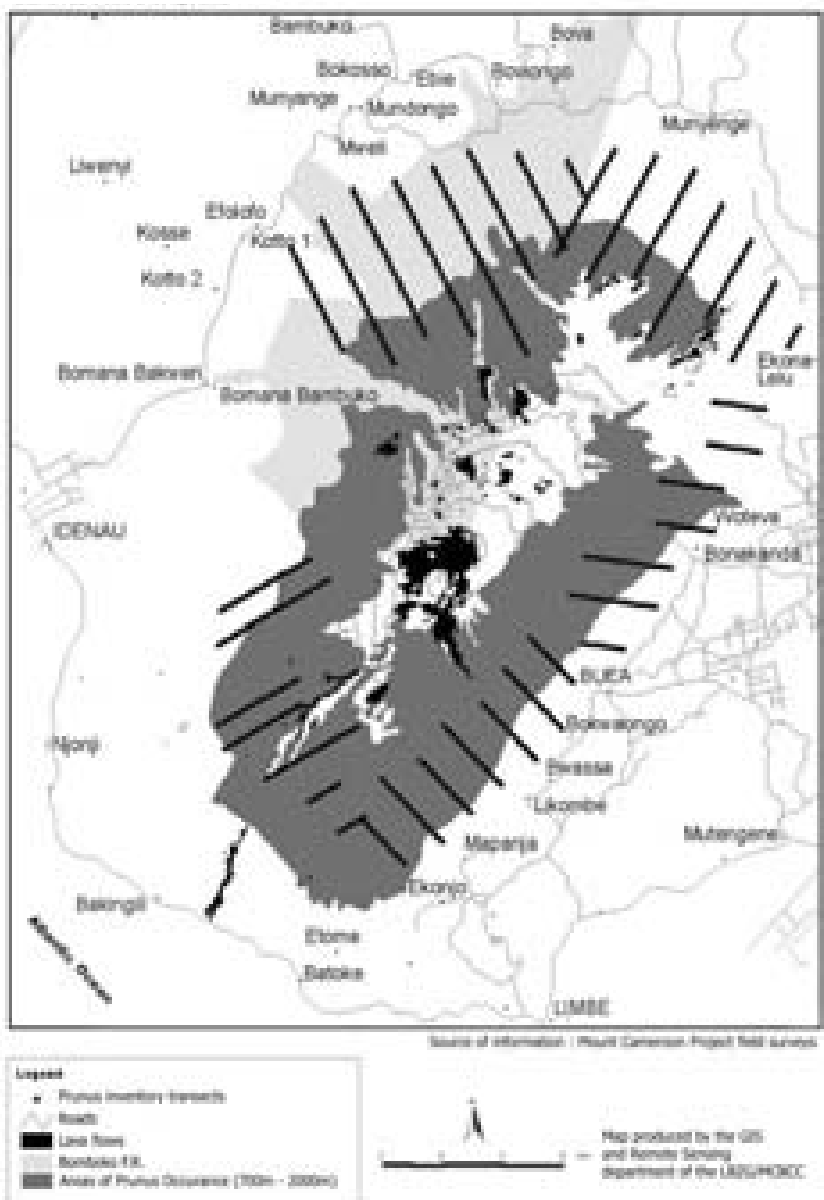
viability and high germination rates. Preliminary results of the study of vegetative propagation of $P$. africana by cuttings showed that the rooting percentage was greatly influenced by rooting medium, auxin content and the cutting leaf area (Tchoundjeu et al. 2002).

In terms of industrial cultivation, to date only 9 ha of pure plantation have been established at Moliwe, just outside Limbe, by the Cameroon Development Corporation. A further 3 ha of enrichment planting (more than 3,000 seedlings) was established by Plantecam in 1998-99 at $1000 \mathrm{~m}$ altitude on the Mount Cameroon in the Bambuko forest reserve area.

Following the prescribed methods (Nkuinkeu and Remi 1998) for sustainable harvesting of $P$. africana, trees are peeled starting at $1.0 \mathrm{~m}$ to $1.5 \mathrm{~m}$ above the ground level removing opposite quarters two or four depending on the diameter of the tree (Figure 3). If the DBH is greater than $50 \mathrm{~cm}$, four sections representing $50 \%$ of the tree circumference will be debarked from opposite sides representing four eighths of the tree circumference from four opposite sections instead of two (Figure 4). Even when harvesters adhere to these guidelines, however, poor techniques expose the trees to pests, diseases and other die-back, much of it stemming from physiological stress. In addition to direct tree felling, dieback following harvest is leading to a significant decrease of the wild population.

Figure 3. Two opposite sections of Prunus tree debarked when $30 \mathrm{~cm}<\mathrm{DBH}<50 \mathrm{~cm}$

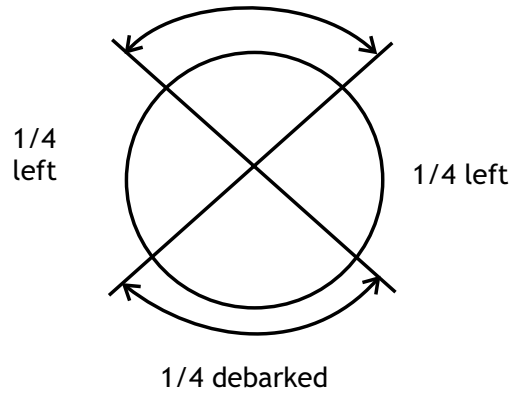

Source: Nkuinkeu and Remi 1998.

Figure 4. Four opposite sections of Prunus tree debarked when $\mathrm{DBH}>50 \mathrm{~cm}$

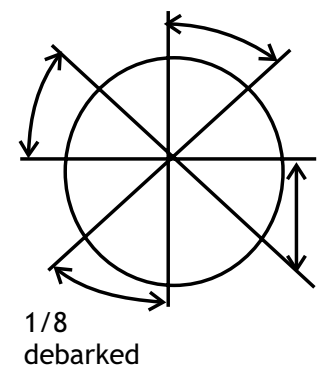

Source: Nkuinkeu and Remi 1998. 
Photo 2. Stripped stem of P. africana. (Photo by T.C.H. Sunderland)

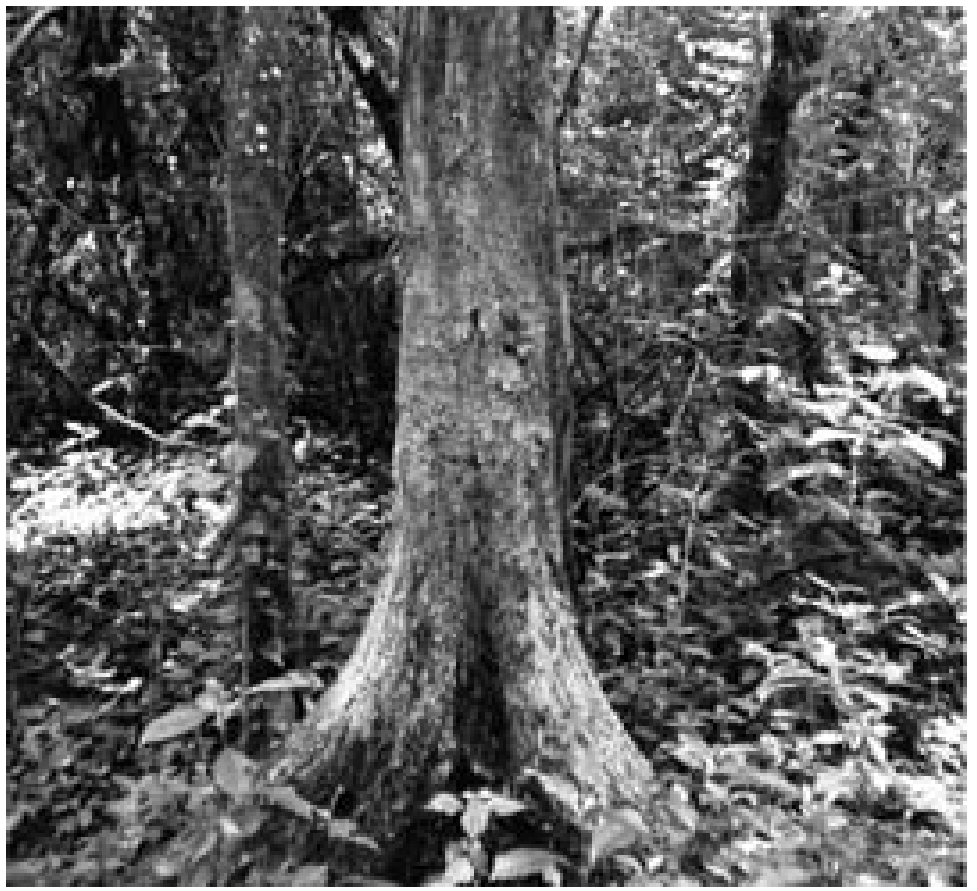

The mean duration of flowering of $P$. africana reported to date is 10 days (Pouakouyou personal communication). P. africana is an outbreeding species, and insects and the wind reportedly are the main pollinators (Hamilton 1972). In the Mount Cameroon area, birds and mammals feeding on the fruits are reported as major dispersers of Prunus seeds (Cunningham and Mbenkum 1993). Light is seemingly required for the regeneration of $P$. africana (Sunderland and Nkefor 1997), and Ndam (1998) found that regeneration of Prunus seedlings is greater in secondary forest.

\section{Raw material producers and the socio-economic context}

The Bakweri people are the major ethnic group on Mount Cameroon, the Bambuko and Balundu also being indigenous to the region. However, there are significant numbers of migrant labourers also involved in non-timber forest products (NTFP) exploitation, and particularly in $P$. africana harvesting. At the outset when Plantecam was launching Prunus activities in the area, skilled workers were brought from the north-west and western provinces of Cameroon, where exploitation had first started. Gradually, the communities around Mount Cameroon began to realise the economic importance of the species and became increasingly involved in its exploitation. Today, the sale of Prunus bark is one of their major sources of periodic income. The communities in this area are mostly living from farming activities, growing food crops such as coco-yam, pepper, plantains etc., which are sold in the nearby periodic markets. Farming 
is the major activity in the area, and Prunus africana harvesting supplements household income.

Prunus exploitation and harvesting is a strenuous activity mostly involving young men in the village. Female participation is limited to feeding their husband to get them ready for their strenuous daily duties. Women are also responsible for planting Prunus seedlings (often wildlings collected by their husband) on their farms. During the production season from May to September $60 \%$ of the households in the raw material production area are involved in the production-to-consumption system. $P$. africana is the major source of their income and accounts for $70 \%$ of the US\$71 average annual income from their various activities. This income is very low, compared to the US\$600 national average recorded in 2003 or the US\$500 for the data year of 2000. On average, rural producers spend about US\$2.15 for daily labour expenses, mainly to purchase drugs and the inconsistent daily meal. Married rural workers may spend less than this amount considering they get their breakfast at home and carry up to the mountain the meal required for the day.

\section{The processing industry}

Tonye et al. (1999) reported on the various steps involved in the processing of $P$. africana bark. In this chain, the input of local workers is limited to the drying stage at the outset of the process, where bundles of 20 to 30 pieces of fresh bark are sun-dried to less than $38.5 \%$ moisture content. The dried bark is then supplied to Plantecam which, until recently, was the sole processing industry in the Mount Cameroon area ${ }^{4}$. Plantecam used to pulverise or 'chip' the bark before the extraction process. Further processing leads to a noncrystalline extract in a red transparent paste with as much as $20 \%$ pure extract depending on the solvent used. These can include methanol, distilled water, chloroform, methylene chloride, benzene, cyclohexane, petroleum ether, acetone and methylethylketone. From recent data, it is estimated that $200 \mathrm{~kg}$ of fresh bark yields $1 \mathrm{~kg}$ of extract (Pomatto unpublished report).

\section{Trade and marketing}

At the time of data collection Plantecam was the only company in the study area processing $P$. africana bark supplied or acquired directly from the harvesters without intermediaries or middlemen. The market line therefore starts from the products extracted from the wild, continues to the village storing place, where the sun-drying takes place and from where Plantecam collects the products that will be weighed at the entrance of the factory (Figure 5). The raw material price depends on the product's moisture content and degree of adulteration with non-Prunus bark. With these criteria the price range is estimated at US\$0.3 to US\$0.41 per kilogram of bark at the factory gate (Tonye et al. 1999).

The extract processed here was subsequently exported to Groupe Fournier. It is not the only destination. Plantecam also sold raw extract to other processors and pharmaceutical companies, where it is refined and capsules or tablets (final products) are filled with $25 \mathrm{mg}$ to $50 \mathrm{mg}$ of Prunus extract ready for 


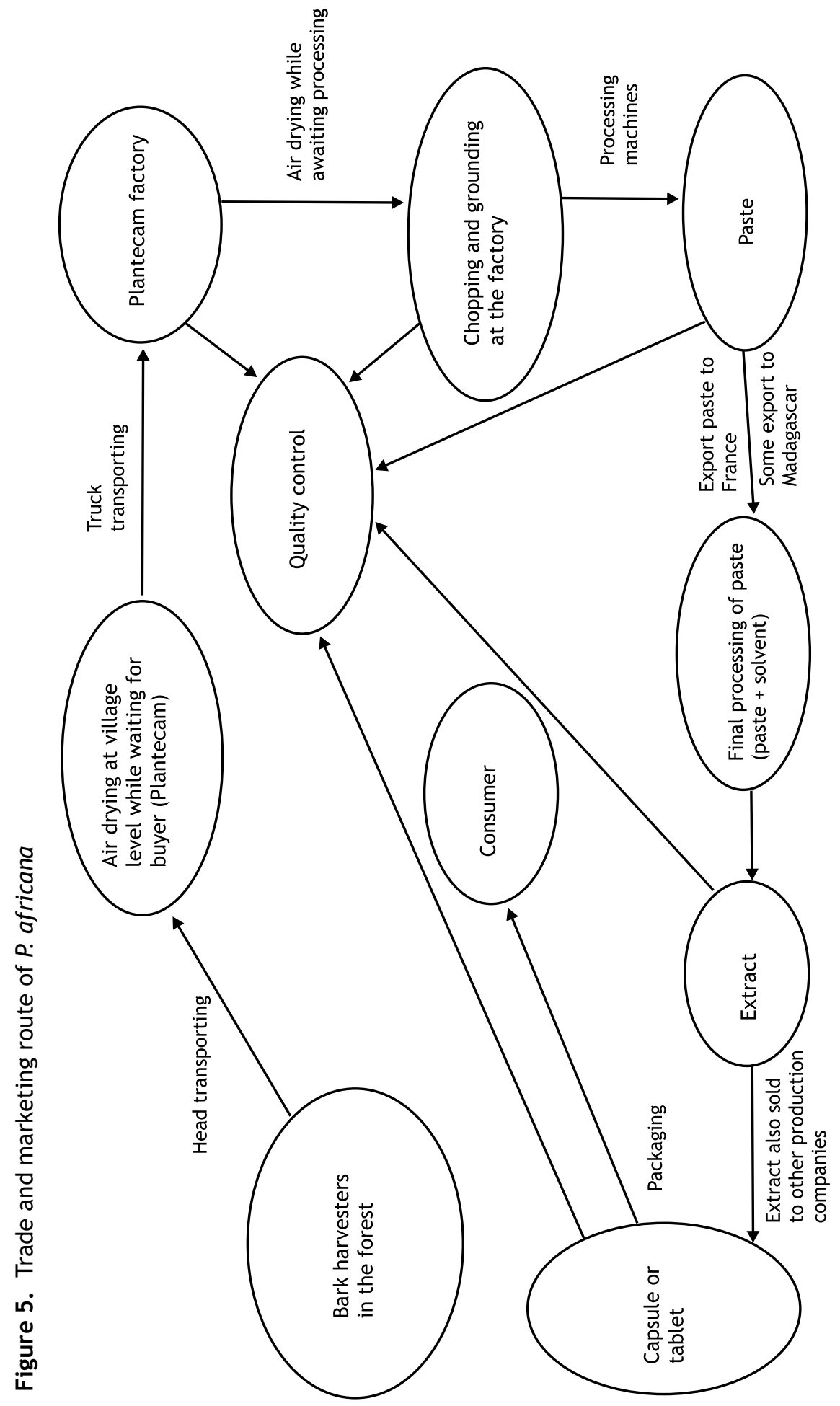


consumption (Nkuinkeu and Ndam unpublished report). In the year of data collection, the international trade volume of $P$. africana bark extract was $10,000 \mathrm{~kg}$ to $15,000 \mathrm{~kg}$. Groupe Fournier accounted for approximately 5,000 $\mathrm{kg}$ to $7,000 \mathrm{~kg}$ of the overall quantity (Acworth unpublished report), which is the equivalent of between 1,000 tonnes and 1,400 tonnes of fresh bark. These figures correspond well with those reported for annual exports of $P$. africana bark in the late 1990s (Cunningham et al. 1997). During the period 1994-96 this amount was harvested annually by Plantecam and illegal operators from Mount Cameroon alone, resulting in a severe overexploitation of the natural population.

\section{Policy environment}

The policy and regulations affecting the exploitation of NTFPs and special products in Cameroon, and $P$. africana in particular, are primarily influenced by the National Forestry Law. Law No. 94/01 of 20 January 1994 specifies forestry, wildlife and fisheries regulations and covers $P$. africana. In addition, the National Forestry Action Plan developed in 1996 and the Emergency Action Plan put in place in 1999 as an implementation mechanism of the outcomes of the Central African heads of state summit all have provisions for the sustainable management of forest resources and recognise $P$. africana as a resource of important contribution to Cameroon's national economy. The creation by presidential decree No. 98/345 on 21 December 1998 of the Directorate of Promotion and Transformation in the Ministry of Environment and Forestry, including the subdirectorate in charge of NTFPs, emphasised the consideration authorities gave the NTFP sector (Ndibi and Kay 1997).

The financial laws also have significant impact on this sector as far as regulating taxes is concerned. Specifically, Article 5 of the 1998/99 and Article 11 of the 1999/2000 finance law fix a tax of CFA10/kg of any resources harvested and a duty of $5 \%$ on any resources exported. The impact is minimal in terms of the overall value of the product as the tax represents less than $5 \%$ of the value of the raw material. Moreover, this money has not been reinvested in regeneration of $P$. africana. However, in the field of NTFP exploitation policy tools often suffer from either lack of adequate implementation or considerable weaknesses in monitoring.

\section{TRENDS AND ISSUES}

\section{Dynamic changes}

Bush fire and volcanic eruptions constitute the major natural disturbances of the case study area. In the Mount Cameroon area, no products are competing with $P$. africana in the commercial treatment of prostate disorders. Additionally, the plant's products such as leaves and bark are used in the treatment of other sicknesses including stomach ache and malaria. Hence the plant is an important component in the traditional health care of the communities around Mount Cameroon (Cunningham and Mbenkum 1993). 
The majority of the exploitation is carried out in state forests; $90 \%$ of the production takes place on state land, the rest on communal land, allowing for less conflict among the population for access to this species. So far most of the production is undertaken from wild populations and managed populations in the natural environment of the production area. The drastic decrease of the wild population because of overharvesting should be an incentive for more emphasis on cultivation in order to meet the future demand for raw material. Although Prunus planting is gaining ground in people's habits around the mountain, only about 20,000 seedlings have so far been planted in individual farms within the framework of agroforestry practices. In addition to higher levels of planting in the North West Province of Cameroon (Cunningham et al. 1997), some notable efforts have been undertaken by the industry (Plantecam) in the field of artificial regeneration around the Mount Cameroon area. With $P$. africana cultivated stands by the village surroundings, the balance sheet of gender representation in the raw material production system could change in the future, allowing more women to be involved in the production. Indeed, so far $75 \%$ of men are reported to be involved in production in the raw material production area, with around $25 \%$ of women participating mainly in the cultivation aspect, when men have already carried the wildlings from the forest to the farms.

In the year of data collection, although state intervention was increasing, trade and marketing of $P$. africana products was also increasing because of the nearby demand for raw materials by Plantecam trying to supply the powerful production machines of its factory at Mutengene. The communities organised in Harvesters Unions developed internal rules of sharing the outcomes from Prunus activities. But it should be understood that it is the processing industries and factories which benefit much from Prunus trade and marketing, considering the price variation of $26 \%$ to $28 \%$ between raw material and end product at the consumption stage. The laws in place unfortunately do not allow the communities to fully participate and earn consistent benefits from the exploitation and trade of $P$. africana products. Even the communities around Mount Cameroon, which show their commitment to the sustainability of this species, have serious constraints on their participation in Prunus trade and marketing. But with even the little the communities can earn from their involvement in these activities, it is clear that their means to satisfy their needs have improved. The youths have learned enough about sustainable exploitation and cultivation techniques. With these results from $P$. africana alone, local communities have realised the high importance of forests resources in poverty alleviation, and now the tendency is to get more involved in forest production activities in general and the production-to-consumption system in particular. Thus, the NTFP portfolio of communities around Mount Cameroon is obviously not limited to $P$. africana, but integrates other forest resources such as bush meat, eru (Gnetum spp.), bush onion (Afrostyrax spp.) and bush mango (Irvingia spp.).

As far back as at the outset of the exploitation and trade of $P$. africana products in Cameroon, international donors and processing industries have been the main counterpart in conservation as well as exploitation activities. Concerning exploitation, with the 1994 Forestry Law, more Cameroonians were 
provided with the opportunity to get more involved in this activity. As for conservation, numerous international organisations such as Britain's Department for International Development, Germany's Gesellschaft für Technische Zusammenarbeit, the World Wildlife Fund, ICRAF, the Center for International Forestry Research, etc. have had considerable impact in the enhancement of research in various angles on $P$. africana. This has helped in the organisation of communities for wise management.

\section{Key issues and problems}

With the series of measures taken for the sustainable management of $P$. africana within its range of distribution, Cameroon has emerged as an example in the good management of this useful species. To date, within the raw material production sector in Cameroon, there already exists at the national level an organisation of $P$. africana exploiters, which brings together all exploiters and exporters of Prunus products in annual meetings to discuss issues of common concerns. The organisation is more than five years old and consists of around 60 members. While there are no social or economic barriers, both technological and regulatory barriers seriously impede the functioning of this organisation. The exploiters in this organisation are not trained foresters and therefore the majority of them are unaware of good forest management practices. Furthermore, they do not have any permanent field qualified forest technician in the teams operating in their forest concessions, as required by the forestry law. In the raw material production area, there are in general customary laws in relation to access and use of natural resources as a whole, but during our research, we did not come across rules with specific references for $P$. africana. At the government level, there exist regulations that influence raw material production, but their impact on the promotion of equitable sharing of outcomes deriving from $P$. africana or really influencing the production of raw material have been mitigated. A key problem the policy and regulatory should solve is setting measures that facilitate better access to exploitation permits and other licensing procedures for the local communities that have already proven their commitment to sustainable management of the species. The government also should give regulatory incentives to professional private operators (with an agreed limit) who need to transform Prunus bark collection locally. By so doing we shall move gradually to equitable sharing of outcomes deriving from $P$. africana.

Apart from this regulatory aspect, further research is urgently needed that will provide a scientific base for the development of better harvesting methods of Prunus bark. The harvesting methods being applied are suggested from observations made during field surveys and have no scientific base, though they have so far proven their efficiency so far as bark recovery has already been observed. The study currently being undertaken by the National Museum of Paris in conjunction with Université de Jussieu Paris 6 of Paris, France, on the physiology of $P$. africana bark recovery will throw more light on this issue. Other gaps and studies underway include research into the understanding of the reproductive biology of $P$. africana and the mechanisms involved in the flowering and fruiting of the species (Pouakouyou personal communication). 
Further studies on the natural regeneration of Prunus in the wild with the establishment of permanent plots for regular monitoring will solve several problems and therefore improve the state of research on $P$. africana (Ndam 1998). Another interesting development being implemented by ICRAF is the 'effective selection of $P$. africana using active ingredient content' (Nkuinkeu 2001), a study which intends to supply farmers around Mount Cameroon with superior planting materials (clones).

In addition, the study underway aiming at developing a legislative framework for the setting of exploitation and exportation quota, in compliance with the Convention on the International Trade in Endangered Species of Flora and Fauna (CITES) requirements for developing Non-Detriment findings for species in the international trade will be a serious step forward towards getting laws and regulations developed that will have positive impacts on raw material production and consequently promote the sustainability of the species (Cunningham et al. 1997).

Other issues of relevance in the Prunus sector relate to the integration of household income into the cash economy within the production-to-consumption system. The provision of this particular information, which might come from indepth socio-economical investigations in the area, will guide conservationists and development agencies in their approach particularly to the management of wild populations. The link between the communities around Mount Cameroon and this particular resource could then be fully evaluated.

Still in connection to this relationship between resource and community, while checking how the rural population in the Mount Cameroon area depends economically on the income generated from $P$. africana activities, traditional matters that have so far been overshadowed by the various stakeholders (communities, researchers, conservationist, policy makers) should henceforth be considered as issues of high concern. Like any other community, the people around Mount Cameroon area have inherited customary rules from their ancestors, rules which have from time immemorial been applied in their traditional system of natural resources management. However, the populations in this area have not yet affirmed themselves regarding traditional rules governing specifically the exploitation of $P$. africana. Along this line, more emphasis should be put on the enhancement of local communities' awareness of their traditional rights to resources.

In the trade and marketing components, two main operators can be mentioned without going into first, second or third order trader. There was the main buyer, Plantecam, and the local communities, i.e., the harvesters, as the supplier of raw material. Other actors are the Mount Cameroon Project/Limbe Botanic Garden and the Ministry of Environment and Forestry, playing the roles of facilitator and controller and helping the principal actors in the set-up of and compliance with equitable benefit sharing schemes. Occasionally, illegal exploitation and trade are reported in the area adding difficulties to the provision of absolute numbers of operators involved in these activities around the mountain. It is consequently understandable that the assessment of the size of trade in the raw material production area and the related issues of the size of national trade and of the raw and semiprocessed products export trade are unclear and need further attention.

Apart from Plantecam, which was the sole processing industry established in the raw material production area and known as being an extension of Groupe Fournier, no other clear relationship between the communities and any other 
processing firm with a contact in the raw material production area was mentioned to us, unless it falls within illegal practices. Even as far as international surveys are concerned (undertaken by ICRAF), the pharmaceutical industries in the West are tight-lipped about their sources of raw materials acquisition.

\section{CONSERVATION AND DEVELOPMENT LESSONS OF CASE STUDY}

As earlier mentioned, the communities involved in $P$. africana activities are earning much needed income from their participation in the trade. This income could be increased if communities reviewed their partnerships with exporters or processing industries and the legislative and regulatory framework provided them with more tenure security over the resource.

The international trade in $P$. africana bark has long been recognised and the species was included in Appendix II of CITES during the ninth meeting held in 1994 in Harare, Zimbabwe. So far, however, information for the determination of sustainable yields, needed for the adequate implementation of legislation, is limited. Hence the study underway on the physiology of bark recovery of this tree under various harvesting regimes is crucially relevant. With the significant increase in the world's ageing male population and the increasing interest in natural products, demand in $P$. africana is likely to increase in coming years. The rate at which this species is exploited-and therefore declining in the wild-raises doubts on whether the wild populations will be able to satisfy demand in the future. Therefore, emphasis should be laid now on conservation through cultivation. That would likely satisfy future demand for $P$. africana products. Strategies that are being developed in Cameroon and other countries for the sustainable management of remnant wild populations with the participation of interested communities need to be continued. The benefits to local communities from involvement in $P$. africana activities are a significant incentive for their commitment to the conservation of this species. Decision makers should put in place a transparent mechanism that will enable farmers and community based organisations to use forest regeneration taxes (paid by Prunus exploiters) directly in order to finance a planting programme. But as far as considering industrial exploiters and exporters of Prunus products, the desire to always increase their benefit margin by exploiting as much as possible often leads to overexploitation-and even illegal activities. However, although such excessive exploitation was common in the past, with the participation of the communities today, these problems are being solved with the setting of exploitation quotas for individual harvesters and the reorganisation of harvesters into monitoring and control groups. Occasionally these groups seize the products of those who dare to undertake illegal practices.

\section{ACKNOWLEDGMENTS}

The authors of this report, and through them the Limbe Botanic Garden, warmly express their gratitude to the Centre for International Forestry Research for giving them another opportunity to contribute to this important process using $P$. africana as a case study. This 'case comparison' study project has been 
highly relevant to the NTFP sector in the Mount Cameroon region, particularly in highlighting gaps in our knowledge base. Hopefully, these identified gaps will be filled by future studies.

\section{ENDNOTES}

1. "Chop, but no broke pot" is an African statement that calls for sustainablity when using resources, it means use the resources now and save some for the future.

2. Conservator and Research Coordinator, Limbe Botanic Garden P.O. Box 437 Limbe, Cameroon. E-mail: nouhou_n@yahoo.com; Lbg@bifunde.com; Lbgmcp@camnet.cm

3. Phd student Queen Mary College, University of London. E-mail: tonyemah@yahoo.com

4. Plantecam ceased operations in Cameroon in 2000.

\section{REFERENCES}

Achoundong, G. 1995 Prunus africana, Rosacée, essence á découvrir. Bois et Forêts des Tropiques 245: 122-124.

Bombardelli, E. and Morazzoni, P. 1997 Prunus africana Hook.f. Kalkman. Fitoterapia 68(3): 205-218.

Carter, E.J. 1992 Limbe Botanic Garden and Rainforest Genetic Conservation Project: socio-economic and institutional study. Final Report to the Overseas Development Agency, London. 52p.

Cunningham, M., Cunningham, A.B. and Schippmann, U. 1997 Trade in $P$. africana and the implementation of CITES. German Federal Agency for Nature Conservation, Bonn. 67p.

Cunningham, A.B. and Mbenkum, F.T. 1993 Sustainability of harvesting Prunus africana bark in Cameroon: a medicinal plant in international trade. WWF/ UNESCO/KEW People and Plants Working Paper No. 2. 28p.

Food and Agriculture Organisation- United Nations Educational, Scientific and Cultural Organisation. 1997 Soil map of the world: 1:5,000,000. 6. Africa. UNESCO, Paris. 299p.

Hall J.B., O’Brien, E.M. and Sinclair, F.L. 2000 Prunus africana: a monograph. A report to the Forestry Research Programme of the UK's Department for International Development. 91p.

Hamilton, A.C. 1972 The interpretation of pollen diagrams from highland Uganda. Palaeocology of Africa 7: 45-149.

Hutchinson, J. and Dalziel, J.M. 1958 Flora of west tropical Africa, vol. 1 pt. 2. Crown Agents, London. 426p.

Ndam, N. 1998. Tree regeneration, vegetation dynamics and the maintenance of biodiversity on Mount Cameroon; the relative impact of natural and human disturbance. Ph.D. Thesis, University of Wales, Bangor. 315p.

Ndam N., and Ewusi, B. 2000. Case study: income from P. africana. In: Price, M.F. and Butt, N. (eds.) Forests in sustainable mountain development, a state of the knowledge report, 306-309. CABI Publishing, Wallingford, UK. 
Ndibi, B.P. and Kay, E.J. 1997. The regulatory framework for the exploitation of medicinal plants in Cameroon: the case of Prunus africana. Biodiversity and Conservation 6: 1409-1412.

Nkuinkeu, R. 2001 Effective selection of P. africana Hook.f. Kalkman using active ingredient content. Funding proposal submitted to ANAFE. 11p.

Nkuinkeu, R. and Remi, V. 1998. Procedure de la technique d'ecorcage du Pygeum africanum. (Unpubl.) report to the Mount Cameroon Project Limbe. 22pp.

Sunderland, T. and Nkefor, J. 1997. Conservation through cultivation, a case study: the propagation of Prunus africana. Tropical Agriculture Association Newsletter (Dec.): 5-12.

Tchoundjeu, Z., Avana, M.L., Leakey, R.R.B., Simons, A.J., Asaah, E., Duguma, B. and Bell, J.M. 2002 Vegetative propagation of Prunus africana: effects of rooting medium, auxin concentrations and leaf area. Agroforestry Systems 54: 183-192.

Tonye, M.M., Asaha, S., Ndam, N. and Blackmore, P. 1999. A state-of-theknowledge study of Prunus africana. (Unpubl.) report to the Central African Regional Program for the Environment (CARPE). Washington DC. 82pp. 


\title{
Chapter 4
}

\section{Achieving a fair and sustainable trade in devil's claw (Harpagophytum spp.)}

\author{
Rachel Wynberg ${ }^{1}$
}

\begin{tabular}{llllll}
\hline Common names & $\begin{array}{l}\text { Part of the } \\
\text { resource used }\end{array}$ & Management & $\begin{array}{l}\text { Degree of } \\
\text { transformation }\end{array}$ & $\begin{array}{l}\text { Scale of } \\
\text { trade }\end{array}$ & $\begin{array}{l}\text { Geographic } \\
\text { range }\end{array}$ \\
\hline $\begin{array}{l}\text { Devil's claw, } \\
\text { Arthritis root }\end{array}$ & Root & Managed & High & International & Medium \\
\hline
\end{tabular}

\begin{abstract}
There is growing international trade in Harpagophytum spp. (devil's claw), a Kalahari plant used to treat rheumatism and arthritis. At least 9,000 rural people in Namibia, Botswana and South Africa rely on wild harvesting the plant, often as their only source of income. Increased commercialisation, combined with harmful harvesting techniques, has led to concerns about overexploitation and the status of Harpagophytum populations, and a proposed CITES listing. This paper investigates the harvesting and use of devil's claw, analyses the potential impacts of its domestication, and provides an overview of its production and trade. Three models of commercialisation are described for the species, each yielding different sets of benefits and constraints. The paper concludes that the plant holds considerable potential as a non-timber forest product that can both be harvested sustainably and deliver significant development benefits to marginalized rural communities. Several barriers, however, impede this potential from being realised, including a lack of tenure security, insufficient monitoring capacity, poor business and organisational skills, and inadequate quality and resource management. Monopoly control at the international level severely compromises the ability of communities and range states to receive optimum benefits. Constructive interventions to address these constraints are urgently needed and are receiving increased attention from decision-makers and industry.
\end{abstract}




\section{INTRODUCTION AND OVERVIEW}

One of the most thought-provoking and complex cases of commercialisation in southern Africa is that of devil's claw (Harpagophytum spp.). Roots of the plant are commonly used to treat rheumatism and arthritis and this has led to a growing international trade over the past 50 years. Increased commercialisation has also resulted in an escalation of local harvesting of the plant, and concerns about the sustainability of wild extraction. This, together with a desire to improve pharmaceutical quality, has led to investigations in the feasibility of cultivation, often without consideration of the broader social, economic and environmental impacts. The imperative for sustainable use is not only ecological. At least 9,000 rural people in Botswana, Namibia and, to a lesser extent, South Africa rely on the wild-crafting of devil's claw, often as their only source of cash income. They include some of the most marginalized communities in the region.

In all, some 600 tons to 700 tons of dried material is traded each year, worth an estimated US\$100 million in the international trade. A complex set of relationships characterises trade in devil's claw, determined to a large extent by the role of the state, and that of industry, the non-governmental sector and community-based organisations. These scenarios in turn provide different sets of national and local benefits. Overall, however, devil's claw commercialisation results in local harvesters and national economies receiving a minute proportion of benefits from the trade, and virtually no value adding occurs within the region. Although government policies are in place to protect the species and monitor its trade, their implementation is weak and thwarted by a lack of human and financial capacity. The difficulties of competing against highly sophisticated industries, combined with poor collaboration between producers and local traders, further weakens the bargaining power of developing countries in the region.

This paper explores these issues in more detail, providing an overview of the ecology of the plant, its use and sustainability, and the questions raised by efforts to domesticate the species. Insights are provided in the social and cultural aspects of devil's claw production and its trade, with emphasis on the raw material production area in Omaheke Region, Namibia. The paper concludes with a short analysis of key trends and issues, lessons learned from the case and suggested strategies to address current pitfalls.

\section{STUDY AREA AND CONTEXT}

This chapter provides an overview of trade in devil's claw in southern Africa. However, to allow for comparisons across case studies and to facilitate statistical analysis, the focus is Omaheke Region of Namibia (Figure 1). Omaheke represents one of 13 regions in Namibia, and one of the poorest in the country. It is located within the Central Kalahari Savannah, an area that receives highly variable rainfall, averaging $250 \mathrm{~mm}$ to $450 \mathrm{~mm}$ per year. In parts of this area, 328 harvesters are engaged in the "Sustainably Harvested Devil's Claw Project" (SHDC), a project facilitated by non-governmental organisations (NGO), which focuses on 12 pre-independence resettlement farms including Vergenoeg, Gemboksfontein, Blouberg, Kalahari Prag and eight farms linked 
Figure 1. Omaheke Region, Namibia

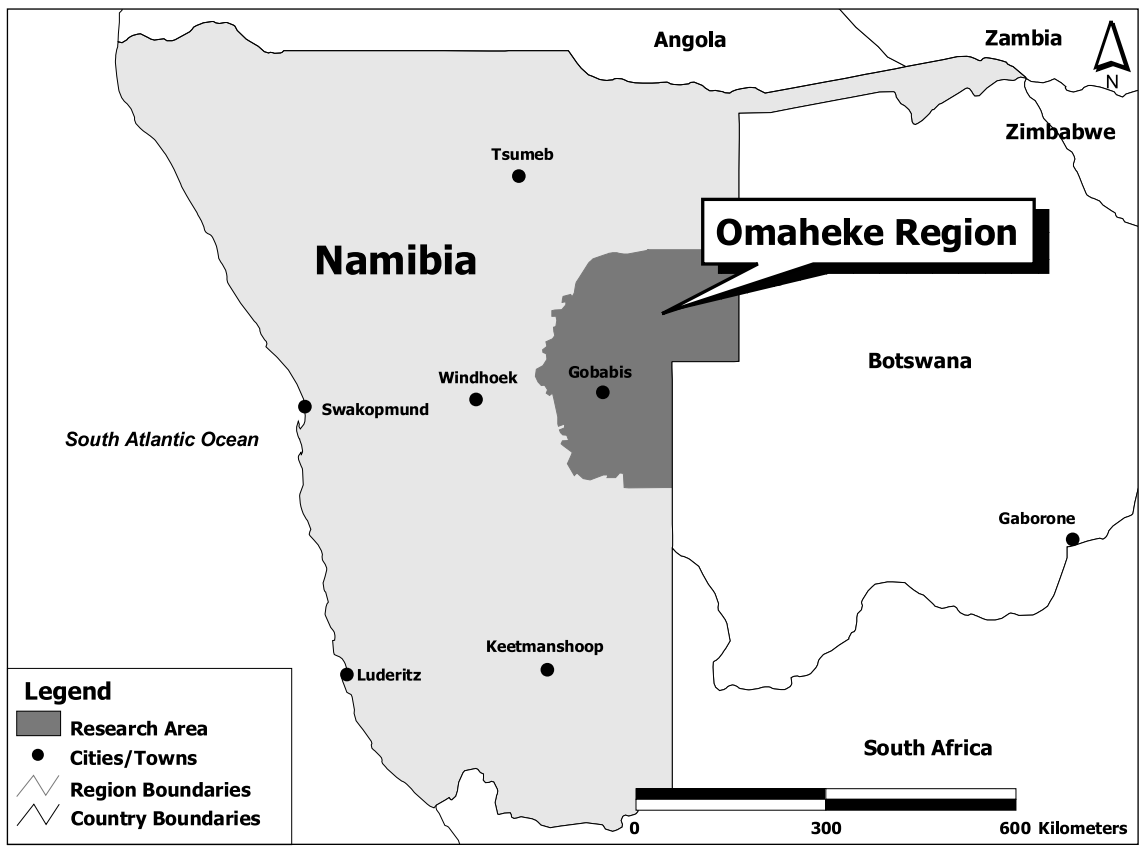

Sources: ESRI data and Maps 2002; Barnard, P. 1998; Wynberg, R. forthcoming.

to the Tjaka Ben Hur complex. These cover an area of 307,415 ha, much of which is degraded through overgrazing. Some 10 tons of raw material are traded from this area, representing $1.7 \%$ of the total devil's claw trade. The objectives of the SHDC project are:

- to enable marginalized rural communities to improve their household food security through earning a reasonable income from sustainably harvested devil's claw;

- to equip harvester groups to manage and utilise their resource independently on a sustainable basis and to facilitate their direct involvement in the trade; and

- to further demonstrate, on a scale large enough to be significant in the overall market, the viability of a fair trade in sustainably harvested devil's claw (CRIAA SA-DC 2002).

The SHDC project is atypical and illustrates the situation in a minority of communities in Namibia. Its origins lie in the initiation of a project by the Namibian NGO Centre for Research and Information Action in Africa - Southern African Development and Consulting (CRIAA SA-DC), which has enabled communities to link directly with a local exporting firm and to put in place measures to achieve sustainable harvesting. Elsewhere in Namibia, an unfacilitated 'free market' approach to the trade is in place, and harvesters are more vulnerable to exploitation. 


\section{THE RESOURCE BASE}

\section{The ecology of devil's claw}

Devil's claw, of the genus Harpagophytum DC. ex Meissn., in the family Pedaliaceae, is endemic to the Kalahari region. The plant is perennial and has a tuberous rootstock, from which prostrate annual stems spread bearing greyishgreen leaves. Its tubular flowers have a maroon to pink colour and develop into the characteristic fruits that give the genus Harpagophytum ('hook plant', when translated from the Greek) its colloquial name, devil's claw. The fruits have numerous long arms with sharp, hooked thorns, as well as two straight thorns on the upper surface (Photo 1). Dispersal of the seed occurs through entanglement of the fruit in the wool, tails or feet of animals and its subsequent implant in sandy soils (Phillips 1938), leading some to state that the name devil's claw originates from the bedevilled dance that animals do to get rid of the fruit that has run into their hooves (Moatti et al. 1983). While devil's claw is the name most widely associated with the plant, at least 20 other names are used to refer to it.

Harpagophytum occurs between $15^{\circ}$ and $30^{\circ}$ latitude in Namibia, Botswana, South Africa, Angola and, to a lesser extent, Zambia, Zimbabwe and Mozambique (Ihlenfeldt and Hartmann 1970). Two species occur in southern Africa, Harpagophytum procumbens and Harpagophytum zeyheri, which can be subdivided into five subspecies differentiated by their fruit and leaf characteristics and geographical distribution. While both species are accepted for medicinal use, it is $H$. procumbens that is mostly traded and recognised by the international pharmacopoeia (Blumenthal 1998). However, H. zeyheri is very similar in appearance to $H$. procumbens and the two species may be easily confused.

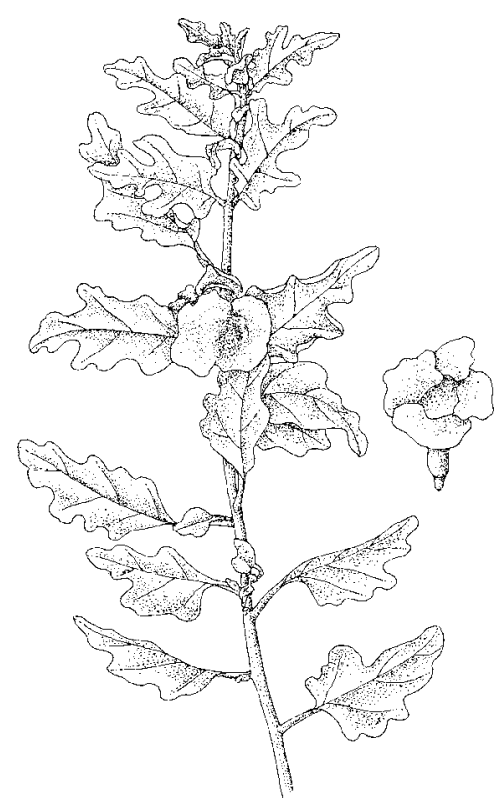

(Harpagophytum procumbens) 
Photo 1. Devil's claw flower with leaves (Photo by R. Wynberg)

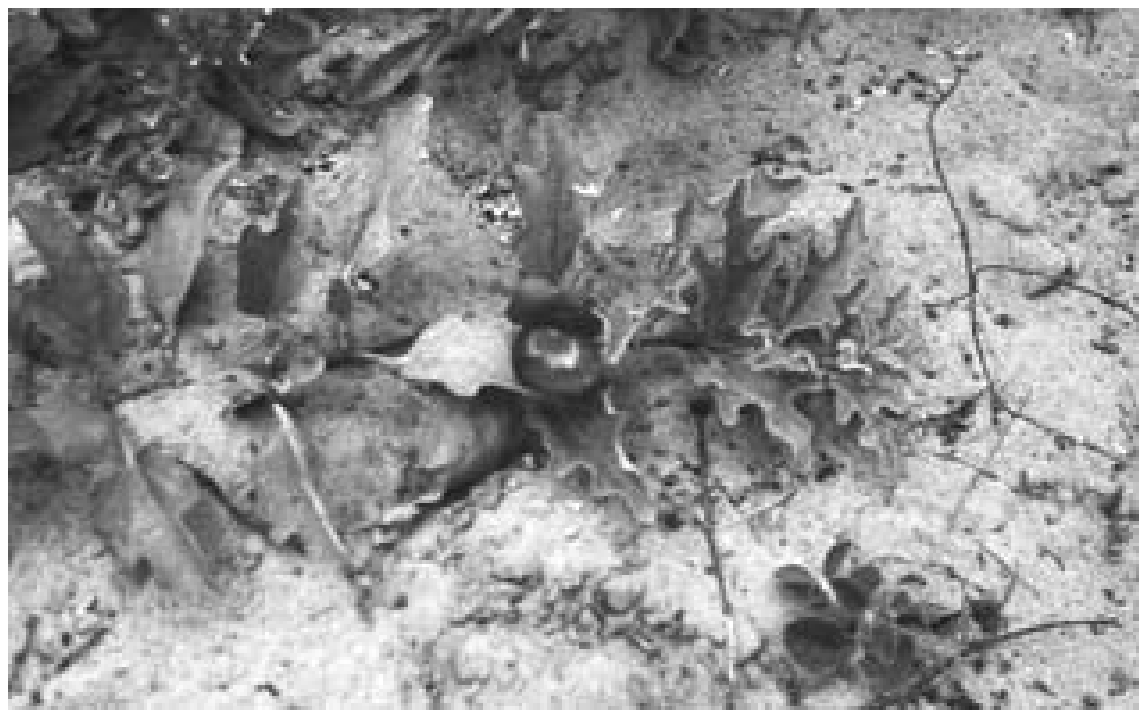

Both species are considered in this paper because of the difficulties of distinguishing between them, and because of an increasing trade in $\mathrm{H}$. zeyheri, but for the most part discussion is focused on $H$. procumbens, the species found in the study area.

H. procumbens typically occurs in the red sandy soils of the Kalahari desert, in areas coinciding with some of the driest parts of the region (Figure 2). To survive the dry period the plant forms water-storing secondary root tubers which branch off horizontally from the primary taproot, and it is these roots that are used in phytotherapy to treat a wide variety of ailments. Varying assessments suggest the secondary tubers can attain depths of $2 \mathrm{~m}$, lengths from $4 \mathrm{~cm}$ to $25 \mathrm{~cm}$, and a diameter up to $6 \mathrm{~cm}$ (Taylor and Moss 1982; Hachfeld 1999). The growing season of the plant typically commences in December, following sufficient rains, and ends in April-June after the plant has produced seeds and accumulated adequate phytosynthates to facilitate growth in the following season (Strobach 1999). Flowers and leaves of the plant are visible only during the active growing season, when suitable climatic conditions prevail. After rains these parts of the plant dry out rapidly and soon disappear, making location of the tubers extremely difficult. Both the abundance and visibility of the plant are strongly correlated to rainfall.

H. procumbens is considered a 'common weed' (Phillips 1938; Henderson and Anderson 1966) and is frequently reported to be more abundant in disturbed, trampled or overgrazed areas including road verges, firebreaks and dune slopes (Ihlendfeldt and Hartmann 1970; Nott 1986; Hachfeld 1999). Nott (1986) attributes this to the deep root systems of $H$. procumbens and the inability of the plant to compete with the shallow root systems of grasses. Because grasses use topsoil water, moisture penetration to the subsoil is reduced, as is the ability to sustain the deeper root systems of $H$. procumbens. Indeed, several authors note that the plant occurs in greater numbers where 
Figure 2. Distribution of $H$. procumbens. Data provided by National Herbarium, Pretoria Computerised Information System (PRECIS)

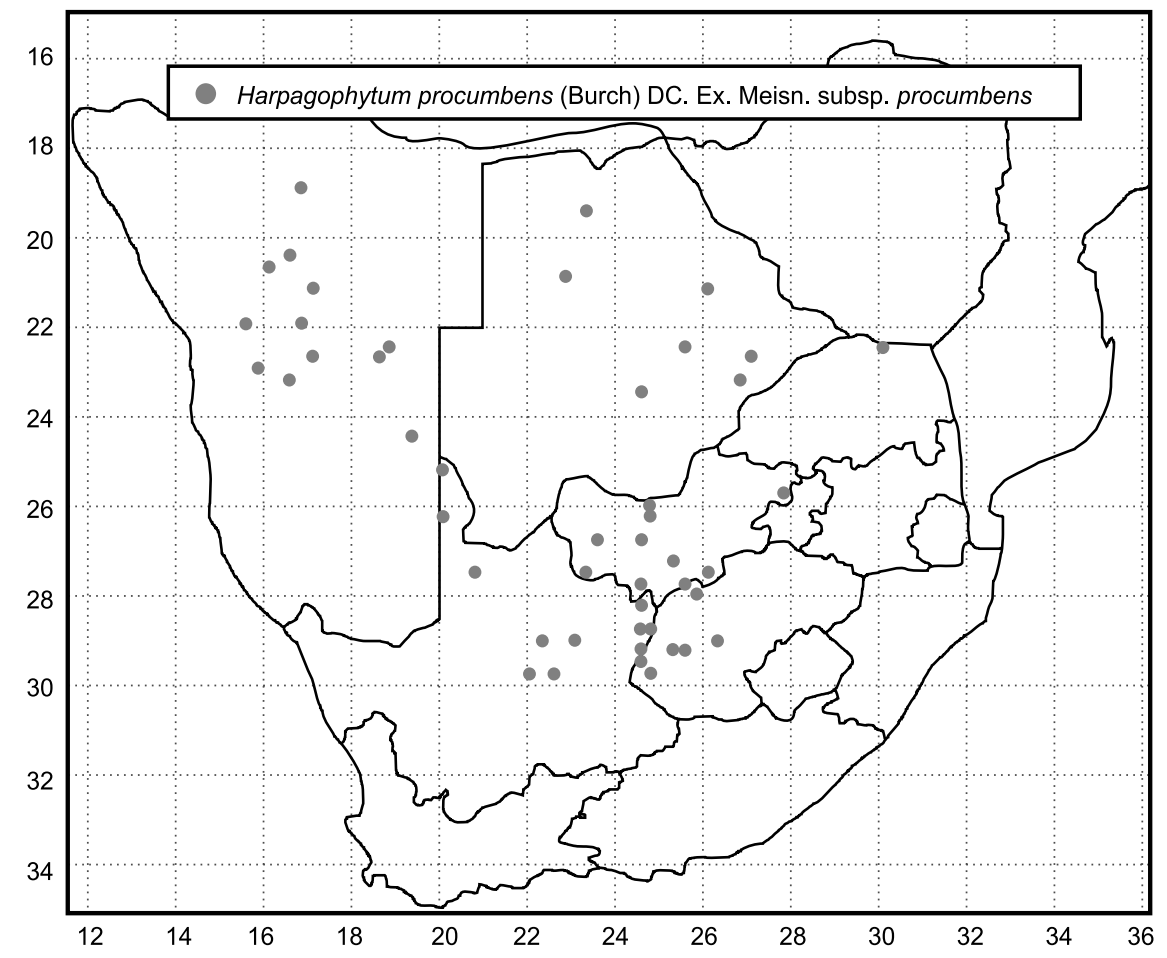

there is little perennial grass cover and sparse distribution of shrubs and trees, an observation confirmed by a recent survey among farmers in Namibia (Hachfeld 1999). Based on an average yield of $600 \mathrm{~g}$ per plant and densities of 2 to 2,000 plants/ha, biomass production of $H$. procumbens can vary from 120 $\mathrm{g}$ to $120 \mathrm{~kg} / \mathrm{ha}$ air dry weight (Wynberg forthcoming).

\section{Harvesting and processing}

Methods for harvesting Harpagophytum vary considerably from location to location and depend to a large extent on the intensity of the operation, the level of awareness among harvesters and the implements at hand. These factors in turn are greatly influenced by the levels of organisation among harvesters and by the presence of extension and support services. Although Harpagophytum can be harvested at any time of the year, digging tends to be easier and yields greater during the rainy season, when the sand is moist (Nott 1986). This advantage is offset to some extent by the difficulties experienced in drying material during the rainy season. Permit conditions introduced by both Namibia and Botswana confine harvesting to the dry period between March/April and September/October, a restriction imposed largely to curtail overharvesting. 
Two main methods of harvesting can be distinguished: complete removal of the plant and the environmentally superior 'superficial' method, which entails harvesting of the secondary tubers whilst leaving the parent tuber intact (Ntseane 1993) (Photo 2). Harmful harvesting practices are widely practised but the advantages of superficial harvesting are increasingly being recognised, and a number of government departments, NGOs and some exporters have introduced programmes to raise awareness about appropriate harvesting techniques. This includes interventions by CRIAA SA-DC described in the raw material production area of this study.

Photo 2. Secondary tuber of H. procumbens (Photo by R. Wynberg)

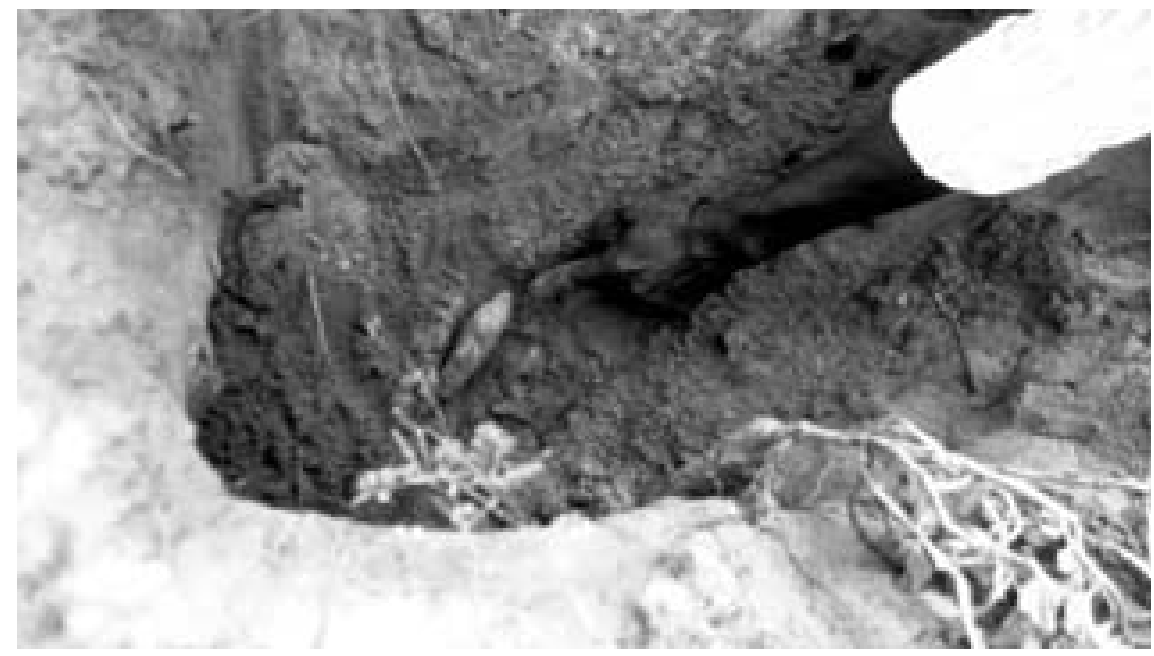

Processing of the root is relatively simple and entails washing, peeling and slicing the tuber into approximately $0.5 \mathrm{~mm}$ thick pieces, generally on the same day as harvest. Slices are then typically sun dried in a well-ventilated area, sometimes on nets suspended off the ground. The drying procedure takes two to five days but is dependent on the time of year and weather conditions. Dried and sliced devil's claw is subsequently packed into bags and stored, awaiting sale.

\section{Resource use and sustainability}

Harmful harvesting techniques, combined with the escalation of international trade in the plant, have led to growing concerns about overexploitation and the status of Harpagophytum populations. Although localised declines in $H$. procumbens populations have been recorded by several studies, little information exists on its overall population status in the region. Nonetheless, based on World Conservation Union (IUCN) criteria for overall population size, extent of occurrence or area of occupancy its status is not considered threatened (Raimondo and Donaldson 2002). Assessment is complicated by the close interrelationship between production, overgrazing and rainfall 
(Taylor and Moss 1982) and by substantial oscillations in the natural densities of Harpagophytum-both from area to area and from year to year. However, given the right conditions, including rotational harvesting, sustainable harvesting is possible, as has been successfully demonstrated by a number of important examples (Taylor and Moss 1982; Nott 1986; Schneider 1997; Lombard 2000). As a case in point, the SHDC Project conducts pre- and postharvest ecological surveys to set harvesting quotas and equips harvesters with the tools and knowledge to control quality, to monitor harvesting and to record supplies (Lombard 2000).

\section{Cultivation}

Virtually all current trade in Harpagophtyum draws on harvests from wild populations, but commercial interest in the plant, combined with concern about the overexploitation of natural populations and a desire to improve pharmaceutical quality, have led to a range of studies to investigate the plant's potential for cultivation (e.g., Blank 1973; Thusano Lefatsheng, 1995; Schmidt et al. 1998; Levieille et al. 2000). Two trends are worth noting. First, there is a high level of competition among projects, evidenced by a complete shroud of secrecy (often formalised through confidentiality provisions in contracts), an astonishing absence of collaboration and a distinct lack of published information about the technical aspects of the disparate projects. A second and related trend concerns the increasing involvement of the pharmaceutical industry and private sector in sponsoring and initiating cultivation projects, a development that reflects the vested interests of the industry to secure long-term supplies of the drug and to ensure a high quality product. With a few notable exceptions this is associated with the virtual exclusion of local research institutions from participation in the technical work required and negligible involvement of rural communities in the establishment and ongoing maintenance of projects. Instead, most cultivation initiatives to date draw upon foreign scientists and are located on the lands of commercial white farmers in South Africa or Namibia. In all likelihood these patterns do not reflect any technical constraints associated with the difficulties of cultivation, but rather a preference on the part of industry to follow paths of greatest ease.

In light of these developments it is not surprising that a vigorous and highly polarised debate has evolved as to the advantages and disadvantages of cultivating Harpagophytum, catalysed to a large extent by a proposal from Germany in 2000 to list the plant on Appendix II of the Convention on the International Trade in Endangered Species of Flora and Fauna (CITES). The proposal was later withdrawn, partly as a result of protests from range states and NGOs, leading to a CITES decision for range states and importing states to submit information on trade, management and the biological status of Harpagophytum species to the secretariat. At the recent $12^{\text {th }}$ meeting of the Conference of the Parties to CITES, the decision was taken for range states to provide an update to the next meeting on implementation of policies and management programmes and to negotiate with the industry to obtain support for management programmes that support sustainable use and community development. 
One of the main effects of CITES has been a decline in market demand, but it has also given renewed impetus to domestication and cultivation efforts, stemming from the perceptions created of an endangered resource. Although Appendix II allows for 'controlled trade' in a species rather than imposing an outright ban, successful listing will undoubtedly affect trade from the wild-and thus the livelihoods of thousands of harvesters dependent on the resource for income. Including Harpagophytum on Appendix II, it is argued, will shift the market towards preferring a cultivated product over one that is wild harvested, and thus an environment that favours agribusiness and commercial farmers over and above marginalised small farmers and local livelihoods (CRIAA SA-DC 2000a). A major concern in this regard is the role played by South Africa in successfully cultivating Harpagophytum and its potential, as a highly developed agricultural economy, to completely usurp production of devil's claw in the region and make wild harvesting redundant (Cole and du Plessis 2001). Planned cultivation projects outside of range states present a similar threat for harvesting communities and national economies in southern Africa.

What are the inputs required for cultivation and how might these restrict the involvement of small farmers and marginalized people in these activities? Although specific information is difficult to come by, irrigation is an essential requirement for devil's claw cultivation, estimated by some to be 6 liters of water per plant per week (Powell and Moolman 1999). Such requirements are clearly an impediment for marginalized communities in remote settlements, few of which have access to potable water let alone sufficient quantities for irrigation. Also pertinent is the question of the willingness and ability of communities to engage in devil's claw cultivation and the importance of (often nonexistent) extension services to support such activities (Matlhare 1994). The reality of the situation, borne out by the majority of experiences and by the stated interest of commercial farmers, is that cultivation of devil's claw is most likely to be pursued by economically privileged farmers with ready access to water, land, transport and knowledge.

This notwithstanding, many of those engaged in the devil's claw trade in southern Africa see cultivation as an inevitability that should be controlled and turned to their best advantage, rather than an activity that should be prohibited on the basis of its social impacts. The issue is obviously not cut and dry, nor the potential impacts. Although often touted as a solution to unsustainable use, Harpagophytum cultivation brings with it its own set of environmental problems, notably those associated with soil erosion, land clearing, increased salinity and genetic uniformity. Strict controls on cultivation, such as those introduced recently by the Namibian government, clearly require widespread monitoring, adherence and application throughout the region.

\section{SOCIAL AND CULTURAL ASPECTS OF DEVIL'S CLAW PRODUCTION}

Devil's claw production in southern Africa takes place in some of the most inhospitable and arid parts of the region, considered marginal for conventional agricultural production and suitable mostly for grazing. Livelihood options are thus extremely limited, and devil's claw extraction is a highly important survival strategy for the poor. Indeed, the 9,000 or so devil's claw harvesters represent 
some of the most marginalized communities in southern Africa, characterised by extremely low levels of education, acute poverty and limited access to incomeearning opportunities. This, combined with the arduous nature of the work and its low income-earning potential, has led many to comment that the harvesting of devil's claw is a 'low status' activity reserved for the poorest of the poor (see, for example, Ntseane 1993). In Namibia, CRIAA SA-DC (2000b) reports an average annual income of N\$264 (US\$26) per harvester, although this applies specifically to resettlement farms involved in the SHDC Project. Elsewhere in the country incomes of harvesters are highly erratic, varying from N\$100 to $\mathrm{N} \$ 500$ (US\$10-50), depending on the volumes harvested. While these earnings may seem low, and certainly fall well below the poverty line, they nonetheless represent an extremely important source of income in communities in which only a minority of people have formal jobs.

A diverse range of ethnic groups are engaged in harvesting and trading devil's claw, including the San, Herero, Damara, Ovambo and Bakgalagadi. Virtually no anthropological accounts exist of the trade, although it is fair to say that the most marginalized groups, and most notably the San, are those most active in harvesting the plant (Ntseane 1993). A long history of dispossession and relocation has accompanied the San, described comprehensively in Suzman (2001) and illustrated well by the situation of the Omaheke San in Namibia, who represent the majority of participants in the SHDC Project. Cole and du Plessis (2001) chart the complex history of this group who, prior to conquest by the Herero and later colonisation by Germany and South Africa, were organised into relatively stable social units attached to particular areas known as n!ores. After colonisation, groups of San were retained on commercial farms as a source of cheap labour, but over time became redundant as farm labour was reduced, and were forced to squat in road reserves or informal settlements. Following independence the Omaheke San were 'resettled' on government-owned farms in the region, together with displaced farm workers of other ethnic origins. This story of resettlement and persecution is one that has played itself out in many other parts of the region as well. It is also a narrative that forms only part of a much wider political texture for the case of devil's claw.

\section{TRADE AND MARKETS}

\section{Use and pharmacological effects}

The root of devil's claw is used widely as a medicine, both traditionally and in Western preparations. Traditional use of the tuber for fever relief, blood diseases, muscular aches and pains, digestive disorders, syphilis and as an analgesic during pregnancy is widely recorded, as is the use of pulverised root material as an ointment for sores, ulcers and boils and for difficult births (Watt and Breyer-Brandwijk 1962; Giess and Snyman 1995). Indeed, traditional knowledge was the basis for initiating Western interest in the plant at the turn of the twentieth century, thus marking one of the first and certainly one of the most significant 'biopiracy' incidents in Namibia.

Today the plant has a reputation for efficacy in the treatment of arthritis and rheumatism in Western medicine. Extracts of the tubers are used widely as ingredients in pharmaceutical preparations, herbal remedies and cosmetics 
either in preparations in the form of raw or powdered material or as standardised extracts in the form of capsules, tablets, tinctures and ointments. The main active molecules are the iridoid glycosides: harpagoside (the main compound in the fresh and dried root), harpagide, procumbide and procumboside, all of which show analgesic and anti-inflammatory properties (Czygan et al. 1977). Other potentially active chemical constituents include phenols, phytosterols and flavonoids (Ziller and Franz 1979; Burger 1987). A number of studies have demonstrated the efficacy of devil's claw as an anti-inflammatory (e.g., Lanhers et al. 1992; Chrubasik et al. 1996), and its properties are considered comparable to cortisone and phenylbutazone but without the accompanying side effects (Moussard et al. 1992). This, combined with the proven safety and efficacy of the plant and its recognition by the international pharmacopoeia (Blumenthal 1998), has led to a rapid escalation in demand in devil's claw, far surpassing historical levels of use.

\section{Trade history}

Devil's Claw has been traded internationally for some 50 years, most exports going from Namibia to Germany. Although the trade has been erratic, there has over the years been a steady increase in export volume, which in turn has led to an expansion of the area from which material is sourced to include Botswana and South Africa as well as the more remote parts of Namibia. The past five years in particular have been distinguished by a three- to six-fold increase in the amount of Harpagophytum traded, reaching a level of over 600 tons exported from Namibia alone in 1998 and 1999, and nearly 700 tons in 2001 (Wynberg forthcoming). In 2001, 92\% of the trade originated from Namibia, 5\% from Botswana, and 3\% from South Africa. Importing countries include Germany (predominantly), France, Switzerland, Spain, Portugal, Italy, the United Kingdom, the United States, South Korea, Japan, Belgium and Brazil (Wynberg forthcoming). On average, the raw material is exported for US\$1.40/kg to US\$1.80/ kg, while the finished product retails for approximately US\$140/kg. Harvesters typically receive US\$0.50/kg to US\$1.20/kg (Wynberg forthcoming).

\section{The production-to-consumption system: models of commercialisation}

A complex set of relationships characterises trade in Harpagophytum, and trade chains vary considerably from country to country and region to region. Three general models of trade can, however, be discerned at the local level (Wynberg forthcoming). The first and most prevalent pattern, which I call the 'Free Enterprise' model, typifies the situation in Namibia and involves up to 6,000 harvesters of Harpagophytum supplying local traders, who in turn supply four or five main exporting companies (Figure 3). Material may be purchased and resold several times by local traders before being sold to one of the exporters. Local traders are typically urban-based, employed entrepreneurs who have the benefit both of owning transport and of established relationships with Harpagophytum exporters. Although this model has the greatest outreach, harvesters receive the lowest proportion of financial benefits $-0.36 \%$ of the retail price. 
Figure 3. 'Free Enterprise' model of Namibia and South Africa

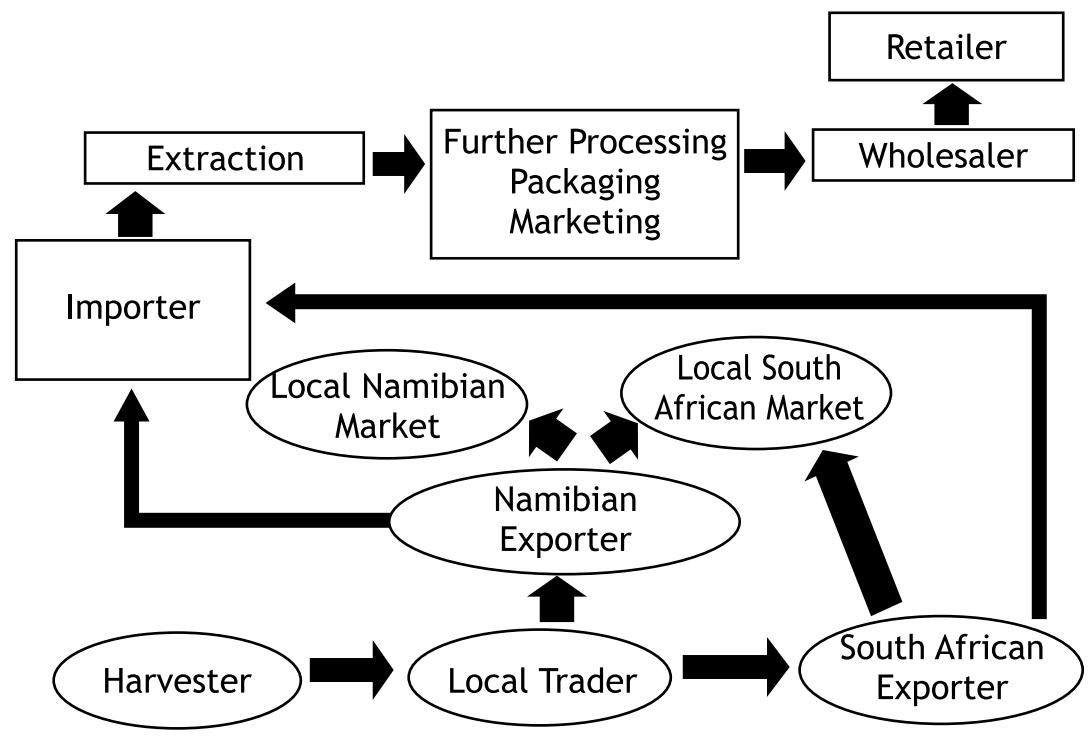

Exporters within this model are represented by about four to five established companies within Namibia, one large French exporter which works independently of either Namibian or South African firms, and an increasing number of smaller enterprises. Raw material may be (a) packaged and sold within Namibia for limited local trade, (b) exported directly from Namibia to Europe or the U.S., (c) exported to Europe or the U.S. via South African firms, or (d) exported to South Africa for local trade. Typically, it will then be passed onto an extractor who, depending on circumstances, will likely pass on the extracts to a company for manufacturing, packaging and marketing of the drug.

The second model of trade, the 'Honest Broker' model, illustrates the situation in a minority of communities in Namibia, where support from CRIAA SA-DC has enabled communities to link directly with a local exporting firm (Figure 4). This is also the model described by the accompanying data to this study. The exporter collects material directly from involved communities and pays a premium price on the basis of the material being certified organic and of a high quality. In total, some 10 tons are traded. Although this model has limited outreach, the 328 participating harvesters receive a greater proportion of the retail price $(0.85 \%)$ than harvesters of the other two models. After export, the product follows the same route as that described above.

The third model of trade, which I have dubbed the 'State-NGO' model, typifies the situation in Botswana, where a single NGO has dominated trade in Harpagophytum over the past 10 years. Here, a strategy of targeted intervention has lead to Harpagophytum being purchased directly from marginalized rural communities in the country by a rural development NGO, Thusano Lefatsheng, which also markets the product (Figure 5). A significant variation from the Namibian models is that only a small proportion of material from Botswana is exported directly to target markets; most material leaving 
Figure 4. 'Honest Broker' model of the Sustainably Harvested Devil's Claw Project, Namibia

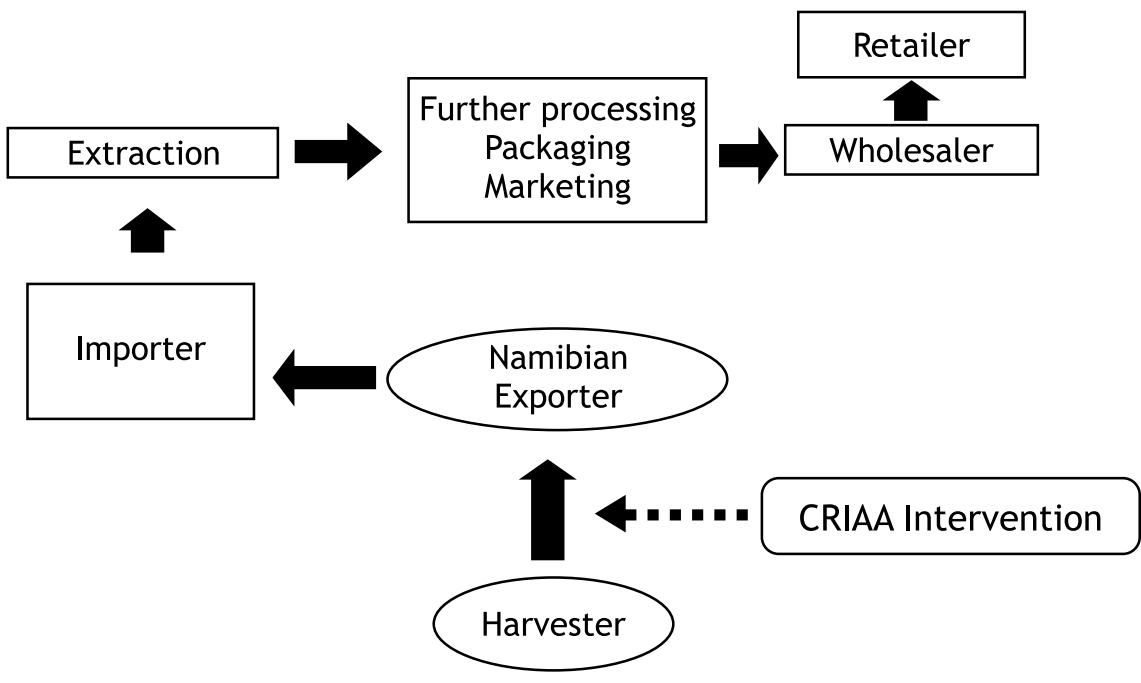

Figure 5. 'State-NGO' model of Botswana

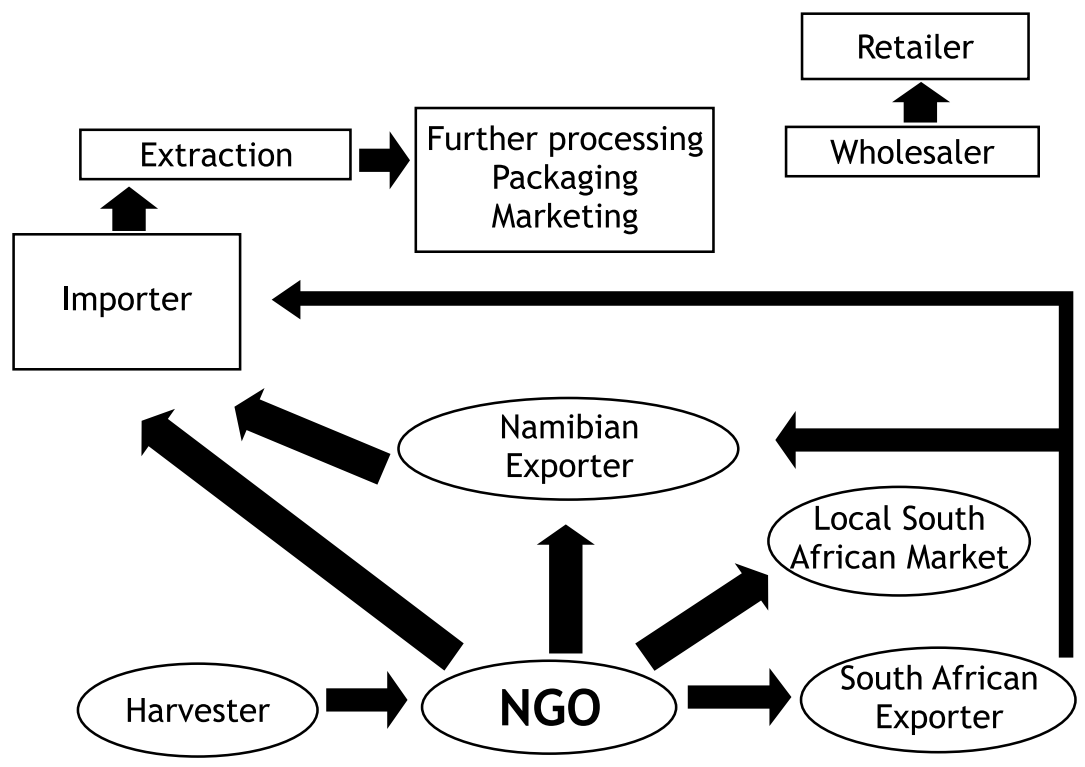

Botswana is exported to Europe and the U.S. via Namibia and South Africa, and thereafter follows the same route as that described for the other two models. This model has significant outreach, benefiting some 2,500 harvesters who receive $0.64 \%$ of the retail price. 
Global patterns of trade in Harpagophytum are far more uniform, albeit more complex, than those described at the local level. An intricate web of importers, traders, wholesalers, processors, and retailers are engaged in marketing, branding and adding value to devil's claw, with the largest and most established markets by far being those in Germany. Five to 10 companies dominate the European trade, the most predominant being the German Martin Bauer Group, estimated to control $75 \%$ of world trade in devil's claw. Important subsidiaries recently established under the Martin Bauer umbrella include Paul Muggenburg, responsible for supplying and sourcing raw material; Plant Extract, which produces extracts; and Finzelberg $\mathrm{GmbH}$ and Co., which manufactures herbal extracts for the pharmaceutical industry.

\section{POLICY ENVIRONMENT}

For the most part, devil's claw is extracted in the communal areas of Namibia, Botswana, and South Africa. Most of these areas have suffered a long and chequered history under years of colonial and apartheid administration and, more recently, through a suite of problematic government policies that discriminate against the use of non-timber forest products such as devil's claw. In Botswana, for example, the 1975 Tribal Grazing Land Policy and 1991 National Agricultural Development Policy have been central in diminishing access of rural people to natural resources, instead reserving communal areas for grazing to accommodate increased beef production (Molebatsi and Atlhopheng 1998). This has been accompanied by the privatisation and fencing of communal grazing areas. The increasing enclosure of communal lands through private fencing is also a trend in Namibia, stemming partly from a legal vacuum in regard to ownership and management of these areas. The lack of tenure security is a major constraint precluding more effective management of devil's claw in Namibia, where communities face difficulties in excluding others from extracting the resource on their lands. The problem is particularly acute in the study area, where customary controls have been steadily eroded through resettlement and social dislocation. As in Botswana, Namibian policies such as the 1995 Agricultural (Commercial) Land Reform Act and the 2000 Communal Land Bill have set forth new agendas on fencing and individual leasehold tenure (Alden Wily 2000). Concern has been expressed about the inappropriate adoption of the titling model by these new laws, based on Western notions of ownership rather than African systems of tenure (Cousins 2002).

A more conducive policy environment exists for the management of devil's claw, and a variety of laws and policies aim to control its exploitation and trade in the region. These date back to the 1970s and the onset of growth in international trade of the species. In Namibia, the first efforts to control exploitation of devil's claw were introduced in June 1975 with the declaration of $H$. procumbens as a protected plant under Schedule 9 of the Nature Conservation Ordinance (4 of 1975) and the introduction of a permit system to control the gathering, purchase and export of plant material. While the permit system for exporting material worked relatively well, that for controlling harvesting proved extremely problematic. This resulted in permit requirements for harvesting, possession and transportation being suspended in 1986, and maintained for export and phytosanitary purposes only. 
In 1999 renewed concerns about overharvesting and unsustainable methods of harvesting, as well as the unauthorised harvesting on communal and private lands, led to a reassessment of the situation and the issuance of the overarching Policy on the Harvesting and Export of Harpagophytum by the Ministry of Environment and Tourism. The policy stipulates a harvesting season from March to October for both species of Harpagophytum, no permits being issued outside of this period. Harvesting will be subject to a nontransferable permit valid for the duration of the harvesting season and applicable for a particular locality only. Permit holders, which may be individuals or a group, are required to obtain the permission of the landowner prior to harvesting and are also required to report the number of bags harvested, to whom such bags were sold and on which dates. New permits will be issued only on receipt of such a report and confirmation of compliance with sustainable harvesting techniques. Furthermore, persons dealing (purchasing, transporting, selling, exporting, importing) in Harpagophytum are required to register annually with the ministry, to keep a register of all transactions, in collaboration with harvesters, and to clearly distinguish between the two species of Harpagophytum in reporting. Export permits are still required for the export of Harpagophytum, to be accompanied by information on the origin of all material, as are phytosanitary certificates. Permits are also required for any cultivation of Harpagophytum, for research on the plant and for any feasibility studies into cultivation. The policy also supports projects that add value to Harpagophytum in the interest of national development. Decision-making is effected through the Devil's Claw Working Group, a stakeholder group set up in 1999, and the government gives increasing recognition to the importance of maintaining a sustainable trade in the plant.

\section{TRENDS AND ISSUES}

\section{The Resource Base}

Although the commercial harvesting of Harpagophytum can have negative ecological impacts, evidence points towards the excellent potential of the plant as a resource that can be harvested sustainably. However, this requires the implementation of appropriate management practices and plans at local, regional and national levels. These are to varying degrees already in place but, because of the patchiness of the resource, are locally specific and often project specific, hinging on the involvement of NGOs. A major constraint is the ability to monitor and enforce harvesting and trade policies, particularly in remoter harvesting areas. Little capacity exists within government, requiring adoption of innovative approaches, including self-policing and monitoring by communities (van der Vleuten 1998). This in turn requires capacity-building programmes at the local level and an enhancement of existing extension services. A further constraint is the lack of reliable information on the population status of Harpagophytum species, which precludes effective resource management and points to the need for systematic and comprehensive research.

Despite these constraints, there is increasing political will and growing awareness of the importance of conserving devil's claw and ensuring its sustainable use. One of the beneficial effects of CITES proposals to list devil's 
claw has been enhanced regional collaboration between range states, and increased efforts are being made to harmonise policies, standardise the monitoring of trade and harvesting and improve enforcement of regulations. This will not only lead to improved conservation of the resource, but will also enhance the bargaining power of producers and exporters.

\section{Livelihoods and benefit-sharing}

The importance of sustainable use is not only ecological given that the harvesting of devil's claw represents an extremely important survival strategy for some of the most marginalized communities in southern Africa. Both mismanagement of the resource and domestication will have negative ramifications for those harvesting from the wild. While trends towards enhanced management of the resource will support sustained trade in wild-crafted material, range states have an important role to play in ensuring that domestication strategies are locally appropriate, do not jeopardise local livelihoods and spread the benefits as widely as possible. Steps are needed to pool and share existing knowledge on cultivation, for the benefit of the industry as a whole. One of the most startling aspects of the study is the wholesale lack of involvement of nationals from range states in research and development activities, and in cultivation projects in particular.

A key issue raised by this case concerns the negligible benefits procured by range states through trade in devil's claw. At the community level, direct financial benefits rarely exceed $0.85 \%$ of the retail price, and typically comprise only $0.4 \%$. Local exporters usually obtain only $0.2 \%$ to $0.4 \%$ of the retail price. Although there are obvious costs involved in the processing and marketing of the imported product, in reality the trade is monopolised by a small cohort of international companies and increased profits (or favourable changes in exchange rates) are seldom passed down the chain to producers. In a similar vein, processing activities take place almost exclusively in Europe, and the bulk of material is exported in a raw and largely unprocessed form. Although some companies are now seeking to redress this and to build value-adding facilities in the region to undertake additional processing steps such as milling, grinding, crushing and extraction, there is as yet no demonstrable evidence of real commitment. Of significance is that foreigners hold virtually all the existing patents for the processing of devil's claw.

Finally, the lack of tenure security for communities harvesting devil's claw remains an unresolved issue requiring attention by range states. This is an essential component of any strategy aimed at ensuring a more sustainable and equitable trade in devil's claw.

\section{Trade}

Continued growth in demand for Harpagophytum-based products is likely, in keeping with the past five to six years which have seen a three- to six-fold increase in amounts traded. These trends parallel those of the phytotherapeutics market in general over the past decade and can be attributed to a growing interest in 'natural' biological alternatives to chemical-based 
drugs and increased coverage by health insurance companies of herbal remedies (Grünwald and Büttel 1996). Increased demand for devil's claw in particular can be attributed to the proven safety and efficacy of the plant, well-founded clinical data, an increase in patients suffering from arthritis and substantial marketing. Continued efforts on the part of the industry to cultivate the plant are likely, stemming from the desire to improve and standardise pharmaceutical quality and concerns about the overexploitation of wild populations. A key concern is that misperceptions on the part of industry and consumers regarding wild-crafted populations will lead to increased demand for cultivated material and a shift in production systems from poor communities to rich farmers or multinational companies.

Direct sourcing partnerships could be a valuable strategy to develop sustainable and fair trade sources of raw materials, including the negotiation of long-term contracts at fixed (US\$) prices. That such a strategy can work is well demonstrated by the efforts of the SHDC Project, which has linked communities directly to a local export firm that markets the product and sells it at a premium price. A noteworthy feature of the project is the personal commitment of both the exporter and importers to a fair and sustainable trade. However, experiences from both Namibia and Botswana point to the financial difficulties of sustaining NGOs as long-term intermediaries, the importance of private-sector partners and the critical need for external marketing support. Tools that warrant further investigation include the development of certification standards and a set of specific guidelines for industries involved in trading devil's claw that describe specific criteria for fair trade, environmental sustainability and quality standards. This could stimulate positive changes in current practice and provide an important monitoring tool. Improved branding and consumer awareness is also important to market the beneficial socio-economic impacts of the product and its links to a specific geographical area.

\section{CONCLUSIONS}

Devil's claw holds considerable potential as a non-timber forest product that can both be harvested sustainably and deliver significant development benefits to marginalized rural communities. Its occurrence on degraded lands and opportunistic nature suggests negligible harvesting impacts on ecosystems; its ability to regenerate after harvesting indicates opportunities for sustainable use; and its distribution in the communal lands of the Kalahari enables households with few other livelihood options to earn an income, albeit small, for part of the year. National benefits are also significant, both in terms of taxes generated, employment generation and export revenue. Furthermore, the long history of trade in devil's claw, its continued growth and the established safety and efficacy of the plant suggest a reliable market upon which long-term strategies can be developed. Increased interest in fair and sustainable trade products provides further potential for developing niche markets and improving local prices.

Several barriers, however, impede the full realisation of the plant's conservation and development potential. At the local level, these include a lack of tenure security, insufficient monitoring capacity, poor business and management skills and low levels of organisation. Inadequate quality and resource 
management also present major hurdles. At the international level, monopoly control severely compromises the ability of local producers and range states to receive optimum benefits and prevents range states from adding full value to their resources. Cultivation efforts represent a further threat to ensuring a reliable stream of benefits for harvesting communities.

Despite these constraints, constructive interventions are both possible and probable as support is growing from both decision-makers and industry for a sustainable trade in the species. Certainly they point towards devil's claw being one example that can attempt to marry the sometimes conflicting objectives of conservation and development.

\section{ACKNOWLEDGEMENTS}

This paper draws from a series of rich discussions held with role players in the devil's claw trade and forms part of doctoral research being undertaken on the commercialisation of southern African biodiversity. All those who have participated in this research are gratefully acknowledged for giving so generously of their time and information. Particular thanks are due to Dave Cole (CRIAA-SA DC), Marianne Strobach and Mike Krafft for assisting with information for the database. Scholarships awarded for this study by the National Research Foundation, Annell Trust and Smartt Memorial Trust are thankfully acknowledged. The National Botanical Institute is thanked for permission to use data from the National Herbarium, Pretoria Computerised Information System (PRECIS). Tony Cunningham and Terry Sunderland provided useful comments on earlier drafts of this paper.

\section{ENDNOTES}

1. Graduate School of Environmental Studies, University of Strathclyde. P.O. Box 83 Kalk Bay 7990, South Africa. E-mail: rachel@iafrica.com

\section{REFERENCES}

Alden Wily, L. 2000. Democratising the commonage: the changing legal framework for natural resource management in eastern and southern Africa with particular reference to forests. http: / /www.cbnrm.net/library (14 Aug. 2003).

Barnard, P. (ed.). 1998. Biological diversity in Namibia: a country study. Namibian National Biodiversity Task Force, Windhoek. 332p.

Blank, R.J. 1973. Voraussetzungen und Möglichkeiten für einen feldmäßigen Anbau der Wildpflanze Harpagophytum procumbens DC. (Teufelskralle). University of Hohenheim.

Blumenthal, M. (ed.) 1998. The complete German Commission E conographs: therapeutic guide to herbal medicines. American Botanical Council, Austin, Texas.

Burger, J. 1987. Iridoid and phenolic glycosides from Harpagophytum procumbens. Phytochemistry 26: 1453-1457.

Chrubasik, S., Zimpfer, C., Schutt, U. and Ziegler, R. 1996. Effectiveness of Harpagophytum procumbens in treatment of acute low back pain. Phytomedicine 3: 1-10. 
Cole, D. and du Plessis, P. 2001. Namibian devil's claw (Harpagophytum spp.): a case study on benefit-sharing arrangements. Prepared for the Ministry of Environment and Tourism by CRIAA SA-DC. Namibian National Biodiversity Programme, Windhoek, Namibia.

Cousins, B. 2002. Reforming communal land tenure in South Africa: why land titling is not the answer. Programme for Land and Agrarian Studies, School of Government, University of the Western Cape, South Africa.

CRIAA SA-DC. 2000a. Petition to prevent the listing of devil's claw (Harpagophytum spp.) on CITES Appendix II pending further research on the status of the resource. Unpublished document.

CRIAA SA-DC. 2000b. The sustainably Harvested Devil's Claw Project: expansion of pilot project in Omaheke Region of Namibia. Final report submitted to the delegation of the European Commission in Namibia and the National Planning Commission.

CRIAA SA-DC. 2002. The Sustainably Harvested Devil's Claw Project, phase II: extension of the expansion of the pilot project in Omaheke Region on Namibia. Final Report submitted to the 1995 European Commission Food Aid Counterpart Fund.

Czygan, F.C., Kruger, A., Schier, W. and Volk, O. 1977. Pharmaceutical-biological analysis of the family Harpagophytum (Bruch.) DC ex Meissn. part 1. Deutsche Apotheker Zeitung 117: 1431-1434.

Giess, W. and Snyman, J.W. 1995. The naming and utilisation of plantlife by the Žu 'hõasi bushmen of the Kau-kauveld. In: Vossen, R. and Keuthmann, K. (eds.) Contemporary studies on Khoisan 1: Quellen zur Khoisan-Forschung. Helmut Buske Verlag, Hamburg.

Grünwald, J. and Büttel, K. 1996. The European phytotherapeutics market: figures, trends, analyses. Drugs Made in Germany 39(1): 6-11.

Hachfeld, B. 1999. Analysis of the trade potential and possible over-exploitation of a southern African medicinal plant-Harpagophytum procumbens. Unpublished report prepared for the Bundesamt für Naturschutz.

Henderson, M. and Anderson, J.G. 1966. Common weeds of South Africa. Botanical Research Institute, Pretoria.

Ihlenfeldt, H.D. and Hartmann, H. 1970. Die Gattung Harpagophytum (Burch.) devil's claw ex Meissn. Mitt. Staatinst. Allg. Bot. Hamburg 13: 15-69.

Lanhers, M.C., Fleurentin, J., Mortier, F., Vinche, A. and Younos, C. 1992. Antiinflammatory and analgesic effects of an aqueous extract of Harpagophytum procumbens. Planta Medica 58: 117-123.

Levieille, G., Wilson, G., Robin, J.R. and Cambornac, M. 2000. In vitro micropropagation of fertile plants of Harpagophytum procumbens and $H$. zeyheri. Medicinal Plant Conservation 6: 10-11.

Lombard, C. 2000. The Sustainably Harvested Devil's Claw Project in Namibia. Medicinal Plant Conservation 6: 9-10.

Matlhare, T. (ed.) 1994. Improving remote area dwellers participation in the management and utilisation of natural resources, thereby generating income. Proceedings of a workshop held in Ukhwi Settlement, Kgalagadi North, 6-10 December 1993. Thusano Lefatsheng, Gaborone.

Moatti, R., Fauron, R. and Donadieu, Y. 1983. La phytothérapie. Librairie Maloine, Paris. $82 p$. 
Molebatsi, C.O. and Athopheng, J.R. 1998. Veld products: availability, utilisation, over-utilisation and depletion. In: Atlhopheng, J., Molebatsi, C., Toteng, E. and Totolo, O. (eds.) Environmental issues in Botswana. Lightbooks, Gaborone, Botswana.

Moussard, C., Alber, D., Toubin, M.M., Thevenon, N. and Henry, J.C. 1992. A drug used in traditional medicine, Harpagophytum procumbens: no evidence for NSAID-like effect on whole blood eicosanoid production in human. Prostaglandins Leukotrienes and Essential Fatty Acids 46: 283-286.

Nott, K. 1986. A survey of the harvesting and export of Harpagophytum procumbens and $H$. zeyheri in SWA/Namibia. Etosha Ecological Institute, Okaukuejo. 24p.

Ntseane, P.G. 1993. Socio-economic survey on grapple plant (Harpagophytum procumbens DC): utilization and commercialization. Kweneng, Southern, Kgalagadi and Ghantsi Districts. National Institute of Development Research and Documentation, University of Botswana, Gaborone.

Phillips, E.P. 1938. The weeds of South Africa. Government Printer, South Africa.

Powell, E. and Moolman, M. 1999. The sustainable use of the medicinal plant Harpagophytum procumbens DC (devil's claw). Unpublished paper.

Raimondo, D. and Donaldson, J. 2002. The trade, management and biological status of Harpagophytum spp. in southern African range states. A report submitted to the CITES Plants Committee. National Botanical Institute, South Africa.

Schmidt, M., Eich, J., Kreimeyer, G. and Betti, G. 1998. Improvement of pharmaceutical drug quality: a cultivation project for Harpagophytum procumbens in Namibia. Drogenreport 11: 3-9.

Schneider, E. 1997. Sustainable use in semi-wild populations of Harpagophytum procumbens in Namibia. Medicinal Plant Conservation 4 (November): 7-9.

Strohbach, M. 1999. The Sustainably Harvested Devil's Claw Project: ecological survey. Unpublished report.

Suzman, J. 2001. As assessment of the status of Namibia's San population. Legal Assistance Centre, Windhoek.

Taylor, F.W. and Moss, H. 1982. Final report on the potential for commercial utilisation of veld products. Plan No. TB 7/1/14/80-81. Volume I: the resource and its management. Government Printer, Gaborone.

Thusano Lefatsheng. 1995. Annual report 1994/95. Thusano Lefatsheng, Gaborone.

van der Vleuten, J. 1998. Community-based monitoring of non-timber forest products: possibilities for the community based monitoring of veld products for sustainable income generation in Kweneng west district, Botswana. Larenstein International Agricultural College, Velp, Netherlands.

Watt, J.M. and Breyer-Brandwijk, M.G. 1962. The medicinal and poisonous plants of southern and eastern Africa, 2nd ed. Livingstone, London.

Wynberg, R. forthcoming. The commercialisation of southern African biodiversity. Ph.D. Thesis, University of Strathclyde.

Ziller, K. and Franz, G. 1979. Analysis of the water-soluble fraction from the roots of Harpagophytum procumbens. Planta Med 37: 340-348. 


\title{
Chapter 5
}

\section{The informal trade of Cassipourea flanaganii as a cosmetic in South Africa}

\author{
Michelle Cocks ${ }^{1}$ and Tony Dold ${ }^{2}$
}

\begin{tabular}{llllll}
\hline Common name & $\begin{array}{l}\text { Part of the } \\
\text { resource used }\end{array}$ & Management & $\begin{array}{l}\text { Degree of } \\
\text { transformation }\end{array}$ & $\begin{array}{l}\text { Scale of } \\
\text { trade }\end{array}$ & $\begin{array}{l}\text { Geographic } \\
\text { range }\end{array}$ \\
\hline Umemezi & Bark & Wild & Low & National & Small \\
\hline
\end{tabular}

\begin{abstract}
A rare forest tree, Cassipourea flanaganii (Schinz) Alston (Rhizophoraceae), has, in the last 25 years, been harvested indiscriminately for sale in informal herbal markets and amayeza (Muthi) stores in South Africa. The bark is removed, often resulting in the death of the tree, and sold locally and nationally as a skin lightening cosmetic known as umemezi in both Zulu and Xhosa languages. The effect of uncontrolled harvesting has had negative consequences on the ecology of the species and its habitat. It is, however, an important means of income to poverty stricken peri-urban women who are reliant on the sale of wild harvested plant material to support their families. The findings of an ecological survey of $C$. flanaganii and a survey of the socio-economic conditions of the trade of its bark is presented.
\end{abstract}

\section{INTRODUCTION}

As early as 1936, Hunter reported that a light skin complexion was favoured by Nguni women (amaXhosa) and was considered attractive. Furthermore, she noted that women made use of 'Tambookie grass' (Cymbopogon, Hyparrhenia or Miscanthidium (Smith 1966)) as a strong bleaching agent by means of chewing the roots and applying the saliva to the face at least twice a day (Hunter 1936). This desire for a lighter complexion has not diminished in recent times and various cosmetics, both natural and synthetic, are still used today. 
The cosmetic use of Cassipourea flanaganii (Schinz) Alston as a skin lightener appears to be relatively recent, as the first mention of it in the literature surveyed was in 1976 (Earle 1976). Surprisingly, the use of the species was not recorded in the extensive work undertaken by Watt and Breyer-Brandwyk (1962) or De Lange's (1963) investigation into Xhosa cosmetic practices. This is confirmed by a review of the literature (Gerstner 1942; De Lange 1963; Earle 1976; Coates Palgrave 1977; Broster 1981; De Villiers 1984; Cunningham 1988, 1993; Hutchings et al. 1996; Khan 1996a, b, c; Cocks 1997; Dold and Cocks 1997, 1999). The absence of recorded use of $C$. flanaganii suggests that the use and trade of the species was uncommon before the early 1970s. It was not until the mid 1970s that Earle (1976) reported that the chemical skin lightening industry in South Africa was worth US\$12.8 million (converted at a rate of approximately ZAR1.00 to US\$1 as in 1976) for that year and noted that vegetable preparations of the bark of several species, including $C$. flanaganii, represented a lucrative informal trade. Earle (1976) called for strictly controlled harvesting and predicted inevitable overutilisation of some species. From 1976 to 1990 the trade in manufactured skin lightening products increased considerably (Khan 1996c). However, many of these products were mercury based and caused serious damage to the skin. These products saw widespread use from about 1956 to the early 1970s, when they were finally banned. The sale of skin lightening products containing hydroquinone, another mercury-based lightener (Butler's Pharmacy personal communication), dates back only to 1961 (Khan 1996c). As a result, lobby groups protested against over-the-counter skin lightening products. In August 1990 the National Minister of Health finally proclaimed hydroquinone a substance controlled by law, to be sold only by pharmacists (Khan 1996c).

Khan's survey, undertaken in 1996 in the townships of Cape Town, revealed that skin lightening products were still available and continued to be sold from pharmacies although not as commonly, nor in as great a quantity as previously. It is believed that this lack of availability in chemical products is fuelling the growing trade in traditional skin lightening preparations based on plants such as C. flanaganii (Khan 1996c). This study revealed that the majority of users equated a lighter skin colour with beauty, most likely enforced by feelings of racial inferiority as a result of the psychological legacy of apartheid. Khan (1996c) concluded by highlighting the fact that this social factor, the desire to be lightskinned, is responsible for posing a threat to these species as a result of overharvesting to supply the markets in urban centres.

Another species of Cassipourea, C. gerrardii (Schinz) Alston, has also been recorded as umemezi and is used and traded in the same way as $C$. flanaganii in KwaZulu-Natal and Gauteng (Cunningham 1988; Hutchings et al. 1996; Van Wyk and Gericke 2000). The bark of these two species are undifferentiated in the trade (A.B. Cunningham personal communication). The name umemezi has been referred to by some authors for several unrelated taxa including Calodendrum capense (L.f.) Thunb. and Rapanea melanophloeos (L.) Mez. In this regard it is important to differentiate between two important subclassifications of umemezi, that of umemezi-omhlope (Calodendrum capense) and umemezi-obomvu ( $C$. flanaganii and $C$. gerrardii). The suffixes refer to the colour of the cosmetic paste, omhlope being white and obomvu reddish-brown. These are clearly differentiated in the trade, but as Calodendrum capense is seldom sold in 
the Eastern Cape (Cocks and Dold 2000), the suffix is not used by traders. Therefore all umemezi in the study site refers to $C$. flanaganii.

The bark of $C$. flanaganii is sold in an unprocessed state in the study site. Consumers simply purchase a piece of dry bark, which is then ground on a granite stone and mixed with water to form a paste that is applied daily to the face as a skin lightener. The vernacular name umemezi is derived from the Xhosa verb ukumemeza, meaning to 'call aloud' or to 'attract attention' (Nomtunzi Sizane personal communication).

Hilton-Taylor (1996) lists Cassipourea flanaganii as 'rare' in the Cape region and globally, and as endemic to the Southern Africa floristic region. The current plant Red Data list (Victor 2002) does not treat this species. The species has a scattered distribution and is present in highly localised forest patches in the Eastern Cape Province from King William's Town in the west to southern KwaZuluNatal in the east. $C$. gerrardii occurs primarily further to the north-east of the Eastern Cape in KwaZulu-Natal and in tropical east Africa (Pooley 1993).

The bark is currently harvested from wild populations only. Cocks (1997) reports an extensive informal trade in the bark, both in street markets and in amayeza stores (African chemists), in King William's Town with demand from as far as Cape Town. Khan's (1996c) survey revealed that the $97.9 \%$ majority of traders obtained C. flanaganii from the Eastern Cape. Cunningham (1993) confirms this finding and includes $C$. flanaganii in a list of traditional medicines commercially traded nationally in South Africa (1988), particularly KwaZuluNatal. In response to demand for umemezi, local manufacturing companies have begun to purchase bark material in bulk, which is ground into a powder and packaged in small plastic containers. These products are sold in stores in the larger urban centres across the country, such as Cape Town, Gauteng and Durban (A.B. Cunningham personal communication). This indicates an increased demand for the product resulting in further commercialisation by means of preprocessing and packaging.

A market survey of medicinal plants traded in the Eastern Cape (Cocks and Dold 2000) revealed that Pirie State Forest near King William's Town is the primary source of traded $C$. flanaganii bark, a smaller quantity coming from Gatyana Forest in the Willowvale District, approximately $150 \mathrm{~km}$ to the east. Pirie Forest is state owned and managed by the Department of Water Affairs and Forestry (DWAF). It is surrounded by several villages typical of rural communities in the province that are equivalent to peri-urban settlements (Figure 1). Families are more or less integrated into the wider economy as they depend on cash or food from family members in urban centres and commuters with jobs in the nearby towns. Crop production is virtually nonexistent but families invest in small and large stock, resulting in large numbers of livestock in the area. The villages are situated approximately $8 \mathrm{~km}$ from a main access route to King William's Town.

\section{CHARACTERISTICS OF THE PRODUCTION SYSTEM}

Pirie State Forest ( $\left.32^{\circ} 44^{\prime} \mathrm{S} 27^{\circ} 17^{\prime} \mathrm{E}\right)$, classified by Low and Rebelo (1996) as Afromontane forest, is situated between $580 \mathrm{~m}$ and $1200 \mathrm{~m}$ above sea level with an average annual rainfall of $890 \mathrm{~mm}$. The geological formations are mudstone, shale, and sandstone with dolerite intrusions. The forest comprises 
Figure 1. Study site: Pirie State Forest, Hobo and Cwengcwe
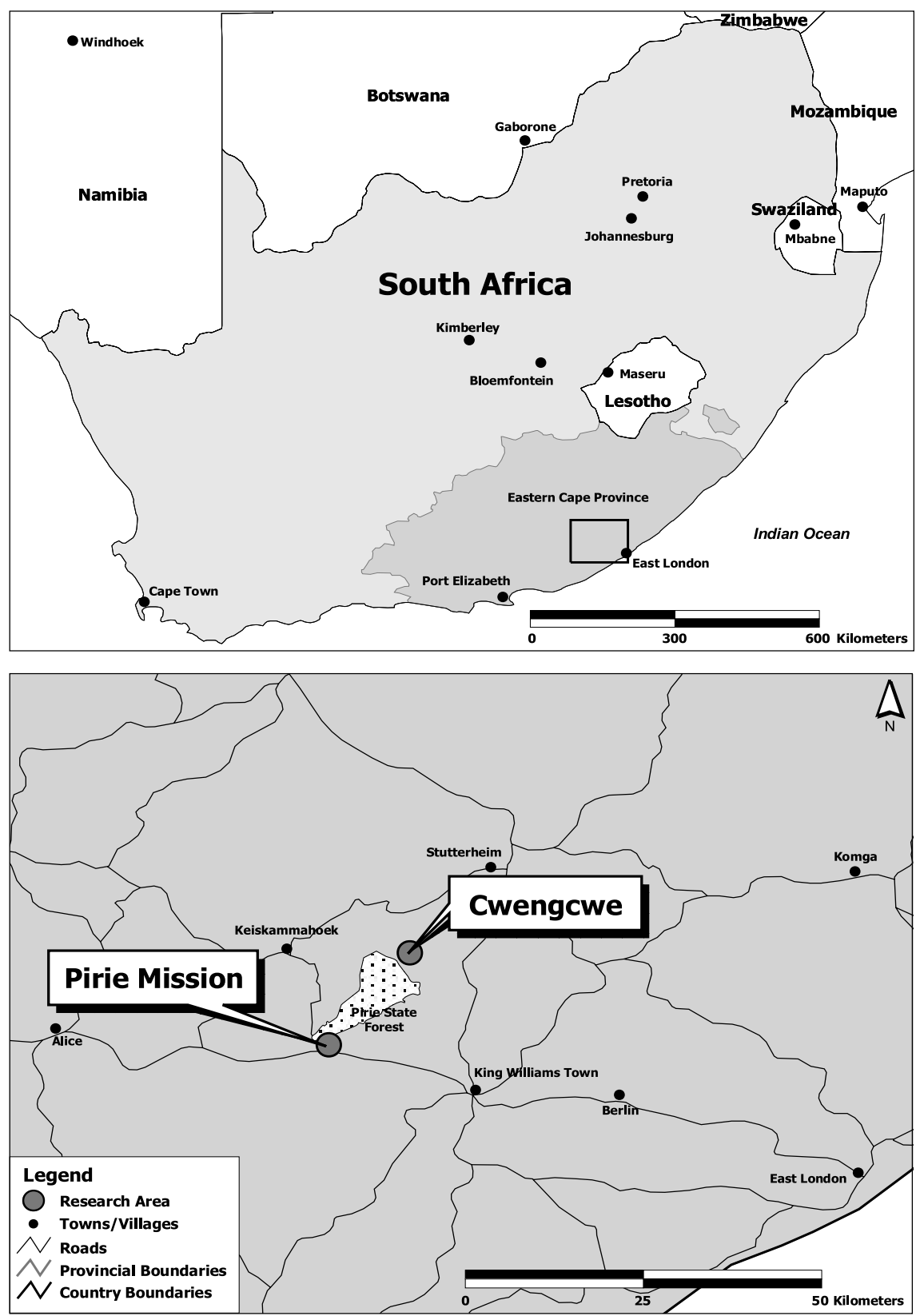

Source: ESRI Data and Maps 2002. 
43 tree species dominated by Olea capensis L. ssp. macrocarpa (C.H. Wr.) Verdoorn, Podocarpus falcatus (Thunb.) R.Br. ex Mirb., Mimusops obovata Sond. and Nuxia floribunda Benth. in the canopy, and Trichocladus ellipticus Eckl. and Zeyh. and Canthium ciliatum (Klotzsch) Kuntze in the subcanopy (Bailey et al. 1999).

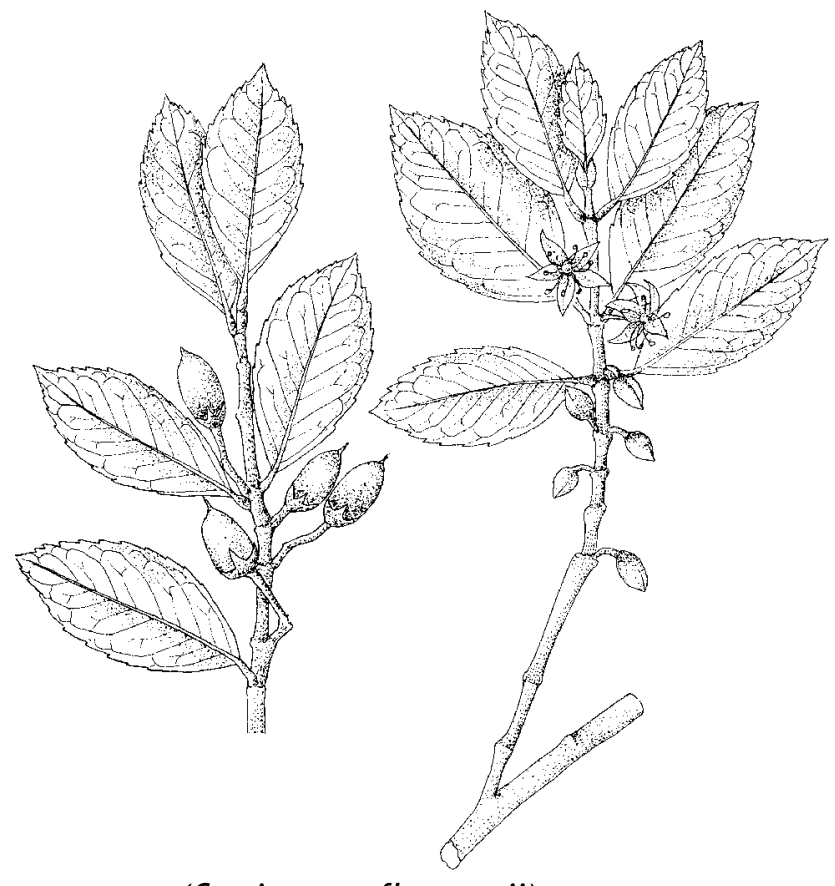

(Cassipourea flanaganii)

C. flanaganii is located in primary and secondary forest areas as it is a mid-canopy species reaching a height of $8 \mathrm{~m}$ (Coates Palgrave 1997). The bark is harvested throughout the year. Smaller diameter individuals $(<41 \mathrm{~mm})$ are not harvested because of the difficulty experienced in removing the thin bark. Hence, the main limiting factor for harvesting is size, and therefore the age of the tree. Within the study site the tree is common in tall $(15 \mathrm{~m}+)$ forest on the south-facing slope and considerably less common on drier east facing aspects. $C$. flanaganii individuals in the forest show no immediate associations or distinct areas in which they are more common. The species appears to have a loose clumping habit, as in some areas there were many seedlings present, whilst in other areas there were none. The clumping is attributed to restricted seed dispersal. Occasional mature trees were found that could be identified as possible progenitors of clumps of seedlings. Little is known about biology and reproduction of $C$. flanaganii as no detailed studies have been conducted on the species. Spatially, trees in the Hobo forest showed similar densities throughout, and only a few sections were devoid of $C$. flanaganii. It is suggested 
that $C$. flanaganii is a generalist in where it grows within the south-facing Afromontane forests, being present in a variety of canopy heights and forest types. The coppicing potential of $C$. flanaganii appears to be limited as all ring-barked trees were dead.

It has been reported that between 1986 and 1989, at the peak of the trade in C. flanaganii, uncontrolled harvesting was undertaken on a large scale in Pirie State Forest resulting in an almost total loss of adult trees (C. Kameni personal communication). Within the study site all $C$. flanaganii material is harvested from Pirie Forest. There are no managed or cultivated populations and there are no recognisable trends towards domesticating or cultivating the species. In addition to $C$. flanaganii, 11 other species are regularly harvested for their bark for the medicinal plant trade. These are Cassine papillosa (Hochst.) Kuntze, Curtisia dentata (Burm.f.) C.A.Sm., Harpephyllum caffrum Bernh. ex Krauss, Hippobromus pauciflorus (L.f.) Radlk., Pleurostylia capensis (Turcz.) Loes., Protorhus longifolia (Bernh.) Engl., Ptaeroxylon obliquum (Thunb.) Radlk., Rapanea melanophloeos L. Mez, Schotia latifolia Jacq., Scolopia zeyheri (Nees) Harv. and Strychnos henningsii Gilg. It has been established that approximately 4 tons of forest-harvested plant material, with a value of approximately US\$9,000 is harvested annually from the Pirie State Forest. Just over $50 \%$ of this is derived from the bark of these 11 tree species with a street market value of approximately US\$4,000 (Cocks and Dold 2000).

An ecological survey was undertaken to determine the density of, and assess harvesting damage to, the populations of $C$. flanaganii in Hobo and Cwengcwe forests. These two forests form part of the larger Pirie State Forest (Figure 1). The survey sampled two representative areas of Hobo and Cwengcwe. Two 1,000 m transects were plotted and random $100 \mathrm{~m}^{2}$ quadrates sampled along the transects; in this way reliable density estimates where made. In total, 156 quadrates comprising 249 C. flanaganii trees were sampled. The parameters recorded for each tree were the diameter at breast height $(\mathrm{DBH})$ where applicable, total height and level of bark damage to the tree following Cunningham's (1988) seven-point scale.

Hobo forest has a density of approximately 125 C. flanaganii trees per hectare; $76 \%$ of these are seedlings $(0 \mathrm{~mm}-10 \mathrm{~mm}$ in diameter $) ; 19.7 \%$ are saplings (10 mm-46 mm in diameter) and only $4.3 \%$ are above $46 \mathrm{~mm} \mathrm{DBH}$, the minimum reproductive diameter encountered in the study. Cwengcwe forest has a density of approximately 210 trees per hectare, $94.4 \%$ of which are seedlings and $5.6 \%$ saplings. No reproductive or potentially reproductive trees were found.

Plots of comparable sizes in inaccessible areas of Pirie forest, with consequently low intensity harvesting, revealed tree density to be approximately 588 individuals per hectare with 35.5 trees per hectare above the minimum harvesting size, whereas in Hobo only 5.2 harvestable trees per hectare were recorded while in Cwengcwe none were found. In the survey of Hobo and Cwengcwe all sampled trees were undamaged as only $2.1 \%$ of the trees had a diameter greater than $41 \mathrm{~mm}$. Furthermore only a single reproductive tree was found with a $\mathrm{DBH}$ of $46 \mathrm{~mm}$.

No data were found in the literature reviewed on the reproduction of the species, and therefore the reproductive size is unknown. One individual of 
$46 \mathrm{~mm} \mathrm{DBH}$ was found with severe harvesting damage but with many flowers. This represents the smallest flowering $C$. flanaganii found and sets the minimum reproductive size for harvested $C$. flanaganii. However, this size may not represent the minimum reproductive size for a nonharvested tree as the profuse flowering may have been a result of harvesting stress. Should stress play a role in early flowering of this specimen, the size estimate would be a conservative underestimation, meaning that there are even less potentially reproductive trees in the forest.

The survey clearly reveals a lack of large individuals. Palmer and Pitman (1972) and Pooley (1993) state that the tree attains a diameter of up to 230 $\mathrm{mm}$, whereas the largest individual recorded in the study site was only 120 $\mathrm{mm} \mathrm{DBH}$. There is no doubt that this discrepancy is due to excessive bark harvesting (complete ring-barking) resulting in fatality of the larger trees. This has important ecological implications as the species is being harvested unsustainably and there are virtually no mature individuals in the populations to ensure its continued reproduction. $C$. flanaganii has a relatively thin bole and bark that tends to peel off easily in sheets. Sustainable harvesting based upon harvesting one side of the trunk is therefore not considered a viable strategy. It is suggested that $C$. flanaganii has a low potential for sustainable harvesting. Currently there are no studies investigating the impact of different harvesting regimes on the long-term survival of this species.

Photo 1. Evidence of bark harvesting within Cwengcwe Forest (Photo by T. Dold)

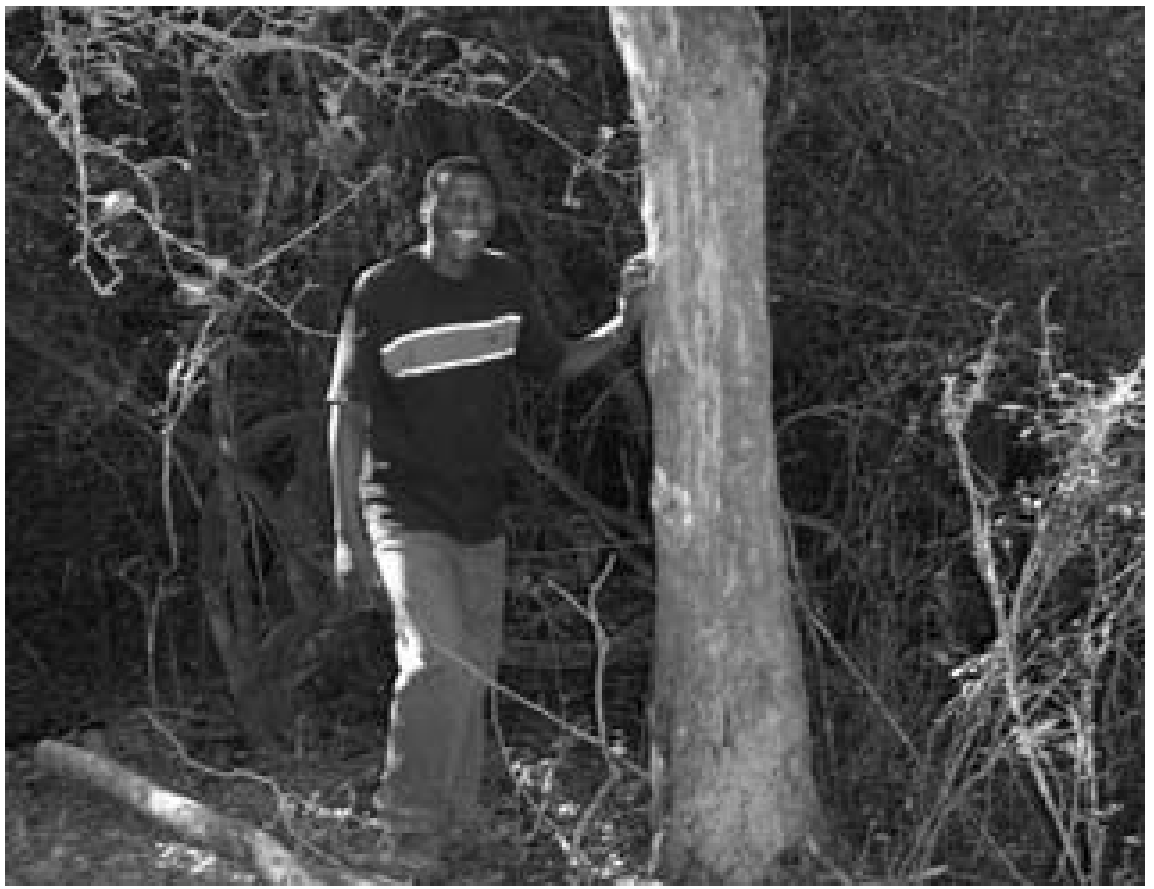




\section{SOCIO-ECONOMIC CHARACTERISTICS OF THE RAW MATERIAL PRODUCTION AREA}

Four distinct questionnaires were administered to the stakeholder groups involved in the trade of medicinal plants (herbal gatherers/hawkers, amayeza storeowners, traditional healers and customers). Within King William's Town 46 questionnaires were administered, 8 of these to traditional healers, 14 to street traders, 7 to amayeza storeowners, and 20 to consumers. Figures given for street traders and amayeza storeowners represent a $100 \%$ sample. However, only a small proportion of traditional healers were interviewed, and it is unknown how many are currently operating in the town. The authors established that $C$. flanaganii is more frequently sold by street traders than traditional healers and amayeza storeowners as it is a cosmetic rather than a medicine (Cocks and Dold 2000). In-depth interviews were conducted with raw material producers (RMPs) from two study sites to address issues regarding the harvesting and marketing of $C$. flanaganii.

A structured interview survey was conducted with household members (33.3\%) from the raw material production area of Pirie Mission and Cwengcwe villages. The survey aimed to determine household wealth, reliance on arable land and home garden production, investment in livestock production and reliance on cash obtained through fixed and informal employment, pensions and remittances.

The RMPs reside in the villages of Pirie Mission and Cwengcwe adjacent to Pirie State Forest (Figure 1). Both villages are relatively small, with populations of between 460 and 600 people. The majority of the population is relatively stable as over $86 \%$ and $97 \%$ of the individuals of Pirie Mission and Cwengcwe, respectively, were born in and still reside in the villages. The two settlements are characterised by environmental degradation, very low or nonexistent levels of economic activity, a heavy dependence on urban earnings and welfare payments, high unemployment and poor infrastructure. The majority of households lack access to running water and the villages were electrified only in 1999. Access to poorly serviced schools and clinics is available in both villages.

The two villages are typical of communities in the surrounding district being classified as peri-urban settlements. Peri-urban settlements came about under the former apartheid government and its policies, which have left a distinct pattern in terms of location of the country's rural population and on the existing economies in these areas (Viljoen 1994). These policies, for example, have led to high density population figures in rural areas with little infrastructure. This has resulted in the land becoming overcropped, overgrazed and subject to soil erosion. The peri-urban communities in these areas are largely dependent on money from formal employment, the informal sector, government pensions and remittances rather than having a subsistence based economy (Palmer 1996).

Differences between the two communities reflect poorer conditions within Cwengcwe. For example, $46 \%$ of the houses in Pirie Mission make use of modern building materials, including bricks for the structure and zinc sheets for the roof, whereas in Cwengcwe only $25 \%$ were built solely of manufactured materials. The remaining households were built from natural indigenous materials. The Cwengcwe community is considerably more reliant on an agriculture-based 
production system and this is reflected in the higher number of households owning arable lands (47\%), whereas in Pirie Mission only $20 \%$ acknowledged ownership of arable fields land. No families in Pirie Mission currently utilise their fields for cultivation, whereas $26 \%$ of the households in Cwengcwe make regular use of their fields. However, in both villages there is some reliance on cultivation of home gardens. For example, $80 \%$ of the households in Pirie Mission still have access to home gardens and $72 \%$ cultivate them. Similarly, $89 \%$ of the households in Cwengcwe have access to home gardens and $84 \%$ make use of them on a regular basis. The majority of products from home gardens are consumed by the household rather than sold. In Pirie Mission the gardens contribute approximately $2.1 \%$ towards the total household income. Similarly, in Cwengcwe the vegetables cultivated contribute approximately $2.4 \%$ of the household total income despite the higher number of households cultivating their fields. None of the families of RMPs own their own fields but they do cultivate home gardens.

Households in both villages have invested in livestock. In Pirie Mission 25\% of the households have cattle, while in Cwengcwe 33\% do. Livestock and poultry products such as milk, eggs, and meat consumed within households in Pirie Mission contribute approximately $2 \%$ of their total income. In Cwengcwe livestockbased products contribute $5 \%$ of the average household total income. None of the RMPs own large livestock, but the majority own some pigs and chickens.

Cash contributes significantly higher amounts to total household income than subsistence-based products in both villages. (Cash in this instance refers to cash earned and obtained through fixed and informal employment, pensions and remittances.) For example, $78 \%$ of total household income in Pirie Mission is cash, whereas in Cwengcwe cash contributes approximately $66 \%$ of households' total income. A significant portion of the total amount of cash generated and obtained stems from state pensions and grants. ${ }^{3}$ For example, in Pirie Mission $35 \%$ of households' cash income is obtained via state pensions, and in Cwengcwe $29 \%$. These figures clearly reveal the extent to which households within these communities rely on the state for their survival. These findings reflect the communities' movement away from a subsistence-based economy and towards a cash-based economy.

Within the two villages $3.2 \%(n=10)$ of households are involved in the harvesting of Cassipourea bark. It appears likely that access to pensions as well as the strong social stigma against the collection of medicinal products prohibits more households from engaging in the activity. Gatherers frequent the forest so regularly that they are often viewed as sorcerers. Similarly, at national level, gatherers of medicinal plants do not have a high social status.

Of the 10 gatherers in the two communities, eight are women and two are men. Women gatherers trade only in the informal market in King William's Town, whereas male gatherers commute to markets further afield and sell their material to traders in informal markets and amayeza stores as far away as Cape Town. Harvesting of $C$. flanaganii is undertaken weekly throughout most of the year except during the rainy season. It occupies between five and seven hours a week, including time spent harvesting other medicinal plant materials. The only initial cost in the harvesting process is the purchase of an axe, which costs approximately US\$3.5. On average each female gatherer/ 
trader earns US\$271 annually from C. flanaganii sales (converted at a rate of R6.41 to US\$1 as reported on 10 March 2000), ranging from US\$124 to US\$748, annually. It is estimated that each female gatherer/trader earns an annual average of US\$2,004 (ranging from US\$1,121 to US\$3,790) in total sales of plant material traded. The sale of $C$. flanaganii contributes approximately $14 \%$ of their total income. The gatherers/traders have no other means of income other than the sale of medicinal plants.

\section{INSTITUTIONAL CHARACTERISTICS OF PRODUCERS}

Although the trade in medicinal plants is well established countrywide, it operates entirely informally at the production/harvest end of the marketing chain (Cunningham 1988). There is no formal organisation amongst gatherers in the study site and they operate as independent agents when it comes to the harvesting of material. The main barriers to additional households becoming gatherers are the skills needed to identify plant species and the negative social stigma attached to the activity. In the study site no customary rules apply to the management of the forest, as it is state owned and access was previously strictly controlled. It is clear that gatherers harbour feelings of resentment and animosity towards government authorities and regard access to these resources as their right because they live adjacent to the forest. Although they readily acknowledge that greater distances need to be covered to obtain material, the gatherers perceive all forest resources, including $C$. flanaganii, to be inexhaustible.

\section{CHARACTERISTICS OF THE PRODUCT}

Hardly any transformation takes place from raw material to end product within the study area. The bark is removed from trees, brought home, scraped to remove debris such as lichen and left to dry for two days. It is then cut into pieces approximately $120 \mathrm{~mm}$ long. The pieces are transported to the neighbouring and larger urban markets across the country. However, with the increased commercialisation of the product, a factory-processed and packaged product has recently become available in the central business districts of some provinces. The authors have not yet recorded these products in the Eastern Cape.

\section{CHARACTERISTICS OF TRADE AND MARKETING}

The female gatherers/traders from Pirie Mission and Cwengcwe sell their material in King William's Town. The material is harvested on weekends or in the early morning hours during the week. The work is strenuous, and women take their older children to assist with the harvesting, but no additional labour is employed. The majority of gatherers/traders is between 45 and 65 years old. They represent the poorest sector of their communities and have little or no formal education.

The medicinal plant market in King William's Town has been in existence for 12 years, during which time its size has both fluctuated and increased. 
It peaked in the 1980s in Cape Town and dropped in the early and mid 1990s. In 1997 the trade started to increase as wholesalers began purchasing material from the informal market in King William's Town for resale in other city centres. A distinct chain of role players are involved in the trade of C. flanaganii. For many of the female traders, plant material sales are their sole source of income besides the pensions for those over the age of 60. The women commute the approximately $20 \mathrm{~km}$ to King William's Town six days a week to sell the harvested material, each incurring transport costs of approximately US\$40 per month (converted at a rate of R6.41 to US\$1 as reported on 10 March 2000). King William's Town (Figure 1) is a large town with a population of approximately 28,000 people (Statistics South Africa 1996). It has a dynamic business centre that supplies a growing urban population as well as a large rural population of the former homeland of Ciskei surrounding it. It is located on a national road linking rural areas to urban centres as well as the major developing centres of East London and Port Elizabeth and therefore is an important commuter point. The total number of RMPs and herbal street traders (first order traders) is eight and they sell their product at an informal herbal market situated at the taxi rank, where herbal material is simply displayed openly on the sidewalk. Street traders are predominately women who make their living from selling herbal material in urban centres. In some instances they collect their own material or they rely on gatherers to supply them with material (Cocks and Dold 2000). The RMPs and herbal street traders in this instance are the same people.

Photo 2. Street traders selling medicinal plants within the informal market in King William's Town (Photo by T. Dold)

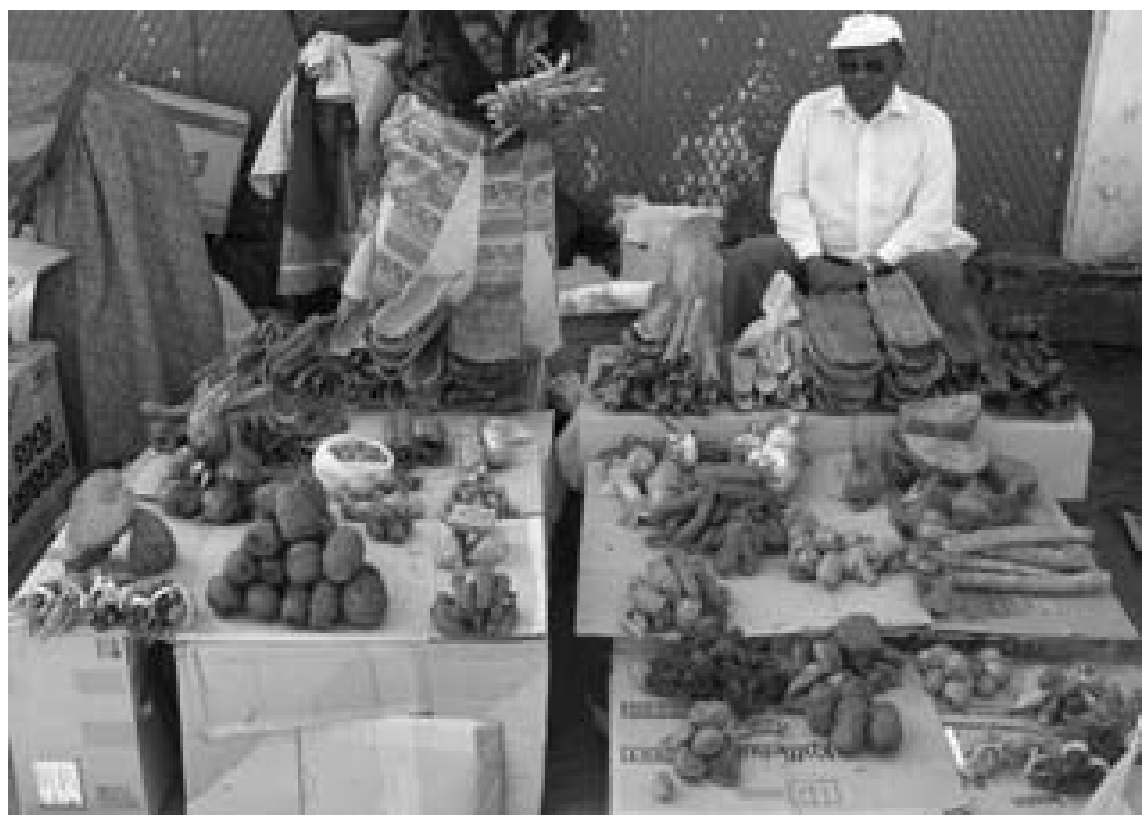


Surplus material is sold to the third link in the chain, amayeza stores. These stores are owned by either traditional healers or entrepreneurs of various ethnic groups who employ traditional healers. The amayeza stores form part of the formal commercial sector as these stores are run as businesses and the owners have rent and business expenses to pay (Cocks 1997). The stores are generally situated in the formal central business district and operate as dispensaries of both herbal and patent products. Amayeza stores sell $C$. flanaganii for US\$15.60 per kilogram. The mark-up is as high as $150 \%$ compared to the street market price, which is US\$6.24 per kilogram.

RMPs have various options to sell their products. The price per kilogram is up to six times greater, however, when they sell the material from their street stalls rather than to storeowners or middlemen. RMPs ranked $C$. flanaganii as the fifth most common species sold, whereas traditional healers and amayeza storeowners did not include it amongst the top 10. This is so because $C$. flanaganii is a cosmetic generally sold by itself rather than being used as an ingredient for herbal medicinal mixtures prepared by traditional healers. A large percentage of the population is aware of $C$. flanaganii use and consumers purchase it without consulting a traditional healer. Consequently the majority of material sold is from street markets.

Because the gatherers are also the first level traders, they are aware of the use and value of the product and are therefore in a position to adjust the price of wholesale material depending on the buyer. For example, white entrepreneurs pay significantly higher prices for the material than black entrepreneurs. No grading system is currently utilised and there is no significant alteration to the product as only the bark is sold.

Neither the gatherers nor the street traders belong to any formal trade organisation. There do appear to be basic conventions, however, that street traders have formalised amongst themselves. In King William's Town there are two groups of street traders. The older of the two groups has monopolised the opportunity to supply amayeza stores on a weekly basis and wholesalers from neighbouring towns such as Grahamstown and Port Elizabeth on a monthly basis.

\section{TRADE TO LARGER CENTRES}

Within the study site, only two male gatherers commute regularly to the large urban centres of Cape Town, Johannesburg and Kimberley as well as Alice, Port Elizabeth and Graaf Reinet (Figure 2) to sell $C$. flanaganii bark. It is likely that this product also reaches Durban through resale, although gatherers/ traders in this study did not report commuting there. The demand for $C$. flanaganii in KwaZulu-Natal is in competition with $C$. gerrardii and therefore probably not as lucrative.

These traders considered their activities to be far more profitable than selling in the herbal market in King William's Town. Male gatherers are willing to travel alone to as far as Cape Town whereas the women prefer to operate closer to home. The former have been harvesting for 12 years in the study site. C. flanaganii is one of 12 medicinal plant species harvested for external sale. The male gatherers showed similar social characteristics to herbal hawkers, i.e., low levels of education and the same age group categories. 
Figure 2. Documented trade routes of $\mathcal{C}$. flanaganii bark from Pirie Forest

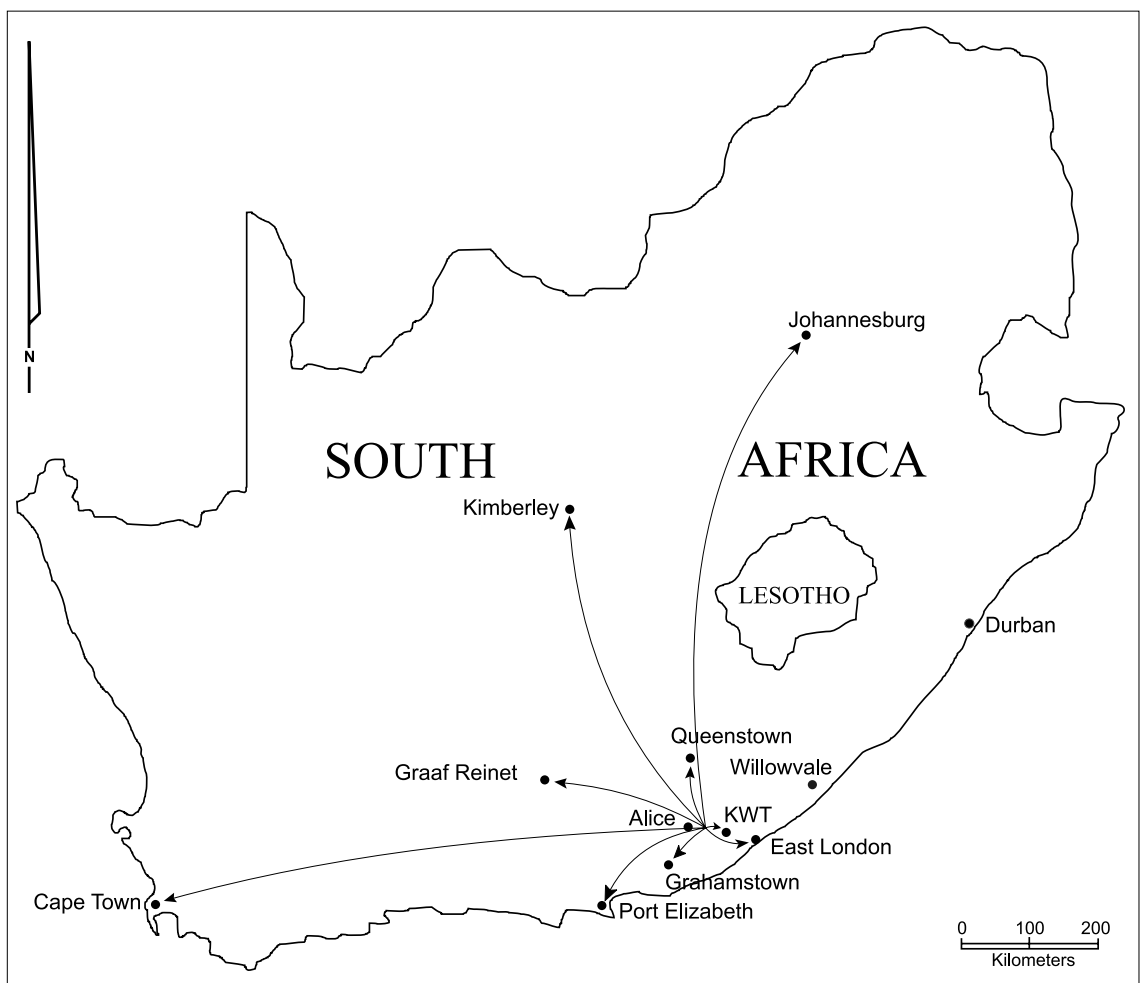

Map by Rhodes University Graphics Services Unit

Source: Cocks and Dold 2002

The difference in price for $C$. flanaganii is substantial in the various urban centres. For example, between King William's Town and Grahamstown $(110 \mathrm{~km})$ the mark-up is approximately $213 \%$. Recordings were made of the price of $C$. flanaganii at secondary markets in the neighbouring districts and the increase in price per kilogram was significant.

\section{POLICIES AFFECTING RAW MATERIAL PRODUCTION}

Pirie State Forest has been heavily exploited both by herbal gatherers and historically by woodcutters (Board 1962). Furthermore, past and recent political changes in South Africa have seriously impacted upon the management of Pirie Forest. For example, under the previous administration forest management was under the jurisdiction of the former homeland. During that era, communities were strictly prohibited from accessing forest resources. Forest guards patrolled the area to ensure that no one accessed resources. This changed, however, in 1994 after the first South African democratic election when the Chief Directorate of Forestry inherited de jure responsibility for all forests previously under the jurisdiction of the former provinces, homelands and self-governing territories. This constituted a substantial 
increase in the number of forests under the department's control. Since this change, however, the Department of Water Affairs and Forestry has struggled unsuccessfully to manage these areas because of increasing financial and staffing constraints. Decision-making bodies have subsequently realised that the department would never be in position to manage the indigenous forest effectively without the co-operation and assistance of local communities and other stakeholders. This thinking was reinforced by growing international trends and pressures for increased community involvement and participation in the management of indigenous forests. Since 1998 the department has subsequently adopted an institutional and legislative context that supports the implementation of participatory forest management, which aims to include all stakeholders in collaborative forest management-be it in the form of agreements, shared regulatory roles or community monitoring systems (N. Michell personal communication). In 1998 the department also passed the National Forest Act, which makes provision for the special protection of forests and trees as well as the setting aside of protected areas. Sustainable utilisation is, however, an important component of indigenous forest management. Consequently the department has adopted a mission statement emphasising the conservation (preservation and utilisation) of natural forests and wood lots on a sustainable and scientific basis for the benefit of all (RSA Government Gazette 1998). Inhabitants of communities in proximity to state forests are thus permitted to harvest an armload of dry material per person per day for household use. No tools to chop or containers to transport material are permitted. Only subsistence use of forest products is permitted and commercial harvesting is illegal (Anonymous 1997).

This stance has also resulted in the department's policy no longer being one of patrolling and imposing law enforcement to keep people out of the forests. In 1996 the department removed weapons from the forest guards. In Pirie State Forest, the forest guards retaliated and refused to patrol the area after a forest guard was killed by illegal timber harvesters in the area (C. Kameni personal communication).

Despite adoption of the Participatory Forest Management Policy program by the Department of Water Affairs and Forestry in 1998 no concrete steps have been undertaken towards its implementation in Pirie State Forest. The government has, however, indirectly increased its involvement in raw material production through the new legislation by permitting access to harvest for subsistence purposes. Currently no effective management structures are in place and neither the community structures nor the department is effectively managing the indigenous forest (C. Kameni personal communication). As a result gatherers in the surrounding communities have relatively free access to indigenous resources. The gatherers are aware, however, that their commercial activities are considered illegal and harvesting is undertaken apprehensively. Nevertheless, harvesting is undertaken on an unsustainable basis and is having a detrimental impact on the survival of $C$. flanaganii and other species. 


\section{CONCLUSION}

The study has revealed that large quantities of wild plant material are being harvested from Pirie State Forest-as much as $1,592 \mathrm{~kg}$ of bark annually. The sale of $C$. flanaganii contributes substantially to medicinal plant traders' annual income as $14 \%$ of their total earnings are derived from this species. The high economic value of $C$. flanaganii, as much as US\$46.80 per kilogram, in neighbouring cities has resulted in it being an extremely valuable product, but the current harvesting levels are not sustainable in the long term.

Without appropriate steps being taken to increase user groups' ownership and responsibility of the resource the likelihood of sustainability is extremely low. Despite the Department of Forestry's policy to increase access to resources and the implementation of joint management programs in the area, no effective structures are in place as yet. It is therefore strongly recommended that cultivation programs and alternative harvesting methods be initiated at the grassroots level to ensure that the species is not harvested to extinction. Preliminary work on other rare species in South Africa has shown that active ingredients can be found in parts other than the bark-such as the leaves-and that these alternatives to the highly destructive harvesting of bark should be explored (M. Mander personal communication).

The advantages of cultivation are not only confined to the individual taxa but also to the maintenance of ecological integrity. For example, the continual felling of Prunus africana (Hook.f.) Kalkm. (Nkefor et al. 1999) and Pausinystalia johimbe (K. Schum.) Pierre ex Bielle (Sunderland et al. 1999) in Cameroon to exploit the maximum bark yield causes large and discontinuous gaps in the forest, affecting dynamic processes. In both cases successful domestication and cultivation of the species are being undertaken by means of a welldocumented process (Nkefor et al. 1999; Sunderland et al. 1999) that could be applied in South Africa. Furthermore, income generated from the sale of C. flanaganii bark from sustainable sources would help alleviate the abject poverty of the communities of Pirie Mission and Cwengcwe who would be guaranteed an income from already well-established markets. The gatherers, predominantly women, are also traditionally subsistence farmers and have both farming skills and ecological knowledge of the forest as well as of the species itself, which would be essential to the successful domestication of C. flanaganii.

It is clear that, in accordance with the proposed implementation of a participatory forest management programme by the Department of Water Affairs and Forestry, the communities of Pirie Mission and Cwengcwe would benefit from a collaborative, interdisciplinary effort to make optimum use of a forest product and ensure its sustainability through domestication. The benefits would be participatory and therefore afford truly sustainable management as well as economic empowerment to local communities. 


\section{ACKNOWLEDGEMENTS}

We thank the Department of Water Affairs and Forestry, Centre for International Forestry Research and Rhodes University Joint Research Council for funding; Professor Roy Lubke and Matthew Gilbert for their assistance with the ecological survey; Patrick Kralo and Nomtunzi Sizane for their help in the field; and the communities of Pirie Mission and Cwengcwe for their co-operation.

\section{ENDNOTES}

1. Institute for Social and Economic Research (ISER) Rhodes University, P.O. Box 94 Grahamstown 6140 South Africa. E-mail: M.Cocks@ru.ac.za

2. Selmar Schonland Herbarium Rhodes University, P.O. Box 94 Grahamstown 6140 South Africa. E-mail: T.Dold@ru.ac.za

3. Government pensions for the superannuated-men over 65 , women over 60-and the permanently disabled were introduced for rural populations, including those in the former homelands in the late 1960s (Palmer 1996) and constituted US\$86 per month in 2001.

\section{REFERENCES}

Anonymous. 1997. The policy of the government of national unity white paper. Ministry of Water Affairs and Forestry, Pretoria, South Africa.

Bailey, C.L., Shackelton, C.M., Geldenhuys, C.J., Moshe, D., Flemming, G., Vink, E.R., Rathogwa, N.R. and Cawe, S.G. 1999. Guide to and summary of the meta-database pertaining to selected attributes of South African indigenous forests and woodlands. Division of Water, Environment and Forest Technology, CSIR, Pretoria.

Board, C. 1962. The border region. Oxford University Press, Cape Town.

Broster, J. 1981. Amagqirha: religion, magic and medicine in Transkei. Via Afrika Limited, Goodwood.

Coates Palgrave, K. 1977. Trees of southern Africa. C. Struik, Cape Town and Johannesburg.

Cocks, M.L. 1997. Towards an understanding of amayeza esiXhosa stores (African chemists). M.A. Thesis, Rhodes University, Grahamstown.

Cocks, M.L. and Dold, A.P. 2000. The medicinal plant trade in the Eastern Cape. Unpublished report, National Department of Water Affairs and Forestry, Pretoria. 70p.

Cocks, M.L. \& Dold, A.P. 2002. The informal trade of Cassipourea flanaganii as a cosmetic in South Africa. In: Ethnobiology and Biocultural Diversity: Proceedings of the 7th International Congress of Ethnobiology. (eds) Stepp, J.R., Wyndham, F.S. \& Zarger, R.K. University of Georgia Press.

Cunningham, A.B. 1988. An investigation of the herbal medicine trade in Natal/ KwaZulu. Institute of Natural Resources Investigational Report No. 29. 144p.

Cunningham, A.B. 1993. African medicinal plants: setting priorities at the interface between conservation and primary healthcare. People and Plants Working Paper 1. 50p.

De Lange, M. 1963. Some traditional cosmetic practices of the Xhosa. Annals of the Cape Museums 3: 85-94. 
De Villiers, S. 1984. Popular medicine among the Xhosa-speaking farm workers. M.A. Thesis, Rhodes University, Grahamstown.

Dold, A.P. and Cocks, M.L. 1999. Preliminary list of Xhosa plant names from the Eastern Cape, South Africa. Bothalia 29: 267-292.

Dold, T. and Cocks, M.L. 1997. Amayeza esiXhosa - an insight into Xhosa medicine. The Phoenix, Eastern Cape Museum Magazine 9: 4-9.

Earle, R. 1976. Can the Nubian change his skin or the leopard his spots? African Wildlife 30(6): 8.

Gerstner, J. 1942. A preliminary checklist of Zulu names of plants with short notes. Bantu Studies 15(3): 277-301.

Hilton-Taylor, C. 1996. Red data list of southern African plants. Strelitzia 4: 36. Hunter, M. 1936. Reaction to conquest. Oxford University Press, London.

Hutchings, A., Scott, A.H., Lewis, G. and Cunningham, A.B. 1996. Zulu medicinal plants: an inventory. University of Natal Press, Pietermaritzburg.

Khan, F. 1996a. Black beauty, white mask: the use of traditional plant-based skin lightening preparations in the Western Cape. Veld and Flora 82(1): 15.

Khan, F. 1996b. Beauty, myths and trees. Agenda 29: 37-42.

Khan, F. 1996c. Skin lightening in South Africa: a report on the use of skin lightening preparations, with specific reference to the extent and nature of the use of indigenous plant materials in Cape Town. Environmental Advisory Unit Report No. 01/96/10. University of Cape Town. 39p.

Low, A.B. and Rebelo, A. 1996. Vegetation of South Africa, Lesotho and Swaziland. Department of Environmental Affairs and Tourism, Pretoria.

Nkefor, J., Ndam, N., Blackmore, P. and Sunderland, T. 1999. The conservation through cultivation programme at the Limbe Botanic Garden: achievements and benefits. In: Sunderland, T., Clark, L. and Vantomme, P. (eds.) Current research issues and prospects for conservation and development, 79-87. Food and Agriculture Organization of the United Nations, Rome.

Palmer, R. 1996. Gender, households and environmental changes in two rural communities in South Africa's former Ciskei: gender, households and environmental changes, a regional project. For the Institute of Southern African Studies at the National University of Lesotho.

Palmer, E. and Pitman, N. 1972. Trees of southern Africa, vol. 3. Balkema., Cape Town. 1613p.

Pooley, E. 1993. Trees of Natal, Zululand and Transkei. Natal Flora Publications Trust, Durban.

Republic of South Africa Government Gazette No. 19408. 1998. National Forests Act, Cape Town.

Smith, C.A. 1966. Common names of South African plants. Botanical Survey Memoir No. 35.

Statistics South Africa. Census 1996. http://www.statssa.gov.za/census.

Sunderland, T., Ngo-Mpeck, M., Tchoundjeu, Z. and Akoa, A. 1999. The ecology and sustainability of Pausinystalia johimbe: an over-exploited medicinal plant from the forests of Central Africa. In: Sunderland, T., Clark, L. and Vantomme, P. (eds.) Current research issues and prospects for conservation and development, 67-79. Food and Agriculture Organization of the United Nations, Rome. 
Van Wyk, B-E. and Gericke, N. 2000. People's plants. Briza Publications, Pretoria.

Victor J.E. 2002. South Africa. In: Golding, J.S. (ed.) Southern African plant red data lists. Southern African Botanical Diversity Network Report 14: 93-120. Sabonet, Pretoria..

Viljoen R. 1994. Fuelwood, social forestry and rural development. In: Plant for life: the Biomass Initiative conference report. Pretoria, 28-29 September 1994.

Watt, J.M. and Breyer-Brandwyk, M.G. 1962. The medicinal and poisonous plants of southern and eastern Africa. Livingstone, London. 


\section{Chapter 6}

\section{The contribution of shea butter (Vitellaria paradoxa C.F. Gaertner) to local livelihoods in Benin}

Kathrin Schreckenberg ${ }^{1}$

\begin{tabular}{llllll}
\hline Common names & $\begin{array}{l}\text { Part of the } \\
\text { resource used }\end{array}$ & Management & $\begin{array}{l}\text { Degree of } \\
\text { transformation }\end{array}$ & $\begin{array}{l}\text { Scale of } \\
\text { trade }\end{array}$ & $\begin{array}{l}\text { Geographic } \\
\text { range }\end{array}$ \\
\hline Shea, Karité & Kernels & Wild/Managed & High & International & Large \\
\hline
\end{tabular}

\section{ABSTRACT}

The data for this paper were collected in 1992/3 as part of a larger Ph.D. study investigating the supply and demand of non-timber forest products in the Bassila region of Benin. Shea (Vitellaria paradoxa C.F. Gaertner) is the principal tree component of the agroforestry parklands in the region and, in spite of changes in agricultural practices, will continue to be so for the near future. Shea butter is a staple component of the local diet and the kernels are a significant source of income for women. They have been traded internationally for over a century for use in the food (margarine and chocolate) industry. Changes in consumption patterns and the availability of alternative, more reliable and less arduous, income-earning activities suggest that local interest in shea may decline in the long-term. This may be counteracted, however, by increased interest internationally as shea butter gains a growing foothold in the cosmetics market, leading to greater demand for kernels and, particularly, locally produced butter. No specific policy interventions are required to ensure that shea remains an important livelihood option for local women in the case study area.

\section{INTRODUCTION}

\section{Why the interest in shea?}

Known as karité in French, the shea tree (Vitellaria paradoxa C.F. Gaertner) is the most common species in the parklands of semi-arid West Africa (Breman and Kessler 1995). The edible butter made from its kernels was reported to be 
traded in the fourteenth century (Busson 1965, cited in Hall et al. 1996) and was mentioned frequently in the writings of early European travellers in West Africa (Park 1799; Clapperton 1829; Caillié 1830). Export of what was then known as Butyrospermum parkii, to supply European production of margarine and candles, began well before World War I. Figures for the current European import market are highly unreliable but a conservative estimate suggests it is worth US\$13 million per year (Fintrac 1999). The main producers are the Sahelian countries, shea being the third most important export crop in Burkina Faso, for instance. Most of the trade (and all the data presented in this chapter) concerns the more common subspecies paradoxa, which occurs in a wide belt from Senegal to the Central African Republic (Hall et al. 1996). The liquid fat produced from the second subspecies nilotica hardly features on the export market, possibly because of the tree's location in the relatively unstable areas of southern Sudan and Ethiopia, Uganda and north-east Zaire (Hall et al. 1996).

Processing into butter is predominantly carried out in the importing country. Much of it is used as a cocoa butter equivalent (CBE) in the chocolate industry, often being mixed in various proportions with fats derived from other non-timber forest products (NTFPs) such as palm oil (Elaeis guineensis Jacq.) and illipe (Shorea macrophylla (Vriese) Ashton). Shea is considered to be the best of the CBEs and is particularly useful in chocolate manufacture as it raises the melting point, giving increased shine and hardness at room temperature (Boffa 1999). While the chocolate and confectionery industry uses the butter (stearin) fraction of shea butter, its oil (olein) fraction is also used in margarines and baking.

In recent years, the food industry market has been supplemented by a small but dynamic market emerging for use of shea butter in 'natural' cosmetic products. Its high triglyceride content gives it a rich consistency which is valuable for skin creams, shampoos and other cosmetic products because of its hydrating, protecting and softening properties.

At the same time as being an important traded crop, shea plays an integral role in rural people's subsistence. In most of the southern Sahel and Sudan zones in Africa, shea butter is the most affordable and extensively used edible fat (Boffa 1999). In non-pastoral areas it is sometimes the only source of fat for rural populations (Hyman 1991). The fruit flesh (a thin but delicious layer around the nut) provides an important snack during the early agricultural or 'lean' period, when stocks from the previous harvest are low but energy needs are high (Boffa 1999). Shea butter has numerous traditional medicinal applications. Rancid butter is traditionally used to make soap, the by-product of butter-making is used to waterproof earthen hut walls (Schreckenberg 1996), and the wood burns well and makes good charcoal. As a source of income, all shea-related activities are entirely in the women's domain.

\section{Context of the study}

The data were collected as part of a Ph.D. study (Schreckenberg 1996) to investigate supply and demand of NTFPs in the Bassila region of Benin. Continuous fieldwork was carried out from September 1992 to September 1993, focusing on three case study villages. The supply of NTFPs was investigated through fortnightly phenological observations on 193 trees representing 11 species, 
including yield estimates for shea and African locust-bean (Parkia biglobosa (Jacq.) Benth). This was combined with an inventory of land-use types and tree densities in a circle (with $3.3 \mathrm{~km}$ radius) around each village, this being the approximate area from which NTFPs were collected and in which the majority of fields lay. On the demand side, community-level meetings were followed by regular group discussions with women in all three villages to discuss the role of NTFP incomes in their livelihoods as well as weekly observations at two weekly markets for a whole calendar year. This was supplemented by a complete household survey to determine the amounts of NTFPs used (for subsistence and sale) in the previous year.

Much NTFP research focuses on products that have suddenly caught the public eye because of the rapid decline in resources (e.g., woodcarving and trophy hunting in southern Africa), the boom-and-bust nature of markets (e.g., rubber and brazil nut in Bolivia), the impact of high-profile outside interventions ('rainforest crunch' literature) and concern for the empowerment of local people (e.g., Brazilian chicleros and rubber tappers). This shea case study is perhaps unusual in that it is a by-product of a larger study on NTFPs in an area that was chosen primarily for logistical reasons ${ }^{2}$ rather than because NTFPs were considered to be an issue of any particular importance, and where processing and trade have not been supported by any external interventions. While the chapter refers to the shea trade more generally, the specific case study is not representative of the key shea-producing areas in the drier Sahelian region.

\section{Regional setting}

The research was carried out in three villages (Kodowari, Djantala and Diepani PK8) in the Bassila subprefecture, Atacora Department, Benin. The three villages were selected as being average-sized (50-500 inhabitants) communities representing a cross-section of ethnic groups. Bassila, a small town of 5,500 inhabitants, lies about $350 \mathrm{~km}$ inland, close to the Togo border (Figure 1). Together with most of the local villages it is sited along the main road leading from the coast to Burkina Faso in the north. Although unpaved, this road is a major trade route and two of the study villages (Djantala and Diepani PK8) were established here by immigrants in the late 1960s and early '70s to take advantage of relatively empty land along a good road. The indigenous village, Kodowari, moved from its original forest location to its present roadside location at the same time.

Vegetation in the Bassila region is a typical 'savanna landscape' (Bourlière and Hadley 1983), in which savanna vegetation dominates but is interrupted by a series of distinctive gallery forests along mostly seasonal watercourses. With its unimodal rainfall (May-October) of around 1,300 mm, the Bassila region falls into the Northern Guinea savanna category in the Keay (1953) classification or the broader category of 'Sudanian woodland' according to White (1983). This is the southern and wettest end of the shea distribution.

This area of Benin was once the 'wood-basket' of the country. By the time this study was carried out in 1992/3, however, the area around the villages was dominated by field, fallow, bush savanna (savane arbustive) and tree savanna (savane arborée) in almost equal proportions (around 20\% each), the remainder 
Figure 1. Map of Benin and study site
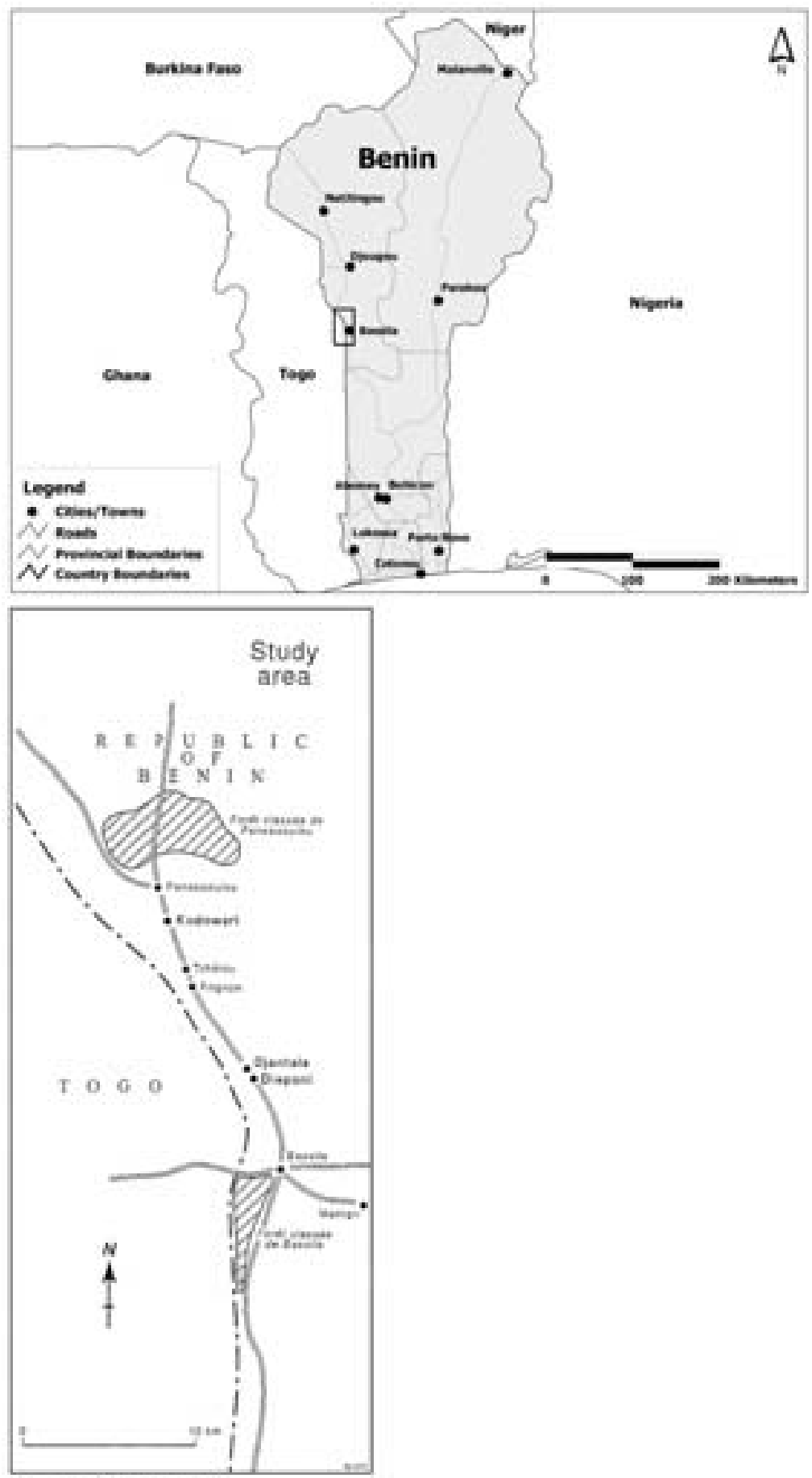

Source: ESRI Data and Maps 2002. 
consisting of dense dry forest and gallery forests. During clearing, farmers retain mature individuals of a number of useful tree species in their fields (Photo 1), thus converting the landscape into a characteristic parkland. These are land use systems in which trees are deliberately preserved in association with crops and/or animals in a spatially dispersed arrangement and constitute the predominant agroforestry system in semi-arid West Africa (Nair 1993; Bonkoungou et al. 1994). Parklands are usually dominated by one or two tree species, which may vary with climatic zone and agricultural practices (Boffa 1999). In the case of shea, the typical companion tree is the African locustbean, the seeds of which are fermented to make a protein-rich seasoning used in most sauces in the Bassila area.

Photo 1. Farmers retain mature individuals of useful tree species in fields (Photo by K. Schreckenberg)

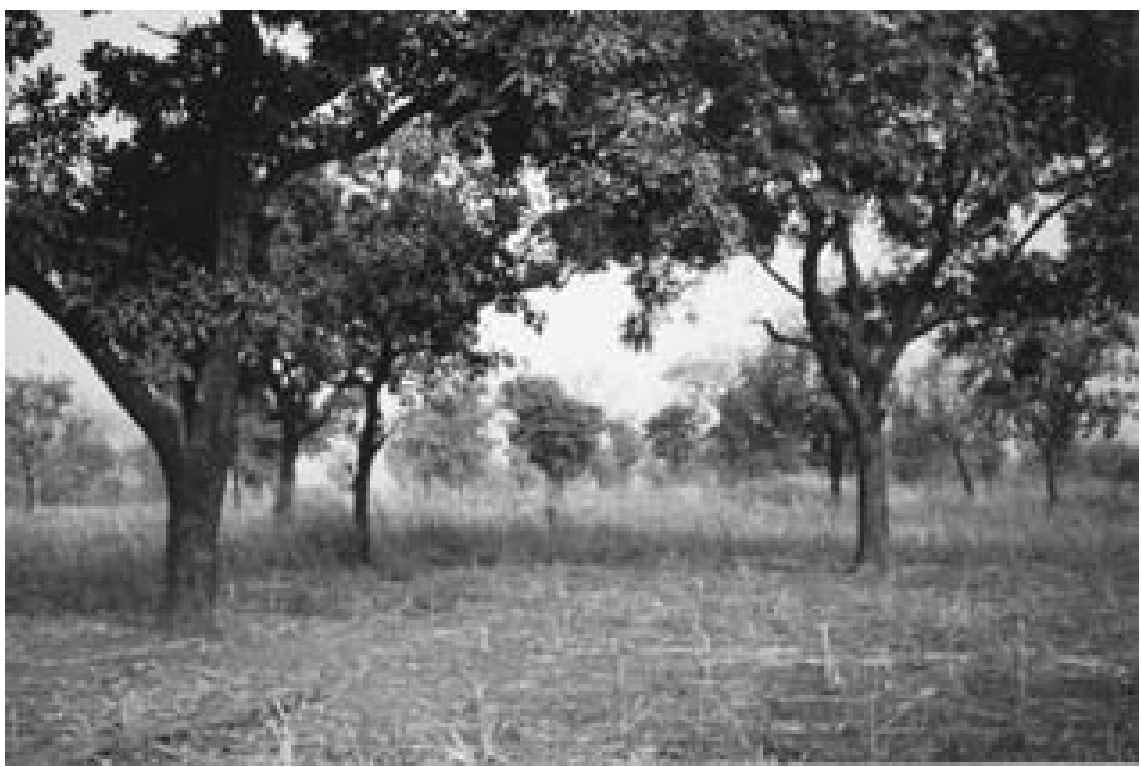

\section{THE PRODUCTION-TO-CONSUMPTION SYSTEM}

\section{The resource base}

Shea is one of several species (others are the African locust-bean and the timber tree Khaya senegalensis (Desr.) A. Juss.) in Benin for which farmers must obtain a permit before clearing. As the underfunded forestry department is not in a position to enforce these regulations (Schreckenberg 1999), it is just as well that the law mirrors local practice. As also reported from Mali (Bagnoud et al. 1995), men in the study area stated that they often maintained more shea trees than they consider optimal from a crop point of view because they were a key source of income for their wives. 


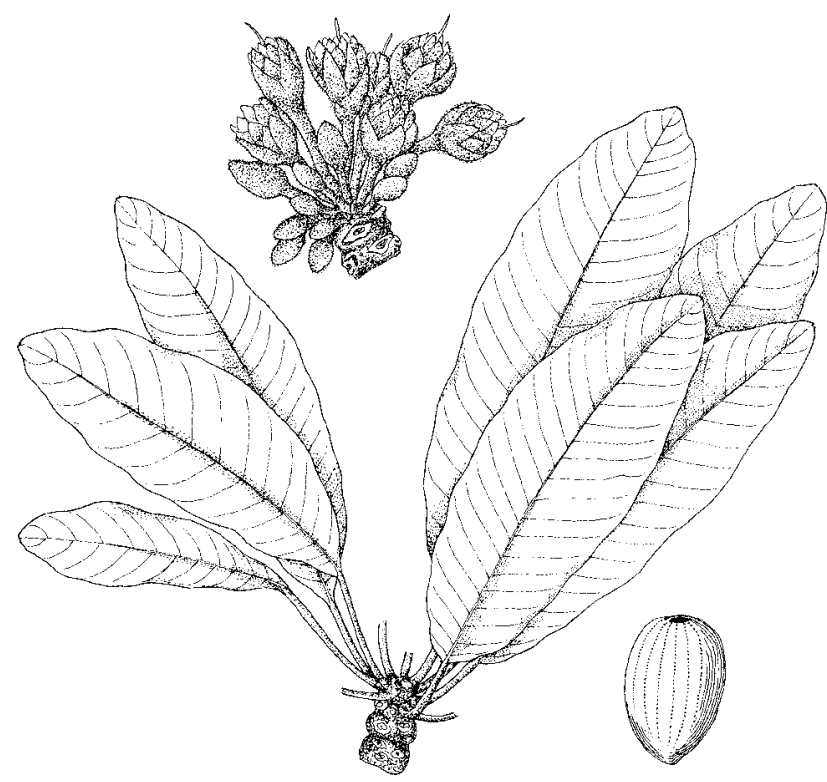

(Vitellaria paradoxa)

Selective retention of shea has increased its relative density in the fields to three times that in the savanna (Schreckenberg 1996). Of 63 trees (of all species) per hectare in the fields, 25 are shea. This compares well with the figure of 30 to 60 shea trees per hectare recorded slightly to the north-east by Agbahungba and Depommier (1989) and is double that typically found in Burkina Faso and Mali (Kater et al. 1992; Gijsbers et al. 1994; Boffa 1995). Well over half the trees in the fields and fallows are productive as farmers tend to clear younger trees. As a result, regeneration-which is entirely natural-occurs primarily in the fallows. The only management intervention is the removal of unwanted individuals (excess regeneration and trees with consistently poor yields). As has been described for northern Ghana (Lovett and Haq 2000), selection by farmers of healthy, productive individuals well suited to the managed field environment is an indication that the species is in the early stages of domestication.

Like many indigenous species, shea is renowned for its variable yields from year to year (Schmidt-Leplaideur 1987; Agbahungba and Depommier 1989). Women said that out of every three years, they expected one good, one bad and one average year. No clear relationship between annual yield variation and environmental factors was recognised by farmers; nor has it been identified in the literature (Boffa 1999). In addition to variability from year to year, there is also variability between trees (Ruyssen 1957), which farmers explain by saying, 'Trees are like people, some are bad, some are middling, and some are very good' (Schreckenberg 1996). Farmers considered 1993 a 'good' year, the average yield being $19.6 \mathrm{~kg}$ of fruit per tree, which corresponds to $5 \mathrm{~kg}$ of dried kernels. 


\section{Raw material producers and socio-economic context}

\section{The population}

The Bassila region is a veritable ethnic melting pot. The indigenous Anii are restricted to this area and a few villages in neighbouring Togo. They are Muslims and make up the entire population (585 people) of one of the case study communities, Kodowari. The two main immigrant groups are the Logba (from Ouaké, $80 \mathrm{~km}$ to the north-west) and the Otamari (from Natitingou, $170 \mathrm{~km}$ to the north-west). The community of Diepani PK8 (108 people) consists almost entirely of the Protestant Otamari, while the Logba in Djantala (147 people) are a mixture of Muslims and Catholics and are joined by several Peulh families. These semisedentarised cattle herders originate from areas to the north and north-east of Bassila as well as from Togo, and live in isolated family camps in the bush around the villages. They practise agriculture and hold small herds of cattle and livestock on behalf of settled villagers.

Population density in the Bassila subprefecture remains relatively low at 9.5 people per square kilometre (1992 census) and there is no shortage of land. Tenure, however, is a complicated matter. Although all land formally belongs to the state, customary tenure still applies around Bassila and in much of the north of Benin. Local authorities recognise the rights of the 13 Anii customary landowners in the study area, who hold the land in trust for their lineage in a quasi-'private' way. Farmers must request their permission to clear land, but can then farm without paying rent (though occasional gifts to the landlord are advised). As the landowners have large holdings (in several cases many thousands of hectares), they are often unable to control them and land becomes a de facto open access resource.

All three communities live along the main road linking the coast with the north. Each has access to a local school and a less than functional health post. Kodowari has a lively market attracting around 100 traders after Friday mosque, whereas the more recent shared market of Diepani PK8 and Djantala draws in 30 to 40 traders on Tuesday afternoons. Neither market is large enough for the prefecture to collect taxes. Most traders are simultaneously sellers and buyers, mainly of agricultural produce. In addition, each market has a number of 'petty' traders selling batteries, soap, sugar, matches and medicines, and an important drinking area where traditional sorghum beer, palm wine and food are served.

\section{Agriculture and other income-earning activities}

In the study area fields are cleared and farmed for around four to six years before being left fallow, sometimes for only two to four years. The main cash crops are maize, groundnuts, cotton and cashew nuts. Sorghum, yam and cassava are also important for subsistence. Traditional tools are the shorthandled hoe and the machete, animal traction being a recent (but popular) introduction to the area. Artificial fertilisers and pesticides application is limited to cotton and (rarely) maize. In general, the division of labour by gender is still fairly traditional. Men clear and prepare land, weed, and harvest rootcrops, while women sow and harvest all other crops. Women rarely have fields of their own and generally work on their husbands' or fathers' fields. The heaviest labour period is May to July when some crops are being planted, some already 
harvested and others requiring weeding. Livestock are restricted to a few goats or sheep per household and some cattle, kept by the Peulh.

Agriculture is the main income-earning activity for men of all ethnic groups. Only a few men still hunt regularly, following a decline in game stocks. A growing number of men supplement their farm income by collecting palm nuts or honey. This is true particularly for young men and recent immigrants who do not yet have land of their own to farm. They may also earn small amounts by transporting goods on their bicycles, and the few who own bullock pairs rent out their animals or use them to transport goods and people. A few immigrants from the south earn money from tapping oil palms and distilling palm wine.

Women earn very little for the time spent working in their husbands' fields. An exception are the Otamari women, who control most of the vegetable harvest. In other ethnic groups, unless women own their own fields (relatively uncommon except for widows), agriculture is their least important income-earning activity. Most important are various forms of food processing, petty trade, collection and sale of fuelwood, and the gathering and processing of a range of NTFPs.

\section{Income from shea}

The importance of shea income for women is recognised by all. It is often considered a 'gift from god' enabling them to survive. Well over $90 \%$ of women were involved in collecting nuts. Those that failed to collect were either too ill or absent (travelling to visit family) during the harvest season. Some of the latter immediately bought stocks of kernels on their return. Yet when averaged over all households, the income from shea (including sale of kernels, sale of butter and own consumption of butter) makes up only about $2.8 \%$ of total household income. To understand the significance of even this income, for women in particular, a brief description of household budgeting is required.

In the study area, as in much of West Africa, men and women have very separate budgets. Men primarily earn money from the sale of their agricultural produce and are responsible for providing the staple food (maize, cassava, yam) and covering school fees and children's medical costs. Women have two types of income:

- 'Weekly' income is derived from daily or weekly activities such as cleaning rice, preparing food for sale, processing shea butter or African locust-bean moutarde, collecting fuelwood for sale. The income is used to cover daily expenditure on sauce ingredients, school lunch money, soap, kerosene and grain milling, and ranges from about CFA450 to CFA2,600 (US\$1.6-9.4) per week depending on the woman's ethnic group and the size of her family.

- Annual lump sums income is derived from activities such as the sale of stocked produce (including shea kernels), seasonal sale of palm oil and honey. This kind of income is essential for women to fund investments both in consumptive activities (such as new clothes, school uniforms, gifts at Christmas, pots and pans) and in productive activities (building a storage hut, purchasing a goat, purchasing agricultural stocks for later resale, etc.). Annual expenditure of this kind costs a minimum of CFA10,000 (US\$36) per year. 
It is particularly as a source of lump sum income, obtainable with no investment other than labour, that shea kernels are important to women. In 1993, income from kernel sales varied from CFA2,000 to CFA10,000 (US\$7-36) and, for many women, was sufficient to cover a substantial part of their 'annual expenditure'. Similar figures were recorded in south-western Burkina Faso (US\$15-35) by Crélerot (1995, cited in Boffa 1999). Incomes depend on the amount of kernels a woman can collect and the time at which they are sold. Poorer women cannot wait for prices to rise and are obliged to sell all their kernels as soon as they are sufficiently dry, whilst others can hold on to their stocks to benefit from seasonal price rises. In 1992/3, the price for kernels rose from CFA17 per kilogram at harvest time to CFA52 per kilogram just before the harvest. In spite of variable yields, it seems that annual incomes may not be so different from year to year-in a good harvest year women can collect more but have to sell at a lower price, while in a poor harvest year the little they can collect fetches a higher price. Certainly at a national level, Hyman (1991) has argued that annual variations in yield are partly offset by changes in the proportions of nuts collected.

Income from the sale of shea kernels was one of a number of NTFP-based incomes found to be particularly important in bridging the financial shortfall at the start of the agricultural season (May/June) (Schreckenberg 2000). Many women even suspended their usual income-generating activities so that they could invest time in collecting shea nuts. The average amounts collected by women in the different ethnic groups are shown in Table 1.

Table 1. Kernel collection, shea butter consumption and NTFP consumption

\begin{tabular}{lccc}
\hline & $\begin{array}{c}\text { Anii } \\
\text { (in Kodowari) }\end{array}$ & $\begin{array}{c}\text { Logba } \\
\text { (in Djantala) }\end{array}$ & $\begin{array}{c}\text { Otamari } \\
\text { (in Diepani PK8) }\end{array}$ \\
\hline $\begin{array}{l}\text { Average amount (kg) } \\
\text { of kernels collected } \\
\text { per woman in 1993 }\end{array}$ & 159 & 202 & 288 \\
$\begin{array}{l}\text { Average annual value (CFA) } \\
\text { of shea butter consumed } \\
\text { per household }\end{array}$ & 516 & 1261 & 9193 \\
$\begin{array}{l}\text { Average annual value (CFA) } \\
\text { of all main NTFPs consumed } \\
\text { per household }\end{array}$ & 18,427 & 23,493 & 25,834 \\
\end{tabular}

Source: Schreckenberg 1996.

Shea is less important as a source of 'weekly' income as only 6 out of the 201 women in the study villages processed kernels into butter for sale. These were mostly Peulh women, who are known locally as the 'butter-making specialists'. Making shea butter is a laborious (see below) and not very profitable business. On average, women transform about $12 \mathrm{~kg}$ of kernels, giving them a total profit (not taking into account the opportunity cost of their labour) of about CFA200 (US\$0.7) per week. Although at the low end of the range, this is similar to profits made from other 'weekly' activities. Women maintain their profits at this level regardless of the price of kernels by altering the unit price 
of butter. Butter 'pats' are always sold for CFA25, but their weight varies from $110 \mathrm{~g}$ just before the harvest to $266 \mathrm{~g}$ a few months later. Profits are low because the women's own stocks of kernels rarely last more than a few months and none have sufficient capital to lay aside a large stock when the price is low at harvest time. Instead they buy the kernels they need each week and are often obliged to buy them on credit, repaying with the proceeds of the butter sale. However, because they often sell their products on credit, they can easily fall into a credit trap and lose their capital. Any factor that disrupts this earning and spending cycle, such as illness, pregnancy or unexpected expenditure, can lead to impoverishment.

\section{Direct consumption of shea butter}

In addition to income from the sale of shea kernels and/or butter, many families also benefit from the consumption of shea butter. Farther north in Benin, beyond the natural range of oil palms, shea butter is the most important source of edible oil (Agbahungba and Depommier 1989). It plays a particularly important nutritional role as a source of fat in children's diets (Crélerot 1995, cited in Boffa 1999). In the Bassila area, where both shea trees and oil palms grow, the various ethnic groups are divided in their use of these two vegetable fats. Though generally cheaper, shea butter is the main cooking fat only for the Otamari and the Peulh. The Logba and the Anii prefer to use palm oil or, if available, groundnut oil. The Otamari women in Diepani PK8 process around 3 $\mathrm{kg}$ of kernels per week, producing about $1 \mathrm{~kg}$ of butter, which would cost them CFA100 to CFA225 (US\$0.36-0.8) on the market, depending on the season. This is very close to the $150 \mathrm{~g}$ of butter used each day by a Malian family of seven (Fleury 1981) and converts into an annual per capita consumption of about $10.3 \mathrm{~kg}$. The average value of annual household consumption of shea butter for the three settled ethnic groups in the study area is shown in Table 1.

\section{Processing industry}

\section{Harvesting and drying the kernels}

As in the rest of West Africa (Boffa 1999), in the case study area it is women and children who collect shea nuts. As nuts in fields are reserved for the female relatives of the farmer, women start collecting in bush areas where competition from other women is greater. Fruit ripen and fall from April until August and women begin to collect almost immediately, investing as much time as possible in the early part of the agricultural season (April-June), when they are not yet preoccupied with weeding and harvesting. Most women collect nuts on their way to and from the fields and, if time allows, will also undertake special half-day collecting expeditions to remoter areas with a friend or cowife. Headloads of up to $47 \mathrm{~kg}$ were recorded.

Once collected, fruits are prepared for sale or storage. This requires inactivation of the lipase enzymes, which increase the concentration of free fatty acids and thereby reduce the butter quality. Two methods are used. The Otamari roast the nuts in a tall oven for 12 hours to 24 hours, and then store 
them in their shells. The Anii, Logba and Peulh first boil the fruit for an hour before sun-drying them on the ground. This takes one to two weeks depending on the weather, during which time the nuts have to be turned occasionally. Once dry, the nuts are pounded gently to remove the shells. The kernels are then sun-dried for a few more days before being stored in sacks. Once dry, the kernels can be stored for up to two years.

\section{Local butter-making}

Kernels are first coarsely pounded in a wooden mortar and then roasted in a large iron pot. A temperature of about $120^{\circ} \mathrm{C}$ is key to achieving maximum butter extraction without burning the kernels. These are then pounded again and ground into a smooth brown paste, either by hand on a flat stone or, if funds are available, at a local cereal mill. The paste is then beaten with water. Knowing how much warm or cold water to add is a skilful task and, after about 30 minutes, the mixture separates. The solid fat is scooped out and washed until it is almost white. It is then boiled and decanted to remove any remaining impurities, leaving a clear yellow oil that solidifies to a pale yellow butter. The butter can now be stored in a cool place (often covered with a wet cloth) for several months. If it is to be sold, it is formed into small pats by gently warming the butter, scooping it into small calabashes and dipping these into a bowl of cold water. This makes the pats solidify and float to the surface. The pats are then placed on a large plate covered in wet leaves to keep them cool for sale (Photo 2).

Photo 2. Pats of shea butter ready for sale (Photo by K. Schreckenberg)

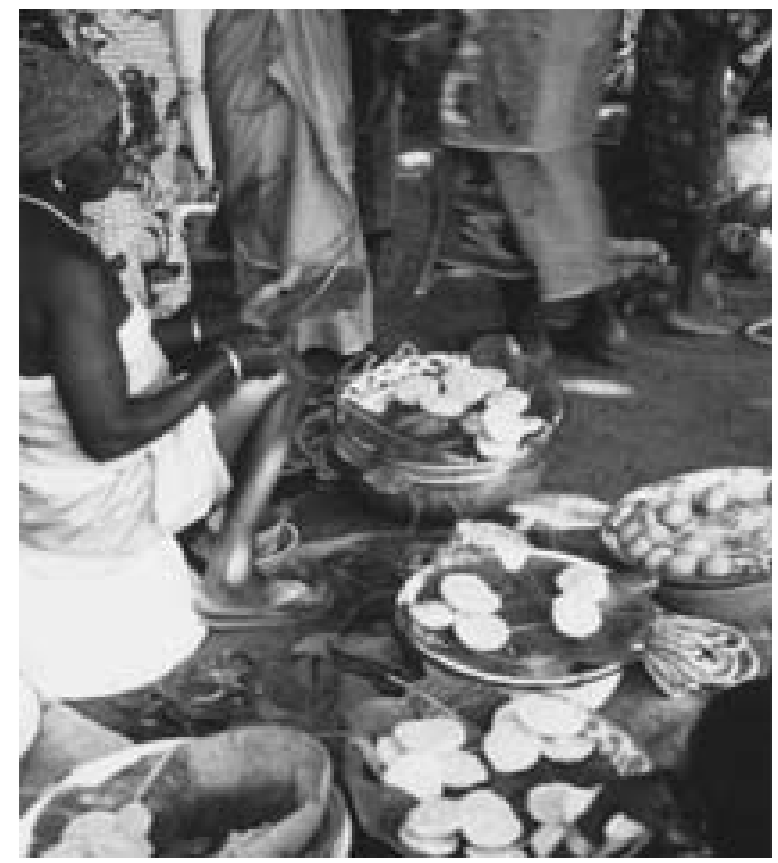




\section{Industrial processing}

In the Sahelian countries, where shea is one of the few income-earning activities available to rural women, development projects have invested much effort in finding ways to mechanise butter-making. None of the resulting manual and mechanised presses were known in the Bassila area at the time of this study. All industrial processing in Benin was carried out at the government Société Nationale pour l'Industrie des Corps Gras (SONICOG) factory in the capital, Cotonou. This facility was dedicated mostly to the manufacture of palm oil and palm kernel oil and only made shea butter when contracted by a number of local exporters. Processing involved grinding the kernels and then heating and pressing them to extract the oil. In European factories, shea butter is produced using hydraulic presses on the kernels and then placing them in hot air ovens. The product is then bleached with a hexane solvent and must be stored and transported in cool, airtight containers to prevent it from becoming rancid (Fintrac 1999).

\section{Trade and marketing}

The trade diagram (Figure 2) provides an overview of the main movements of the principal shea products-kernels, butter and soap. The information relates primarily to trade within Benin as information beyond the borders is difficult to obtain.

\section{Kernel trade}

While the Otamari, Peulh and Logba all retain some of their kernels for processing into butter, most kernels in the Bassila area are collected and dried for sale. The first kernels come to market in May and the volume sold peaks in September. At this time, the main buyers are bulk buyers who purchase several sacks (of $115 \mathrm{~kg}$ ). These are women, often from the nearby town of Bassila, who are either agents for national companies or suppliers for such agents. Agents are usually provided with sacks and an advance by the company. In addition to purchasing kernels at local markets, they also go directly to villages, particularly those situated conveniently along the road, to buy from the women.

Discussions with companies based in Cotonou suggest that they require orders of at least 500 tonnes before initiating a purchasing campaign. Only a handful of companies export shea kernels and they are often also involved in exporting other products such as palm oil and palm kernels. Cashew nuts are a particularly good complement to shea as they require the same transport infrastructure and are available in the alternate season.

The first year in which the government itself, as required by structural adjustment, did not purchase any kernels was 1992. The department responsible for quality control of exported products, Direction du Contrôle du Conditionnement des Produits (DCCP), did, however, continue to set the minimum purchase price in consultation with the main export companies. The price is set in July and takes into account prices in neighbouring countries, the cost of transport and international market prices. In 1993 it was set at CFA40 per kilogram but traders in the Bassila area ignored it as good yields 


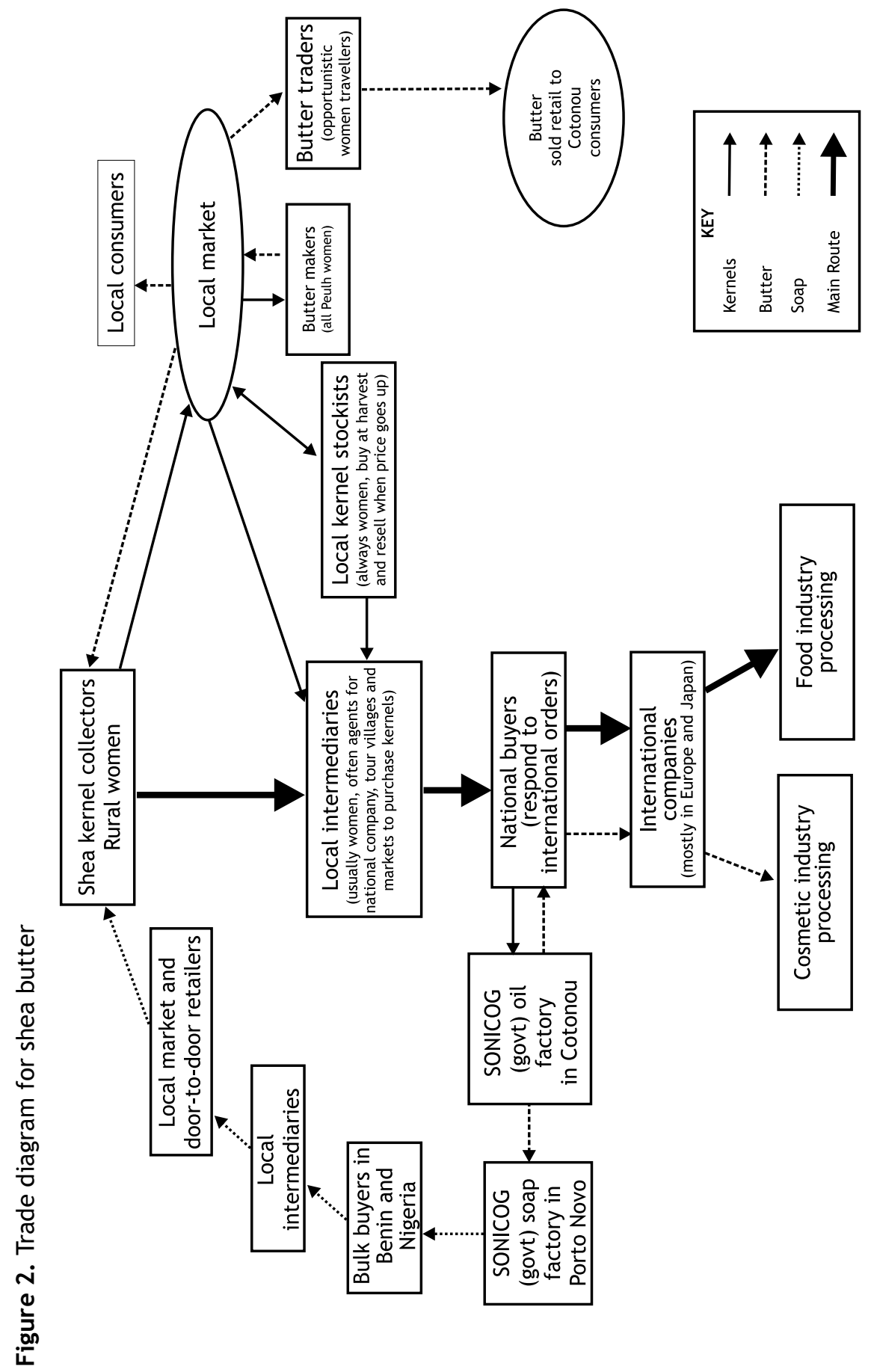


had caused the price to fall to CFA17 per kilogram. By contrast, poor yields in 1992 resulted in a higher local market price (CFA50/kg) than the official minimum (CFA40/kg). The international price for shea is closely linked to that of cocoa, and the highest official minimum price in Benin (CFA100/ kg) was set in 1985/6 when there was a shortage of cocoa butter on the international market (Kagnassy personal communication).

Official export figures from Benin are highly variable and unreliable. One large export company claimed to have exported 13,000 t of kernels in 1992, though the DCCP estimated total exports at only 9,100 t. FAO statistics suggest that exports in 1993 were only about 7,870 t and then nearly doubled in 1994 (FAO 2001).

Several sources suggest that both potential and actual supplies of shea kernels in West Africa exceed local and international demand (Boffa 1999). Certainly this was true in the study area, where less than $5 \%$ of total production was collected in 1993. On the international demand side, European food industries are not concerned about a shortage in supply (Boffa 1999) given that demand has never exceeded supply in the history of the crop.

The international shea market is a narrow and confidential one, for which it is rather difficult to obtain prices, quantities purchased, demand or other data (Boffa 1999). FAO (2001) estimated total exports from West Africa in 1994 to be around 58,700 t of dried kernels. Savadogo et al. (1998) estimated that $40 \mathrm{t}$ to $75,000 \mathrm{t}$ were destined for Europe with a further $10 \mathrm{t}$ to $15,000 \mathrm{t}$ being exported to Japan. More recent estimates, however, suggest that the real volume leaving West Africa each year may be closer to 500,000 t (P. Lovett personal communication).

\section{Butter trade}

Locally processed butter is essentially for the local market. A few women also made opportunistic use of trips to Cotonou to take baskets of butter pats with them for door-to-door sales. At national level, butter is exported by just a handful of companies. All of these contract the SONICOG factory in Cotonou to do the processing. According to the government, 1,879 t of butter were exported in 1992 but the figures are unreliable.

\section{Soap trade}

In the Bassila area, the women who make butter for sale may also make traditional soap from left-over and rancid butter. This black and crumbly soap is made from shea butter (or palm kernel oil), which is saponified using potash derived from the ash of trees such as Piliostigma thonningii (Schum.) MilneRedhead or sorghum stalks. Some people prefer this soap to manufactured soap because of its reputed skin-healing properties. At national level, the SONICOG soap factory in Porto Novo uses small proportions (less than 5\%) of shea (together with palm oil and palm kernel oil) in some of the soap it makes. This Palmida brand soap eventually ends up back in the village via a series of intermediary traders. 


\section{Policy environment}

At the time the research was carried out in 1992/3 there was no direct government intervention in the shea trade in Benin (Table 2). Until the year before the study, shea kernels had been purchased by a government parastatal, along with other cash crops such as cotton and cashew nuts, but the practice was suspended as part of the structural adjustment process. Unlike in many Sahelian countries, where there has been much external project investment to promote shea butter as an income source for women, there was no external support to any shea activities in the study area. The existing international policies (Table 2) also appear to have little impact on the ground.

Table 2. Impact of national and international policy interventions

\begin{tabular}{lll}
\hline Policy & & Impact \\
\hline National & The Forest Department encourages & The regulation mirrors traditional \\
& farmers to leave 25 to 40 trees & practice so has no particular impact. \\
standing per hectare when clearing & Should traditional practice change, the \\
new fields (Fagbémy and Sodeik & Forest Department would not have the \\
1993). Permits are required to fell & resources to enforce the regulation.
\end{tabular}
shea trees.

Government sets minimum price for shea kernels each year in an attempt to ensure a fair deal for sellers and traders alike.

International Production of CBEs is prohibited in many European countries and the United States, although the sale of CBE products is permitted. In the interests of product purity the European Union has restricted the proportion of CBEs in chocolate to $5 \%$ (Boffa 1999).
The set price is irrelevant at local level as it is based on international prices and does not reflect production levels. Local market prices may be higher or lower than the set price depending on local yields.

There has been much debate within the European Union about this issue, with cocoa-producers concerned that greater acceptance of CBEs will damage their interests and the chocolate industry arguing that the impact on the cocoa trade would be negligible. The fact that many of the coastal West African countries export both cocoa and shea complicates the story but, largely speaking, they are still more pro cocoa due to the unreliable and unmanaged nature of shea yields from year to year. The practical impact in the field appears to be minor. Shea prices continue to shadow those of cocoa but at a substantially lower level (Fintrac 1999). 


\section{TRENDS AND ISSUES}

The contribution of NTFPs to local livelihoods is variable both within communities and over time. The short duration of this study means that it was impossible to provide any long-term observations of trends relating to local shea consumption and trade. But trends may be observed across space as well as time, and the different behaviours of the four ethnic groups included in the study do appear to indicate the direction of change. This change is evident in three closely related areas-the resource base, direct consumption and shea as an income-earning activity. Trends at local level are complicated by change in a fourth area, namely the international trade in shea. Each of these is dealt with separately below.

\section{Changes in the resource base}

As a typical parkland species, the future of shea is closely linked to the future of the parklands system itself. In the Bassila area, three changes in agricultural practices may threaten the survival of parklands in their present form:

- A growing number of young men have been trained as 'modern' bullock plough farmers and have removed all the trees from their fields. While they are encouraged to replant trees around field boundaries or in small woodlots, most prefer to plant pole or timber-producing species or sometimes exotic fruit trees (particularly mango and/or cashew) rather than indigenous NTFP species, which are slow to mature and the benefits of which are traditionally associated with women (Schreckenberg 1999).

- The introduction of cotton-now the major cash-crop in the area-has, for the first time, taught farmers to monocrop. Cotton is often cultivated by groups of men and complete removal of trees is recommended.

- Shea regeneration occurs predominantly in the fallows. The current trend of shortened fallows, combined with the fact that shea can only reproduce from about 20 years (Ruyssen 1957), means that the population in the fields is an ageing one (Schreckenberg 1999). Given the longevity of shea (easily up to 200 years), this trend is unlikely to become a problem in the immediate future but may be cause for longer-term concern.

Similar changes have been reported from Senegal (Bergeret and Ribot 1990), Côte d'Ivoire (Bernard et al. 1996) and Burkina Faso (Kessler 1992; Gijsbers et al. 1994; Boffa 1995). Yet evidence suggests that parklands are unlikely to disappear overnight. They are, on the whole, highly dynamic systems that may develop over many generations, reflecting changes in the physical and socio-economic environment (Boffa 1999). Despite the long time before shea reaches maturity, the key factor determining its future is clearly the market. Thus Louppe and Outtara (1996) report from northern Côte d'Ivoire that management of shea trees responds rapidly to changes in prices of its products with regeneration being promoted when the kernels or butter sell for high prices. Conversely if the fuelwood prices outstrip those of other shea products, trees tend to be felled and sold as fuelwood. 


\section{Substitution in direct consumption}

Shea fruit remain important as a nutritional snack during the early agricultural season. Yet the use of shea butter may be changing. Today its main local use is in cooking and it is currently the cheapest cooking oil available year-round. However, both the indigenous Anii and the immigrant Logba prefer to use palm oil if they can afford it, and all the ethnic groups like the even more expensive groundnut oil. Apart from taste, the latter has several other advantages. Groundnuts are one of the few crops increasingly cultivated by women, who are therefore less dependent on the vagaries of natural production (as in the case of shea) and male collectors (as in the case of palm oil), and processing the oil is much less labour intensive and time consuming (Schreckenberg 2000). Across the border in Togo the preference for groundnut oil has apparently already led to a reduction in the number of shea trees retained in fields (Sauvaget 1981).

A minor but still common local use of shea butter is in the manufacture of traditional soap (also made with palm kernel oil). This soap has been widely replaced by manufactured soap for both laundry and personal hygiene and is now primarily used for medicinal purposes.

\section{Substitution in income-generation}

NTFPs are often considered to be particularly important as a source of income for poorer groups within society (Neumann and Hirsch 2000). Although no data on relative well-being were collected in this study, there was a consensus among women that shea nuts were particularly important for those with few other income-generating options. These include the elderly (often widows, and without the physical strength necessary to engage in other activities) and young women newly married into the villages who had not yet had the time or capital to get started in other activities. Like most NTFP-based activities in the study area, trading in shea kernels has the advantage of requiring no capital investment but collection is time consuming and uncertain (owing both to variable natural yields and fluctuating prices). Most women therefore aspire to more consistently lucrative activities such as petty trade, storage and resale of agricultural crops or investing in smallstock (Schreckenberg 2000).

The trend away from NTFP-based incomes in general is demonstrated by the fact that the Peulh women, who live further from the main road and access to markets, rely to a much greater extent on NTFP-based incomes than the women of the three ethnic groups settled along the major road. Even among these there are significant differences in the volume of shea kernels collected, with the highest level of collection among the Otamari (Table 1). The indigenous Anii, who consider themselves to be the most 'modern' of the ethnic groups, collect the lowest amounts of kernels, no longer know how to make shea butter and generally rely little on NTFP-based incomes.

The trend away from shea amongst the indigenous Anii, both in consumption and as a source of income, appears to be confirmed by another indigenous group, the Nagot, in the nearby small town of Manigri. The Nagot women have a number of other income-earning opportunities based principally on cassava cultivation and processing. Combined with the existence of a more active fuelwood market, this has led to shea being one of the main fuelwood species sold (Grund 1993). 


\section{The impact of the international trade on the local future of shea}

The international and, to some extent, the domestic trade of shea is likely to be the determining factor in the future of shea in the study area. Local consumption of shea butter will probably continue to decline gradually and decisions about whether or not to retain shea trees in the fields will depend primarily on their value as a source of income. This value, in turn, depends on the demand generated by the international trade. The scanty information available about this topic has been reviewed by Boffa (1999) and is summarised in Box 1. If demand for kernels rises, the high density of shea trees and excellent transport links of the study area would put local women in a good position to benefit from increased sales, providing they received reliable and timely market information. Currently, women get a feel for prices only once the purchasing campaign starts in mid August, at which point it is already too late in the season to adjust collection strategies. If demand is high, their best option is to sell a greater proportion of the stock of kernels they would normally have reserved for their own consumption. Given the oversupply on the international market, this is not considered a problem for the industry.

\section{Box 1. What future for the global trade in shea?}

The evidence suggests that there is potential for increase in the domestic markets of shea in producer countries, both for use as a food item and in the cosmetics industry. The 1994 devaluation of the CFA franc increased the price of imported oils thus favouring internally produced palm oil and shea butter. In Burkina Faso, for example, the two main oil-producing companies appear to have devoted all their stocks to domestic soap production rather than to export, and a number of new small-scale processing enterprises have appeared. The potential probably exists for developing cheap, stable and odourless packaged industrial products for local markets. At the international level, it appears that demand for shea for food purposes has declined in recent years. In part this drop is caused by a fall in demand for chocolate products in Eastern Europe (where they may contain up to $15 \%$ shea butter) as a result of economic difficulties, and in part because of competition with cocoa butter and other CBEs.

The area with the most immediate potential for expansion is the cosmetics sector, although its maximum potential has been estimated by Brun (1996) at just 1,500 t/year. Half of the demand of the cosmetics industry is supplied by the food processing industry at a price twice that for food applications. While the refining process used by the food industries has the advantage of stabilising the butter, it also reduces the unsaponifiable fraction desired for cosmetics use. A number of cosmetics companies are therefore trying to obtain their butter directly from African processors in spite of the difficulties in working with this pure and often less stable product. Production in partnership with African suppliers and processors could meet the current demand among consumers for natural products produced in environmentfriendly ways. 
Whether local women would benefit if the international cosmetics sector demand for artisan produced butter increased is debatable. It is more likely that such demand would be met by producers in countries with a high prior investment (by government, projects and private sector) in the technology and organisation of butter making, such as Burkina Faso (Diallo n.d.), Mali (Hyman 1991) and Ghana (Pugansoa and Amuah 1991; Wallace-Bruce 1995).

\section{CONSERVATION AND DEVELOPMENT LESSONS OF CASE}

\section{Conservation lessons}

There tend to be two areas of concern linking conservation and NTFPs, neither of which is especially relevant to the shea case. The first derives from the early hope, particularly in Latin America, that incomes from NTFPs would provide sufficient incentive to local people to ensure the conservation of rainforest resources. This case study, however, joins a growing body of literature from Africa (Lindström and Kingamkono 1991; Falconer 1992; Scoones et al. 1992) indicating the importance of fields and fallows for NTFP collection. Shea will therefore never contribute to the conservation of rainforests, nor even to the conservation of its natural savanna vegetation, as it thrives particularly well in a cultivated parkland environment. The second area of concern relates to the future of the NTFP itself and the fear that successful commercialisation may lead to overexploitation of the resource. In the case of shea the high level of potential supply (in terms of the existing resource base) relative to demand, combined with a nondestructive method of harvesting, means that there is no danger of overexploitation.

\section{Development lessons}

The interest in shea is related almost exclusively to its potential to contribute to livelihoods, which it does both as a staple ingredient in the local diet and as an important source of income for women. De Jong et al. (2000) argue that the literature rarely deals with the extent to which NTFPs can drive socioeconomic development on a sustainable basis. They identify five threats to sustained income from NTFPs:

1. destruction of resource base through overharvesting;

2. appropriation of benefits by more powerful stakeholders as commercialisation becomes successful;

3. domestication and production in intensive plantations far away from original collectors;

4. reduced demand because of products going out of fashion; and

5. substitution of product by manufactured goods.

None of these threats applies to the shea case. The first and third are only relevant if demand outstrips supply, and the reverse is true for shea (Fintrac 1999). The second does not appear to be a problem, perhaps because profits have always been modest and have therefore not attracted the attention of the powerful. The fourth threat (reduced demand) could have been a longer- 
term concern if local consumption of the butter were the only outlet for shea. However, the international market provides a second outlet, moderating the impact of any changes in local demand. Finally, in the fifth case, shea butter already has a number of substitutes (though all derived from cultivated crops rather than manufactured products) but because it also has multiple uses at both local and particularly international level-and new uses continue to be identified-this potential threat has been counteracted.

It seems then that the long and relatively stable history of moderate income generation from shea is likely to continue for years to come. Most women in the study area, unlike those in less accessible communities or in the drier Sahelian countries, have a choice of income-generating activities. It is unlikely that they would seek a greater involvement in shea kernels and/or butter trade unless it became much more advantageous (in terms of financial returns and the amount of labour invested) than the available alternatives. At present, therefore, there is no need for any development interventions directed specifically at the local shea sector. Any scaling up of activities is likely to be achieved through individual initiatives. This state of affairs is illustrated by a group of women in the town of Bassila, who have obtained a small business development grant to produce butter for sale to a hairdressing salon in Cotonou. To facilitate this kind of initiative, the usual development recommendations apply: better market information, easier access to formal credit for women and capacity building in organisational, administrative and financial management.

Given the current abundance of the resource internationally there is little justification to invest in increased production of shea. In the longer term, should demand increase beyond supply, there would be an interest in more research into how best to integrate shea with other crops, reducing the age to maturity and improving the year-to-year consistency of yields. Initially, however, international efforts should focus on improving the economic contribution of shea by promoting quality at all production and processing stages, improving market information systems, developing appropriate and cost-effective extraction technologies and diversifying the product (and packaging) range at the national and international levels (FAO 1998; Savadogo et al. 1998).

\section{CONCLUSION}

Shea is a widely available resource in the West African savanna zone. No inputs other than labour are needed to harvest and process it and it fits in well with the local agricultural landscape and range of income-earning activities. While official figures can be extremely misleading, it appears that the market has been relatively stable over many generations, largely because the product can be either consumed locally or traded into the international market, where its multiple uses have protected it from the threat of substitution. Moreover, shea is an extremely egalitarian product collected by nearly all women in the area and with little evidence of particularly uneven appropriation of benefits along the marketing chain. No particular policy interventions are needed to ensure that the trade continues its history of providing a vital livelihood option for local women, the importance of which fluctuates from year to year but remains relatively stable over the longer term. Development interventions 
need to be concentrated on those regions where women have fewer alternative income-generating opportunities (e.g., the Sahel) and should focus on identifying and alleviating constraints to marketing.

\section{ENDNOTES}

1. Research Fellow, Forest Policy and Environment Group, Overseas Development Institute, London SE1 7JD, United Kingdom. Email: k.schreckenberg@odi.org.uk

2. The research was mainly funded by the German agency for technical cooperation, Gesellschaft für technische Zusammenarbeit (GTZ), and originally planned for a GTZ forestry project in Togo. Because of political unrest, the study was relocated to a GTZ forestry project in Benin which, at the time, had no interest in NTFPs.

\section{REFERENCES}

Agbahungba, G. and Depommier, D. 1989. Aspects du parc à karités-nérés (Vitellaria paradoxa Gaertn. f. Parkia biglobosa Jacq. Benth.) dans le sud du Borgou (Benin). Bois et Forêts des Tropiques 222: 41-54.

Bagnoud, N., Schmithüsen, F. and Sorg, J.-P. 1995. Le système agroforestier des parcs à karité et néré au Mali-Sud: vers un nouvel équilibre entre arbres et cultures. Schweizer Zeitschrift für Forstwesen 146 (2): 137-145.

Bergeret, A. and Ribot, J. 1990. L'arbre nourricier en pays Sahéliens. Editions de la Maison des Sciences de l'homme, Paris.

Bernard, C., Outtara, N. and Peltier, R. 1996. Place du parc à Faidherbia albida dans un terroir soudanien : le cas d'un village Sénoufou au nord de la Côte d'Ivoire. Cahiers Scientifiques du CIRAD-Forêt 12 : 173-189.

Boffa, J.-M. 1995. Productivity and management of agroforestry parklands in the Sudan zone of Burkina Faso, West Africa. Ph.D. Thesis, Purdue University, West Lafayette, Indiana, USA.

Boffa, J.-M. 1999. Agroforestry parklands in sub-Saharan Africa. FAO Conservation Guide 34. FAO, Rome.

Bonkoungou, E.G., Alexandre, D-Y., Ayuk, E.T., Depommier, D., Morant, P. and Ouadba, J-M. 1994. Agroforestry parklands of the West African semi-arid lands. Conclusions and recommendations of an international symposium, Ouagadougou, 25-27 October 1993. ICRAF/SALWA, Nairobi.

Bourlière, F. and Hadley, M. 1983. Present-day savannas: an overview. In: Bourlière, F. (ed.) Tropical Savannas, 1-17. Elsevier, Amsterdam.

Breman, H. and Kessler, J.J. 1995. Woody plants in agro-ecosystems of semiarid regions, with an emphasis on the Sahelian countries. Springer Verlag, Berlin.

Busson, I. 1965. Plantes alimentaires de l'Ouest Africain: etude botanique, biologique et chimique. Leconte, Marseilles.

Caillié, R. 1830. Travels through Central Africa to Timbuctoo, and across the Great Desert to Morocco, performed in the years 1824-28. Volume 1. Henry Colburn \& Richard Bentley, London. New impression 1992, DRAF Publishers, London. 
Clapperton, H. 1829. Journal of a second expedition into the interior of Africa from the Bight of Benin to Soccatoo. Murray, London.

Crélerot, F.M. 1995. Importance of shea nuts for women's activities and young children's nutrition in Burkina Faso: the case of the Lobi. Ph.D. Thesis, University of Wisconsin, USA.

De Jong, W., Campbell, B.M. and Schröder, J.-M. 2000. Sustaining incomes from non timber forest products: introduction and synthesis. International Tree Crops Journal 10(4): 267-275.

Diallo, D. Local initiative attacks poverty. Africa Recovery Online 13 (1), http: / /www.un.org/ecosocdev/geninfo/afrec/vol13no1/baobab.htm (12 July 2001).

Fagbémy, M. and Sodeik, E. 1993. De la participation des populations locales à la restauration des resources forestières de la region de Bassila : project report. ONAB/MIFOR. Cotonou.

Falconer, J. 1992. Non-timber forest products in southern Ghana. Forestry Series 2. Overseas Development Administration, London. 23p.

Fintrac Inc. 1999. Market and technical survey: shea nuts. http:// www.raise.org/natural (13 July 2001).

Fleury, J-M. 1981. The butter tree. IDRC Reports 10 (2): 6-9.

Food and Agriculture Organisation. 2001. Karité. Non-wood News 8: 38-39.

Gijsbers, H.J.M., Kessler, J.J. and Knevel, M.K. 1994. Dynamics and natural regeneration of woody species in farmed parklands in the Sahel region (Province of Passore, Burkina Faso). Forest Ecology and Management 63: 112.

Grund, S. 1993. Brennholz im Raum Bassila: Ergebnisse einer Umfrage von Sep./Okt. 1993. Internal report, DED, Cotonou.

Hall, J.B., Aebischer, D.P., Tomlinson, H.F., Osei-Amaning, E. and Hindle, J.R. 1996. Vitellaria paradoxa: a monograph. School of Agricultural and Forest Sciences Publication Number 8. University of Wales, Bangor.

Hyman, E.L. 1991. A comparison of labor-saving technologies for processing shea nut butter in Mali. World Development 19 (9): 1247-1268.

Kater, L.J.M., Kante, S. and Budelman, A. 1992. Karité (Vitellaria paradoxa) and néré (Parkia biglobosa) associated with crops in South Mali. Agroforestry Systems 18(2): 89-105.

Keay, R.W.J. 1953. An outline of Nigerian vegetation, 2nd ed. Government Printer, Lagos.

Kessler, J.J. 1992. The influence of karité (Vitellaria paradoxa) and néré (Parkia biglobosa) trees on sorghum production in Burkina Faso. Agroforestry Systems 17 (2): 97-118.

Lindström, J. and Kingamkono, R. 1991. Foods from the forests, fields and fallows: nutritional and food security roles of gathered food and livestock keeping in two villages of Babati District, Northern Tanzania. Working Paper 184, Swedish University of Agricultural Sciences and International Rural Development Centre, Uppsala.

Louppe, D. and Ouattara, N. 1996. Influence du karité sur les productions agricoles du nord de la Côte d'Ivoire. Paper submitted to the XI World Forestry Congress, 13-22 October 1997. Antalya, Turkey. 
Lovett, P.N. and Haq, N. 2000. Evidence for anthropic selection of the sheanut tree (Vitellaria paradoxa). Agroforestry Systems 48: 273-288.

Nair, P.K.R. 1993. An introduction to agroforestry. Kluwer Academic Publishers, Dordrecht, Netherlands.

Neumann, R.P. and Hirsch, E. 2000. Commercialisation of non-timber forest products: review and analysis of research. CIFOR, 2000.

Park, M. 1799. Travels in the interior districts of Africa performed under the direction and patronage of the African Association in the years 1795, 1796 and 1797, with an appendix containing geographical illustrations of Africa by Major Rennell. G.\&W. Nicol, London.

Pugansoa, B. and Amuah, D. 1991. Resources for women: a case study of the Oxfam sheanut loan scheme in Ghana. In: Wallace, T. and March, C. (eds.) Changing perceptions. Writings on gender and development, 236-244. Oxfam, Oxford.

Ruyssen, B. 1957. Le karité au Soudan: première et deuxième parties. L'agronomie tropicale 12 (2): 143-172. Troisième partie. L'agronomie tropicale 12 (3): 279-306.

Sauvaget, C. 1981. Boua Village de Koudé: un terroir Kabyè (Togo septentrional). Atlas des structures agraires au Sud du Sahara 16. ORSTOM, Paris.

Savadogo, S., Ouédraogo, B. and Ouédraogo, D. 1998. Actes de l'ateliersynthèse du projet filière karité au Burkina Faso, Ouagadougou, 23-25 juin 1998. Etat des lieux de la filière karité, gestion de la qualité, connaissances et savoir, marchés, cadre de concertation des intervenants de la filière. CECl-ACDI, Ministry of Agriculture, Burkina Faso.

Schmidt-Leplaideur, M.-A. 1987. Le long voyage du karité. Intertropiques 21: 2123.

Schreckenberg, K. 1996. Forest, fields and markets: a study of indigenous tree products in the woody savannas of the Bassila region, Benin. Ph.D. Thesis, University of London.

Schreckenberg, K. 1999. Products of a managed landscape: non-timber forest products in the parklands of the Bassila region, Benin. Global Ecology and Biogeography 8: 279-289.

Schreckenberg, K. 2000. Non-timber forest products in the woody savannas of Benin Republic. In: Cline-Cole, R. and Madge, C. (eds.) Contesting forestry in West Africa, 285-306. Ashgate, Aldershot.

Scoones, I., Melnyk, M. and Pretty, J. 1992. The hidden harvest: wild foods and agricultural systems: a literature review and annotated bibliography. IIED, London.

Wallace-Bruce, Y. 1995. Shea butter extraction in Ghana. In: Appleton, H. (ed.) Do it herself: women and technical innovation, 157-161. Intermediate Technology Publications, London.

White, F. 1983. The vegetation of Africa. UNESCO Natural Resources Research, 20:1-356. 


\title{
Chapter 7
}

\section{A case study of Garcinia kola nut production-to-consumption system in $\mathrm{J} 4$ area of Omo forest reserve, South-west Nigeria}

\author{
Atilade Akanmu Adebisi ${ }^{1}$
}

\begin{tabular}{llllll}
\hline Common names & $\begin{array}{l}\text { Part of the } \\
\text { resource used }\end{array}$ & Management & $\begin{array}{l}\text { Degree of } \\
\text { transformation }\end{array}$ & $\begin{array}{l}\text { Scale of } \\
\text { trade }\end{array}$ & $\begin{array}{l}\text { Geographic } \\
\text { range }\end{array}$ \\
\hline $\begin{array}{l}\text { Bitter cola, } \\
\text { Orogbo }\end{array}$ & Seeds & Wild/managed & Low & National & Medium \\
\hline
\end{tabular}

\begin{abstract}
This chapter sheds light on the importance of bitter kola (Garcinia kola Heckel) as one of the many non-timber forest products that are of socio-economic importance in the $\mathrm{J} 4$ area of the Omo Forest Reserve of south-west Nigeria. Its commercialisation in both the domestic and national markets raises the standard of living of those involved in its trading activities, both in the rural and urban centres. Trade of bitter kola is more profitable than trade in other non-timber forest products such as wonder cola (Buccholzia coriacea), sponge (Acanthus montanus) and cola nuts (Cola nitida/acuminata). This is because of its high amenability to storage, both fresh and dried.

The ongoing increase in commercial value of bitter kola has made the cultivation of the tree more important-and of greater interest-to the villagers of the J4 area of Omo Forest Reserve. The development of domestication processes to reduce the time to fruit bearing age, coupled with improved marketing opportunities, should improve bitter kola production.
\end{abstract}

\section{INTRODUCTION}

Studies of non-timber forest products (NTFPs) have shown the importance of NTFPs' contribution to the rural socio-economy of many developing countries. Among many others, such studies include those of Falconer (1990, 1992), Ndoye (1995), Townson (1995), Adebisi (1997), Ndoye et al. (1998) and Shiembo (1999). 
The contributions of these scholars to the study of NTFPs provide the basic and rudimentary answers to the following questions:

a. How do NTFPs generate revenue?

b. What are the qualitative and quantifiable expression and figures for a variety of NTFP in their areas of endemism?

c. How does each NTFP contribute to the socio-economic development of a particular area?

d. What are the results and economic advantage of trade and commercialisation of an individual NTFP within local, national, region and global consideration?

e. How can the quality and yield of an NTFP be improved, and what are ways to increase the adoption of these steps among farmers?

$\mathrm{f}$. What are the major constraints to the commercial development of the individual product from cottage to large-scale commercial levels?

g. How can government policy be influenced to promote sustainable cultivation, harvest and trade of these NTFPs like other agronomic crops, such as Cola nitida?

h. What are the steps necessary to promote international trade of NTFPs and to provide effective packaging systems for long distance marketing?

These studies have helped to raise awareness of the contributions of NTFPs to household economies and the security of food and health. However, specific data on the contribution individual NTFPs make to a particular area, or to the national economy, have been scant. Previous reports have been descriptive and effective in highlighting the need to promote detailed studies of individual NTFPs. Now NTFPs have joined the globalisation trend in real research and development and this has been made possible by the Centre for International Forestry Research. CIFOR has set the pace in promoting acquisition of relevant data for the development of these NTFPs for sustainable production.

\section{IMPORTANCE OF GARCINIA KOLA}

Garcinia kola Heckel nuts, otherwise known as 'bitter kola', have suffered neglect in the areas of research and development. Despite its socio-economic and cultural importance, few attempts have been made to improve the tree species or to reduce the 10 to 15 years it takes to reach seed and fruit production.

An important and ancient trade product, the nuts of Garcinia kola are available in markets throughout West and Central Africa, from Senega town in Sierra Leone to south-west Cameroon (Isawumi 1993). In Nigeria, its trade is as important as that of cola nut (Cola nitida and C. acuminata) in major towns and cities in the southern parts of the country, where the tree is endemic.

Bitter kola is favoured by the three major ethnic groups in Nigeria, the Yoruba, Igbos and Hausa. Its domestic trade thus extends beyond the southern production areas to the northern parts of the country. Apart from being a stimulant, it has in chewing a bitter astringent and resinous taste and is often used as an aphrodisiac. Its highly valued perceived medicinal attributes, and the fact that consumption of large quantities does not cause indigestion (as cola nuts do), make it a highly desired product (Dalziel 1937). 


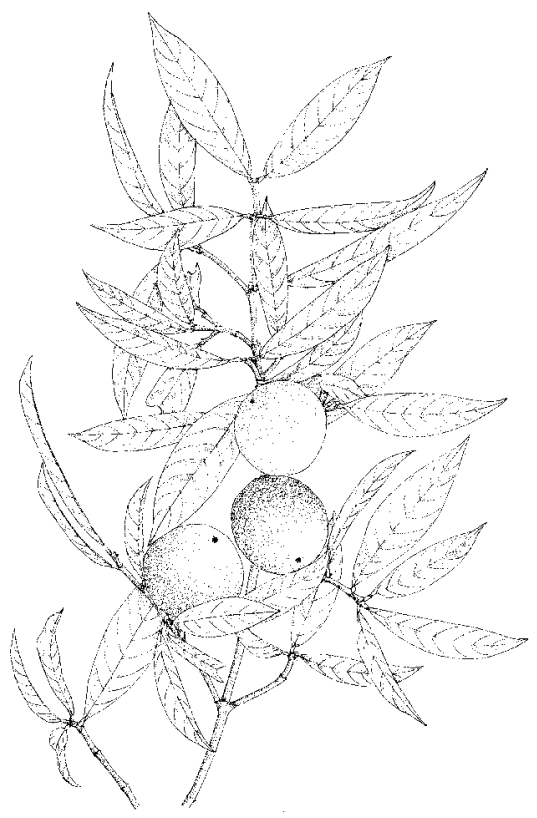

(Garcinia kola)

Garcinia kola is endemic in the humid lowland rainforest vegetation of the West and Central African subregions. It is found in coastal areas and lowland plains up to $300 \mathrm{~m}$ above sea level with an average of 2,500 $\mathrm{mm}$ of rainfall per annum. The trees are abundant in densely populated areas of natural and secondary forests where the predominant land use system is tree crop plantation farming (Aiyelaagbe and Adeola 1993). As well, people residing in or near forest reserves collect bitter kola fruits, extract and process the seeds and trade them. Therefore the major places where the commodity is found growing wild are forest reserves and free areas of the rainforest, or it is either planted or conserved in on-farm oil palm-cocoa-yam plantations. These two growing regions will be found in low altitude areas with annual rainfall of $2,000 \mathrm{~mm}$ to $2,500 \mathrm{~mm}$, temperature ranges from $32.15^{\circ} \mathrm{C}$ to $21.4^{\circ} \mathrm{C}$ and a minimum relative humidity of $76.34 \%$ (Ntamag 1997).

For this particular case study, a camp was established in the $\mathrm{J} 4$ area of Omo Forest Reserve, Ogun State, Nigeria (Figure 1). This area was selected because the collection and trade of bitter kola is an important contributor to local household per capita income.

\section{Cultural importance of bitter kola}

Bitter kola holds a high position of cultural importance among all the Nigerian tribes, particularly the Yoruba and Ibo communities. The Yoruba use bitter kola as an important component of the material used in traditional naming and marriage ceremonies, while the Ibos use it in their traditional 'fetish' 
Figure 1. Omo Forest Reserve
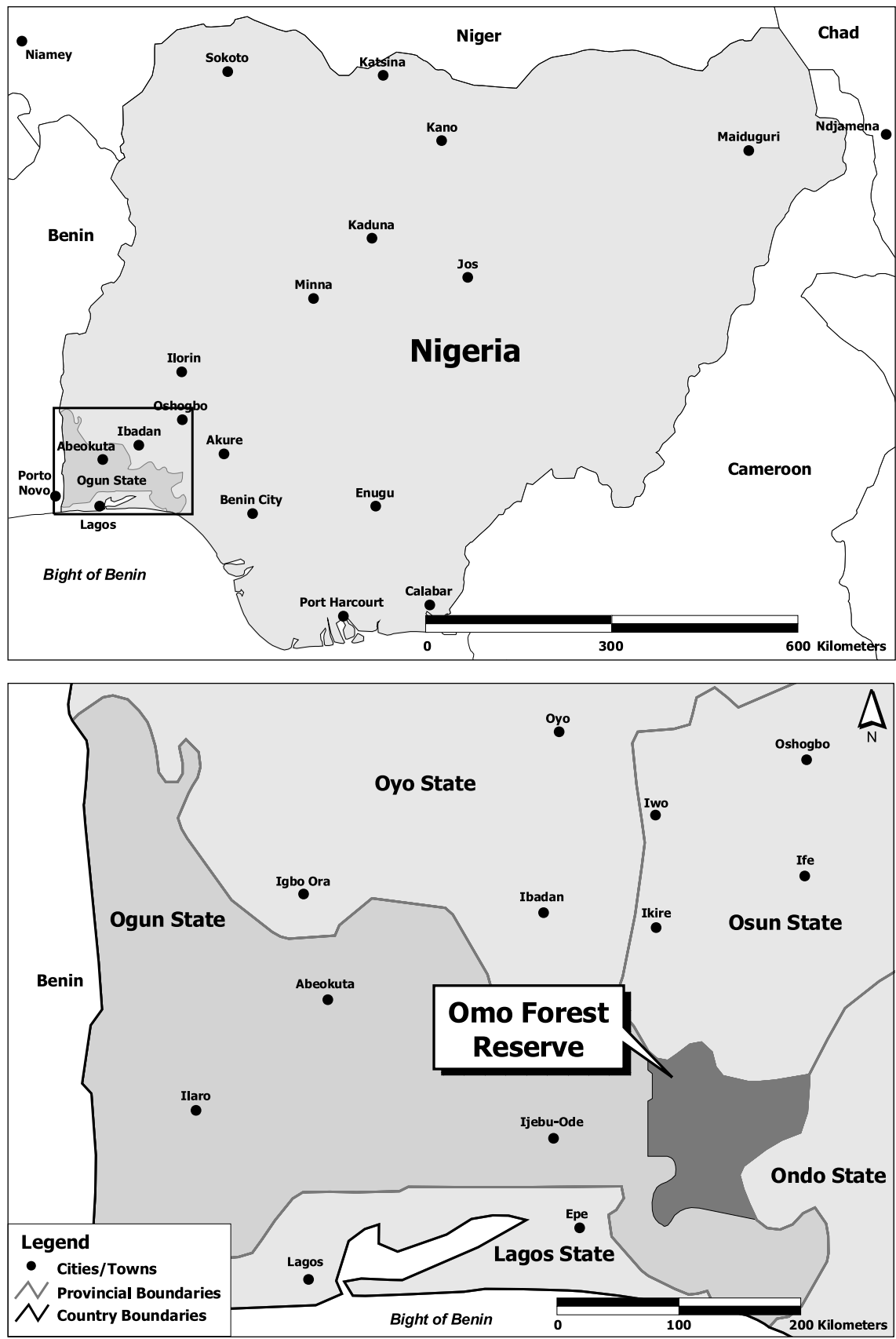

Source: ESRI Data and Maps 2002. 
recipes. Traditional herbalists use bitter kola in various pharmacopoeia preparations for various ailments (Adjanouhun et al. 1991).

\section{Impact of bitter kola production on the livelihoods of J4 Omo Forest Reserve villagers}

The production-to-consumption system of Garcinia kola seeds has an obvious positive impact on the households of the $\mathrm{J} 4$ communities. In particular its commercialisation has contributed to improving the standard of living of the villagers. The production system of bitter kola is very simple; the fruits are collected and the nuts extracted, washed and stored for later sale. Production costs are minimal. The activity is usually a household affair and most of the income generated through the sale of bitter kola nuts is spent on household commitments such as school fees and materials and contracting out the household work during non-cash crop season, when villagers are able to use their profits to participate in family ceremonies. The extra income derived from the sale of bitter kola is thus important to meeting social and educational obligations for the rural poor from resource farmer to forest dweller (Kabuye 1998).

\section{Economic importance of bitter kola}

The economic importance of bitter kola cannot be underestimated, especially in the area of poverty alleviation among rural people. A cursory survey of people involved in the trade of this product established that a substantial amount of revenue can be realised from farm gate to village and urban markets. Table 1 clearly indicates the revenue position from the resource base ( $\mathrm{J} 4$ area of Omo Forest Reserve) up to the common itinerant vendor on the roadside. The price increases as the commodity changes hands from first degree to third degree traders. Handling costs and other expenses involved in bringing the commodity to market contribut immensely to this increase, but looking at the figures critically demonstrates that the base collectors are at an advantage. Their only expenses are periodic transportation costs from their villages to the Fowowa/J4 Junction market if the buyer could not meet them in their enclaves. The market chain vividly describes the situation. The national, regional, and global statistics for the economic importance of this commodity are yet to be computed.

\section{THE PRODUCTION-TO-CONSUMPTION SYSTEM}

\section{Resource base of bitter kola}

Garcinia kola (Heckel) and its relatives-including G. livingstonei, G. gnetoides, G. staudtii, G. smeathemannii, G. ovalivolia, G. brevipediellata and G. manniiare found in Nigeria as well as generally across the humid lowland plains of West Africa extending from Sierra Leone to Zaire (Vivien and Faure 1996) and Angola (Keay 1989).

All the Garcinia species have different uses, using different parts of the plant, depending on the location where an individual is endemic. In the J4 area 


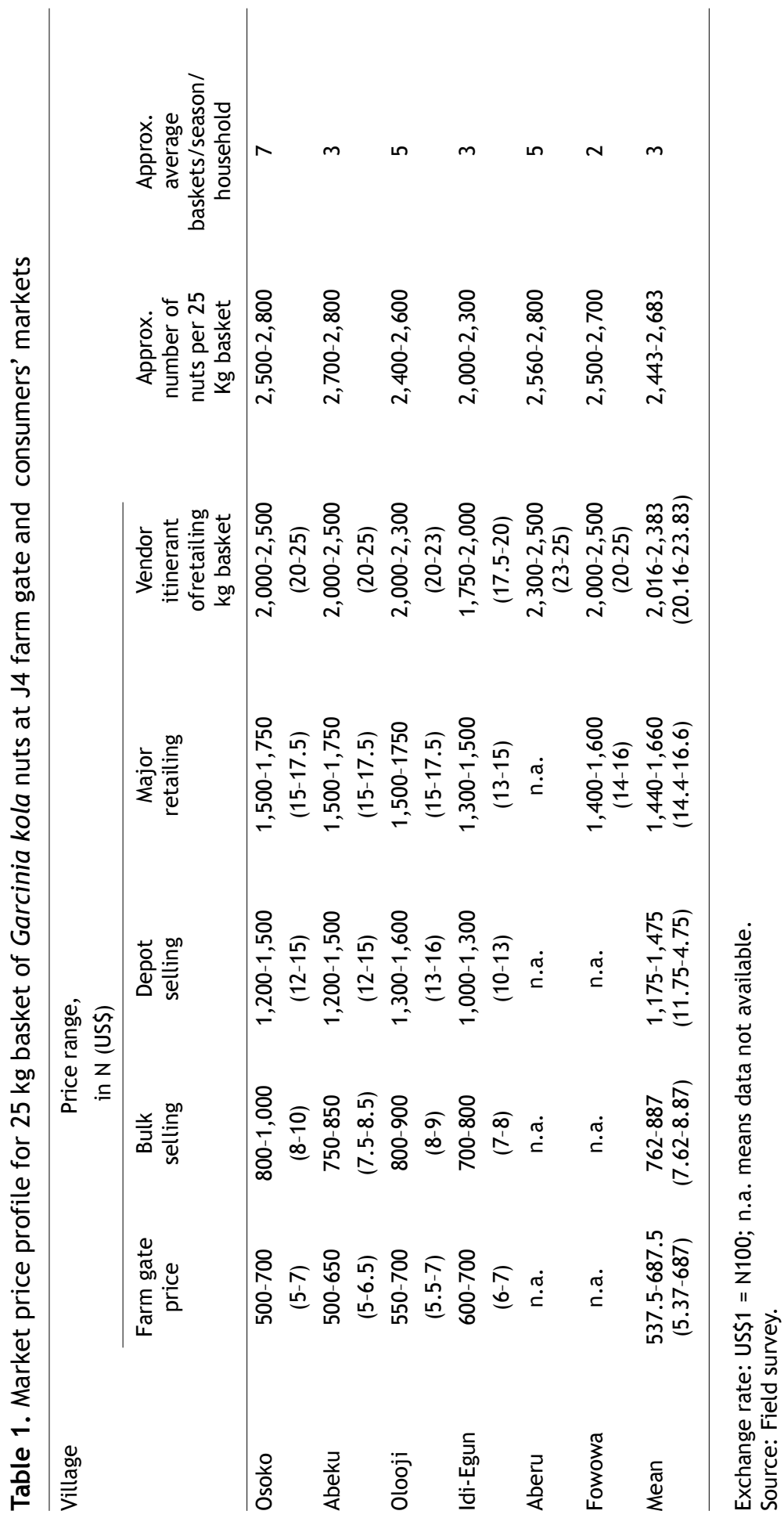


and in Nigeria as a whole, however, Garcinia kola is by far the best recognised. Most of the productive trees now found within the range of the J4 villages were left standing when farm plots were cut out of the forest or are transplanted wildlings or volunteers. In ljebu Division, Garcinia kola trees are found in compound or homestead farming systems of relatives of villagers living at the $\mathrm{J} 4$ study site. It is believed that the species was introduced through the cultivation of wildlings brought home from the Forest Reserve. The quantity and economic value of seed from Garcinia kola trees make it an important component tree in compound farming systems in Nigeria, as well as contribute to its conservation value (Aiyelaagbe et al. 1996).

As a tropical fruit tree species, it is characterised by slow rate of growth (Ladipo 1995). Factors that have discouraged farmers from growing Garcinia kola include difficulties encountered in attempting to raise seedlings in nurseries and the long gestation period before flowering and fruiting. However, many of the germination difficulties have been overcome by methods developed by Okafor (1998), and interest is developing to cultivate the tree species in plantations. With this in mind, Ladipo (1995) has developed projected production figures, as follows. A mature fruit tree produces 85 to 1,717 fruits, with 208 to 6,112 seeds annually. Taking the mean of these values at 834 fruits and 2,627 nuts per tree, he has projected a fruit production of 26 tonnes/ha/annum, with 278 trees/ha at $6 \mathrm{~m} \times 6 \mathrm{~m}$ spacing.

Fruiting in the tree commences in July and ends in October. Fruit harvest continues intermittently as ripe fruit fall and are then collected for the extraction of seeds. The fruit is reddish-yellow, about $6.25 \mathrm{~cm}$ in diameter, and each fruit contains two to four brown seeds embedded in orange-coloured pulp (Ladipo 1995; Keay 1989).

Photo 1. Garcinia kola (Photo by T.C.H. Sunderland)

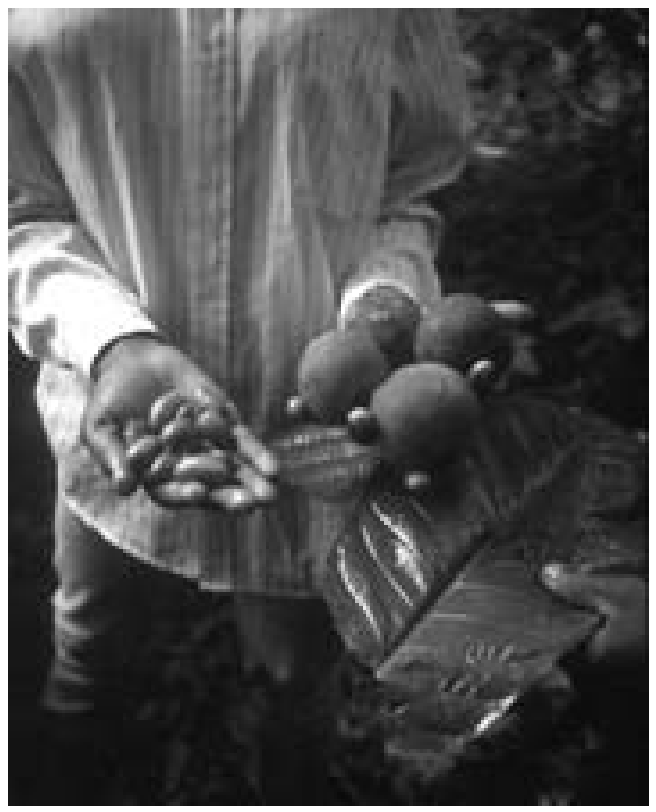




\section{Bitter kola producers in the socio-economic context}

Within the J4 area of Omo Forest Reserve, the villages of Osoko, Abeku, Olooji, Mile 1, Fowowa and Etemi are well known to traders in NTFPs (see Table 2). Apart from the planting of cash crops such as plantain, cocoa, cola nuts and a few arable crops, the collection and processing of NTFPs for sale are a major preoccupation throughout the season. Such NTFPs include Buchhlozia coriacea ('wonder cola'), Copolobia lutea (Fulani nomadic staff), Mitragyna ciliata (Abura; wrapping leaves for cola nuts), bush meat from various game species, bark and roots of various trees, Acanthus montanus (washing sponge) and more importantly, the nuts of Garcinia kola.

Table 2. Distribution of tribes living within the J4 area

\begin{tabular}{lrl}
\hline Tribe & $\%$ & Remarks \\
\hline ljebu & 60 & The landlords (descendants) \\
Oyo (Ibadan) & 10 & Cocoa tree crop farming \\
Ondo & 10 & Cola nitida/acuminata \\
Igbo & 5 & Trade in NTFPs \\
Hausa & 5 & Trade in NTFPs and provide labour \\
Others & 10 & Food crop farming and trade in NTFPs \\
\hline
\end{tabular}

Source: Karimu 1999.

The population of $\mathrm{J} 4$ has increased in numbers from initial surveys carried out in 1916-18 and 1925 (see Table 3). A survey in 1949-50 recorded a population of about 2,500 , a $40 \%$ increase. Today it is clear that both the population and number of settlements have continued to expand. For example, Aberu, which was a camp with two huts and 11 people in 1949-50, is presently a large village of about 100 houses and 2,500 people. The village now has a primary school, a rural health centre and a bore-hole well that supplies potable water. Another example is Fowowa Camp. In 1949 it was an insignificant camp, but now it is a popular 'nerve-centre', an assembly point for all other villagers in the $\mathrm{J} 4$ area and the seat of the Ogun State Aforestation Programme with a population of about 5,000 in 1997 (Karimu 1999; Ladipo 1999; Ojo 1999). At the time of this study the project manager of the Ogun State Plantation Programme estimated the total population of the $\mathrm{J} 4$ area at between 10,000 and 12,000 .

Table 3. Population growth within $\mathrm{J} 4$ area villages

\begin{tabular}{lcccc}
\hline Period & $1916-1918$ & 1925 & $1949-1950$ & 1999 \\
\hline Number of settlements & 30 & 45 & 100 & 205 \\
Number of villages & 5 & 20 & 50 & 100 \\
Population & 610 & 1,300 & $>5,000$ & $10,000-12,000$ \\
\hline
\end{tabular}

Source: Karimu 1999. 
Farming, fishing, hunting and the collection of NTFPs, including bitter kola, are the primary occupations for the majority of the J4 population (Ojo 1999). The average annual household income has been estimated at N70,971.6 (US\$709.72). About $60 \%$ of the total land use is in rain fed arable farming, while $18.5 \%$ is put to permanent crop trees like cocoa, citrus and cola nuts. Villages in the $\mathrm{J} 4$ area produce substantial amounts of plantain and still have extensive forest areas for timber tree exploitation and extraction of NTFPs. This variety of income and food generating activities brings the socio-economic status of the people within $\mathrm{J} 4$ above the poverty line. Rough estimates of per capita income for both national and $\mathrm{J} 4$ area households are shown in Table 4.

In December 2000, the federal and state governments of Nigeria increased the minimum basic salaries in the civil service to N60,000 and N36,000 (US\$600 and US\$360) per annum respectively. The estimated average per capita income in J4 was between N25,704 and N37,200 (US\$257 and US\$372) per annum. There is not a significant difference between state and J4 area per capita income. However, labour wages within the $\mathrm{J} 4$ area are still relatively low compared with larger cities. For example as of December 2000, within the J4 area the labour rate at 15 man-days/ha (weeding operation) was on average N236 (US\$2.36) per day as compared with N400 to N500 (US\$4-US\$5) per day in urban areas.

With these economic returns, the inhabitants of area J4 can expect nothing less than an amiable standard of living. Their interactions with people within and outside the area have been cordial and primarily based on trade activities of NTFPs, cash and arable crops, and plantains and bananas. All these items of trade invite a handsome number of merchants from far and wide to the $\mathrm{J} 4$ area. Purchasers are encountered throughout the year, buying various commodities as they come into season. The sales of fresh or dry bitter kola begin in July for onward transportation to big cities and towns like Lagos, Ijebu-ode, Abeokuta and Ibadan, and to some northern parts of the country. Women and children often perform the processing and sale of bitter kola seeds in markets.

\section{Processing industry}

The processing and sale of bitter kola is largely a family-based home industry, which, when the product is harvested at sustainable levels, has little negative impact on the mother tree. When ripe, the green pericarp turns a reddish yellow colour, and the fruit falls from the tree. The fruit are collected and kept in an open, cool place till the pericarp and the pulpy mesocarp become soft. Once softened, the fruits are threshed to release the nuts, which are thoroughly washed to remove the sticky mucilaginous material that sheaths the nut. Nuts that are not sold fresh are then spread out and air-dried in preparation for storage, which is provided by wrapping the nuts in leaves and storing them in a basket lined with jute bag material. This process is repeated as fruit ripens and is collected throughout the harvesting period. There is normally no secondary or industrial transformation of the nuts, with the exception of uses in breweries, where bitter kola nuts are further dried and ground into powder before use (Ibanga 1993). 


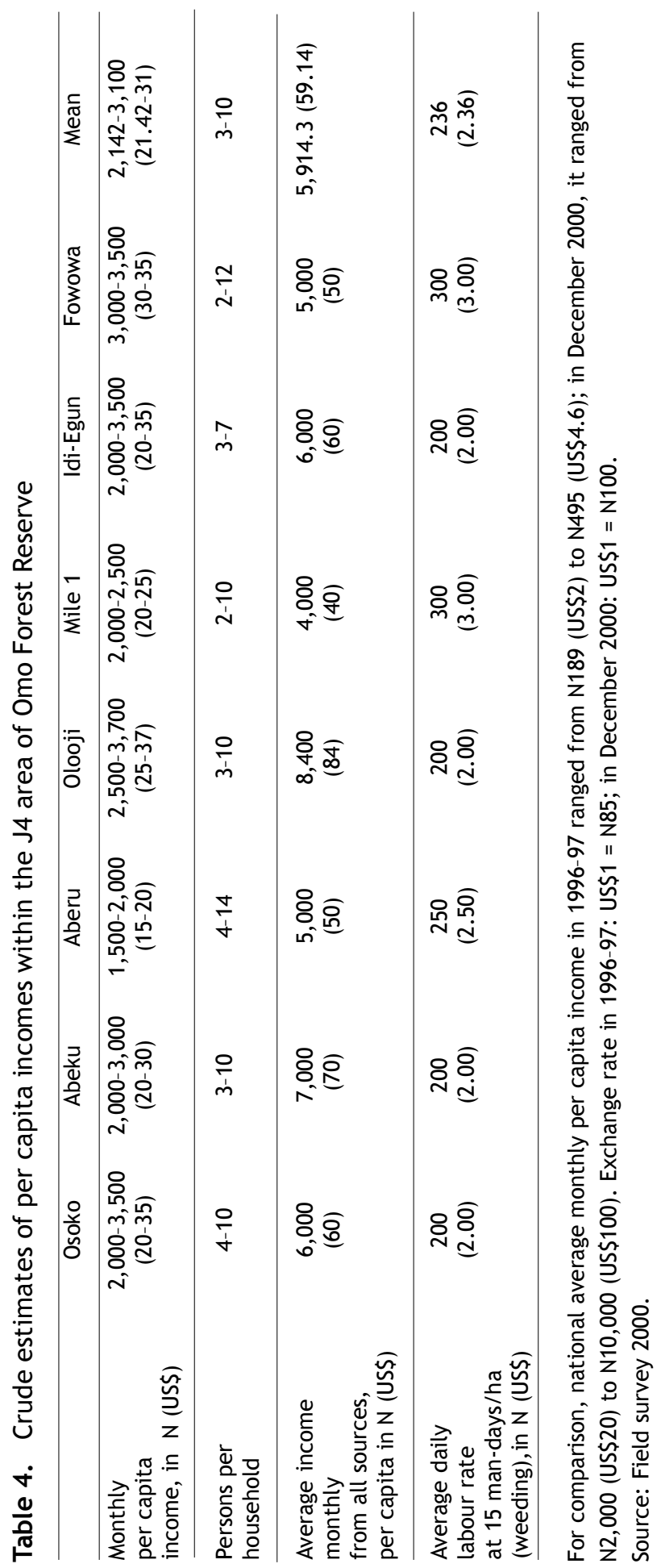




\section{Trade and marketing}

More often than not, after removing a small quantity for household consumption (including entertainment and medicinal purposes), the processed bitter kola are sold. The nuts selected for sale are usually the neatly processed ones without a scratched nut coat. Fresh, well air-dried and ambiently stored bitter kola commands the highest market price. At the farm gate level, bitter kola nuts are sold to consumers, or collectors may appoint a representative. This person buys the small quantities of nuts brought by collectors, which are then sold at the $\mathrm{J} 4$ Junction market in $5 \mathrm{~kg}, 10 \mathrm{~kg}$ or $25 \mathrm{~kg}$ basket sizes (Photo 2).

Photo 2. Garcinia kola nuts in the market (Photo by T.C.H. Sunderland)

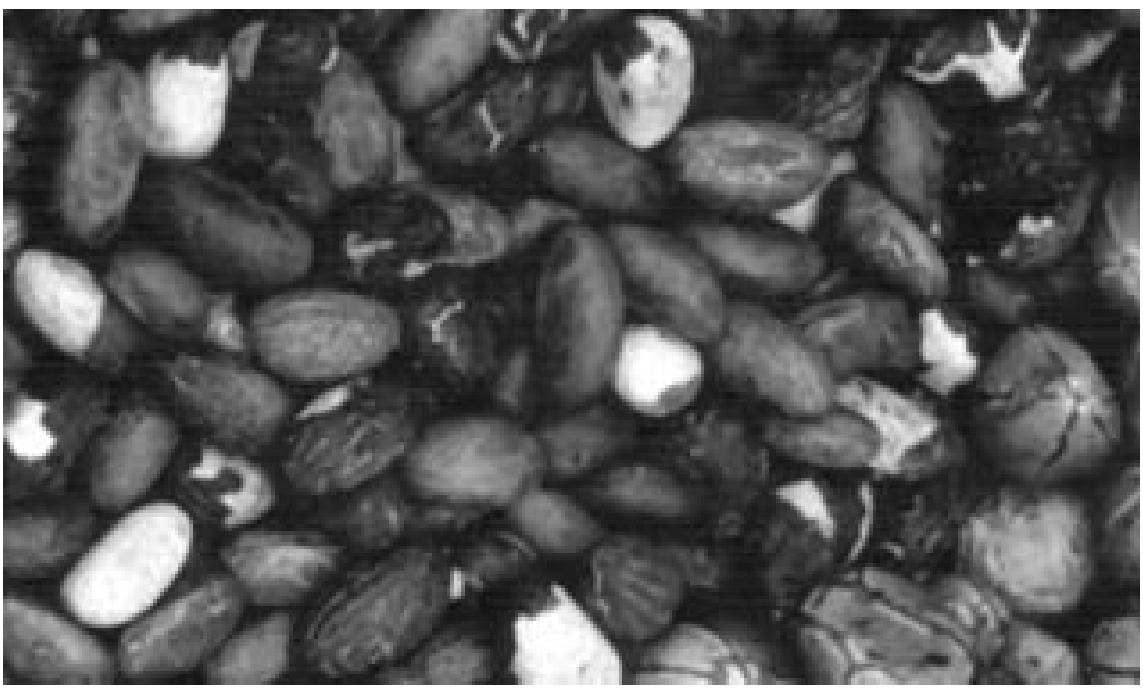

The trade and marketing of bitter kola within the J4 production area and its immediate environs are as old as Omo Forest Reserve, and even before that, NTFP collection was a major occupation of the local population. In the last 10 years, however, the trend in the marketing of NTFPs in the study area has expanded through bulk buyers coming from nearby towns and cities. This increasing commercialisation has led to a tremendous expansion of the bitter kola marketing network. This network has evolved as an intricate chain of intermediaries, village traders, wholesalers, and interstate traders, with avenues reaching the consumers at each stage.

\section{POLICY AND ENVIRONMENT}

The formulation of government environmental and conservation policies has been the specialised area of ecologists and conservationists. These policies fit the management of conservation areas into the general policy framework of the government. Thus, the environmental policy has a single objective, conservation, which of course ultimately has influence over the attitude of the government with respect to forest-dependent communities. 
When Omo Forest Reserve was created about 100 years ago, it was subdivided for effective management into areas called J1, J3, J4 and J6. Then the subdivisions were apportioned to people already living in the reserve in isolated villages and camps. This was to enable the subsequent effective participatory management approach by the (then) Western State Government of Nigeria. In the J4 area, about 15 villages and camps were demarcated, with specific instructions that farming areas for either arable or cash crops not be expanded beyond the plots originally occupied. Furthermore villagers were instructed that on no account trees be felled without the expressed permission of the Chief Conservator of Forests. The only 'minor forest products' (now NTFPs) the inhabitants were allowed to take included nuts, fruits and probably wild game (for which a hunting permit had to be obtained). These policies are still in force today. Although the forest is ample and few human beings frequent this area, the whole area would probably have been environmentally degraded had there been no such policy. Even so, through government permits, the exploitation of timber trees and clearing for plantations almost two-third of the forest has been degraded to secondary forest. In the process many of the NTFP resources have been destroyed or grossly decimated. For example, in his enumerations conducted in the last four decades, Lowe (1993) estimated the density of Garcinia kola trees at $0.5 / \mathrm{ha}$. This relative scarcity has affected the production of bitter kola, and the volume of its trade decreased when compared with that of the early 1960s. However, the trading volumes may increase in the nearest future, as the forest inhabitants are now growing Garcinia kola trees using wildlings.

\section{TRENDS AND ISSUES}

\section{Dynamic changes}

In general, the abundance of a NTFP in a particular area where it is endemic is determined by the variation in natural conditions and the degree of human interventions. These determinant factors include government policies and the type and method of harvesting of the NTFP. First and foremost, various government policies may have negative impacts through the destruction of a specific NTFP resource base. For example, the clearing of almost half of the $\mathrm{J} 4$ area to establish plantations of Gmelina arborea and indigenous timber tree species has had an unfavourable impact on the understorey species that produce abundant NTFPs. These include bitter kola, and many Garcinia kola trees that used to produce abundant fruits have been destroyed by the felling of trees and under brushing processes. Current inhabitants of the J4 area can only tell of the past abundance of bitter kola seeds. Their only hope for regaining the past glory of abundant harvest lies in the preciously few replantings and trees already conserved in their cocoa plantations.

The climatic conditions and the physiography of the vegetation of the whole area are now changing, and the human population is increasing. It is unlikely that supply and demand for bitter kola in the production area will ever reach equilibrium. On the other hand, the collection of Garcinia kola nut is sustainable as the cycle of flowering to fruiting period is not tampered with when harvesting. 
In the J4 area, individual households have particular bitter kola trees from which they harvest without hindrance. The number of trees could be increased by planting Garcinia kola wildlings. This has just begun in the last 10 years, when forest inhabitants learned that the tree could be cultivated.

There are indications that there is an accelerated decline in the abundance of Garcinia kola trees and other NTFPs in the tropical rainforest of Africa, most especially those that are of socio-economic importance and have long been commercialised. Deforestation and various processes of clearing vegetation have changed habitats, in part as a result of changes in climatic conditions in the past five decades. This, coupled with various intensities of exploitation by stakeholders, has been held responsible for the decline in the abundance of some major NTFPs. The lack of modern, efficient and appropriate processing technologies has contributed to the underutilisation of many NTFPsand caused great economic loss. The impact of this lack of processing technology is considered to have limited the trade of many NTFPs to domestic markets. For example, trade in bitter kola is still within the domain of domestic and national markets, though regional and international markets are known to exist (although the volume of trade is yet to be ascertained). Furthermore the government of Nigeria has not promoted the production and trade of bitter kola like it has its counterpart, the cola nut, which in the past six decades has been variously favoured and developed to the extent that Nigeria is now one of the biggest producers and exporters of cola nuts. Increasing the production of bitter kola may expand its trade, market stability and add more economic value. The government, multilateral, nongovernmental and private organisations and industrial entrepreneurs should sponsor various programmes and projects to study and support the development of bitter kola. Such efforts could accomplish the desired development in cultivation and improve the tree's slow growth rate, industrial use and overseas promotion of bitter kola trade.

\section{KEY ISSUES/PROBLEMS}

\section{Decline in forest cover}

Nigerian forest covers a total land area of $360,000 \mathrm{~km}^{2}$ (Bada 1984), $27 \%$ of which makes up the forest reserves of the country. The remaining forest cover is regarded as free areas, and it is from these areas that most of the wood requirements of the country have been met. However, as economically valuable species were cleared from the free areas, the forest reserves were exploited. Nigerian forest area has declined greatly because of uncontrolled deforestation.

Although efforts are being made to plant fast growing exotic and indigenous species to replace the overexploited tropical forest, the rate of establishment does not match the rate of exploitation. By 1990, plantations of various species and purposes covering a total of 216,026 ha had been established in various parts of Nigeria, particularly in the forest reserve areas (Omoluabi et al. 1990). It is feared that unless something is done, the remaining pockets of tropical forest in Nigeria may have vanished by the end of the twenty-first century (Okojie et al. 1988). 


\section{Decline in the value of the standing forest resource}

Almost $70 \%$ of the bitter kola production in Nigeria stems from natural or secondary forest of the government forest reserves, while just about $30 \%$ are from the cocoa-cola farming system production areas of south-western parts and the oil palm-cassava and home or compound garden farming system of the south-eastern part of Nigeria. The entire $\mathrm{J} 4$ area is a secondary forest and logged-over habitat of about 59,610 ha in extent; almost half of the area has been cleared for agriculture and forest plantations. The major land use system is rain-fed arable cropping, characterised by swidden fallow and permanent crop plantations of cocoa, cola, and plantain. Apart from this, each village has an average of 13.91 ha of forest for collection of NTFPs. Both commercial timber logging and agricultural clearing in the $\mathrm{J} 4$ study area in the recent past have affected the availability of NTFPs, especially Garcinia kola.

The abundance and distribution of Garcinia kola trees within the study area is highly variable. The density of this species is low, in spite of recent individual planting efforts. Though these efforts, if continued, will contribute to increasing the abundance of the species, they will not immediately contribute to bitter kola production. In addition to the recent plantings, wild seedlings occur in secondary forests, fallow lands and cocoa plantations, but as an understorey species Garcinia kola is generally absent in the largely disturbed forest of the study area. The number of Garcinia kola trees per hectare has now been reduced from 0.5 to 0.33 . The reduction in the number of productive Garcinia kola trees has adversely affected the production of bitter kola.

\section{Need to support domestication of Garcinia kola and the development of greater markets}

The harvest and collection of Garcinia kola nuts has always being sustainable since no parts of the tree are destroyed in the process. However, increased commercialisation could threaten that sustainability if proper care is not taken to ensure the development of new generations of Garcinia kola trees with desired characteristics through careful breeding from selected sources. The existing populations of Garcinia kola, easy physical access, the high control over access, control of the land and other resources provided by the Ogun State Forestry Department and the dwellers within the J4 study area provide an excellent opportunity to further the development of bitter kola production.

This study has found that a large number of NTFPs within the J4 area are used locally for subsistence consumption, while any surplus is traded in the local markets. Some NTFPs are collected mainly for commercial purposes, among them bitter kola. The level of commercialisation of bitter kola is low because of the tree's scattered presence in the forests, low population densities, and limited marketing opportunities. The development of domestication processes to reduce the time to fruit bearing age, coupled with improved marketing opportunities (as has been done with cola nuts), should improve bitter kola production. With the prospect of more immediate returns on their investment (of time and labour, if not cash), local farmers may be encouraged to introduce plantings of Garcinia kola, and thus increase the stocking levels of the species in the $\mathrm{J} 4$ area. It is logical that this development 
would contribute to local incomes and encourage sustainable forest management.

\section{CONSERVATION AND DEVELOPMENT LESSONS OF THE CASE}

Recommendations of what to do to improve the conservation and marketing of bitter kola in the $\mathrm{J} 4$ area of Omo Forest Reserve are made below.

- Policy for sustainable production and trading of bitter kola. Appropriate conservation strategies need to be developed based on a baseline inventory of Garcinia kola within the $\mathrm{J} 4$ area and Omo Forest Reserve in general. This important step will lead to the formulation of management options, which might include production of planting stock through the creation of forest nurseries by the Forestry Department.

- Income generating activities. The harvest of bitter kola nuts is primarily for commercial gain. It follows that greater numbers of healthy trees producing nuts will generate greater amounts of income. To foster this development, farming activities that benefit or are compatible with bitter kola tree cultivation should be encouraged. This would include farming activities such as planting cocoa, cola nuts and other NTFP species that have similar growth requirements as Garcinia kola. These compatible land use activities are considered important as they increase the revenue realisable from the collection and sale of NTFPs. In corollary to this, fertiliser and improved seedlings should be allowed free entry to promote intensive management and increased bitter kola production.

- Respect of isolated village population's rights. Mutual respect for the rights of isolated villages within the Omo Forest Reserve by government agencies and for government rules and regulations by local villagers will promote the management of the forest reserve by the local population. The villagers within the reserve should not be treated as squatters. The original agreements concerning rights to farming, fishing, hunting and collection of royalties should remain, as these are heritable rights. Villagers within the reserve too must abide with the rules and regulations that will guide the sustainable yield and protection of the ecological and environmental being of the whole area. It would behove the government to develop policy and laws for local use jointly with the local people according to their customs and beliefs. Similarly, any review of forestry management policies should favour a bottom-up approach.

In short, the trade of bitter kola and other NTFPs has helped tremendously in the promotion of conservation and the development of socio-economic links and relationships between the isolated village populations of Omo Forest Reserve and project officials on one hand and among all the stakeholders on the other. The afforestation programme in the $\mathrm{J} 4$ area brought in infrastructure development that benefits all involved and that is not found in any other part of the reserve. This development includes the provision of potable water, schools, clinics, electricity, and all-weather roads for evacuation of NTFPs, monitoring of projects, collaboration with all stakeholders and a host of other opportunities. 


\section{CONCLUSIONS}

This chapter has elucidated the importance of bitter kola as one of the many NTFPs that are of socio-economic importance in the rainforest of south-west Nigeria. Its commercialisation both in the domestic and national markets would result in raising the standard of living of those involved in its trading activities, in both the rural and urban centres. It is clear that through the volume of production each season the bitter kola trade is more profitable than other NTFPs such as wonder cola (Bulchhoizia coriacea), sponge (Acanthus montanus) and cola nuts (Cola nitida/acuminata) in the J4 area. In part because of its high amenability to storage, both fresh and dried, traders' market margins were also found to be higher than those of other NTFPs.

The ongoing increase in commercial value of bitter kola has made the cultivation of the tree more important-and of greater interest-to the isolated villagers of the J4 area of Omo Forest Reserve as well as other bitter kola production areas in Nigeria. The development of domestication and cultivation strategies for improving Garcinia kola trees should be possible, as has been undertaken with many other NTFPs.

\section{ACKNOWLEDGEMENTS}

I wish to thank the Centre for International Forestry Research and all members of staff, both in Cameroon and Bogor, for their particular interest in the study of NTFPs in general and for sponsoring this case study. I am grateful for the opportunity given to me by the Centre for Environment, Renewable Natural Resources, Management, Research and Development to carry out the study. Special thanks to Dr. L. A. Adebisi and Dr. (Mrs.) A. O. Adu of University of Ibadan, Nigeria, and Forestry Research Institute of Nigeria, respectively, for their willingness and prompt action in reviewing earlier versions of this paper.

\section{ENDNOTES}

1. CENRAD, P. M. B. 5052, Ibadan, Nigeria. E-mail: cenrad@skannet.com

\section{REFERENCES}

Adebisi, A.A. 1997 Marketing and post-harvest constraints of the African star apple (Agbalumo). In: Ladipo, D.O. and Denton, A.O. (eds.) Proceedings on the potential and conservation of chrysophyllum albidum in Nigeria. NIHORT/NACGRAB/CENRAD.

Adjanohun, E. et al. 1991 Traditional medicine and pharmacopoeia: contribution to ethnobotanical and floristic studies in western Nigeria. OAU/STRC.

Aiyelaagbe, I.O. and Adeola, A.O. 1993 Fruit trees for future agroforestry initiation in the humid zone of Nigeria: the farmer priority list. Paper presented at the ICRAF meeting on prioritisation of MPTs for humid lowlands of West Africa. 24-25 June 1993. IITA, Ibadan, Nigeria.

Aiyelaagbe, I.O., Labode Popoola, Adeola, A.O., Obisesan, K.O. and Ladipo, D.0. 1996 Garcinia kola: its prevalence, farmer valuation and strategies for its conservation in the rainforest of southeastern Nigeria. Paper 
contributed to the workshop on the Rainforest of Southeastern Nigeria and Southwestern Cameroon. 21-23 October, Cross River National Park, Obudu Ranch, Nigeria.

Bada, S.O. 1984 Growth pattern in an untreated tropical forest ecosystem.

Ph.D. Thesis, University of Ibadan, Nigeria. 204p.

Dalziel, J.M. 1937 The useful plants of west tropical Africa, being an appendix to the flora of West Africa by Hutchinson, J. and J. M. Dalziel. The Crown Agent for the Colonies.

Falconer, J. 1990 The major significance of 'minor' forest products: the local use and value of forests in the West African humid forest zone. Forest, Trees and People. FAO Community Forestry Note 6. FAO, Rome. 232p.

Falconer J. 1992 Non-timber forest products in southern Ghana. ODA Forestry Series 2. UK Overseas Development Administration, London. 23p.

Ibanga, I.A. 1993 Use of Garcinia kola as bittering agent in brewery industry. B.Sc. Project, University of Calabar, Nigeria.

Isawumi, A.M. 1993 The common edible fruits of Nigeria, part II. The Nigerian Field 58: 1-2.

Kabuye, C. 1998 Socio-economic research and non-wood forest products: an overview. In: Sunderland, T.C.H., Clark, L.E. and Vantomme, P. (eds.) Current research issues and prospects for conservation and development. Non-wood Forest Products. Limbe Botanical Garden, Cameroon.

Karimu, S.A. 1999 The role to surrounding communities on the management of Omo Forest Reserve. Consultant report for FORMECU, Federal Department of Forestry, Abuja, Nigeria.

Keay, R.W. 1989 Trees of Nigeria. Clarendon Press, Oxford. 476p.

Ladipo, D.0.1995 Physiological/morphological growth rate and fruit/nut yields in G. kola tree on acid soil of Onne, Port-Harcourt. ICRAF In-House Report. Ladipo, D.O. 1999 Evaluation of agroforestry practices in Omo Forest Reserve. Consultant report. FORMECU, Federal Department of Forestry, Abuja, Nigeria.

Lowe, R.G. 1993 More experiences of a forest officer in western Nigeria, part II: forest monitoring in Omo Forest Reserve. The Nigerian Field 58: 137156.

Ndoye 0. 1995 The markets for non-timber forest products (NTFP's) in the humid forest zone of Cameroon and its borders: structure, conduct, performance and policy implication. CIFOR.

Ndoye, O., Ruiz-Perez, M. and Eyebe, A. 1998 NTFP's markets and potential forest resources degradation in Central Africa: the role of research for a balance between welfare improvement and forest conservation. Paper presented at the International Export Workshop on Non-wood Forest Products (NWFPs) for Central Africa, Limbe Botanic Garden, 10-15 May 1998.

Ntamag, C.N. 1997 Spatial distribution of non-timber forest production collection: a case study of south Cameroon. M.Sc. Thesis, Wageningen Agricultural University.

Ojo, G.O.A. 1999 Survey of non-timber forest products (NTFPs) in the Omo Forest Reserve, including their use and values. Consultant Report, FORMECU. Federal Department of Forestry, Abuja, Nigeria. 48p. 
Okafor, J.C. 1998 Mass propagation of species for immediate utilization. Paper presented at the meeting of underutilized crops of Nigeria. 4-8 May 1998. NACGRAB Moor Plantation, Ibadan, Nigeria.

Okojie, J.A., Bailey, R.L. and Borders. B.E. 1988 Spacing effects in an unthinned 11 year old Terminalia superba plantation in the dry lowland rainforest of Nigeria. Forest Ecology and Management 23: 253-260.

Omoluabi, A.C., Ogundare, L.G., Omuka, L.G. and Martins, V. 1990 Nigeria forest plantation development. FORMECU, Federal Department of Forestry, Ibadan, Nigeria.

Shiembo, P.N. 1999 The sustainability of eru (Gnetum africanum and Gnetum buchholzianum): an overexploited non-wood forest product from the forests of Central Africa. In: Sunderland, T.C.H., Clark, L.E. and Vantomme, P. (eds.) Non-Wood Forest Products of Central Africa, 61-66. Current Research Issues and Prospects for Conservation and Development. FAO, Rome.

Townson, I.M. 1995 Incomes from non-timber forest products: patterns of enterprise activity in the forest zone of southern Ghana: summary report. Oxford Forestry Institute, United Kingdom. 40p.

Vivien J. and Faure, J.J. 1996 Fruitiers sauvages d'Afrique: espèces du Cameroun. Ministère de la Coopération/CTA, Paris/Wageningen. 416p. 


\title{
Chapter 8
}

\section{Potential for development and conservation of Dacryodes edulis in Sakpoba Forest Reserve, Edo State, in the Niger Delta area of Nigeria}

\author{
Hassan Gbadebo Adewusi ${ }^{1}$
}

\begin{tabular}{llllll}
\hline Common names & $\begin{array}{l}\text { Part of the } \\
\text { resource used }\end{array}$ & Management & $\begin{array}{l}\text { Degree of } \\
\text { transformation }\end{array}$ & $\begin{array}{l}\text { Scale of } \\
\text { trade }\end{array}$ & $\begin{array}{l}\text { Geographic } \\
\text { range }\end{array}$ \\
\hline $\begin{array}{l}\text { Safou, Bush pear, } \\
\text { Orumu }\end{array}$ & Fruit & $\begin{array}{l}\text { Managed/ } \\
\text { Cultivated }\end{array}$ & Low & National & Medium \\
\hline
\end{tabular}

\begin{abstract}
The edible fruits of Dacryodes edulis are one of the most important nontimber forest products in Sakpoba Forest Reserve. The species has been cultivated and commercialised in the far west of the reserve for over six decades, with a corresponding trade network stretching as far as Benin City, Sapele, Agbor and Lagos. The $95 \%$ majority of $D$. edulis production is obtained from cultivated stands in agricultural fields, agroforestry plantings and compound farms. The remaining $5 \%$ is obtained from the wild although considerable variation exists among the wild taxa. Of the cultivated production of $D$. edulis, $80 \%$ is from private land and $10 \%$ from open access communal land. The average size of producer households is about seven people, about $50 \%$ of whom engage in $D$. edulis production and $30 \%$ in marketing. Production and marketing of $D$. edulis is on the increase while processing remains unchanged. The road network within the production site is in serious disrepair, deleteriously affecting the movement of product to market. Encouraging the cultivation and commercialisation of $D$. edulis will encourage the selection of superior varieties from the highly variable wild materials. It is hoped that this will in turn increase and ensure the adoption and practice of conservation strategies for the remaining wild genetic resources of the species.
\end{abstract}




\section{INTRODUCTION}

Various authors have described the contributions of wild fruits, nuts, seeds and vegetables to the African diet and their potential in overcoming or ameliorating the problems of inadequate food supply and nutrient deficiencies among the people, particularly rural dwellers, who are often perceived to be under serious threat of malnutrition (Getahun 1974; Roche 1975; Okigbo 1977, 1978; Okafor 1975, 1980).

A multiple-value trees and shrubs prioritisation exercise conducted for the humid lowland of West Africa (HULWA) by the International Centre for Research in Agroforestry in 1993 indicated that $D$. edulis is one of the preferred wild fruit tree species in the region. It is particularly valued in south-eastern and parts of south-western Nigeria (Adeola et al. 1994), ranking just behind the bush mango in livelihood importance.

However, few of the top 10 species in the HULWA region have acquired international recognition, particularly in their importance in the agroforestry system, contribution to income generation of farmers, nutritional values and growing commercial importance locally. Data on local commercial and production trends as well as export earnings from this group of resources need to be collected. This study evaluates the production, uses and commercialisation pattern of $D$. edulis in the Sakpoba Forest Reserve area of Nigeria, with the objective of identifying the potential for harmonising the development and encouraging the in situ conservation of the species.

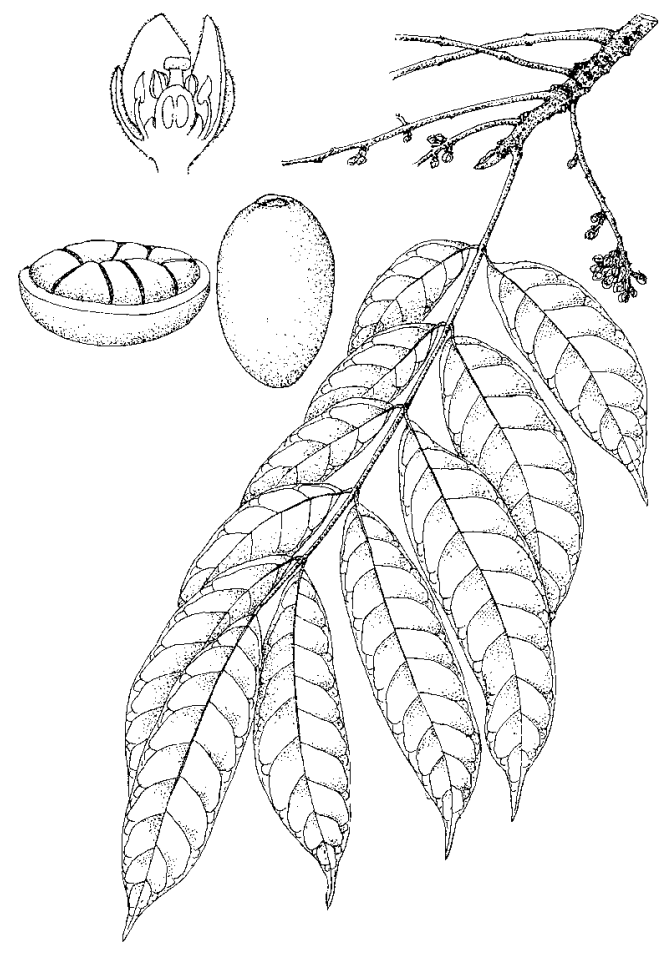

(Dacryodes edulis) 


\section{THE PRODUCTION-TO-CONSUMPTION SYSTEM}

\section{Resource base}

The Sakpoba (or Sapoba) Forest Reserve $\left(06^{\circ} 05^{\prime} \mathrm{N}, 05^{\circ} 52^{\prime} \mathrm{E}\right)$ including numerous villages, campsites, and enclaves is situated in Edo State, in the south-southwest area of Nigeria (Figure 1). It is located about 45 kilometres south-east of Benin City and 26 kilometres north-east of Sapele, in the moist lowland rainforest. The entire forest reserve covers an estimated area of $521 \mathrm{~km}^{2}$ (FORMECU 1998).

Figure 1. Location of the study area

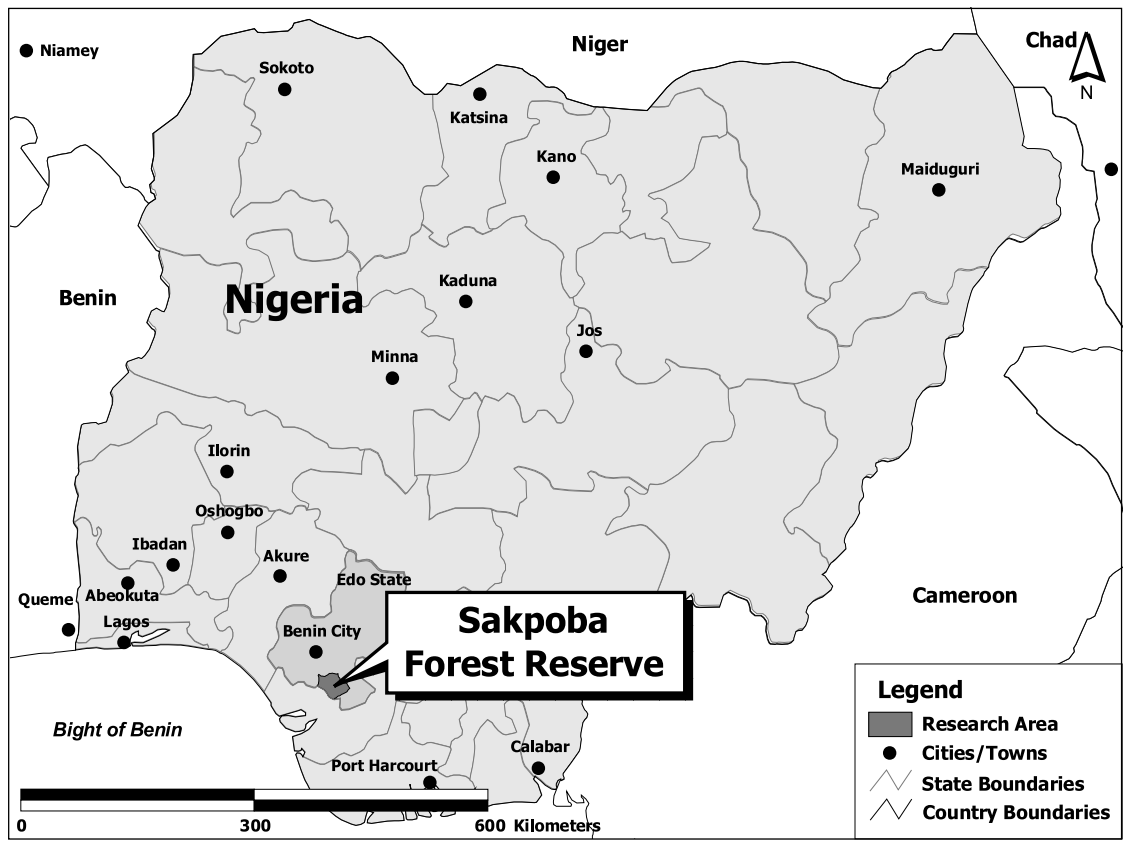

Source: ESRI Data and Maps 2002.

Villages within the forest reserve area include Evbuosa, Aideyanba, Igbekhue, Iguemokwa, Ona, Akpobi, Abe, Evbeka, Obozogbe, Evbarkhue and Iduowina (Idu). For this study, Ona village and Akpobi camp with a combined area of 5 $\mathrm{km}^{2}$ were selected. The population of the two communities is estimated to be around 3,000, representing an average density of 600 persons per square kilometre. The population has increased over the last 10 years, with an average influx of about 50 people annually (Efhosa personal communication). While the indigenes drift to the urban centres for white collar and artisan jobs, nonindigenes, particularly timber exploiters and non-timber product extractors mostly from the Hausas and the Igbos tribes, constitute the majority of immigrants into the communities (Yesufu personal communication). 
The major land use patterns in Sakpoba Forest Reserve are farming (predominantly arable, plantation), taungya agroforestry systems and areas set aside for biodiversity conservation and forest regeneration (Table 1). The area was constituted and gazetted into forest reserve by the regional government in 1912. Ownership and authority have changed hands between regional and native authorities several times, but the Edo State government now controls the management of the reserve. Since its constitution into government forest reserve, natives have been granted the privilege to reside and practice sedentary agriculture within approved demarcated areas close to the communities. Traditional communal landowners enjoy the rights to hunt and fish and to access other water resources as well as the right of way along the Sapele-Sakpoba-Igbekhue motor road. Sakpoba Forest Reserve occupies a significant position in forestry practices in Nigeria. Its proximity to Benin City, Sapele and Agbor markets make it an attractive area of continued forest development.

Table 1. Predominant land use pattern in Sakpoba Forest Reserve

\begin{tabular}{lcc}
\hline Land use system & Area $\left(\mathrm{km}^{2}\right)$ & $\begin{array}{c}\text { Percentage } \\
\text { of total area(\%) }\end{array}$ \\
\hline Rain-fed arable & 20 & 4 \\
Irrigation arable & 0 & 0 \\
Permanent crops & 104 & 20 \\
Pasture & 5 & 0.96 \\
Swidden fallow & 5.2 & 1 \\
Forest & 160 & 30.6 \\
Urban/settlement & 2 & 10.804 \\
Marshy/swamped & 26 & 5
\end{tabular}

Source: FORMECU 1998.

Settlements in the Sakpoba Forest Reserve used to be served with good motorable roads totaling about 320 kilometres (Table 2 ). The perennial rivers used for transportation include the Jamieson and Ossiomo rivers. The main Agbor-Sapele and Sakpoba-Idu roads were constructed in 1926 and 1940, respectively, and timber exploiters have constructed various short logextraction routes. These roads are in terrible states of disrepair and available for product extraction and transportation to major markets only during the short dry period of the year.

The forest/vegetation type is moist evergreen lowland rainforest. This zone is characterized by a potential evapotranspiration ratio of between 0.125 and 2. The average annual rainfall ranges between $1,000 \mathrm{~mm}$ and $3,000 \mathrm{~mm}$, while the mean daily temperature is about $24^{\circ} \mathrm{C}$. The climatic classification of the recorded production area according to the Köppen system falls within the rainy climate with or without dry season winter. The temperature of the coolest month is above $18^{\circ} \mathrm{C}$. It is constantly moist, and rainfall in the driest month is not less than $60 \mathrm{~mm}$ (UNEP 1995). 
Table 2. Transportation network around Sakpoba Forest Reserve

\begin{tabular}{lcl}
\hline Roads & Distance $(\mathrm{km})$ & Status \\
\hline Roads and rides & 160 & $\begin{array}{l}\text { Fairly well motorable } \\
\text { Complete state of } \\
\text { Agbor-Sapele road }\end{array}$ \\
disrepair \\
Sakpoba-Benin road & 460 & $\begin{array}{l}\text { Partly paved, other } \\
\text { parts not motorable } \\
\text { in rainy season }\end{array}$ \\
& 365 & \\
Total & 365 & \\
\hline
\end{tabular}

Despite its high value and the nutritional and economic importance of $D$. edulis to the socio-cultural life of the people of the area, monocropping or plantation development of the species is rarely found. Instead small stands are randomly planted in a complex agroforestry system of compound farms, home gardens and outlying farms. The present production stocks of the species are old, while the juvenile ones, expected to commence production soon, are from protected on-farm growth wildlings or from lifted wildlings planted within the compound agroforestry complex. Irrigated farming is not practised in the Sakpoba Forest Reserve area because of the nearly year-round constant moisture availability and very short dry period (Table 1 ).

The major item of commercial interest is the fruit of $D$. edulis. The current source of the fruit is predominantly from semidomesticated stands in home gardens and tree crop farms, and rarely from the wild. The tree has been delimited into two varieties, namely, D. edulis var edulis and D. edulis var parvicarpa, based on fruit traits identified by Okafor (1983). Recent germplasm exploration studies, however, indicate wide variability within the fruit, particularly in colour (especially after ripening), size, shape and mesocarp thickness (Omaliko et al. 1998). Although seven distinct fruit shape types are recognised, four fruit types are consistent enough to be applied. These are ellipsoid, oblong, cylindrical and spindle shapes.

D. edulis fruit is consumed as food supplement. It is eaten either raw, roasted or boiled, usually between meals, particularly together with boiled or roasted maize, during the 'hungry season' when staples are yet to mature and become ready for consumption (Okafor 1983; Emebiri and Nwufo 1990). The edible portion (mesocarp) is protein rich (between 9\% and 12\%) (Emebiri personal communication) and has a good amino-acid balance (Omoti and Okiy 1987). The fruit yields about $48 \%$ edible oil, which is rich in unsaturated fatty acid (44\%) (Ucciani and Busson 1963). This is relatively stable, satisfactorily nutritional and compares favourably with other major widely used vegetable oils (Ucciani and Busson 1963; Osagie and Odutuga 1986; Omoti and Okiy 1987). After oil extraction the cotyledon, or kernel, can be fed to sheep and goats. In addition to the edible fruit, the resin obtained from the bark is variously used as sealing pitch on calabashes and for mending earthenware. The wood from D. edulis is used for making tool handles, axe shafts, mortars and in carpentry. Various parts also have cure for a variety of ailments. 
Photo 1. Fruit of Dacryodes edulis (Photo by H.G. Adewusi)

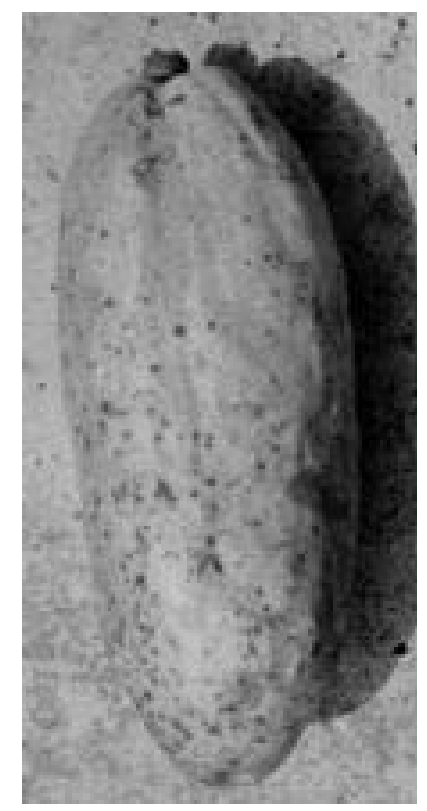

While fruit harvesting per se does not kill the tree, roasting or boiling the fruit for consumption has a deleterious effects on the seed embryo. However, Okafor and Okolo (1974) reported that germination was obtained with such seeds. The intraspecific variations found in the trees and fruits (Okafor 1983; Omaliko et al. 1998; Kengue et al. 2002) are clear indications of high prospects for conservation. These include extending the period of fruit availability, increasing the range of products and yield as well as choice of desirable traits, pattern and season of yield. The shelf life is generally less than a week (Aiyelaagbe et al. 1998), but it can be prolonged beyond eight days through refrigeration (Okafor 1990). Under ambient conditions, some genotypes stay beyond the normal period before deteriorating, a desirable trait for selection of cultivars (Leakey 1999). Okafor (1990) reported an inverse relationship between fruit length, mesocarp thickness and shelf life.

Okafor (1998) has successfully budded D. edulis, however, with some difficulty because of the resinous exudates that makes cambial unification between rootstock and scion difficult. Okafor (1998) advocated the adoption of apical decapitation method, with similar advantages as in budding. However, marcotting has been successful on $D$. edulis in Nigeria. This has similar advantages as budding and decapitation. $D$. edulis is known to germinate easily from seed, with over $80 \%$ cumulative germination between 10 and 21 days after sowing (Okafor 1998).

The dietary contribution of $D$. edulis is enhanced because of its season of availability, the 'hungry season' (Okafor 1998) when most staples such as yam, cocoyam and rice are not mature. Potential commercial or industrial products 
obtainable from $D$. edulis include cooking (edible) oil and margarine, soap manufacturing and pharmaceutical preparations (Okafor and Okolo 1974; Udeala et al. 1980; Omoti and Okiy 1987).

Using data from two independent forest enumerations, Okafor (1993) found that per hectare between 0.21 and 0.4 trees of $D$. edulis were present in the wild. This is a very low density, compared with Irvingia spp., Pentaclethra macrophylla and Chrysophyllum albidum among other high priority indigenous fruit trees. However, in the traditional farming systems over three $D$. edulis trees per hectare have been observed (Okafor 1993). Based on this and on an average fruit yield of $223 \mathrm{~kg}$ to $335 \mathrm{~kg}$ per tree, an annual fruit yield per hectare of 7 tons to 10.5 tons has been recorded (Omoti and Okiy 1987). In a similar vein, other studies recorded an oil yield of about 16 tons per hectare, twice the production capacity of oil palm (Emebiri et al. 1993). Most farmers' holdings consisted of an average of four trees per farmer (Adeola et al. 1994).

In the absence of monocrop or plantation farming of $D$. edulis in this area, the current source of the fruit is predominantly from compound farms and agroforestry plots. This accounts for about $90 \%$ of the total production. Trait preferences for domestication of $D$. edulis as suggested by respondents (Adeola et al. 1994; Aiyelaagbe et al. 1998; Okafor 1999) have been documented; these include bigger fruits, creamier fruits, thick mesocarp, small seeded fruits, short and early producing varieties. These trais could increase production and probably encourage monocrop cultivation of $D$. edulis, if improved materials were available. The percentage contribution to the entire production by the habitat/ forest types showed that primary, disturbed primary and secondary forests contributed about 5\% (at 1\%, $2 \%$ and $2 \%$, respectively). Agricultural fields also make a significant contribution (5\%). These fields, primarily devoted to arable crops productions, have scattered fruit trees retained, hence are distinctly different from any agroforestry system.

Fruit availability in the market is expected by late May and could last until October in most cases, therefore providing a five-month harvesting period, however the effective harvesting may last only four months (June-September). Fruiting periodicity variations have been observed across the distribution range (Kengue et al. 2002). Off-season genotypes/cultivars are also available and their fruits ripen tardily between November and January (Okafor 1979). In Rivers State, with a swamp ecology, a fruiting period from May to June has been recorded; in Abia State, with a rain forest ecology, from May to October; in Anambra State, with a forest-savanna transition ecology, from June to November (Aiyelaagbe et al. 1998). Wider variation may occur in a drier environment. Access to the forest may be hampered during the peak of the rainy season (July-September) because of the terrain.

Since most lands carrying $D$. edulis are in the mixed or intercrop status, the best alternative use of the land-whether for monocrop production of $D$. edulis or other uses-has not been determined. Rubber (Hevea brasiliensis) and oil palm (Elaeis guinensis) are the common plantation crops in Sakpoba Forest Reserve. Although production is obtained from all categories of land tenure, the percentage distribution is as follows: private land, $80 \%$; state land, $5 \%$; communal land, $5 \%$ and open access, $10 \%$. If these land types were rented out, the annual rent would be US\$49 per hectare. The sale price for a hectare of similar land is 
US\$490. The government, however, charges US\$10 per annum as concession fee for the extraction of non-timber forest products (NTFPs).

Unlike most NTFPs, the harvesting of $D$. edulis fruits does not involve physical removal of individual trees, but the propagules are removed and carried away from the production site. Okafor (1998) asserted that wild D. edulis trees could reach reproductive maturity in 10 to 15 years, although pruned cultivated trees have fruited within three years and unpruned cultivated trees could take five years before fruiting (Aiyelaagbe et.al. 1998).

Like most tree growth and production, the trend of fruit production is expected to increase with age, before declining. Aiyelaagbe et al. (1998) reported a significant decline in production after 60 years. Since the majority of the current stock of production is old and improved varieties of the species are uncommon, the population of $D$. edulis in the production area may be declining.

\section{Raw material producers and socio-economic context}

The average household size in Ona and Akpobi villages is seven people, no fewer than $40 \%$ of them engaged in $D$. edulis production. The average annual household income in Sakpoba Forest Reserve is about US\$500, a little higher than the national average of US\$490. Close to $40 \%$ of the annual household income is integrated into the cash economy of the communities. Fifty percent of household members are involved in production, while only $30 \%$ are involved in marketing. The average annual income of $D$. edulis producer households in the study area is US\$650 with $5 \%$ contribution from $D$. edulis. These household collect other NTFPs as well, including Xylopia aethiopica, Garcinia kola, Irvingia gabonensis, Irvingia wombulu, Piper guinensis, Aframomum melagueta, Pentaclethra macrophylla and Treculia africana among others. NTFPs production continues to be on the increase, and producers enjoy medium class status within the community.

The contribution of $D$. edulis to the rural economy is primarily based on the income it generates through fruit sales, but the total amount of cash that exchanging hands is difficult to ascertain. Likewise, the value of such a product is unquantifiable. For example, the leaves and seed kernels are useful as animal feed and the species has other cultural uses such as to portray hospitality or hostility to visitors in certain parts of Iboland (south-east Nigeria) and for oracle divination (Okafor 1979).

Fruit collection, both in the wild and on planted farms, is labour dependent. The labour requirement for collection and packing of a $100 \mathrm{~kg}$ bag is about three man-days (Adewusi personal communication). Unlike in the introduced cash/industrial monocrop or plantation crops such as cocoa, coffee, kola and cashew, where there are producers' association, there are no established producers' groups for the majority of indigenous fruits. Individual farmers may belong to various co-operative societies and non-governmental institutions such as the Farmers' Development Union or the Farmers' Association of Nigeria, yet specific crop or farm produce associations are rare among farmers. Informal associations may exist, however, among the brokers and distributors who trade in the fruits. Using the level of participation of farmers in similar societies, 
particularly co-operative ones, there is high optimism for widespread participation among all the stakeholders in $D$. edulis production, if such organisation were to exist. The non-existence of a formal producing organisation makes it difficult to establish guidelines for entrance of new members. The land tenure system could be one of the major constraints to recruiting new members into the production system; similarly, the capital outlay of produce buying may restrict new entrants into the distribution system as well as diversified business of stakeholders.

\section{Processing industry}

The current degree of transformation of $D$. edulis to finished product is low, $i$. e., the fruit is eaten without any value added. However, when extractives (oil, resin etc.) are obtained, the transformation may be high. The proportion of farm produce to finished product currently remains total (100\%). Other species with value similar to $D$. edulis are $D$. klaineana and Canarium schweinfurthii. However, no synthetic substitute is known at present. Experience with other fruit trees showed that vendors employ labour to harvest at peak periods, similar method are not known to be employed for $D$. edulis. Current knowledge only indicates the use of family labour in the sequential harvest, and this is not often costed. At present, little or no technology is used in the processing of $D$. edulis. The technologies being developed and used in studying the potential industrial uses of natural products at the Products Research and Development Agency (PRODA) in Enugu, Nigeria, the Federal Institute for Industrial Research Oshodi (FIIRO) in Lagos, Nigeria, and the Food Technology and Food Sciences Departments in Nigerian Universities and Polytechnics should be adopted and improved upon.

\section{Trade and marketing}

The trade of $D$. edulis in Nigeria can be described as 'cash and carry'. Daily paid workers within the National Agricultural Research System currently earn US\$2.5 per day (N100 = US\$1 at the official rate of exchange). However, at Sakpoba-an oil producing area-the average daily wage range is between US\$4 and US\$5 depending on the nature of a job and labour availability. The farmers in addition provide transportation and a mid-day meal. Labour charges are higher in the oil producing areas of the Niger Delta.

An annual yield of 1,500 to 10,000 fruits per mature tree, with a corresponding cash income of about US\$75 to US\$150 has been recorded for $D$. edulis (Okafor 1990). In the same area (the Niger Delta), an economic evaluation by Aiyelaagbe et al. (1998) reported an annual yield of $8 \mathrm{~kg}$ to $110 \mathrm{~kg}$ per tree, depending on tree age. This represented an average cash income of about US\$0.03 to US\$0.75 with a yield of $20 \mathrm{~kg}$ to $50 \mathrm{~kg}$ per tree (Aiyelaagbe et al. 1998). The price in local currency of $D$. edulis continues to increase steadily, particularly in the off-seasons and years of poor production. However, the differences in the above economic evaluations stem from variations in assessment period and rate as well as rate of inflation. The income accruing to the household from the trade may continue to increase, but inflation and declining value of the national currency continue to obscure this trend. 
An average of 12 producers were observed to trade $D$. edulis in local markets per period (day), with an average of 37.5 twenty-five $\mathrm{kg}$ bags or baskets per market period. During the peak period, a bag or basket sold for between N95 and N170 at the farm gate and increased to N100 to N160 at the depots. Iguemokwa market recorded the highest number of producers (22), while Ona market had the least (10). In a similar vein, producers traded more quantities of D.edulis in Iguemokwa market, while few baskets were traded in Iduowina market. Accessibility and proximity to markets may be one of the factors responsible for the observed pattern.

In the absence of official or documented records, interviews and interactions with elders in the community provided clues that introduction of $D$. edulis into the local marketing system may have occurred after the introduction of exotic fruits like citrus, mango and cashew. Wide acceptance, requests from people outside the production zone and dwindling resources may be some of the factors responsible for its commercialisation and subsequent introduction into the marketing system. Therefore $D$. edulis may have been traded for over 50 years in the Sakpoba area.

\section{Policy environment}

From the wild $D$. edulis is obtained from government reserves and communal lands, and no individual is granted the authority to change the land-use pattern or sell such lands. Private landowners, however, have the right to use their land as they deem fit. Not much land has been granted to rubber plantation development, to discourage incursion into forestland particularly in the taungya plots. All the community members are aware of the customs that govern the utilisation of common properties, except perhaps indigenes born outside the community who later settled in the village. State and customary laws have been harmonised, and where there is conflict, state interest overrides. Within the communities, the majority of producers are not single-commodity producers. Locally they have medium to high level status, probably depending on the educational level, while nationally they belong to the low socio-economic stratum.

The national agricultural policy includes the policy on the forestry sector, yet government rights on forest reserves are primarily restricted to timber extraction. Villages within reserves retain the right to extract non-timber forest resources without obtaining permission from the forestry department. The government monitors the movement of forest produce between states, with much emphasis on wood products (timber, poles, firewood etc.). The state forestry department charges a quarterly permit fee of US\$2 per head for minor forest produce, including $D$. edulis. Vehicles that carry forest produce are charged US\$10 per annum. Within the communities, all members regulate the method of NTFPs collection to ensure the sustainability of the produce. The lack of control of NTFPs by the government has allowed the communities to exercise indigenous wisdom in the management of such resources. This method has indirectly ensured sustainability in the production through noncollection of immature materials. D. edulis, like other NTFPs, responds to regulations governing such commodities. Private ownership of farmlands with 
D. edulis ensures uninterrupted control on the management of the produce. Since the export potential of $D$. edulis has only recently been recognised, no state regulation governs its production. The Nigerian Export Promotion Council is however encouraging the exportation of non-oil products, particularly agricultural and forest products. The Raw Material Research Council of Nigeria is currently working on available local sources of raw materials for different industries. Tax exemption for locally sourced materials could be another incentive for the use of NTFPs, and D. edulis occupies a strategic position in this regard.

Two members of the National Agricultural Research Institutes (the National Horticultural Research Institute and the Forestry Research Institute of Nigeria); the Forestry Commission, Enugu; the botany, forestry, agricultural sciences and food technology departments of most Nigerian universities, particularly those within the humid lowland ecological zone, are provided with facilities and the mandate to carry out research on non-timber forest products in general, including indigenous fruits. In a similar vein, PRODA, FIIRO, and the Raw Material Research Council of Nigeria are being sponsored to develop industrial products from NTFPs, including $D$. edulis.

The non-inclusion of the contribution of certain NTFPs in the national and states food balance sheet, despite their importance in the informal economy, was highlighted by Olayide et al. (1972). This situation has remained unchanged. The Federal Office of Statistics in Nigeria is yet to include the contribution of NTFPs to the national economy in its database.

\section{TRENDS AND ISSUES}

\section{Dynamic changes}

Despite the recognised economic importance of $D$. edulis in farming as well as in the nutrition of the people, the majority of studies of the species have focussed on the biology, socio-cultural or ethnobotany, physico-chemical properties and industrial potentials of the species (Emebiri and Nwufo 1990; Emebiri 1993; Ejiofor and Okafor 1997; Okafor 1975, 1979, 1980, 1983, 1998a, b). However, the need to select and breed for improved varieties for effective domestication is critical. These should also include the selection of germplasm for multiplication and conservation of the genetic resources for immediate and future needs.

An improvement in the production, processing and marketing of $D$. edulis in Sakpoba Forest Reserve will better the living conditions and enhance the status of the producers. This will have multiplier effects on the conservation of the available wild materials, including the wild relatives. Since the $D$. edulis fruit has been traded for years in the study site, its global commercialisation will encourage more cultivation.

\section{Key issues/problems}

With about $95 \%$ production from cultivation and 5\% from wild collection in the case study area, understanding the proportional contribution of wild gathering 
and cultivated harvesting to the national production system will form the basis of the global contribution.

The amount of labour required and the cost implication for $D$. edulis production in Sakpoba Forest Reserve indicated its low input requirement. The majority of production has been found in the tree-crop interaction systems, which poses little or no problem to the ecology. In the absence of regional gross domestic product figures, it was difficult to estimate the regional or local per capita income.

Our experience in Sakpoba Forest Reserve in the last 10 years indicates a serious degradation of the natural forest, the major cause being timber exploitation. This has negative effects and impact on non-timber forest resources, particularly among natural regenerated and understorey species. The verification exercise carried out in 2001 revealed the degree of degradation and extent of deterioration of infrastructural facilities within the reserve in the last 10 years. The major roads have become impassable, especially during the peak of the rainy season when the species of interest ( $D$. edulis) is supposed to be brought to market.

\section{CONSERVATION AND DEVELOPMENT LESSONS OF CASE}

\section{Lessons}

D. edulis has enjoyed local and national commercial importance for over six decades. Widening the market for the product, particularly capturing its export potentials and selection of a genotype acceptable to international markets, will enable producers to look inward, into the available genetic resources in the wild. Conservation of these genetic resources will enhance the future ability of producers to participate in and respond to the international trade of the commodity, while continuous development to meet the standard set by the markets will be a priority issue.

Trade in $D$. edulis has benefited all the stakeholders from the villages in the reserve to those involved in the market chain. Organized production and marketing strategies will further benefit and encourage rapid socio-economic development of the producing communities. The current system of harvesting the species is not detrimental and it is sustainable. The available information on yield is insufficient, and farmers are unwilling to disseminate such information in order to avoid taxation. However, detailed studies on the production per tree and per hectare will provide useful information on yield. Current production is insufficient to satisfy the local demand. Producers still manage their old stock and regeneration occurs mainly through wildlings from existing stock.

The slow growth of indigenous fruit trees and longer time required to produce fruit, compared with exotic species, has seriously influenced the demand for planting materials among poor rural farmers. Increased commercialization of $D$. edulis is expected to be an incentive for increased interest in further selection and improvement in the species. This should be backed with supply of improved planting materials. This will encourage the conservation of wild stock and further selections can be made from that. 
Increased commercialization without corresponding stock improvement would put high pressure on stock available in the wild; harvesting or production techniques may become unsustainable. This would further negate the conservation procedures already put in place, both by the government and the local community.

\section{Conclusion}

$D$. edulis has attained elevated status among indigenous fruit trees of the HULWA, hence the increased interest in its domestication and commercialization. With the current knowledge on status and economic and conservation potentials of the species within the study site, $D$. edulis will be better appreciated and efforts increased towards its increased utilization and conservation.

\section{ACKNOWLEDGEMENTS}

I wish to acknowledge the assistance received from farmers and producers I came in contact with during the last verification studies. The valuable assistance of the station officer and other staff of the Forestry Research Institute of Nigeria Sakpoba Sub-Station is fully acknowledged. The Center for International Forestry Research, Bogor, Indonesia, provided the funding for the concluding part of this study, and I am grateful for this laudable assistance in the service of humanity. The leadership role of Ousseynou Ndoye and Brian Belcher in the co-ordination of this study is highly appreciated and gratefully acknowledged. I say a big thank you to all of you.

\section{ENDNOTES}

1. Department of Forest Resources Management, University of Ibadan, Nigeria. E-mail: ajilete@hotmail.com

\section{REFERENCES}

Adeola, A.O., Aiyelaagbe, I.O.O., Ladipo D.O. and Popoola, L. 1994. Survey of multipurpose tree species for prioritization in the humid lowland of $\mathrm{Ni}$ geria. Report to ICRAF, February 1994. 11p.

Aiyelaagbe, I.O.O., Adeola, A.O., Popoola, L. and Obisesan, K.O. 1998. Agroforestry potentials of Dacryodes edulis in the oil palm-cassava belt of southeastern Nigeria. Agroforestry Systems 40(3): 263-274.

Ejiofor, M.A.N. and Okafor, J.C. 1997. Prospects for commercial exploitation of Nigerian indigenous trees, vegetables, fruits and seeds through food and industrial products formulation. International Tree Crops Journal 9(2): 119-129.

Emebiri, L.C. and Nwufo, M.I. 1990. Effects of fruit type and storage treatment on the biodeterioration of African pear (Dacryodes edulis). International Biodeterioration 26: 43-50.

Emebiri, L.G., Obiefuna, J.C. and Nwufo, M.I. 1993. Technological innovation, problems and prospects for domestication of some neglected crops of 
southeasten Nigeria. In: Okogie, J.A. and Okali, D.U.U. (eds.) Lost crops of Nigeria: implications for food security, 193-202.

Getahun, A. 1974. The role of wild fruit plants in the native diet in Ethiopia. Agro-Ecosystems 1: 45-56.

Kengue, J., Tchuenguem Fohouo, F.N. and Adewusi, H.G. (2002). Towards the improvement of the African plum (Dacryodes edulis): population variation and reproductive biology. Forests, Trees and Livelihoods 12(1-2): 74-84.

Leakey, R.R.B. 1999. Farmer's top priority fruit trees. Agroforestry Today 11(34): $11-15$.

Okafor, J.C. 1975. The place of wild (uncultivated) fruits and vegetables in the Nigerian diet. Proceedings National Seminar on Fruits and Vegetables, Ibadan, 153-171.

Okafor, J.C. 1979. Edible indigenous woody plants in the rural economy of the Nigerian forest zone. In: Okali, D.U.U. (ed.) The Nigeria rainforest ecosystem. Proceedings of MAB Workshop on the Nigerian Rainforest Ecosystem. University of Ibadan, Nigeria.

Okafor, J.C. 1980. Edible indigenous woody plants in the rural economy of the Nigeria forest zone. Forest Ecology and Management 3: 45-55.

Okafor, J.C. 1983. Varietal delimitation in Dacryodes edulis (G. Don) H. J. Lam (Burseraceae). The International Tree Crops Journal 2: 255-265.

Okafor, J.C. 1990. Development and selection of commercially viable cultivars from forest species for fruit. Proceedings of the Twelfth Plenary Meeting of aetfat Symposium, Hamburg. 4-10 September 1990. 81-97.

Okafor, J.C. 1993. Lost crops of Nigeria: an overview. In: Okogie, J.A. and Okali, D.U.U. (eds.) Lost crops of Nigeria: implications for food security, 232.

Okafor, J.C. 1998a. Mass propagation of species for immediate utilization. Paper presented at a National Workshop on Under-Utilized Crops and Animals in Nigeria. NACGRAB, Moor Plantation, Ibadan, Nigeria. 4-8 May 1998. 20.

Okafor, J.C. 1998b. Indigenous crops in national food supply system: traditional roles and potential contributions. Paper presented at a National Workshop on Under-Utilized Crops and Animals in Nigeria. NACGRAB, Moor Plantation, Ibadan, Nigeria. 4-8 May 1998. 20.

Okafor, J.C. 1999. The use of farmer knowledge in non-wood forest product research. In: Sunderland, T.C.H., Clark, L.E. and Vantome, P. (eds.): Current research issues and prospects for conservation and development: non-wood forest products of Central Africa, 123-132. FAO, Rome.

Okafor, J.C. and Okolo, H.C. 1974. Potentials of some indigenous fruit trees of Nigeria. Proceedings 5th FAN Annual Conference, Jos, Nigeria.

Okigbo, B.N. 1977. Neglected plants of horticultural importance in traditional farming systems of tropical Africa. Acta Horticulture 53: 131-150.

Okigbo, B.N. 1978. Vegetables in tropical Africa. In: Crop genetic resources in Africa. Proceedings Association for the Advancement of Agricultural Sciences in Africa Workshop, IITA, Ibadan, Nigeria. 128-147.

Olayide, S.O., Olatunbosun, D., Idusogie, E.O. and Abiagom, J.D. 1972. A quantitative analysis of food requirements, supplies and demands in Nigeria 1968-1985. Federal Department of Agriculture, Lagos, Nigeria. 
Omaliko, C.P.E., Ladipo, D.O., Sarumi, M.B., Adewusi, H.G., Adebisi, A.A., Okeke, A.I. and Asiegbu, J.E. 1998. Exploration and collection of Dacryodes edulis in the southwest and southeast of Nigeria. NACGRAB-CENRAD Collection Report. 19p.

Omoti, U. and Okiy, D.A. 1987. Characteristics and composition of the pulp oil and cake of the African pear (Dacryodes edulis). Journal on the Science of Food and Agriculture 38: 67-72.

Osagie, A.U. and Odutuga, A.A. 1986. Chemical characterisation and edibility of the oils extracted from four Nigerian oil seeds. Nigerian J. Pure \& Applied Sci. 1: 15-25.

Roche, L. 1975. Major trends and issues in forestry education in Africa: a view from Ibadan. Commonwealth Forestry Review 54: 166-175.

Ucciani, E. and Busson, F. 1963. Contribution a l'etude des corps gras de Pachybolous edulis Don (Burseraose). Oleagineux 18: 253-255.

Udeala, O.K., Onyechi, J.O. and Agu, S.I. 1980. Preliminary evaluation of dika fat, a new tablet lubricant. J. Pharm. Pharmacol. 32: 6-9.

United Nations Program on Environment. 1995. Global biodiversity assessment. Cambridge. 1140p. 


\title{
Chapter 9
}

\section{The woodcarving industry in Kenya}

\author{
Simon Kosgei Choge ${ }^{1}$
}

\begin{tabular}{llllll}
\hline Common names & $\begin{array}{l}\text { Part of the } \\
\text { resource used }\end{array}$ & Management & $\begin{array}{l}\text { Degree of } \\
\text { transformation }\end{array}$ & $\begin{array}{l}\text { Scale of } \\
\text { trade }\end{array}$ & $\begin{array}{l}\text { Geographic } \\
\text { range }\end{array}$ \\
\hline $\begin{array}{l}\text { Mahogany, } \\
\text { Muhu }\end{array}$ & Wood & Wild & Medium & International & Medium \\
\hline
\end{tabular}

\begin{abstract}
Woodcarving provides one of the most important uses of wood in Kenya both in terms of economic returns (export value of carvings estimated at over US\$20 million annually) and generation of self-employment opportunities (about 80,000 carvers who are breadwinners for over 400,000 family members). As an informal sector economic activity, the woodcarving industry has continued to attract a large number of unemployed people. Its enormous growth in terms of the number of people engaged in the industry and the extent of spread in the country is causing a major conservation problem through depletion of limited stocks of highly favoured tree species among other socio-economic and management challenges. This chapter describes the organisation and conduct of the woodcarving industry in Kenya, delineates the nature of the challenges facing it, and highlights the probable pathways through which the industry may be sustained.
\end{abstract}

\section{INTRODUCTION}

Woodcarving in Kenya is one of the forest-related enterprises with a fascinating history dating back to 1919 (Elkan 1958; Troughear 1987). Since then the industry has gradually expanded over the years to become one of the largest handicraft industries in the country, and arguably in Africa, worth over US\$20 million ${ }^{2}$ annually in value of exported products and being a vital source of livelihood for tens of thousands of carvers and hundreds of thousands of extended family members (Obunga unpublished; Choge 2002). While it is impossible to obtain accurate figures owing to the dynamic nature and spread of the industry, extensive surveys carried out in the mid-1990s showed that the number of active carvers then was between 60,000 and 80,000 , supporting over 400,000 
dependants (Obunga unpublished). The growth of the industry is strongly correlated to the arrival of rising numbers of European settlers and missionaries (1920s and 1930s), British soldiers (1940s and 1950s), tourists (1960s to date) and the expanding international market for Kenyan carvings ${ }^{3}$.

Although carving is practised by all linguistic groups in Kenya, the Wakamba people are most successful at commercial woodcarving in the country. Wakamba carvers have established a well-organised structural industry of wood producers, carvers and marketing agents, most of whom are bound by close ties of extended families and clans. Much of the landscape traditionally occupied by the Wakamba is dry savanna, with limited prospects for agricultural development. As a result, woodcarving remains an important and popular economic occupation option.

Woodcarving is considered an informal sector economic activity in Kenya. The sector covers all small-scale activities, usually semi-organized, unregulated and using simple labour intensive technologies. A large proportion of the unemployed in Kenya join the expanding informal sector, which includes woodcarving. For example in 1999, an estimated 1,705,400, persons in Nairobi, Eastern Province and Coast Province (the prevalent woodcarving areas of Kenya) were engaged in the informal sector with an annual increase of about $11 \%$ (GOK 2000). Although the industry is considered informal, woodcarvers have formed co-operative societies in different parts of the country following encouragement by the government shortly after independence in the early 1960s. Presently six major woodcarving co-operatives exist. They came together in 1982 to form a union to further their ideals and interests. However, the large size of the industry and other internal and external factors are posing new administrative and management challenges discussed elsewhere in this chapter.

Besides the emerging administrative challenges associated with the enormous growth of the industry in Kenya, it is increasingly posing a major conservation problem through depletion of highly favoured tree species from their existing natural habitats. Nationally, over $15,000 \mathrm{~m}^{3}$ of wood is used by the industry per year, a rather small volume considering the large number of carvers. However, the devastating impact of the industry on favoured tree species can be understood when one considers that only a narrow range meet the desirable carving qualities. These include hardwoods such as Brachylaena huillensis O. Hoffm (muhugu), Dalbergia melanoxylon Guill. \& Perr. (ebony/ mpingo), Olea europaea L. var. africana (Mill.) P. Green (olive/mutamaiyu), Spirostachys africana Sond. (mutanga) and Combretum schumanii (mkongolo). The overexploitation of these species is further complicated by their slow growth rates and limited recruitment potential under natural conditions (Choge 2002). The widespread depletion of traditional carving woods has led to increased utilisation of alternative species such as Azadirachta indica A. Juss (neem), Jacaranda mimosifolia, Mangifera indica (mango), Terminalia brownii Fresen., Grevillea robusta (mukima) and others.

Owing to the shortage of woodcarving raw materials and limited market outlets for carved products within their native areas of occupation, the Wakamba carvers have responded to these constraints by gradually moving hundreds of kilometres to other forest and savannah areas, particularly to the Kenyan Coast Province, the geographical focus for this case study. 


\section{STUDY AREA}

The case study area is the region between Kilifi and Malindi districts, around Arabuko Sokoke Forest Reserve, which remains the main source area of Brachylaena huillensis and Azadirachta indica, currently the two most extensively utilised ${ }^{4}$ species in the Kenyan woodcarving industry (Figure 1). Kilifi and Malindi districts cover an area of $12,483 \mathrm{~km}^{2}(1,248,300 \mathrm{ha})$, out of which the study area covers about 92,000 ha (Arabuko Sokoke alone occupies some 41,000 ha), with a population of 312,000 (Mogaka 1991; GOK 2000).

The region has a monsoon type of climate. It is hot and dry in December to May, while the coolest months are June to August. The mean minimum temperature rarely falls below $25^{\circ} \mathrm{C}$. Rainfall, ranging from $900 \mathrm{~mm}$ to 1200 $\mathrm{mm}$ annually, is characterised by a bimodal pattern with long rains during March to June and short rains in November and December (GOK and UNICEF 1990). The area lies within a major cropping zone with fertile soils. The major crops cultivated are maize, coconut, cashew nut, mango, sorghum, cowpea, sweet potato and vegetables. Livestock production is also common.

The area is inhabited by the Mijikenda linguistic group but has been able to accommodate the immigrant Wakamba within their traditional lands and nearby urban areas. Although they are not woodcarvers, the Mijikenda act as raw material producers and facilitators, and hence their contribution to the woodcarving industry, directly or indirectly, is significant.

\section{METHODS}

The findings of this chapter are based on detailed studies of the woodcarving industry in Kenya (Obunga unpublished; Choge 2002) conducted under the People and Plants Initiative jointly funded by World Wide Fund for Nature, UK; the United Nations Educational, Scientific and Cultural Organisation; and the Royal Botanic Gardens, Kew. The study entailed determination of prices of raw materials along the marketing chain (from source to final user), determination of wood volumes by tree species entering the carving market and the products' respective sizes. In addition, the study also documented the competing uses of carving wood where unit prices of each use were determined for uses such as firewood, charcoal production, poles and sawn timber. This was undertaken to guide policy formulation towards more economical utilisation of scarce wood resources in Kenya. Woodcarving returns per unit, labour and profit margins were also determined aimed at identifying the critical stages in the carving process, which require some form of training or other necessary intervention measures towards optimisation of resources and profit maximisation in the light of wood scarcity. Policy reforms covering all these areas were advanced, including the overall structural setup and co-ordination of the industry for a more enabling environment and holistic approach towards the development of a sustainable woodcarving industry in Kenya. 
Figure 1. Map of the case study area
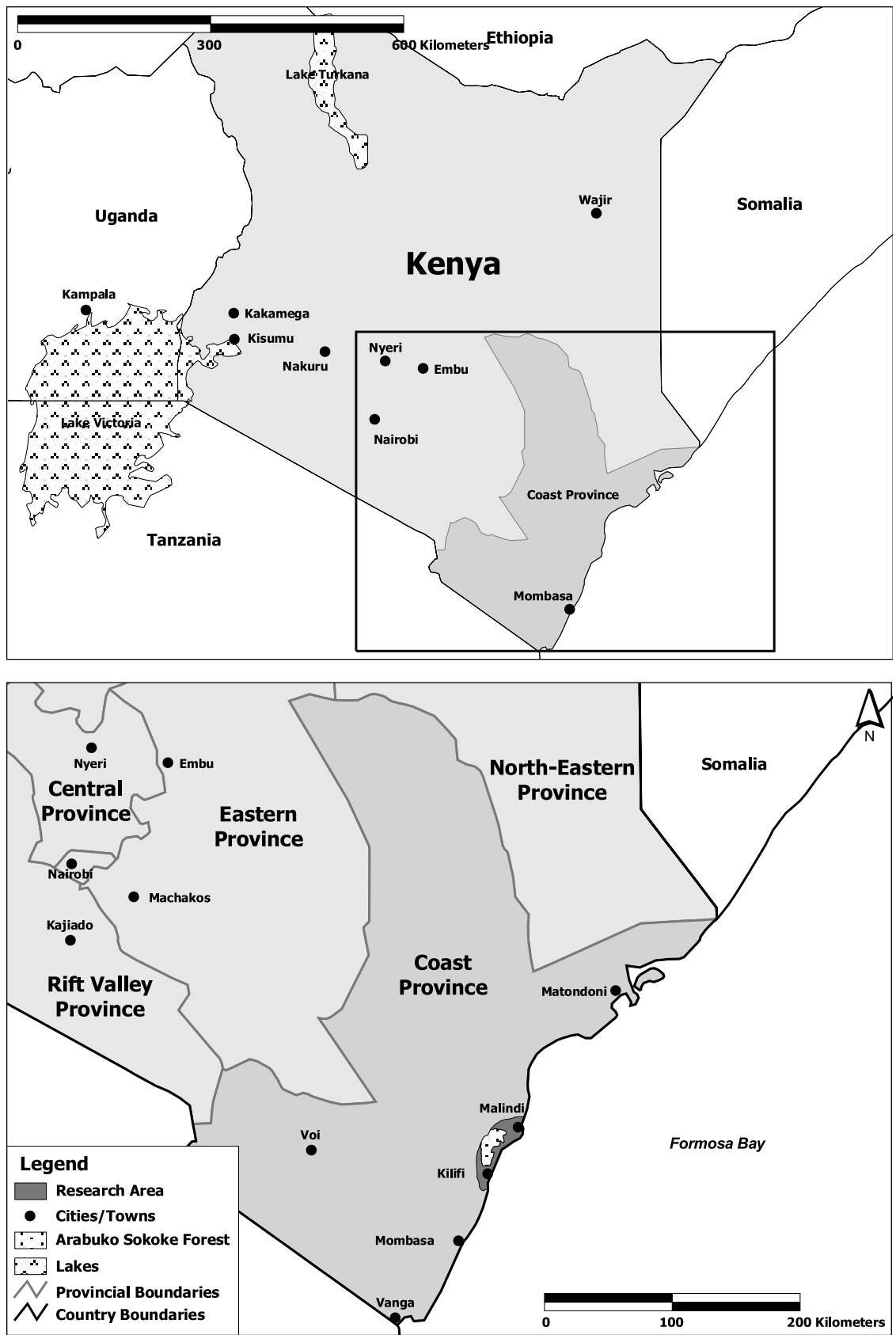

Source: ESRI Data and Maps 2002. 


\section{THE RESOURCE BASE}

\section{Brachylaena huillensis}

Arabuko Sokoke Forest Reserve is the main source of Brachylaena huillensis to woodcarvers within the study area and beyond. It is the last remaining tract of lowland forests in Kenya (MENR 1994). Within Arabuko Sokoke Forest Reserve, Brachylaena huillensis occurs on deep and well developed red volcanic clay loam soils and is closely associated with Cynometra vegetation types, of which two discrete populations in the forest are found. From the forest formations where Brachylaena huillensis are found, wood volumes are estimated at 2.7 $\mathrm{m}^{3} /$ ha in trees of size above $30 \mathrm{~cm}$ diameter at breast height, $50 \%$ of which is assumed to be suitable for carving (KIFCON 1991). In addition, the recruitment potential in these areas was also found to be healthy with over 2,500 seedlings per hectare (KIFCON 1991). However, a rapid decline in numbers of mature Brachylaena huillensis trees through overexploitation for carving is the most serious conservation threat. Although the recommended sustainable annual extractable volume of the species from the forest was estimated at $47 \mathrm{~m}^{3}$ in the late 1980s and early 1990s, licensed extraction of over $400 \mathrm{~m}^{3}$ and illegal harvests of over 2,100 $\mathrm{m}^{3}$ were observed, at which rate the species could be exterminated from the forest in about 17 to 25 years (KIFCON 1991). Better enforcement of policing and protection of the forest in the late 1990s led to controlled harvesting. For example in 1998 to 2000, about $340 \mathrm{~m}^{3}$ Brachylaena huillensis round wood was extracted annually from the forest (Choge 2002).

Brachylaena huillensis is a dioecious tree pollinated by insects. The flowering period tends to follow the rainy seasons and rainfall quantity determines whether the tree will flower or abort the young developed flower buds (Albrecht 1993). Seed viability is extremely low (2\%-10\%) and is completely lost after six months of storage at room temperature (Kigomo 1989; Albrecht 1993). In natural

Photo 1. The raw material (Photo by S.K. Choge)

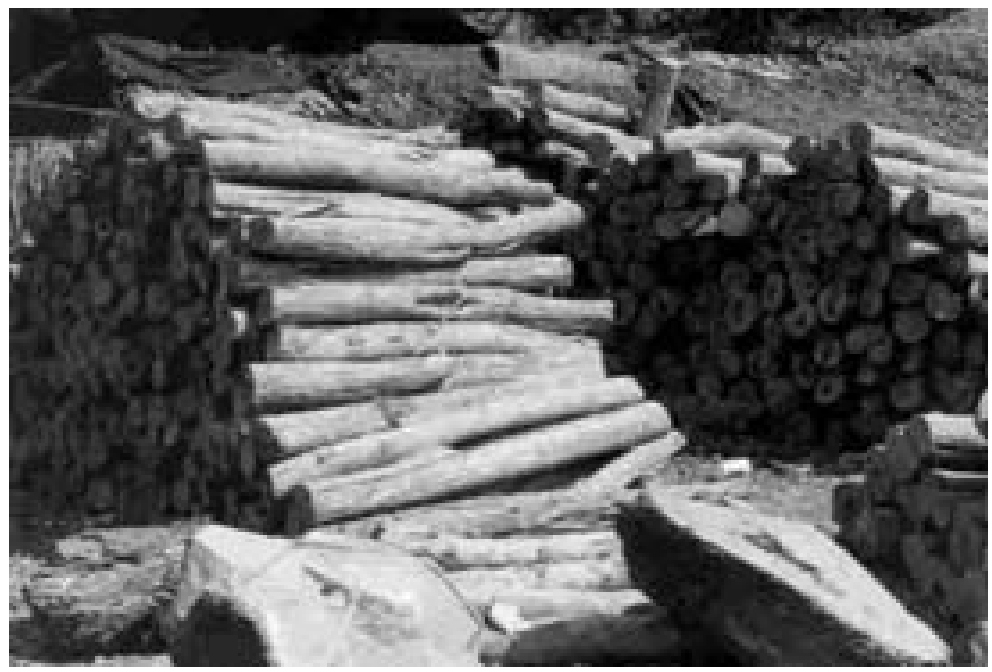


conditions, seed germination is enhanced under conditions with little or no forest floor litter. Areas with substantial litter require unusually high amounts of rainfall for successful germination, conditions which rarely occur naturally and which would require human intervention in order to maximise the recruitment potential.

\section{Azadirachta indica}

The use of Azadirachta indica for woodcarving is a fairly recent phenomenon. The wood was discovered accidentally as other favourable species were getting more difficult to obtain. The climatic conditions along the Kenyan coast are well suited to the growth of the species and Azadirachta indica is now widely spread in the region ${ }^{5}$. Azadirachta indica, an open pollinated tree species, has high abundance, fast growth and high regeneration within the study area. It offers excellent prospects for sustainable utilisation and support to the woodcarving industry. It is naturally dispersed by birds, animals and humans, making it an important vegetation component on farmlands, private compounds and cemeteries within the study area. It is widely regarded as a weed because of its profuse regeneration particularly in disturbed areas where food crops are grown. A recent survey and inventory of Azadirachta indica along the coast showed mature tree densities varying between six trees per hectare and 0.2 trees per hectare as well as high recruitment potential ranging from over 1,000 seedlings per hectare to 100 seedlings per hectare (Choge and Mbuvi unpublished).

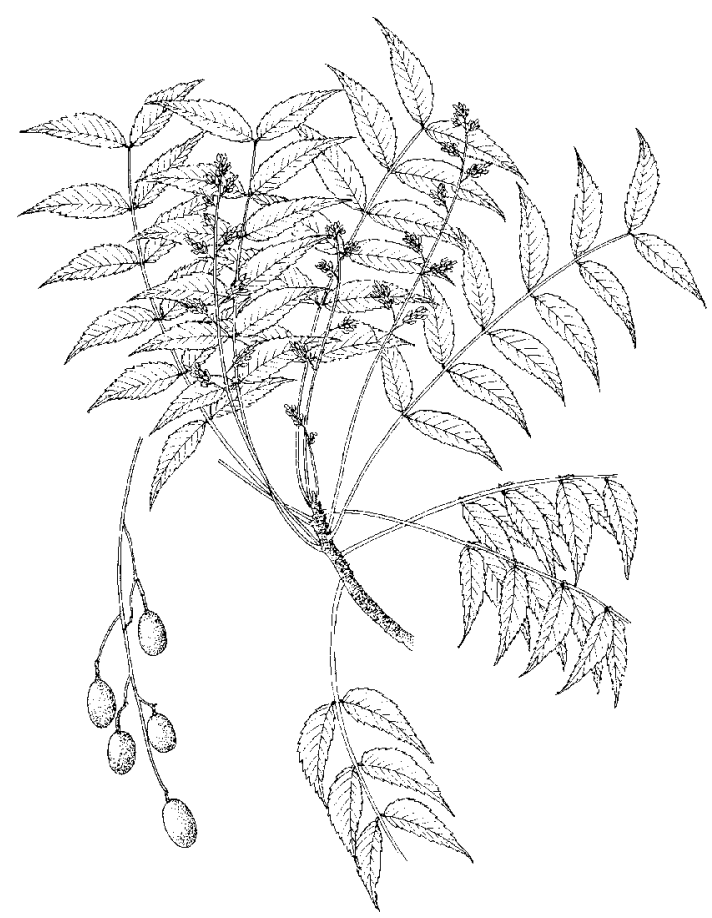

(Azadirachta indica) 
The initial popularity of Azadirachta indica in Kenya was largely due to its curative attributes, hence the common Kiswahili name by which the tree is known, mwarubaini, which means 'reliever of 40 disorders'. Other than in the carving industry, the wood is used for house construction, in the furniture and soap making industries and as cooking energy. In 1998 to 2002 an estimated $200 \mathrm{~m}^{3}$ of Azadirachta indica wood for carving was traded per year within the study area, but the volume has since increased (Choge 2002).

\section{RAW MATERIAL PRODUCERS}

As traditional inhabitants of the study area, the Mijikenda are the main producers and suppliers of carving raw materials traded to the Wakamba carvers, who mostly reside in Malindi town. Although trading in woodcarving raw materials is common, the Mijikenda mainly depend on crop production to meet economic and social obligations (Mogaka 1991; Maundu et al. unpublished). Coconut-based products such as coconut oil, juice, brew, thatching material, baskets, mats, house sweeping brushes and building poles are probably the most popular locally traded products and remain the leading source of income for most households within the study area. The income from traded products, including carving wood, is generally low, ranging from US\$4 to US\$40 (mean of US\$18.5) per capita with a wide disparity in amounts of income per households despite the similarity of sources (Mogaka 1991). Generally, trading in carving wood is not a hugely profitable undertaking to producers because of exploitation by agents and availability of cheap wood mostly stolen from the nearby state forest and communal woodlands. In addition, waste Azadirachta indica wood at construction sites in urban areas is common, harvesters obtaining the wood for free if they clear an area of trees.

The annual volume of carving wood from the study area is estimated at $807.5 \mathrm{~m}^{3}$ worth US $\$ 10,093.75$ (based on producer prices), about $331.1 \mathrm{~m}^{3}$ of which is used within Malindi and $476.4 \mathrm{~m}^{3}$ is taken to carvers outside the study area, mainly to Mombasa (Choge 2002). Benefits from these sales are therefore thinly distributed among the many producers.

\section{THE PROCESSING INDUSTRY}

Woodcarving is an extremely labour intensive activity. A recent study (Choge 2002) shows that although the woodcarving industry in Kenya consumes over $15,000 \mathrm{~m}^{3}$ annually, representing $0.7 \%$ of the total round wood market share in Kenya, the revenue that accrues from the woodcarving industry represents about $25 \%$ of the total revenue from the commercial timber industry whereas the woodcarving labour accounts for more than $40 \%$ of the formal timber industry labour in the country.

Within the study area and elsewhere in Kenya woodcarvers usually work together in large groups or co-operatives to share tools and experiences and profit from the convenience of receiving bulk raw material supplies and marketing of the products. Carvers are experienced in carving only certain products. For example, those experienced in carving animal shapes such as lion, rhino and buffalo do not carve those of giraffes, masks, bowls and spoons. 
The different niches of the carving market are therefore easily met by different members within the group. Certain stages of carving such as filing, sanding and painting require the services, for a fee, of highly experienced members specialised to perform those operations.

\section{Photo 2. Processing (Photo by S.K. Choge)}

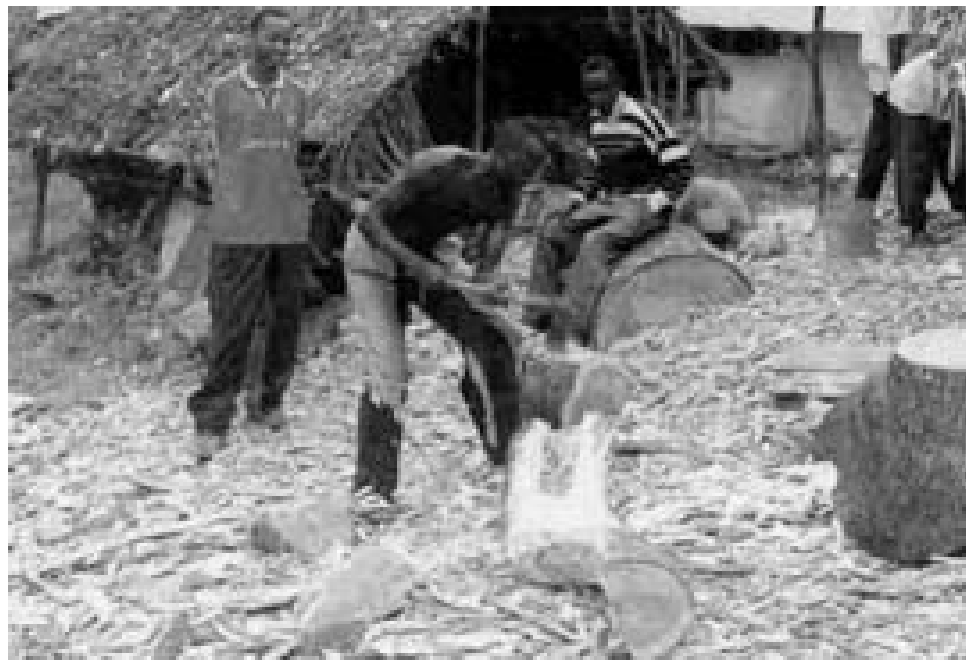

Within the study area about 15 groups exist with memberships ranging from 10 to 700 members. Five groups are located within Malindi town alone. The rest are dispersed all over the study area mostly in villages surrounding Arabuko Sokoke Forest Reserve for easy access to the source of carving wood. They construct temporary sheds in which they carve for several days and then take the semifinished products to Malindi for finishing and sale to tourists and other buyers.

Once delivered to the carving centre, the wood is cross-cut and split to the desired sizes. The individual components are then transformed into standardised animal, human figure, spoon and bowl shapes, or anything else desired by the market, using narrow bladed adzes, files, knives and other tools for precision carving. A completed carving is filled to refine the shape, sanded to smoothen and painted or polished to make it shine and more appealing. In a typical woodcarving centre or group of carvers working together $2 \%$ split the wood, $60 \%$ do the actual carving, $10 \%$ do the filing, $20 \%$ perform sanding and $8 \%$ perform the rest of the operations such as polishing, painting and wiping the finished carvings.

Most of the carvings made are polished with clear vanish to make them shine brightly, even those from woods with good grain patterns such as Dalbergia melanoxylon, Combretum schumanni, Olea europaea, Brachylaena huillensis. Use of black polish is often associated with faking, making carvings from alternative woods look like those from a more desired species, which usually have the characteristic of black heartwood. 
The distribution of costs was found to be the cost of wood (30\%), splitting and cross-cutting of wood (5\%), filing of carvings (8\%), sanding (30\%), painting $(12 \%)$ and polishing (15\%) (Choge 2002). Sanding is thus a critical stage that requires considerable concentration and greatly influences the price of the finished product. In certain cases, for example, when carvers are carving individually outside any groups or co-operatives, all the carving stages are undertaken by one person. However, products made by individuals are often sold in a less finished state, mostly to more established groups or dealers.

\section{TRADE AND MARKETING}

Middlemen or agents dominate the supply of wood to the carvers. The agents, most of whom are members of the resident Mijikenda, often scout for wood among local farmers ready to dispose of mature Azadirachta indica or other carving trees within their farmlands or liaise with wood poachers to deliver the highly priced Brachylaena huillensis from state forest of Arabuko Sokoke. Prices at source were observed to range from US $\$ 12.5 / \mathrm{m}^{3}$ to US\$37.3/ $\mathrm{m}^{3}$ depending on the species and sizes available, the bargaining power of the resource owner and a range of other factors (Figure 2). Brachylaena huillensis and Azadirachta indica, for example, cost about US $\$ 12.5 / \mathrm{m}^{3}$ and are always negotiable. Harvesting charges were estimated at US $\$ 2.5 / \mathrm{m}^{3}$, loading charges

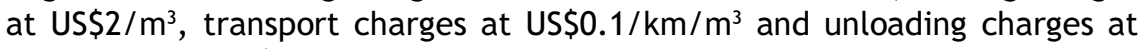
destination at US\$2/ $\mathrm{m}^{3}$ for all the species. At the destination, agents dispose the consignments at wholesale (US\$36/ $\mathrm{m}^{3}$ ) or retail prices $\left(\mathrm{US} \$ 66 / \mathrm{m}^{3}\right.$ for Brachylaena huillensis wood). Usually there is no wholesale trading of Azadirachta indica, with retail prices ranging from US\$30.5/ $\mathrm{m}^{3}$ to US\$50/ $\mathrm{m}^{3}$ (Figure 2).

Carving adds a high value to the wood. For example when medium sized articles $^{6}$ are made, an estimated 600 articles are produced per unit volume (1 $\mathrm{m}^{3}$ of solid wood), selling as low as US\$1 per article (or US\$600/ $\mathrm{m}^{3}$ ) in a domestic market to as much as US\$5.6 per article (or US\$3,600/ $\mathrm{m}^{3}$ ) or higher in tourists markets.

\section{POLICY ENVIRONMENT}

Despite its economic importance, the woodcarving industry in Kenya has not received the same government attention as the larger commercial logging industry. The woodcarving industry is built on a rapidly declining resource base whose control and management, directly or indirectly, largely falls within the state mandate. A recent study (Choge 2002) identified easy access to carving wood from state forests (due to poor management) as one of the main causes of the observed unsustainable utilisation of these prime carving species in Kenya. This situation has contributed immensely to the failure of wood market mechanisms to operate efficiently. As other studies have shown (Repetto 1987; Repetto and Gillis 1988), it acts as a powerful incentive for resource mining if government leaves all the profits of a resource harvest to exploiters without seeking appropriate returns. This is the exact situation regarding the woodcarving industry in Kenya today. 


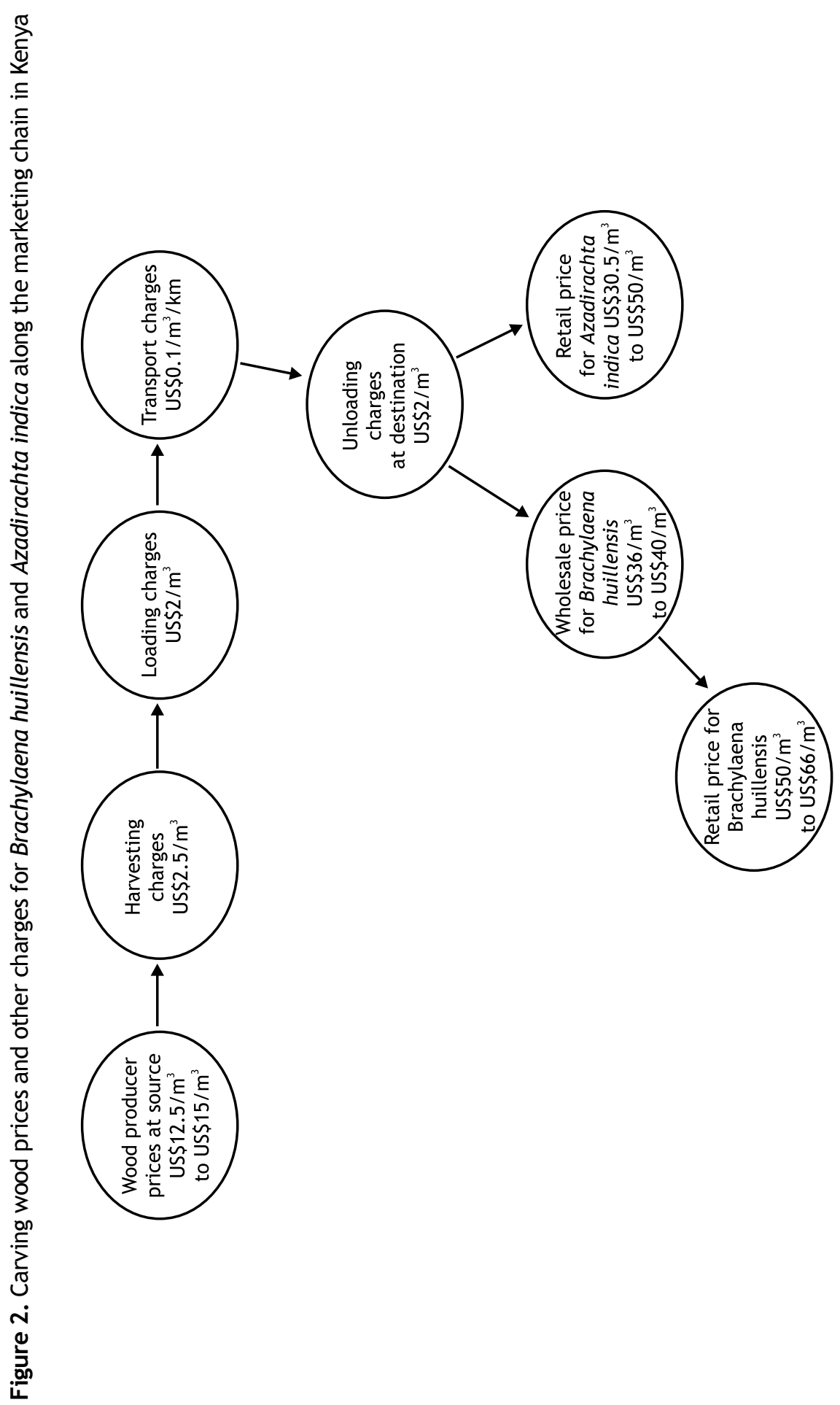


Forest and tree resource exploitation in Kenya is subject to various state laws and policies, including Presidential Decrees and directives that have a direct impact on conservation, utilisation, alteration or removal of forests. Although the regulations are fairly comprehensive, they are spread over various acts which are administered without co-ordination by a wide range of authorised public bodies and individuals, some of whom are even unaware of their responsibilities (MENR 1994). Lack of political will in support of the forest sector in Kenya further complicates the problem where sanctioned forest excisions are rife and where effective deterrents against economic activities that degrade forest resources are lacking. The present exploitation pattern maximises short term private benefits at the expense of long term sustainable utilisation and conservation values. If the policies and laws relevant to the woodcarving industry were administered more efficiently, potential benefits would ensue as listed in Table 1.

Generally, the scattered and poorly harmonised legislation governing utilisation of tree resources in Kenya is being addressed under the Forest Policy and Law. The bill seeks to establish a legal body responsible for environmental conservation, to co-ordinate environmental management between different sectors and to set binding standards and liabilities against environmental damage (Emerton et al. 1998). More importantly, the introduction of stakeholder involvement in decision making, planning and management of existing forest resources, including the local communities and perhaps a supportive political will to implement these changes, is likely to impart positively on the woodcarving industry in Kenya.

\section{TRENDS AND ISSUES}

The wood industry in Kenya is characterised by overexploitation of the favoured tree species from one area to the next, and carvers have to constantly shift to new areas with sufficient raw materials. As the most intensively utilised species, Brachylaena huillensis has been most negatively impacted. Its scarcity has also led to importation of Brachylaena logs from Tanzania. For example, between 1988 and 2000 34\% of the wood used in Kenya was represented by Brachylaena logs smuggled from Tanzania. While alternative species have increasingly been used by carvers, the question remains whether these new woods can support the growing industry. Wood scarcity is affecting not only the woodcarving industry but furniture and other industries as well. This underlines the need for diversification of wood types used in the carving industry and on-farm cultivation of fast growing trees for supply to the woodcarving industry. The switch to alternative carving species and the use of juveniles or wood of unknown carving qualities have introduced a number of challenges, most of them revolving around cracking of finished carvings. This has resulted in enormous wood waste, loss of income and loss in market share. The effects of scarcity the carving wood scarcity in Kenya are shown in Figure 3. Presently there is a general acute imbalance in carving wood supply and demand in the country, manifested through higher prices of wood, longer distances covered by carvers in search of wood, more use of immature wood and a wide range of other varied responses. This shortage has led to increased incidences of 
Table 1. Chronology of major forestry legislation and its potential impact on the woodcarving industry in Kenya

\begin{tabular}{|c|c|c|}
\hline Year & Legislation & Potential impact on woodcarving industry \\
\hline 1957 & $\begin{array}{l}\text { First forest } \\
\text { policy drafted }\end{array}$ & Provides for government involvement in all commercial wood sectors. \\
\hline 1962 & $\begin{array}{l}\text { Forest Act, } \\
\text { Cap } 385\end{array}$ & $\begin{array}{l}\text { Enforced by the Minister for Environment and Natural Resources, it } \\
\text { addresses reservation, protection, management, enforcement and } \\
\text { utilization of forest resources on government lands by mechanisms } \\
\text { such as organized licensing, setting of royalty rates and sale of } \\
\text { Brachylaena and other hardwoods within natural forests. }\end{array}$ \\
\hline 1962 & $\begin{array}{l}\text { Trust Land Act, } \\
\text { Cap } 288\end{array}$ & $\begin{array}{l}\text { Enforced by the Minister for Local Government, it controls unauthorized } \\
\text { occupation and utilization of trees on land not covered by Forest Act; } \\
\text { allows controlled use of Dalbergia, Combretum and others on trust } \\
\text { land. }\end{array}$ \\
\hline
\end{tabular}

1968 National Forest Formulated 10 principles for forest management for the greatest Policy (first session paper) common good and on sustained yield basis. Annual extraction quantities for Brachylaena and other species in state forests could easily have been worked out. Extraction now is based on impression of local officers.

1970 Revision of the Requires authorization of District Commissioner or other persons Trust Land Act, designated by the Local or Urban Councils to grant licenses for extraction Cap 288

1970 Chief's Authority Act, Cap 128 of natural resources on trust lands. Has been greatly abused, leading to uncontrolled poaching of prime species on trust lands in many areas.

Controls use of tree resources on private land and prohibits destruction of vegetation and wasteful use of trees and other products. Low penalties for violations resulted in widespread depletion of Dalbergia and other major species on private lands.

1976 The Wildlife Act, Conservation of forests within National Parks, Games Reserves and Cap 376 Sanctuaries and other forest areas is covered under the memorandum of understanding between Forest Department and Kenya Wildlife Service.

1980 The Agriculture Implemented by Provincial and District Agricultural Committees and Act, Cap 318 Boards, it is meant to prevent destruction of natural vegetation on private land and loss of habitat of important species through bush and tree clearing, but is rarely put into practice.

1981 National Food Policy (fourth session paper)

Underlines the role of forests and trees in climate stabilization and other ecological significance. While sections of the law restrict tree cutting and encourage conservation, the government often goes against this purpose through sanctioning of forest excisions to settle people on the same land meant for conservation.

1986 Presidential ban Completely bans felling of indigenous trees in Kenya with little or no on logging of indigenous timber alternatives, triggering a ripple effect of depletion of resources because of artificial resource shortages. No legislation exists to back its implementation.

1990 The wildlife policy

The policy specifies non-consumptive use of forest resources through benefit sharing of revenue for recreation between the government and local communities. Implementation of the policy in late 1990s has to led to decreased extraction of Brachylaena from Arabuko Sokoke forest.

1994 Revised Forest Addresses new concerns and realities by envisaging greater involvement Policy of local communities and other stakeholders in management decisions of forest and natural resources, benefit sharing, private investments in tree growing, non-consumptive use of forests, etc. 


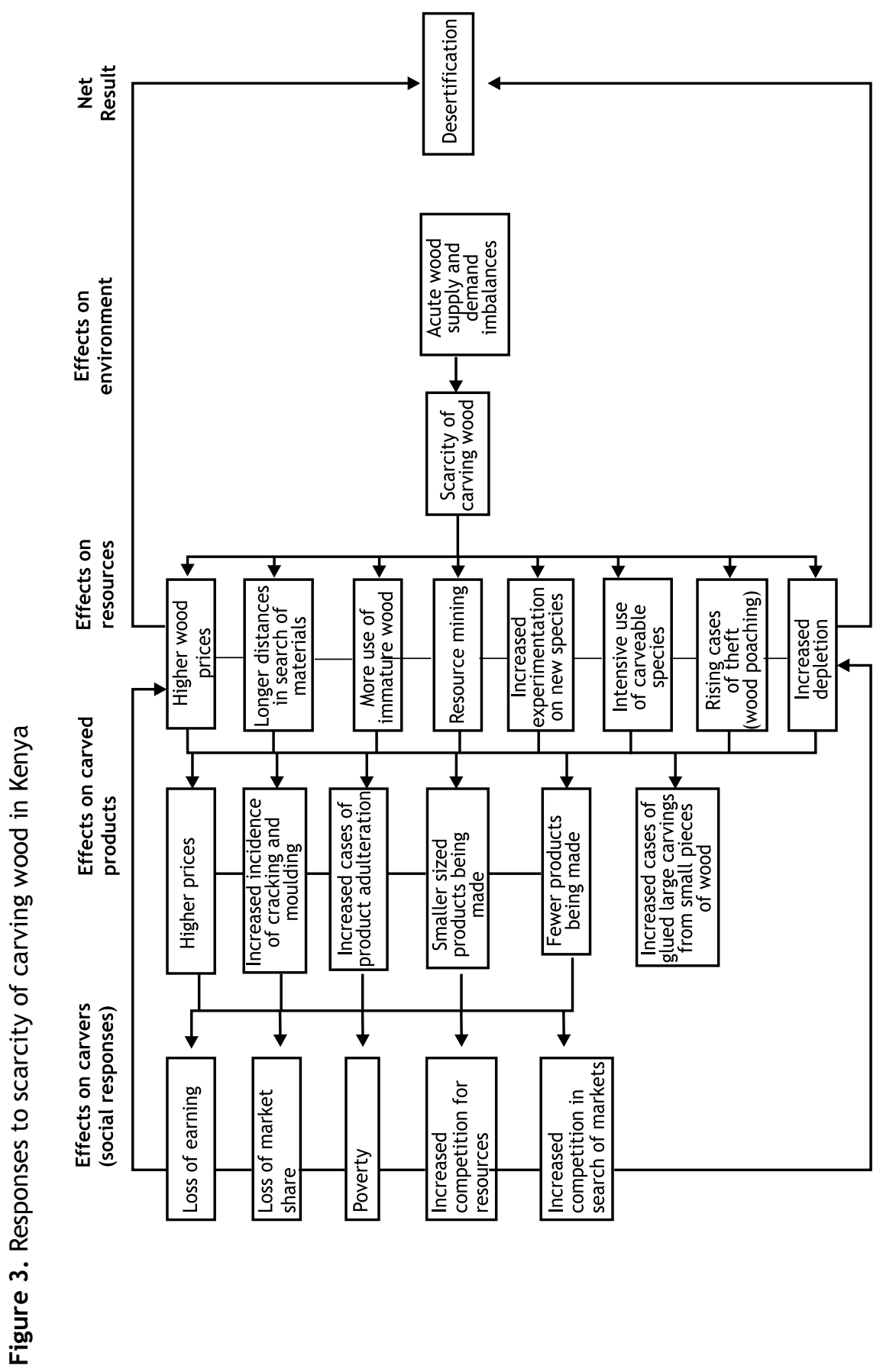


adulterated carvings, cracking and making of smaller sized products among other workarounds (Figure 3). These effects need to be urgently addressed in the interest of conservation and to provide an assurance for the livelihoods of carvers and their families.

The growth of the industry in terms of new entrants has resulted in many management problems within the existing groups and co-operatives, already riddled with poor management, incompetence and corruption. The existence of many independent carving groups, co-operatives and individuals all competing for a place in the same carvings market has created a fertile ground for destructive competition for marketing of carvings so that products are generally priced below the realistic market price, which ideally should reflect the prevailing situation of wood scarcity. Low product prices result in low incomes and enhance the chances of resource mining as carvers make many more products to meet basic family expenses and other obligations.

A recent study (Choge 2002) has shown that a carver who is a member of the co-operative system in Kenya is able to make at least 200 complete medium sized articles per month and trade about 50 of them, earning a net income of at least US\$1,125 per month for sales made through the co-operative (Table 2 ). The rest of the articles (150, or $75 \%$ ) may remain unsold for several months or even years, hence tying up capital for considerable periods. However, most of the carvers prefer to sell surplus goods to middlemen and other dealers outside of the co-operatives (who offer instant cash), usually for a fraction of the actual price (as low as US\$1 to US\$1.5 instead of the co-operative price of US\$5.6 per product), for an additional US\$150 per month if they are lucky.

Table 2. Marketing scenario of carvings under the existing co-operative management system in Kenya

\begin{tabular}{lc}
\hline Approximate number of & 200 medium sized carvings \\
products made per month & 1,125 \\
Value of products (US\$) & 250 \\
Cost of production (US\$) & 743.8 \\
Less taxes (15\%) (US\$) & 669.4 \\
Less marketing charges (10\%) (US\$) & 602.4 \\
Less other overheads (10\%) (US\$) & 150.6 \\
Value of sales made (25\%) (US\$) & 451.8 \\
Tied up capital (75\%) (US\$) &
\end{tabular}

Generally, the government has not been directly involved in the woodcarving industry, particularly regarding policy instruments on regulation of wood supply, marketing of products, formation of co-operatives and other incentives towards sustaining the industry-areas that obviously lie within its mandate.

\section{UNDERLYING ISSUES}

The accelerating decline of the world's forests is viewed as one of the greatest threats to conservation of biodiversity (Myers 1996). Already there is growing 
shortage of specialised hardwoods from the tropics as a result of overharvesting (Sharman 1992; Barbier and Burgess 1994), imposing severe economic consequences on sectors that depend on these hardwoods. Woodcarving, now commonplace in may countries in Africa, is experiencing a loss of self-sufficiency in favoured wood species (Cunningham and Choge in press).

The woodcarving industry in Kenya has received some national and international attention in recent years when a number of studies under the People and Plants Initiative addressed concerns about lack of sustainability. Some of the key recommendations from these initiatives regarding woodcarving follow.

\section{Supply dynamics of carving wood}

- Inventories of available stocks of hardwoods and alternative species are needed for all the existing sources as a guide to planning, consumption projection, determination of off-take volumes and other aspects related to policy formulation on utilisation.

- A temporary ban on extraction of prime carving hardwoods from more affected natural forests is required until stocks recover.

- Use of alternative woods needs to be encouraged and aggressively promoted as a buffer against loss of earnings by carvers.

- Alternative woods need to be seasoned to maintain confidence of buyers and market share.

- Private investment in cultivation of fast growing alternative species should be encouraged.

\section{Marketing of carving wood}

- Better enforcement of extraction restrictions from natural forests and revision of royalty rates to reflect wood scarcity are needed. Royalty rates should be based on the market price of woodcarving products, not sawn timber. This shift would widen the revenue base and minimise competition for prime carving species by other sectors.

- Woodcarvers, and not agents, should be licensed to extract carving wood to minimise wood price distortion and resource mining and to increase income for carvers.

- Resource owners should consider starting associations to counter exploitation by agents and other wood dealers.

- There needs to be professional management of the woodcarving cooperatives for enhanced transparency in financial dealings with members and aggressive products marketing strategies.

\section{Economic returns of carving}

- There is need for improved wood recovery through use of better tools, improved designs of carvings and use of seasoned woods. Training on these aspects is essential. 
- Carvers should be encouraged to make fewer products of higher quality and use less wood in the process. Prime wood of high quality should be carved only by qualified carvers to minimise wastage.

- There is need for independent carvers to join co-operatives to eliminate destructive competition in marketing and pricing of products.

\section{Policy aspects}

- There is need to harmonise, co-ordinate and enforce more strictly the extraction and utilisation of carving wood from state forests and private farmlands.

- There needs to be a revision of penalties for illegal extraction of wood so as to be more in line with the value of the resources.

- Community involvement in management, decision making and sharing of benefits from forests needs to be addressed.

- Government and donor support is required to sustain the woodcarving industry in Kenya.

\section{CONSERVATION AND DEVELOPMENT LESSONS}

The problems of wood scarcity in the woodcarving industry and the apparent lack of concern on the part of the carvers about the source of their material poses considerable conservation and development challenges. Carvers see themselves as detached from the resources and most of them have a culture of working day-to-day without much concern for the future. They still believe that wood will always be available as it has always been, and planning for future resources is a problem for other people. This mindset has been demonstrated through the lack of enthusiasm in tree nursery development and the initial resistance to the use of alternative carving woods. However, through awareness creation coupled with acute shortages of favoured species, these perceptions are gradually beginning to change, but more efforts and resources are needed to educate carvers on these issues.

Useful marketing tools that have been identified as potential incentives for a switch to the use of alternative species are eco-labeling of products made from alternative woods and certification of plantations or forestry systems where these woods are obtained. While these efforts are still in their infancy, it is envisaged that the growing consumer interest in ethical buying of carvings from Kenya will greatly influence the conduct of the woodcarving industry. The use of endangered hardwoods will likely be phased out and alternative woods will take their place.

The problem facing the woodcarving industry in Kenya remained officially unnoticed for many decades and became apparent only in the early 1990s through the efforts of the World Wide Fund for Nature and the United Nations Educational, Scientific and Cultural Organisation through their People and Plants Initiative in collaboration with Kenya Forestry Research Institute, National Museums of Kenya, Mennonite Central Committee (MCC) and Kenya Crafts Cooperative Union (KCCU). Policy issues aimed at making the industry sustainable have since been addressed and some remedies are already being implemented on a pilot basis. These include, for example, the tree nursery 
development at woodcarving co-operative premises. The idea behind tree nurseries is to encourage carvers to plant carving trees on their own land for future use or for trading to other carvers. Four tree nurseries are already in operation and supported by the MCC in collaboration with the Micro-Enterprises Support Programme (MESP, under the European Union) and the Ten Thousands Villages Programme. MCC is also working closely with woodcarvers to dry and season the carving wood and products, develop and train carvers to develop new product designs and to be more creative and innovative.

Through the People and Plants Initiative, a pilot certification program for Azadirachta indica wood sourced from farmers around Malindi (the study area) is being developed in collaboration with the Forest Stewardship Council and Smart Wood Program of the Rainforest Alliance and Soil Association. Appropriate eco-labels for carvings made from Azadirachta indica are also being considered. Generally the impact of these programmes is such that the international markets are learning much about the carving wood types available in Kenya and are increasingly becoming conscious about conservation and hence the need for a switch to buying products from sustainably managed and guaranteed sources.

The issue of resource development and scarcity aside, the heart and breath of a sustainable woodcarving industry in Kenya largely hinges on a centralised form of organisation of carvers in which their interests, and those of the industry generally, are easily met. Well organised associations are likely to take full advantage of the economies of scale in resource acquisition, access to credit facilities, product marketing, standardisation of products and prices, customer contacts and relations, customer confidence and the ease of donor interventions among a wide range of other benefits. The setting up of the KCCU was intended to do exactly that, but it is now overly mismanaged to the extent that it is becoming increasingly irrelevant as carvers opt out to join other groups or work independently. Lack of transparency in dealing with its supportive development partners, donors and other organisations working closely with it has been a great disservice to the carving community in recent years and has caused major problems between them. This should not be allowed to continue.

The greatest dividends of the remaining organised associations are likely to be realised through the improved marketing of carvings. The impact of poor marketing under the current management scenario within the existing co-operatives was demonstrated as shown in Table 2 , with $75 \%$ of the products remaining unsold ${ }^{7}$.

These findings show that there is everything to be gained by remaining organised and everything to be lost by encouraging destructive competition. Owing to the current problems facing the co-operatives and the union, the carving community and their leaders need to go back to the drawing board, do some soul searching and formulate lasting solutions for their unity of purpose in response to the changing trends in global economic climate, environmental order and consumer behaviour and demands. In the interim, the bottom line is that education of carvers about the country's rapidly disappearing forests is crucial, and more importantly, their individual and collective contribution towards developing a sustainable industry to complement the efforts already in place which exist for only one reason-to protect their interests and those of their dependants. 


\section{ACKNOWLEDGEMENTS}

The author thanks the World Wide Fund for Nature and the United Nations Educational, Scientific and Cultural Organisation's People and Plants Initiative for the kind support of the study and the Center for International Forestry Research for initiating and facilitating the comparative studies of similar cases in the use of non-timber forest products.

\section{ENDNOTES}

1. Kenya Forestry Research Institute, P.O Box 20412 Nairobi, Kenya. E-mail: kefri@arcc.or.ke

2. Exchange rate US\$1 = Ksh80.

3. Export data for Kenyan carvings show that the main destinations are USA (47\%), Japan (10\%), Spain (7\%), South Africa (7\%), Germany (6\%) and United Kingdom (6\%) (Obunga unpublished).

4. Brachylaena huillensis and Azadirachta indica accounted for $57.4 \%$ and $17.2 \%$ respectively of all the wood used in the industry in Kenya in the years 1998 to 2000 (Choge 2002).

5. The definite date of introduction of Azadirachta indica to Kenya is unknown, but it is widely believed to have been introduced to the country by migrant Indian workers who first settled in Kenyan Coast Province during construction of the Kenya-Uganda Railway in the late nineteenth century.

6. A medium sized article measures about $15 \mathrm{~cm}$ to $20 \mathrm{~cm}$ in height. Articles this size are the most popular and constitute $70 \%$ to $80 \%$ of the products made by carvers.

7. Trade statistics and estimates made using wood consumption trends in Malindi and Mombasa carving centres showed that on average $70 \%$ of articles produced by members are sold outside of co-operatives.

\section{REFERENCES}

Albrecht, J. (ed.) 1993 Tree seed handbook of Kenya. GTZ Forestry Seed Centre, KEFRI, GTZ, Nairobi. 264p.

Barbier, E.B and Burgess, J. 1994 Timber trade and tropical deforestation: global trends and evidence from Indonesia. Department of Environmental Economics and Environmental Management, University of York, UK.

Choge, S.K. 2002 Study of economic aspects of the woodcarving industry in Kenya: implications for policy development to make the industry more sustainable. M.Sc. Thesis, University of Natal, South Africa.

Cunningham, A.B and Choge, S.K. (in press) Crafts and conservation: the ecological footprints of international markets on African resource. Advances in Economic Botany.

Emerton, L., Ndugire, N. and Bokea, C. 1998 The costs of environmental degradation to the Kenyan economy: a review of literature. Policy Research and Development Services, Nairobi.

Elkan, W. 1958 The East African trade in woodcarving. Africa 57(2): 314-323. Government of Kenya. 2000 Economic survey 2000. Government Printer, Nairobi, Kenya. 
Government of Kenya and UNICEF. 1990. Socio-economic profiles: Kwale and Kitui districts. Government Printer, Nairobi. Kenya.

Kenya Indigenous Forest Conservation Programme. 1991 Kenya Indigenous Forest Conservation Programme. Forest Inventory Reports (series). Forest Department, Nairobi, Kenya.

Kigomo, B.N. 1989 Studies on regeneration and growth characteristics of Brachylaena huillensis in semi-deciduous tropical forests of Kenya. Ph.D. Thesis, University of Oxford, UK.

Ministry of Environment and Natural Resources. 1994. Socio-economic and participatory aspects of forestry development. Forest Department, Kenya. Government Printer, Nairobi, Kenya.

Mogaka, H. 1991 Local utilization of Arabuko Sokoke Forest Reserve. KIFCON and KEFRI, Nairobi. 100p.

Myers, N. 1996 The world's forests: problems and potentials. Environmental Conservation 23(2): 156-168.

Repetto, R. 1987 Creating incentives for sustainable development. Ambio 16(23).

Repetto, R. and Gillis, M. 1988 Public policies and misuse of forest resources. Cambridge University Press, Cambridge.

Sharman, N. 1992 Managing the world's forests: looking for balance between conservation and development. Kendall/Hunt Publishers, Dubuque, lowa.

Troughear, A. 1984 Akamba carving: art or industry? Kenya past and present. Africa 19: 15-25. 


\title{
Chapter 10
}

\section{Carved wooden drums and trade in Mpigi district, Uganda}

\author{
Patrick Omeja ${ }^{1}$, Joseph Obua ${ }^{2}$ and Anthony B. Cunningham ${ }^{3}$
}

\begin{tabular}{llllll}
\hline Common names & $\begin{array}{l}\text { Part of the } \\
\text { resource used }\end{array}$ & Management & $\begin{array}{l}\text { Degree of } \\
\text { transformation }\end{array}$ & $\begin{array}{l}\text { Scale of } \\
\text { trade }\end{array}$ & $\begin{array}{l}\text { Geographic } \\
\text { range }\end{array}$ \\
\hline $\begin{array}{l}\text { Mutati, Parasol tree, } \\
\text { Setaala }\end{array}$ & Wood & Wild & Medium & International & Medium \\
\hline
\end{tabular}

\begin{abstract}
In contrast to commercial woodcarving in Fiji, India, Kenya and Vietnam, where hardwood species are favoured, the Ugandan carving industry uses softwood species, primarily trees in the fig family (Moraceae). The major items made are traditional musical instruments such as drums, harps, tube-fiddles and xylophones. These are exported and sold to tourists as well as being sold locally to schools, churches and musical groups, which keep Uganda's vibrant music tradition alive.

This chapter is based on studies undertaken in Mpanga, Degeya and Lufuka forest reserves and the drum making stalls in Mpigi district in central Uganda. A specific focus of the study was the importance of drum making, the impact of drum making on the population structure of species used, their regeneration rates and the current demand for the wood of these species.

It was found that the reliance on woodcarving in Mpigi district is significant. Drums in particular had great significance in alerting people to meetings, weddings, funerals, dancing competitions, and as gifts during give-away ceremonies. Despite all the potential benefits, carvers do not have associations through which to act quickly and effectively at the national level. The results also showed that the intensity of use and concentration on only a limited number of most favoured tree species have led to overexploitation. To guarantee future supply of wood, a move to on-farm production of the desired species such as Polyscias fulva is recommended.
\end{abstract}




\section{INTRODUCTION}

The wood carving industry in Uganda produces mainly musical instruments while other carvings such as animals are imported from neighbouring Kenya. Unlike in many African countries, where the use of traditional instruments has given way to electronic sound and Western type musical instruments, most areas in Uganda still have a rich cultural instrument tradition. In central Uganda, wood carving is one of the important economic activities offering full time employment to over 250 households in Mpigi district alone (Samula 2001). Although it is a means of making a living, it is also a way of keeping culture and indigenous knowledge alive. Wood carvers in central Uganda make musical instruments such as short and long drums, bow harps and xylophones. This chapter presents the findings of a study on the short and long drums, the predominantly carved instruments in the area. The centre for making and marketing of carved wooden drums is Mpigi district in central Uganda, especially around Mpigi town. The stalls dotted along the Kampala-Masaka highway and in Kampala city are basically sale outlets for drums.

The wood used for making these instruments is obtained from natural forests, which have been harvested for a long time (Hamilton 1984; Taylor et al. 1996). While subsistence production rarely has negative ecological or social impacts, the same is not true of commercial trade in these wooden drum carvings made from favoured tree species which in most cases take over 10 years to reach mature and harvestable sizes of $20 \mathrm{~cm}$ diameter at breast height.

Commercial production of wooden drums in this area, where there are few other economic opportunities, has become an important means through which poorer rural people enter the cash economy (Samula 2001). Increase in the drum making business in Mpigi district has raised concern about the population structure and supplies of the tree species being used, the socio-economic impacts and the ecology of the natural forests where they occur and are exploited. As a result, two studies were undertaken between August 1998 and January 2000 to determine the population structure of the tree species used, their distribution, regeneration rates and the current demand and supply.

\section{DESCRIPTION OF THE STUDY AREA}

\section{Location and physiognomy}

Mpigi district is located between latitudes $00^{\circ} 00^{\prime}$ and $00^{\circ} 30^{\prime} \mathrm{N}$ and longitudes $31^{\circ} 45^{\prime}$ and $32^{\circ} 31^{\prime} \mathrm{E}$ (Figure 1). The altitude range is $1,150 \mathrm{~m}$ to $1,270 \mathrm{~m}$ above sea level. The area occupies the lower slopes and floor of Nabukongole valley, which has a permanent stream that drains southwards into Lake Victoria (Howard 1991). The underlying rocks are of Pre-Cambrian origin belonging to the Karagwe-Ankolean system and consisting of granitoid gneisses and schists (Lingdale-Brown 1960).

\section{Climate}

Mpigi district lies outside the influence of early morning storms but receives afternoon rainfall. The rainfall has bimodal distribution, that is, March to May 
Figure 1. Map of the case study area
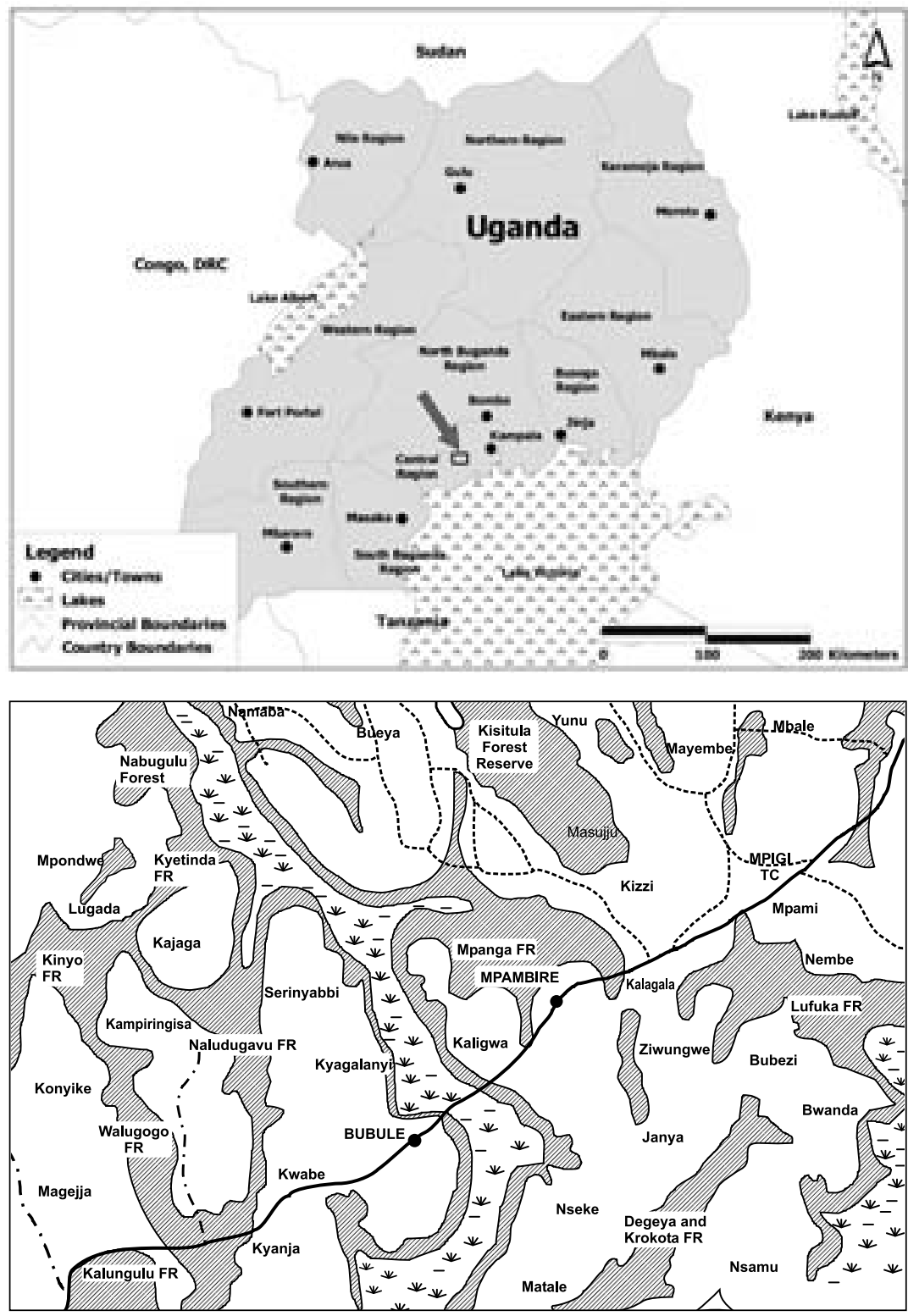

\section{Legend}

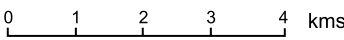

\footnotetext{
VIIUIID Forests

Masaka-kampala main road

- - - - M Murram roads

Dry weather roads

Mpambire and bubule drum making points

娄_*E Papyrus swamp
}

Sources: ESRI Data and Maps 2002 and Samula Aisa and Omeja A. Patrick 2003. 
and September to November, with a principal peak in April and a minor peak in November. The annual rainfall is $889 \mathrm{~mm}$ to $1,676 \mathrm{~mm}$. Minimum temperature ranges from $11.7^{\circ} \mathrm{C}$ to $16.1^{\circ} \mathrm{C}$, maximum from $26.1^{\circ} \mathrm{C}$ to $33.3^{\circ} \mathrm{C}$ (Howard 1991 ; NEMA 1997).

\section{Vegetation and fauna}

The forests in Mpigi district may be broadly classified as medium altitude moist evergreen Piptadeniastrum-Uapaca forest and medium forest/savannah mosaic. The flora of these reserves is not especially diverse and relatively few rare or restricted range species are present (Howard et al. 1996). The forests have close affinities with certain Congo and west African forest types in general appearance and structure, and practically all genera found in these areas are also found in the west. The vegetation is composed of medium altitude moist evergreen forest to high altitude forest (Hamilton 1984), Celtis, Morus, Aningeria and Bosqueia being the common tree species. According to Howard (1991), 345 plant species (28\% of Uganda's total) have been recorded in this area. The forests also have a diverse mammalian and avian fauna such as black-billed turaco (Tauraco schuetta), black and white casqued hornbill (Bycanistes subcylindricus), red tail monkeys (Cercopithecus ascanius), and black and white Colobus monkeys (Colobus guereza).

\section{Study forests}

Three forest types having different management histories were selected for this study. One is Lufuka forest, located $1 \mathrm{~km}$ south-east of Mpanga forest. It has experienced high human activity by the immediate local community and people elsewhere. Activities like extraction of logs for drum making, charcoal burning, pit sawing with no or little restriction coupled with its location near the main road has made the forest highly degraded. The second, Degeya forest, is located $4 \mathrm{~km}$ south of Mpanga forest reserve. Long distance from the drum making community and vigilant forest law enforcement by forest guards and local leaders have left this forest relatively less disturbed. The third area, Mpanga forest reserve, has been minimally disturbed because of conservation concerns and therefore was designated as a research forest by the Forest Department in 1951.

\section{GENERAL METHODS}

\section{Study design}

Socio-economic and forest inventory methods were used to collect data. During the social survey a range of interest groups involved in drum making were interviewed using structured and unstructured questionnaires to collect information on the sources of wood used for making drums, the tree species used and those preferred, their availability (supply), distribution and fluctuation in abundance. The forests were surveyed to collect data on population structure, diameter at breast height and distribution of tree species that were 
highly demanded by the drum makers. Demand for carved wooden drum frames by drum makers was assessed using data from Samula (2001). Survey data from the major drum producing area of Mpambire village were used. Demand was assessed by examining the weekly volume of wood required by each drum making stall and the total number of such stalls in the Mpambire area.

\section{RESULTS AND DISCUSSIONS}

\section{Drum making history and trade}

Oral accounts by Kibira, Kawuma and mzee 4 Gayira indicated that drum making is a specialised branch of woodwork that also requires knowledge of leather working. The drum making industry in central Uganda, according to them, evolved out of the carving traditions of Baganda people from Masaka district. These people migrated to central Uganda in search of land and settled in Mpambire, $40 \mathrm{~km}$ west of Kampala. They started making drums for the kabaka (traditional king), abakungu (resident district commissioners) and the abatongole (local councillors).

Trade in drums, however, began internally within villages in Mpigi, where heads of families bought drums as symbols of leadership and also used them for informing people about important events and local meetings. As this business was promising, in the early 1970s some stalls were established along the Kampala-Masaka highway in Mpambire to meet demands from Asians living in Kampala. By the mid-1970s the roadside businesses had attracted Akamba businessmen from Kenya, and this marked the onset of drum trade at a regional scale. The Akamba travelled on foot to central Uganda, gathered a number of musical instruments and returned to Kenya.

Photo 1. Short drums of various sizes (Photo by P. Omeja)

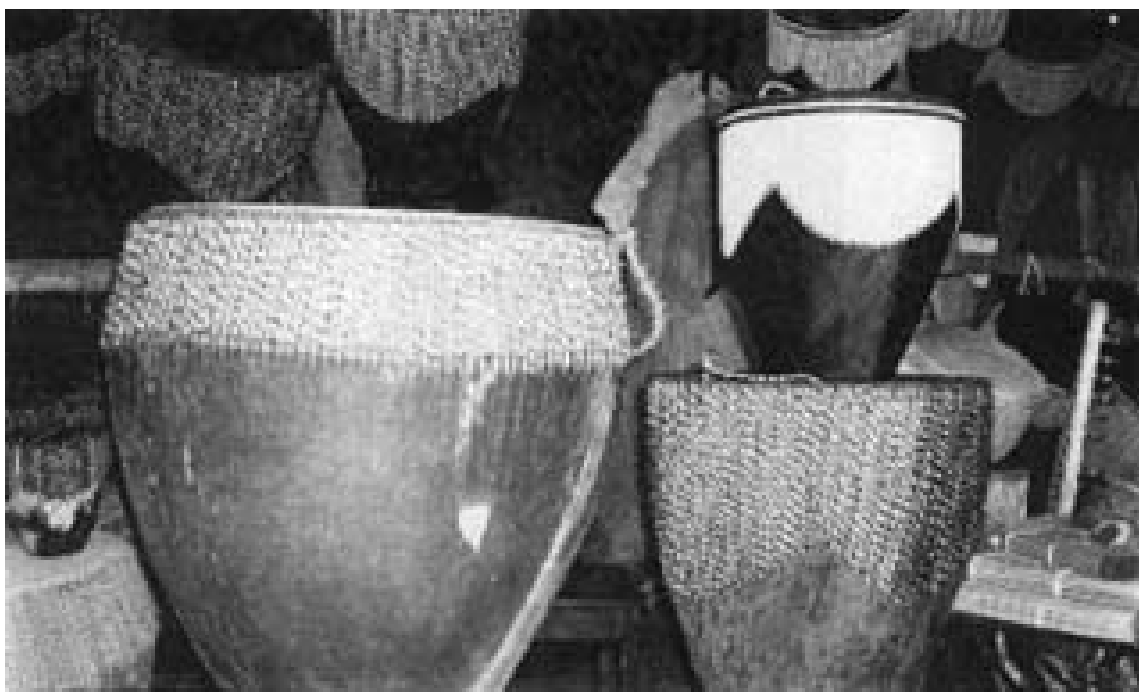


Photo 2. Tables with musical instruments in the background (Photo P. Omeja)

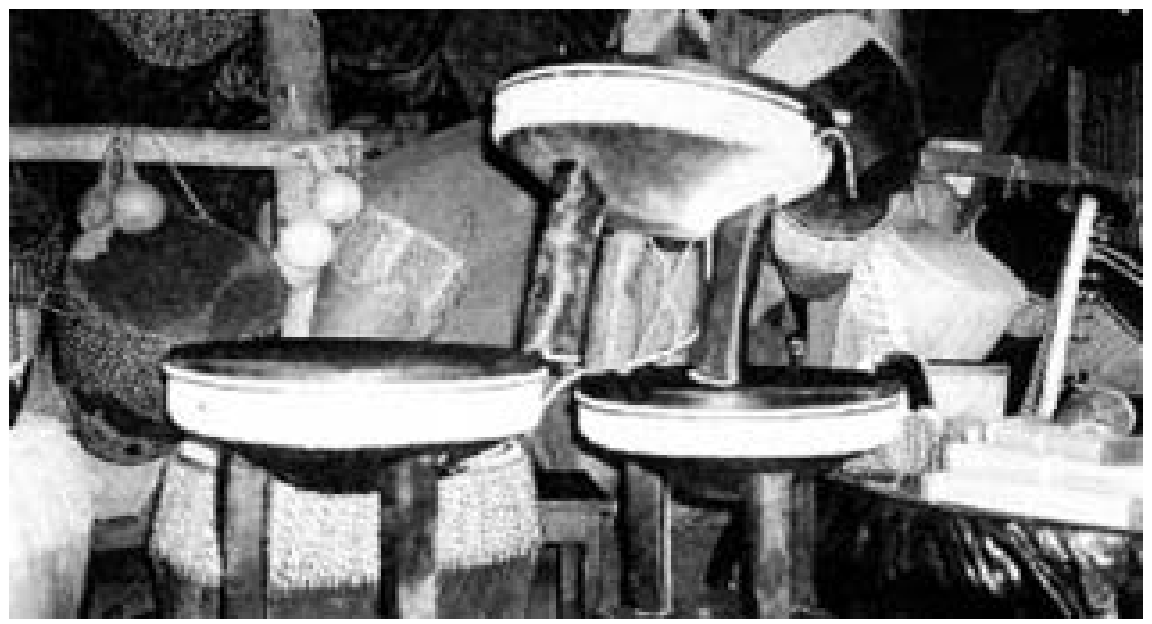

In the late 1970s, the Ugandan government got involved in this business and opened the Uganda Craft Shop (now The Grand Imperial Hotel). Government interest arose because of the good foreign market at that time and the increased tourism influx. This boom, however, did not last long because of the general collapse of the Ugandan economy following the military coup in 1971 and the expulsion of Asians in 1972. But these events did not mark the end of the drum industry because the Akamba remained active in the drum trade up to 1979. Since the early 1990s, the industry has expanded, most of the products being bought by tourists. Political stability and economic recovery since 1986 and growth in the tourism industry have helped to sustain the drum trade in Uganda.

\section{Benefits from the drum making industry}

The most important impact of drum making has been its ability to generate gainful employment for over 300 people, especially remote area dwellers and those with little or no formal education. Between September 1999 and October 2000 drum sales from this area alone amounted to US\$11,000. Drum making is an important income earning opportunity for local people, especially since agricultural productivity was low in the last decade because of coffee wilt disease and banana weevil attack and there are few income generating options available to them.

The second important benefit to producers is of social and psychological nature. The creative and flexible nature of drum making bestows a variety of personal benefits including a sense of identity, self-reliance, self-awareness, empowerment, confidence, respect and cultural self-esteem. Drum making has elevated the social status of individual producer households. For example, two old men, mzee Gayira and mzee Miiro, are known in the area as the first people to develop drum making culture and trade in Mpumudde area. Various individual attributes have also been enhanced including entrepreneurship, initiative, leadership, risk-taking and management skills. 
Drum making has also provided gainful employment to local people, hence contributing to social stability. In particular it has helped to reduce rural exodus and associated social problems, which in turn has reinforced family cohesion and stability.

In addition, drum making has helped strengthen the cultural traditions for both individuals and society. Drum makers in Mpigi supply drums to the National Theatre in Kampala. Primary and postprimary schools participating in national cultural festivals buy the drums. As a result drum making offers an opportunity for cultural self-examination and awareness and preserves local culture. The cultural aspect of the drums inherently helps the government in its policy to make culture accessible as 'living and evolving tradition'. Through drums the promotion of cultural activities and collection and distribution of cultural information adds to positive cultural identity, enhances national identity, national building and international co-operation.

\section{The resource base}

Drum making is based on extraction and processing of stems of softwood species since timber harvesters have depleted the desired hardwoods in the 1980s, when there was a breakdown in law and order. Utilisation of softwoods implies that there are few competing uses for the resource. Although many species can be carved into drums, wood qualities of a relatively small range of species have favoured only a few species over others (Table 1). In the past, special types of drums for the kabaka were made exclusively from muvule (Milicia excelsa) trees (Lush 1935), while other drums were, and still are, made from other suitable timbers depending on the size of drum and the quality of the wood.

Table 1. Tree species used in the drum making industry

\begin{tabular}{lll}
\hline Scientific name & Local or & Family \\
& Luganda name & \\
\hline Alstonia boonei & Musoga & Apocynaceae \\
Antiaris toxicaria & Kirundu & Moraceae \\
Bosquiea phoberos & Mugwii & Moraceae \\
(Trilepsium madagascariensis) & & \\
Canarium schweinfurthii* & Muwawu & Burseraceae \\
Cordia africana* & Mukebu & Boraginaceae \\
Cordia millenii* & Mukebu & Boraginaceae \\
Erythrina excelsa & Bajangabo & Leguminosae \\
Ficus exasperata & Luwawu & Moraceae \\
Ficus natalensis & Mutuba & Moraceae \\
Ficus mucuso & Kabalira & Moraceae \\
Ficus sur & Kabalira & Moraceae \\
Ficus sycomorous & Mukunyu & Moraceae \\
Funtumia africana & Nkago & Apocynaceae \\
Maesopsis eminii* & Musizi & Rhamnaceae \\
Milicia excelsa* & Muvule & Moraceae \\
Morus mesozygia* & Mukoge & Moraceae \\
Musanga cecropioides & Namaguro & Moraceae \\
Polycias fulva & Setala & Araliaceae \\
\hline
\end{tabular}

* Reserved species occurring in some parts as pure stands.

Source: Samula 2001. 
Generally the wood must be:

- easily workable, i.e., easy to hollow out and carve into a desired drum shape without damage;

- light in weight because drums are portable instruments;

- easy to sun dry without warping and cracking;

- of straight, unblemished boles free of branches;

- available in the vicinity; and

- resistant to insect and pest attack (especially wood borers).

It was found that harvesting of trees for drum making in two of the study forests, viz., Lufuka and Degeya, was not sustainable. The volume of round wood used by drum makers in 1999 was $1,113.76 \mathrm{~m}^{3}$, whereas the calculated combined annual allowable cut volume was $502.9 \mathrm{~m}^{3}$. These figures imply an excess demand of $610.8 \mathrm{~m}^{3}$ of wood for drum making. The excess demand against a low annual allowable cut coupled with a history of heavy exploitation and poor recruitment pattern clearly do not make drum making a viable enterprise for meeting the market demand in the medium to long term unless on-farm tree planting of the desired species is promoted to supply the wood.

Trees were already being harvested from the edges of Mpanga forest reserve. If this trend continues, the conservation of Mpanga forest, which is being facilitated by development of ecotourism, may be jeopardised because of the adverse impacts of tree harvesting on bird and primate populations that are potential ecotourist attractions.

\section{Production, trade and marketing}

Drum production in Mpigi district started as early as the nineteenth century, although trade increased to current levels about 30 years ago (Samula 2001). Carvers market their products by the roadside, where they are displayed or sold in bulk to outlets in the city centre and then sold to tourists and other buyers. Unlike farmers and other traders who market products through a co-operative movement, drum makers and traders do not have such a body. The small size of the industry and lack of a market information system have constrained the growth of the drum making industry, which can be described as 'stall', 'home based' or 'roadside' trade. Moreover, it is difficult to draw a clear line between drum makers (producers) and drum traders because the business is holistic in nature. The production-marketing chain is therefore summarised in Figure 2.

\section{Policy issues, support and interventions in drum making industry}

There is no policy on production and marketing of wooden drums in Uganda. Any policy aimed at promoting woodcarving in Uganda would depend on the interrelation between production and marketing. As such, there is a need for both supply and demand oriented policies and strategies. There is also a need to guide the interrelationships among culture, crafts, tourism, handicrafts and natural resources used in the woodcarving industry. Where possible, policies, plans and programs should be formulated to address the needs of specific crafts subsectors and geographic areas. 
Figure 2. Diagrammatic representation of the production-marketing chain for wooden drums

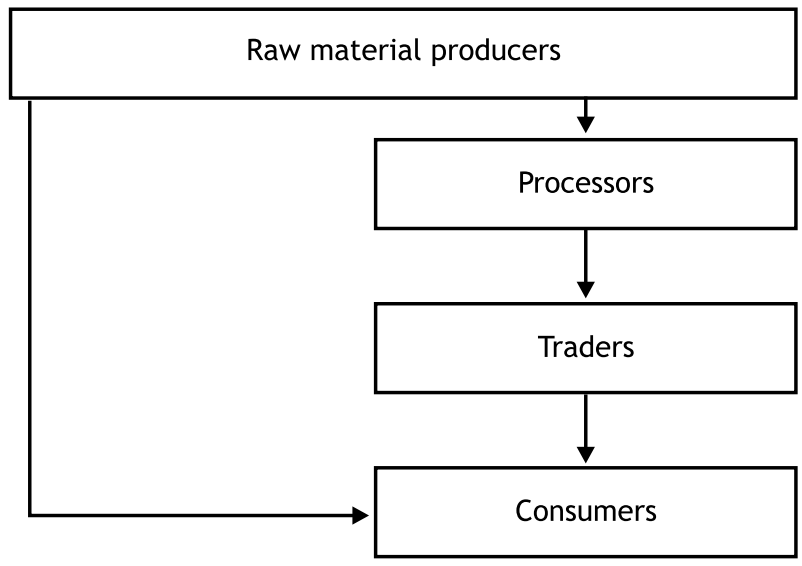

It is clear from Uganda's national planning document Vision 2025 that environmental conservation and management are crucial for sociocultural and economic development and national prosperity. To achieve these goals there have been significant policy changes in the management of natural forests and biodiversity conservation such as the development of the National Forest Plan and the National Biodiversity Conservation Strategy. These are important provisions in the National Environment Statute No. 5 of 1995 and the Forest Policy. The National Environment Statute contains guidelines to promote sustainable forest resource use and environment management and assigns roles to various agencies in this regard.

In the case of the drum making industry the relevant statute is the Forest Act of 1964, included in the 2002 Forest Policy for Uganda after a global shift in management goals of natural resources (IUCN 1986; NEMA 1994). It therefore incorporates the needs of human populations living adjacent to forest reserves while at the same time protecting the biodiversity and integrity of physical and ecological processes of reserves. Successful implementation of this policy would serve as viable measures for conservation of natural forests and biodiversity that form the base for wooden drum makers.

According to the Uganda Forest Policy of 2002, drum making and use is still recognised as a subsistence activity because carved wooden drums have been used in the Buganda Kingdom palaces for a long time and the history of their use dates back as far as the eighteenth century (Lush 1935). The long history of drum use in the whole of Uganda also explains why a drum is part of the Uganda national coat of arms (Figure 3), which depicts the cultural significance attached to it. But the situation has changed over the years and drums are now significant commodities in both the local and tourist markets.

It is illegal for drum makers to cut trees from forests for making drum frames because they do not have permits or licenses, but once the drum frames are transported to the drum making stalls by the roadside they become legal items. This situation implies that, despite the adoption of new policies, 
Figure 3. The Republic of Uganda's coat of arms includes a drum

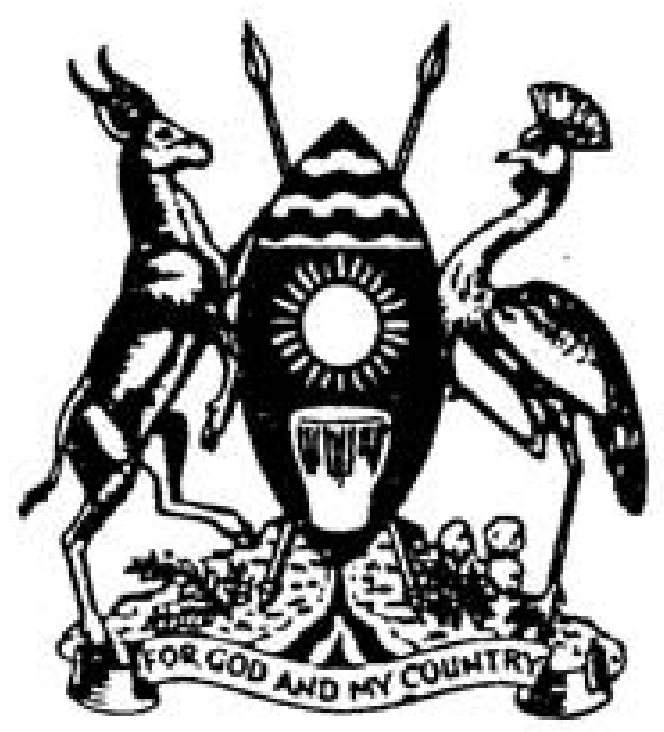

the government still fails to offer any direct investment or incentives for development of raw material production. The wood harvesters are aware that their activities are carried out illegally.

Forest Department records of 1998 to 2000 showed that a running volume of softwood species (under which the drum making tree species fall) is valued at US $\$ 20 / \mathrm{m}^{3}$ (on average a whole tree stem). This volume yields on average 10 drums of $30 \mathrm{~cm}$ to $45 \mathrm{~cm}$ top diameter, which earns US\$200 to US\$300, and another 10 drums of $10 \mathrm{~cm}$ to $15 \mathrm{~cm}$ top diameter, which bring an additional income of US\$100 to US\$150. This calculation excludes smaller drums of less than $10 \mathrm{~cm}$ top diameter obtained from tree branches. Despite these financial benefits there is no clear policy to regulate drum making, something that should have been spelt out clearly in the Forest Policy.

The collaborative forest management unit of the Forest Department and the Mpanga Forest Ecotourism Project offered the opportunity for involving the local community in forest management while generating revenue from the forest. Owing to financial constraints and inadequate staff, the Forest Department has failed to implement collaborative forest management successfully in Mpanga and the unit was disbanded. Continued tree harvesting in Mpanga forest reserve for drum making therefore is a disincentive to tree planting to provide wood for making drum frames. Plantation of the favoured tree species on the other hand would act as a source of income from sustainable sources. In the long run this would alleviate the abject poverty of the communities in Mpigi district by guaranteeing an income from the already well-established markets. Successful collaboration among drum makers, local community and Forest Department would be a sound basis for achieving the goals of forest conservation and sustainable use of forest resources in Mpigi district. 


\section{CONSERVATION, DEVELOPMENT IMPLICATIONS AND RECOMMENDATIONS}

This study has shown that there is a combination of diminishing raw material supply, increased demand of finished product and almost complete policy neglect of wood carving in Uganda. Existing policy emphasises that a balance be created between using the environment for economic development and conserving it for future generations. Lacking other information one can only assume that this is the policy to follow. However, at the moment these two factors, viz. economic development and conservation, are largely pulling in different directions. Drum makers are trying to maximise use values without looking at sustainability, while forest resource managers are concentrating on conservation without fulfilling the policy that forest resources should be used for sustainable economic development.

It has also become clear from a narrow economic viewpoint that providing assistance to preserve and encourage the drum making industry may be unsound. However, from a broader economic perspective that includes cultural values, cultural preservation is desirable and subsidies that help promote carved wooden drums would be perfectly legitimate. In addition, it shows that some of the changes taking place are tending to limit the ability of the poor to exploit the opportunities available from drum making activity. Carvers posses the skills and technology to benefit from the opportunities presented by the market, but depend mainly on traders and other intermediaries for access to export markets. Thus the benefits and sometimes control end up in the hands of outsiders.

In this case, a more extensive campaign is needed to ensure that drum makers are fully aware of their responsibilities related to resource use and the effects of improper and proper utilisation. More opportunity is needed for drum makers to discuss and make decisions on issues concerning their own livelihoods. Drum makers and other resource users should be mobilised and helped to form the appropriate bodies (e.g., community institutions) to manage the craft sector's natural resources pro-actively. Craft development organisations and interested and capable marketing enterprises should be assisted to work alongside the drum makers in forest management.

The government of Uganda should look into ways of reducing the cost of producing and marketing carved wooden drums. This most crucial aspect can be addressed through support and subsidy measures. Since the drum making industry is economically viable, subsidies are justifiable to ensure that financial incentives continue to exist for producers and marketers. By subsidising certain aspects of the drum making industry, greater proportions of income remain in the hands of producers, their families and communities. In this way, more benefits accrue to the local people. Areas that can be most easily subsidised include transport (product collection and purchasing, and raw material collection and marketing), design and skill upgrading and various other marketing costs such as production of informational and promotional materials. Reduction of transport costs should be considered because certain high quality drums made in rural areas lose their comparative advantages because of the high cost of transportation to the market. 
There is also a need for improving the quality of existing drums and make them sellable in a competitive market. Qualities such as a good array of woven skin strings must be evident to the buyer if the drums are to sell well. Although some of the drums in the market already have this advantage, the quality of other products needs to be raised to command higher prices.

Just as the need for support and subsidisation would generate a greater share of the profit to producers, the policy related to quality improvements should lead to increased income levels, because producers can receive more money for the same amount of work. For example, it takes an equal volume of wood to make a high quality drum as a poor one, but the high quality drum can fetch more than five times the price.

In view of the above, another policy area should address stabilisation and expanding the market by encouraging drum production and market access for expatriates, residents, local upper-class buyers, tourists and export. To safeguard a stable demand, financial and technical support is needed to undertake market research and develop a market information system. This is not something that producers can be expected to know; nor do they have the income to undertake such an effort. The market needs to be continually assessed, feedback provided to drum makers and the quality of carved wooden drums developed and refined accordingly.

The way forward presented above and the associated strategies need to be implemented effectively in order to improve the drum making industry. Greater benefits to those involved, specifically improvements in the present income levels, should be realised so that the drum making industry in Uganda can generate income commensurate with the level of quality and effort invested. In so doing, those involved in the industry could obtain the benefits they deserve.

\section{ACKNOWLEDGEMENTS}

We thank the World Wide Fund for Nature, UK; the United Nations Educational, Scientific and Cultural Organisation; and the Royal Botanic Gardens, Kew for jointly funding the People and Plants Initiative Project, on which this report is based. We also thank $\mathrm{Dr}$ J. Obua and Dr B. Campbell for their valuable comments on the original version of the manuscript draft.

\section{ENDNOTES}

1. Department of Forest Biology and Ecosystems Management, Faculty of Forestry and Nature Conservation, Makerere University P.O. Box 7062, Kampala, Uganda. E-mail: omejap@hotmail.com

2. Department of Forest Biology and Ecosystems Management, Faculty of Forestry and Nature Conservation, Makerere University P.O. Box 7062, Kampala, Uganda. E-mail: obua@forest.mak.ac.ug

3. People and Plants Initiative 84 Watkins Street White Gum Valley, Fremantle, Australia. E-mail: peopleplants@bigpond.com

4. Mzee denotes an elder in Luganda language. 


\section{REFERENCES}

Hamilton, A.C. 1984 Deforestation in Uganda. Oxford University Press, Nairobi. Howard, P. 1991 Nature conservation in Uganda's forest reserves. Gland, Switzerland.

Howard, P., Davenport, T. and Dickinson, C. 1996 Mpanga, Zika and Mpigi district forest reserves: biodiversity report. Forest Department, Kampala, Uganda. International Union for Conservation of Nature and Natural Resources. 1986. Managing protected areas in the tropics. IUCN/UNEP, Gland, Switzerland and Cambridge, UK.

Lingdale-Brown, I. 1960 The vegetation of Uganda. Memoirs of the Research Division Series 2. Department of Agriculture, Uganda Protectorate.

Lush, A. 1935 Kiganda drums. The Uganda Journal 3: 52-97.

National Environment Management Authority. 1994 State of the environment report for Uganda, 1994. Ministry of Natural Resources, Kampala. 65p.

National Environment Management Authority. 1997 State of the environment report for Mpigi District. Ministry of Natural Resources, Kampala.

Samula, A. 2001 The dynamics of wood volume and values of trade in musical instruments in central Uganda. M.Sc. Thesis, Makerere University, Kampala.

Taylor, D., Hamilton, A., Whyatt, D., Bukenya, R. and Mucunguzi, P. 1996 Stand dynamics in Mpanga Research Forest reserve, Uganda, 1968-1993. Journal of Tropical Ecology, 12: 583-597. 


\title{
Chapter 11
}

\section{Trading forest products in South- Eastern Zimbabwe: ecology, economics and politics of woodcarving}

Wavell Standa-Gunda $a^{1}$ and Oliver Braedt ${ }^{2}$

\begin{tabular}{llllll}
\hline Common names & $\begin{array}{l}\text { Part of the } \\
\text { resource used }\end{array}$ & Management & $\begin{array}{l}\text { Degree of } \\
\text { transformation }\end{array}$ & $\begin{array}{l}\text { Scale of } \\
\text { trade }\end{array}$ & $\begin{array}{l}\text { Geographic } \\
\text { range }\end{array}$ \\
\hline $\begin{array}{l}\text { Afzelia, Pod mahogany, } \\
\text { Mukamba }\end{array}$ & Wood & Wild & Medium & International & Large \\
\hline
\end{tabular}

\begin{abstract}
The commercial use of natural resources to manufacture products for sale to tourists has become a significant supplementary source of income to rural people in all areas of Zimbabwe. The use of natural resources to produce woodcarvings has been controversial because of the volume of wood used and the impact on woodlands. This article explores some of the baseline data, which have been gathered under an economic study of the woodcarving industry along the Masvingo-Beitbridge road. Results of the analysis show that returns to time invested in carving are higher than from other locally available alternatives. The growth of the industry is primarily attributed to (a) the drought years, which forced people to seek alternative livelihood options; (b) the economic structural adjustment programme that devalued the Zimbabwean dollar thereby attracting more foreign visitors while at the same time resulting in loss of jobs especially in the public sector as well as a lowering of real wages across all sectors as subsidies were removed; (c) the collapse of apartheid in South Africa and the several years of domestic political stability in Zimbabwe, which led to a significant increase in tourist traffic between the two countries. The implications of the results are considered with respect to the sustainability of this growing sector.
\end{abstract}

\section{INTRODUCTION}

In the past, non-timber forest products (NTFP) were largely used to meet household requirements. However with changing socio-economic situations, 
many individuals have started selling some of these products (Arnold et al. 1994; Browder 1992). In Zimbabwe, it is now a common feature along major roads passing through rural areas to see people selling a diverse range of forest products. These products include carvings from both stone and wood, thatch, baskets, sisal mats, wild fruits, fuel wood, mushrooms, mopane worms, and clay pots (Braedt and Standa-Gunda 2000). The increased commercialisation of these forest products, and in particular wood carvings, has resulted in many questions including:

- How has the increased commercialisation of these products affected rural economies?

- What benefits are there in participating in these markets?

- What has been the response by relevant policy making institutions?

- What has been the sector's impact on the natural resource base?

These questions have not been confined to Zimbabwe, but remain central to research in most countries where the use of forest products by urban and rural households is prominent. As such, diverse views exist on NTFP trade, use and management (Dove 1993; Homma 1992; Momberg et al. 1997). There is a growing consensus that woodcarving enterprises are a potential tool for rural development in selected areas. This recognition has led to more institutions putting effort into studying the enterprises with the aim of improving woodland resource use sustainability and traders' returns through better marketing practices. Such efforts in Zimbabwe are exemplified by the work of the Forestry Commission, the Ministry of Employment Creation and National Affairs and the University of Zimbabwe.

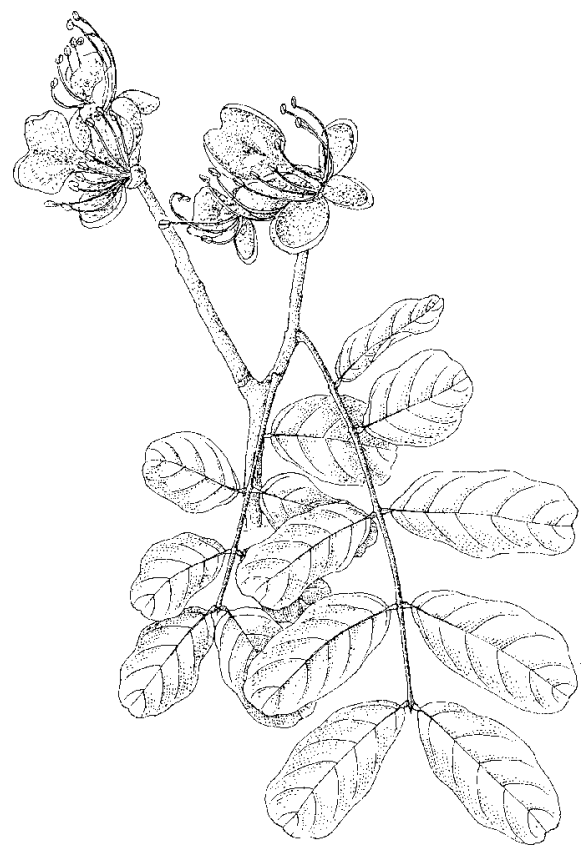

(Afzelia quanzensis) 
This chapter is a compilation of the work on woodcarvings in south-eastern Zimbabwe, as part of the Center for International Forestry Research's global research on the utilisation of NTFP in developing countries. This case makes use of results from the works of Braedt (2002) and Braedt and Standa-Gunda (2000). The case data have been collected over a period of three years (19961998) through market, ecological, and household surveys in southern Zimbabwe.

\section{THE STUDY AREA}

The study area is centred on the northern portion of the road between the towns of Masvingo and Beitbridge in southern Zimbabwe (Figure 1). This road links South Africa with central Zimbabwe. Between Masvingo and Beitbridge, a distance of $300 \mathrm{~km}$, there are approximately 25-29 craft markets. One overriding feature of these markets is their variability with respect to the size, age, materials used (stone carving, wood carving, clay and needle work products), the types of carvings, the membership of the markets and the seasonality of demand for products (Braedt and Standa-Gunda 2000).

Three of Zimbabwe's four major land tenure systems are found along the road: communal land, resettlement land and commercial/freehold land. Most of the markets are located in Chivi District $(69 \%)$, which is a predominantly communal area, and in Masvingo District (21\%), located mainly on resettlement land. The bulk of the land in the case study area is communal land.

Various factors have probably contributed to the development of the craft sector. Since the late 1980s and the beginning of the 1990s, tourism in Zimbabwe has steadily risen. Zimbabwe's independence in 1980 and the signing of a peace accord between rival political parties in 1987 brought peace to a country engaged in guerrilla activities and civil war since the 1970s. The trend of increasing tourism has probably also been enhanced through the introduction of the Economic Structural Adjustment Program and the resultant devaluation of the Zimbabwe dollar. The purchasing power of tourists using foreign currency was favoured by this development (Braedt and Standa-Gunda 2000). In addition, low quality land, land shortage (Johnston and Kilby 1975; Rukuni 1994) and natural phenomena such as the extreme drought in 1992 left many households, especially the very poor, with few livelihood options. This resulted in the upsurge of off-farm activities such as beer brewing, gold panning, prostitution and woodcarving (Scoones et al. 1996).

The population density in the three wards presented in Figure 1 lies at 51 persons per square kilometre. The area falls into agro-ecological Regions IV and $\mathrm{V}$, where rainfall is low (mean annual rainfall is less than $650 \mathrm{~mm}$ ) and highly variable (coefficients of variation of mean annual rainfall are $35-40 \%$ ) (Gambiza and Nyama 2001). The soils are largely sandy and of low fertility. The high frequency of droughts and the decreasing availability of off-farm employment have created household livelihood problems for many rural households (Rukuni 1994; Cavendish 1997). Despite the unfavourable conditions, agriculture remains the main economic activity in the area (Figure 2).

In the communal and resettlement areas woodland resources are generally severely depleted and highly fragmented because of agriculture and settlement. Miombo woodland, where the logs for carving are harvested, is deciduous 
Figure 1. Map of the study area
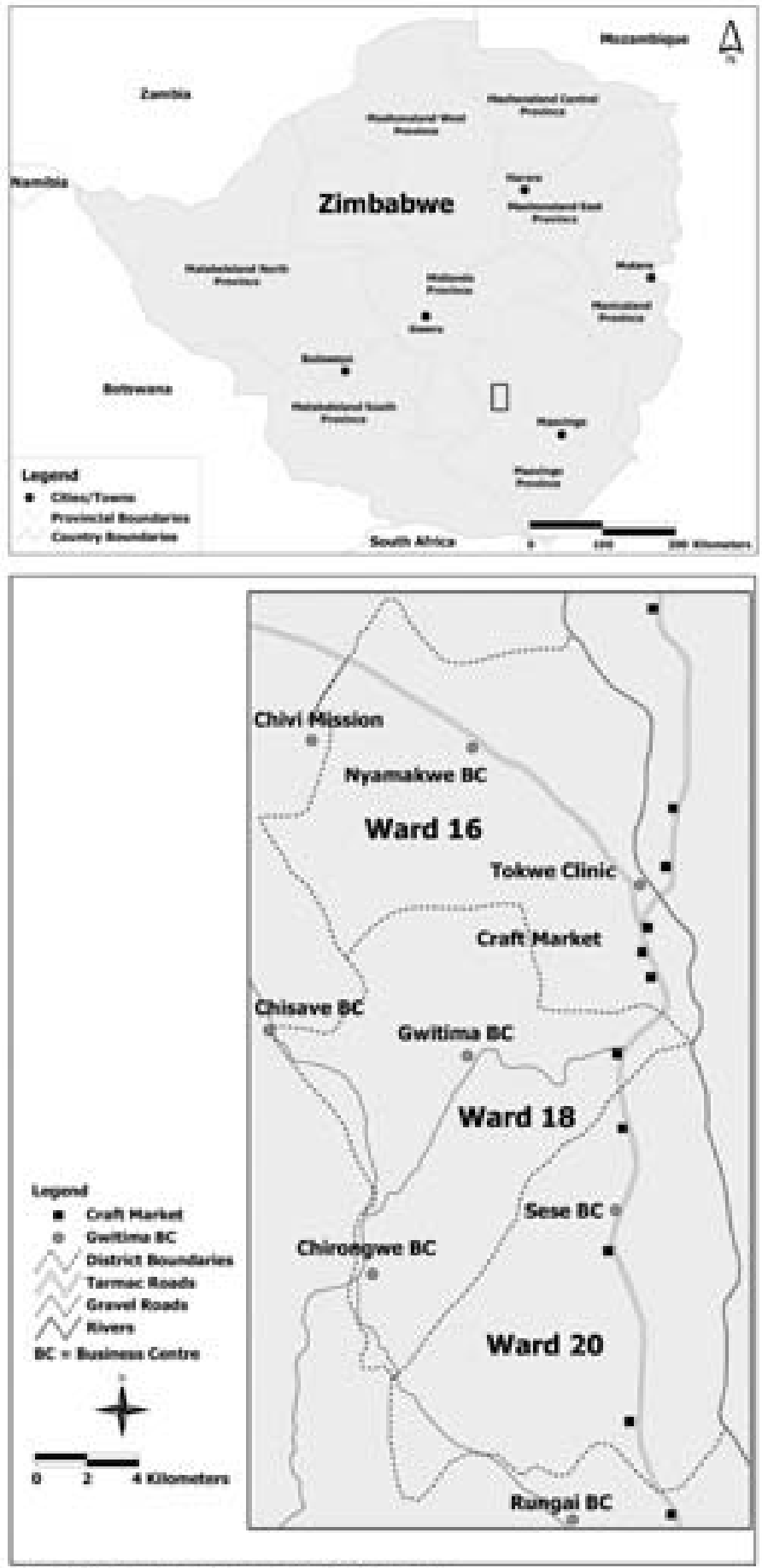

Source: ESRI Data and Maps 2002. 
Figure 2. Percentages of total household cash incomes for craft sector and non-craft sector participants $(n=139)$

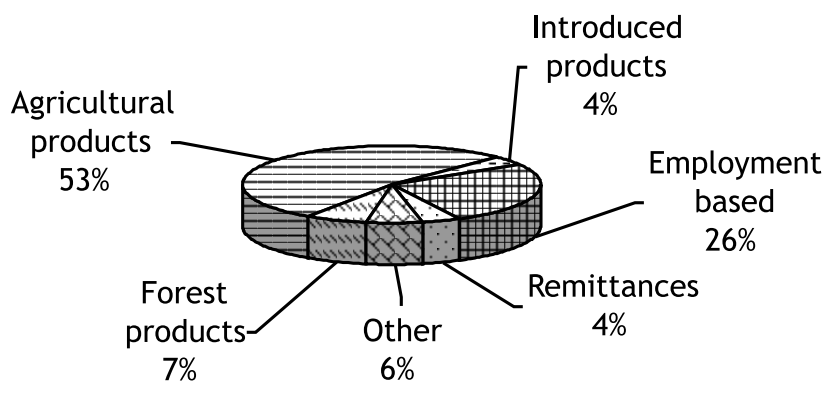

Note: Mean annual cash revenue equals $Z \$ 2,776$ (95\% confidence interval for mean $=2,147$ - 3,407) (US\$1 = Z\$11.30). Cash income sources: Forest products = sale of indigenous fruit; sale of firewood; woodcarving; brick making; basketry; pottery; stone carving; gold panning; sale of wild meat; sale of fish; wild fruit beer. Agricultural products = sale of livestock; sale of livestock products; hiring out of livestock; sale of field crops; sale of vegetables; sale of exotic fruits; crop beer; farm work. Introduced products = carpentry; knitting; crochet; sewing; tie and dye. Employment based = formal employment; social welfare; pension. Other = gifts; respondents unwilling to specify source.

Source: Braedt 2002.

woodland dominated by the genera Brachystegia and Julbernardia (Frost 1996). The abundance of tree species used in the woodcarving sector showed an average 3.9 trees per hectare with a carveable wood volume of $4.6 \mathrm{~m}^{3} / \mathrm{ha}$ (Braedt 2002). The tree species used for woodcarving account for over $25 \%$ of the wood volume of all the 78 tree species recorded (total average carveable volume for all tree species $=17.5 \mathrm{~m}^{3} / \mathrm{ha}$ ).

Historically, wood was carved for cultural and religious symbols and as household utensils. Now woodcarvings are produced primarily for sale to tourists. Woodcarving production is an important activity throughout the region, e.g. in South Africa (Steenkamp 1999, citing Clark and Magagula 1994), Malawi (Marshall et al. 2000), Kenya (Obunga 1995), Namibia (The Namibian 1999) and Zimbabwe (Braedt and Standa-Gunda 2000; Matose et al. 1997). In southern African countries the sector tends to be unstructured with the bulk of carvings sold at roadside markets.

\section{CHARACTERISTICS OF THE CRAFT MARKETS}

\section{Location and ownership of raw materials}

The major raw materials in the carving business are logs, usually collected from natural woodlands. None of the tree species used for carving is cultivated. Eighty-seven percent of the people in the whole road survey suggested that they harvested and collected logs from communal areas, whilst the remainder said they collected from small-scale commercial farms and resettlement areas. Although it is locally perceived that logs in communal areas and resettlement 
areas fall under the collective ownership of the local communities, the underlying legislation for the communal land implies that ownership and use of logs is the prerogative of the local Rural District Councils (RDCs), assisted by the Natural Resources Board (NRB) and Forestry Commission (FC) in overseeing the harvesting patterns. For resettlement land, the resettlement officials, also assisted by the NRB and FC, are responsible. Logs in small-scale commercial farms are 'privately owned', though the NRB and FC are entitled to control their commercial use.

\section{Available technology and infrastructure}

The most important infrastructural feature in the study area is the well maintained network of all-weather surface roads running from Beitbridge through Masvingo town to Harare and the Eastern Highlands. The roads provide the interface between traders and tourists. Fifty eight percent of the markets had some form of shelter to protect carvings from bad weather conditions, $50 \%$ had pit-latrine toilets, and $16 \%$ had piped water. Shelters ranged from pole and mud walls with thatched roofs to brick walls with corrugated iron roofs.

The equipment used in the woodcarving enterprise ranges from rudimentary to more sophisticated tools, but the latter are infrequent. Only one individual owned a chainsaw and most people use axes to cut trees. The chisels used vary from professional ones to those manufactured by local blacksmiths. It was observed that even professional chisels were locally modified at the end of their normal life to enhance their performance.

Photo 1. Primary processing of logs done adjacent to the market site (Photo by Wavell Standa-Gunda)

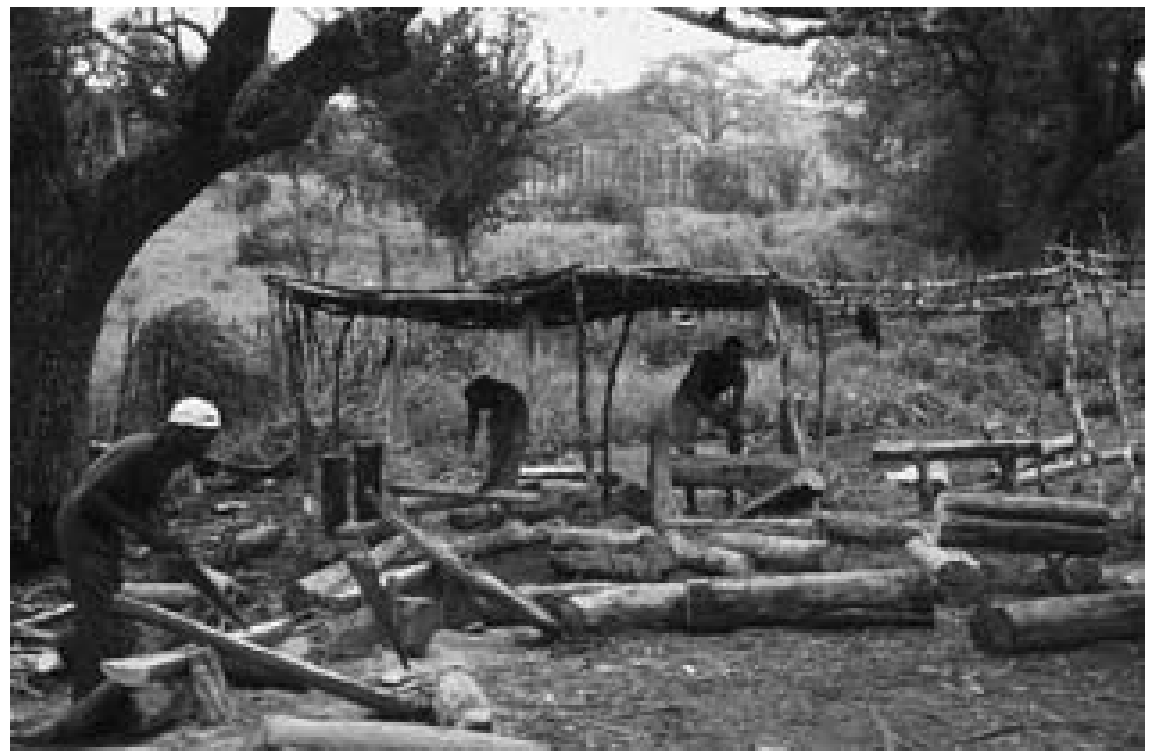




\section{Who is involved in the production and trading of woodcarvings?}

Prior to 1980 women dominated craft production along the Masvingo-Beitbridge road, largely selling pottery. However, men, who focus mainly on stone and woodcrafts, currently dominate the craft sector (57\% of market participants). Half of the women participants (total $=43 \%$ ) are confined to markets where pottery and crochet products are being produced and sold (Table 1). When involved in carvings and sculptures, women restrict themselves to the final stages of production, the finishing of the product with sandpaper and polish, and the selling of the product. There is not a single female carver on the Masvingo-Beitbridge road, although many carvings end up with women who sell finished products. The men control most of the processes of craft production. The low levels of participation by females are made more apparent by the lack of involvement by young women in the craft sector. While craft production in colonial and precolonial times used to be the preserve of mature members, young males are now dominant in the market.

Table 1. Market participants along the Masvingo-Beitbridge road by activity, gender and age in 1997

\begin{tabular}{|c|c|c|c|c|c|}
\hline \multirow[t]{2}{*}{ Activity } & & \multirow[t]{2}{*}{$\begin{array}{l}\text { No. of } \\
\text { participants }\end{array}$} & \multicolumn{3}{|c|}{$\begin{array}{l}\text { Distribution by age grouping (\%) } \\
\text { in each activity group }\end{array}$} \\
\hline & & & $<25$ years & $26-49$ years & $>50$ years \\
\hline Carving & Males & $390(11 \%)$ & $6 \%$ & $4 \%$ & $1 \%$ \\
\hline \multirow[t]{2}{*}{ Selling } & Males & $1,696(46 \%)$ & \multirow{2}{*}{$46 \%$} & \multirow{2}{*}{$33 \%$} & \multirow{2}{*}{$10 \%$} \\
\hline & Females* & $1,549(43 \%)$ & & & \\
\hline Total & & $3,635(100 \%)$ & $52 \%$ & $37 \%$ & $11 \%$ \\
\hline
\end{tabular}

*The 583 female participants (38\%) primarily concentrate on non-woodcarving activities such as pottery and crochet knitting, but occasionally do sell woodcarvings (main road survey).

The distance between homestead and the nearest market also influences participation in a market. As the distance increases it is especially the number of participating women that declines. Women are willing to travel around 2.0 $\mathrm{km}$ to $2.5 \mathrm{~km}$ to a market, whereas men move across districts and provinces. Men from as far as Birchenough Bridge $(150 \mathrm{~km})$, Harare $(350 \mathrm{~km})$, Bulawayo $(300 \mathrm{~km})$ and Bindura $(400 \mathrm{~km})$ take part in the trading of carvings on the Masvingo-Beitbridge road, though there are more local people than outsiders at each market. Household duties of women restrict their movement.

Carvers differentiate themselves into three broad categories. 'Artists', said to constitute $15 \%$ of the total number of carvers, are people renowned for the high quality their work. They have generally been in the business since long before the recent upsurge in craft activity. The next category, 'carvers', constitute about $30 \%$ of the total. Carvers are said to also produce good quality products, but were forced by economic circumstances to join the craft sector. The last category, 'part-time carvers', have also been forced into the sector by the need to raise cash. Their products are said to be substandard. This group usually includes farmers who want to supplement their agricultural incomes and 
retrenched urban workers. Just over half of the participants involved in woodcarving are in this group.

Most participants in the craft sector are only partially involved, doing carving or trading in crafts when other livelihood options fail or in seasons when agricultural activities are less labour intensive. Generally, the ordinary households from the communal area are well represented in the sector. The participants interviewed gave no indication that certain kinds of households (in terms of wealth status, for example) were dominating the craft sector.

The distribution of market participants is somewhat skewed. Sese Craft Center, some $50 \mathrm{~km}$ from Masvingo, is the biggest and oldest market along the Masvingo-Beitbridge road, comprising $28 \%$ of all participants. The four next largest markets constitute $57 \%$ of the participants. The number of participants at each market was positively correlated to the volume and level of product diversity.

\section{What is traded in these markets?}

In the 1960s market stalls along the Masvingo-Beitbridge road in Chivi District were mostly pottery outlets. The main resource, clay, is found on termite mounds close to most homesteads. However, as buyers acquired new tastes from markets in Harare and Bulawayo, stone carvings were introduced in 1976 at the Masvingo Craft School (which later became defunct). Stones found at most local sites, e.g. Chikofa, were less suited for carving so carvers travelled more than $50 \mathrm{~km}$ to collect good stones in Mashava or Zvishavane. However, this distance and the associated transportation costs became prohibitive for most people and thus it became common to substitute stone carvings with wood. At the beginning of the 1980s the marketing of woodcrafts began to gain prominence at Sese Craft Center.

Photo 2. A woodcarving market in Chivi district, Zimbabwe trading Afzelia quanzensis and Combretum imberbe products (Photo by Wavell Standa-Gunda)

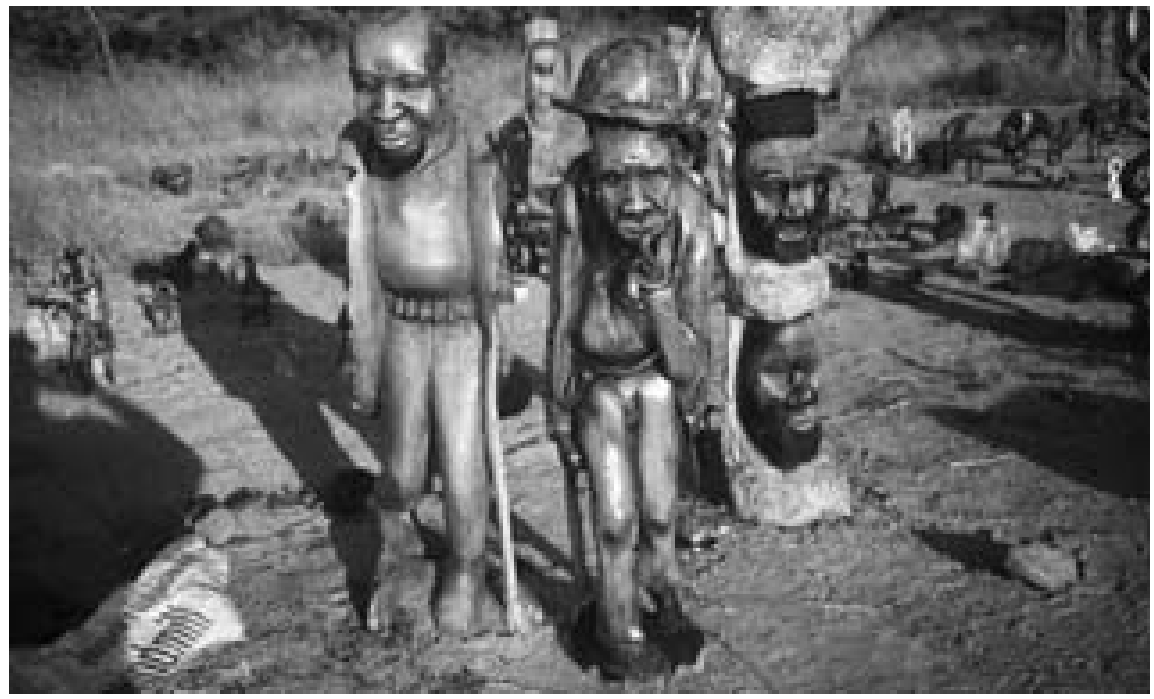


Table 2. Volumes and prices of woodcarvings according to species used for products on the Masvingo-Beitbridge road in 1997 ( $\mathrm{n}=27$ markets, one time survey)

\begin{tabular}{|c|c|c|c|c|c|}
\hline \multirow[t]{2}{*}{ Main species } & \multirow[t]{2}{*}{$\begin{array}{l}\text { Volume } \\
\qquad\left(\mathrm{m}^{3}\right)\end{array}$} & \multicolumn{3}{|c|}{$\begin{array}{c}\text { Average prices } \\
\text { (US\$/piece) }\end{array}$} & \multirow[t]{2}{*}{ Main product type } \\
\hline & & $\begin{array}{l}\text { Small } \\
(0.001 \text { to } \\
\left.0.01 \mathrm{~m}^{3}\right)\end{array}$ & $\begin{array}{l}\text { Medium } \\
(0.02 \text { to } \\
\left.0.1 \mathrm{~m}^{3}\right)\end{array}$ & $\begin{array}{l}\text { Large } \\
(0.2 \text { to } \\
\left.0.5 \mathrm{~m}^{3}\right)\end{array}$ & \\
\hline Afzelia quanzensis & 79 & 4.7 & 28.8 & 342.9 & Animals, abstracts \\
\hline Pterocarpus angolensis & 10 & 4.7 & 28.8 & 342.9 & Animals, abstracts \\
\hline Combretum imberbe & 42 & 9.0 & 42.0 & 393.8 & $\begin{array}{l}\text { Human heads, } \\
\text { figures }\end{array}$ \\
\hline Kirkia acuminata & 13 & 4.0 & 22.3 & 64.0 & $\begin{array}{l}\text { Animals (giraffes), } \\
\text { mortars, cooking } \\
\text { utensils }\end{array}$ \\
\hline Dalbergia melanoxylon & 5 & 5.4 & 11.2 & - & $\begin{array}{l}\text { Walking } \\
\text { sticks,spears }\end{array}$ \\
\hline Spirostachys africana & $<1$ & 5.4 & 11.2 & - & $\begin{array}{l}\text { Walking sticks, } \\
\text { spears }\end{array}$ \\
\hline $\begin{array}{l}\text { Ozoroa insignis ssp. } \\
\text { reticulata }\end{array}$ & $<1$ & 4.7 & 28.8 & 180.0 & Animals (eagles) \\
\hline Albizia amara & $<1$ & 4.7 & 27.0 & 180.0 & Animals \\
\hline Sclerocarya birrea & $<1$ & 3.5 & 18.0 & 45.0 & Household items \\
\hline Berchemia discolor & $<1$ & 9.0 & 42.0 & 393.8 & $\begin{array}{l}\text { Human heads, } \\
\text { figures }\end{array}$ \\
\hline Soapstone & 111.6 & 4.0 & 24.3 & - & Animals, abstracts \\
\hline
\end{tabular}

At the time of the whole road survey US\$1 $=Z \$ 11.30$.

Source: Braedt and Standa-Gunda 2000.

The diversity of types of carvings is relatively high. The eight main product types are sold are produced from mainly six different tree species, thus increasing product variation even further to about 36 different wood products (Table 2 ). There is a close linkage between product type and the tree species used to produce them.

By far the most common species on the market along the MasvingoBeitbridge road is Afzelia quanzensis (pod mahogany), followed by Combretum imberbe (leadwood), Kirkia acuminata (bastard marula), Pterocarpus angolensis (mukwa) and Dalbergia melanoxylon (African blackwood). Although over half of the products were made out of $A$. quanzensis, its predominance at most of the markets is not a reflection of its abundance in the forest.

\section{Pricing of products}

The pricing of products is a complex issue. Prices are set as a result of knowledge of previous market transactions, characteristics of buyers and needs of the trader at the time of transaction. The buyer is usually characterised as either 
a tourist or a local. The buyer's willingness to bargain indicated by exiting the car and moving around the market gives the trader extra time to bargain. The situation is different when the buyer remains in the car, asking prices through the window. Traders will then have to give buyers favourable bargains as they are likely to leave at any time. Through participatory activities with traders and buyers it was observed that buyers travel into Zimbabwe by road acquiring some information on product diversity and prices. By the time they travel back to South Africa, they will be more aware of the products they want to buy and the place to acquire them. Each trader bargains individually with the buyer until a price is established. Such 'private treaty' negotiations are very common in woodcarving marketing. As such the resulting fairness of prices depends upon the information, trading skills and relative bargaining power of buyers and sellers. Prices discovered in this way tend to vary with every transaction. Although individual traders transact with buyers, the information from the transaction is never private, but being shared amongst traders. This gives the woodcarving markets one characteristic of organised central markets. This information sharing is essential because traders are able to sell products controlled by other traders when those other traders are absent from the market. It is often the case that only a proportion of the market sellers are at the market at any one point in time (approximately $20 \%$, depending on the time of the year).

\section{THE POLICY ENVIRONMENT}

\section{Rules regulating markets}

Only five of the markets in Chivi District on the Masvingo-Beitbridge road operate with the full approval of the Chivi RDC. The rest either operate illegally or their registration with the council has not been ratified. In 1992 the RDC, seeing the potential of the woodcraft sector to raise revenues for itself, levied a tax on all participants involved at the retail level. Because of labor shortages in collecting fees, the expected revenues were never realised. In the Masvingo Urban Council the market rules are more stringent (Table 3). For someone to be given a stall at the Masvingo urban market, the person has to be a 'resident of the town'. Defaulters on market rentals risk the disconnection of their residential water supply. Formerly, Mwenezi RDC, also along the MasvingoBeitbridge road, charged a monthly rental of Z\$150 for marketing space and an extra monthly charge of $Z \$ 30$ for defaulters. By 1999 these fees had dropped, perhaps indicating a slackening of the system of rules. The fees reduced the development of the sector in that district as many people from Mwenezi cross the Runde River to market their products in Chivi District, where rules were less stringently adhered to. In Chivi, the level of control of markets by the district office is greater when the market has more participants.

Most markets on the Masvingo-Beitbridge road have a committee that runs the affairs of the market. Some barriers to entry in the craft sector exist as most markets have joining fees that range from $Z \$ 10$ to $Z \$ 75$ depending on the infrastructure of the particular market. These fees are paid to the committee that runs the affairs of the market. A common feature at most 
Table 3. Differences in official operational rules regulating markets in districts along the Masvingo-Beitbridge road in 1997

\begin{tabular}{lll}
\hline District & \multicolumn{2}{c}{ Operation Rules } \\
\cline { 2 - 3 } & Participation in the market & $\begin{array}{l}\text { Reasons for } \\
\text { expulsion from } \\
\text { the market }\end{array}$ \\
\hline
\end{tabular}

Masvingo Should be a resident of the Urban town. Payment of a

Council registration fee of US\$4.5 to the council.

Masvingo Entry into the sector is the Rural prerogative of the market District management committee. Council No joining fees or council rentals.

$\begin{array}{ll}\text { Chivi } & \text { Ministry of National Affairs } \\ \text { Rural } & \text { regarded as pre-co- } \\ \text { District } & \text { operatives only markets } \\ \text { Council } & \text { that could present an } \\ & \text { organized structure (i.e., } \\ & \text { chairperson, secretary and } \\ & \text { treasurer) with records of } \\ & \text { accounts. }\end{array}$

Mwenezi Joining fees are paid at the Rural council offices.

District

Council
Non-payment of rental; sharing a stall with an unregistered person.

(The council has no control over the sector.)

(The council has no control over the sector.)
Monthly rental of US\$6.6 for the council controlled market stall. Stall was built by the council.

None. Most of the markets operate on private or resettlement land. Council does not provide stalls.

No one pays the council for operating these markets. A tax was introduced in the early 1990 s but could not be effected. Council does not provide stalls.
Non-payment of rental (but the payment system was abandoned in 1998).
People pay monthly rentals of US\$13.3, with an additional monthly fine of US\$2.7 for defaulters. Council does not provide stalls. The payment system was abandoned in 1998.

All

The Ministry of Roads controls where markets are located along the road, though with little success. Officials had in one or two cases requested relocations of markets to safer sites. by The Ministry of National Affairs had sporadically registered craft markets-none in Chivi District operate legally, but six are in the process of fulfilling the requirements for registration, e.g., having records of accounts.

Note: At the time of the survey US\$1 = Z\$11.30.

markets is that the use of this joining fee is left to the discretion of the chairperson. New members who cannot pay the fee at joining are allowed to pay after their first sales. At times, the relaxation of rules has meant no rules at all. At only one third of the markets with rules on entry and expulsion have these been implemented since the markets came into being. In extreme cases membership is forfeited if an individual does not abide by the regulations of the market committee. Stealing other people's products, absenteeism from security duty at night and selling other people's products without accounting for the sale are reasons for which people get reprimanded or expelled. 
Generally, expulsion of an individual depends on who they are and their position at the market. Important carvers and people such as the headmen are not easily fired. Relaxed entry requirements have meant that an expelled member from one market can still join or form another market.

Seasonality of rule enforcement is evident. During the peak tourist period (December to January) people tend to abide by the rules. However, in February and March there are many fewer buyers and traders and the traders flout the rules in order to make a sale. It is, for instance, not acceptable to disrupt another person's transaction by moving in with your own piece at a reduced price. This rule is often flouted when few buyers are visiting the market.

Leaders at smaller markets have the capacity to deal with matters of discipline and can easily influence other participants to follow the rules, but it is much more difficult to reach a consensus at the bigger markets. At Sese Craft Center, the 750 members (not all are always present at the market) could not agree on whether to build shelters. On the other hand, the 10member group at Ngundu Craft Center managed to source funds and built concrete shelters in less than 10 years of its existence.

\section{Legislation and rules governing the resources}

The NRB, the FC and the RDCs have conducted campaigns to enforce the legal regulations governing the utilisation of wood. This endeavor created mistrust between market participants and the authorities. There are four main legal instruments that relate to the wood resources in Zimbabwe. These are the Natural Resource Act of 1941, revised in 1975 and 1981, which created the NRB that controls the use of all natural resources; the Forestry Act of 1949, which created the FC and charged it with control of deforestation, amongst other functions; the Communal Lands Acts of 1982, which gives RDCs the rights to control the harvest of resources in their areas of jurisdiction; and the Communal Lands Forest Produce Act of 1987, which controls the harvesting of listed plant species from communal areas and regulates selling of tree species in communal areas. The latter act legislates that residents of communal areas may use tree resources for their own use but may not sell them, unless a permit is acquired. Most species used in the woodcraft sector are listed species and may not be cut, for example, $P$. angolensis, $C$. imberbe, $A$. quanzensis and Spirostachys africana (African sandalwood). The Communal Lands Acts of 1982 gives RDCs the rights to control the harvest of resources in their areas of jurisdiction. Although NRB and FC assist the RDCs in the enforcement of rules, the past has seen some haphazard raids on some of the markets, mainly by the FC, and subsequent confiscation of the products. But such enforcement is rare and, in general, the markets continue to operate with minimal to no interference from the state.

At the village level, the traditional leadership is the most important overseer of resource use. As there is no clear linkage between village authorities and RDCs, the council has little impact and local rules may differ significantly among villages. A number of village leaders have become involved in the woodcraft sector; they thus have difficulty justifying and enforcing traditional rules that limit the cutting of trees. 
As carvers move farther away from their markets in search of logs, their control over accessibility diminishes as different rules and regulations come into play. Hence in those places where tree resources are still available, people from resource-deficit zones find access to those resources, legally or otherwise, difficult (Braedt 2002).

\section{TRENDS AND MARGINS IN THE WOODCARVING MARKETS}

\section{Periodicity and trends in the marketing of woodcarvings}

A detailed survey was carried out at three markets where there were 105 participants. Over the period of analysis from June 1997 to November 1998 the highest income from the sales of carvings was Z\$120,000 in February (Figure 3). This period is not associated with high numbers of tourist visits, making it difficult to use the seasonality hypothesis to explain these sales. The month of June, however, is a South African holiday season, and this is reflected in higher incomes for woodcarving traders. It would be folly to try to extract seasonal fluctuations of incomes linked to the fluctuations in tourism, as data from Figure 3 do not fully support such a hypothesis. The fact that the markets that have been assessed have low sales rates (trading an average of 18 products per month) could explain the lack of clear trends.

Figure 3. Monthly income from the sale of woodcarvings for three craft markets along the Masvingo-Beitbridge road

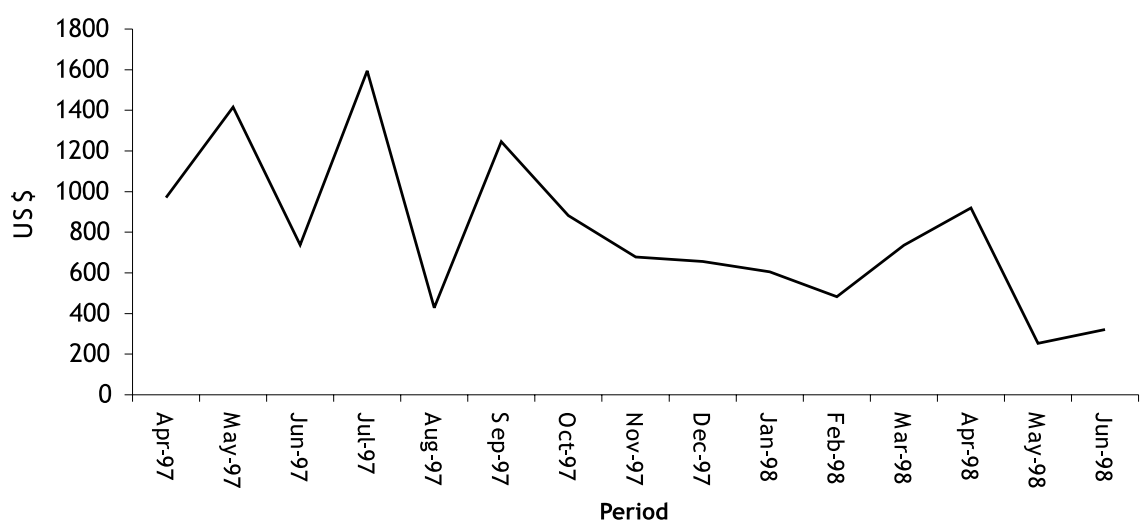

\section{Stages in the production of carvings}

The woodcarving process involves four main stages (Figure 4). The first level is the acquisition of raw materials from the woodland and their transportation to the market or another carving site. Using an adze the wood is usually carved to a very rough stage, at the place where the tree is felled. This practice removes unneeded wood, so that only carveable wood is being transported. The second stage is the carving of the wood into the final product. The third stage is the finishing of the piece with sandpaper and polish, whilst the last stage is the actual selling of the carving. 
Figure 4. Dominant market channel used by woodcarvers

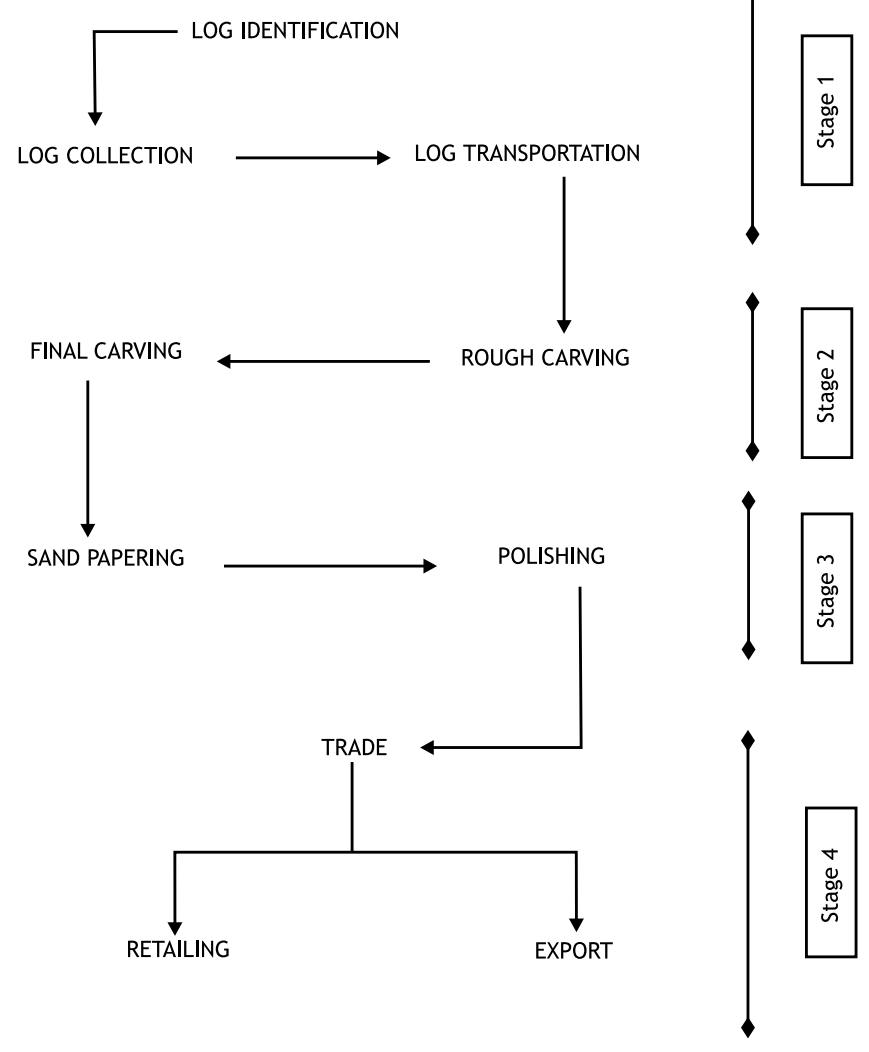

\section{Net returns to labor from carving}

Within the context of investigating fiscal instruments for promoting sustainability in the woodcarving sector the net margins to labor were calculated. A simple model that calculates the net return per unit hour of carver's time was developed for hippopotamuses carved from $A$. quanzensis $(n=55)$. Using the expected prices given by the carvers, the model shows that the net return to labour (including rough carving, carving, sanding, and polishing but excluding the cost of sales) was $Z \mathbf{Z} 10.37$ per hour (Table 4). Significantly, the net return per unit hour was two and one half times the Government Gazetted minimum agricultural wage for unskilled workers, which is $Z \$ 4.04$ per hour (Agricultural Labor Bureau personal communication).

Carvers prefer to purchase their raw material because the time required to identify, cut and transport a log to market (where most of the carving takes place) takes too much time. Respondents answered that they purchased $87 \%$ of their logs. Though purchasing of logs reduces carvers' perceived returns, the time saved is more valuable. There is widespread harvesting of timber from adjacent commercial farms. Although this practice is illegal it contributes about $13 \%$ of traded products. It is likely that carvers value their time at a much 
Table 4. Net returns on labour from carving a hippopotamus from Afzelia quanzensis $(\mathrm{n}=54)^{*}$

\begin{tabular}{|c|c|c|c|c|c|c|}
\hline & $\begin{array}{l}\text { Mean } \\
\text { price of } \\
\text { wood } \\
(\text { US\$/ } \\
\text { carving }^{* *} \text { ) }\end{array}$ & $\begin{array}{l}\text { Other } \\
\text { costs } \\
\text { recurrent } \\
\text { (US\$/ } \\
\text { carving) }\end{array}$ & $\begin{array}{l}\text { Total } \\
\text { cost } \\
\text { (US\$/ } \\
\text { carving) }\end{array}$ & $\begin{array}{l}\text { Price of } \\
\text { carving } \\
\text { (US\$/ } \\
\text { carving) }\end{array}$ & $\begin{array}{l}\text { Net } \\
\text { margin } \\
\text { (US\$/ } \\
\text { carving) }\end{array}$ & $\begin{array}{l}\text { Net } \\
\text { return on } \\
\text { labour } \\
\text { (US\$/hour) }\end{array}$ \\
\hline $\begin{array}{l}\text { Based on } \\
\text { expected } \\
\text { sale price } \\
\text { no stumpage } \\
\text { fees }\end{array}$ & 4.89 & 18.53 & 23.42 & 45.16 & 21.73 & 0.92 \\
\hline $\begin{array}{l}\text { Based on } \\
\text { adjusted } \\
\text { sale price }{ }^{* * *} ; \\
\text { no stumpage } \\
\text { fees }\end{array}$ & 4.89 & 18.53 & 23.42 & 41.09 & 17.67 & 0.75 \\
\hline $\begin{array}{l}\text { Based on } \\
\text { adjusted } \\
\text { sale price; } \\
\text { US } \$ 400 / \mathrm{m}^{3} \\
\text { stumpage } \\
\text { fees }\end{array}$ & 12.53 & 18.53 & 31.06 & 41.09 & 10.29 & 0.43 \\
\hline $\begin{array}{l}\text { Based on } \\
\text { adjusted } \\
\text { sale price; } \\
\text { US\$1,918/m³ } \\
\text { stumpage } \\
\text { fees }\end{array}$ & 22.57 & 18.53 & 41.10 & 41.09 & -0.01 & 0.00 \\
\hline
\end{tabular}

${ }^{*}$ At the time of the market survey US\$1 $=\mathbf{Z} \$ 11.30$. On average each carving takes 23.7 hours. ** The first five data columns are expressed on a 'per carving' basis, where the average volume of log used for a carving was $0.108 \mathrm{~m}^{3}$, whilst the average final product produced was $0.043 \mathrm{~m}^{3}$.

${ }^{* * *}$ For each carving in the survey an expected price was solicited from the carver. The adjusted price represents the price more likely received. The adjustment was done through a survey of carvings for which expected and actual selling prices were available.

higher rate than the prevailing local wage rates and so it is entirely rational for them to purchase wood rather than to collect it themselves. This explanation is supported by studies of the woodcarving sector in South Africa, which have estimated that the time taken to harvest timber was the single biggest cost facing a wood carver (Shackleton 1996).

This simple model was further used to investigate the likely impact of the introduction of fiscal incentives for conservation. In practice the simplest form of fiscal tool would be a levy or stumpage fee paid by the carver or wood harvester to the community controlling the resource. To the carvers these fees would increase the costs of wood. Based on the FC's stumpage fee at the time 
of the original studies from 1995 to $1997, Z \$ 400 / \mathrm{m}^{3}$, the introduction of a similar levy paid to the timber producing community would result in a drop in the net return for labour to the carver to $Z \$ 4.79 /$ hour. Using the same assumptions, a levy or stumpage fee of $Z \$ 1,918 / \mathrm{m}^{3}$ would reduce the net return to labour to zero. Thus a stumpage fee similar to that of the FC would make the woodcarving profession unattractive.

\section{CONSERVATION AND DEVELOPMENT LESSONS}

Any proposal to introduce fiscal tools for conservation must consider the financial incentives to the producer community as well as the increased costs and willingness to pay by the resource users. It is possible to define a set of economic criteria under which institutional change is likely to occur (Ostrom 1998) ${ }^{3}$. These state that the net benefit of new institutions, $\mathrm{NB}_{\text {new, }}$ should strongly exceed the net benefit of the old institutions or lack of institutions ( $\left.\mathrm{NB}_{\text {old }}\right)$ to the individual. Importantly, institutional change is not costless and the full costs of the proposed or desired changes need to be considered. These can be divided into four categories: the time and effort needed to devise and agree on the new institutions, $C_{1}$ ); the direct costs of the new institutions, $C_{2}$; the long term monitoring and enforcement costs of the new institutions, $\mathrm{C}_{3}$; and the opportunity costs foregone, $\mathrm{Copp}_{\text {. }}$

If $\mathrm{NB}_{\text {new }}<\mathrm{NB}_{\text {old }}$ it is highly unlikely that institutional change will be possible. If $\mathrm{NB}_{\text {new }}=\mathrm{NB}_{\text {old }}$ or $\mathrm{NB}_{\text {new }}>\mathrm{NB}_{\text {old }}$ then the probability of institutional change taking place is increased. Only when the net benefits of the new institutions strongly outweigh the net benefits of the old institutions, i.e. $N B_{\text {new }}>N_{\text {old }}$, is institutional change likely to occur. In the context of fiscal incentives it is extremely important that these benefits and costs are clearly identified and quantified.

The preceding framework considers the probability of institutional change solely in terms of a cost-benefit analysis. A major constraint to any form of institutional change for the management of indigenous woodlands in Zimbabwe is the Communal Lands Forests Products Act, under which the woodcarving sector and many current uses of woodlands by communal land residents are illegal (Scoones and Matose 1993; Bird et al. 1995). This is because the act limits communal land households to non-commercial uses of woodland products, including wood. The only legitimate commercial marketers of wood and woodland products from communal lands are the RDCs, which can, in conjunction with the FC and NRB, grant authority to commercially extract timber. Because of the emphasis on criminalisation, and the unenforceable nature of much of the legislation contained within the Communal Lands Forests Products Act, the Land Tenure Commission Report (Rukuni 1994) recommended that the act be amended so that 'communal land farmers can collectively take responsibility for forests, forest resources, and produce in their areas'.

The experience of the Communal Areas Management Programme for Indigenous Resources (CAMPFIRE) provides a substantial body of evidence against which the probability of success of fiscal incentives for woodland management can be assessed. Analysis of the annual gross benefit at household level has shown that in half of the wards the financial benefits were relatively 
low (Z\$34 per household). An analysis of these changes has suggested that the actual and even potential revenue that can be earned from wildlife is probably insufficient to achieve the necessary levels of institutional change for the management of wildlife and wildlife habitats.

The implications of the collective CAMPFIRE experience are critical in the assessment of the probability of success of fiscal incentives for woodland management in southern Zimbabwe. This research has shown that there is already a significant market for wood and that carvers are buying wood harvested in areas other than their immediate environments. This suggests that the main carveable species are already scarce within the communal lands where the markets are located, and that the creation of common-pool institutions for the management of woodlands is highly unlikely, solely on the basis of the financial incentives that can be generated from within the sector.

Important lessons for the woodcarving sector can be learned from Kenya, where both the scale and the intensity of the problem are far greater. Because of the scarcity of important carveable species, particularly Brachylaena huillensis and $D$. melanoxylon, carvers have substituted them with other species, most notably Olea europaeae ssp. africana, and Combretum schumannii. As carvers are aware of the threat of species depletion and the concomitant threat to their livelihoods, increasingly the exotic species of mango (Mangifera indica), jacaranda (Jacaranda mimosifolia), grevillea (Grevillea robusta), and neem (Azadirachta indica) are used as alternatives to the slow growing indigenous species (also referred to as 'good woods'). However, there is also a large scale illegal provision of indigenous wood to the carvers from state land and neighbouring countries such as Tanzania. This suggests that the government needs to urgently consider developing mechanisms whereby carvers, or the suppliers of wood to carvers, can legally access carveable species in the state forests. Without this provision it is likely that the illegal harvesting of wood will only escalate. In Kenya, another approach that has been tried is the provision of indigenous seedlings to carvers. However, a simple cost-benefit analysis of planting for the relatively fast growing $B$. huillensis shows that it is not financially viable (Bond et al. unpublished data). Whilst the provision of seedlings and the establishment of nurseries is aesthetically attractive, the absence of secure tenure over woodlands, the demand for land, the high grazing pressure and high interest rate make it financially unviable.

Under these conditions, it appears that the most viable options for ensuring the sustainability of the sector at the macrolevel are the following:

- First, to encourage the diversification of carvers to 'good woods', exotics such as jacaranda, neem, grevillea, mango and possibly some eucalyptus species. This can be done through programmes aimed at buyers and carvers.

- Second, the state should implement mechanisms by which carvers and wood merchants can legally obtain wood at market rates from state land. 


\section{ENDNOTES}

1. Center for International Forestry Research Regional Office for East and Southern Africa, No. 73 Harare Drive Northwood, Mount Pleasant Harare, Zimbabwe. E-mail: w.standa@cgiar.org

2. Institute for World Forestry, Federal Research Centre for Forestry and Forest Products, Leuschnerstrasse 91 D-21031 Hamburg, Germany. E-mail: braedt@holz.uni-hamburg.de

3. Ostrom (1999) defines seven design principles for common property management.

\section{REFERENCES}

Arnold, J.E.M., Liedholm, C., Mead, D. and Townson, I.M. 1994 Structure and growth of small enterprises in the forest sector in southern and eastern Africa. OFI occasional paper 47. University of Oxford, Oxford, UK.

Bird, C., Clarke, J., Moyo, J., Moyo, J.M., Nyakunu, P. and Thomas, S. 1995 Was Mrs Mutendi only joking? Access to timber in Zimbabwe's Communal Areas. Wildlife and Development Series 6: 20-26.

Braedt, 0. 2002 Forest products and rural households: woodcraft commercialisation in southern Zimbabwe. Ph.D. Thesis, University of Hamburg, Germany.

Braedt, O. and Standa-Gunda, W. 2000 Woodcraft markets in Zimbabwe. International Tree Crops Journal 10(4): 367-384.

Browder, J.O. 1992 Social and economic constraints on the development of market oriented extractive reserves in Amazon rain forests. Advances in Economic Botany 9: 33-41.

Cavendish, P. 1997 The economics of natural resource utilisation by communal area farmers of Zimbabwe. Ph.D. Thesis, University of Oxford.

Dove, M. 1993 A revisionist view of tropical deforestation and development. Environmental Conservation 20: 17-25.

Frost, P. 1996 The ecology of Miombo woodlands. In: Campbell, B.M. (ed.) The Miombo in transition: woodlands and welfare in Africa, 11-57. Center for International Forestry Research, Indonesia.

Gambiza, J. and Nyama C. 2001 Country pasture/forage resource profiles. http: / /www.fao.org/ag/AGP/AGPC/doc/Counprof/zimbab (10 Aug. 2002).

Homma, A.K.O. 1992 The dynamics of extraction in Amazonia: a historical perspective. Advances in Economic Botany 9: 23-32.

Johnston, B.F. and Kilby, P. 1975 Agricultural and structural transformation. Oxford University Press, Baltimore and London.

Marshall, N., Mulolani, D. and Sangalakula, L. 2000 A preliminary report of Malawi's woodcarving industry. Traffic East/Southern Africa Report, WWF, Zimbabwe.

Matose, F., Mudhara, M. and Mushove, P. 1997 The woodcraft industry of the Bulawayo-Victoria Falls road. Institute of Environmental Studies, University of Zimbabwe, Harare.

Momberg, F., Puri, R. and Jessup, T. 1997 Extractivism and extractive reserves in the Kayan Menterang Nature Reserve: is gaharu a sustainably manageable resource? In: Sorensen, K. and Morris, B. (eds.) People and plants of Kayan 
Menterang, 165-180. World Wide Fund for Nature Indonesia Programme and UNESCO, Indonesia.

The Namibian. 1999 Namibia's woodcarvers: a growing industry. http:// www.namibian.com.na/expert.carvers.html (4 Aug. 2002).

Obunga, R. 1995 Sustainable development of the wood craft industry in Kenya. National Museums of Kenya, Nairobi.

Ostrom, E. 1998 How communities beat the tragedy of the commons. Keynote presentation to an International Workshop on Community Based Natural Resource Management. Washington, D.C., May 1998.

Ostrom, E. 1999 Self-governance and forest resources. CIFOR Occasional Paper 20. Center for International Forestry Research, Bogor, Indonesia.

Rukuni, M. 1994 Report of the commission of inquiry into appropriate agricultural land tenure systems, vol. I. Harare, Zimbabwe.

Scoones, I. and Matose, F. 1993 Local woodland management: constraints and opportunities for sustainable resource use. In: Bradley, P.N. and McNamara, K. (eds.) Living with trees: policies for forestry management in Zimbabwe, 329-341. The World Bank, Washington, D.C.

Scoones, l. et al. 1996 Hazards and opportunities: farming livelihoods in dryland Africa, lessons from Zimbabwe. International Institute for Environment and Development and Zed Books Ltd., London, UK.

Shackleton, S. 1996 The woodcraft industry in the Bushbuckridge district of the Mpumalanga lowveld, South Africa. In: Campbell, B.M. (ed.) The Miombo in Transition: Woodlands and Welfare in Africa, 163-164. Center for International Forestry Research, Bogor, Indonesia.

Steenkamp, K. 1999 South Africa's woodcarving industry. TRAFFIC Bulletin 18(1):11-20. 


\title{
Chapter 12
}

\section{The Pterocarpus angolensis DC. based woodcraft industry in the Bushbuckridge district, South Africa}

Sheona E. Shackleton ${ }^{1}$ and Charlie M. Shackleton ${ }^{2}$

\begin{tabular}{llllll}
\hline Common names & $\begin{array}{l}\text { Part of the } \\
\text { resource used }\end{array}$ & Management & $\begin{array}{l}\text { Degree of } \\
\text { transformation }\end{array}$ & $\begin{array}{l}\text { Scale of } \\
\text { trade }\end{array}$ & $\begin{array}{l}\text { Geographic } \\
\text { range }\end{array}$ \\
\hline $\begin{array}{l}\text { Kiaat, African teak, } \\
\text { Murotso }\end{array}$ & Wood & Wild & Medium & National & Large \\
\hline
\end{tabular}

\begin{abstract}
Commercial carving and furniture manufacture using indigenous species, in particular Pterocarpus angolensis, harvested from communal lands has been a household activity in the Bushbuckridge district for several decades. It provides an important source of income for approximately 130 households in an area where the unemployment rate often exceeds $75 \%$. Carvers produce utility items such as bowls, spoons and walking sticks that are marketed outside of the district through curio outlets and informal markets. Furniture makers produce mainly tables, chairs and benches for sale at the roadside in urban centres as far afield as Pretoria and Johannesburg. Production contributes approximately $75 \%$ to total household income. Incomes are extremely variable ranging between $\mathrm{R} 4,416$ and $\mathrm{R} 14,328$ per annum. Wood scarcity is fast becoming the greatest constraint to continued production and growth of the industry, despite $P$. angolensis being subjected to various controls as a protected species. Access to alternative sources of wood is essential, and efforts must be made to involve producers in managing the resource. New skills, products, organisational structures and perspectives are required to develop the sector further and bring local woodworkers into the mainstream craft and curio industry. This is particularly so in light of the strong competition from imports from other African countries and the formal sector.
\end{abstract}




\section{INTRODUCTION}

In many parts of South Africa a diversity of forest and woodland species have long provided the raw material for the production of wooden household items (spoons, bowls, mortars and pestles, agricultural implements) and artefacts of cultural and ceremonial significance (sticks, drums, head rests). In more recent years, particularly in areas of high tourism potential, this traditional practice has expanded into an important income generating activity (Newton 1998, Steenkamp 1999a, b). One of the largest growth areas in the country for the woodcraft industry is the lowveld ${ }^{3}$ region of Mpumalanga and Limpopo Province bordering the Kruger National Park (KNP). Although commercialisation brings welcome economic opportunity to otherwise isolated and remote rural areas, it also results in increased pressure on the resource base. This ultimately threatens both the sustainability of the resource and the livelihoods of the craftspeople dependent on it (Arnold and Ruiz Perez 1998). The impacts are especially profound where slow growing hardwoods like Pterocarpus angolensis DC. and Dalbergia melanoxylon Guillemin \& Perrottet are favoured. This paper addresses some of these issues through a detailed description and analysis of the woodcraft industry in the Bushbuckridge district of the Limpopo Province lowveld.

\section{STUDY AREA}

The Bushbuckridge district $\left(31^{\circ} 0^{\prime}-31^{\circ} 35^{\prime} \mathrm{E} ; 24^{\circ} 30^{\prime}-25^{\circ} 0^{\prime} \mathrm{S}\right)$, corresponding to the Mhala and Mapulaneng areas of the former Gazankulu and Lebowa homelands ${ }^{4}$, covers an area of $2,417 \mathrm{~km}^{2}$ (Figure 1). Approximately $23.7 \%$ of this territory is under state owned plantation forestry and conservation and inaccessible to local residents. This leaves an area of $1,843 \mathrm{~km}^{2}$, of which $84.9 \%$ is designated as communal grazing land (about $1,564 \mathrm{~km}^{2}$ ), $8.7 \%$ is rainfed crop production, $2.9 \%$ is irrigated agriculture and $3.5 \%$ is residential.

There is a strong gradient of decreasing rainfall from west $(1,200 \mathrm{~mm}$ per annum) to east (500 mm per annum) across the district. Erratic rainfall and frequent droughts (once every four years) coupled with shallow, nutrient poor soils and land scarcity severely limit arable production and force most of the population to seek alternative means of livelihood. The natural vegetation is open woodland (subtropical dry forest, according to the Holdridge Life Zone system). The distribution of $P$. angolensis and other favoured carving species varies across the region, with higher densities found in the wetter western and southern parts of the district. The soils are mainly cambisols and regosols.

Projections from a detailed demographic study estimate the population at about 660,000 (Tollman et al. 1995). Population density is high at approximately 150 people $\mathrm{km}^{-2}$ in the east and 300 people $\mathrm{km}^{-2}$ in the west. Annual population growth rate is about 2.4\%. Average household size is 6.2 people (Tollman et al. 1995). Unemployment runs between $40 \%$ and $80 \%$ (Pollard et al. 1998). There is a heavy reliance on the cash economy and on state grants, mainly old age pensions. Approximately $50 \%$ of the adult male population and $14 \%$ of women engage in migrant labour (Pollard et al. 1998). Average household incomes range from R178 to R1,131 per month, with most households living below the poverty line of R700 per month (Tapson 1996). Informal sector activities such as woodworking are generally entered into out of pure economic necessity. 
Figure 1. Map of the study area
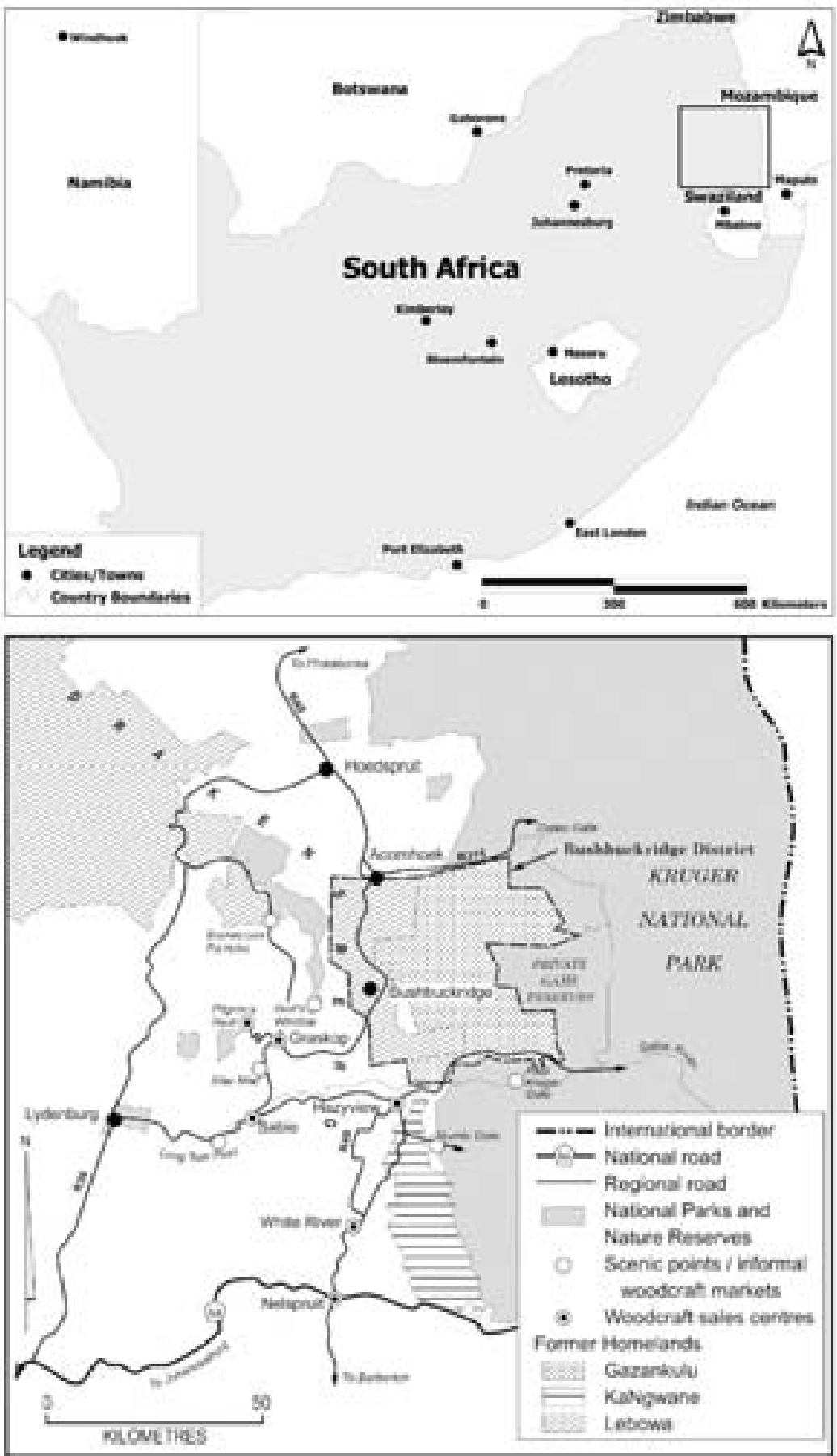

Source: ESRI Data and Maps 2002. 
Infrastructure and services are poor, although water, electricity supply and road infrastructure have improved since the political transition in 1994. There are approximately $125 \mathrm{~km}$ of tarred roads within the study area, along with several hundred kilometres of good quality gravel roads. Bulk water supplies are available to most villages, but few households have private connections. National grid electricity is available to villages and peri-urban 'townships', serving approximately half the population.

Bushbuckridge was (and to some extent still is) a disputed area in terms of provincial boundaries, causing political problems and a lack of government commitment to the district. The uncontrolled pillage of $P$. angolensis from Bushbuckridge Nature Reserve has been but one of the repercussions following confusion regarding the division of responsibilities between provincial authorities. The wider region is an important tourist destination because of its proximity to KNP, numerous private game farms, and the scenic areas and towns of the Drakensberg mountain range. This has been a crucial factor in the development of the carving industry and has positioned producers and traders well for tapping the tourism industry.

\section{APPROACH AND METHODS}

The information and data reported in this case study are based primarily on a detailed situation analysis of the woodcraft industry conducted in Bushbuckridge in 1992 and 1993 (Shackleton, S.E. 1993). This original study, in which an action research approach was adopted, involved in-depth interviews with 45 woodcraft producers as well as other role players in the craft industry including retailers and government officials. This primary material is supported by numerous secondary sources providing background information on the district (e.g., Shackleton et al. 1995; Pollard et al. 1998), the national woodcarving industry (e.g., Newton 1998; Steenkamp 1999a) and on the growth and harvesting rates of Pterocarpus angolensis and other carving species (e.g., Desmet et al. 1996; Clarke 1997; Shackleton 1997, 2002). A follow-up survey, in which much of the information was updated and augmented, was conducted in September 2000. This included interviews with woodworkers, conservation authorities, and representatives from various support organisations. All the main markets and retailers were revisited and traders interviewed.

The Rand/US dollar exchange rate in September 2000, when the new data were collected, was US\$1 $=$ R7.00. Because of rapid devaluation, the exchange rate at the time of writing was US\$1 = R9.00. When the 1993 study was conducted US\$1 was worth approximately R3.10.

\section{THE BUSHBUCKRIDGE WOODCRAFT INDUSTRY IN CONTEXT}

\section{History and cultural significance}

Carving traditionally formed part of Tsonga culture, and the Tsonga people were well known for the headrests and walking sticks they produced (Shackleton and Adelfang 1992). This tradition has had little influence on the contemporary carving industry, however, in contrast with other parts of Africa, such as Cameroon, where 
traditional artefacts like carved stools and masks still form a vital part of local culture as well as being sold commercially (Cunningham and Choge in press).

The use of $P$. angolensis for carvings and furniture commenced at the turn of the last century (Shackleton, S.E. 1993). Its value as a commercial timber was recognised and stimulated by the arrival of colonial settlers, who created a market for it. Indeed, white traders allegedly removed large amounts of timber from the area until as recently as the 1970s (Shackleton, S.E. 1993). Whilst the majority of home carvers and furniture makers in Bushbuckridge entered the industry in the last 15 to 20 years, a number have been plying their trade for over 50 years (Shackleton, S.E. 1993). This contrasts with the softwood animal figurine carving industry of the neighbouring district, which evolved and grew in the early to mid 1990s.

\section{Impact on livelihoods}

High levels of unemployment combined with a shrinking job market, a lack of land for farming purposes and increased need for cash income have driven many households in the rural areas of South Africa to seek alternative income earning opportunities. Involvement in woodcarving and furniture production is one strategy that has been widely adopted in parts of the country where suitable carving species occur (e.g., Venda and Bushbuckridge in Limpopo Province, Mpumalanga, and the Zululand and Maputuland areas of KwaZuluNatal) (Newton 1998; Steenkamp 1999a).

Craftsmen tend to enter the woodcraft industry following retrenchment (Shackleton, S.E. 1993; Moloi 1999a), some moving back and forth repeatedly between it and formal employment (Moloi 1999a). The ability to access wood and fashion it into saleable products is thus an important safety net and coping strategy for the unemployed. Based on a comprehensive poverty index, Steenkamp (1999b) found that the woodcarving industry supports the poorest sectors of the community, the households involved being highly dependent on the proceeds generated. Employment opportunities also are created for assistants, traders, informal vendors and retailers. Thus, the industry provides work for numerous people supporting a large network of dependents. It is estimated that more than 4,000 people benefit from the woodcraft industry in Bushbuckridge and the wider production-to-consumption system area.

\section{Economic importance}

The woodcarving industry in South Africa is small relative to other African countries (see other case studies in this book), partly because of the limited distribution of suitable carving species and partly because there is no strong tradition of elaborate carving. Currently, at a national level, the economic value of imports from elsewhere in Africa is higher than that of the domestic carving industry (Steenkamp 1999a). Newton (1998) found that informal sector participation in the South African woodcraft industry generates about R2.48 million per annum, whilst vendors from southern, eastern and western Africa generate about R29 million (Table 1). In Bushbuckridge, the carving and informal furniture manufacturing industry was estimated to be worth about R365,000 
per annum in 1993 (Shackleton 1996). Desmet et al. (1996) report trade in $P$. angolensis carvings and furniture amounting to over R5 million annually for Mpumalanga and Limpopo provinces. Although the industry is small, the impacts on the resource base and the conservation and development consequences are no different to other countries, while the situation is made more complex by the restricted distribution of many of the key carving species.

Table 1. The South African woodcarving industry in perspective: the value of the domestic industry relative to imports from elsewhere in Africa

\begin{tabular}{|c|c|c|c|}
\hline \multicolumn{2}{|c|}{$\begin{array}{l}\text { Annual value } \\
\text { of South African } \\
\text { woodcarvings }\end{array}$} & \multirow{2}{*}{$\begin{array}{l}\text { Annual value of } \\
\text { woodcarvings } \\
\text { from southern Africa } \\
\text { sold in the informal } \\
\text { sector in South Africa }\end{array}$} & \multirow{2}{*}{$\begin{array}{l}\text { Annual value of } \\
\text { woodcarvings from } \\
\text { west and east Africa sold } \\
\text { in the informal sector } \\
\text { in South Africa }\end{array}$} \\
\hline $\begin{array}{l}\text { Informal } \\
\text { sector }\end{array}$ & $\begin{array}{l}\text { Formal } \\
\text { sector }\end{array}$ & & \\
\hline R2.48 million* & R4.89 million & R5.8 million & R23.1 million \\
\hline
\end{tabular}

* Note: The authors believe this value to be an underestimate as it was based on a very conservative estimate of the number of woodcarvers in South Africa. In 1998 US\$1 = R6.

Source: Newton 1998.

\section{Regional and national context and production strategies}

The Bushbuckridge woodcraft industry is imbedded in a wider, rapidly changing and complex craft industry that links the formal sector (factories and shops) with the informal sector (local producers, roadside stalls, flea markets) at sourcing, production and sales levels (Steenkamp 1999a). South Africa is both a producer of wood products and an importer, with the volume of imports increasing dramatically in the last five years following the lifting of trade embargoes (Steenkamp 1999a). Domestic production varies from low technology household or group-based enterprises that harvest their own wood (as described here) to large-scale, urban-based factories that acquire wood via timber merchants and produce machine made goods. All these businesses and their products compete for a place in the market.

Within the informal sector, two main categories of woodcraft producers have been identified based on their production and marketing strategiesroadside carver vendors and home carvers (Steenkamp 1999a, b). The Bushbuckridge producers described in this paper fall almost entirely into the latter category. By contrast, carvers from neighbouring Hazyview and Nsikazi typically are carver vendors. These two groups differ significantly in their modes of production, products, marketing strategies and types of wood used (Table 2) (Steenkamp 1999a).

\section{THE RAW PRODUCT AND RESOURCE BASE}

\section{Sources of wood}

Bushbuckridge producers obtain their wood primarily from wild populations in the communal lands, although some illegal harvesting occurs within 
Table 2. Different woodcarving production strategies found in the region

\begin{tabular}{|c|c|}
\hline Home carvers, Bushbuckridge & $\begin{array}{l}\text { Roadside carver vendors, } \\
\text { neighbouring Nsikazi }\end{array}$ \\
\hline - work from home & - produce and sell from makeshift \\
\hline - independent entrepreneurs & - groups of carvers or individuals \\
\hline $\begin{array}{l}\text { - family-based production, } \\
\text { women and children assist } \\
\text { in finishing }\end{array}$ & - males, mainly young \\
\hline - use hard woods & - use softer woods \\
\hline - produce utilitarian objects & $\begin{array}{l}\text { - produce animals and figurines (up } \\
\text { to } 2 \mathrm{~m} \text { tall) }\end{array}$ \\
\hline - sell to vendors and retailers & - sell directly to tourists \\
\hline $\begin{array}{l}\text { - carving seen as a permanent } \\
\text { livelihood activity }\end{array}$ & $\begin{array}{l}\text { - transient, carving forms safety net } \\
\text { in times of unemployment }\end{array}$ \\
\hline $\begin{array}{l}\text { - better equipment } \\
\text { (chain saws, bought tools, } \\
\text { power tools) }\end{array}$ & $\begin{array}{l}\text { - low technology facilities (home- } \\
\text { made tools) }\end{array}$ \\
\hline - access to electricity & - no access to electricity \\
\hline $\begin{array}{l}\text { - work in covered workshops } \\
\text { or shelters }\end{array}$ & - work in the open on the ground \\
\hline $\begin{array}{l}\text { - older industry-since 1970s } \\
\text { and before }\end{array}$ & - younger industry-since 1990s \\
\hline $\begin{array}{l}\text { - industry stable with } \\
\text { few new entrants }\end{array}$ & $\begin{array}{l}\text { - industry has grown rapidly and is } \\
\text { still growing }\end{array}$ \\
\hline
\end{tabular}

conservation areas. Seventeen species in total are used (Table 3). P. angolensis is by far the most important, followed by Spirostachys africana, Dalbergia melanoxylon, Berchemia zeyheri (Sonder) Grubov and Olea europea L. ssp. africana (Miller) P.S. Green (Shackleton, S.E. 1993). A few woodworkers obtain Apodytes dimidiata E. Meyer ex Arn. from private farms in a nearby commercial farming area. This case study analysis focuses on $P$. angolensis as the most favoured and most abundant species in the study area.

Because of scarcity of wood, especially over the last decade, alternative sources are being sought at the instigation of both craftsmen and support agencies. Recent work revealed that carvers are now accessing wood from neighbours' home plots and fields as well as revisiting previous harvesting sites to salvage 'waste' wood. Furniture makers reported purchasing $P$. angolensis planks imported from Mozambique and Zambia from timber merchants in Johannesburg, Pretoria and Nelspruit. The Danish Cooperation for Environment and Development Community Forestry Project and the KNP Socio-Ecology Programme have assisted woodworkers in obtaining wood from the national Working for Water Programme ${ }^{5}$ and from areas cleared for mining and other developments (Yeatman personal communication). One carverfurniture maker successfully negotiated with a farmer to harvest the exotic species jacaranda (Jacaranda mimosifolia D. Don) and syringa (Melia azedarach L.) from his farm. 
Table 3. Species used by woodworkers in Bushbuckridge and their main uses

\begin{tabular}{|c|c|c|c|}
\hline Botanical name & Common name & Major uses & Conservation status \\
\hline $\begin{array}{l}\text { Pterocarpus } \\
\text { angolensis }\end{array}$ & Kiaat & $\begin{array}{l}\text { Bowls, spoons, } \\
\text { plates, trays, } \\
\text { furniture }\end{array}$ & Protected \\
\hline $\begin{array}{l}\text { Dalbergia } \\
\text { melanoxylon }\end{array}$ & $\begin{array}{l}\text { Black ivory/ } \\
\text { zebrawood }\end{array}$ & $\begin{array}{l}\text { Small dishes, } \\
\text { spoons, } \\
\text { walking sticks, } \\
\text { candles sticks, } \\
\text { small tables }\end{array}$ & $\begin{array}{l}\text { Threatened } \\
\text { throughout } \\
\text { the region, scarce }\end{array}$ \\
\hline $\begin{array}{l}\text { Berchemia } \\
\text { zeyheri }\end{array}$ & Red ivory & $\begin{array}{l}\text { Walking sticks, } \\
\text { spoons, } \\
\text { forks, bowls, eggs, } \\
\text { small tables }\end{array}$ & Scarce \\
\hline $\begin{array}{l}\text { Olea europea } \\
\text { ssp. africana }\end{array}$ & Wild olive & $\begin{array}{l}\text { Spoons, small bowls, } \\
\text { eggs, walking sticks, } \\
\text { small tables }\end{array}$ & Protected, scarce \\
\hline $\begin{array}{l}\text { Spirostachys } \\
\text { africana }\end{array}$ & Tamboti & $\begin{array}{l}\text { Trays, furniture, } \\
\text { walking sticks }\end{array}$ & Protected \\
\hline $\begin{array}{l}\text { Apodytes } \\
\text { dimidiata }\end{array}$ & White pear & $\begin{array}{l}\text { Walking sticks, } \\
\text { batons, eggs }\end{array}$ & Protected \\
\hline $\begin{array}{l}\text { Combretum } \\
\text { imberbe Wawra }\end{array}$ & Lead wood & $\begin{array}{l}\text { Furniture, } \\
\text { walking sticks, } \\
\text { plates and boards }\end{array}$ & Protected \\
\hline $\begin{array}{l}\text { Acacia } \\
\text { ataxacantha DC. }\end{array}$ & Flame thorn & Teaspoons & Common \\
\hline $\begin{array}{l}\text { Breonadia } \\
\text { microcephala } \\
\text { (Delile) Ridsd. }\end{array}$ & Matumi & $\begin{array}{l}\text { Bowls, spoons, } \\
\text { small tables }\end{array}$ & Limited \\
\hline $\begin{array}{l}\text { Terminalia } \\
\text { sericea } \\
\text { Burch. Ex DC. }\end{array}$ & Silver cluster leaf & $\begin{array}{l}\text { Furniture, trays, } \\
\text { spoons, bowls }\end{array}$ & Common \\
\hline $\begin{array}{l}\text { Dombeya rotundifolia } \\
\text { (Hochst.)Planchon }\end{array}$ & Wild pear & Spoons & Common \\
\hline $\begin{array}{l}\text { Schotia } \\
\text { brachypetala Sonder }\end{array}$ & Weeping boer bean & Walking sticks & Limited \\
\hline $\begin{array}{l}\text { Acacia } \\
\text { nigrescens Oliver }\end{array}$ & Knob thorn & $\begin{array}{l}\text { Candle sticks, } \\
\text { spoons }\end{array}$ & Common \\
\hline $\begin{array}{l}\text { Albizia versicolor } \\
\text { Welw. Ex Oliver }\end{array}$ & Poison-pod albizia & Mortar and pestles & Common \\
\hline $\begin{array}{l}\text { Sclerocarya birrea } \\
\text { (A. Rich.) Hochst }\end{array}$ & Marula & Stools, animals & Common \\
\hline $\begin{array}{l}\text { Dichrostachys cinerea } \\
\text { (L.) Wight \& Arn. }\end{array}$ & Sickle bush & $\begin{array}{l}\text { Spoons, forks, } \\
\text { bowls }\end{array}$ & $\begin{array}{l}\text { Common and a bush } \\
\text { encroacher }\end{array}$ \\
\hline $\begin{array}{l}\text { Jacaranda } \\
\text { mimosifolia }\end{array}$ & Jacaranda & $\begin{array}{l}\text { Bowls, spoons, } \\
\text { animals }\end{array}$ & Exotic and invasive \\
\hline
\end{tabular}

Note: Species are listed in order of frequency of use.

Sources: Shackleton 1993, Newton 1998. 


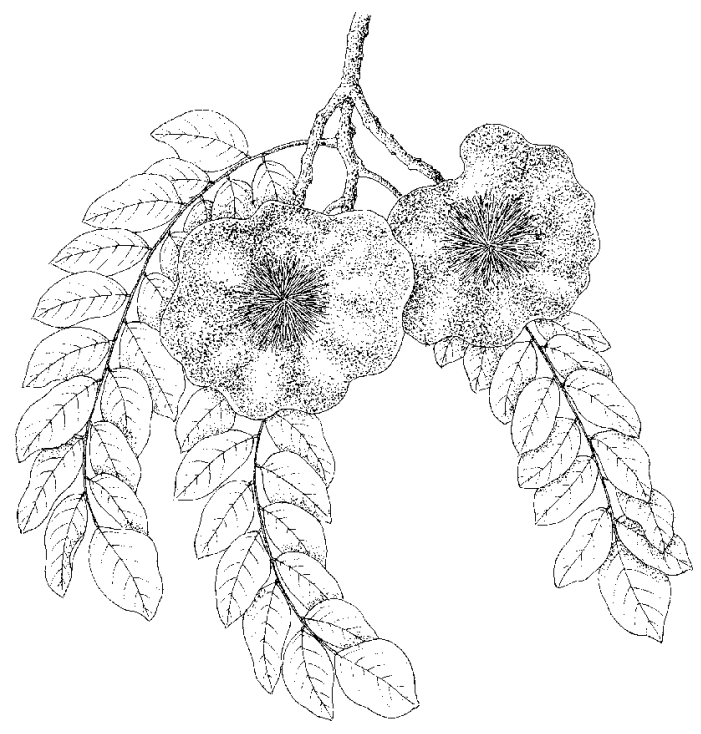

(Pterocarpus angolensis)

\section{Harvesting procedure}

$P$. angolensis is a protected species (through various provincial laws and ordinances) and effectively state property. It must not be harvested without a permit. Trading in raw wood is prohibited, and in the former Gazankulu and Lebowa only local producers had legal access to wood. A variety of institutional mechanisms and processes apply to the harvesting of protected species in different parts of the country. In Bushbuckridge the system legislated under the Gazankulu Nature Conservation Act is essentially still in place, although this may change as the authorities amalgamate and develop new conservation legislation under the new provincial structures.

Previously, to access $P$. angolensis, producers required a licence that permitted them to practice (Shackleton, S.E. 1993). The permit was acquired through a fairly complex process involving tribal authorities, the local magistrate and the (former) Gazankulu Department of Finance. The licence made the holder eligible to harvest wood. Woodworkers without licences either harvested illegally, obtained a temporary permit or solicited wood from a licensed individual. This licensing system was rescinded following the incorporation of Gazankulu into Limpopo Province, easing the situation for those producers without licences and removing a significant barrier of entry to the trade.

Unlike the licensing system, the steps to obtain wood have changed little. The woodworker selects two to five trees within the communal lands. On felling, the trees are measured by the local ranger, who accompanies the producer on his harvesting trip, and the amount owed calculated (at R6 per running metre). The sum of about R250 to R400 per harvesting trip is paid in cash and a receipt issued. The stumps and logs are stamped to denote the legality of the harvest. The revenue is banked by the provincial Department of Agriculture and Environment (Tsweni personal communication). 
This system relies heavily on law enforcement by rangers and tribal authorities. To date little attempt has been made to include woodworkers in resource management. Producers found with illegal wood (usually in periodic home raids) are apprehended and fined. Consequently, most craftsmen, while recognising the need for protection of the resource, do not support the current system (Shackleton 1993). Harassment, alleged corruption (rangers taking wood or issuing incorrect receipts) and a lack of credit to purchase wood were provided as further reasons for carvers' discontent. However, craftsmen expressed concern about the decline in the resource base and the increased appropriation of wood by external groups. Indeed, there is growing anecdotal evidence to suggest that many of the controls have broken down (Macleod 1999; Shabangu personal communication), mainly a result of institutional confusion and a lack of clarity regarding which authorities at both provincial and local level (i.e., local government or chiefs) are responsible for this function, as well as budgetary and capacity constraints. Recent efforts by Limpopo Province, however, are attempting to address this by supporting traditional leaders in reasserting their customary control over the natural resource base. A Deforestation Liaison Committee has recently been formed for Bushbuckridge.

\section{Ecological characteristics of $\mathrm{P}$. angolensis and impacts of harvesting}

$P$. angolensis has few characteristics that favour its sustainable use as a carving wood. Although a fairly ubiquitous species occurring throughout southern and eastern Africa, its geographic distribution in South Africa is narrow and limited to parts of Limpopo Province, Mpumalanga and northern KwaZulu-Natal. It demonstrates poor sprouting ability (Shackleton 1997; Krynauw 1999), and most trees die after felling. Recruitment is episodic as illustrated by size class profiles (Shackleton, C.M. 1993; Clarke 1997). Tree density is low at about 2 to 3 adults per hectare (Desmet et al. 1996), although the total number of stems (seedlings and saplings) can be as high as 26 to 59 per hectare (Krynauw 1999). Little is known about its growth rate. $P$. angolensis has a peculiar trait of remaining as a suffrutex (small sapling) for a number of years, possibly up to 24 years (Vermeulen 1990). The cues that stimulate it to enter a phase of rapid vertical growth are unknown, but have been speculated as fire, browsing, a year of high rainfall or release from competition. Data collected by Shackleton (1997) over a period of seven years for 99 trees estimated that the time to reach a minimum harvestable size of $84 \mathrm{~cm}$ circumference (Desmet et al. 1996) was approximately 82 years. ${ }^{6}$ The model derived by Desmet et al. (1996) between diameter and absolute mean annual increment based on one year's growth data resulted in an estimate of approximately 93 years. Neither of these includes time in the suffrutex stage. The length of time to reproductive age is also long. Shackleton (1997) found the smallest size of fruiting for $P$. angolensis was $25 \mathrm{~cm}$ circumference (about 36 years old), but only a few trees of this size bore fruit. Half of all trees $60 \mathrm{~cm}$ circumference possessed fruit (about 59 years old), and all trees $80 \mathrm{~cm}$ circumference (approximately 78 years old) or greater had fruit. Fruiting is regular and pollination and seed dispersal is by wind. 
The rate of harvesting of $P$. angolensis in 1994 was estimated as $5.6 \%$ of harvestable individuals per year (Desmet et al. 1996). A simple Leslie matrix model indicated that this was unsustainable over the long-term. Clarke (1997) compared the demand data of Shackleton, S.E. (1993) with supply data (density and size-class profiles) for several species and similarly concluded that the current rate of demand is unsustainable. Certainly, wood scarcity has become a major concern for producers and has been the most significant change observed in the local industry. None of the harvesting sites mentioned in 1993 were still in use, and craftspeople were moving further north as well as looking to populations outside the study area for wood (Shabangu personal communication). However, recruitment appears adequate (Desmet et al. 1996), with producers commenting on the large number of young individuals that exist in selected areas. In particular, Bushbuckridge Nature Reserve has large dense stands of immature trees (Shackleton 1997; Shabangu personal communication), although most mature trees have been illegally removed (Macleod 1999). There is evidence that pressure on young trees is increasing as mature trees become scarcer, with some carvers harvesting small diameter trees for walking sticks.

\section{Policy and management issues}

Newton (1998) has argued that at the national level the "confusing and complex legislative situation in South Africa represents one of the greatest obstacles in the way of socially and environmentally appropriate development of the woodcarving industry'. Legislation presently under development should take cognisance of the socio-economic realities on the ground, so that disparaging confrontation between rural communities and conservation authorities can be avoided. Law enforcement needs to be downplayed in favour of greater participation of woodworkers in resource management, and perhaps local producers should be afforded some legal recognition that provides them with preferential rights of access to wood. Controlled access to wood within conservation areas, as well as the promotion of alternative species, would help to reduce pressure on currently exploited populations. Uniform legislation would contribute greatly towards an improvement in implementation and monitoring (Newton 1998).

At present there is no ecological management of $P$. angolensis outside of conservation areas. A management plan for this species in a communal area was drawn up by the Mpumalanga Parks Board, but not implemented (Krynauw 1999) owing to a lack of resources and poor organisational capacity in the local community. The extensive and intensive management of tree populations within communal lands is a sphere that requires urgent attention if the local extinction of key species is to be prevented. Some work in this regard has been done for timber and carving species in east Africa (Holmes 1995), and Vermeulen (1990) makes some suggestions for the management of natural populations of $P$. angolensis. 


\section{PROCESSING INDUSTRY}

\section{Production and income}

Woodcarvers and furniture manufacturers using indigenous woods constitute only a small proportion of the total population of Bushbuckridge. Exact numbers are difficult to obtain, but there are an estimated 50 woodcarving and 60 furniture making households in the area supporting, directly and indirectly, some 2,000 employees and family members.

Carvers produce undecorated utility items such as bowls, spoons from ladles to serving spoons and teaspoons, platters, trays in a variety of sizes and walking sticks, which are marketed outside the district. Some items such as mortars and pestles, spoons and traditional sticks may be made for the local market on request. Less frequently produced goods include bangles, candlesticks, key rings, batons and eggs. Furniture makers can produce almost any item of furniture. These may be sold directly to buyers based on prior orders or sold on the roadside in urban centres as far afield as Johannesburg and Pretoria (Shabangu personal communication). One income enhancement strategy adopted by carvers between 1993 and 2000 has been to diversify into furniture production. This move was facilitated by connection to the electricity grid.

Photo 1. Range of woodcraft products produced by Bushbuckridge hardwood carvers (Photo by C.M. Shackleton)

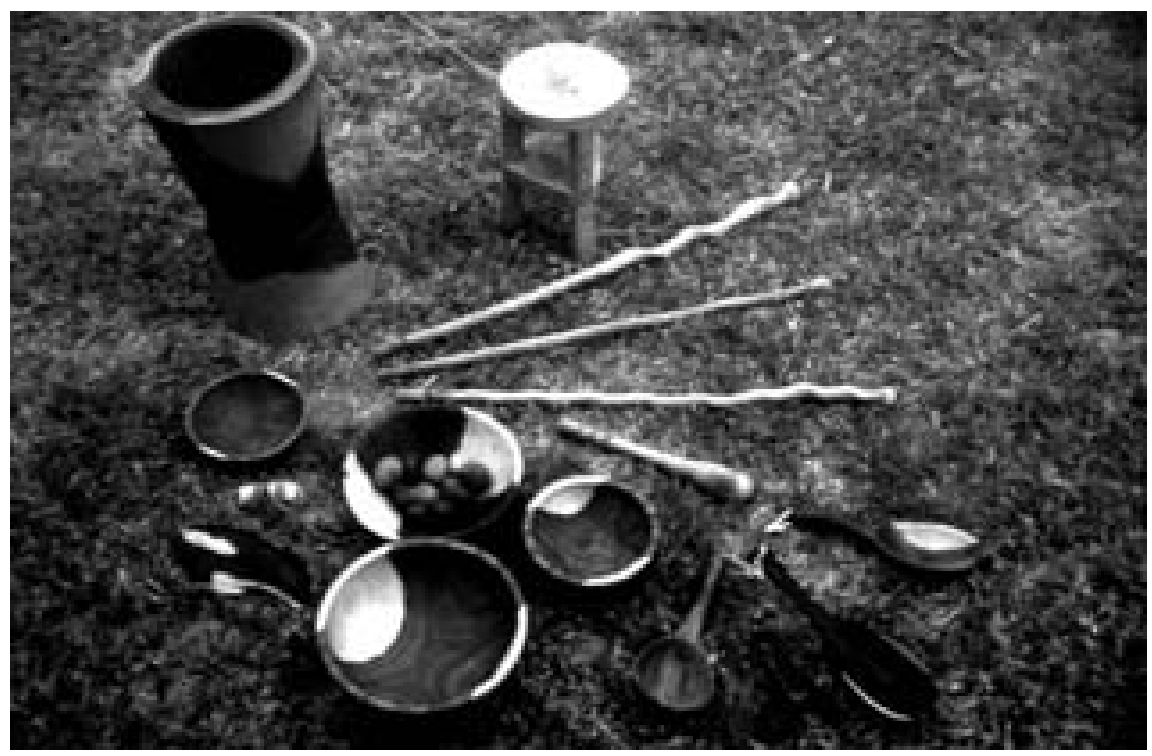

Amongst producer households an average of $75 \%$ of cash income is derived from the sale of carvings and furniture. Other contributors to income include state grants such as old age pensions and disability grants (which account for most of the additional income), sales of products such as firewood, pottery, medicine and thatch, and cash earned from ad hoc activities like farming, 
building, roofing and general repairs. In all cases, the producers themselves are the primary income earners in the household and, in general, furniture makers have a greater diversity of income sources than carvers. Total cash incomes for producer households in 2000 were estimated as R4,416, R23,084, and R14,328 per annum for carvers, carver-furniture makers and furniture makers, respectively (Table 4).

Table 4. Average net annual incomes earned by carvers and furniture makers in Bushbuckridge, 1993 and 2000

\begin{tabular}{llll}
\hline $\begin{array}{l}\text { Year and } \\
\text { 'form' of income }\end{array}$ & Carvers & $\begin{array}{l}\text { Carvers-furniture } \\
\text { makers }\end{array}$ & Furniture makers \\
\hline $\begin{array}{l}1993 \text { - Average net } \\
\text { annual income } \\
\text { from sales } \\
\text { of wood products }\end{array}$ & $\mathrm{R} 1,710$ & - & $\mathrm{R} 7,140$ \\
$\begin{array}{l}2000 \text { - Average net } \\
\text { annual income } \\
\text { from sales } \\
\text { of wood products }\end{array}$ & $\mathrm{R} 3,603$ & $\mathrm{R} 15,648$ & $\mathrm{R} 7,065$ (small \\
$\begin{array}{l}\text { 2000 - Average net } \\
\text { annual total cash } \\
\text { income (all sources) }\end{array}$ & $\mathrm{R} 4,416$ & $\begin{array}{l}\text { R23,084 } \\
\text { (biased by } \\
\text { one producer,who was } \\
\text { participating in a range } \\
\text { of entrepreneurial } \\
\text { activities) }\end{array}$ & \\
\hline
\end{tabular}

Net income is calculated as gross income minus costs (i.e., materials, travel, equipment, employees wages etc. but excluding own labour). US\$1 = R3.10 in 1993; US\$1 = $\mathrm{R} 7.00$ in 2000.

Production, sales and, consequently, income tends tend to be erratic, influenced by factors such as tourist season, amount, size and species of wood (no wood at all was a frequent problem encountered in the follow-up survey), working order of machinery, cash flow situation, success with selling stocks, and number and size of orders. Many of the woodworkers experience several months of the year without income (Shackleton, S.E. 1993). For these reasons, and because none of the producers keep books or records, income proved an extremely difficult variable to determine accurately in a once-off survey.

In 1993, in a 'good' month, net income ${ }^{7}$ from sales ranged from R100 to R600 for carvers and from R500 to R2,750 for furniture makers (Shackleton, S.E. 1993). Average net annual incomes from woodcraft and furniture sales in 1993 were approximately R1,710 for carvers and R7,140 for furniture makers (Table 4). In 2000, the corresponding figures were R3,603 for carvers, R15,648 for carver-furniture makers and R7,065 for furniture makers (Table 4). Overall, these data are comparable to those for carvers from other rural communal areas (Steenkamp et al. undated). The longitudinal data indicate that although absolute values are mostly higher, incomes have not matched inflation and some households are possibly worse off than they were a decade ago. 
The greatest costs for both groups are incurred during harvesting and marketing. The main input costs for harvesting include capital to purchase a chain saw, chain saw maintenance and fuel, payment of additional labour, travel costs for two or three trips to the harvesting site and the hire of a truck to transport logs home. The average annual harvesting cost is R3,459. Other overheads include the purchase of tools and consumables such as sandpaper and polish. Many woodworkers have invested in power tools over the last few years. Wages are another relatively high outlay. Furniture makers employ from 6 to 17 workers on a part-time or full-time basis, whereas few carvers employ additional help. Instead, most recruit the unpaid assistance of family members. Wages are variable and a common method of payment is a set rate per item completed. Men are usually employed for carpentry or carving work, and women for sanding and polishing. Unstable income was mentioned as the main reason for not employing assistants, or for employing them on a part-time basis only.

The returns relative to the cost of the raw material are high, the farmgate price of wood being approximately R0.60 per kilogram relative to an average of R46 per kilogram for finished products (Steenkamp 1999b). Known artists can obtain as much as R400 per kilogram. Wastage, however, occurs owing to design, poor tools, cracking, and borer damage. Much of the raw timber is thus lost. The local price for wood is highly subsidised and the value of $P$. angolensis timber in the commercial market is many times higher (R8,000 per cubic meter).

Major constraints to the industry, as perceived by woodworkers, include a lack of credit facilities and the consequent inability to purchase or hire sufficient machinery, tools, wood, and transport; wood scarcity; poor business and organisational skills; and a limited market. Two problems highlighted in 1993, i.e., difficulties obtaining licences and a lack of electricity, were no longer applicable in 2000. Buyers and external organisations have also identified poor and inconsistent quality, irregularity of supply, a limited product range and a lack of individuality, innovation and creativity as problems (Bristow-Bovey 1998).

Such constraints are not unique to woodcaft producers. The difficulties rural craftspeople experience in meeting the quality standards and aesthetic and fashion trends of high-value markets, as well as the logistical and financial constraints they face in the production process, have been highlighted by other writers (Marcus 2000; MDA 2000). Marcus (2000) concludes, for an area of KwaZulu-Natal, that 'presently craft production in poor households is beset by a lack of variety, variability in quality of output, narrow markets that are spatially and materially limited, and limited production flexibility'. The lack of access to microcredit also prevents producers who have broken into the market, and managed to secure large orders, from prefinancing the scale of production required to meet demand. The result is that 'the market is unforgiving: it moves on' (MDA 2000).

\section{Levels of organisation}

Some researchers believe that poor organisational ability is one of the biggest limitations to growth in the woodcraft industry nationwide (Bristow-Bovey 1998; Steenkamp 1999b). Home crafters have always tended to operate independently, which has been both a strength and a weakness. The strength lies in the fact that these producers have successfully managed to earn a living for themselves 
with little outside support. The weakness lies in the many missed opportunities for growth and development of the local industry because of failure to co-operate and make use of the considerable collective potential that exists. The last decade, however, has seen the formation of a number of producer organisations, of varying effectiveness, in the area.

The Mhala Woodworkers Association (MWA) was formed in 1993 (Shackleton, S.E. 1993). Its aims were to increase marketing opportunities, access external support, secure wood by collective means, and enhance co-operation between woodworkers. Since then, three woodworkers' associations within the broader region-the Nyongane, Mhala and Lubambiswano associations-amalgamated to form the Skukuza Alliance in 1997. This move was facilitated by the South African National Parks and is primarily market orientated, providing producers with covered markets adjacent to two of the entrance gates to KNP.

The MWA is relatively inactive although its existence has been important in securing donor funding and allowing carvers to participate in the Skukuza Alliance. One of the factors limiting the effectiveness of the MWA is the wide spatial dispersion of home producers who have neither time nor money to get together. Many members also favour operating on their own and demonstrate reluctance to share potential business opportunities.

The Skukuza Alliance is a formal organisation that has been effective in opening up marketing opportunities but has also had its share of organisational difficulties and conflict (abuse of positions of power, unaccounted expenditures, micropolitics etc.). Bushbuckridge carvers have reservations about aspects of its functioning and feel neglected in favour of the roadside carver-vendors. It is ironic that a lack of organisational capacity and co-operation should limit development and progress, but at the same time the formation of new organisations inevitably increases conflict and competition and leads to discord and a lack of trust between producers.

The woodcarvers in the former Lebowa area of Bushbuckridge formed their own association, which doubled as a lending club. This organisation ran into problems, however, when lenders failed to repay their loans and is currently dysfunctional.

\section{TRADE AND MARKETS}

\section{Marketing}

Most marketing is carried out by producers themselves on an individual basis (Figure 2). The road network in Bushbuckridge is fairly well developed and the majority of households are within easy walking distance $(2 \mathrm{~km})$ of a road and taxi route. Carvers make one or two selling trips per month, and furniture makers one every two months. For carvers, most markets are between one hour (Kruger Gate of KNP) and three hours (Pilgrim's Rest) away. Producers may take a day to visit all the main selling points (some 90 outlets). Furniture makers generally drive up to Gauteng $(500 \mathrm{~km})$, and usually stay there for a week or more selling at the roadside. Carvers usually travel by minibus taxi whilst furniture makers hire a small pick-up truck. The average cost to market goods is approximately R90 per month for carvers and as much as R2,000 per trip for furniture makers. 


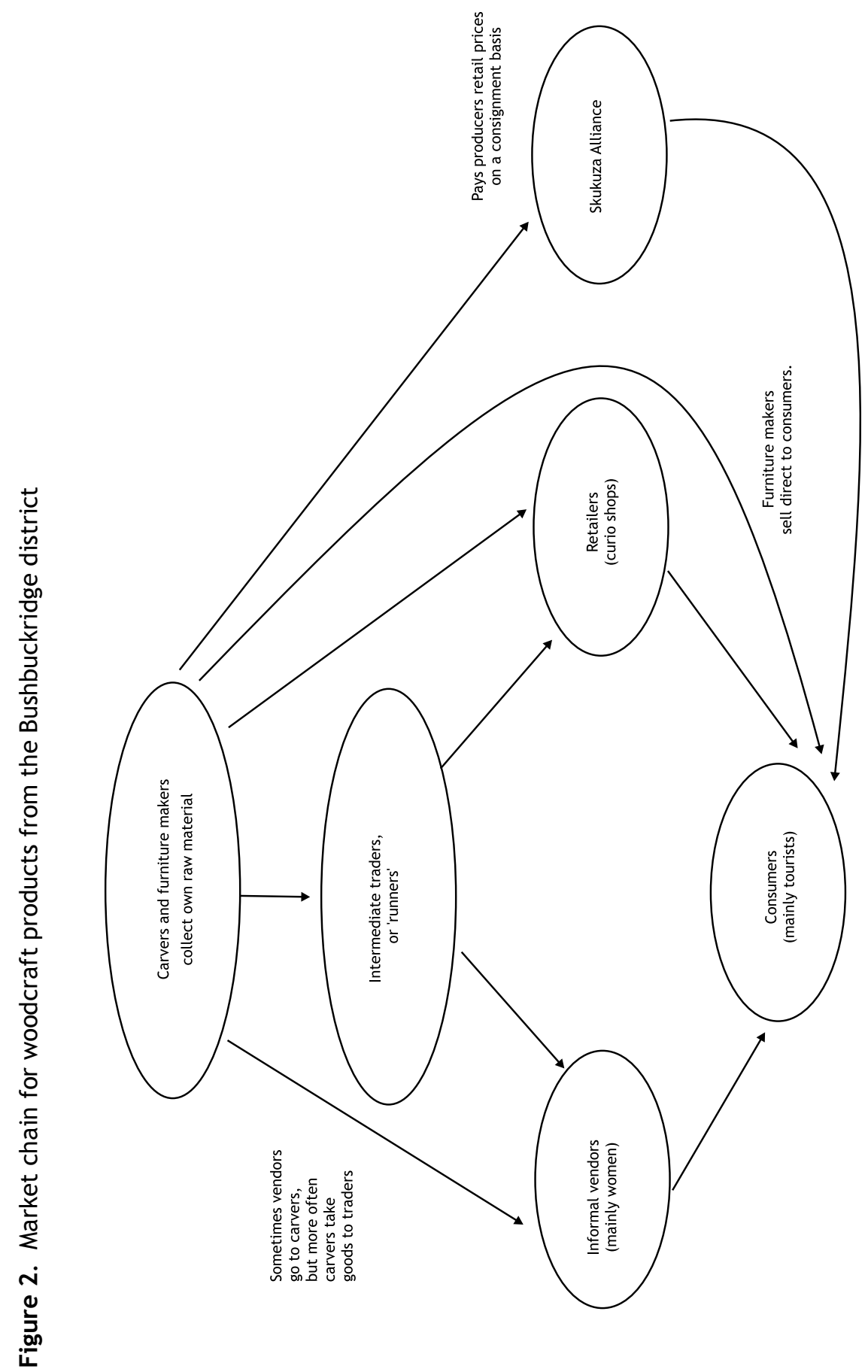


The main markets for carvers in 1993 were craft shops located in and around six main towns of the tourist region: Hazyview, White River, Nelspruit, Sabie, Graskop and Pilgrim's Rest (Figure 1). While these markets are still important, a number of informal markets have emerged in the last 10 years following the relaxation of informal trading by-laws, which now serve as main outlets for carvers. Curio shops have instead moved towards stocking imported African goods. Steenkamp (1999b) found that, on average, there were more imported goods $(55 \%)$ than local products $(43 \%)$ in these shops. Of the local products, approximately $32 \%$ were produced by local factories, $10 \%$ by carvervendors and only $5 \%$ by home carvers.

Some of the informal markets have further developed through interventions from government, primarily the Mpumalanga Department of Finance, and parastatal agencies such as the Mpumalanga Parks Board and South African Forestry Company. Support has included the provision of permanent cover, individual stalls, car parks and water and ablution facilities, creating a much safer environment for both traders and tourists. The markets are located along main tourist routes, the primary vending areas being Panorama Gorge, God's Window and Natural Bridge near Graskop, and MacMac Falls and Long Tom's Pass near Sabie (Figure 1). Committees oversee the management of the markets, and most have codes of conduct that traders must adhere to. Vendors usually pay a small fee (R5-R25 per month) for their stall. Tensions, conflicts and even factionalism between traders who operated in the area prior to the markets being formalised and new traders or those seeking places have occurred in some markets.

Photo 2. Local conservation authorities provide support to informal woodcraft markets (Photo by S.E. Shackleton)

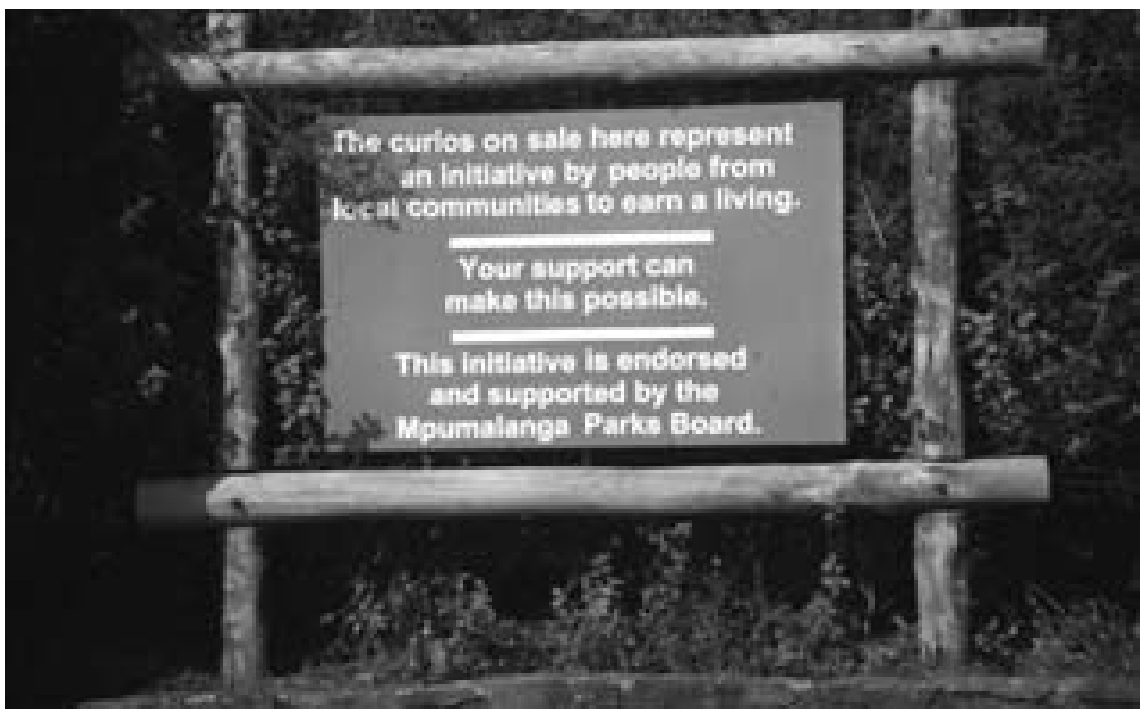


Vendors are generally female. They purchase their goods from intermediate traders or directly from producers, selecting home carver products and imports from neighbouring countries, especially Zimbabwe and Swaziland. Local woodcarvings compose some $20 \%$ of stock. Most vendors were previously employed and have been vending for between two and eight years (Steenkamp 1999a). Eighty percent express high job satisfaction (Steenkamp 1999a), their economic independence (from men) being an important contributing factor.

Many of the carvers indicated they were 'tired' of selling to the women vendors because they pay such poor prices-usually about one quarter of the asking price (Table 5). But few can afford to pay more: their profits are marginal and cash flow is limited. Some carvers sell unfinished goods at lower prices to vendors, who then do the finishing. There is a similar arrangement with the shopkeeper at Kruger Gate. A number of retailers interviewed mentioned that they cannot compete with the prices charged by informal vendors and are unable to put a high mark-up on locally produced carvings. This reduces their interest in stocking local goods. Part of the problem is that the end consumer still expects to pay very little for locally produced craft products, especially if sold in the informal sector. The result is that producers and traders, because they operate on what is effectively a subsistence level, are at the mercy of the market and are frequently forced to accept unrealistic prices in order to earn sufficient money to pay the taxi fare home and to provide food for their families (Bristow-Bovey 1998) (Table 4).

Most carvers are now also marketing their goods through the Skukuza Alliance outlets. Prices are better (Table 5), but goods are sold on consignment and it can take months before producers receive any income. Nonetheless this market has been identified as one of the more positive developments in the industry over the last few years. Finances to run the outlets are generated by deducting $10 \%$ from the sale of each item. Although these markets appear to be functioning, there are some problems. These include the undercutting of prices by producers selling on the roadside (Moloi 1999a; SANP 2000), the fact that tourist bus drivers must be bribed before they will stop, selective support by the KNP administration (e.g., it declined an appeal by the alliance to allow the sale of drinks and snacks), and the lack of facilities to accept credit cards and to package and export goods for overseas buyers.

\section{CURRENT POLICIES, SUPPORT AND INTERVENTIONS}

At the time of the original study there was virtually no external support for the woodcraft industry. Now, various agencies are investigating ways in which the industry can be developed, whilst simultaneously ensuring conservation of the resource base (Steenkamp 1999b).

Generally, in South Africa, government is paying more attention to stimulating the informal sector than it did in the past. The Department of Arts, Culture, Science and Technology recently adopted a plan to promote job creation and growth in four areas: crafts, music, publishing and film (Duncan 1999). This plan proposes the establishment of a Cultural Industry Development Agency (Moloi 1999b). There is also considerably more effort to encourage community-private sector partnerships in a range of sectors including crafts, 


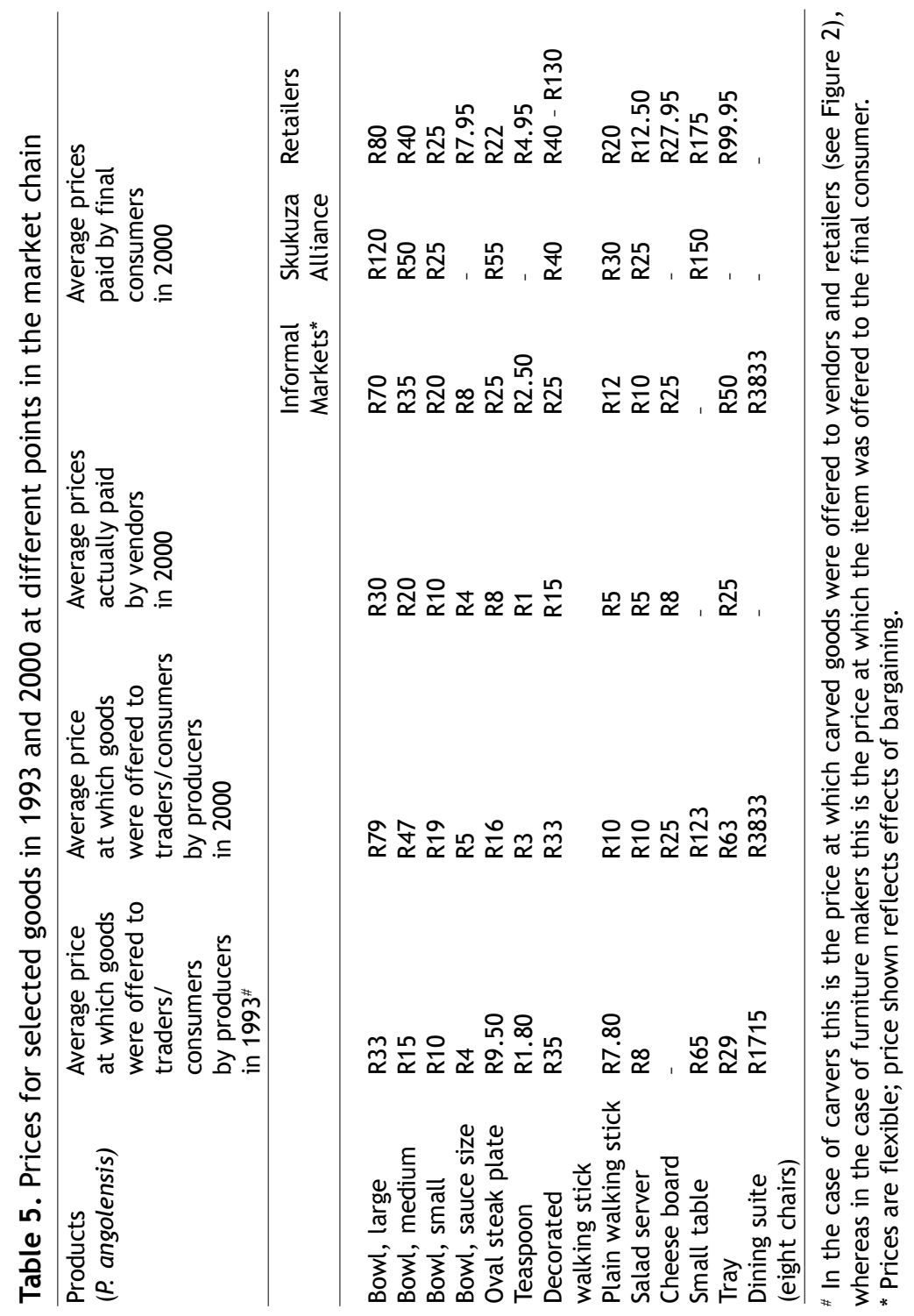


as highlighted in a national craft industry report (DACST 1998) and demonstrated by the interdepartmental Spatial Development Initiatives process. Although these policies have not yet filtered through to the local woodcarving industry, the situation does bode well for the future for a sector previously ignored by government.

At provincial and local levels there have been a number of initiatives targeting the woodcraft industry, most of which have already been mentioned and are summarised in Table 6. This has included support with marketing, skills and business training and the provision of wood.

Table 6. External support for the woodcraft industry in Bushbuckridge

\begin{tabular}{|c|c|c|}
\hline Institution & Sector & Objectives/contribution/interest \\
\hline $\begin{array}{l}\text { National Department of Water } \\
\text { Affairs and Forestry/Danish } \\
\text { Cooperation for Environment } \\
\text { and Development Bushbuckridge } \\
\text { Community Forestry Project }\end{array}$ & $\begin{array}{l}\text { Donor with } \\
\text { government }\end{array}$ & $\begin{array}{l}\text { Sustainable utilisation of } \\
\text { woodland resource, improvement } \\
\text { of livelihoods, capacity building, } \\
\text { alternative sources of wood }\end{array}$ \\
\hline $\begin{array}{l}\text { UK Department for International } \\
\text { Development }\end{array}$ & Donor & Market outlet at Kruger Gate \\
\hline $\begin{array}{l}\text { Mpumalanga Department of } \\
\text { Sports, Recreation, Arts and } \\
\text { Culture }\end{array}$ & Government & $\begin{array}{l}\text { Create job opportunities, } \\
\text { preserve skills (craft heritage), } \\
\text { stimulate creative process }\end{array}$ \\
\hline $\begin{array}{l}\text { Mpumalanga Department of } \\
\text { Environmental Affairs and } \\
\text { Tourism }\end{array}$ & Government & $\begin{array}{l}\text { Right to earn a sustainable living, } \\
\text { sustainable resource harvesting }\end{array}$ \\
\hline Mpumalanga Parks Board & Parastatal & $\begin{array}{l}\text { Harvesting controls, informal } \\
\text { market stalls }\end{array}$ \\
\hline $\begin{array}{l}\text { South African National Parks, } \\
\text { Social Ecology/ Danish } \\
\text { Cooperation for Environment } \\
\text { and Development }\end{array}$ & $\begin{array}{l}\text { Parastatal } \\
\text { Donor }\end{array}$ & $\begin{array}{l}\text { Economic empowerment, Skukuza } \\
\text { Alliance, market outlets, } \\
\text { integration into park activities, } \\
\text { sustainability of carving industry }\end{array}$ \\
\hline $\begin{array}{l}\text { South African Forestry Company } \\
\text { Limited }\end{array}$ & $\begin{array}{l}\text { Parastatal } \\
\text { Private }\end{array}$ & Markets \\
\hline Seagram SA & $\begin{array}{l}\text { Private sector } \\
\text { (social } \\
\text { responsibility } \\
\text { programme) }\end{array}$ & $\begin{array}{l}\text { Skills development for carvers, } \\
\text { tools }\end{array}$ \\
\hline Independent Development Trust & $\begin{array}{l}\text { Non-governmental } \\
\text { organisation/donor }\end{array}$ & $\begin{array}{l}\text { Building of a workshop (this has } \\
\text { not yet been equipped). }\end{array}$ \\
\hline
\end{tabular}

It is difficult to determine the effect these interventions have had on the woodcarving industry, particularly in Bushbuckridge. Preliminary reports are mixed. The impact of the Skukuza Alliance appears to have been positive, as the collective income of some 400 crafters rose from R2,000 to R50,000 within five months of moving into the Numbi Gate complex (SANP 2000). Numbi Gate is, however, distant from the Bushbuckridge woodworkers and they are much 
more likely to benefit from the Kruger Gate development, which is still in its early stages. The facilitation of the two sales outlets appears to be the main strength of the alliance, whereas its performance as an association of craftspeople is questionable. One stakeholder declared 'the Skukuza Alliance does not function, [but serves] only as convenience to get money in from the outside' (L. Yeatman personal communication). Certainly, Bushbuckridge carvers had reservations about its ability to benefit producers.

Observations and discussions during the September 2000 revisit to the area suggest that the business skills and product development workshops (see Table 6) had little impact. Carvers are still producing the same product range, and the same difficulties were experienced obtaining data on income, costs and pricing strategies, indicating that few of the producers are operating according to business principles. Indeed it was surprising how little had changed considering that South Africa has undergone major political and institutional transitions in the last eight years. Home producers have been observed as a 'difficult group to work with', being reluctant to participate in collective initiatives and resistant to change. Most demonstrate a tendency to stick to proven, low risk products (Steenkamp 1999b), although it should be recognised that it is by no means easy for producers operating on a hand-to-mouth basis to carry the costs associated with experimentation.

\section{SOME CONSERVATION AND DEVELOPMENT IMPLICATIONS AND RECOMMENDATIONS}

This case study has demonstrated that the woodcraft industry is a sector with potential for development and for providing rural communities with a viable source of income. Growth in the industry is evident, and all stakeholders expect it to grow further. Much needs to be done, however, to ensure that this happens in a positive and sustainable manner. Of particular concern should be management of the inevitable tensions between developing the trade and minimising environmental and biodiversity impacts.

\section{Development of the industry}

The broader woodcraft industry in South Africa, as mentioned previously, is complex, and local producers are competing directly with African imports and formal sector factory goods (Steenkamp 1999b). Both these competitors tend to be high volume, wholesale specialists, whereas local craftsmen fit into a low volume, direct sales category and thus are unable to compete successfully in the wholesale or export market. Some development specialists feel that unless local producers find the means to enter this market (see Kenya case study), they will continue to be marginalised, invisible to formalised business and commerce, under threat by more organised sectors of the industry and vulnerable to exploitation and the day-to-day uncertainties of a subsistence existence-especially since the local niche market appears to be already saturated (Steenkamp 1999b). A number of external agencies believe that local carvers could compete more successfully in the wider market if they were to focus on a range of small, specialised products following the Mexican 
success story (Steenkamp 1999b). Others suggest that products with more 'cultural' or 'artistic' significance should be encouraged. However, this usually requires intrinsic artistic talent rather than just craftsmanship, thus benefiting only a limited number of carvers. It is also a fickle market, prone to boom and bust characteristics, as evidenced by the collapse of the Venda art market even after many of the sculptors had attained international acclaim (Duncan 1999). New specialised, but less tourist-dependent, markets could also be explored. For example, one restaurant in the Sabie area is furnished effectively with locally produced $P$. angolensis furniture, and another is using salad bowls, steak plates and pizza boards carved by home carvers. There is no reason why this practice could not be extended to other parts of the country.

Whatever the way forward, Steenkamp (1999b) stresses that a specialised marketing study needs to be conducted before any decisions are taken. Such a study should take into account a long-term development framework for the woodcraft industry, as well as any changes in production mode and strategy that would accompany the targeting of new markets. Certainly, entering the wholesale market presupposes increased organisational specialisation and cooperation amongst producers, perhaps within a small factory situationsomething towards which carvers have demonstrated reluctance. Joint partnerships with the private sector have also been suggested, and there are examples within the basketry industry. Such an approach would provide the capital injection to set up bulk production and provide a guaranteed market for at least some products. In the end, it is likely that a mix of different strategies and markets, suiting a range of producer needs and preferences, would be most appropriate. It is important that what has been achieved so far, mainly through the enterprise of producers themselves, not be ignored. After all, the woodcraft trade has been able to provide one of the poorest sectors of the Bushbuckridge community with a means of livelihood since the early 1970s (Shackleton, S.E. 1993). From this perspective it is also critical that any new development does not create unhealthy dependencies on agencies, companies or products that may have short-term horizons or unpredictable futures.

\section{Resource conservation}

The impacts on key carving species, in particular $P$. angolensis, have been substantial. A response to this situation in other parts of the world has been to turn to propagation and cultivation. This strategy has been most successful in the case of fast-growing softwood species. $P$. angolensis has, however, proven extremely difficult to cultivate, and most attempts to grow it have met with limited success throughout the southern African region (Vermeulen 1990). It is also very slow growing. Cultivation is therefore unlikely to be a solution to the wood supply problems for $P$. angolensis users. Instead substitute species, including exotics, and alternative sources need to be identified. Better management of the existing resource base is crucial, but highly complex. Carvers and furniture makers are not the only users of communal woodlands, and different stakeholders have variable and contended understandings of boundaries and de facto access rights. Moreover, existing institutional and legal arrangements are confused, 
controversial and ineffective. Any community-based management plan would need to be a broad contract involving various user groups and authority structures, and would need to recognise the dependency of producers on the resource. Thus, whilst it may be difficult to restrict the use of mature trees, there could be improved and more active management of young trees and saplings. As discussed for the development of the trade, a multipronged approach involving all of the above strands is likely to be most effective, although it is important not to romanticise the notion of sustainable use. Indeed, so long as there is wood and the opportunity to earn an income from it, rural households on the breadline will continue to appropriate the resource to feed their families. They simply cannot afford not to.

\section{SUMMARY AND CONCLUSIONS}

The woodcraft industry in Bushbuckridge makes a significant contribution to the livelihoods of a small sector of local residents. The impacts of decades of wood use are now apparent and wood scarcity is fast becoming the greatest constraint to continued production and growth. Although there has been an increase in external support for both producers and traders in the last five years, much of it is piecemeal and uncoordinated. A more focussed long-term effort by all key stakeholders is necessary if a sustainable industry is to be achieved. This presents a considerable challenge. Access to alternative sources of wood is essential. Producers also need to be more involved in management of the existing resource base. New skills, products, structures and perspectives are required to bring woodworkers from the margin into the mainstream craft and curio industry. Lessons from other African countries and elsewhere should be incorporated into new development strategies. Consumers need to be made aware of the value of the wood and the time and effort required to produce woodcarvings and handmade furniture. Local products should be promoted and be seen as having a special niche in the market instead of being regarded as inferior to imports or factory produced items. If these issues are addressed, then there is hope and a future for the woodcraft industry in the Bushbuckridge lowveld.

\section{ACKNOWLEDGEMENTS}

Much of our knowledge relating to the woodcraft industry in Bushbuckridge has been facilitated by Alfred Shabangu, an intrepid entrepreneur and carver. Thanks are also due all the woodworkers and representatives from a number of government and non-government organisations who took the time to talk to us. Useful comments on a draft version of this case study were provided by Tony Cunningham, Bruce Campbell, John Reynolds and Wavell Standa-Gunda. The research was funded by Wits Rural Facility (1993) and CIFOR (2000).

\section{ENDNOTES}

1. Environmental Science Department, Rhodes University, Grahamstown, 6140 South Africa. E-mail: s.shackleton@ru.ac.za 
2. Environmental Science Department, Rhodes University, Grahamstown, 6140 South Africa. E-mail: c.shackleton@ru.ac.za

3. The term lowveld refers to the relatively flat, low-lying, semi-arid savannah region in the north-east of the country positioned between the Drakensburg escarpment in the west and the Mozambique border in the east.

4. Homelands, constituting $13 \%$ of the surface area of South Africa, were created as labour reserves legitimated by a complex of apartheid ideals and policies that emphasised the importance of separate development. They were the only areas where black people could access land, which was held in 'trust' by the state and administered through the tribal authorities. In the early 1990s, all homelands were reincorporated into South Africa.

5 . Working for Water is a national programme of the Department of Water Affairs and Forestry aimed at clearing invasive alien vegetation from catchment areas and riverine zones to enhance water production, biodiversity and local employment opportunities.

6. Calculated using the function: percent annual basal area increment $=-$ 0.161 (stem circumference) $+14.49(r=0.984 ; p<0.001)$, and assuming a starting stem circumference of $3 \mathrm{~cm}$.

7. Net income in this case is calculated as the cash income generated from the sales of products minus costs including consumables, tools, transport to market, wood harvesting and wage labour. Cost of own labour is not included.

\section{REFERENCES}

Arnold, J.E.M. and Ruiz Perez, M. 1998. The role of non-timber forest products in conservation. In: Wollenberg, E. and Ingles, A. (eds) Incomes from the forest: methods for the development and conservation of forest products for local communities. CIFOR, Bogor, Indonesia.

Bristow-Bovey, D. 1998. Proceedings of the People and Plants Workshop for Woodcarvers. Prepared for the Danish Cooperation for Environment and Development Community Forestry Project in the Bushbuckridge Area. Department of Water Affairs and Forestry, Nelspruit.

Clarke, A.B. 1997. Sustainability of harvesting seven favoured plant species used in the indigenous wood carving industry in the Bushbuckridge district of the Northern Province lowveld. B.Sc. Hons. Dissertation, University of the Witwatersrand, Johannesburg.

Cunningham, A. B. and Choge, S.K. In press. Crafts and conservation: the ecological footprint of international markets on an African resource. Advances in Economic Botany.

Department of Arts, Culture, Science and Technology. 1998. South African crafts industry report 1998. DACST, Pretoria.

Desmet, P.G., Shackleton, C.M. and Robinson, E.R. 1996. The population dynamics and life-history attributes of a Pterocarpus angolensis DC. population in the Northern Province, South Africa. South African Journal of Botany 62: 160-166.

Duncan, J. 1999. Artists from the Northern Province. Land and Rural Digest 7 (July/August): 9-12. 
Holmes, J. 1995. Natural forest handbook for Tanzania. Volume 1: Forest ecology and management. Sokoine University of Agriculture, Morogoro, Tanzania.

Krynauw, S. 1999. Report on the feasibility of the proposed utilisation of kiaat (Pterocarpus angolensis DC) on Mawewe Nature Reserve (Phase 2). Mpumalanga Parks Board, Research and Development, Lydenburg, South Africa.

Macleod, F. 1999. Syndicates strip Bushbuckridge reserve. Weekly Mail and Guardian, 17 December 1999.

Marcus, T. 2000. Crafting in the context of AIDS and rural poverty: a livelihood strategy with prospects. Transformation 44: 17-35.

Mine Workers Development Agency. 2000. Mine Workers Development Agency: bridging the gap for job creation. Press release prior to a National Workshop on 19-30 March 2001. MDA, Johannesburg.

Moloi, D. 1999a. Eking out a living from wood. Land and Rural Digest 7 (July/ August): 9-12.

Moloi, D. 1999b. The potential of the crafts industry. Land and Rural Digest 7 (July/August): 12-14.

Newton, D. 1998. South Africans carve a niche in the woodcarving industry. http: / /www.ewt.org.za/journal/0397_woodcarve.html (15 April 2000).

Pollard, S.R., Perez de Mendiguren, J.C., Joubert, A., Shackleton, C.M., Walker, P., Poulter, T. and White, M. 1998. Save the Sand phase 1 feasibility study: the development of a proposal for a catchment plan for the Sand River catchment. Department of Water Affairs \& Forestry, Pretoria.

Shackleton, C.M. 1993. Demography and dynamics of the dominant woody species in a communal and protected area of the eastern Transvaal lowveld. South African Journal of Botany 59: 569-574.

Shackleton, C.M. 1997. The prediction of woody primary productivity in the savanna biome, South Africa. Ph.D. Thesis, University of the Witwatersrand, Johannesburg.

Shackleton, C.M. 2002. Growth patterns of Pterocarpus angolensis in savannas of the South African lowveld. Forest Ecology and Management 166:85-97.

Shackleton, S.E. 1993. A situation analysis of the woodcraft industry in the Bushbuckridge district of the eastern Transvaal, with particular reference to resource use. Unpublished report, Wits Rural Facility, Acornhoek. 82p.

Shackleton, S.E. 1996. The woodcraft industry in the Bushbuckridge district of the Mpumalanga lowveld, South Africa, Box 6.5. In: Campbell, B. (ed.) The Miombo in transition: woodlands and welfare in Africa. CIFOR, Bogor.

Shackleton, S.E. and Adelfang, I. 1992. An appraisal of attitudes of retailers in the eastern Transvaal lowveld: suggestions for handicraft producers in Mhala. Unpublished report, Wits Rural Facility, Acornhoek.

Shackleton, S.E., Stadler, J.J., Jeenes, K.A., Pollard, S.R. and Gear, J.S. 1995. Adaptive strategies of the poor in arid and semi-arid lands-in search of sustainable livelihoods: a case study of the Bushbuckridge district, Eastern Transvaal, South Africa. Unpublished report, Wits Rural Facility, Acornhoek.

South African National Parks. 2000. Visions of change: social ecology and South African National Parks. SANP, Pretoria.

Steenkamp, C. 1999a. South Africa's woodcarving industry. Traffic Bulletin 18 (1): 11-20. 
Steenkamp. C. 1999b. Analysis of the woodcarving industry in the Bushbuckridge area. Prepared for the Danish Cooperation for Environment and Development Community Forestry Project in the Bushbuckridge Area. Department of Water Affairs and Forestry, Nelspruit.

Steenkamp, C., Trancred, E., Dludlu, S., Eber, S. and Esterhuisen, M. Undated. The woodcarving industry in South Africa. Traffic Southern African Office, Johannesburg.

Tapson, D.R. 1996. The technical component of mixed and livestock farming in semi-arid lands. In: Lipton, M.E. and Lipton, M. (eds). Land, labour and livelihoods in rural South Africa. Volume Two: KwaZulu-Natal and Northern Province. Indicator Press, Durban.

Tollman, S.M., Herbst, K. and Garenne, M. 1995. The Agincourt demographic and health study: field phase 1. Health Systems Development Unit, University of the Witwatersrand, Johannesburg.

Vermeulen, W.J. 1990. A monograph on Pterocarpus angolensis. SARCCUS Technical Publication, DEA\&T, Pretoria. 


\title{
Chapter 13
}

\section{Fuelwood in the Maroua area of the Far North Province of Cameroon}

\author{
Tata Precillia ljang ${ }^{1}$
}

\begin{tabular}{llllll}
\hline Common names & $\begin{array}{l}\text { Part of the } \\
\text { resource used }\end{array}$ & Management & $\begin{array}{l}\text { Degree of } \\
\text { transformation }\end{array}$ & $\begin{array}{l}\text { Scale of } \\
\text { trade }\end{array}$ & $\begin{array}{l}\text { Geographic } \\
\text { range }\end{array}$ \\
\hline $\begin{array}{l}\text { Seyal, White- } \\
\text { galled acacia, } \\
\text { Ulbe }\end{array}$ & Wood & Wild & Low & National & Large \\
\hline
\end{tabular}

\begin{abstract}
This chapter reports on fuelwood in the Maroua area of the Far North Province of Cameroon. Wood harvesting is the third most important economic activity for the inhabitants of this area, after animal husbandry and agriculture. Fuelwood is harvested, processed, marketed and consumed exclusively in the Maroua area, moving from collectors through wholesalers and retailers to consumers. Whereas in the past only dead trunks and branches were gathered for use as fuelwood, today live trees are felled and left to season. The result has been a dramatic disappearance of forest cover, with trees being harvested at unsustainable rates. Since fuelwood sales are a major source of income for most households, it is difficult to stop the felling of live trees, despite the negative impact on the forest and enormous efforts by the government of Cameroon and various non-governmental organizations.
\end{abstract}

\section{INTRODUCTION}

Non-timber forest products are obtained from both plant and animal sources, and include fruits, nuts, oils, medicinal plants, arabic gum, other foods, bush meat, bark and wood as an energy source and for artisan purposes (Neba 1987; Agroforestry Project 1995; CEDC 1997; Peter 2001). Our interest in this study was the use of wood as an energy source in the Maroua area of the Far North Province of Cameroon, with Acacia sayel, a locally abundant and popular fuelwood species (ABF 1989; CEDC 1997), taken into particular consideration.

The use of wood as a source of energy contributes to environmental degradation as well as income generation around the world, including Cameroon and our study area. A study published by the Food and Agricultural Organization 
of the United Nations illustrated the increasing annual trade in fuelwood around the world, while documenting increased pressures on local resource bases (FAO 1998). For example, Indonesia has emerged as a principal producer and exporter of fuelwood, while others such as Germany have become importers. These same trends are shown in Cameroon. Table 1 shows the steady increase in fuelwood production between 1992 and 1996 in Cameroon and the world.

Table 1. Fuelwood production in Cameroon and the world between 1992 and 1996

\begin{tabular}{lcc}
\hline Year & Cameroon (000 cubic meters) & World (000 cubic meters) \\
\hline 1992 & 4,264 & $1,471,897$ \\
1993 & 4,342 & $1,484,632$ \\
1994 & 4,426 & $1,505,966$ \\
1995 & 4,526 & $1,519,972$ \\
1996 & 4,910 & $1,552,866$ \\
\hline
\end{tabular}

Source: FAO 1998.

For centuries fuelwood has remained an affordable and reliable source of domestic energy for the rural populations of the developing countries (FAO 1990). In Cameroon it constitutes $60.5 \%$ of the total energy consumed in all sectors and $85.5 \%$ of the energy consumed in households (FAO 1990). Assan (unublished) wrote that fuelwood made up $67 \%$ of the total energy consumed by urban households, and $100 \%$ of that consumed in the villages of the Maroua area. In 1999, Tata (1999) estimated that consumption stood at $586 \mathrm{~kg} /$ person/ year in Maroua, with an annual per person cost of CFA13,300, or US\$22.17 (exchange rate US\$1 = CFA600). In comparison, Sow (1990) found that fuelwood consumption stood at $637 \mathrm{~kg} /$ person/year in Mali and $230 \mathrm{~kg} /$ person/year in Niger. Costs per person per year were estimated at CFA4,600 (US\$7.67) in Niger, and CFA12,100 (US\$20.17) in Mali.

In the past wood harvesting in the Maroua area was mainly for home consumption, and it was mostly women who gathered the dry branches and trunks of trees and shrubs for fuelwood (Awah 1995). Today the situation has changed, as increased commercialization of the sector has led to the widespread harvest of both dead and live branches and trunks by men and women (Awah 1995). Factors determining the quality of good fuelwood include a high level of heat generation, little smoke, the production of good charcoal and little wood ash. Apart from its increasing commercial value, factors encouraging the use of fuelwood include cooking habits, purpose of cooking, family size, social rank and food type (Montalembert and Clement 1983; Munslow et al. 1989; Robin and Leach 1989; Musa unpublished).

\section{THE PRODUCTION-TO-CONSUMPTION SYSTEM}

\section{Resource base}

This chapter addresses the woodlands of the Maroua region of the Far North Province of Cameroon, where the increasing amount of fuelwood being removed 
from this Sahelian region is of particular concern (Awah 1995). Although many species are gathered as fuelwood, we chose to highlight the case of Acacia seyal (Mimosaceae) because of its high regeneration capacity, the abundant availability of data, its abundance in the study area and its high quality as fuelwood. Acacia seyal grows abundantly in almost every part of the Maroua area of Cameroon and occurred at levels of at least 20 trees $/ \mathrm{km}^{2}$ in our study area. Regeneration is rapid and seeds germinate and grow to maturity with little or no assistance unless disturbed by browsing cattle or bush fires. In addition to its value as a source of fuelwood, Acacia sayel may be used for timber, animal fodder, arabic gum, food, medicine, and amenity and soil improvement (Agroforestry Project 1995; CEDC 1997).

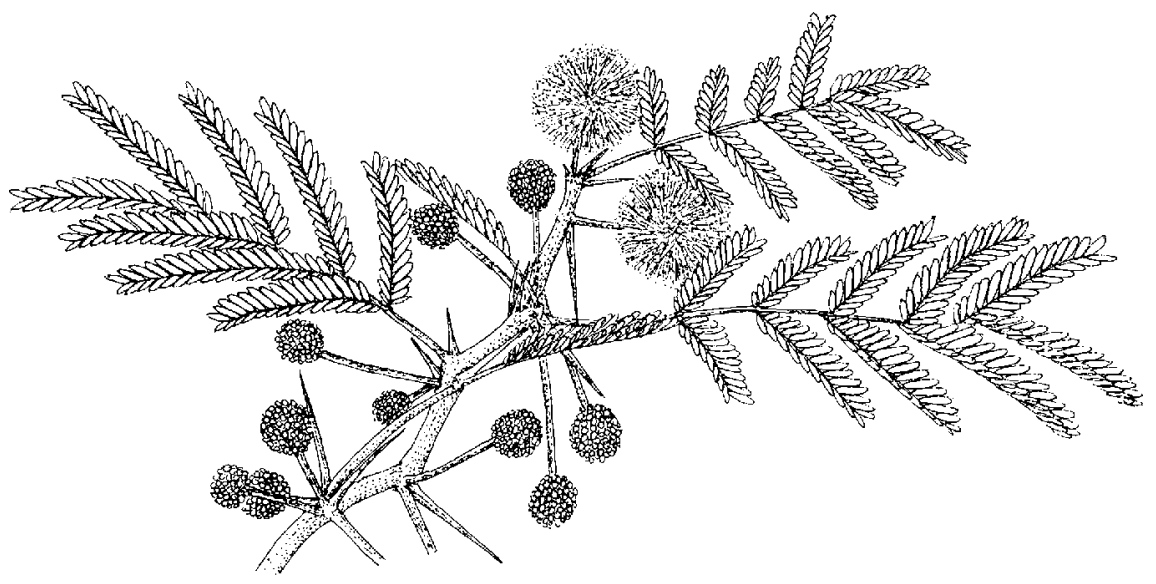

(Acacia seyal)

Acacia seyal has different common names depending on the language, e.g., mimosa epineux in French, sade in Bambara, saykire in Djerma, ulbe in Foulfoulde, erehi in Haussa, boulbi in Peulh and fonah in Wolof (Von Maydell 1990 ). Its growth requires an annual rainfall of $250 \mathrm{~mm}$ to $1,000 \mathrm{~mm}$ on sandy, loamy or clayey soils and permits periodic inundation and desiccation. Growing at a rate of more than $1 \mathrm{~m}$ annually, full growth is attained after about 10 years (Von Maydell 1990; Roussel 1995). At maturity the tree is about $17 \mathrm{~m}$ tall with a diameter of about $60 \mathrm{~cm}$ and an umbrella- shaped crown. The bole bark is green in younger trees, turning a dark gray in older trees, with paired thorns about $7 \mathrm{~cm}$ in length. It has a yellowish, gummy sap. The dark green leaves are complex, with 4 to 12 pairs of pinnae and 10 to 22 pairs of leaflets. Rachis are up to $8 \mathrm{~cm}$ long and flowers are bright yellow. Its seed pods are slightly curved, indehiscent, light brown at maturation, $10 \mathrm{~cm}$ to $15 \mathrm{~cm}$ long and $1 \mathrm{~cm}$ wide, containing 6 to 10 seeds each (ABF 1989; Von Maydell 1990; CEDC 1997; National Forestry Development Agency 1997). 


\section{Raw material production area, producers and socio-economic context}

The area of this study included the villages of Fadere, Niwaji, Laf, Jagara, Gaban, Vaza, and Kossa in the Far North Province of Cameroon as well as Maroua, the capital city of the province (Figure 1). These villages represent the geographical region that produces most of the fuelwood found in the Maroua main market. Located in northern Cameroon, the study area falls between latitudes $10^{\circ} 01^{\prime}$ and $10^{\circ} 47^{\prime}$ north and longitude $14^{\circ} 11^{\prime}$ and $14^{\circ} 55^{\prime}$ east (Fotsing 1997 ) and has a mean elevation of $400 \mathrm{~m}$ (Ngwa 1978). During the long dry season, the nights and mornings are often very cold, while extremely hot daytime temperatures in Maroua range between $19^{\circ} \mathrm{C}$ and $40^{\circ} \mathrm{C}$. The rainy season, brought by the southwest monsoon winds blowing across the Atlantic Ocean from the Gulf of Guinea, is very stormy, and the annual rainfall of 700 $\mathrm{mm}$ to $1000 \mathrm{~mm}$ falls in just the three months from July to September (Neba 1987). Benefiting from the Guinea monsoon climate, the main vegetation cover is characterized by a formation of mixed tree shrubs and forest savanna (ABF 1989), which Leemans (1998), following the Holdridge classification system, classified as 'very dry tropical forest'. Many of the native plants have developed specialized structures to enable them to survive these harsh climatic conditions, such as deep root systems, few and small leaves, thorns, thick bark, and the shedding of leaves during the dry season (Raven and Johnson 1986; Robert 1986; Agroforestry Project 1995). The harsh, dry environment of the study area had been exacerbated by drought, and consequently the vegetation cover was very stunted and sparse, with bare soil exposed in some areas. Plant regeneration was very slow-increasing the rate of forest disappearance already occurring because of overharvesting and natural events (Grainger 1993).

The study area constitutes about $17.7 \%$ of the total population of the country and was made up of many tribes including Moundang, Toupouri and Foulbe amongst others (Review de Géographie du Cameroun 1996; Zoa unpublished; Minister of Economy, Finances and Industry 1999). The most prevalent religion is Islam, though Christians and animists are also present (Van Well 1998). The most important economic activities are animal husbandry, agriculture and woodcutting, trailed by fishing and petty trading (Waffo 1996). Of the three main activities carried out by the local population of this area, animal rearing was not labor intensive since the animals were allowed to graze in the wild. This was because production was mainly for subsistence, cultural uses and local sales. Agriculture, though fruitful, was not as productive as expected because of the dry climate and drought. In consequence, the population has three very farm labor-intensive months during the year. Given the subsistence level of animal husbandry and farming and the consequent lack of cash income of most households, many turn to woodcutting with its ready and growing market (Waffo 1996).

Woodcutting is labor-intensive work performed mostly during the nonfarming months. It represents the most immediate source of cash income for most households as well as the source of fuelwood burned in households during the labor-intensive and rainy farm season. Wood harvesting is mostly done in the cool temperatures of the early hours of the day, while sales take place in the afternoon. The trade, processing and marketing of fuelwood took place 
Figure 1. Map of the study area
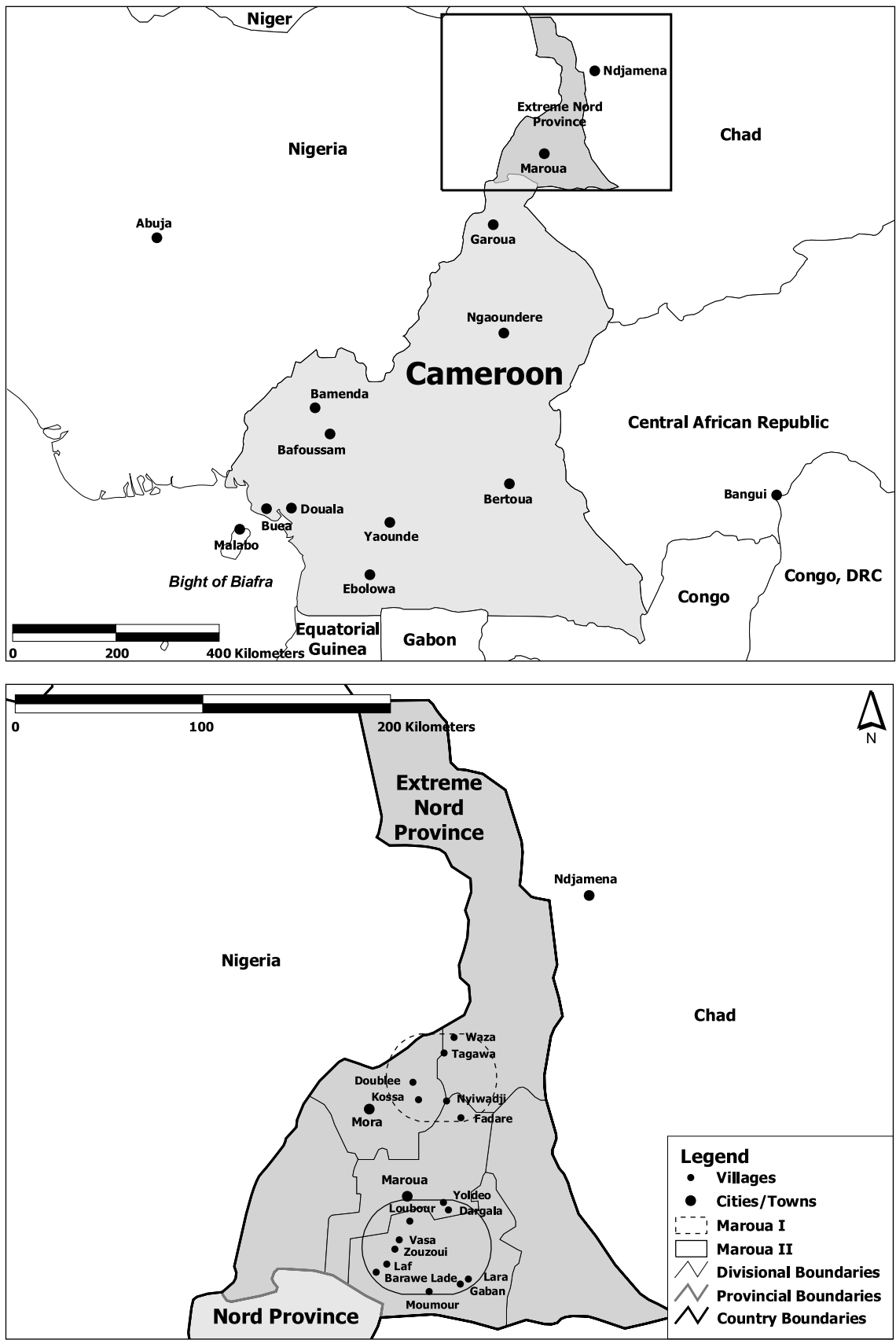

Source: ESRI Data and Maps 2002. 
entirely within the study area, though small quantities are exported to Chad and Nigeria on a very rare and informal basis.

Figure 2. Simplified fuelwood exploitation and marketing agents' chain

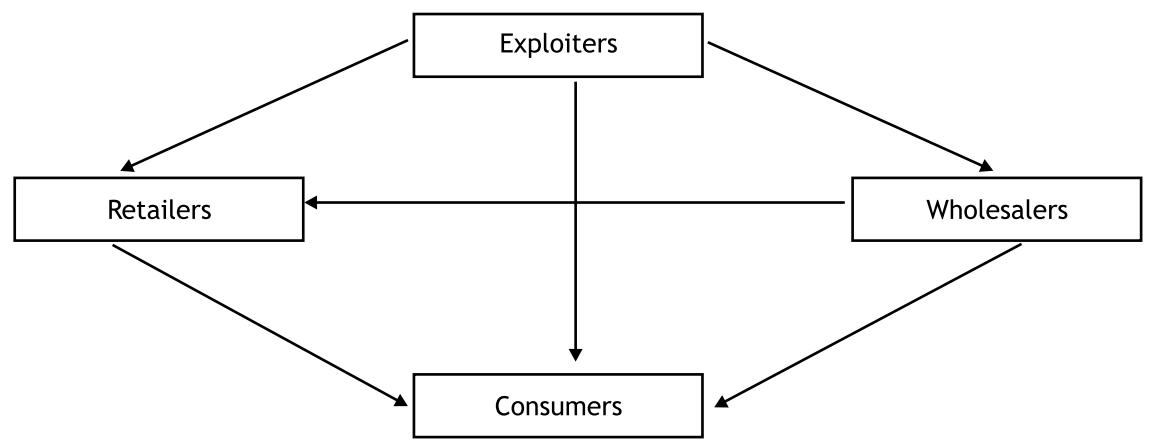

Source: Tata 1999.

\section{Chain of production and trade}

The chain of production and trade is quite short, passing from the forest and village markets through the urban markets and to the consumers. This is most clearly depicted in Figure 2, where the directions of the arrows indicate the movement of wood from exploiters to consumers.

The main processing of this product consisted of splitting logs and big branches into halves and smaller pieces. Wood marketed as large, medium and small halves was what consumers most preferred. A result of this processing was the addition of value; split halves were worth more per unit than logs. At each stage in the marketing chain, the seller captured value by splitting the wood into smaller pieces. The only by-product from the processing and consumption of this product was charcoal, and its use was insignificant to the producer-to-consumer chain in the study area.

Some of the fuelwood gathered was consumed by the exploiters, and passers-by in the village also purchased wood for consumption and retail. However, wholesalers served as the main middlemen between villagers and urban consumers. In urban areas, wholesalers sold the wood to retailers, who finally sold it to consumers. The modified chain of production or fuelwood filiere presented in Figure 3 explains this process in greater detail.

Village markets situated in the forest and roadsides sold to wholesalers, retailers and some consumers. Sellers in the forest markets were mostly young men, whereas at the roadside all classes of people were found, and about $30 \%$ of them were women. Most of the wood harvested in the villages for household use was harvested by women and younger children (Awah 1995), and was transported on head, animal, truck and bicycle. Because women were busy with other household tasks, and their husbands' permission was needed for them to be involved in any external activity, their involvement in wood sales was minimal. 
Figure 3. Fuelwood filière model

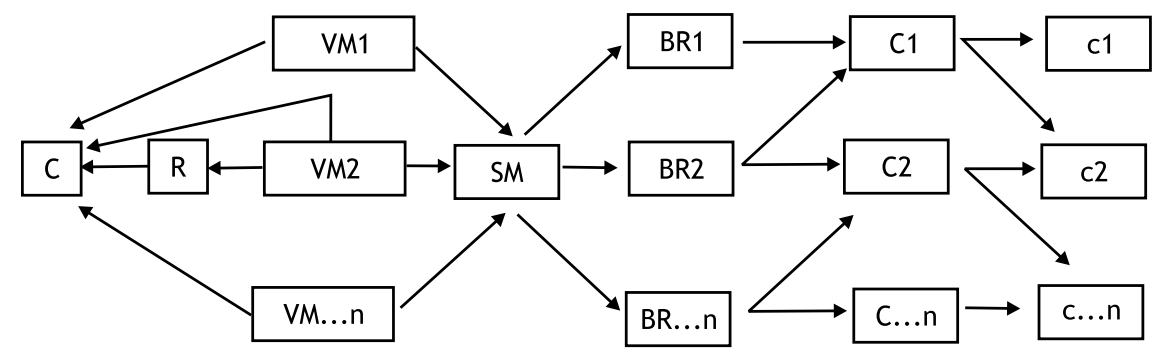

$\begin{array}{ll}\text { VM1...n } & : \text { Village markets } \\ \text { SM } & \text { : Suppliers market (wholesalers) } \\ \text { BR1...n } & : \text { Urban markets (big retailers) } \\ \text { C1...n } & : \text { Small neighborhood markets } \\ \text { C1...n } & : \text { Final consumers } \\ \text { R } & : \text { Small retailers } \\ \mathrm{C} & : \text { Consumers }\end{array}$

Source: Tata 1999.

Wholesalers did not have a fixed market, sold exclusively to retailers, and were all men. Most of the wood, in logs and split-halves (more desired by consumers), was purchased from the village markets and transported, sometimes up to $200 \mathrm{~km}$, to the urban center using 6 and 10 tonne trucks. Suppliers usually bought on order and already had a market where to sell the product before they went to the village markets.

The big retailers at urban markets included two categories of traders: those buying wood from wholesalers and who sold exclusively at wood markets, and those buying wood from village markets and who drove around urban neighborhoods selling from their vehicles. Retailers buying from villages transported the product using mostly the bigger Dina Toyota pickup trucks as well as regular pickup trucks and bought mostly small halves and branches obtained from immature trees (lower quality wood from findings). They did not travel far to buy the wood (less than 70 kilometers from the urban center). In both cases they sold to small retailers and consumers and they were all men. Some of the large harvested branches were used in the urban centers as poles for supporting dilapidated houses, while others were used for the building and roofing of houses.

Sales between small retailers and big consumers took place exclusively in small neighborhood markets and in front of households. More than $80 \%$ of these retailers were women and young children (Awah 1995; Tata 1999). People who gathered wood from degraded forests around the urban center and from other sources were also represented in this category. Most of the wood was of poor quality.

Final consumers such as urban households, meat roasters and restaurant owners made up $67 \%$ of the total energy consumed in the urban center (Assan 1991).

Woodsellers sold to whomever they chose, at any time. They were often needy, jobless men who moved on to other activities as soon as possible. 
However, as the marketing of fuelwood has become more intensive, some rich businessmen (mostly truck owners) have become involved as wholesalers. Others have bought trucks and hired drivers to work as wholesalers.

Photo 1. A pickup truck loaded with fuelwood plies the neighborhoods of Maroua in 1998 (Photo by T.P. ljang)

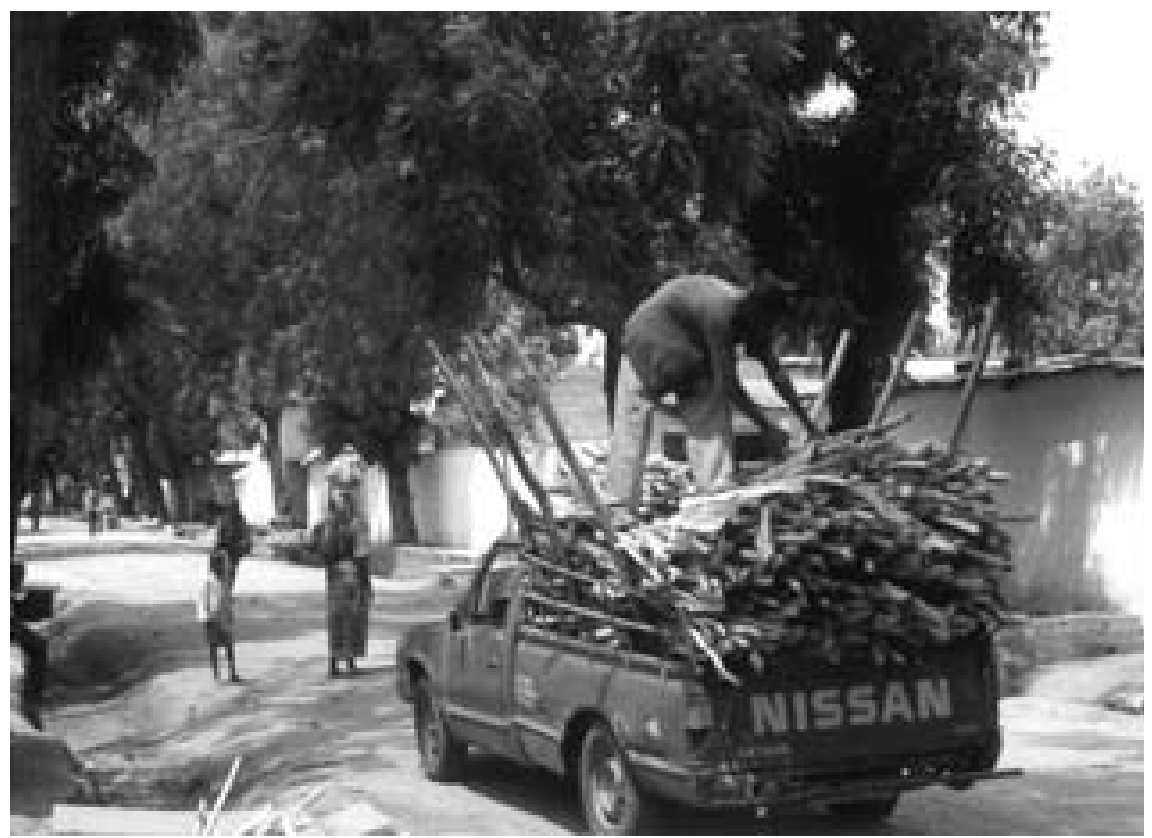

\section{TRENDS AND ISSUES}

\section{Dynamic changes}

The most noticeable change in the landscape within the study area was the disappearance of the natural forest, and the disappearance of some indigenous species was echoed in the arid landscape covered with tree stumps and sand. Efforts to improve the environment had been made through the creation of parks, forest reserves and protected areas and waters. Though initially most of the environmental protection strategies were developed and executed by the government and various non-governmental organizations (NGOs), increasingly villagers are being involved in the process (Republic of Cameroon 1994; Agroforestry Project 1995; Minister of Environment and Forestry 1998). For example, NGOs and the government have helped to establish village-based groups to aid in the planting of species of trees that have otherwise vanished from the environment (DPGT 1996).

Trade in and demand for fuelwood is increasing in Cameroon, but the supply to markets can be inconsistent, especially during the rainy season, when the bad roads, the long distances, and the high cost and difficulty of vehicle hire 
slow the harvesting activities. Increased demand has lead to an overharvest of wood, leaving the landscape full of tree stumps and young trees exposed to the threats of grazing and other human-related activities. Reversing these trends will require improvement in harvesting practices and community forest management, the capture of greater value-added gains, and the development of commercial value for fuelwood products to encourage the management of the basic resource. These trends and issues are summarized in Table 2.

Table 2. Summary of trends and issues

\begin{tabular}{lll}
\hline Aspect of Production-to & Present Trend & Future Trend \\
\hline Ability to meet the needs of exploiters & Moderate & Low \\
Ability to meet the needs of suppliers & Moderate & Low \\
Ability to meet the needs of retailers & Moderate & Low \\
Ability to meet the needs of consumers & Moderate & Low \\
Marketing and transport infrastructure & Moderate & Better \\
Effect on the environment & Bad & Worse \\
Property right and ownership & Low & High \\
Transformation/processing & Moderate & Same \\
Exploitation techniques & Bad & Better \\
Conservation techniques & Low & High \\
Outside intervention & Moderate & Higher \\
State intervention & Neutral & Positive \\
External influence & Moderate & Higher \\
Quality of product & Moderate & Lower \\
Ecological sustainability & Low & Lower \\
Competitiveness with other fuels & Very low & Might change \\
Traditional and cultural impact & Neutral & Positive \\
Effect on economic development & Positive & Negative \\
Cost/benefit allocation (gender allocation) & Women disfavored & Might change \\
Economic value of the product & High & Higher \\
\hline
\end{tabular}

\section{Problems}

The main problem brought about by the collection of fuelwood has been the destruction of forest resources. Research into the causes of environmental degradation show that excessive fuelwood collection has contributed to, and brought about, disruption of the ecosystem (Pelkey and Ali 1996; CEDC 1997). Measures being taken to correct this degradation include working to inform farmers of the importance of rational exploitation, of tree planting, and of the value of maintaining the existing trees on their farm plots.

A second problem associated with fuelwood collection occurred when children involved in fetching and selling wood became excited by their earnings and dropped out of school. Thirdly, this source of income is not sustainable, and it is possible to go for days without any sales. The market is easily saturated, as entry requires little in terms of capital investment and technical understanding, and many people were encouraged by the lack of need for 
permits to exploit the fuelwood resource. The introduction of rational management of the fuelwood resource, including the issuance of permits and better management of the product, would help to stabilize markets, market values, and ensure a steady supply of fuelwood.

\section{CONSERVATION AND DEVELOPMENT LESSONS OF CASE}

\section{Jobs and employment}

The fuelwood sector employs many men, women, and children in both rural and urban areas, offering both temporary and permanent employment opportunities. It is important economically because it offers an immediate source of income to the exploiters. Delinquency is reduced through employment in this interesting and financially rewarding work in the many otherwise unemployed young men who form the majority of the commercial sector.

\section{Capital generation, risk minimization and business and industry}

The exploiters generated social, physical and financial capital. Because of the income afforded, they were able to maintain minimum savings on which they could draw for emergencies or sudden need. However, the income afforded is not large, and the structure of the sector does not lead to increased choice and work opportunities, as the production-to-consumption supply chain is very short. No industrial, banking or lending institutions were developed as a result of this product's exploitation.

A side benefit to the crisis caused by the harvest of fuelwood was the influx of many NGOs and projects into the study area, which made other investments in the villages. They built houses, offices, trained villagers and contributed to their livelihoods in different ways. Through studies on the exploitation of fuelwood, measures were taken to remedy other serious problems faced and identified by the villagers. Finally, the fuelwood markets indirectly and directly increased the sales possibilities of other animal and farm products in the villages.

\section{Capacity building}

Both formal and informal education was gained by involvement in the fuelwood sector. Informal education was obtained through interaction with buyers and other exploiters. Participants were exposed to and learned to speak other languages, developed better bargaining abilities and came to know more about the currency. Many immigrants (mostly Chadians and Arabs) have come to the main producing zones through this sector. Their involvement has brought new ideas into the villages and increased the level of social interaction of the villagers with other people. Some parents sponsored their children through wood sales, while others received training on tree planting and agricultural techniques from the conservation and development projects that have come to fight against environmental degradation. 


\section{Leisure, health and food and nutrition}

The living standards of the people have improved through involvement in the fuelwood sector, as it increases household income. This in turn enables the household to buy more and more nutritious food, better clothes, medications, and household supplies. Though neither extra health services nor relaxation spots were observed as a consequence of the fuelwood sector, it did contribute to existing ones. The fuelwood product has particular impact on the quality of food, as it aids in food preparation. The fact that all villagers have access to cheap and easily manipulated domestic fuel for heating food, cooking and carrying out other activities is very important.

\section{Community facilities}

The housing conditions of the study area, in terms of living conditions, crowding (number of people per room), sanitation, upkeep and appearance, were not developed. Villagers had mostly traditional houses with at least two persons in a room, which in most cases served both as a kitchen and living area. Transportation services between the villages and Maroua consisted of old, dilapidated vehicles travelling on muddy, poorly maintained roads. Transportation within the villages was on foot, animal or bicycle. Most of the villages have neither electricity nor piped water; some villagers were obliged to travel more than $5 \mathrm{~km}$ to obtain water. The few public services existing in the villages were inadequate.

\section{Forest management and exploitation patterns and modalities}

The management of the forest resource is difficult, because people do not feel ownership of the trees or the land and have no incentive to care about what happens to it in the future. Government and NGOs find it difficult to conserve forests and forest resources and are forced to put guards around some forests (such as Waza National Park) in order to meet their management and conservation objectives. In other cases, NGOs are called to build fences to protect forests from encroachment by farmers, as the forest is destroyed when a new farm is opened up. The lack of land tenure surely played a role in the fact that few farmers in the study area made an effort to maintain or plant trees on their farm plots-despite the encouragement from some projects that gave incentives to farmers who maintained or planted the highest numbers of trees on their plots (DPGT 1996).

Forest exploitation in the study area was mainly rudimentary, with no real effort at managing the various forest resources, as harvesters cut indiscriminately, without regard for the tree's age, size and location within the forest and little consideration for the future. Harvested trees were mostly used as fuelwood, though some were used for artisan and building purposes.

\section{Ecological sustainability}

Considering the exploitation patterns and lack of rational management, there is no guarantee that the ecosystem will be maintained. What is left 
are plants and animals resistant to the effects of the changes brought about by the widespread exploitation and which are not themselves desired for exploitation. This was in evidence in the study area in that the villagers complained about the gradual disappearance and scarcity of some animal and plant species. One way to improve the situation would be to encourage the establishment and exploitation of artificial forests while conserving the natural ones, but the feasibility of that proposal would depend on the active participation of the villagers.

The entire population of this area would suffer without the commercial value of fuelwood. It serves as an important source of income to village households, and it is often the only domestic source of fuel. It represents an important source of non-substitutable domestic energy to urban households as well. The urban poor and those who use fuelwood as the only source of domestic energy are vulnerable to changes in the supply and price of fuelwood, as changing to other fuel sources is expensive because it necessitates the purchase of associate appliances. Urban dwellers will suffer if problems associated with the increasing scarcity of this fuel source are not addressed (for example, increasing price, product scarcity, damaged ecosystems).

With regard to the degraded ecosystem, it is difficult to know if the forest would have been more or less degraded if it were not exploited for fuelwood, because it is possible that the alternative resource or income generating strategies would have been still more damaging to the forest resource. However, given the extent of forest disturbance and the growing demand for an increasingly scarce resource, the health of the ecosystem would be more secure in the absence of the harvest of fuelwood.

The development of the fuelwood sector is of interest to both village and urban populations, as both benefit from the cash income and unique product fuelwood provides. The formalization and development of the sector may actually lead to greater conservation of the forests, as people utilize various programs and legislation to secure rights to the forests and their resources, and then to exploit the forest resource more rationally. One way of developing this sector would be to monitor the harvesting, sale and use of fuelwood. Such a policy should also develop strategies to give this energy source a value competitive with other energy sources.

\section{CONCLUSION AND RECOMMENDATIONS}

Fuelwood is not only an economic but also a social good indispensable to both rural and urban populations. It contributes to family income generation in the study area, and by extension in other parts of Cameroon. Despite, or because of, the importance of this product in the Maroua region, its harvest has resulted in serious environmental problems that were difficult to address at the village level. Live trees are still felled for fuelwood, despite the demonstrated negative consequences on the environment.

The chain of production and trade was short and simple, with few intermediaries. Nevertheless it involved the majority of the population of the study area because fuelwood sales were one of the few means of generating income available to them, aided by the constant demand for the product and, 
to some extent, the tastes and preferences of the consumers. Retailers in urban centers employed workers for splitting, bundling and selling of the product in wood markets. Although there were no formal associations of wood marketers, the markets were well organized, and sellers knew each other by name and by the quantity of wood they traded.

The short marketing chain ended in large part with the urban households who are the main consumers of this product. Little transformation occurred between harvest and the final consumer. The only way in which value was added to the product was by splitting it into smaller pieces, which are most desired by consumers. The consumers were mainly price receivers and had very little say in the fixing of prices. The final sales prices were at least twice the farm gate prices in all cases. The difficulties posed by a decreasing resource base have driven suppliers ever farther into the countryside to buy wood from rural villagers, in spite of the attendant difficulties and costs associated with transport and storage of the fuelwood. The wood can be stored for three to five months, after which time insects begin to damage the product.

The government of Cameroon and others are working to maintain both the sustainability and availability of fuelwood as a resource. Their influence in this area has been quite positive, and the many successes and failures provide ample opportunity for 'lessons learned'. The failures have arisen mostly from egoistic behavior, financial shortcomings and lack of understanding by the village population as well as to some extent from poor identification and implementation of certain projects related to this issue. Despite these issues, much work and research is still being done to ensure the longevity of the fuelwood resource in a healthy natural environment.

The various agents involved in this production-to-consumption supply chain should be encouraged to form legal associations within their localities. Formalized associations could channel aid and assistance to their members to help develop the local fuelwood sector and, importantly, represent the members in communications among other associations and institutions involved with environmental protection or developmental actions and programs. Successful implementation of most strategies developed to fight environmental degradation will require some redistribution of land and clarification of both land ownership and property and usufruct rights. This task will be undertaken in collaboration with the statutory and traditional governments of the area.

\section{ENDNOTES}

1. Ministry of Scientific and Technical Research in Cameroon. Institute of Agricultural Research for Development, Dschang. c/o Presbyterian Church Dschang. PO Box 353 Dschang - Cameroon. E-mail: ijang2001@yahoo.fr

\section{REFERENCES}

Agroforestry Project. 1995 Garoua.

Assan, G. 1991 La problématique du bois de feu à Maroua. Student end of course memoir. ENSA, Dschang University Centre, Cameroon. 
Association du Bois de Feu (ABF). 1989 Revue de l'association bois de feu. Bois de feu et energie. Speciale Nord-Cameroun, Maroua.

Awah, S. B. 1995 The rural woman and the importance of fuelwood in household energy consumption in the Diamaré division of the Far North Province. Student end of course memoir. National Institute of Rural Development. Dschang, University Center.

Community Economic Development Centre. 1997 Annual report. Maroua.

Développement Paysannal et Gestion de Terroirs. 1996 Semestrial report. SODOCOTON, Maroua.

Food and Agricultural Organization of the United Nations. 1990 The fuelwood crisis and population Africa. Parts 1-4.

Food and Agricultural Organization of the United Nations. 1998 Forest products, 1992-1996. Rome.

Fotsing, E. 1997 Evaluation et suivi de la dynamique de la biomasse ligneuse dans la province de l'Etreme-Nord Cameroun. CEDC, Maroua.

Grainger, A. 1993 Controlling tropical deforestation.

Leemans. 1998 Holdridge classification: Holdrige life zone data set.

Minister of Economy, Finances and Industry. 1999 Direction de la Statistiques et de la Comptabilité Nationale (DSCN): annuaire statistique du Cameroun, 1998. Yaoundé.

Minister of Environment and Forestry. 1998 Manual for the procedures for the attribution and norms for the management of community forests. Yaounde, Cameroon.

Montalembert, M.R. and Clement, J. 1983 Fuelwood supplies in developing countries. FAO forestry paper 42 . Rome.

Munslow et al. 1989 The fuelwood trap: a study of the SADCC region. Earthscan Publications Limited, London.

National Forestry Development Agency-ONADEF. 1997 Annual report, Maroua antenna.

Neba, A.S. 1987 Geographie moderne de la Republique du Cameroun. $2^{\mathrm{e}}$ edition. Temple University, Philadelphia.

Ngwa, J.A. 1978 A new geography of Cameroon. Longman Publishers.

Pelkey, N. and Ali, R. 1996 Problems with the use of non timber tropical forest products in ecodevelopment: a bioeconomic approach. University of California, Davis, CA.

Peter, M. 2001 A non timber forest products bibliography emphasizing Central Africa. USAID, USDA, CARPE.

Raven, R.H. and Johnson, G.B. 1986 Biology. Times Mirror/Mosby College Publishing, St Louis-Toronto-Santa Clara.

Review de Géographie du Cameroun. 1996. Yaoundé.

Robert, M.B.V. 1986. Biology. A functional approach. Fourth edition. ELBS, London.

Robin, M. and Leach, G. 1989 Energy for livelihoods: putting people back into African wood crisis. IIED, GateKeepers Series № SA18, London.

Roussel, J. 1995 Technical paper: pépinières et plantation forestières en Afrique tropical sèche.

Republic of Cameroon. 1994 The New Forestry Law, No. 94/01 of 20 th January 1994. 
Sow, H. 1990 Le bois: énergie au Sahel: environnement et développement. ACCT-CTA-Karthala.

Tata, P.I. 1999 Determinants of fuelwood selling prices in the rural and urban centers of the Far North Province. Student end of course memoir. Faculty of Agronomy and Agricultural Sciences (FASA). University of Dschang.

Van Well, E.A.P. 1998 A fuelwood model for North Cameroon: Analysis of factors influencing demand and supply. Wageningen, the Netherlands.

Von Maydell, H.-J. 1990 Trees and shrubs of the Sahel: their characteristics and uses.

Waffo 1996 Impact socio-économique de l'exploitation du bois de feu dans Maroua. Student end of course memoir. National Institute for Rural Development (INADER). Dschang University Centre, Cameroon. 


\title{
Chapter 14
}

\section{Palm utilisation for basketry in Xini Ward, Sengwe communal areas, Zimbabwe}

\author{
Phosiso Sola
}

\begin{tabular}{llllll}
\hline Common names & $\begin{array}{l}\text { Part of the } \\
\text { resource used }\end{array}$ & Management & $\begin{array}{l}\text { Degree of } \\
\text { transformation }\end{array}$ & $\begin{array}{l}\text { Scale of } \\
\text { trade }\end{array}$ & $\begin{array}{l}\text { Geographic } \\
\text { range }\end{array}$ \\
\hline Ilala palm, llala & Leaves & Wild & Medium & International & Medium \\
\hline
\end{tabular}

\section{ABSTRACT}

People living in the south-eastern lowveld of Zimbabwe have utilized and managed the palm, Hyphaene petersiana Klotzsch, since time immemorial. In Sengwe the palm grows in the wild, especially in the flood plains of the Mwenezi and Maose rivers. This paper seeks to document and assess the performance of the basket industry in Sengwe Communal Areas.

The data presented in this paper were collated from reports based on various independent studies conducted in this area from 1993 to 1999 but are mainly based on the findings of an M.Sc. thesis completed by the author in 1998. A further study was also conducted in 2001.

In 2001, the basket industry contributed $20 \%$ to annual household income representing an annual income of US\$21 from basket sales compared to US\$14.8 in 1998. To date, the industry has not resulted in visible impacts on the resource base. Major changes have been experienced in areas of social organisation and trade facilitated by various research and rural development institutions. This case study therefore has demonstrated that, with support, communitybased industries can be viable.

\section{INTRODUCTION}

\section{Hyphaene petersiana in southern Africa}

The basketry industry has been growing in most countries in southern Africa. This has come about due to both economic hardships aggravated by persistent 
droughts and developments in the tourism sector, the main market for these products. In Botswana the industry expanded in the early to mid-1970s when marketing organisations were established (Cunningham and Terry 1993). In the Estha region in Botswana the industry had become so important that the resource became scarce and cultivation had to be adopted (Cunningham and Terry 1993).

Studies in Namibia showed that the basketry industry was very important to the livelihoods of the people of Owambo region, as it provides both household utensils and the means of generating income (Konstant et al. 1995). Hyphaene petersiana does not grow in South Africa, but rural people use a similar species, $H$. coriacea. Craft work from $H$. coriacea accounted for $75 \%$ of the craft products made in Maputaland in 1983 (Cunningham 1987).

Indigenous people of Zimbabwe have utilised the palm $H$. petersiana for sap tapping and craft work for centuries (Meredith 1948; Pardy 1955). The young leaf is used for baskets, the fresh rachis for mats and the dry petioles for doors and chairs. Women use the fan leaves in making tablemats and also as a thatching material (ENDA unpublished; Sola 1998).

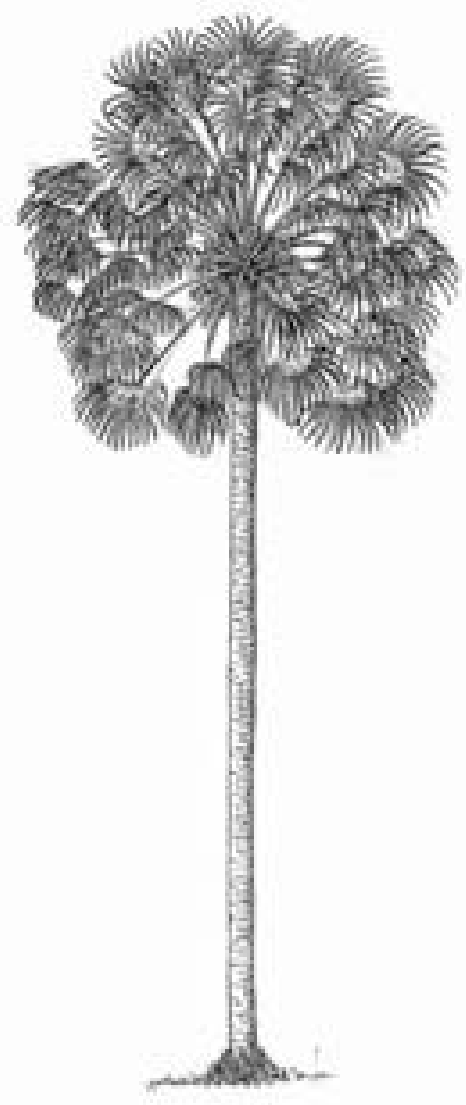

(Hyphaene petersiana) 


\section{Distribution and growth}

$H$. petersiana is found in most southern African countries (Figure 1) on alkaline, saline, sodic soils and clay rich sands (Cunningham and Terry 1993; Sola 1998). In Zambia, $H$. petersiana has been described as occurring in hot and dry valleys in gregarious stands, on friable loams to heavy clays (Fanshawe 1967). In Zimbabwe, Wild and Grandvaux Barbosa (1967) stated that this palm grows in riverine areas and in locations where water is available. In Botswana, on the other hand, the palm occurs in sandy soils, while in Namibia it is restricted to windblown coastal sands (Cunningham and Terry 1993).

During the initial growth stages the palm concentrates on the development of the underground stem and aboveground maintains little foliage of only about seven leaves in an adaptation to low water table conditions. So, besides massive, long subsurface roots that capture floodwaters the palm has a long tap root for dry season water acquisitions (observation). Once the underground stem is well established-a process that takes about seven years-the palm begins to develop the aboveground stem (Fanshawe 1967). However, Sola's (1998) study on sap tapping showed that all ramets have an underground carbohydrate storage organ from which roots emanate. It could be the development of this organ that delays the aboveground stem development. After this stage the palm is able to produce harvestable leaves of more than $60 \mathrm{~cm}$, presumably because the stem is big enough to support them.

Figure 1. The distribution of the palm Hyphaene petersiana in southern Africa

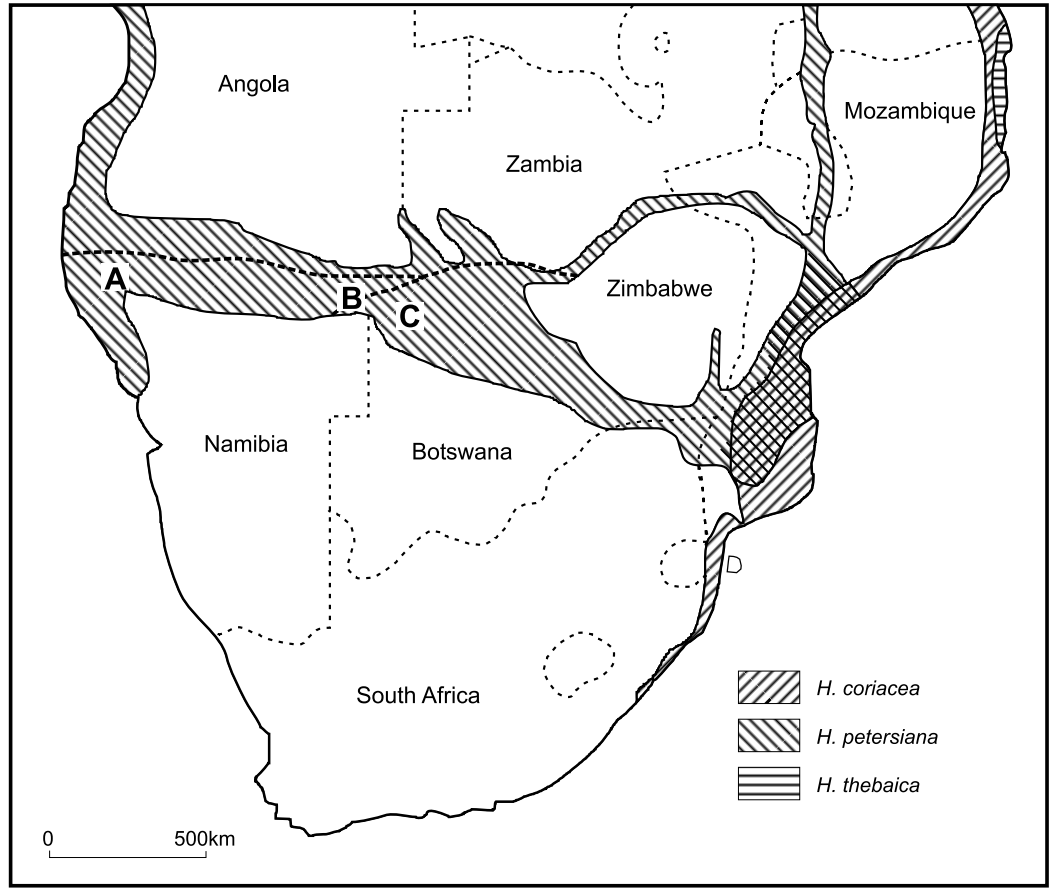

Source: Cunningham and Terry 1993. 
Once the stem is more than $1.5 \mathrm{~m}$ tall the palm is rarely harvested for craft production since cutting of the leaf at the rachii-petiole junction is complicated by the height and usually these palms produce hard leaves which are too brittle and unpliable for craft production. It takes 90 years for a palm to reach a height of $30 \mathrm{~m}$ (Fanshawe 1967).

Leaf production in $\mathrm{H}$. petersiana juvenile plants is a continuous process at the rate of 1.0 to 1.5 leaves per month (Fanshawe 1967). Cunningham and Milton (1987), however, found that palm suckers produced 3.8 leaves per year in plants of leaf-size class $101 \mathrm{~cm}$ to $120 \mathrm{~cm}$ and 2.8 leaves per year in plants of leaf-size class $41 \mathrm{~cm}$ to $60 \mathrm{~cm}$. In another study conducted in Zimbabwe a similar result of four leaves per year for the size class $101 \mathrm{~cm}$ to $120 \mathrm{~cm}$ was recorded (Sola 1998).

Besides craft production $H$. petersiana is also used for sap tapping for the production of a local wine. Tapping is usually done between August and March of the following year. It is a man's activity and a skilled tapper can tap 25 to 50 ramets per day. The wine sells for US\$0.162 per litre (Sola 1998). Sap tapping involves burning of clumps to remove dead leaves and pruning of the ramets to expose the underground carbohydrate storage organ. Tappers insert V-shaped leaves into trimmed ramets for sap collection. Tapping continues until most, if not all, of the meristem has been removed. It is this process that poses a threat to the basket industry since not all ramets recover, especially when all the meristem has been removed (Sola 1998). However, most of the ramets recovered through suckering and shoots if some meristem remained.

Another threat to the basketry industry is resource scarcity. Cunningham and Milton (1987) found that as the craft industry expanded, the leaves became time-consuming and expensive to obtain because of ever increasing distances to harvesting areas. In Botswana, high harvesting intensities with an offtake rate of 30\% resulted in a decrease in leaf size (Cunningham and Milton 1987). Besides leaf harvesting and grazing by livestock the greatest threat to $H$. petersiana is land use conversion.

\section{Study area: Sengwe Communal Areas}

Sengwe Communal Areas is located in south-eastern Zimbabwe, in an area bordering South Africa and Mozambique (Figure 2). Low rainfall and frequent droughts threaten household food security as they negatively impact on crop and livestock production, the two major sources of household income (Sola 1998). To supplement their household income the people of Sengwe have adopted craft production activities using forest resources, of which the palm is the most widely used (ENDA unpublished).

\section{Study site: Xini ward}

This study focuses on Xini ( $\left.22^{\circ} 05^{\prime} \mathrm{S}: 31^{\circ} 20^{\prime} \mathrm{E}\right)$, one of the four wards in Sengwe Communal Areas. The area is bounded by the Zimbabwe-Mozambique border, Gona re Zhou National Park and Malipati safari area. Xini ward shares borders with Sengwe ward and with Xibavahlengwe ward in the north. 
Figure 2. Map of the study area

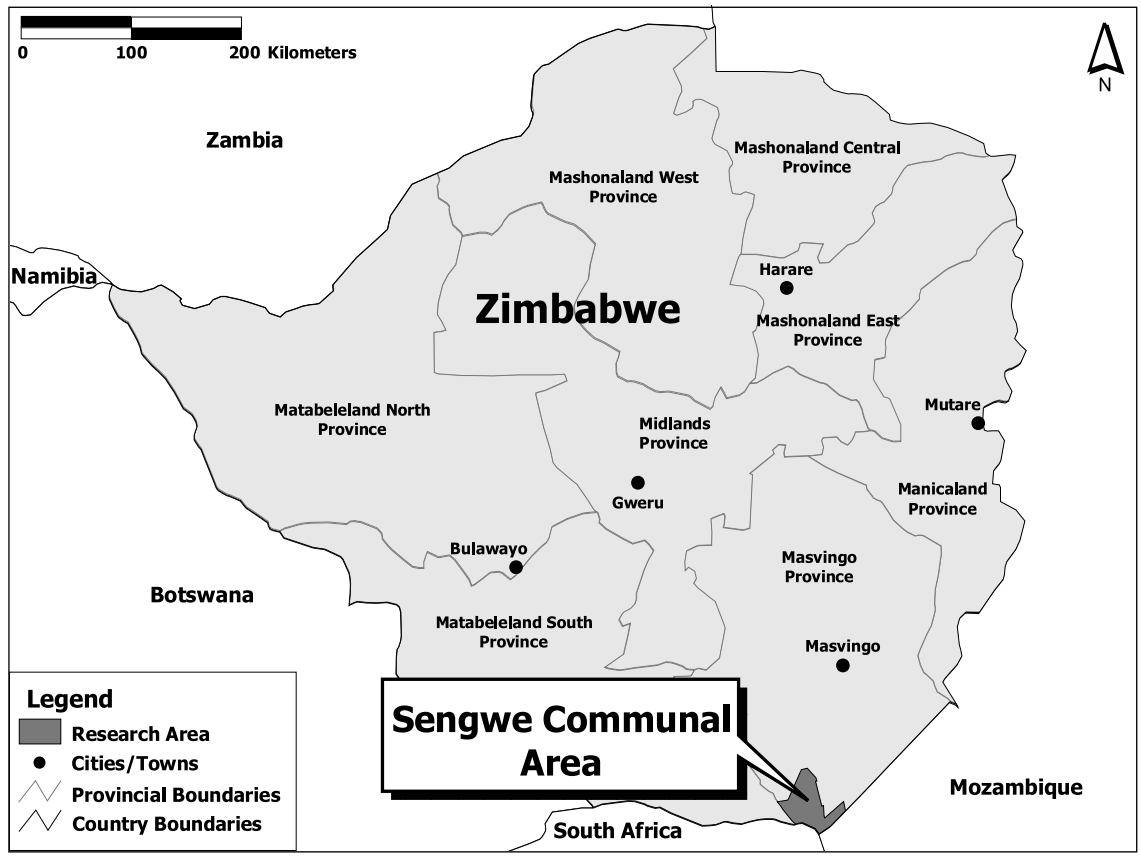

Source: ESRI Data and Maps 2002.

The mean annual temperature is $24.4^{\circ} \mathrm{C}$, while mean maximum and mean minimum temperatures are $32.3^{\circ} \mathrm{C}$ and $16.5^{\circ} \mathrm{C}$, respectively. High temperatures occur between October and March when they can exceed $40^{\circ} \mathrm{C}$ (ARDA unpublished). Most of the area is between $302 \mathrm{~m}$ and $610 \mathrm{~m}$ above sea level. The annual rainfall is low and erratic, measuring around $450 \mathrm{~mm}$ per year.

The study area covers about $820 \mathrm{~km}^{2}$ with a total population of 9,080 distributed over 1,597 households. It has a natural annual growth rate at $3.3 \%$ (ARDA unpublished). Access to the study area is by all-weather road approximately $200 \mathrm{~km}$ (ARDA unpublished). The road network within the study area measures about $100 \mathrm{~km}$ of seasonal roads, which are strongly affected by the yearly flooding of the rivers.

Soils vary according to distance from the main river, Mwenezi. Adjacent to the river, soils are deep sands from recent alluvium (ARDA unpublished). Further inland there are siallitic soils and heavy textured soils together with vertisols (ARDA unpublished).

No detailed vegetation surveys have been carried out in Sengwe. Wild and Grandvaux Barbosa (1967) described the vegetation, on a large scale, as discontinuous dry savanna woodland and thicket with tree or shrub savanna of Acacia and the palm Hyphaene petersiana. A more recent study indicated that the most dominant tree species on the heavy clays (which are closely associated with the palm) is Salvadora augustifolia (Sola 1998). 


\section{THE PRODUCTION-TO-CONSUMPTION SYSTEM}

\section{Resource base}

The palm $H$. petersiana belongs to the family Palmae (Photo 1 ). The species is dioecious and the proportion of male to female plants is usually 1:2 (Fanshawe, 1967). The short lived male flowers are produced in fairly short tangled spikes among the leaf bases. The larger, short stalked female flowers are produced in large branched sprays, which develop into heavily branched trusses of fruits (September to October), as is typical of the species. Fruits are produced in large quantities (up to 2,000) and take two years to mature. Seeds are borne in the globular fruit in a fleshy and edible endocarp. They are susceptible to desiccation and have a short dormancy period (Fanshawe 1967; Palgrave 1988).

The life of a juvenile leaf is approximately 12 months (Fanshawe 1967), but dead leaves remain on the stem for over two years (Cunningham 1988). The stems of juvenile palms are short and are well underground, about $25 \mathrm{~cm}$ below the soil surface (Corley et al. 1971). The palm shoot grows by continuous leaf production from a single apical meristem (Fanshawe 1967; Cunningham 1988; De Steven 1989), whose loss is not compensated for by lateral branching. $H$. petersiana, like all clonal growing plants, produces iterated modular units (ramets) of the same genotype that are potentially capable of independent growth and reproduction.

Photo 1. A mature $H$. petersiana tree with a few fruits in the mopani woodland in Chishinya, Sengwe Communal Areas (Photo by P. Sola)

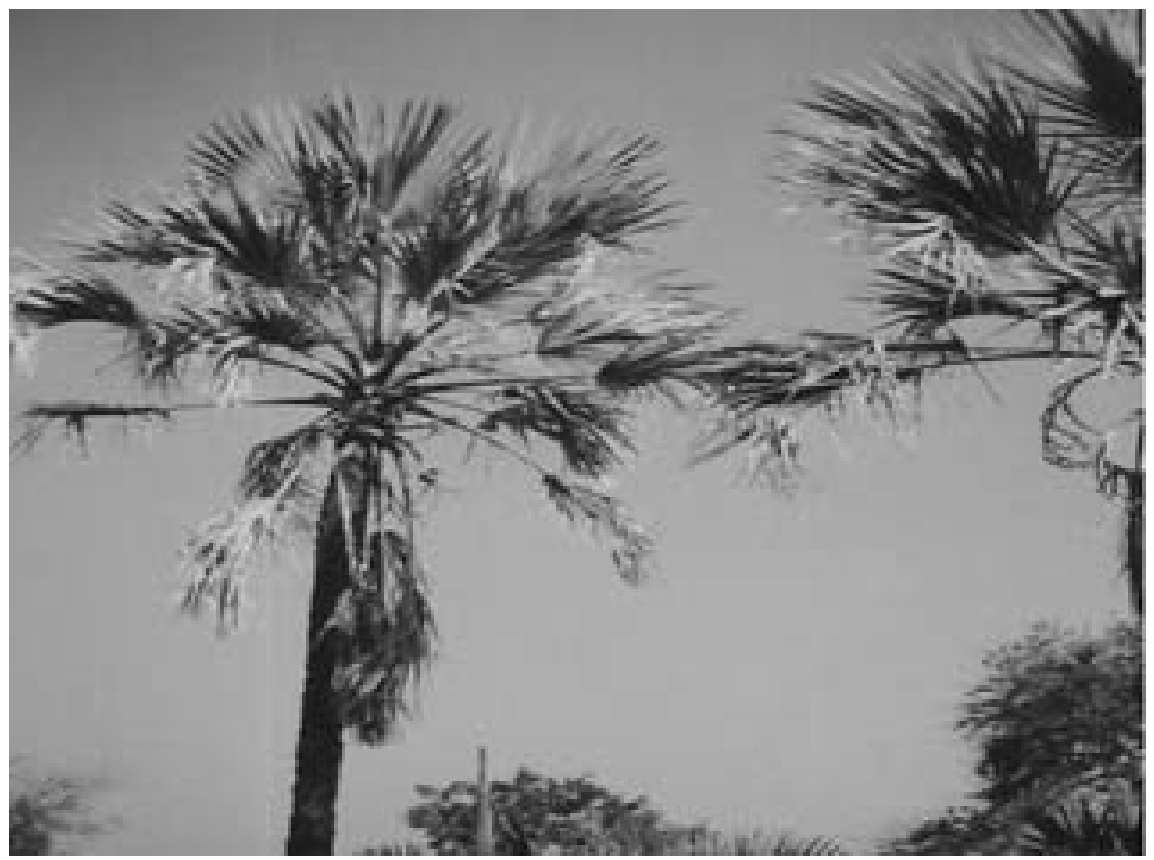


Craft production depends heavily on the rate of leaf production and on the growth rate of new leaves. Leaf production determines the number of leaves on each plant while the growth rate determines how many leaves can be harvested at any one time. On average the ramets produced one leaf in three months, which gave an estimate of four leaves per ramet per year (Sola 1998).

The structure is not the typical reverse $\mathrm{J}$, an indicator of growing populations. This is so because stems are repeatedly cut for sap tapping and as such are not naturally growing. As a result there are few adult trees. Hence palms in the harvestable categories accounted for $95.09 \%$ of the total population with a density of 974.5 ramets per hectare (Table 1).

On average each ramet has 1.72 harvestable leaves (longer than $60 \mathrm{~cm}$ ), which gave 808.41 harvestable leaves per hectare; these accounted for $48.27 \%$ of the total leaves (Table 1). Using the annual leaf production rate of four leaves per ramet (Sola 1998) the production potential of the ramets in Xini ward is therefore 3,233.75 leaves/ha/year.

\section{RAW MATERIAL PRODUCERS AND THE SOCIO-ECONOMIC CONTEXT}

\section{Population}

In 1993, Xini ward had a population of 9,080 people, 5,173 of them females and 3,907 males (CSO 1993). While the distribution is similar to the national scenario, the situation in Xini is compounded by the continued migration of young men into South Africa in search for employment. The average household size in Xini ward is 5.7 people.

\section{Livelihood activities}

Farming systems are based on extensive livestock production. Over $86 \%$ of the households in Sengwe own livestock (ARDA unpublished). Rain-fed crop production is the norm. On average a household cultivates 2.2 ha per season. Most of the time activities have to be carried out according to priority. Sola's study of 1998 showed household participation in craft production was inversely related to crop production labour demands (Figure 3).

\section{Household income}

According to the Mabalauta Working Group (2000), most cash from livestock sales comes from cattle even though $40 \%$ of the Xini population do not own cattle. Goats and chickens are the most widely owned domestic animals. There are five irrigation schemes in Xini, all situated in the flood plain of Mwenezi River within the palm area. During good seasons a family can make as much as US\$4.00 per week from sales of horticultural produce.

Remittances play a big role in family income generation (ARDA unpublished; ENDA unpublished; Sola 1998; MWG 2000). According to ENDA, 45\% of the people in the study area have family members-in most cases, sons-elsewhere who send money or goods to them (MWG 2000). 


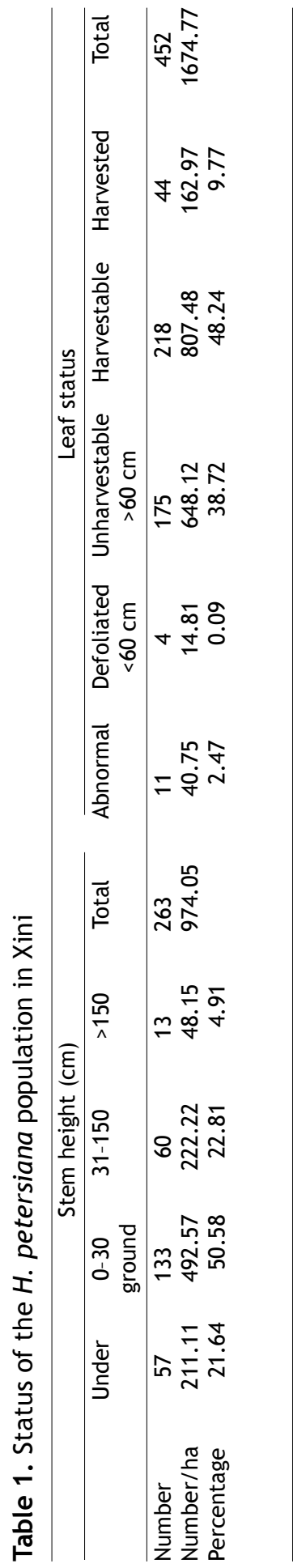


Figure 3. Proportions of Xini households engaged in particular livelihood activities during $1998(\%, \mathrm{n}=54)$

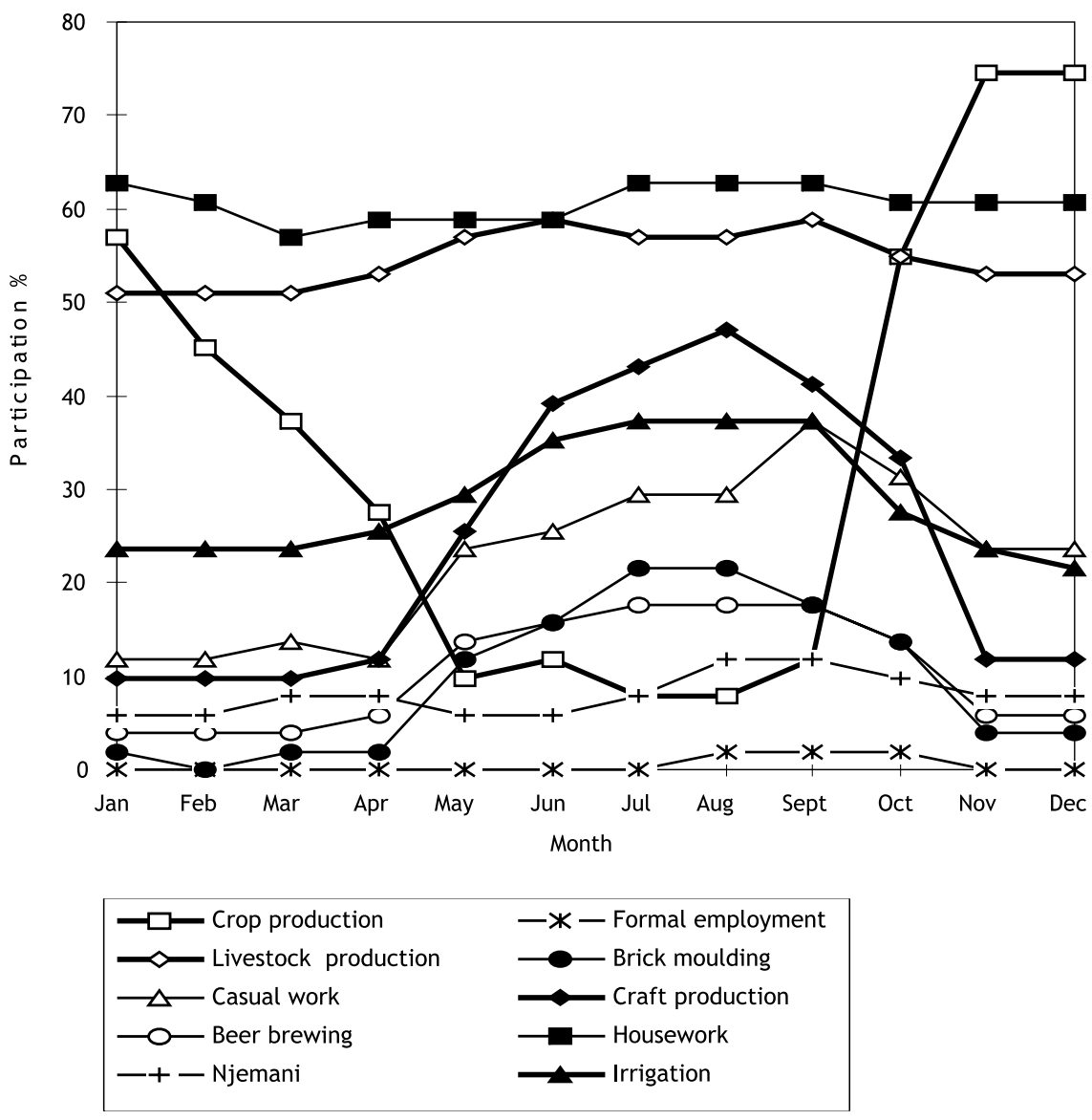

\section{Craft production}

Approximately $93 \%$ of all the community members have at one time or another participated in palm activities (Sola 1998). As a result, palm craft sales, especially mats, brooms, and baskets are ranked third as sources of household income by women palm producers (ENDA 1993; Sola 1998; MWG 2000). However, the proportions of cash income from palm sales were different for men and women. According to the Mabalauta Working Group, receipts from palm-related products make up $7.6 \%$ of the men's income and $19.6 \%$ of the women's.

Sola's (1998) study suggested that about $60 \%$ of the households in the ward are involved in basket making and made an income of US\$14.80 per year. However, Xini households generated US\$81.82 on average during that year. An assessment made in 2001 reveals that incomes from the basketry industry accounted for $20.5 \%$, the average annual income of producer households being 
US\$102.80. Therefore in 2001 the basketry industry contributed US\$21.07 to producer household income, an increase of about 42\% from the 1998 level.

\section{Access and control}

The palm $H$. petersiana grows naturally and as such is a communally owned resource. In Zimbabwe all the land in communal areas is owned by the state while the traditional leadership and local government are just the custodians of the resources growing thereof.

In Sengwe all the palm stands are customarily owned by the Shangaan people by virtue of their being indigenous to the area. The ownership is strictly for sap tapping for wine production, and leaves for crafts may be accessed by all (Sola 1998). Additionally, transfer rights of palm resources by individual producers are based on a patrilineal system.

Each village under a kraal head has its own designated tapping fields and leaf harvesting areas. The chiefs, working through headman, have overall control of palm utilisation. To date they have managed to stop the transportation and sale of unprocessed palm leaves. So far, the impact of traditional rules has been generally positive as it has resulted in the palm being conserved whilst everyone in the designated area has access to the palm for leaf harvesting.

\section{Leaf processing for craft}

Leaf processing and weaving is undertaken at the household level by one or two family members. In basket making it is mostly the unopened leaves that are used and they consists of several leaflets, which are opened during drying. The unopened leaf is cut and split into double-leaflets numbering between 21 and 34 per leaf. Leaflets are stranded using a big needle, the midrib is removed and the outer edges of the leaflet are discarded. Midribs are used as the filling material in making fruit and shopping baskets, while in winnowing baskets they are used as weft threads and the inner parts as the weaving material; this makes the product 100\% palm (Photo 2). Big artefacts (winnowing baskets, harvest baskets and washing baskets) are made from leaves of about $100 \mathrm{~cm}$ length, while smaller artefacts such as wall hangings, fruit baskets and sugar basins are made from leaves of shorter length (Table 2) (Sola 1998).

Weavers were able to differentiate between the sexes of the palm. The male plant was said to have whitish-green leaves that are very brittle and therefore unsuited for craft production, whereas the female plant has dark green leaves that are very pliable and most suited for craft making. Dye production has also to be considered, as it is an activity that is part of the basket making. The dye used to colour the baskets is taken from an indigenous tree, Bechermia discolor (munyiyi). Craft makers collect the bark of the tree, grind it and or mix it with charcoal to produce a dark brown colour, which is preferred over brick red or reddish brown. They then add the bark-charcoal mixture to the palm leaves in boiling water. 
Photo 2. SEVACA women in Chishinya village show their artefacts made from palm: winnowing baskets/wall hangings, fruit baskets and mats (Photo by P. Sola)

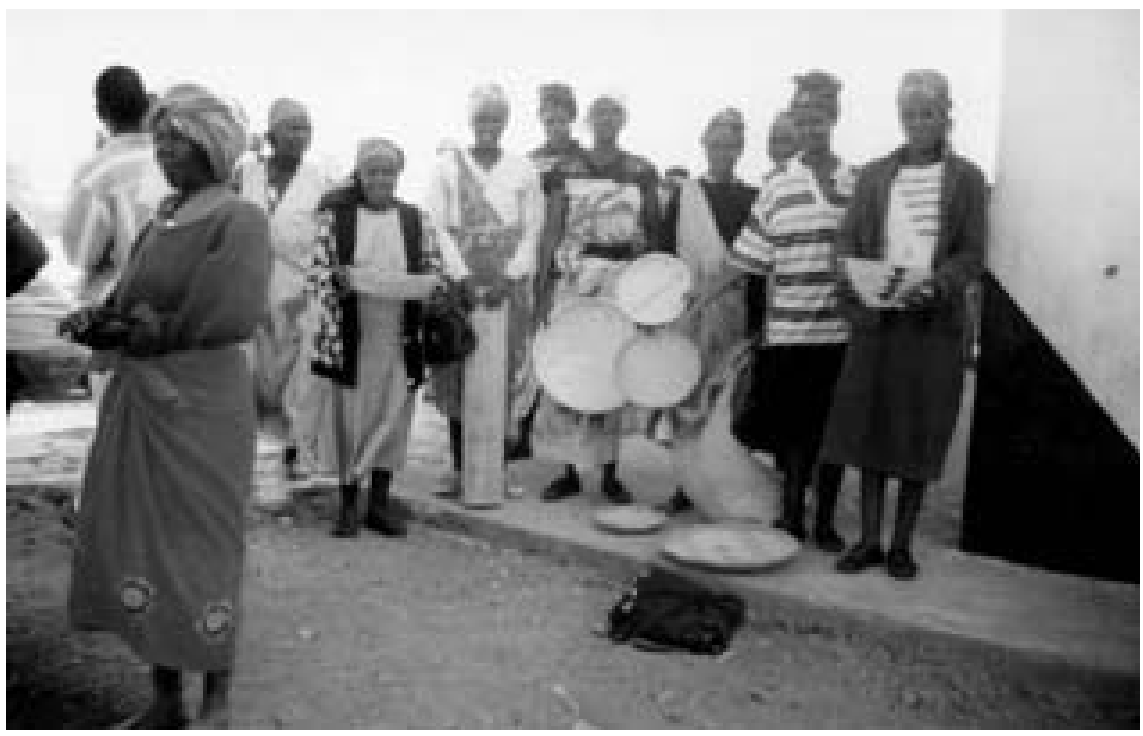

Table 2. Basket making in Xini

\begin{tabular}{|c|c|c|c|c|}
\hline \multicolumn{2}{|l|}{ Item } & \multirow{2}{*}{$\begin{array}{l}\text { Fruit } \\
\text { basket } \\
\text { Unopened } \\
\text { leaf }\end{array}$} & \multirow{2}{*}{$\begin{array}{l}\text { Shopping } \\
\text { basket } \\
\text { Unopened } \\
\text { leaf }\end{array}$} & \multirow{2}{*}{$\begin{array}{l}\text { Winnowing } \\
\text { basket } \\
\text { Unopened } \\
\text { leaf }\end{array}$} \\
\hline Part used & & & & \\
\hline Length of part used & $\begin{array}{l}\text { Mean } \\
\text { Standard } \\
\text { deviation }\end{array}$ & $\begin{array}{l}83 \\
50\end{array}$ & $\begin{array}{r}103 \\
41\end{array}$ & $\begin{array}{r}117 \\
26\end{array}$ \\
\hline $\begin{array}{l}\text { Number of parts } \\
\text { used per item }\end{array}$ & $\begin{array}{l}\text { Mean } \\
\text { Standard } \\
\text { deviation }\end{array}$ & $\begin{array}{l}9.33 \\
1.21\end{array}$ & $\begin{array}{l}6.25 \\
3.95\end{array}$ & $\begin{array}{l}9 \\
1\end{array}$ \\
\hline Making (days) & $\begin{array}{l}\text { Mean } \\
\text { Standard } \\
\text { deviation }\end{array}$ & $\begin{array}{l}1.6 \\
5\end{array}$ & $\begin{array}{l}1.75 \\
0.96\end{array}$ & $\begin{array}{l}3.0 \\
1.41\end{array}$ \\
\hline $\begin{array}{l}\text { Number produced } \\
\text { per household } \\
\text { per year }\end{array}$ & $\begin{array}{l}\text { Mean } \\
\text { Standard } \\
\text { deviation }\end{array}$ & $\begin{array}{l}11.3 \\
4.73\end{array}$ & $\begin{array}{l}7.5 \\
3.54\end{array}$ & $\begin{array}{l}6.67 \\
0.587\end{array}$ \\
\hline Producers (\%) & & 41 & 44 & 19 \\
\hline
\end{tabular}




\section{The characteristics of trade and marketing systems}

A large number of households with one or two producer members are engaged in palm harvesting and processing. Of the $93 \%$ of households that produced crafts, $76.6 \%$ produced baskets on a commercial basis while the rest produced for own use and gifts. Also, 57.5\% of the commercial producers work in groups, namely the Sengwe Vanani Craft Association (SEVACA). Little technology is used in the production, nothing more than a knife for leaf harvesting and a needle for stranding and weaving. Each individual produces more than one type of artefact (Table 3), perhaps in response to orders from SEVACA.

\section{The Sengwe Vanani Craft Association}

SEVACA, a craft-trading organisation based in the Sengwe Communal Areas, was formed in 1997 with financial assistance from the German nongovernmental organisation Terre des Hommes. SEVACA secured support from another two nongovernmental organisations, Environmental Development ActivitiesZimbabwe (ENDA-Zimbabwe) and Southern Alliance for Indigenous Resources (SAFIRE), with regards to capacity building and marketing. Like all the other wards in Sengwe communal lands, Xini ward has three producer groups affiliated with SEVACA and a craft shop manned by a sales person. The shop was established mainly for storage and limited local sales. The main activity members were engaged in at group level was training in production for orders. Between 2000 and 2001 SEVACA was receiving orders of up to 6,000 items for four different products.

\section{Trading of palm baskets}

About $63 \%$ of the produced items are traded for cash. Individuals produced baskets, which are traded locally or are collected by producer groups, graded and sold to the SEVACA association. SEVACA bought the items for US\$0.7 to US\$1.33, which gave each craft producer a minimum of US\$13.09 per annum. The main buyers for SEVACA were the National Handcraft Centre, National Art Gallery, and some foreign buyers in Mexico and Europe. The items were sold with a $20 \%$ to $30 \%$ mark-up, giving selling prices of US\$1.67 to US\$2.0. Between 1999 and 2000 SEVACA made a turnover of about US\$500 annually.

Besides the mentioned markets, SEVACA sold some of its items at the Zimbabwe International Trade Fair as well as at Zimbabwe national and provincial agricultural shows. By participating in these events SEVACA managed to secure orders from foreign markets but strong external trade links have not yet formed. The trade in crafts from Xini is summarized in Figure 4.

Most of the grading is undertaken at the association level, where baskets are classified according to set and agreed standards by peer groups. There are many players involved in determining the sales prices, including product owners, buyers and projects officers supporting and employed by SEVACA. Main determinants of the final sales price are size, time it took to produce an item, complexity of shape and patterns used. 


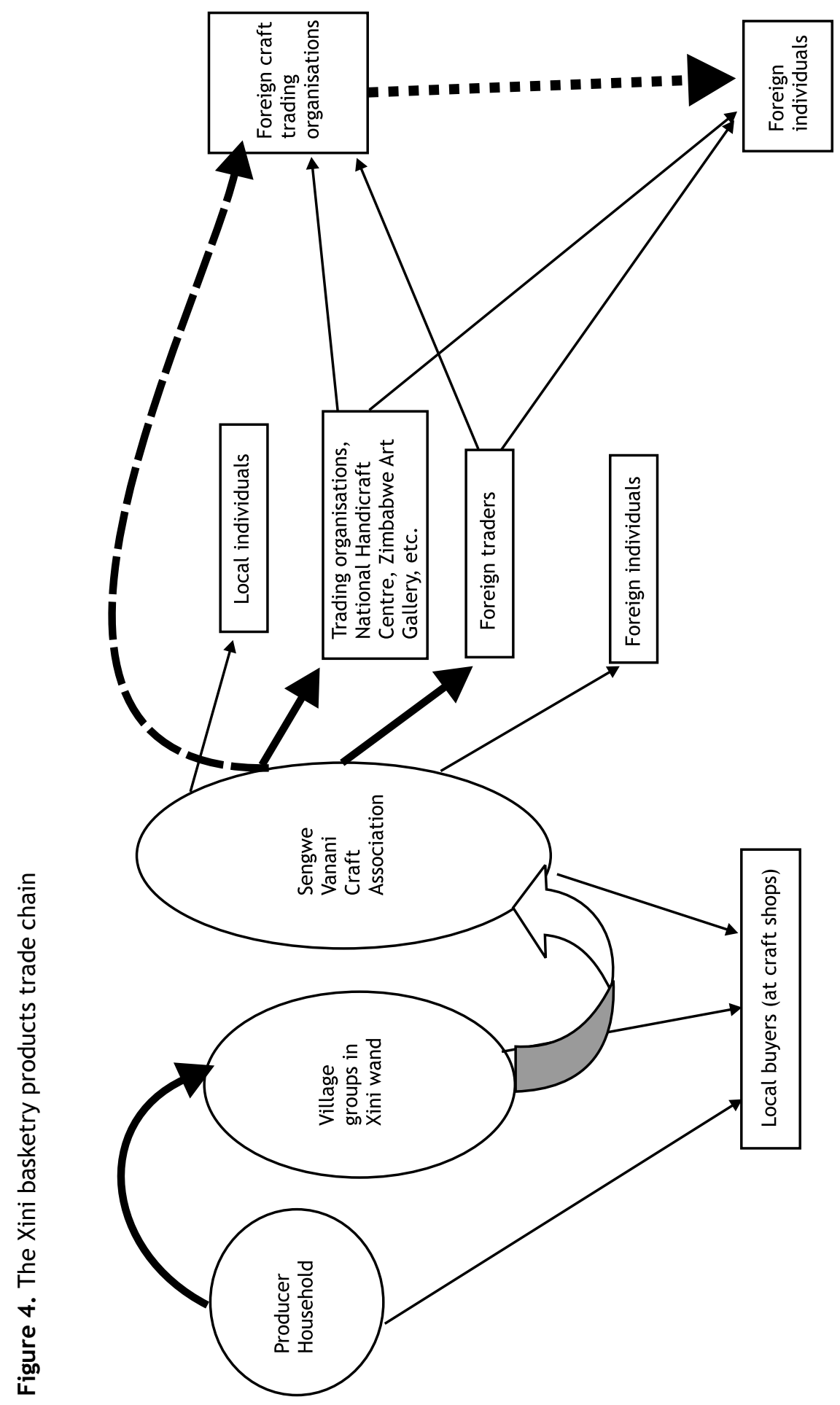


Table 3. Baskets production and income analysis

\begin{tabular}{lccccc}
\hline $\begin{array}{l}\text { Stakeholder } \\
\text { group and } \\
\text { product }\end{array}$ & $\begin{array}{l}\text { Producers } \\
(\%)\end{array}$ & $\begin{array}{l}\text { Average } \\
\text { production } \\
\text { per producer } \\
\text { household, } \\
1998\end{array}$ & $\begin{array}{l}\text { Labour } \\
\text { inputs } \\
\text { (hours } \\
\text { per item) }\end{array}$ & $\begin{array}{l}\text { Market } \\
\text { prices } \\
\text { (US\$ per } \\
\text { item) }\end{array}$ & $\begin{array}{l}\text { Average } \\
\text { income } \\
\text { per producer } \\
\text { household, } \\
1998 \text { (US\$) }\end{array}$ \\
\hline Fruit baskets & 40 & 14 & 12 & 1.45 & 6.37 \\
Shopping baskets & 32 & 6 & 16 & 1.82 & 3.64 \\
Winnowing baskets & 32 & 8 & 11 & 3.64 & 6.37 \\
Overall & 9.5 & & 2.46 & 14.8 \\
\hline
\end{tabular}

\section{Policy framework}

Government regulations influencing the production of crafts from palm leaves are enshrined in the Rural District Councils Act of 1988, Natural Resources Act chapter 20:13 of 1996 and most importantly the Communal Land Forest Produce Act chapter 19:04 of 1987 (Table 4). The Communal Land Forest Produce Act regulates the exploitation and protection of forest produce within communal lands. The act specifically permits the exploitation of these produces for household use and can only be commercialised through a permit or license. The permits or licenses are issued and monitored by the respective Rural District Councils (in this case the Chiredzi RDC) in consultation with the Forestry Commission. These regulations exist in theory but rarely has their effect been realised in the Sengwe area.

\section{TRENDS AND ISSUES}

SAFIRE and ENDA-Zimbabwe introduced financial, technical and institutional support to the Sengwe basketry industry. During the early to mid-1990s ENDAZimbabwe worked to promote commercialisation of palm products as well as infrastructural development in the form of marketing and administrative structures. The training subsequently provided focused mainly on product development, marketing and financial management.

SAFIRE moved into the area in the late 1990s providing institutional development support in terms of establishment of processors' organisational structures and natural resources management systems to ensure the sustainable utilisation of the palm. The linking of the Sengwe community to outside markets has resulted in a shift in craft production. In the early days this community used to produce big artefacts, which were easy to use in case there were no buyers. This scenario resulted in lots of craft ware piling up in houses and deteriorating beyond marketable standards. Now the community has organised marketing and produces on order. Most of these orders are for artefacts smaller than the traditional large utility baskets.

If the craft industry is to survive some management strategies should be employed to enhance, or at least maintain, the palm stocking levels. This was 
Table 4. National regulations that affect the production of palms and the marketing of baskets

\begin{tabular}{lll}
\hline Regulation & Main & Theme \\
\hline 1. Forest Act & $\begin{array}{l}\text { Provides mandates for the Forestry Commission as a forestry authority } \\
\text { to protect and conserve forests for the benefit of the nation-including } \\
\text { control, management and leasing of state forests-and to regulate and } \\
\text { supervise timber extraction by private landholders and concessionaires }\end{array}$
\end{tabular}

2. Communal

3. Natural

4. Communal

5. Rural District Councils' Act

6. Traditional
- Restricts use of forest products in communal lands to own use Land Forest

- Provides for rural district councils (RDCs) to grant licenses to Produce Act concessionaires to cut trees for commercial purposes

- Restricts movement of produce from communal areas

- Prohibits use of forest products from protected forest areas and reserved tree species

- Prohibits removal of trees from within $100 \mathrm{~m}$ of riverbanks

- Allows for the formation of Natural Resource Management Commit Resources Act tees with powers to levy taxes and seek grants and loans

- Empowers the Department of Natural Resources to monitor use of communal resources

- Calls for clear quantification of costs in monetary and environmental terms for any development projects, limiting unnecessary clearing of woodlands in development projects

- Puts control of communal lands under the president through Land Act RDCs rather than traditional leaders

- RDCs are allowed to develop land use plans that override customary land claims

- RDCs are empowered to control cutting of trees

- Provides for RDCs to grant permits to communities for the use of natural resources

- Empowers RDCs to enact natural resources management by-laws

- Provides for RDCs to enact by-laws to regulate natural resource use

- Issues licenses for commercial extraction of wood products

- Empowers natural resources management committees to enforce the Natural Resources Act

- Makes RDCs responsible for long term planning and development

- This new act with the objective of empowering traditional leaders Leaders Act to become custodians of natural resources, including land, is not yet fully understood and accepted

Source: Nhira et al. 1998.

already facilitated by SAFIRE through development of community resource management plans. The objectives of these plans are to balance resource utilisation and conservation through the enhancement of local control systems. However, the community still thought there were enough palm resources and enhancement mechanisms were unnecessary. 
Palm utilisation regimes in Xini have shown that it is not so much resource ownership that is crucial for community-based industries to succeed but issues of access. In this community there were no indications of resource exploitation by non-owners. Population growth remains a key factor that influences the amount of palm resources available as it contributes directly to the rate of land use conversion to settlement and crop production.

\section{CONSERVATION AND DEVELOPMENT: LESSONS FROM THE CASE}

\section{Resource base}

Generally $H$. petersiana palms occur in large clusters scattered within the woodland. In terms of habitat disruption the harvesting process has caused very little change to the vegetation but impacts on the animal species should be evaluated. The area used to have more palm veld but because of land use conversion to crop fields most of it has been lost. As such the production-toconsumption system has not changed the palm resource status.

The people of Sengwe have always harvested young leaves for basket making and this has had no visible impact on the resource base. To date, both harvesting techniques and harvesting levels have resulted in no apparent impacts on palm leaf productivity. Because of this lack of visible impacts the people of Xini-and indeed Sengwe as a whole-have not embarked on any palm domestication strategies.

\section{Craft processing}

Before the advent of craft commercialisation people of Sengwe made big utility artifacts. The quality of products was poor and their range small. Production levels were also limited. Basketry was carried out as an off-agricultural season activity. Most of the products were piled up in houses in case buyers passed by. As such, selling was by chance. The advent of the basketry industry and improved market accessibility have resulted in increased craft production.

\section{Market and trade}

The formation of the marketing organisation SEVACA was undertaken to increase the processors' bargaining power. Before its formation individual basket producers negotiated their own prices, which led to exploitation even with the limited chance sale. SEVACA has facilitated penetration into distant markets where baskets are fetching relatively higher sales prices. Another apparent impact from the organisational structure of the processors was the increase in skills levels due to a number of training sessions offered for the production of specific and new types of baskets.

\section{Sociocultural aspects}

New social groups were forming across ethnic groupings and the impact of this is not known. However, it is envisaged that it would lead to social acceptance 
and stability between the major groups, the Ndebele and the Shangaan. This social regrouping did not seem to affect cultural systems of palm utilisation but just might facilitate resource management by owners and nonowners.

\section{CONCLUSION}

The greatest threat to the basketry industry is land use conversion, which has reduced the palm standing stock, and hence also the harvestable material for basket making. Leaf harvesting techniques have not had any apparent adverse impacts as extraction rates are lower than annual leaf production rates.

The basketry industry, which began as chance sales by a few households, has grown to encompass about $60 \%$ of the households in the study area. The community based trading association SEVACA has facilitated the expansion of markets, thereby increasing community income so that the basketry industry now is contributing more to household income than it did before. This case study has demonstrated that with support community based industries can be viable.

\section{ENDNOTES}

1. Southern Alliance for Indigenous Resources, 10 Lawson Avenue, Milton Park. Box BE 398, Belvedere, Harare, Zimbabwe. E-mail: sola@safire.co.zW

2. Exchange rate: US\$1 = ZWD38.98.

\section{REFERENCES}

Central Statistics Office. 19931992 census: Zimbabwe preliminary report. Government of Zimbabwe, Harare.

Corley, R.H.V., Gray, B.S. and Siew Kee, N.G. 1971 Productivity of the oil palm Elaies Guinness Jacq. in Malaysia. Experimental Agriculture 7: 129-136.

Cunningham, A.B. 1987 Commercial craftwork: balancing out human needs and resources. South African Journal of Botany 53(4): 256-259.

Cunningham, A.B. 1988 Leaf production and utilisation in Hyphaene coriacea: management guidelines for commercial harvesting. South African Journal of Botany 54(3): 189-195.

Cunningham, A.B. and Milton, S.J. 1987 Effects of basket weaving industry on Mokola palm and dye plants in north western Botswana. Economic Botany 41(3): 386-402.

Cunningham, A.B. and Terry, M.E. 1993. Basketry, people and resources management in southern Africa. In: Ganry, F. and Campbell, B. (eds.) Sustainable land management in African semi-arid and subhumid regions: proceedings SCOPE workshop 15-19 November 1993, Dakar.

De Steven, D. 1989. Genet and ramet demography of Oenocarpus mapora ssp. a clonal palm of Panamanian tropical moist forest. Journal of Ecology 77: 579-596.

Environmental Development Activities. 1993 Socio-economic and natural resource survey of Sengwe communal lands, Zimbabwe. Government of Zimbabwe, Harare. 
Fanshawe D.B. 1967 The vegetable ivory $H$. ventricosa Kirk, its ecology, siviculture and utilisation. Kirkia 6(1): 105-116.

Konstant, T.L., Sullivan, S. and Cunningham, A.B. 1995 The effects of utilisation by people and livestock on $H$. petersiana (Arecaceae) basketry resources in the palm savanna of north central Namibia. Economic Botany 49(4): 345-356.

Mabalauta Working Group. 2000 The ecology, control and economics of ilala palm in Sengwe Communal Area, Zimbabwe. ElS Working Paper No. 15.

Meredith, C.C. 1948 Vegetable ivory palm: notes on the collection of sap of the vegetable ivory palm $(H$. ventricosa) and manufacture of palm wine spirit. Rhodesian Journal of Agriculture 45(5): 414-417.

Nhira, C. et al. 1998 Contesting inequality in access to forests: policy that works for forests and people.

Palgrave, K.C. 1988 Trees of southern Africa. Struik Publishers, Cape Town.

Pardy, A.A. 1955 Notes on indigenous trees and shrubs of southern Rhodesia, $H$. crinata, and $H$. ventricosa. Rhodesian Journal of Agriculture 52(4): 330331.

Sola, P. 1998 The performance of Hyphaene petersiana under community-based utilisation in Sengwe communal lands, Zimbabwe. M.Sc. Thesis, University of Zimbabwe, Harare.

Wild, H. and Grandvaux Barbosa, L.A. 1967 Vegetation map of the Flora Zambesiaca Area: supplement to Flora Zambesiaca. M. O. Collins (Pvt) Ltd. and Government Printer, Salisbury. 


\title{
Chapter 15
}

\section{The rattan industry in the Ashanti and Western regions of Ghana}

\author{
Charles Adu-Anning ${ }^{1}$
}

\begin{tabular}{llllll}
\hline Common names & $\begin{array}{l}\text { Part of the } \\
\text { resource used }\end{array}$ & Management & $\begin{array}{l}\text { Degree of } \\
\text { transformation }\end{array}$ & $\begin{array}{l}\text { Scale of } \\
\text { trade }\end{array}$ & $\begin{array}{l}\text { Geographic } \\
\text { range }\end{array}$ \\
\hline $\begin{array}{l}\text { Rattan, } \\
\text { Mfia, Ayie }\end{array}$ & Stem & Wild & Medium & International & Large \\
\hline
\end{tabular}

\begin{abstract}
This chapter presents the findings of a socio-economic analysis of the rattan industry in the Ashanti Region of Ghana. The study was carried out with particular emphasis on urban and peri-urban areas identified in previous research (Darko 1981; Falconer 1994; Oteng-Amoako and Obiri-Darko 2001) and was extended to the Western Region to analyse the raw rattan production system in view of the fact that almost all rattans being commercially utilised are from this region. The scope of the research covers the raw material production, processing and marketing subsectors of the rattan industry in Ghana. It was found that males dominate the ranks of producers and the majority of these have some level of formal education. The average income from rattan production is US\$150 to US\$200 per annum. Self-financing is the major source of capital funding for rattan producers. Suggestions and recommendations to promote the industry include the sustainable harvesting of wild sources of rattan, the establishment of plantations, increased availability of affordable sources of capital and the standardisation of quality grading rules.
\end{abstract}

\section{INTRODUCTION}

The rattan industry in Ghana is made up of a group of small scale entrepreneurs engaged in various activities from the production of raw rattan from either natural forest or fallow lands to manual processing of the rattan using simple tools into various products. The rattan industry is a major source of income for both rural and urban livelihoods (Falconer 1994; Townson 1995; 
Holbech unpublished; Tabi-Gyansah 2001). The industry relies on the moist evergreen forests of the Western Region for the production of raw cane (Wong unpublished). Three main species provide the raw material for the commercial rattan sector: Eremospatha macrocarpa (mfia), Laccosperma secundiflorum (ayie) and Calamus deerratus (demmere) (Abbiw 1990; Oteng-Amoako and ObiriDarko 2001). The production-to-consumption system for rattan in Ghana is complex and involves a number of stages from the raw material production to the sale of finished products. This is particularly the case because of the distance from the raw material production area (Western Region) to the major area of final consumption (Ashanti Region) and the socio-economic disparity between the regions.

\section{METHODOLOGY}

\section{The approach}

The production-to-consumption system approach concept was the framework adopted for conducting this study as defined by Belcher (1995) and OtengAmoako and Obiri-Darko (2001) as the entire chain of activities, from production of raw material through various stages of processing to finished products and marketing of the products to the consumer. The system includes the mechanisms involved in the technologies used to process the material as well as the sociopolitical and economic environments in which these processes operate.

\section{Selection of study sites}

Surveys were confined to the Ashanti and Western regions of Ghana (Figure 1). They were conducted at various locations and concentrated on three main subsystems, i.e. collection and production, processing and manufacturing and marketing and trading. The raw material and the processing and marketing studies were confined to the Western and Ashanti regions respectively.

\section{Data collection}

Structured questionnaires were employed in gathering the necessary data on the rattan production-to-consumption system for both rural and urban surveys. The survey questionnaires were categorised into harvesting, processing and marketing of the rattans in selected areas in the Western and Ashanti regions. During the survey, rattan processing and trading centres in the Ashanti Region known to team members and those identified from past studies were visited and the processors and traders were interviewed.

Using the participatory rural appraisal methodology, focus and target group discussions were held with chiefs, producer groups and traders. In addition, structured questionnaires were also used to solicit information from individuals and households. The questionnaires centred on the general overview and development of the rattan industry with respect to raw material availability, processing capacities and marketing scenarios both locally and externally. Other areas include traditional rules, ownership rights, and rules and regulations 
Figure 1. Map of the study area

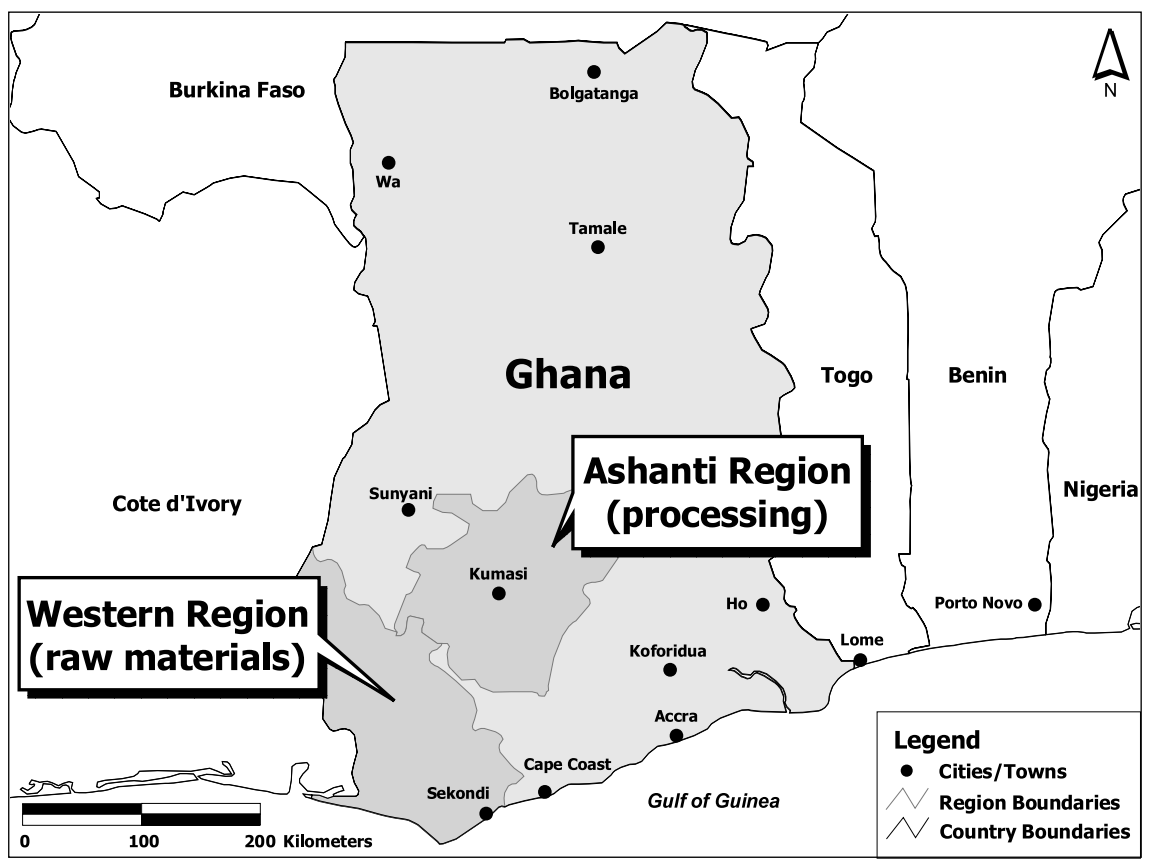

Source: ESRI Data and Maps 2002.

on rattan exploitation. The discussion with Forest Service Division officials focussed mainly on regulations, taxes and the control of illegal activities. Additional discussions with personnel of the Ghana Export Promotion Council involved an assessment of the export potential of rattan products, business assistance and tax concessions for producers.

\section{RAW MATERIAL PRODUCTION AREA}

The raw material production areas are located in the south-western part of Ghana, in the 'wet' and 'moist evergreen' forest types (Foggie 1941; Hall and Swaine 1976). The annual rainfall of between $1,800 \mathrm{~mm}$ and 2,200 $\mathrm{mm}$ is the highest in Ghana (Quarshie-Sam et al. 1990). The soils are predominantly oxysols, few parts having a combination of oxysol and ochrosol. Hence these soils are highly acidic and poor in nutrients because of excessive leaching (Hall and Swaine 1976). The major occupation of the majority of the people of the area is farming, on both subsistence and commercial scales. Only $60 \%$ of the villages in the region have some form of access roads from the production sites to the marketing centres.

\section{Harvesting of canes rattans}

Rattan is harvested mainly from disturbed forest reserves, fallow lands and community forests. Collection for commercial purposes is undertaken 
particularly in the dry season, when most roads are motorable. Small scale local weavers, however, harvest all year round as the quantity needed is small. They normally harvest when they go to work on their farms. In areas where the collection is undertaken there are no rattan plantations nor has there been any history of planting or cultivation. Since the outer bark, the sheath and the tips of the leaves are covered with thorns or spines the collection of cane is a difficult work. Harvesters begin the collection of rattan by severing the stems with a cutlass. After cutting and dragging the stems from the canopy, they are cleared of spines and leaves. The stems are then cut again to the desired merchantable length, which depends on the species, and packed into bundles of 50 to 80 pieces, again depending on the species, and transported to the roadside. The bundles are then further transported to the processing or marketing centres. Urban-based collectors usually undertake collection trips of up to 21 days. After collection the stems are stored and, when enough cane has been gathered, they are transported to the processing centres. Resource availability and accessibility of areas in the forest where rattan is growing are the most critical factors that determine the quantity of rattan harvested.

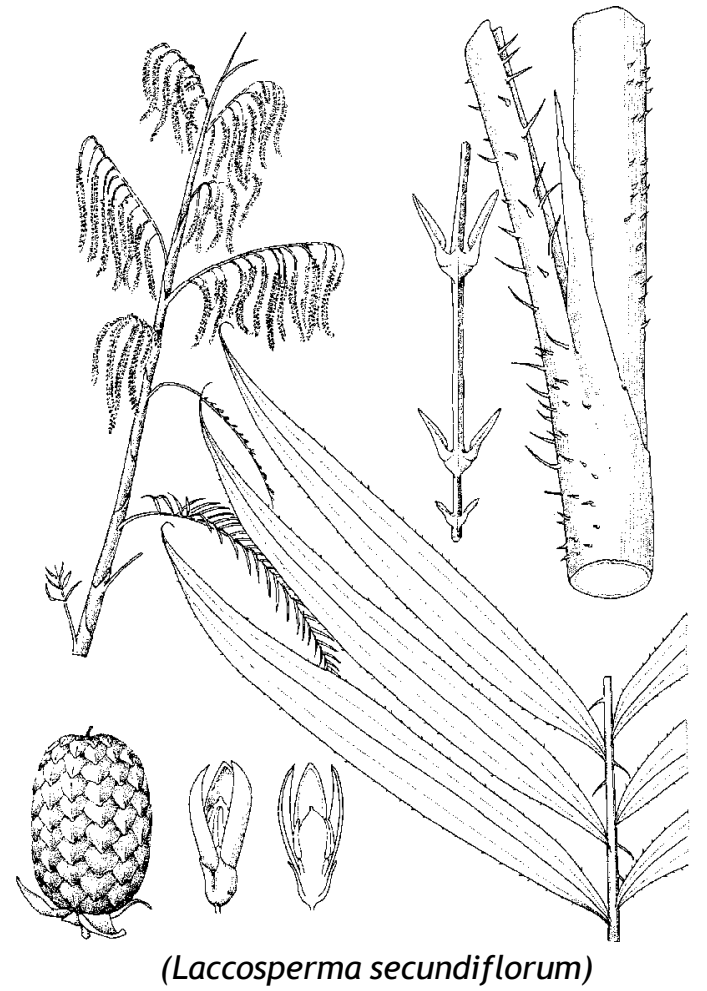




\section{Socio-economic characteristics of raw material production area}

Because the process of rattan extraction is so labour intensive and has a high risk of accident and injuries, collection is a male dominated activity undertaken mainly by the youths of a community. Thus all of the raw material producers surveyed as part of this study were male, with the $40 \%$ plurality falling in the range of 30 to 39 years old (Figure 2). The average age is 38 years. Sixty per cent of the collectors have settled in the extraction areas after moving there from other parts of the country to engage in farming activities.

Figure 2. Age distribution of rattan collectors

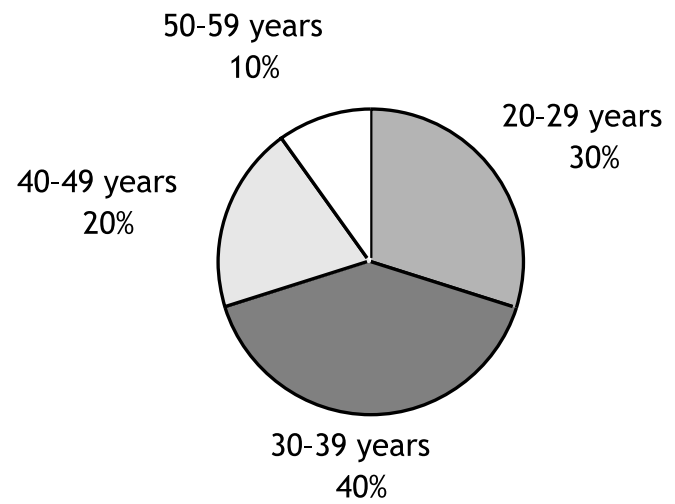

Eighty per cent of the rattan collectors interviewed were middle school leavers, $5 \%$ have postsecondary education while $10 \%$ have primary education. The remaining $5 \%$ had no formal education (Figure 3). Rattan collectors are also involved in other income generating activities, namely farming, tailoring and carpentry. Table 1 shows the average incomes obtained from these endeavours.

Figure 3. Educational status of rattan collectors

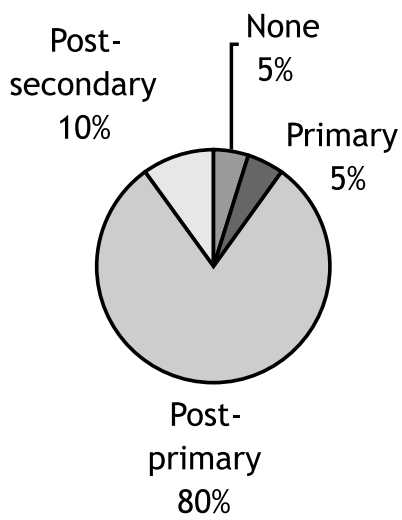


Table 1. Average gross income of collectors

\begin{tabular}{lcc}
\hline Major occupation & Average gross income (US\$) & $\begin{array}{c}\text { Percentage of } \\
\text { collectors }\end{array}$ \\
\hline Carpentry & 100 & 10 \\
Business (trading) & 100 & 200 \\
Rattan production & 150 & 30 \\
Farm production & 50 & 10 \\
\hline
\end{tabular}

Our field surveys showed that around $80 \%$ of rattan collectors financed their collection activities from personal sources. Other sources of finance identified were customers (6\%), friends or relatives ( $2 \%)$, and loans from money lenders (12\%) (Figure 4). Loans from money leaders were the least sought after method of financing since interest rates were usually unbearable. Financial support from either government or any other formal organisation has never been obtained.

Figure 4. Sources of funding for rattan collection

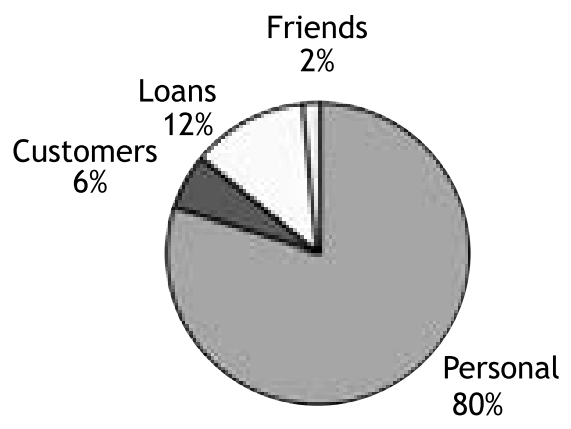

\section{PROCESSING AND MANUFACTURING}

Freshly cut cane is highly susceptible to attack of staining fungi and to insect infestation. Ordinario (1973) noted that careful drying and treatment are important steps before its utilisation. The problem is aggravated when canes are not dried immediately or left in the forests for longer periods without any prophylactic treatment.

Harvested canes are dried for about seven days either directly on the ground or on a special frame raised above the ground to promote even drying, but our studies revealed 14 days as effective drying period. During the wet season, canes are dried over fire to ensure a faster rate of drying. Initial field drying of cane does not provide maximum protection since the moisture content of the canes is considerable and the relative humidity in the wet evergreen forest zone is usually extremely high. Therefore subsequent drying and treatment are essential to enhance durability and prevent staining and borer attacks. All harvested canes are allowed to dry before being stored and are best stored flat (large-diameter canes) or in broad loop (small-diameter canes). 
The production processes and techniques employed differ little within the industry. Thus, the techniques used in Ghana can be grouped into the following processes (Page 1973; Oteng-Amoako and Obiri-Darko 2001).

- Raw material processing and storage of the cane in the form of either bundles or singles.

- Rough deglazing, or removal of the spiny leaf sheathes and hard, shiny, silicified epidermis.

- Machine room operations, whereby the stock from the rough deglaze is shaped or moulded into final dimensions through application of heat from liquefied petroleum gas stoves.

- Assembly, whereby all parts previously prepared are collected and assembled into final products. This section is equipped with jigs, clamps and fixtures.

- Finishing to enhance beauty and provide extra protection. The basic operations in furniture finishing are staining, colouring, painting, filling and sealing.

\section{MARKETING AND TRADING}

Two main types of rattan trading were identified, raw rattan and processed rattan trade. At the time of the surveys (2000) raw rattans were scarce and processors claimed they often had to fight over the few bundles that were available. They indicated that this scarcity had persisted for quite some time and that no one knew when the situation was going to improve. In this regard it is clear that the rattan resource is becoming depleted, which underscores the need for plantations to be established.

\section{Raw rattan trade}

Raw rattan is marketed in rural or urban markets in bundles of 25 to 40 sticks, usually being sold directly by a leader of the collection team. It is also supplied directly to processors either by order or under direct contract. The raw rattans are now in short supply and processors have to queue and fight for them. The cost of raw rattans is shown in Table 2.

Table 2. Cost of raw rattans

\begin{tabular}{lll}
\hline Species & Quantity & Amount (cedis) \\
\hline Laccosperma secundiflorum & Bundle of 20 pieces & 50,000 \\
Eremospatha macrocarpa & Bundle of 80 pieces & 50,000 \\
\hline
\end{tabular}

US $\$ 1=6,550$ cedis

\section{Processed rattan trade}

Finished products are marketed mostly in the urban centres. This trade involves the sale of products like furniture, laundry baskets, shopping and flower baskets, serving trays, dining sets etc. (Photos 1 and 2). The processors, based 
on their own discretion, mostly determined the prices of these products. The export market for these products is not well defined.

The sale of processed rattan goods is highly dependent upon the season and the time of year. During Christmas, Easter and other religious holidays more products are bought than during ordinary days, and sales are better in the dry season than the wet seasons because during the latter access to raw materials becomes difficult.

Profit margins were slightly higher in the urban markets than the rural markets, the reason being that the standard of living is higher in urban areas than in rural areas. It was also because products sold in urban areas were better designed and had more value added with respect to chemical preservation and finishing than those generally found in rural areas. Carpenters in urban areas sometimes used some rattans to decorate part of their furniture, to add value and style.

\section{Price setting}

The pricing of products usually depends on the type of product, amount and cost of raw material used and the finishing of the products. The price of the product tends to be higher with improved finishing (Table 3), that is, similar products may have different prices depending on the processing and finishing technology used. No standardisation is done, and price variation among processors was almost nil. However, depending on the bargaining skills of a buyer and the economic position of processors a particular item may be sold lower than a similar item elsewhere.

Table 3. Prices for finished products

\begin{tabular}{llr}
\hline Product & Processing technology & Price in cedis \\
\hline \multirow{2}{*}{ Living room furniture } & Low & 100,000 \\
& Medium & 120,000 \\
& High & 250,000 \\
Dining set & Low & 92,000 \\
& Medium & 100,000 \\
Laundry baskets & High & 200,000 \\
& Low & 6,000 \\
Baby's cot & Medium & 10,000 \\
& & 5,000 \\
Divider shelves & Low & 7,000 \\
& Medium & 20,000 \\
& Low & 50,000 \\
\hline
\end{tabular}


Photo 1. Rattan living room furniture and laundry baskets on display (Photo by C. Adu-Anning)

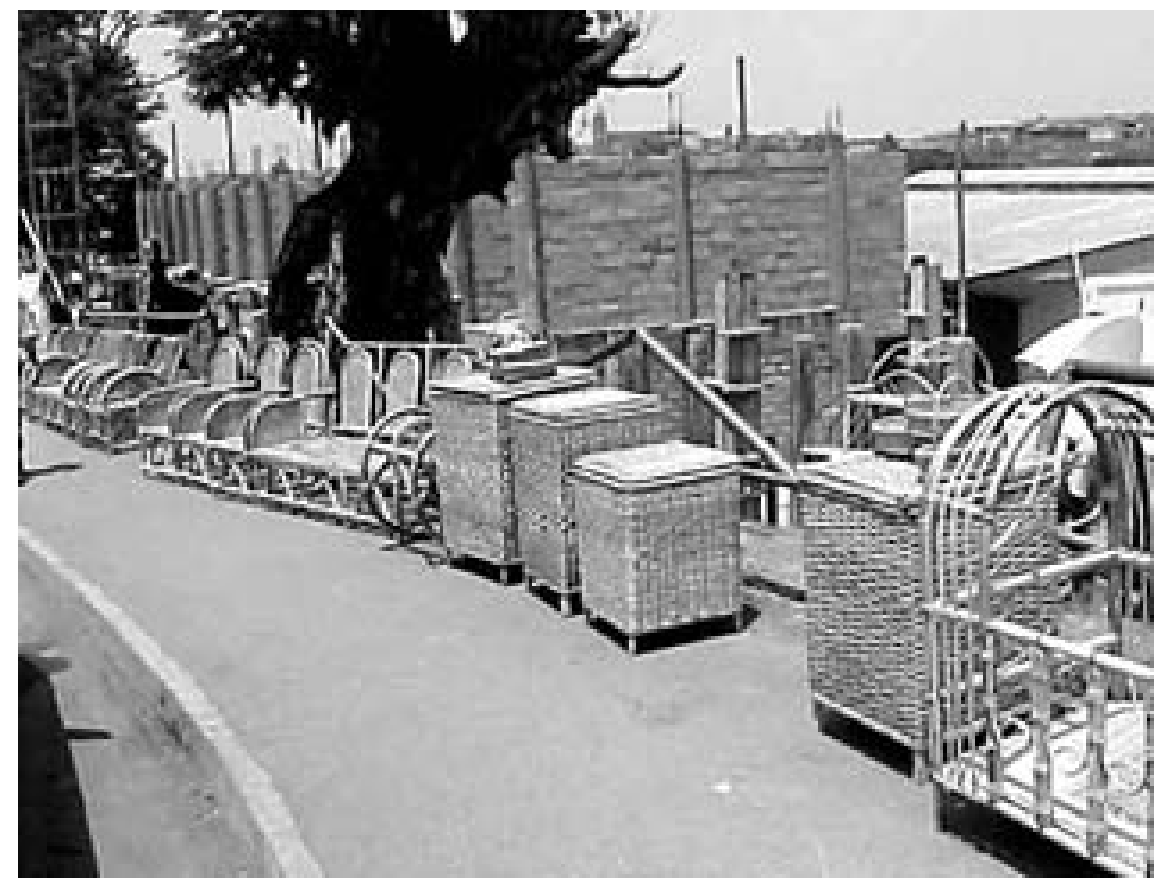

Photo 2. Processed rattan goods displayed for sale (Photo by C. Adu-Anning)

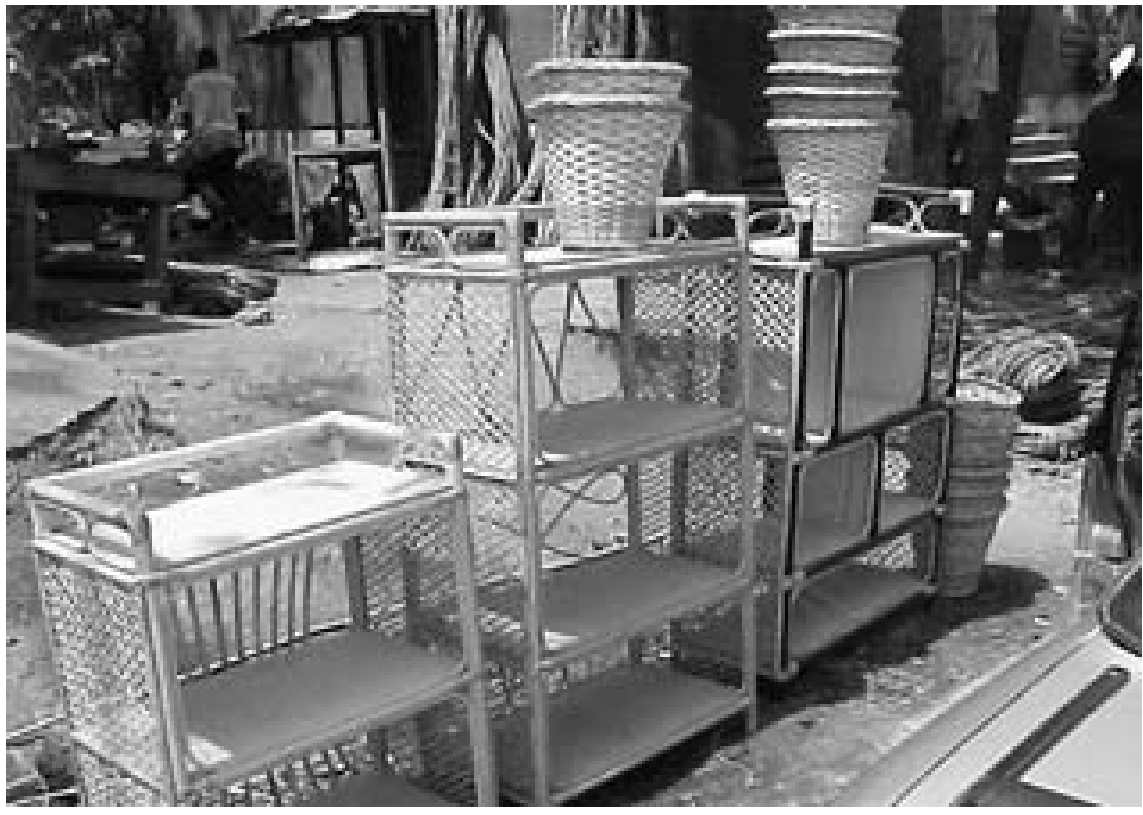




\section{RULES AND REGULATIONS ON RATTAN PRODUCTION}

\section{Formal legislation}

All members of communities in the immediate environs of a productive Forest Reserve have usufruct rights to collect small quantities of rattan from the reserve for domestic use. For the collection of commercial quantities, the interested party or persons should comply with the following procedures:

- Identify the area where rattan would be collected.

- Apply for permit by writing to District Forest Manager.

- Forest Services Division staff verifies availability of rattan at chosen area.

- Pay royalty and permit fee, the amount of which usually depends on species and quantity, number of trips and the ability of the collector. Fee collection is under the supervision of the Forest Services Division.

- The successful applicant receives an Insurance of Conveyance certificate valid for three days for the transport of collected rattan from one place to another.

Besides these formal requirements, a token fee in the form of cash $(5,000$ 10,000 cedis) and/or a drink (schnapps) might also have to be paid to the traditional chief or council of the area before collection is undertaken. The amount varies from one area to another. However, indigenes and settlers of the area do not pay any of these traditional charges.

\section{Rattan associations}

The rattan producers have formed an association to which all producers are supposed to belong. Our survey indicated, however, that only about $50 \%$ of the producers interviewed belonged to the association. The association is to foster unity and good relation among members, control prices of raw rattan goods and to regulate rattan harvesting to protect the stock and ensure sustainable production from the natural forest. No local regulations or barriers were identified to prevent individuals' or households' involvement in the production of rattans. The only condition hinges on ability of the individual. Traders have formed associations that have been in existence for more than 70 years with a relatively high degree of participation of over $60 \%$.

\section{SUMMARY OF CONSTRAINTS OF THE RATTAN INDUSTRY}

The following were the problems identified in the rattan sector:

- Depletion of the raw material base

- Expensive permit fees and royalties on rattan collection paid to the Ghana Forest Service Division

- Harassment of rattan collectors and processors by Forest Service staff in rural areas in the enforcement of permit fees

- Lack of appropriate area/land for processing

- Lack of standardised grading system

- Lack of suitable equipment 
- Lack of proper preservation facilities

- Poor marketing facilities

- No showroom for exhibition of products

- Price fluctuations and irregular demand for products

- Poor processing techniques and inadequate working capital.

\section{CONCLUSIONS AND RECOMMENDATIONS}

The rattan industry constitutes a vital part of the industrial sector of the country. It contributes significantly to the development of Ghana's economy by providing employment and there is hope for an export market that could earn valuable foreign exchange if appropriate interventions were given to the industry.

The contribution of rattan to rural and urban livelihoods needs to be further recognised and appropriate solutions must be found to solve the existing problems as summarised above. The inadequacy of raw materials and the lack of working capital, basic equipment and technical expertise to operate the industry have adversely affected the production and quality of rattan products. With proper organisation of the processors and proper utilisation of the available support services, the rattan industry can be greatly improved (Oteng-Amoako and Obiri-Darko 2001). This study revealed that the sustainability of the industry depends largely upon the adequate supply of raw material and adherence to optimal exploitation rules. Against this background the following recommendations are made.

- The Resource Management Support Centre needs to look critically at the sustainability of the standing stock versus overexploitation.

- The Forestry Research Institute of Ghana must intensify research efforts in identifying the appropriate silvicultural and ecological conditions for the domestication of rattans.

- The Forest Services Division must establish rattan plantations and encourage rural-based individuals to do likewise.

- The Ministry of Tourism must provide a showroom and better processing sites for processors.

- Affordable and/or low interest sources of funds need to be made available.

\section{ENDNOTES}

1. Department of Agroforestry, Institute of Renewable Natural Resources, Kwame Nkrumah University of Science and Technology, Kumasi, Ghana. E-mail: canning_01@yahoo.com

\section{REFERENCES}

Abbiw, D. 1990 Useful plants of Ghana. Intermediate Technology Publications, London. 337p.

Belcher, B. 1995 Bamboo and rattan production to consumption systems: a framework for assessing development options. INBAR Working Paper No. 4, New Delhi, India. 12p. 
Darko, E. 1981 A survey of cane weaving in Ghana. Dissertation, UST Kumasi. $39 p$.

Falconer, J. 1994 Non timber forest products in southern Ghana: main report. Natural Resources Institute, United Kingdom. 244p.

Foggie, A. 1941 Some ecological observations on a tropical forest in the Gold Coast. Journal of Ecology 34(1): 88-106.

Hall, J.B. and Swaine, M.D. 1976 Classification and ecology of closed canopy forest in Ghana. Journal of Ecology 64: 913-951.

Ordinario, F.F. 1973 Philippines rattans. FOPRIDECOM Technical Report No. 125. Laguna, Philippines. 3p.

Oteng-Amoako, A.A. and Obiri-Darko, B. 2001 Rattan processing and marketing in Africa: technology needs for a sustainable industry. Unasylva 205 (52): 24-25.

Page, J.M. 1973 Economic efficiency and comparative advantage in Ghana's wooden furniture manufacturing industries. Report prepared for United States Agency for International Development. 44p.

Quarshie-Sam, S.J., Dunn, J., Dampson, J.A., Minae, S. and Avila, M. 1990 Agroforestry potential and research for the land use systems in the humid lowlands of Ghana. Afrena Report No. 34, ICRAF, Nairobi, Kenya. 104p.

Tabi-Gyansah, E. 2001. Analysis of the spatial distribution of NTFPs in the tropical forest of Ghana. ETFRN News 32: 21-22.

Townson, I.M. 1995 Incomes from non-timber forest products: patterns of enterprise activity in the forest zone of southern Ghana: summary report. Oxford Forestry Institute, United Kingdom. 40p. 


\title{
Chapter 16
}

\section{The rattan sector of Rio Muni, Equatorial Guinea}

Terry C.H. Sunderland ${ }^{1}$, Michael B. Balinga ${ }^{1}$ and Mercy A. Dione ${ }^{2}$

\begin{tabular}{llllll}
\hline Common names & $\begin{array}{l}\text { Part of the } \\
\text { resource used }\end{array}$ & Management & $\begin{array}{l}\text { Degree of } \\
\text { transformation }\end{array}$ & $\begin{array}{l}\text { Scale of } \\
\text { trade }\end{array}$ & $\begin{array}{l}\text { Geographic } \\
\text { range }\end{array}$ \\
\hline Aka, Rattan & Stem & Wild & Medium & International & Large \\
\hline
\end{tabular}

\begin{abstract}
In Rio Muni, Equatorial Guinea, the harvest and sale of non-timber forest products plays a key role in the economic wellbeing of rural and urban populations (Marín and Cristóbal 1989; Sunderland and Obama 1999). One of the most economically valuable products currently traded is rattan cane (Sunderland 1998; Balinga and Dione 2000). Rattan is transported from the forest areas to supply a thriving cottage industry based in Bata, where relatively large quantities are transformed into a range of products. For many rural communities, the sale of raw cane as well as fabricated products provides invaluable access to the cash economy. In addition, the sector supports many urban artisans for whom rattan processing and transformation is the sole activity. However, the rattan sector is constrained by significant overharvesting, a direct result of rattan being an open-access resource and the lack of a management system, either customary or legislative, to control exploitation. This lack of regulation, and the corresponding mining of the wild resource, is leading to significant local scarcity in the immediate vicinity of Bata and is resulting in substantial price increases at the market level. There is an urgent need to develop sustainable strategies for the harvest of the wild rattan resource in order to supply the ever-growing market for rattan products.
\end{abstract}

\section{INTRODUCTION}

\section{Equatorial Guinea}

The Republic of Equatorial Guinea consists of three diverse and disparate territories: the mainland territory of Rio Muni $\left(26,017 \mathrm{~km}^{2}\right)$ and the islands of 
Bioko $\left(2,017 \mathrm{~km}^{2}\right)$ and Annobon $\left(17 \mathrm{~km}^{2}\right)$ (Figure 1). The former Spanish colony gained independence in 1968, but the results of a tumultuous postcolonial era led to the country being classified as one of the poorest in Africa (LinigerGomez 1988). The recent discovery of large oil deposits, however, and the opening of the country to foreign timber exploiters has recently changed the fortunes of this relatively unknown African enclave and Equatorial Guinea is forecast to become one of the most prosperous countries in sub-Saharan Africa (Goldman 1998).

Figure 1. Map of Equatorial Guinea (excluding Annobon)

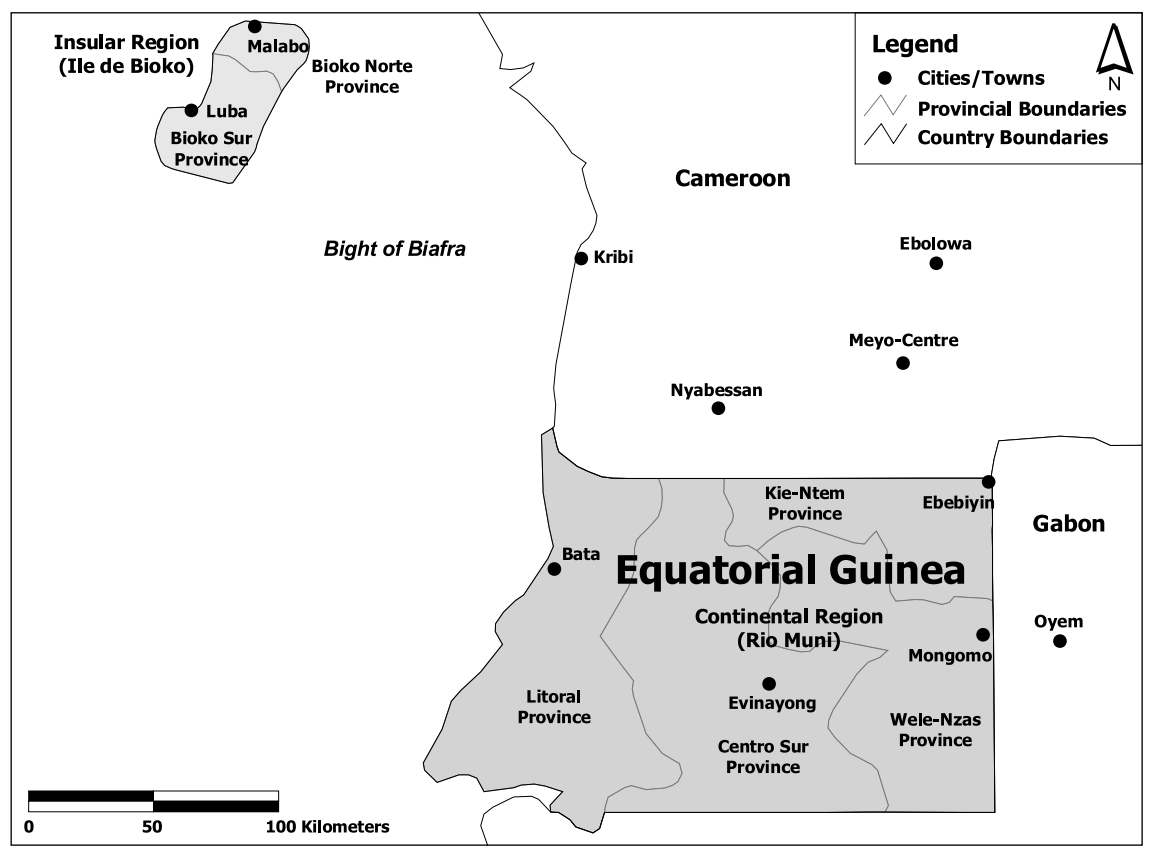

Source: ESRI Data and Maps 2002.

Equatorial Guinea's population of around 400,000 is composed of a number of tribal groups, which were formerly distributed along geographical lines. The Fang and the Ndowe originate from the Rio Muni region, the Bubis from the island of Bioko (Liniger-Gomez 1988). However, much migration by the Fang from the mainland has seen the Bubi become a minority on Bioko (Collel et al. 1994). Other Africans are also present in significant numbers in Equatorial Guinea, including Cameroonians (mostly Hausa traders), Nigerians, and Ghanaians as well as small numbers of people from Chad and Mali. The majority of these people are engaged in small-scale trading and business (Sunderland and Obama 1999). 


\section{The Rio Muni territory}

The continental territory of Equatorial Guinea is a rectangular-shaped piece of land bordered on the west by the Atlantic Ocean, on the east and south by Gabon and on the north by Cameroon. It lies between $1^{\circ} 01^{\prime}$ and $2^{\circ} 21^{\prime} \mathrm{N}$ with its eastern border following the meridian of $11^{\circ} 20^{\prime} \mathrm{E}$. The territory has $222 \mathrm{~km}$ of coastline between the estuaries of Rio Muni at the southern end and Rio Campo (or Ntem) at the northern end. It is from the former that the territory derived its name.

The forested zone of Rio Muni was recently estimated to cover a total of $17,226 \mathrm{~km}^{2}$ (van Breugel and Parren 1997) and is dominated by lowland forest (below 1,000 m). These forests are part of the Guineo-Congolian phytochorian and recent floristic investigations have shown them to be extremely diverse (Lisowski 1997). The interior of the mainland consists of a peneplain with an average altitude of $650 \mathrm{~m}$, and is dominated by a number of protruding inselbergs, the highest of which, Monte Mitra, rises to 1,200 m (Guinea-Lopez 1946).

The lowland forest zone has been much affected in recent time by extensive logging. Timber exploitation was first undertaken in the coastal regionsand, as techniques improved, the practice spread further into the interior (van Breugel and Parren 1997). Today, much of the mainland territory has been logged or is currently under concession (Stenmanns personal communication) despite a proposed network of protected areas (Garcia and Eneme 1997), and selective logging represents the major land use of the territory. Some agricultural plantations of oil palm and rubber are maintained on the coastal plain and some cocoa plantations have long been established along the border with Cameroon. Small-scale agriculture is also widely encountered in the coastal region, but the relatively small population militates against this land use being a major factor in forest conversion (Serrano 1997).

Rattans are one of the most important non-timber forest products (NTFP) of the continental region of Equatorial Guinea and play an integral part in indigenous subsistence strategies (Sunderland 1998; Balinga and Dione 2000). Rattan products also form the basis of a thriving cottage industry centred in Bata producing large quantities of chairs, tables and other household items for sale as well as export to Malabo (ibid.). This trade has grown dramatically in recent years as a result of the increasing number of expatriates arriving to work in the region. In addition, cane furniture has also become fashionable with Guineans and residents from other African countries.

\section{The resource base: rattan species utilised in Rio Muni}

In Rio Muni, mainly three rattan species are collected in the forest for processing and sale. These are the large diameter canes Laccosperma secundiflorum ( $P$. Beauv.) Kuntze and L. robustum (Burr.) J. Dransf. (nkan or aka), used whole for furniture framework and split for coarse basketry, and the juvenile stems of the small diameter cane, Eremospatha macrocarpa (G. Mann \& H. Wendl.) H. Wendl. (nlong). These species provide the resource base of the rattan industry in the country. Despite the heavy reliance of the rattan artisan sector on these three species, other species are also sometimes traded and utilised, and a number of artisans recognise the use of other species of cane (see Table 1). 
Table 1. The rattans of Equatorial Guinea and their use

\begin{tabular}{llll}
\hline Species & $\begin{array}{l}\text { Fang } \\
\text { name }\end{array}$ & Use & Note \\
\hline Calamus deërratus & nding & Unknown &
\end{tabular}

\section{G. Mann \& H.}

Wendl.

\begin{tabular}{|c|c|c|c|}
\hline $\begin{array}{l}\text { Laccosperma } \\
\text { secundiflorum (P. } \\
\text { Beauv.) Kuntze }\end{array}$ & $\begin{array}{l}\text { aka, } \\
\text { nkan, } \\
\text { meka }\end{array}$ & $\begin{array}{l}\text { Cane used as furniture } \\
\text { framework (whole stems); } \\
\text { split stems used in coarse } \\
\text { basketry, e.g., farm baskets } \\
\text { ( } n \text { kueiñ), fish baskets (bidong), } \\
\text { fish traps (bekoro) and bridge } \\
\text { construction; } \\
\text { rachis used as fishing rod; } \\
\text { young leaves eaten in stews; } \\
\text { palm heart eaten }\end{array}$ & $\begin{array}{l}\text { The most important cane } \\
\text { species, widely used on a } \\
\text { subsistence level and } \\
\text { forms the basis of the } \\
\text { commercial cane industry } \\
\text { throughout West and } \\
\text { Central Africa }\end{array}$ \\
\hline $\begin{array}{l}\text { L. robustum (Burr.) } \\
\text { J. Dransf. }\end{array}$ & as above & as above & as above \\
\hline $\begin{array}{l}\text { L. acutiflorum } \\
\text { (Becc.) J. Dransf. }\end{array}$ & ekwassa & $\begin{array}{l}\text { Sometimes used in coarse } \\
\text { basketry as a substitute for } L \text {. } \\
\text { secundiflorum }\end{array}$ & $\begin{array}{l}\text { Despite the } \\
\text { morphological similarity } \\
\text { to } L \text {. secundiflorum, this } \\
\text { cane is not widely used } \\
\text { as it is considered too } \\
\text { inflexible }\end{array}$ \\
\hline
\end{tabular}

L. laeve (G. Mann \& ndele Some minor tying and basketry

$\mathrm{H}$. Wendl.) $\mathrm{H}$. in forest

Wendl.

\begin{tabular}{|c|c|c|c|}
\hline $\begin{array}{l}\text { L. opacum (G. Mann } \\
\text { \& H. Wendl.) Drude }\end{array}$ & $\begin{array}{l}\text { npue- } \\
\text { nkan }\end{array}$ & $\begin{array}{l}\text { Some minor tying and basketry } \\
\text { in forest }\end{array}$ & \\
\hline $\begin{array}{l}\text { Eremospatha } \\
\text { macrocarpa (G. } \\
\text { Mann \& H. Wendl.) } \\
\text { H. Wendl. }\end{array}$ & $\begin{array}{l}\text { asa- } \\
\text { nlong, } \\
\text { melong, } \\
\text { ongam }\end{array}$ & $\begin{array}{l}\text { Juvenile stems split and widely } \\
\text { used for baskets, weaving, } \\
\text { furniture tying }\end{array}$ & $\begin{array}{l}\text { Second most important } \\
\text { cane species; } \\
\text { commercially exploited; } \\
\text { is not used in the adult } \\
\text { state (ongam) as it is } \\
\text { considered too inflexible }\end{array}$ \\
\hline
\end{tabular}

E. laurentii De ebuat Use not recorded

Wild.

E. wendlandiana akot Stem split and used for tying

Dammer ex Becc. roof panels of Raphia hookeri

E. cuspidata (G. ndera Use not recorded

Mann \& H. Wendl.)

H. Wendl.

E. hookeri (G. Mann alua- Use not recorded

\& $\mathrm{H}$. Wendl.) $\mathrm{H}$. nlong

Wendl.

\begin{tabular}{llll}
\hline Oncocalamus & asa- & Juvenile stems used in the & Often confused with \\
mannii $(\mathrm{H}$. Wendl.) & nlong, & same way as Eremospatha & Eremospatha macrocarpa \\
H. Wendl. & $\begin{array}{l}\text { melong, } \\
\text { ndoro }\end{array}$ & $\begin{array}{l}\text { macrocarpa, although on a } \\
\text { much lesser scale as the stems }\end{array}$ & $\begin{array}{l}\text { in the juvenile form } \\
\text { (hence same names) but }\end{array}$ \\
& & & $\begin{array}{l}\text { varies by having stem } \\
\text { armed with black } \\
\text { triangular spines }\end{array}$ \\
& & &
\end{tabular}

Oncocalamus ? Unknown

macrospathus Burr.

Source: modified from Sunderland 1998. 
The majority of rattan species in Africa, particularly those of commercial value, occur in closed tropical forest and are gap colonisers. Any significant increase in forest disturbance, such as through selective logging activities, encourages the regeneration of rattans. With large areas under timber concession in the Rio Muni region it is unlikely that any of the three commercial species, in the regional context, can be considered at risk of depletion. However, because of the current exploitation level and its impact on the regeneration of the species concerned (see below), there is considerable evidence of increasing local scarcity, particularly within the forest areas around Bata. Without exception, the rattan harvested in the Rio Muni region comes from the wild. There are currently no prospects for the development of cultivated sources of cane.

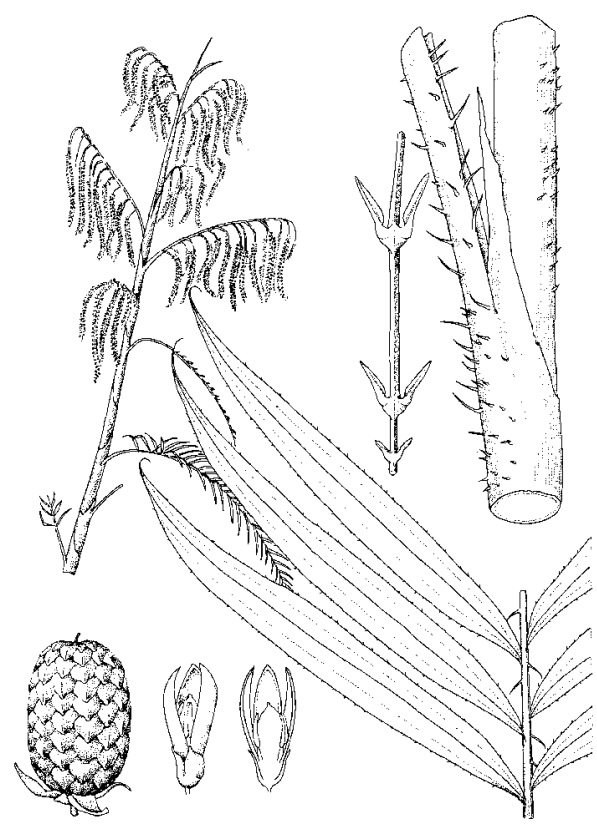

(Laccosperma secundiflorum)

\section{THE PRODUCTION-TO-CONSUMPTION SYSTEM}

\section{Raw material production area}

The main areas of rattan exploitation to supply the markets of Bata with raw cane are listed in Table 2. Essentially the forested area throughout the mainland supplies this thriving market and bundles of cane are often transported large distances (up to $165 \mathrm{~km}$ ). The area comprises an intricate mosaic of logged forest and agricultural fallow, as well as the large protected area of Mont Alen National Park, which is also a major source of rattan cane. 
Table 2. Major supply zones for raw cane to Bata

\begin{tabular}{lllc}
\hline Settlement & Province & District & $\begin{array}{c}\text { Approximate distance } \\
\text { from Bata }(\mathrm{km})\end{array}$ \\
\hline Amvam & Kie-Ntem & Micomisseng & 100 \\
Ayamiken & Litoral & Bata & 40 \\
Bibin & Litoral & Bata & 43 \\
Efulan & Litoral & Bata & 34 \\
Elong-long & Litoral & Bata & 25 \\
Eyamnyong & Litoral & Bata & 30 \\
Machinda & Litoral & Bata & 34 \\
Mbam & Kie-Ntem & Micomisseng & 135 \\
Mboete & Litoral & Bata & 41 \\
Mocomo & Litoral & Bata & 16 \\
Mongo Onvang & Centro Sur & Niefang & 66 \\
Mowomo & Litoral & Bata & 36 \\
Ncoekie & Litoral & Bata & 21 \\
Ncoe-kue & Litoral & Bata & 38 \\
Ncoomidji & Litoral & Bata & 57 \\
Ndogo & Litoral & Bata & 13 \\
Ngouba I & Litoral & Bata & 19 \\
Niefang & Centro Sur & Niefang & 77 \\
Nkue & Kie-Ntem & Micomisseng & 110 \\
Micomisseng & Kie-Ntem & Micomisseng & 165 \\
\hline
\end{tabular}

\section{Raw material producers and the socio-economic context}

\section{Introduction}

The rattan sector of Rio Muni comprises four major activities: harvesting, transportation, processing and consumption. There is no central trading point and trade in raw cane is limited to harvesters selling directly to artisans. In general, two major systems can be identified; harvest and transformation at the rural (village) and the urban levels. However, the final consumption point for both rurally produced and urban manufactured products is Bata.

\section{Village-based harvesting and transformation}

In general, village-based harvesting and transformation of rattan is undertaken almost exclusively by men above 35 years of age, but women are sometimes involved in the small-scale fabrication of temporary market baskets. For many in the rural milieu, the fabrication of rattan products is more often a secondary activity and is undertaken towards the end of the day when the primary activity, commonly agriculture, is completed.

Most cane is harvested whilst the men are outside the village on their farm business, and each day most will return with a small quantity of cane. Some of the older men of the village receive the help of their sons or other family members to collect cane or, more commonly, the younger men are simply sent to the forest to collect in times of need. In general, each village in the raw material production area has one or more local artisans who provide rattan products for the rest of the village, particularly the ubiquitous 'easy chairs'. 
Although some rattan products are bartered locally for traditional medicines or other household items, the majority of these products are exhibited at the roadside and sold directly or are transported in bulk to Bata for sale. Although farm baskets (nkueiñ), and other consumable items are fabricated for use within the household, there is a roadside trade in these products as well. The nkueiñ baskets in particular are very well fabricated and are commonly exported by sea in large quantities for sale in Malabo.

The majority of village-based harvesters complain that they are forced to travel further and further into the forest in order to obtain a good quantity of cane (Sunderland 1998). Over time overharvesting and the expansion of the village agricultural area have caused shortages of raw cane in the immediate vicinity of most villages. The average distance of travel to find rattan from most villages is $5 \mathrm{~km}$ and, in many cases, people complain that it is becoming too great a distance to be worth their while (Balinga and Dione 2000). A considerable number of village-based harvesters cut and harvest cane to order for well-established urban artisans. This activity is discussed in more detail below.

Photo 1. Harvesting rattan in closed-canopy forest (Photo by T.C.H. Sunderland)

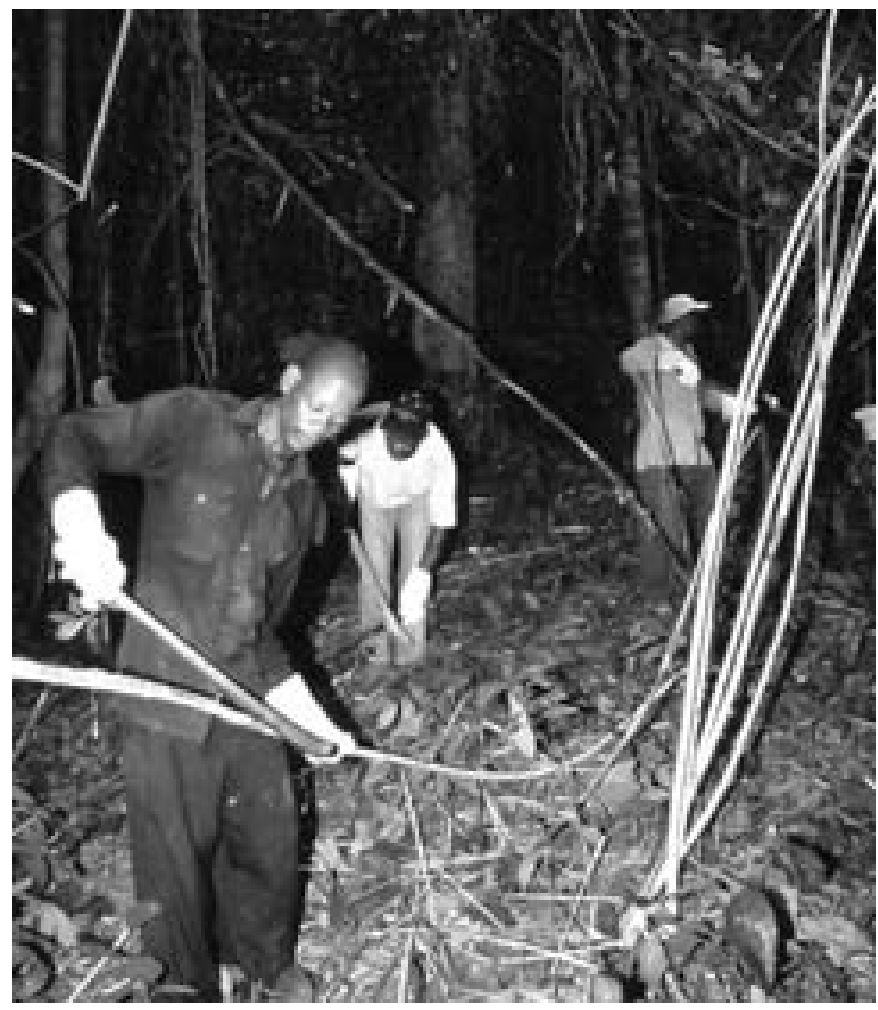




\section{Urban-based harvesting and transformation}

There are around 20 to 25 rattan artisan workshops in Bata ranging in size from one-man operations to large workshops employing up to 20 artisans. All are privately owned. They produce a wide range of rattan products, mainly concentrating on furniture and other household items. All of these workshops rely on a regular supply of raw cane from the forest. Most urban-based artisans are supplied with cane directly from village-based harvesters, but a few artisans sometimes go to the forest themselves to collect cane, particularly in time of high demand. No unsolicited cane comes from the forest for sale in Bata. Rattan is not traded in the market in the same way as other NTFP, i.e., in central markets, and there exists a close and loyal relationship between harvesters and artisans, who are usually extended family members. Almost without exception, harvesters and artisans are male and, aside from the villagebased weaving of market baskets by some women traders, the rattan sector in Rio Muni is dominated by men.

The unit of trade for commercial cane is the 'packet'. For the large diameter cane species such as Laccosperma secundiflorum and $L$. robustum, a packet represents 20 stems, with each stem being $3 \mathrm{~m}$ to $4 \mathrm{~m}$ in length. For the small diameter cane Eremospatha macrocarpa a packet equals 20 stems of $5 \mathrm{~m}$ length. In general, however, the harvester is paid per stem and, depending on quality, a stem of either species is worth CFA100 (US\$0.75) ${ }^{3}$. For very large diameter stems of Laccosperma secundiflorum the price per stem is double that amount. Artisans based in Bata pay the harvesters directly for the cane on delivery. The price includes all transport costs and any associated costs (police 'taxes' etc.).

\section{The processing industry}

The degree of transformation of rattan from raw cane to finished product can probably be best described as rudimentary. Raw cane arriving from the forest needs a good deal of preparation before it can be utilised for furniture production. Although during harvesting some of the spiny sheath is removed this is more to facilitate handling, and much of the outer leaf sheath remains. On arrival at the workshop this sheath is removed with a small knife and the epidermis is systematically scraped away to leave the clean, workable cane beneath. Stems are then left to dry for two (dry season) or three days (rainy season). This process is the same for both species of large-diameter cane, whereas the scraping and splitting of small diameter cane occurs during the fabrication process.

Once it is dry, large diameter cane has unfortunately lost some of its flexibility. In order to facilitate manipulation of the cane into the desired framework, it is bent using heat supplied from a blowtorch. Often a bench with a specific jiglike 'bending tool' is also employed, with most artisans fabricating their own. Some artisans do not like the black scorch marks that the use of the blowtorch produces and prefer to bend the cane to shape whilst the leaf sheaths are still in place. Subsequent cleaning of the cane removes the scorch marks, although the cleaning process is a little more difficult because by then the sheaths are rather dry and persistent. 
The processing of rattan from raw cane to finished product is extremely labour intensive and, as such, represents the highest cost input into the transformation of raw cane. Although some of these costs are offset by the use of 'apprentices'4, they remain high. It is unknown what proportion of these labour costs, or the value of raw cane, is reflected in the costs of the finished product.

The rattan processing units operating in Rio Muni are often of low technology and operate either outdoors or in open workshops with a simple roofed covering. All artisans in Bata are male and most are under the age of 40. The older men in the business are responsible for the design and production of the furniture and, generally, the apprentices provide labour for the laborious task of cleaning and preparing raw cane for production as well as basic weaving and other time-consuming activities. Almost without exception the artisans of Bata are Fang in origin; it is suggested that the Ndowe do not have a tradition of rattan artisan work beyond the production of fish traps, baskets and other subsistence use.

The quality of the finished rattan products varied widely between artisans. In Bata the quality is generally relatively high and compares favourably with rattan production in both Cameroon and Nigeria, often surpassing it. However, many artisans use far too many nails instead of binding a joint with flexible cane and many rely to heavily on the use of the blowtorch for bending the cane, often leaving unsightly scorch marks on the finished product. The best quality finished products are found at the Societe Artisanal de Guinea Ecuatorial workshop in Bata and the formerly Ecologie \& Conservation de la Forestiers d'Afrique Centrale-funded workshop at Mont Alen. The furniture produced by both these concerns is undoubtedly of export quality and the designs are compatible with the known market demands of Europe and North America.

\section{Trade and marketing}

The ways in which rattan moves from the forest to the final consumer are described above. The production-to-consumption system is summarised in Figure 2.

The rattan market in Equatorial Guinea is long established and probably dates from the beginning of the twentieth century (Liniger-Gomez 1988). During the period of isolationist government during the 1970 s forest products, such as rattan, were much relied upon to provide for the majority of household needs and the markets expanded rapidly during this period.

The rattan market is currently continuing to expand, due to the influx of expatriates now working in Bata. Almost without exception, the artisans in Bata state that the use of rattan is increasing and much greater amounts of cane are being processed in Bata today than was being worked 5 or 10 years ago. Customers are from a wide variety of ethnic origins. Many Bata-based artisans established their business for the expatriate market but today many Guineans and other African nationals purchase rattan products. They are no longer regarded as "poor man's furniture" but have become rather en vogue, particularly among the growing middle-class. More recently, it has also been reported that a substantial, and as yet unquantified, proportion of finished furniture is shipped from Bata to the capital city of Malabo as the island of Bioko has no rattan resource of its own (Obama personal communication). 
Photo 2. Fabricated chairs for sale in Bata (Photo by T.C.H. Sunderland)

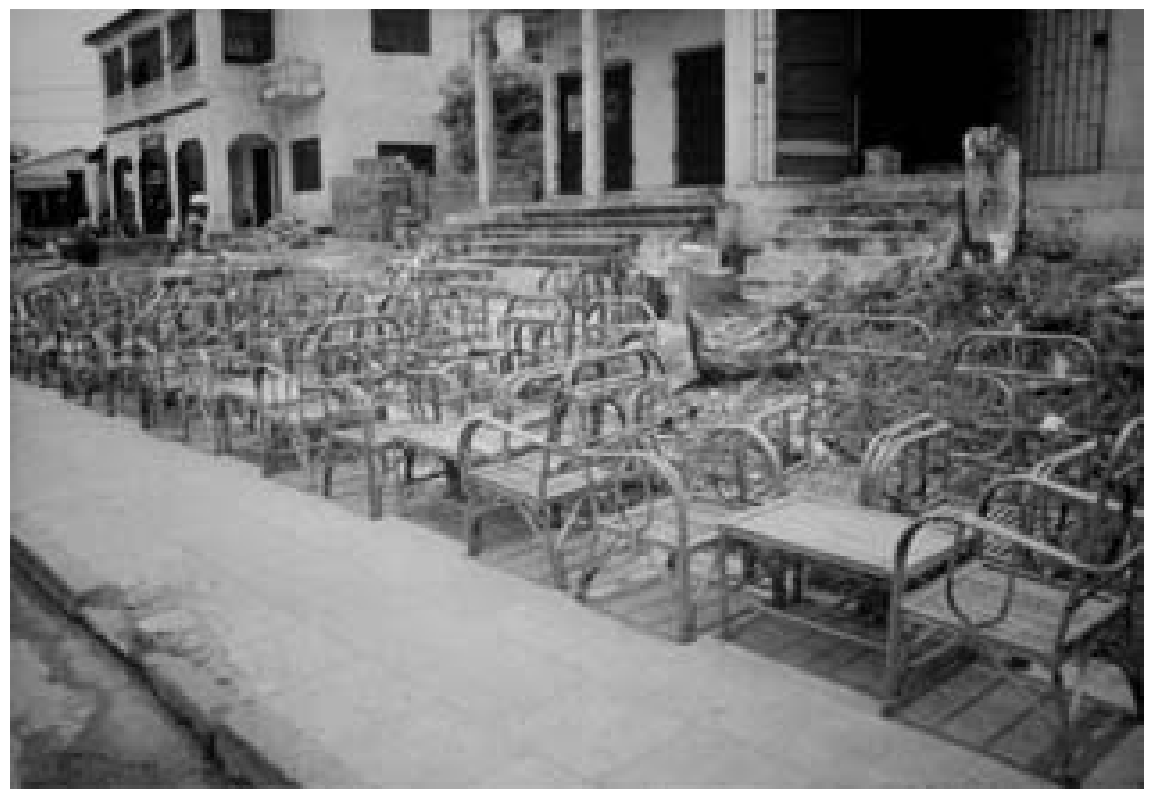

Figure 2. Production-to-consumption system of the rattan trade in Rio Muni

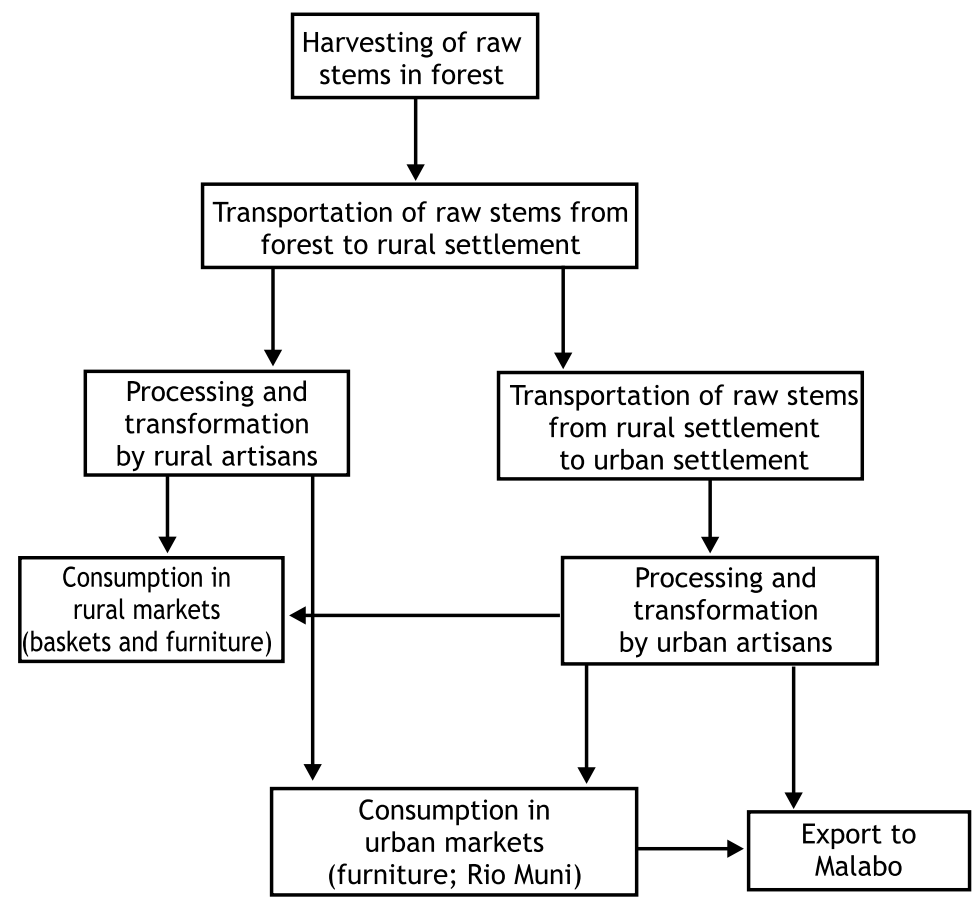


In comparison with other forms of natural resource utilisation, the rattan sector in Rio Muni is highly profitable, surpassed only by the bushmeat trade (Garcia and Eneme 1997). It is an activity that requires little capital investment and, as such, the profit margins are relatively high-between CFA20,000 and CFA170,000 (US\$27-US\$200) per month. The harvest and sale of raw cane and finished products is a means for many rural communities to enter the cash economy, particularly in times of need, such as when school fees are due, medical emergencies arise, or holiday expenses occur. Although there are seasonal fluctuations in sales, the urban cane business remains highly profitable while supplies of raw cane are available (Sunderland 1998; Balinga and Dione 2000) (Figure 3).

Figure 3. Variation of averages for monthly revenue and total monthly output per harvester/artisan

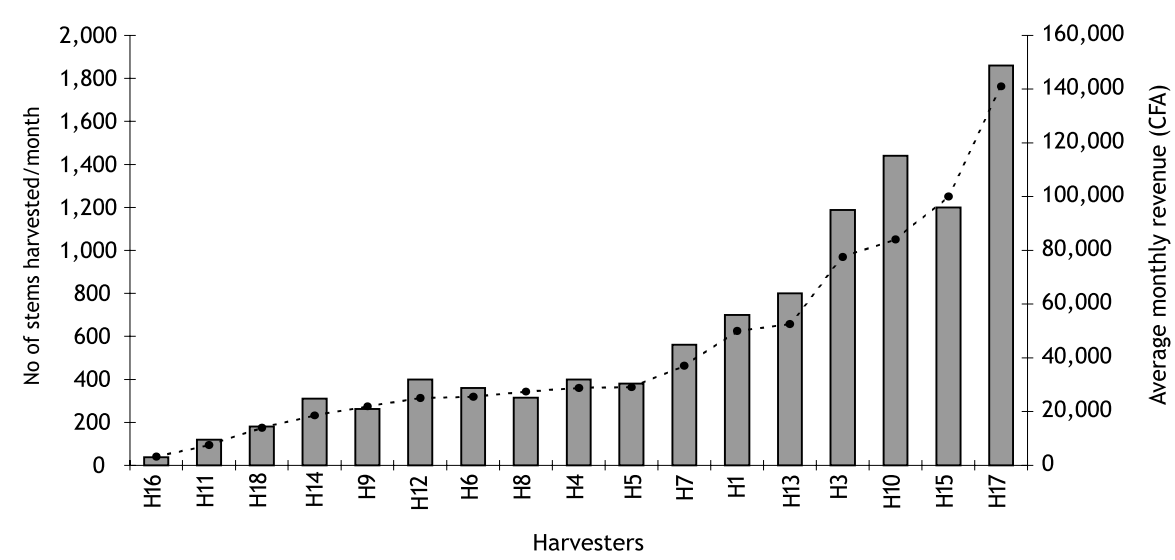

\section{POLICY ENVIRONMENT}

\section{Customary laws and controls}

In the Rio Muni region, as is the case throughout Africa, rattan is an openaccess resource and as such is affected by neither customary law nor resource tenure issues. Generally, harvesters collect cane from the same area of forest. On each visit, the village chief is paid a small levy either in cash (often equivalent to US\$1.40-US\$2.50) or in kind for access to the forest. This system of access applies whether the harvester is native to the village or an outsider. The lack of resource tenure is the largest hindrance to the sustainable management of the rattan resource in Equatorial Guinea; there are few controls to access to the resource or the manner in which it is harvested. 


\section{Legislation and government interventions}

There is currently no direct government investment or intervention in the rattan sector of Equatorial Guinea. The 1997 Appendix to the 1995 Forestry Law of Equatorial Guinea (Reglamento de Applicacion de la Ley Sobre el Uso y Manejo de los Bosques EQG/96/002) makes reference to the sustainable management of commercially exploited NTFP such as Prunus africana and Piper guineensis (Articulo $62^{\circ}$ ). However, no provision is made in this legislation for the management of the rattan resource. Because of this, very little formal revenue is realised from the trade in raw cane and finished products. 'Informal taxation', however, is often paid to forestry officials and members of the police and armed forces who intercept the loads of rattan as they are transported. Both artisans and harvesters state that this is an accepted, if frustrating, aspect of their involvement in the sector.

\section{Formal taxation}

In addition to the payment of informal taxation by rattan harvesters and transporters, urban-based artisans are expected to pay the following fees.

Ministry of Tourism and Information

CFA12,000-CFA25,000 (US\$16-

Ministry of Forests and Environment

Town Council

Ministry of Economy US\$34) per annum

CFA12,000-CFA35,000 (US\$16US\$47) per annum

CFA12,000 (US\$16) per annum CFA15,000 (US\$20) per annum

The level of the fee to be paid is determined according to the physical size and estimated output of each workshop; larger workshops pay more to the Ministries of Tourism and Forests than smaller ones.

\section{Rattan unions}

Currently, there is no organisation or union of rattan harvesters and/or artisans in Equatorial Guinea. However, the need for such an organisation was expressed by the artisans interviewed both by Sunderland (1998) and Balinga and Dione (2000). To date no initiatives have been taken to address the lack of organisation amongst both harvesters and artisans.

\section{TRENDS AND ISSUES}

\section{The resource base}

All of the 22 species of rattan that are distributed throughout the African lowland tropical forest are clustering species, that is, they produce multiple stems from a single rootstock (Sunderland 2001). In theory this morphological advantage suggests that sustainable harvesting through good 'stool management' should be possible. However, due to insecure resource tenure, the clumps are often indiscriminately destroyed by harvesters who cut all of the stems within a clump, not only the mature ones. The resultant regeneration, if it occurs, is extremely 
slow, suggesting to exploiters that harvest cycles are too long to be worth developing. In addition, the large diameter species of cane, L. secundiflorum and L. robustum, are hapaxanthic (Sunderland 2002), which means that they exhibit an extremely long vegetative phase before a reproductive event. As harvesting often occurs before inflorescences, and subsequently seeds, can develop, the regeneration potential of the species is deleteriously affected.

Without adequate resource tenure and corresponding management systems for rattan exploitation, coupled with the ecology of the species concerned, indiscriminate harvesting is affecting both present and future supplies of raw cane. Almost without exception, all of the harvesters interviewed by Sunderland (1998) and Balinga and Dione (2000) lament the fact that they are forced to travel farther into the forest to obtain sufficient quantities of raw cane. This is a strong indication that supplies are diminishing. Further evidence at the market level suggests that the additional transport and opportunity costs of harvesting farther away from the urban markets is slowly resulting in corresponding price increases, both of raw cane and finished products ${ }^{5}$.

In addition to direct overexploitation, agricultural expansion is also deleteriously affecting the rattan resource base. The stems are often cut during farm clearance operations and the whole clump is then destroyed during the subsequent burning. In this regard, the production of food crops is given a higher priority than the rattan resource, despite its economic value.

\section{The trade}

There are strong indications that the market for rattan products is increasing owing to the recent influx of expatriates to Malabo in particular, but also to Bata, and the emergence of an Equato-Guinean middle-class as a direct result of the oil boom in the country. It is these urban dwellers that are now purchasing the better quality rattan products, which have become somewhat fashionable. However, demand often outstrips supply and there are periods during the year when raw cane is difficult to obtain in Bata. These periods correspond with the early rains, when most rural harvesters are more concerned with planting food crops than harvesting cane, and during the latter part of the rainy season, when transportation is extremely difficult because of poor road conditions.

\section{Livelihoods}

The increased demand for rattan products is leading to increased profits for most urban artisans and most report that they have a better standard of living today than previously. However, despite the high profit margins the sector is constrained by scarcity of raw material supplies. In the rural milieu rattan harvest and sale provides access to the cash economy at times of need for many households and, in the absence of other income generating activities, rattan continues to provide this much-needed source of revenue. However, the increased opportunity costs of collecting rattan from far inside the forest are discouraging a number of harvesters from continuing in the sector. With fewer harvesters actively collecting, supplies to both the urban and rural artisans are further affected. 


\section{Development interventions}

With very little government involvement in the rattan sector in Equatorial Guinea there is likewise a corresponding paucity of outside development interventions in the sector. However, the establishment of a community-run transformation unit at Mont Alen is a notable exception to this. In addition, the European Union also commissioned a study of the rattan sector in Rio Muni with a view to developing the sector through the CUREF (Proyecto Conservacion y Utilizacion Recional de los Ecosystemas Forestales) project based in Bata (Sunderland 1998). However, the project completed its operations before the recommendations of the report could be implemented.

\section{CONSERVATION AND DEVELOPMENT LESSONS OF RATTAN HARVESTING IN RIO MUNI}

Unquestionably, the present systems of rattan exploitation practised in Rio Muni are unsustainable. Removal of all of the individual stems within a cluster, coupled with removal of mature stems prior to them having a sexually reproductive event, is affecting the regeneration of rattan populations where they are harvested. This poor management and lack of recruitment is contributing significantly to local resource scarcity. This scarcity is further exacerbated by land clearance for agriculture, whereby individual clumps are burned and destroyed.

Although in theory it is feasible that a rotational harvest system for removing selected mature stems within a clump, leaving immature stems to develop and grow, could be developed, the lack of tenure for the rattan resource precludes any attempt at developing sustainable community-based management strategies. There is no immediate prospect of this situation changing either from the perspective of increased customary control or from formal forestry legislation. The rattan sector in Rio Muni is now faced with the problem of overexploitation, which is leading to considerable scarcity and corresponding price increases at the market level. Yet demand for rattan products continues to grow. In this regard, the prospect of far more serious shortages for the urban artisan seems an inevitability. There is some scope, however, for developing cultivated sources of supply for rattan to make up for the shortfall in future supplies and better forest management regimes aimed at regulating harvest cycles would be an appropriate means to ensure sustainability.

It is clear that rattan in Rio Muni plays a significant role in the economies of both rural and urban households and enables a considerable number of rural harvesters to enter the formal cash economy. Whilst the resource is harvested in an unsustainable manner, the benefits of the rattan sector to the livelihoods of those involved are considerable, and evidence of this is provided by the increase in the number of artisans in Bata in recent years. However, and despite the poor levels of processing and transformation technology, it is this very profitability that is leading to the overexploitation of the rattan resource.

\section{SUMMARY AND CONCLUSIONS}

The initial study of the rattan sector in Equatorial Guinea (Sunderland 1998) was stimulated by the realisation that the NTFP sector contributed significantly to both rural and urban incomes. In particular, rattan was identified as being 
one of these key NTFP resources. The key findings of this study and those of a subsequent study by Balinga and Dione (2000) are summarised below:

- Rattans, in particular the species Laccosperma secundiflorum, L. robustum and Eremospatha macrocarpa, comprise one of the most important NTFP resources of the Rio Muni region of Equatorial Guinea at both the village level and in terms of commercial activity (Sunderland 1998; Sunderland and Obama 1999). Their economic importance at the household level is probably surpassed only by bushmeat (Garcia and Eneme 1997).

- Rattan harvesting and processing is almost exclusively a male occupation with younger men (under age 35 ) being more involved at the commercial level and older men (aged 35 or over) at the village level.

- At the village level, rattan transformation is a secondary activity, the primary activity being agriculture.

- Large quantities of raw cane enter Bata, which are being converted into finished rattan products. This trade is extremely profitable, with low overheads and high marketing margins on finished items.

- There has been an increase in the demand for rattan products in the past 5 to 10 years and many new artisans have established themselves in Bata.

- The majority of the raw cane entering Bata is harvested in the immediate environs of the town, but some harvesters have complained of scarcity due to overharvesting and are having to travel farther away to obtain sufficient quantities of cane.

- The destructive and wasteful harvesting practices often employed by most harvesters do not allow for the majority of clumps to regenerate adequately for subsequent harvests. This is also causing local scarcity of cane supplies.

- Because the rattan resource is considered an open access resource and hence customary laws with regard to land and resource tenure do not apply, poor resource management ensues.

In conclusion, the major problem of the rattan sector in Rio Muni is that the high demand and value of the product itself is leading to overexploitation. The problem is exacerbated by a total lack of management and control of the resource. Interventions aimed at improving the availability of the resource base, both through better natural resource management and possibly through the introduction of cultivated systems, need to be developed. Policy interventions aimed at encouraging the sustainability of the rattan resource should also be encouraged.

\section{ENDNOTES}

1. African Rattan Research Programme, P.O. Box 437, Limbe Botanic Garden, Limbe, Cameroon. E-mail Terry C.H. Sunderland: TCHSunderland@aol.com; E-mail Michael B. Balinga: mpbalinga@yahoo.fr

2. University of Buea, SW Province, Cameroon.

3. Exchange rate in May 1998: US\$1 = CFA600.

4. Many artisans have apprentices, ostensibly to train them. In reality, however, the apprentice undertakes much of the tedious work of cleaning the raw cane ready for transformation. The apprentice's parents usually pay the artisan for the training. 
5. This is evident from the data on the change in product prices collected by Sunderland (1998) and Balinga and Dione (2000), which show significant price increases both for raw cane and for 'standard' finished products.

\section{REFERENCES}

Collel, M., Maté, C. and Fa, J.E. 1994 Hunting among Moka Bubis in Bioko: dynamics of faunal exploitation at village level. Biodiversity and Conservation 3: 939-950.

Balinga, M.P.B. and Dione, M.A. 2000 Socio-economic characteristics of the rattan sector of Rio Muni, Equatorial Guinea. Report for the African Rattan Research Programme, University College, London. 54p.

Garcia, J.E. and Eneme, F. 1997 Diagnóstico de las áreas críticas para la conservación. Report to the Proyecto Conservacion y Utilizacion Recional de los Ecosystemas Forestales (CUREF), Fondo Europeo de Desarrollo, Proyecto No. 6. 88p.

Goldman, A. 1998 Rags among the riches. BBC Focus on Africa 3: 34-35.

Guinea-Lopez, E. 1946 Ensayo Geobotanico de la Guinea Continental Espanola. Direccion de Agricultura de los Territorios Espanoles del Golfo de Guinea, Madrid. 332p.

Liniger-Gomez, M. 1988. Small is not always beautiful: the story of Equatorial Guinea. Hurst \& Sons, London. 198p.

Lisowski, S. 1997 Etude de la biodiversite vegetale dans la region continental de Mbini (Guineé Equatorial). Report to the Proyecto Conservacion y Utilizacion Recional de los Ecosystemas Forestales (CUREF), Fondo Europeo de Desarrollo, Proyecto No. 6. 93p.

Marín, E.G. and Cristóbal, L.M. 1989 Plantas medicinales de Guinea Ecuatorial. Centro Cultural Hispano-Guineo, Malabo. 250p.

Serrano, N.C. 1997 Etude de terrior coutumier du village de Engombegombe a la Réserve de Ndote. Report to the Proyecto Conservacion y Utilizacion Recional de los Ecosystemas Forestales (CUREF), Fondo Europeo de Desarrollo, Proyecto No. 6. 76p.

Sunderland, T.C.H. 1998 The rattans of Rio Muni, Equatorial Guinea: utilisation, biology and distribution. Report to the Proyecto Conservacion $y$ Utilizacion Recional de los Ecosystemas Forestales (CUREF), Fondo Europeo de Desarrollo, Proyecto No. 6. 47p.

Sunderland T.C.H. and Obama, C. 1999 A preliminary market survey of the non-wood forest products of Equatorial Guinea. In: Sunderland, T.C.H. Clark, L.E. and Vantomme, P. (eds.) Non-wood forest products of Central Africa: current research issues and prospects for conservation and development, 211-220. Food and Agriculture Organisation, Rome.

Sunderland T.C.H. 2001. Rattan resources and use in West and Central Africa. Unasylva 52(205): 18-26.

Sunderland T.C.H. 2002. Hapaxanthy and pleonanthy in African rattans (Palmae: Calamoideae). Journal of Bamboo and Rattan 1(2): 131-139.

van Breugel, M. and Parren M. 1997 Forestry in Equatorial Guinea. BOS NiEuWSLETTER 16(3): 76-83. 


\section{Chapter 17}

\section{Rattan exploitation in the Yaoundé Region of Cameroon}

\section{Louis Defo ${ }^{1}$}

\begin{tabular}{llllll}
\hline Common names & $\begin{array}{l}\text { Part of the } \\
\text { resource used }\end{array}$ & Management & $\begin{array}{l}\text { Degree of } \\
\text { transformation }\end{array}$ & $\begin{array}{l}\text { Scale of } \\
\text { trade }\end{array}$ & $\begin{array}{l}\text { Geographic } \\
\text { range }\end{array}$ \\
$\begin{array}{l}\text { Maraca, Rattan, } \\
\text { Ékè }\end{array}$ & Stem & Wild & Medium & International & Large \\
\hline
\end{tabular}

\section{ABSTRACT}

From 1996 to 2000 intensive investigations based on observations, surveys, interviews and the use of standardised questionnaires were carried out in the rattan sector in the Yaoundé region in Cameroon. The following data could be summarised from this research:

a. Rattan (mainly Eremospatha macrocarpa and Laccosperma secundiflorum and Laccosperma robustum) constitutes the most prized non-timber forest products in the villages concerned and assumes an undeniable economic, social and cultural importance. In the village production system, it ranks second only after agriculture.

b. The exploitation of rattan is based exclusively on natural stands and is not undertaken in a sustainable manner. This resource, access to which is easy and free, is being subjected to considerable pressures. All this is detrimental to its productive potential. This situation is partly attributable to the inadequate and summary nature of the regulation.

c. Rattan is collected in the region mostly by young men, who process it on the spot in villages or sell (the greatest part) of it in the unprocessed state directly to craftsmen in Yaoundé. The conjunction of several factors has led to an appreciable increase in the number of processing units and the volume of rattan supply in this city in the course of the last few years.

d. Rattan processing in Yaoundé is operated in a rudimentary manner by about 100 small-scale enterprises run almost entirely by men. The output of these processing units is of average or mediocre quality. It is sold almost exclusively in the domestic market. 
e. The profit margins of the main participants in the sector are far from being negligible in the local context. The impact of rattan-related activities on the lives of the persons concerned is positive. It could be even more positive if the conditions for an increased and rational development of this high value non-timber forest product were created.

f. The rattan production-to-consumption system in Yaoundé region is limited and poorly articulated. The vertical relationships among its components are loose (weak integration of some components of the channel) and its horizontal links are practically non-existent (lack of credible organisations among actors).

\section{INTRODUCTION}

Tropical forest space management currently holds a place of choice in the concerns related to natural resources and to the environment. Before the beginning of the 1990s, however, concerns about the sustainable management of tropical forests in general were disproportionately partial to timber or wood, whereas other forest resources were considered as 'minor' products (Falconer 1990; FAO 1993). This lack of attention with regard to non-timber forest products (NTFPs) is nevertheless still persisting in some countries while pressures to which they are subjected is ever-increasing as a result of deforestation and increased commercial exploitation (Falconer 1990; Peters 1997).

Rattan is indisputably one of the most important NTFPs in the world (Panayotou 1990; Dransfield and Manokaran 1994; Sastry 2001) and that is without doubt one of the reasons for which it has drawn the attention of researchers. Many studies have thus been devoted to rattan, especially to its biology, ecology, cultivation, exploitation, processing and marketing. These studies are concentrated almost exclusively on Asia (see for example Bacillieri and Appanah 1999; Sastry 2001; Baja-Lapis et al. undated) since African rattan has retained very little attention. However, considerable efforts have been devoted to research on rattan in Africa during the past decade (see for example Sunderland and Profizi 2003).

Yet, people in the African forest area have for a long time taken an interest in this liana. For example, the Ewondos and related people in the region of Yaoundé in Cameroon have a long-standing tradition of rattan utilisation. Indeed, since they settled in the equatorial forest zone in the nineteenth century (Mveng 1963, 1985), these people have integrated the use of rattan in various aspects of their lives: building huts, making objects for transportation or conservation, racks, furnishing objects, toothbrushes, consumption for food and medicinal purposes (see Table 1).

Considering the multidimensional importance of rattan and the pressure on this NTFP (Shiembo 1982, 1986; Béné 1994; Ndoye 1994) we decided in 1996 to study it within the framework of our thesis. This study focuses on the rattan industry in south Cameroon and its main goal is to contribute to the development of a policy for the rational management of rattan. The Yaoundé region (see Figure 1) constitutes the intensive research site of this initiative whose main objectives can be summarised as follow: 


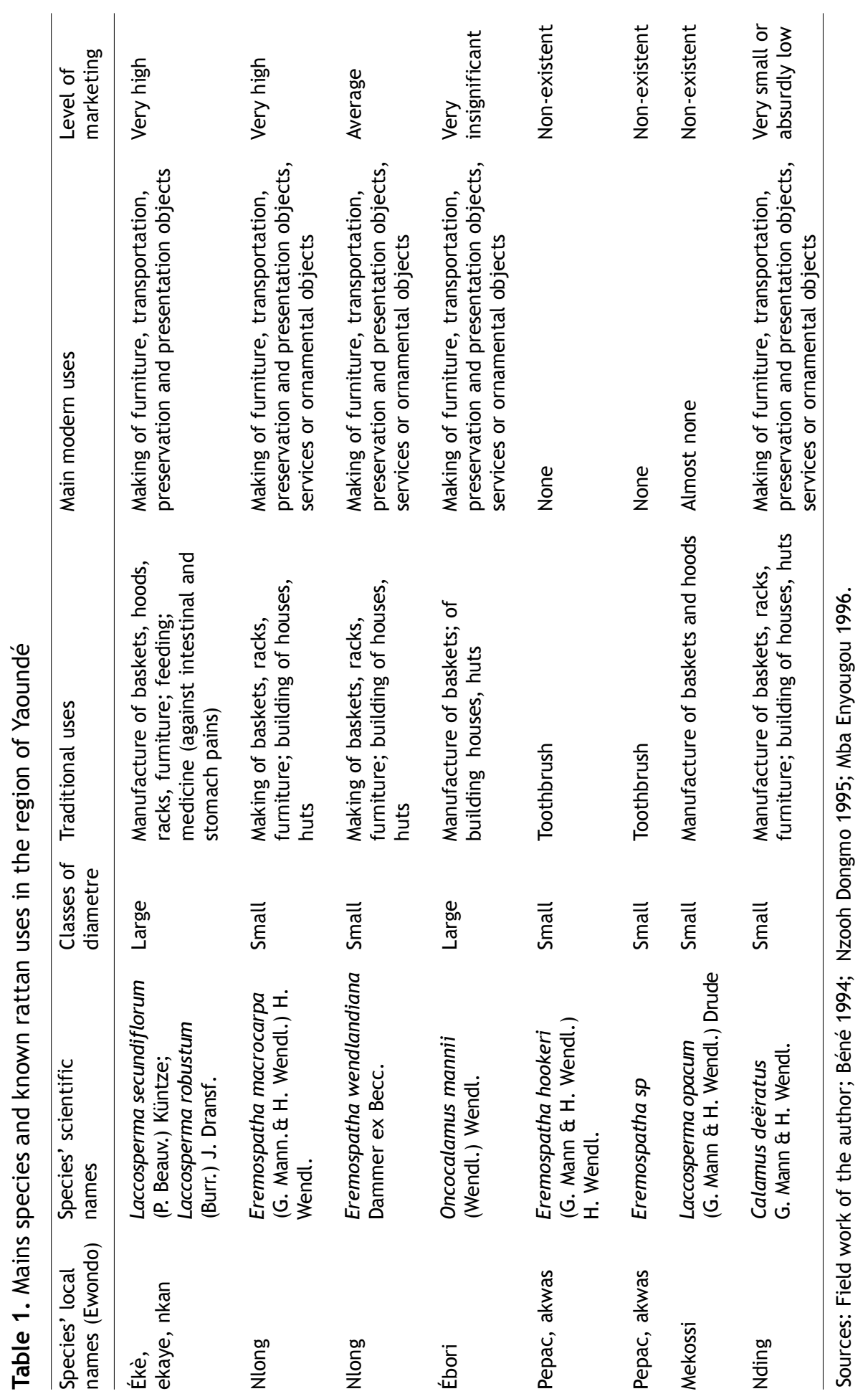


Figure 1. Map of the study area
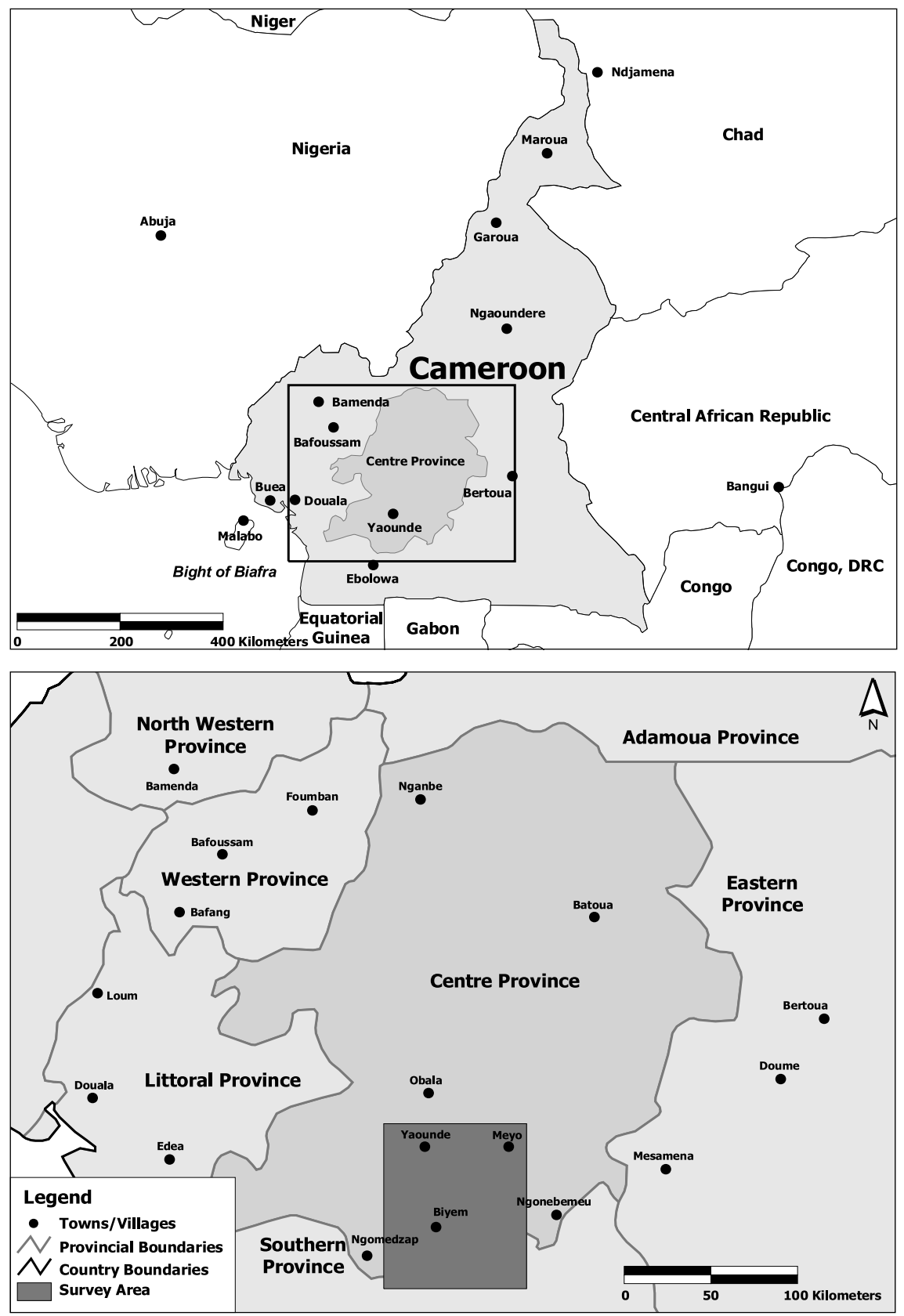

Source: ESRI Data and Maps 2002. 
- To identify components, outline major characteristics, functioning mechanisms, social, economic and cultural importance as well as constraints related to the rattan sector in Cameroon;

- To access the pressure on the resource base and the impact of this NTFP exploitation; and

- To contribute to a strategy that can lead to the development of the rattan industry and the sustainable management of the resource.

Although Cameroon has many regions where rattan exploitation for commercial purposes is relatively important (Sunderland et al. 2003), this chapter focuses exclusively on the Yaoundé basin. The region is situated in the south of Cameroon ( $3^{\circ} 05^{\prime}-4^{\circ} 00^{\prime}$ north; $11^{\circ} 25^{\prime}-12^{\circ} 50^{\prime}$ east) and constitutes the most important rattan exploitation basin of the country. It is a zone in which the Guinea type of Equatorial climate predominates and which is covered by humid dense forest (Laclavère 1979). The study region comprises both towns and rural areas. In villages, agriculture is the most important activity.

This chapter briefly analyses the production-to-consumption system of rattan in this region. It focuses particularly on the raw material production, processing, marketing and the policy environment of rattan. The chapter also presents trends and issues in the sector. Finally, it tackles the conservation and development lessons of rattan exploitation in the region.

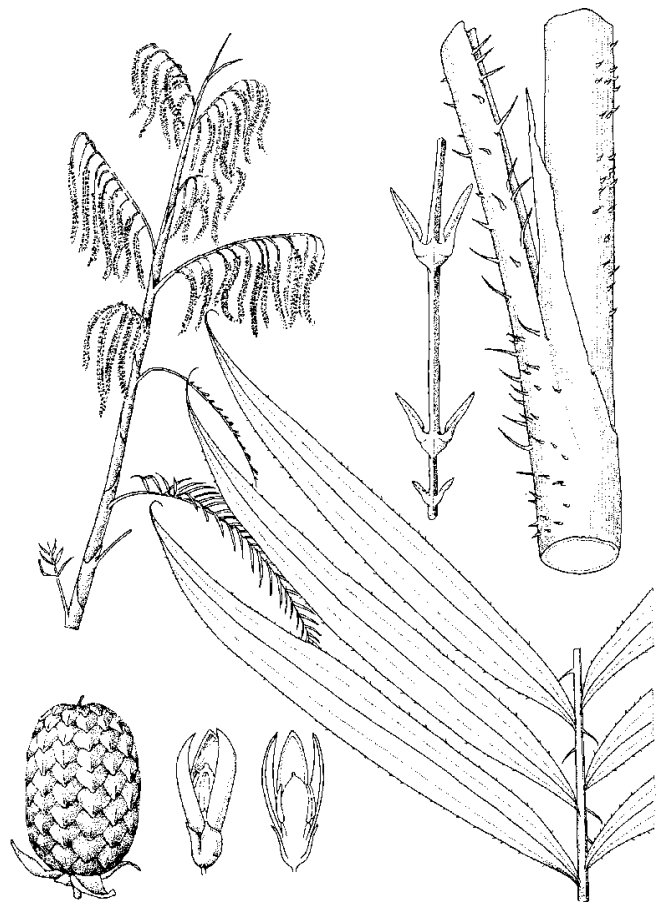

(Laccosperma secundiflorum) 


\section{METHODOLOGY}

In a bid to achieve the above objectives, I adopted a specific data collection procedure in Yaoundé and in seven villages on its outskirts, namely Fakeleu 2, Mbanga-Nkolmekok, Meyo, Ngat Bané, Ozom, Zamakoé and Zoassi/Zock. The villages were selected after pilot surveys using the following criteria: accessibility, type of dominant activity, intensity of involvement in rattan sector and demographic importance. Data collection was based on direct observations, informal discussions, interviews, measurements (distances between inhabited area and harvesting site, length of rattan harvested, surface of breach created by harvesting etc.), tests ('perishability' of raw rattan, resistance of some part of a stem etc.), second hand data collection and the use of standardised questionnaires. In choosing the survey units, our preferential sampling method was the sampling directed by population stratification (stratified random sampling). For example, for surveys in the villages, households where stratified according to the criteria 'involvement or not in rattan exploitation' (two categories: households involved and households not involved) and the type of activity in the rattan sector (three categories: harvesters-sellers of raw material, harvesters-craftsmen, artisans). Furthermore, for the collection of some specific data, we used either the 'instantaneous sampling' or the 'focal subject sampling' method according to the nature of variables and contexts.

The implementation of the surveys took place in three essential phases, namely the presifting (or pre-analysis), the analysis and treatment or processing of data. Data processing was manual for certain aspects and computerised for others. After entering quantitative data into the computer, we did simple statistical processing: numbering, calculation (absolute and relative values, averages etc.), sketch of statistic tables and diagrams etc. Quantitative data were combined with qualitative information for analysis.

\section{BRIEF PRESENTATION OF THE SECTOR IN THE YAOUNDÉ REGION}

Cameroon is one of the richest countries of West and Central Africa as far as rattan species diversity is concerned. Eighteen of the 20 known African rattan species occur in Cameroon (Sunderland 2001). Out of these, three are commercially very important: Laccosperma secundiflorum, Eremospatha macrocarpa and Laccosperma robustum (Sunderland 2001) (see Table 1).

The rattan production-to-consumption system-that is, the entire channel from the production of raw material to the consumption of finished productsin the Yaoundé region is very simple, as illustrated in Figure 2. The major participants of the production-to-consumption system include harvesters, artisans and consumers.

\section{Rattan harvesting in the region}

Up to the 1960s the bulk of rattan harvested from the forest of the area was used as service material within the framework of the village economy. Since then the combination of several factors such as increased urbanisation and Westernisation favoured the speeding up of rattan harvesting, especially Laccosperma secundiflorum and Eremospatha macrocarpa, for large-scale commercial purposes. 


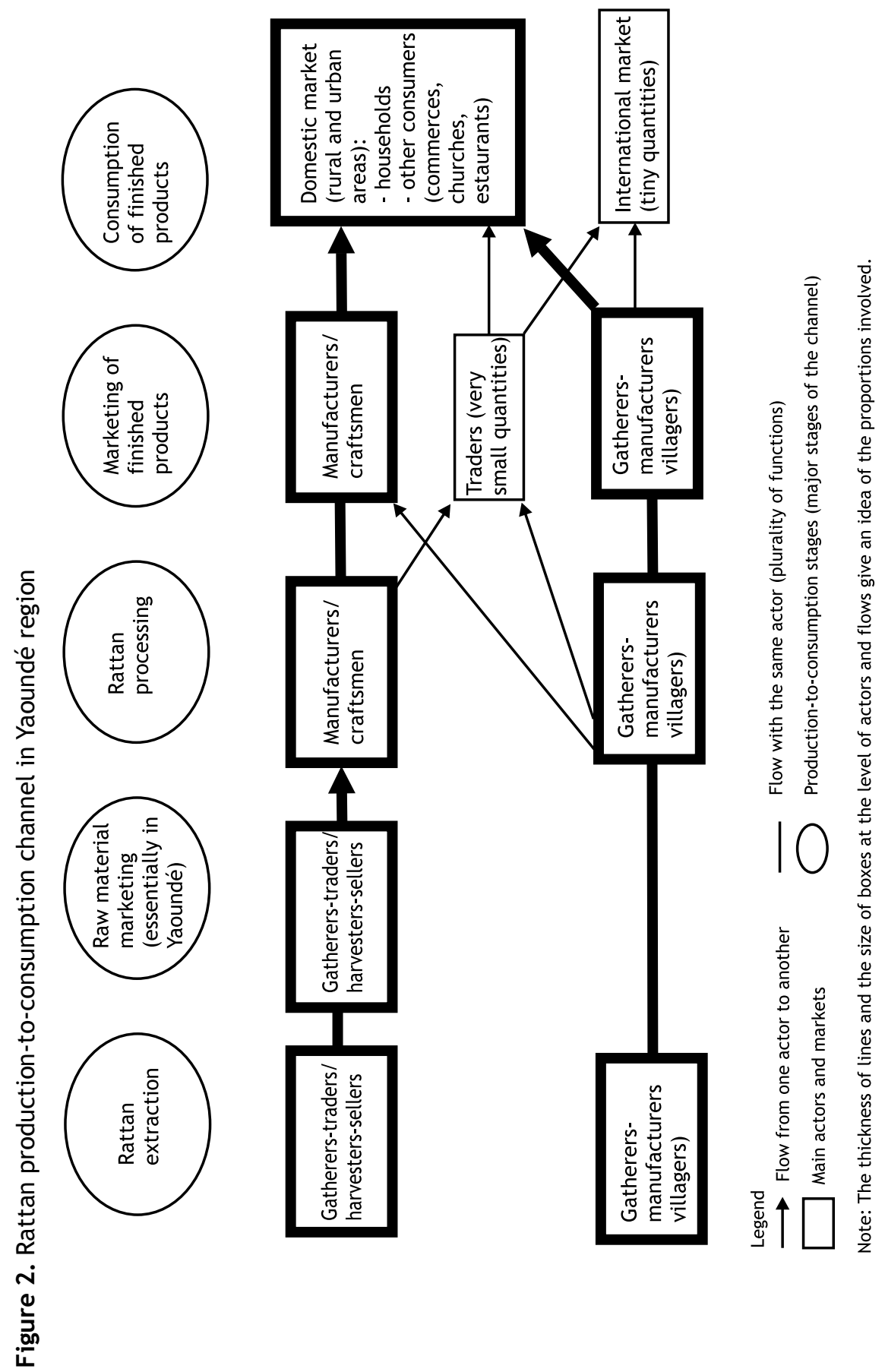


Rattan harvesting takes place exclusively in natural rattan stands in an archaic manner and without any management plan: Rattan is not cultivated in this region. The only tools used by harvesters are a machete and a file, which are used not exclusively for the harvesting of rattan, but equally for almost all production activities. Mature stems are selected (the rate of stem harvesting per cluster varies from approximately 40\% to 100\%), drawn, carefully stripped of their leaves, cut into pieces (eguainées) and/or scraped off (preprocessing operations) and stacked in parcels or bundles.

Extraction output is low: $28 \%$ of the length of $L$. secundiflorum and $44 \%$ of usable $E$. macrocarpa is abandoned on branches or simply in the forest because they are entangled in the canopy, retained by a device or an environment that hooks and twist them up (Defo 1998). Natural populations suffer not only from these huge losses, but also from the harvesting pressure (high demand in some villages), which is sharply detrimental to its dynamics. The exaggerated harvesting of mature stems from clusters limits the production of suckers by clones, or vegetative regeneration (Nzooh Dongmo personal communication). Furthermore, the fact that the clones are permanently besieged does not give the rattan population the possibility of getting to the reproductive and seedling stages. In addition, rattan populations in some sites are subjected to clearing for agricultural purposes.

The extraction of rattan has an impact that is far from being harmless or neutral on the ecosystem. Harvesting in most cases results in the destruction of grass, seedlings, bushes or shrubs and support branches. It deprives some grasses or herbs of their support and sometimes some beetles or coleopterous insects and ants of their habitat (Defo 1998). If perhaps these insects play a fundamental role in vital functions of rattan and if the relationship of dependence at this level is rather specific, the destruction of their habitat would certainly have negative impacts on the dynamics of the plant populations ${ }^{2}$. Furthermore, rattan harvesting in the Yaoundé region frequently contributes to promoting hunting, which in any case is not surprising given the context within which rattan harvesters evolve.

\section{Rattan harvesters and the socio-economic context}

Most of the local rattan harvesters are relatively young married men: $96.4 \%$ of harvesters-sellers are male and $85 \%$ are between 16 and 40 years of age; $63.1 \%$ of harvesters-craftsmen are 18 to 40 years old and $78.0 \%$ of these actors are married; $1.2 \%$ are illiterate, $60.0 \%$ went only to primary school, $38.8 \%$ reached secondary school and none had higher education. They have on the average six persons under their care. Those who presently harvest and sell rattan have not actually been in the business for long, for their average experience or seniority is only approximately four years and $92 \%$ have less than 10 years of experience. These rural harvesters come from average and low social categories from the viewpoint of material wealth. But at the village level they are far from being marginalised persons because they are well integrated in the local socialisation and economic systems. They do not constitute any proper or specific social class or category. 
Harvesters belong to the Ewondo and related groups (subset of the great Bantu family), which is said to have arrived in the forest zone in the nineteenth century from Adamawa (Mveng 1963, 1985)3. The populations are distributed in a myriad of diverse size hamlets and constitute segmental societies (communities without strong sociopolitical leadership). This characteristic has far-reaching implications on natural resource exploitation and at the level of the 'anthropic' 4 ascendancy over space. The region has 10 to 40 inhabitants per square kilometre (Santoir 1992), and the low rural densities contribute to the perpetuation of this situation and have remarkable repercussions on the main economic activity of the region-agriculture (loose land tenure system, bush fallowing). Villagers within the scope of this study mainly practice food producing or crop agriculture (slash and burn shifting cultivation system) and cocoa cultivation (coffee cultivation there is marginal). They equally engage themselves in multiple extra-agricultural activities such as craftsmanship, exploitation of sand, fishing, hunting and the collection or harvest of other NTFPs (Irvingia, Gnetum, Marantaceae, Cola). The social groups are quite integrated in the market economy, essentially by cocoa farming and the sale of foodstuff products.

The harvesting of rattan constitutes an important element of the village production system as indicated notably by the share of households involved (35\%) and the monetary income obtained (approximately $42 \%$ of global income of household concerned; US\$276 of average annual income per household involved against for example US\$174 for cocoa, US\$1,556.5 for small scale wood sawing and US\$202 for foodstuff cultivation for example; annual average monetary income of households involved in the exploitation of rattan amounts to US\$822.3 against US\$654.5 for those who are not involved and US\$704.9 for all categories of household). Figures 3, 4 and 5 show from where households in the seven villages derived income in various contexts. Taking all the indicators into account, rattan exploitation constitutes the second most important activity after agriculture. The money from rattan is important not only in absolute and relative value terms, but also and especially because of its rapid or immediate and relatively regular nature, which makes it a great means to face current cash flow problems.

This and many other characteristics allow the exploitation of rattan to integrate harmoniously in the multiple activities villagers undertake to survive. Monetary income stemming from rattan often contributes to the development of other activities. Rattan exploitation and other economic activities usually alternate in the timetable of villagers. This combination unfortunately does not allow rattan harvesters to have an acceptable standard of living, even if compared to others farmers some rattan harvesters and artisans enjoy a somewhat higher income. Just like the other farmers they live in poorly constructed houses, have difficult access to medical care and have no access to conveniences such as electricity and pure drinking water. They have therefore been evolving in a context of abject poverty (in the context of the whole country and according to the World Bank and IFM indicators) (Banque Mondiale 1995) for more than a decade by way of a severe economic recession and a systematic resignation of the state in the face of some of its fundamental social missions. Actors of the processing sector equally operate in this context of poverty. 
Figure 3. Structure of global cash income of rural households of seven villages in the Yaoundé area

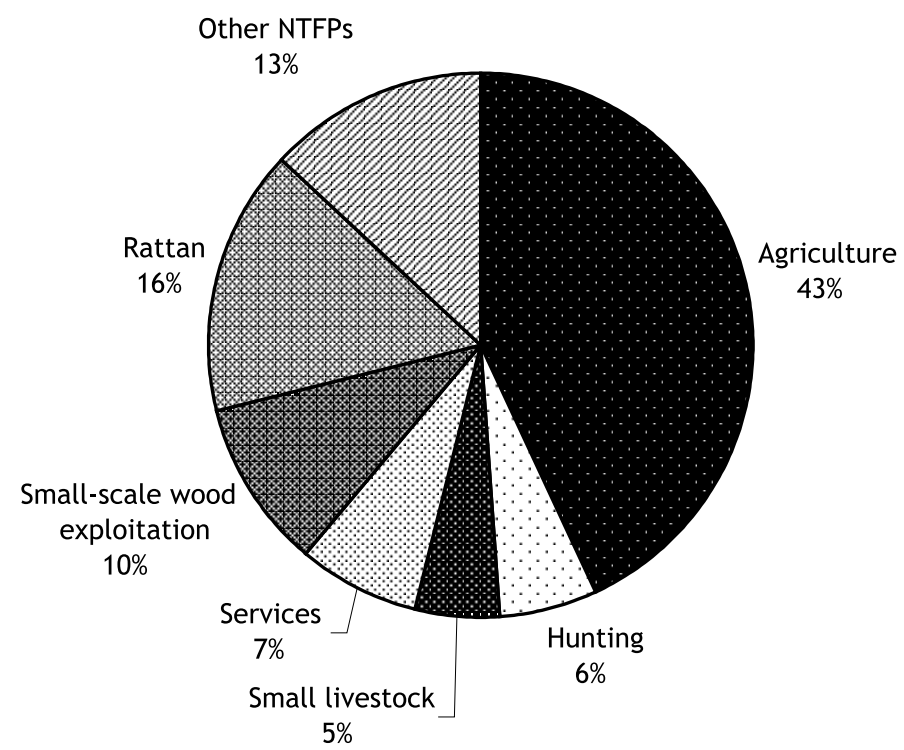

Figure 4. Total cash income of producer households in seven villages in the Yaoundé region

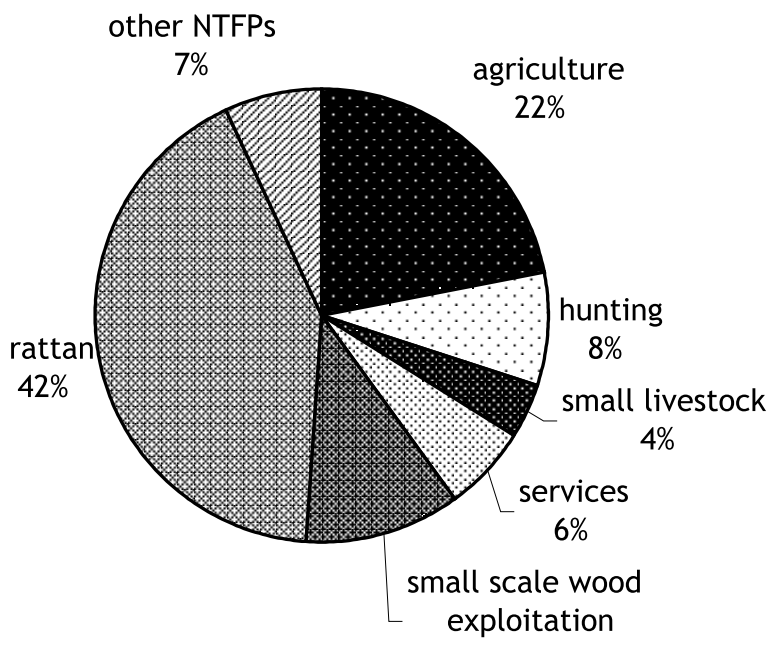

$11 \%$ 
Figure 5. Distribution of annual monetary revenue of rural households in seven villages in the Yaoundé region

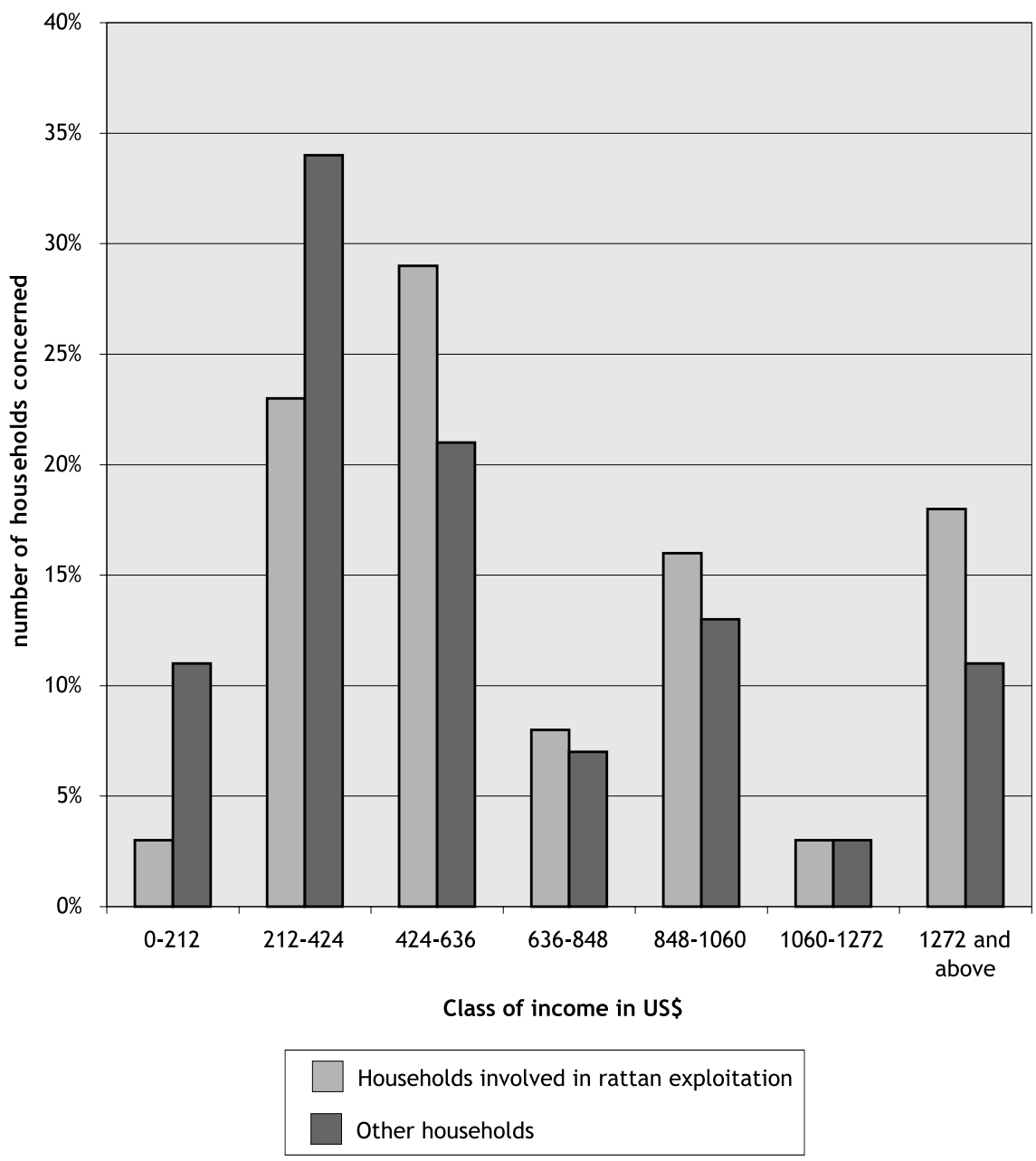

\section{Rattan processing}

Rattan harvested from forests of the region is processed (preparation of the rattan and manufacture of objects) in processing units (PUs) in rural areas, in secondary cities and especially in Yaoundé. This national metropolis polarises the greatest part of commercialised rattan and constitutes the main centres of rattan craftsmanship with about 120 PUs and 272 persons directly involved (proprietors, employees, pieceworkers, apprentices and family help or assistance). This is why in this section, we are going to base our presentation almost exclusively on craftsmanship in Yaoundé. 
The PUs in Yaoundé are to $99.14 \%$ run or operated by men. These artisans are on the average 35.1 years old. The majority $(62.4 \%)$ is married. About onethird (36.6\%) belongs to the Ewondo ethnic group, while Bamiléké represent $17.9 \%$, Widikum $17.0 \%$ and Eton-Manguissa $13.0 \%$. They have an average level of education, for $40 \%$ have been to college and $5 \%$ have undertaken university studies. Their average seniority in rattan processing is approximately 13 years. The economic crisis and its corollary, unemployment, have played a great role in making many of them join the trade; $44 \%$ became basket makers when the recession set off. Craftsmen work under modest material and organisational conditions (Defo 1997, 1998; Sunderland et al. 2003). Rattan processing in Yaoundé as in rural areas takes place in microstructures as shown by the following indicators.

- The average workforce of a PU is just 2.3 persons.

- The working capital and the average cost of equipment are only US\$83 and US\$66 respectively.

- The equipment used is simple, manual, indeed rudimentary and essentially limited to hammer, knife, measuring tape, gas for burning, brushes and metal saw.

- The infrastructure is not enviable. About $44 \%$ of rattan processors work mainly in the open and $40 \%$ in sheds or on a veranda.

Furthermore, $52 \%$ of PUs operate in the homes of craftsmen (house-based rattan processors). A good number of these PUs are family workshops. In contrast, among PUs located outside of residences there are hardly any of a family nature. These are essentially individual microstructures that sometimes hire the services of pieceworkers or temporary technicians on piecework.

The work in workshops takes place in a simple enough manner. Generally, almost all stages of manufacture or production (apart from the preparation of materials) of an article are undertaken by the same craftsman. Processing activities are generally carried out in three main stages: (1) preparation of material, during which the craftsman scrapes, dries, measures, cuts, splits and arches the rattan; (2) assembly or setting, which comprises forming the basic framework or armature, weaving and/or veneering and caning or padding; and (3) finishing, during which the craftsman attaches the blades, decorates and coats (application of paint or varnish). This work ends up in the production of a range of fairly large objects: articles for transportation, conservation and presentation (basket carried on the back, baskets, trays), furnishing objects (armchair, table, shelf), articles for decoration (flower pots), finery objects (hat, bracelet) and service or musical articles (castanets, dummy, picture jah). These objects come under utilitarian craftsmanship as well as under arts craftsmanship. Some amongst them (baskets carried on the back, castanets, baskets) are elements of local cultural identity. Unfortunately they are virtually overshadowed by the exorbitant number of exogenous models (trays for receptions, 'Romantic Lounge', 'Queens Chair', laundry basket, luxury shelf etc.) copied from European and South-east Asian catalogues. Marketing imperatives could partly explain this state of things. 
Photo 1. Making rattan furniture (Photo by L. Defo)

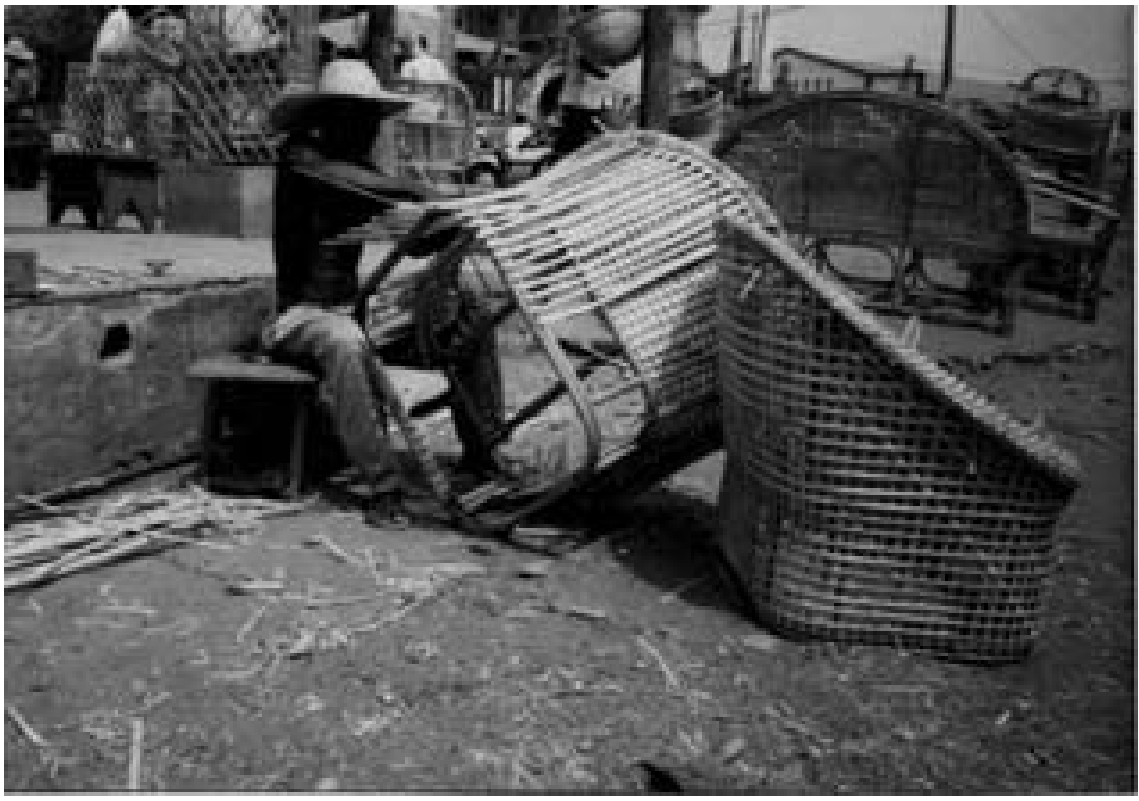

\section{The marketing of unprocessed rattan and finished products}

The marketing circuit is very short and the mechanisms are quite simple. Figure 2 enables us to have an overview of the chain.

\section{The sale of unprocessed rattan}

Two categories of agents harvest rattan from forests of the region, namely harvesters-craftsmen and harvesters-sellers. The system is based on the second category of stakeholders (cutter/harvester-seller) being the most important, and it is this category that really concerns us. After the cutting and constitution of bundles, the cutters-sellers transport the rattan themselves on their heads or shoulders from the forest to roads suitable for motor vehicles or directly to their living quarters, where it is put into storage while waiting to be conveyed by trucks, pick-ups or minibuses to the unprocessed rattan market of Yaoundé. The costs of transportation varies with the distance, the state of the road, the season, the load and the negotiating ability of the cutter-seller. The average cost is US\$0.54 for a parcel of maraca (approximately $70 \mathrm{~m}$ ) and US\$0.36 for a roll (approximately $75 \mathrm{~m}$ ) of small diameter cane (filet rattan) and represents $20 \%$ to $25 \%$ of the price of the goods conveyed to Yaoundé. This cost is relatively exorbitant and represents the harassment by public sector employees (police, 'gendarmes', forestry officials) or 'informal taxation' along the road, and sometimes the lack of transportation opportunities, a real constraint of this trade.

For approximately four decades, Yaoundé has had a sales point for unprocessed rattan situated in the Mvog-Mbi neighbourhood (Defo 1996, 1998). This sales point is provided with fresh supplies from cutters-sellers coming 
Photo 2. Harvester transporting rattan cane (Photo by L. Defo)

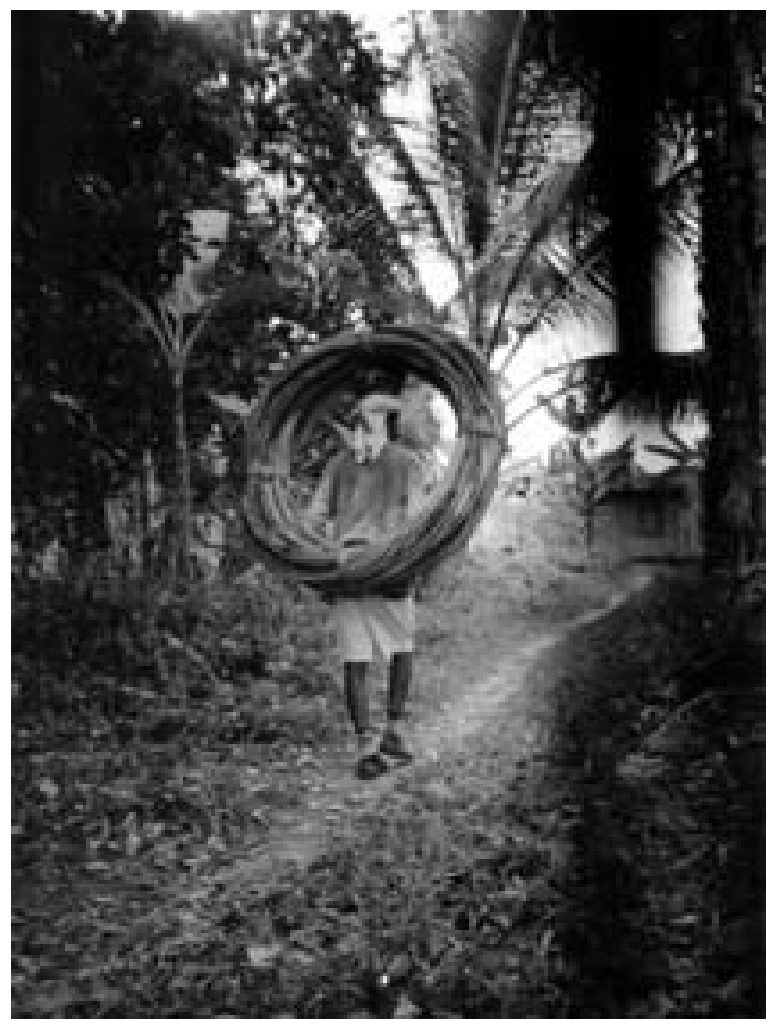

from 40-odd villages of the countryside of Yaoundé. Commercialisation on this sales point is done freely (it suffices to pay the storage fee to the proprietor of the land) and it is carried out by the cutters themselves (hence the name of cutters-sellers) directly to the craftsmen, without any intermediary. They negotiate individually with the craftsmen, without any real agreement among cutters-sellers on prices, which contributes enormously to weaken their position in the face of buyers.

Provision of fresh supplies of cane to the sales point is undertaken spontaneously, in a disorganised manner. The demand for rattan varies according to the agricultural calendar, to seasons, to the school calendar, to that of great feasts and some circumstantial events. Thus for example, between 5 August and 8 September 1996, a time of school holidays in the dry season with low activity on the agricultural calendar, 4,225 parcels and bundles of rattan were received at this sales point as compared with only 1,764 parcels in the busy period from 30 September to 27 October 1996 (the rainy season, school period, periods of dense and restricting agricultural activities) (Defo 1997). Consequently the market witnesses considerable periods of oversupply, but also of periods of shortage during the year. 
Prices of rattan also fluctuate considerably by virtue of the law of demand and supply. The average prices in 1996/97 were close to US\$0.035 and US\$0.022 per metre for the maraca and small diameter cane species respectively.

\section{The trade of finished rattan products}

Rural craftsmen's articles are sold directly to either villagers, city dwellers visiting or passing through the villages (some craftsmen make exhibitions near busy trunk roads) or to city dwellers in the city. In this last case, the village craftsman passes through a retailer installed in the city or supplies his goods directly to the final consumer. A tiny percentage of the articles sometimes find themselves abroad at the end of the circuit through the intermediary of a tourist or an occasional retailer.

The rattan bought from the Yaoundé sales point is conveyed by taxi or rickshaw (pousse-pousse) from Mvog-Mbi to the PUs spread across the city. The manufacture of finished articles by craftsmen is undertaken either on order or for exhibition and sale. The range of selling prices of finished articles is wide. Extreme prices recorded in 1996/97 were US\$0.36 for a small flower pot and US\$381 for a lounge set made from rattan and Chinese or Indian bamboo. Table 2 presents current articles as well as their respective selling prices.

Table 2. Selling prices of the main current articles in the region of Yaoundé

\begin{tabular}{ll}
\hline Object & Price (US\$) \\
\hline Market basket, floor with plywood, simple finishing, L40 W125 p20 & $1.7-2.5$ \\
Market basket, floor with plywood, simple finishing, L50 W30 p20 & $2.5-3$ \\
Round basket, D20 p24 & $1.4-1.7$ \\
Round traditional basket (dziat), D45 p20 & $0.8-1.7$ \\
Tray, floor with plywood, L30 W20 p10 & $1.4-1.7$ \\
Tray, floor with plywood, L36 W17 p7 & $1.4-1.7$ \\
Simple shelf, H110 L60 p30 & $5.9-6.8$ \\
Simple shelf, H130 L70 p30 & $6.8-8.5$ \\
Simple lounge chairs & $15.2-34$ \\
Lounge (aboa) & $84.9-203.7$ \\
Padded lounge & $203.7-271.6$ \\
Simple dining set & $51-118.8$ \\
Laundry basket, D80 p90 & $5.9-7.6$ \\
Flower pot (for hanging), D10 p25 & $0.8-1.4$ \\
Basket with slack handle, D40 p80 & $0.8-1.4$ \\
Basket with tight handle, D36 p55 & $1.4-1.7$ \\
\hline
\end{tabular}

Key (Notes)

$\mathrm{L}=$ length in centimetres

$\mathrm{W}=$ width in centimetres

$\mathrm{H}=$ height in centimetres

$\mathrm{p}=$ depth in centimetres

$\mathrm{D}=$ diameter in centimetres

A lounge consists of four armchairs, one couch (settee) and one centre table.

A dining set consists of six chairs and one table. 
These craftsmen sell their articles themselves, in most cases, to the final consumers. But some among them, especially those that manufacture fine basketwork articles, sometimes supply retailers. The volumes of sales from PUs vary throughout the year. High periods are in December (end of year feasts) and September (arrival or return of holiday makers from the West).

The space used for manufacturing is in most cases also used for exhibition and sales or at the very best, the sales location is adjacent to the production area or not very far from it. Craftsmen in Yaoundé sell almost all of their productions on the domestic market. Very few articles from these craftsmen are sold abroad. Decision-makers should thus make efforts to establish favourable or enabling conditions for exporting Cameroonian articles in order that the country could ${ }^{5}$ benefit from the international market of rattan, which is huge and highly remunerative (ITTO 1997).

\section{POLICY ENVIRONMENT}

Since the colonial period the state has assumed the right to property on almost all land and forest stands of the national territory and left to the populations only the traditional usage right. As concerns particularly forest resources, this principle was given concrete expression through a battery of successive texts: ordinance 73/18 of 22 May 1973, decree 74/357 of 17 April 1974, law 81/13 of 21 November 1981, decree 23/170 of 12 April 1983 and so on. The Cameroonian government reached a decisive stage in the process of improving the framework governing the exploitation of forest resources with law 94/01 of 20 January 1994 to lay down forestry, wildlife and fisheries regulations and decree 95/ $531 /$ PM of 23 August 1995 to determine the conditions for implementing the forestry regulations. Through these texts, public authorities intend to put some order in the forestry sector, to reconcile conservation imperatives and economic constraints and to promote participatory management of forest resources.

According to this new framework, the harvesting of NTFPs for lucrative purposes is subject to obtaining an approval (agrement) and an exploitation permit, the payment of a tax to the public treasury (US\$0.018/ $\mathrm{kg}$ according to the finance law) and the establishment of a way bill for the conveyance of the good. This framework is overly ambiguous as far as NTFPs are concerned (Defo 1999c) and the provisions relating to community forests offer more flexible possibilities (all forest resources of a community forest except the protected species belong to the concerned population and the official formalities to gather these resources are not very heavy).

At the level of marketing of unprocessed rattan and its by-products, following fiscal provisions in force, the seller should pay a tax called impôt liberatoire to the local council where the business is done, the amount of which depends on the turnover. The rattan processing activity is just liable to taxation as the other essential parts of the channel. Considering the reduced volume of their activity, rattan craftsmen of Yaoundé are classified under the global tax scheme of US\$28.25 to US\$141.24 per year according to the size of the PU. 
Despite recent positive evolutions such as the establishment of a subdirectorate for NTFPs in the Ministry of Environment and Forestry, the Cameroonian state has not yet put in place a real intervention policy destined to significantly orient or to promote the development of NTFPs. It is not closely or concretely interested in the harvesting of rattan, it does not grant any subsidy to the small-scale sector and it has not made any significant and direct investment in the sector-which moreover conforms to the policy of liberalisation and privatisation currently in force in the production sector in Cameroon.

The state has nevertheless undertaken some limited actions touching on the rattan industry. The almost yearly organisation of best craftsman contests, the financing of the Cameroonian Enfance Betamba Institution, in which rattan craftsmen (among others) are trained, and the support for rattan basketwork in some penitentiary establishments are the state's only perceptible direct interventions in the rattan environment besides the regulatory and legislative framework mentioned earlier.

\section{KEY ISSUES}

\section{The dynamics of the rattan industry in the Yaoundé area}

The rattan industry has witnessed an interesting evolution over the past several years resulting from certain changes in the cultural, social and economic environments.

\section{At the level of raw material extraction}

The most significant evolution at the level of raw material extraction is the drastic increase in harvested volume and the sustained pressure on the resource, which has resulted in the scarcity of rattans in about $43 \%$ of the study sites (Defo 1998). This increased pressure is given concrete expression among other things in the harvesting of immature stems, the restriction to access in 'private'6 forests, the institution of payments for harvesting rights in these forests, disputes about the harvesting sites in the 'common' forests and open access areas (competition for access to the resource), frequent changes of harvesting zones and the increase in the distance between the harvesting sites and the living quarters (for example in Zimakoé, the average distance has increased from about $6 \mathrm{~km}$ to $9 \mathrm{~km}$ between 1992 and 1997 (Defo 1998, 1999a)). The pressure was mainly due to the persistent population growth and urban development, technical changes, the fall in the prices of cocoa and coffee, the economic crisis, which resulted in underemployment, unemployment, pauperisation of the masses and an appreciable increase in the number of harvesters. The extension of clearing for foodstuff farming to the detriment of rattan sites and the shortening of the fallow period in some villages contributed to the reduction in the availability of the resource and the dynamics of the rattan stands. Furthermore, a significant expansion of the supply area was noticed with the sprouting up in the ranks of harvesting sites around new villages such as Mapan, Avebé, Meguéme, Mbega among others. This extension 


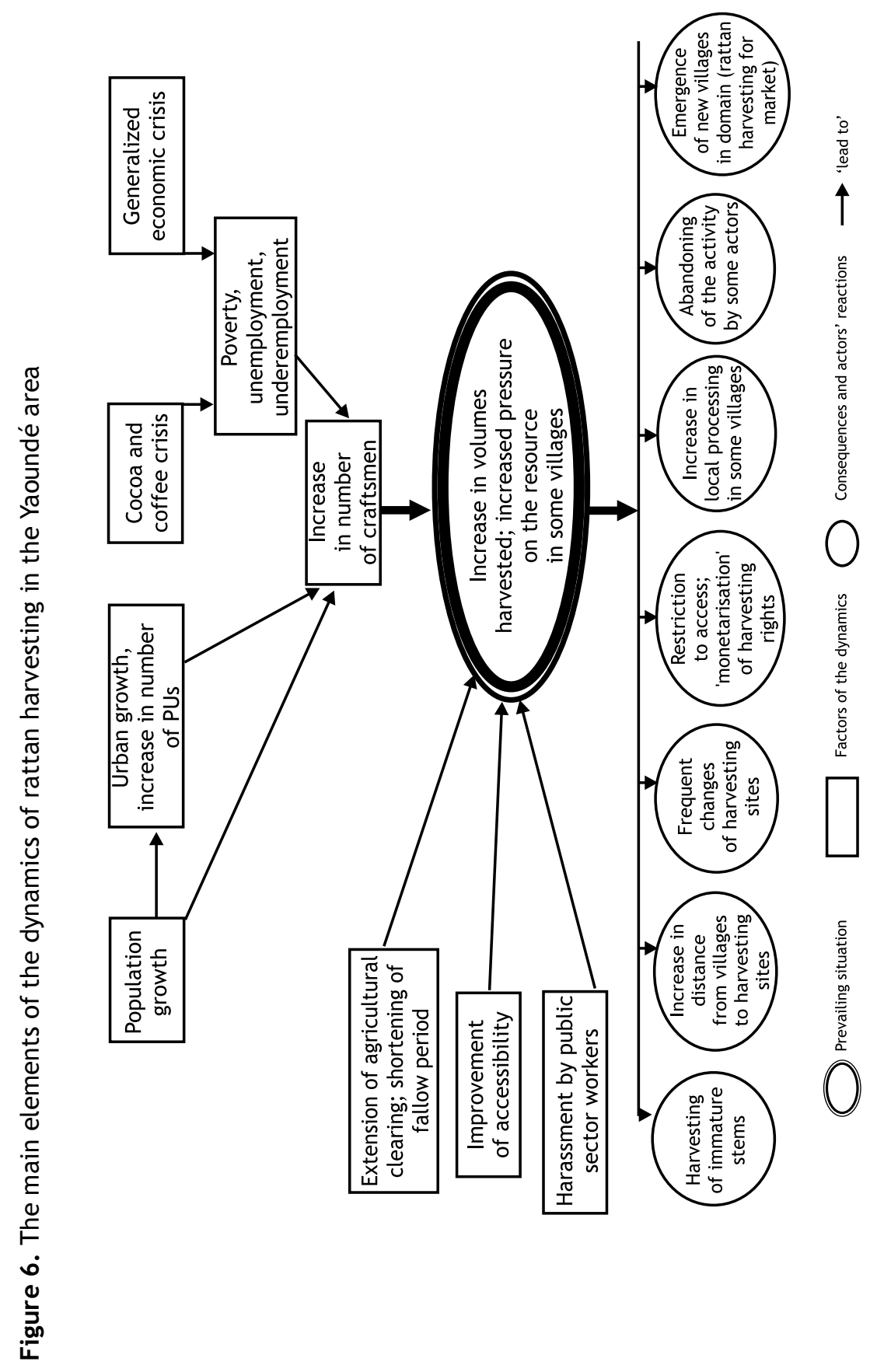


is related to the above-mentioned factors and in some cases it was facilitated by the improvement of accessibility (conditions of transportation) in the area. Lastly, it is equally worth noting that in some villages the speeding up of harvesting and the evolution towards scarcity of the resource contributed to the emergence of the tendency for local processing of rattan for commercial purposes to the detriment of sales in the unprocessed state. This is part of the strategy of farmers aimed at maintaining their rattan income, or better increase its value and make their harvesting efforts profitable. Such are the major characteristics of changes that have occurred at the level of the basic segment of the sector during these past years. Figure 6 summarises these evolutions.

\section{At the level of transportation}

The most important recent change at the level of transportation is the cost increase from about $10 \%$ to $25 \%$, according to villagers, and the increase in harassment of the harvesters-sellers from public sector employees. In fact, with the setting up of the legislative and regulatory framework governing the forestry sector in 1994/95, forest products control posts have multiplied. Since then, using the said provisions (which they however have little or no mastery about) as pretext, the public sector workers have increased illegal financial levies on the rattan harvesters-sellers along the major highways. These practices contribute to increase the pressure on the resource because many harvesters endeavour to harvest the maximum quantity of rattan possible in order to try and meet these losses by anticipation (Defo 1999c).

\section{At the level of rattan sales-points}

The just mentioned strategy of maximising the volume harvested contributedalongside the factors mentioned earlier-these past years to the appreciable increase in the quantities of rattan available at the Yaounde sales point. The volume of rattan trade has witnessed considerable increase, and scarcity periods of rattan have become less frequent and less severe in Yaoundé now as compared to the situation a few years ago. At the moment, the general trend during a good part of the year is to oversupply the market because the increased rate of demand has not also been as considerable and sustained as that of the rise in supply. This situation often inhibits efforts by the harvesters-sellers at raising the price of unprocessed rattan. In spite of the handicap, there has been an overall price increase to the tune of 15\% between 1996 and 2000 (author's unpublished data). This small price increase was among other things favoured by very sporadic appearances of retailers at the Yaoundé sales point. Two of them stayed for a few weeks in the market between 1995 and 1999 and since October 2000, another one is trying to position himself in the sales circuit.

\section{At the level of rattan processing}

The most significant evolution at the level of rattan processing has been the increase in the number of PUs in both rural areas and the city, efforts in the modernisation and improvement of equipment, infrastructures and organisation 
of work of some structures ${ }^{7}$, the diversification of the types and models of objects manufactured ${ }^{8}$, attempts by some craftsmen at regrouping and especially the increase ${ }^{9}$ in the selling price of almost all the finished products. This increase can be explained largely by the price increases for inputs from gas to gum and plywood, which have become all-too-frequent since the devaluation of the local currency.

\section{In the area of outside interventions}

Initiatives have been taken in the study area as well as in the whole humid forest zone of Cameroon. This recent support was especially of a financial, technical and organisational nature. The outside assistance, exclusively directed towards processing, was provided essentially by national or international non-governmental organisations such as Prolabore, which has trained some artisans, and foreign governments such as Germany's Deutscher Entwicklungsdienst, which helps some craftsmen by way of counselling. Unfortunately, these interventions are not of a big scale and thus have limited impact. Besides, they are not only concerned with the rattan sector, but equally with craftsmanship or small trades as a whole.

\section{Some important points and problems}

\section{At the level of resource extraction}

At the level of resource extraction it is worth noting that the totality of rattan used in the Yaounde area is harvested in a rudimentary way from natural stands, without any consideration for or efforts at implementation of rational management. In many forest stands the tendency is that of a free access system within a common exploitation context. The methods, techniques and rhythm of harvesting are far from rational and sustainable (destruction of immature stems in the course of cutting the ripe rattan from the clones, the abandonment of a considerable portion of product in the forest etc.). Coupled with high demand and the agricultural clearing taking place, these practices exert enormous pressure on the rattan and considerably diminish its biomass.

In the villages concerned, rattan exploitation is carried out by relatively young men whose main activity is agriculture, although it is true that rattan has an undisputable economic and social importance to them. These rural harvesters are faced, among other things, with the poor quality of communication channels and 'harassment' from public sector employees who practice 'extortions' which are favoured by the legislative and regulatory framework. This framework (or what it is that plays that role) is limited, not well known and poorly interpreted, indeed almost inapplicable for it is inadequately adapted. There exists no true policy promoting the sustainable development of the sector. The regulations of this sector are ineffective. 


\section{At the marketing level}

Harvesters sell in Yaoundé, individually and directly to craftsmen. The market is quite open.

\section{At the level of rattan processing and sale of finished products}

Processing and sales of rattan in Yaoundé are undertaken by some 100 microstructures run by men originating from diverse ethnic groups. Rattan craftsmanship is their main activity. The infrastructure of these PUs is mediocre, their equipment and techniques simple, indeed archaic compared to the average in South-east Asia. This state of things coupled with the level of the approximate or rough technical and managerial skills of craftsmen contributes to the manufacture of articles of poor, mediocre or at best average quantity and quality compared to Asian products. This partly explains the narrowness of the market and the poor sales often experienced by these PUs (Defo 2002).

PUs are also faced with various other problems including irregular supply of rattan over the year, the preservation of rattan in the workshops, insufficient capital and working capital or contingency funds, the poor quality of equipment, administrative and police harassment, increases in the price of inputs, low selling prices of articles, the absence of a veritable policy of supervision or of promotion of craftsmanship etc.

Moreover, these PUs sell almost all of their production directly to consumers, without intermediaries ${ }^{10}$, and they are limited almost exclusively to the domestic market. Very few of the articles cross the national frontiers. The same observation can be made for unprocessed rattan. The channel is ultrarestricted, less developed, with very weak or lax vertical links and almost non-existent horizontal linkage among its components.

\section{CONSERVATION AND DEVELOPMENT LESSONS}

\section{Conservation}

As we have already mentioned, in the Yaoundé region, rattan is not exploited in a sustainable manner. In some villages, one observes an excessive pressure on clones, which does not leave them enough time to produce regenerating agents (rhizomes, fruits). Extraction often results in the damage of immature stems and considerable pieces of rattan are left on branches of support trees. The pressure on the resource is enormous and the overexploitation is an undeniable reality in some sites (Zamakoé, Zoassi/Zock). Nevertheless, no initiative has been taken that aims at remedying these shortcomings and at promoting a rational management. Moreover, if we consider the present state of knowledge on African rattan species, it would be difficult to elaborate a rational and credible management plan while maintaining the economic exploitation requirements. But compared to the situation before, there are already some data and rough ideas that can be used to build up a simple management plan.

Gaps on various points at the scientific level have to be filled before a credible and strong conservation strategy can be drawn up. Among these points one can cite the evaluation of the biomass, the structure, density and population 
distribution of rattans, the rhythm of production of 'plantules' by clones, the growth of stems under various conditions, the phenology, the impact of harvesting techniques on clones in the various stages of development and the relationships between rattans and elements of the biocénose.

Concerning the conservation of forest resources, rattan in the region has both enormous potential advantages and non-negligible limitations (Defo 1999b). The main assets of rattan include the fact that it requires for its development that the forest cover be maintained (support), the fact that it is accessible to grassroots populations (its exploitation at the present state does not require much technical and financial capital as compared to small scale logging of timber for example) and the considerable size of its potential or effective outlets at the national and international scale. Rattan exploitation (harvesting, processing) and some activities of forest ecosystems degradation (hunting) have the same agents, and as such the rattan work can slow down these activities by competing for time on the work schedule of stakeholders. That is all the more true as rattan brings in money year round and its exploitation is labour intensive. Furthermore, as compared to some activities that cause the degradation of forest resources (hunting for example), the exploitation of rattan presents a sure advantage at the level of the remuneration of working time (US\$1.80 to US\$2.27 per day for the rural rattan processors against US\$1.4 to US\$1.8 for hunting for example, even if it is true that the work effort is more exacting in the case of rattan).

The limitations of rattan in the area of conservation are as impressive as its advantages. Among the most obvious, one can mention the complementarities farmers have created between rattan exploitation and hunting for example (complementarity in the timetable ${ }^{11}$, mutual financing) and the low remuneration of the work as compared to some other activities that cause forest degradation such as the small scale exploitation of timber. In the current state of things, it would be illusory to think that this NTFP could be an alternative to deforestation (Defo 1999b; Trefon and Defo 1999). It is clear that rattan exploitation cannot entirely eliminate the direct and underlying causes of deforestation (agricultural expansion, logging, population pressures, government policy, corruption, markets and macroeconomic conditions). Rattan is certainly no panacea and cannot be expected to be a wonderful remedy preventing deforestation.

The promotion of rural craftsmanship and establishing of more remunerative prices for unprocessed rattan could render this NTFP more competitive and enable it to play a positive role in the forest ecosystems conservation. If rattan provides more substantial gains, given that safeguarding the forest is currently indispensable to its survival, the populations may in some cases no longer destroy (in an accelerated and large scale manner) its ecosystem and this NTFP would have thus contributed to the mitigation or reduction of the deforestation rate. However, this promotion would have to be preceded by a rational management plan for the stands and an adequate regulatory system in order to avoid overexploitation due to the race for rattan, which has become more expensive. This possible race would without doubt have a negative impact on the productive potential and the forest ecosystem if prior appropriate technical, social and regulatory measures or dispositions are not put in place. 


\section{Potential of rattan in the area of development}

We have on several occasions underscored the socio-economic importance of the rattan industry at the levels of employment, income, meeting the needs of stakeholders and culture. Its positive impact in the area of development is irrefutable. The lucrative exploitation of rattan contributes to the alleviation of underemployment and unemployment, enables some rural and urban dwellers to have an income or to increase their financial viability (US\$288.5 per year per harvester-seller, US\$376.7 annually per craftsman in the rural area and US\$969.7 per year per PU proprietor in the city), to meet their needs and those of their family (purchase of medicines, kerosene, drinks, soap, clothes, roofing sheets for their houses and payment of the dowry and school fees). The money derived from rattan contributes to the development of other lucrative activities (purchase of pesticides for cocoa plantations and market gardening, payment for agricultural clearing). Furthermore, rattan processing puts at the disposal of some persons goods corresponding to their standard of living and to their cultural aspirations.

These indices and many others show that rattan has real potential in the area of development in the region. This potential is until now underexploited for the reasons we mentioned earlier. Well defined promotion actions, finely targeted and executed, could enable this NTFP to appreciably increase its contribution to the socio-economic development at the level of harvesters, conveyors, masters-craftsmen, workers, retailers and users of rattan articles. An increased development of rattan within the framework of a sustainable exploitation strategy would be beneficial foremost to harvesters and craftsmen, but equally to the state, which could receive royalties, taxes and earnings.

\section{CONCLUSION AND RECOMMENDATIONS}

\section{Conclusion}

Rattan exploitation in the Yaoundé region is not adequately developed compared to the sectors of this same NTFP in some South-east Asian regions. This average performance is witnessed at several levels. Rattan exploitation is based exclusively on natural stands, its circuit is short, its main stakeholders are not truly organised, the institutional, regulatory and legal framework that governs it is quite restrictive, its factors of production are mediocre, its outlets remain narrow and outside intervention is greatly limited.

It is however undeniable that this activity plays a non-negligible economic, social and cultural role. This role could be more efficient if a battery of constraints did not limit its scope. It is the same situation as prevails in the other rattan exploitation basins of southern Cameroon. If this NTFP should play a more significant role in the fight against poverty at the level of the less privileged social categories such as harvesters and craftsmen, then the bottlenecks would have to be removed.

Recent evolutions in the rattan industry in Cameroon indeed give room for certain optimism for the future of this activity. Currently, however, the forces of these dynamics are insufficient to give rattan the full measure of its potentials in the area of development and conservation in south Cameroon. 


\section{Recommendations}

The first recommendation pertains to the management of the resource. Its conservation deserves sustained attention in the interest of both the main actors of the chain and the biodiversity of the region. It is necessary to develop and to implement viable exploitation methods, extraction techniques that take into account the biotope and means of reducing losses during harvesting to the strict minimum. All these measures should be viewed within the sociopolitical perspective, in a set of mechanisms and standards aimed at contributing to a sustainable management of the resource. It is thus necessary to review the regulatory and legislative framework related to the NTFP industry, to elaborate and control the execution of simple management plans and to make it easily applicable. It would without doubt be more appropriate to integrate rattan in multiresource management plans. Selective and rotation cutting taking place in the various forest areas is a desirable conservatory measure. It would also be necessary to reduce the pressure on natural rattan stands by domesticating rattans and by introducing them into farmers' production systems.

The second recommendation concerns the provision of fresh supplies to processing centres. It is necessary to help cutters-sellers to organise themselves to realise some savings at the level of conveyance, to conform to the regulations, to adopt a better attitude towards public sector employees, to considerably adjust supply to demand and to strive to become less vulnerable in the face of buyers. It is also necessary to help them to develop conservation techniques for harvested rattan over a long period.

The third recommendation is related to the transformation and marketing of articles. It is necessary to considerably improve the infrastructure, technical and organisational levels of PUs and to eliminate waste during processing. It is necessary to train craftsmen in processing techniques, managerial techniques and the area of design. This training would enable them to produce good quality articles that are capable of facing competition. This training would also give craftsmen abilities of commercial aggressiveness that are likely to contribute to the expansion of demand for rattan objects. To palliate the poor sales and the unattractive nature of prices, it is necessary to seek other outlets, especially more remunerative markets at the national and international scales.

These solutions require absolutely that cutters and craftsmen organise themselves for their self-promotion, that intermediate level development actors (non-governmental organisations, town councils) support them and that the state intervene positively at some levels. That is perhaps contrary to the principle of 'less state involvement' currently in force, but it is the price to pay to offer artisans the opportunity of taking care of themselves and of efficiently participating in poor people's income improvement in the future. It is also the price to pay for a sustainable exploitation of the raw material.

\section{ENDNOTES}

1. University of Leiden (The Netherlands), WOTRO Ph.D. Fellowships Programme. P.O. Box 8297, Yaoundé, Cameroon. E-mail: defotls@yahoo.fr

2. This statement is purely an assumption. 
3. These were the last important migrations and settlements in the humid forest zone before the colonial period.

4. This means 'transformed by human beings'.

5. If major constraints are eliminated or attenuated.

6. In almost all cases, what people consider as 'their forest' is state property. In most of these forests peoples only have the right of usage.

7. This effort is manifested through the use of jigsaw and sander and the recruitment of persons for specialised tasks.

8. The diversification of types and models is facilitated by the use of Asian and European catalogues by an increasing number of PUs.

9. Increase from $5 \%$ to about $30 \%$ according to the quantities and the evolution in prices of industrial inputs used in the manufacture of the object in question.

10. This situation is advantageous for the consumer as far as the price is concerned.

11. The two activities are often undertaken together at the same time.

\section{REFERENCES}

Bacillieri, R. and Appanah, S. (eds.). 1999 Rattan cultivation: achievements, problems and prospects. An international consultation of experts for the project: conservation, genetic improvement and silviculture of rattan in South-east Asia. 12-14 May 1998, Kuala Lumpur, CIRAD-Forêt/FRIM, Malaysia.

Baja-Lapis, A., de la Pena-Abarro, V. de la and Pablo Norma, R. (undated) Bibliography on rattan production in the Philippines. Department of Environment and Natural Resources, Laguna, Philippines.

Banque Mondiale. 1995 Cameroun: diversité, croissance et réduction de la pauvreté. World Bank, Washington, DC.

Béné, D. 1994 Etude de la filière de transformation du rotin dans la ville de Yaoundé. Centre Universitaire de Dschang, Dschang.

Defo, L. 1997 La filière des produits forestiers non ligneux. L'exemple du rotin au Sud-Cameroun. Première phase: approvisionnement et transformation: le cas de Yaoundé. Rapport APFT (Avenir des Peuples des Forêts Tropicales), Yaoundé.

Defo, L. 1998 L'exploitation des rotangs dans la proche campagne de Yaoundé. Rapport APFT, Yaoundé.

Defo, L. 1999a Des lianes très sollicitées: les rotangs dans la proche campagne de Yaoundé. APFT News 7: 9-12.

Defo, L. 1999b Rattan or porcupine: benefits and limitations of a high value NWFP for conservation in Yaounde region of Cameroon. In: Sunderland, T.C.H., Clark, L.E. and Vantomme, P. (eds.) Non-wood forest products of Central Africa: current research issues and prospects for conservation and development, 237-244. FAO, Rome.

Defo, L. 1999c Les exploitants des produits forestiers non ligneux, des «hors la loi» ou des «oubliés de la loi». APFT Briefing 19, Bruxelles.

Defo, L. 2002 L'Afrique sur le marché mondial de produits en rotin: une place dérisoire. Non-Wood News 9: 31-32. 
Dransfield, J. and Manokaran, N. (eds.). 1994 Plant resources of South-East Asia. Prosea, Bogor, Indonesia.

Falconer, J. 1990 The major significance of minor forest products. FAO Community Forestry Notes 6. FAO, Rome.

Food and Agriculture Organisation. 1993 More than wood: special options on multiple uses of forests. FAO Forestry Topics Report 4. FAO, Rome.

International Tropical Timber Organization. 1997 Bamboo \& rattan: resources for the 21st century. Tropical Forest Update 7 (4).

Laclavère, G. (ed.). 1979 Atlas de la république unie du Cameroun. Editions Jeune Afrique, Paris.

Mba Enyougou. 1996 La commercialisation du rotin à Yaoundé, le cas du quartier Mvog-Mbi. Université de Yaoundé, Yaoundé.

Mveng, E. 1963 Histoire du Cameroun. Présence Africaine. Yaoundé.

Mveng, E. 1985 Histoire du Cameroun: T1 and T2. CEPER, Yaoundé.

Ndoye, O. 1994 New employment opportunities for farmers in the humid forest zone of Cameroon: the case of palm wine and rattan. Rockefeller Fellow Meeting ILCA, 14-18 November 1994, Addis-Abada.

Nzooh Dongmo, Z.L. 1995 Etude floristique, biologique et écologique des rotangs en forêt dense humide tropicale: cas de la région du Dja (Cameroun). Draft du rapport final (ECOFAC Cameroun) et de la thèse de doctorat de $3^{e}$ cycle (Université de Yaoundé I), Yaoundé.

Panayotou, T. 1990 Introduction: aménagement forestier polyvalent-est-ce la clef de la durée? In: OIBT. Position et potentialités des produits autres que le bois dans la mise en valeur durable des forêts tropicale, 3-8. Série Technique OIBT 11.

Peters, C. 1997 Exploitation soutenue de produits forestiers autres que le bois en forêt tropicale humide: manuel d'initiation écologique. Programme d'Appui à la Biodiversité, Washington, D.C.

Santoir, C. 1992 Sous l'empire du cacao. Etude diachronique de deux terroirs camerounais. Edition de l'ORSTOM, Paris.

Sastry, C.B. 2001 Le rotin au XXle siècle: un aperçu. Unasylva 52 (205): 3-10.

Shiembo, N.P. 1982 Economic analysis of raphia and cane in Cameroon. University of Ibadan, Ibadan.

Shiembo, N.P. 1986 Development and utilization of minor forest produce in Cameroon with particular reference to raphia (Raphia spp.) and cane (rattan palms). University of Ibadan, Ibadan.

Sunderland, T.C.H. 2001 Rattan resources and use in West and Central Africa. Unasylva 52 (205): 18-26.

Sunderland, T.C.H. and Profizi (eds.). 2003 New research on African rattans. Proceedings No. 9. International Network for Bamboo and Rattan. Beijing. 147p.

Sunderland, T.C.H., Defo, L., Ndam, N., Dione, M. and Tamnjong, I. 2003 A socio-economic profile of the rattan trade in Cameroon. In: Sunderland, T.C.H. and Profizi, J.P. (eds.) New research on African rattans. International Network for Bamboo and Rattan (INBAR) Proceedings No. 9, 115-140. Beijing, China.

Trefon, T. and Defo, L. 1999 Can rattan help save the wildlife. Development 42(2): 68-70. 


\title{
Chapter 18
}

\section{Sport hunting of elephant in Zimbabwe: a case study of Kanyurira Ward in Guruve district}

\author{
Dale Doré ${ }^{1}$ and Ivan Bond ${ }^{2}$
}

\begin{tabular}{llllll}
\hline Common Names & $\begin{array}{l}\text { Part of the } \\
\text { resource used }\end{array}$ & Management & $\begin{array}{l}\text { Degree of } \\
\text { transformation }\end{array}$ & $\begin{array}{l}\text { Scale of } \\
\text { trade }\end{array}$ & $\begin{array}{l}\text { Geographic } \\
\text { range }\end{array}$ \\
\hline $\begin{array}{l}\text { African Elephant, } \\
\text { Nzou }\end{array}$ & Elephant & Wild & High & International & Large \\
\hline
\end{tabular}

\begin{abstract}
The Communal Area Management Programme for Indigenous Resources (CAMPFIRE) allows communities to benefit from the management of their wildlife resources. A number of rural district councils, acting on behalf of local communities, have been granted the legal authority to manage wildlife within their communal areas. In Kanyurira Ward, which lies in the Zambezi Valley, the council entered into an agreement granting a safari operator the sole right to hunt a certain quota of animals in a defined wilderness area that is rich in wildlife. The community manages this area by conserving both the habitat and the wildlife itself. In return, households are paid a portion of the revenue earned from sport hunting, especially for elephant. The people of Kanyurira, through its Ward Wildlife Committee, have received substantial financial, technical and organisational assistance from donors and nongovernment organisations.
\end{abstract}

\section{INTRODUCTION}

As human settlement expanded within the communal areas of Zimbabwe, people came into conflict with wildlife. Wild animals, especially elephant and buffalo, damaged crops and livestock and threatened the life and limb of people. Increased settlement, on the other hand, threatened wildlife through the loss of habitat and by subsistence and illegal hunting. In response, the Department of National Parks and Wildlife Management initiated CAMPFIRE, the Communal Areas Programme for Indigenous Resources (Martin 1986). 
The purpose of CAMPFIRE was to provide communities with an incentive to conserve wildlife by treating it as a resource from which they could benefit.

It was therefore decided, as a first step, to confer 'Appropriate Authority' status on rural district councils under the Parks and Wild Life Act of 1975, thus enabling them to manage wildlife resources on behalf of the communities they represented. This allowed them to benefit from a variety of wildlifebased activities. The councils, however, were granted this status on the understanding that they involved 'producer communities' in the management of wildlife and that they passed on a substantial portion of the financial benefits of wildlife management to these communities. Producer communities are those that are in direct contact with wildlife, bear the costs of wildlife damage, and take primary responsibility for managing wildlife (Murphree 1993).

Since 1989, 36 rural district councils throughout Zimbabwe have been granted Appropriate Authority. Approximately 16 of these districts can be considered wildlife producers, i.e., they are able to generate income from wildlife activities. More than $90 \%$ of wildlife revenues have been earned from the lease of sport hunting rights to commercial safari operators. Of this revenue, over $60 \%$ is directly attributable to one species, the elephant (Bond 1994; 1999). Although rural district councils are not legally required to devolve the management of wildlife to producer communities or to pass on the financial benefits, they invariably follow a set of principles contained in the CAMPFIRE guidelines developed by the Department of National Parks and Wildlife in 1991. These guidelines recommended that at least $50 \%$ of the gross wildlife revenue should directly benefit the communities that manage wildlife. (Murphree (1997) argues that CAMPFIRE was initiated by a strategic compromise between devolutionists and centralists.)

Evidence suggests that CAMPFIRE has slowed the rate of habitat loss and that its benefits have been greatest in areas where communities are small, homogenous, and living in a distinct territory (Bond 1996). Bond (2001) has found a clear inverse relationship between human population size and areas of wildlife habitat; in other words, lower human population densities translate into higher wildlife populations. While difficulties persist within the programme, CAMPFIRE's incentive-led conservation model has resulted in substantial development and conservation benefits in some areas. The most notable and frequently quoted example is Kanyurira Ward in Guruve District (Lynam, 1993; Nabane and Matzke 1996; Murphree 1997), the subject of this case study.

In the next section we examine the human and physical geographic features of Kanyurira Ward that make it suitable for sport hunting. Production to consumption activities are described in the following sections, namely, the management of wildlife, the hunting of elephant and the marketing of the product-the hunt itself. Based on a review of these activities, some concluding remarks are made in the final section.

\section{THE STUDY AREA}

Kanyurira Ward, which is also known as 'Masoka' in the literature, lies in the Dande Communal Land of Guruve District, approximately $200 \mathrm{~km}$ north-west of Zimbabwe's capital, Harare (Figure 1). Bounded in the south by Doma Safari 
Figure 1. Location of Kanyurira Ward
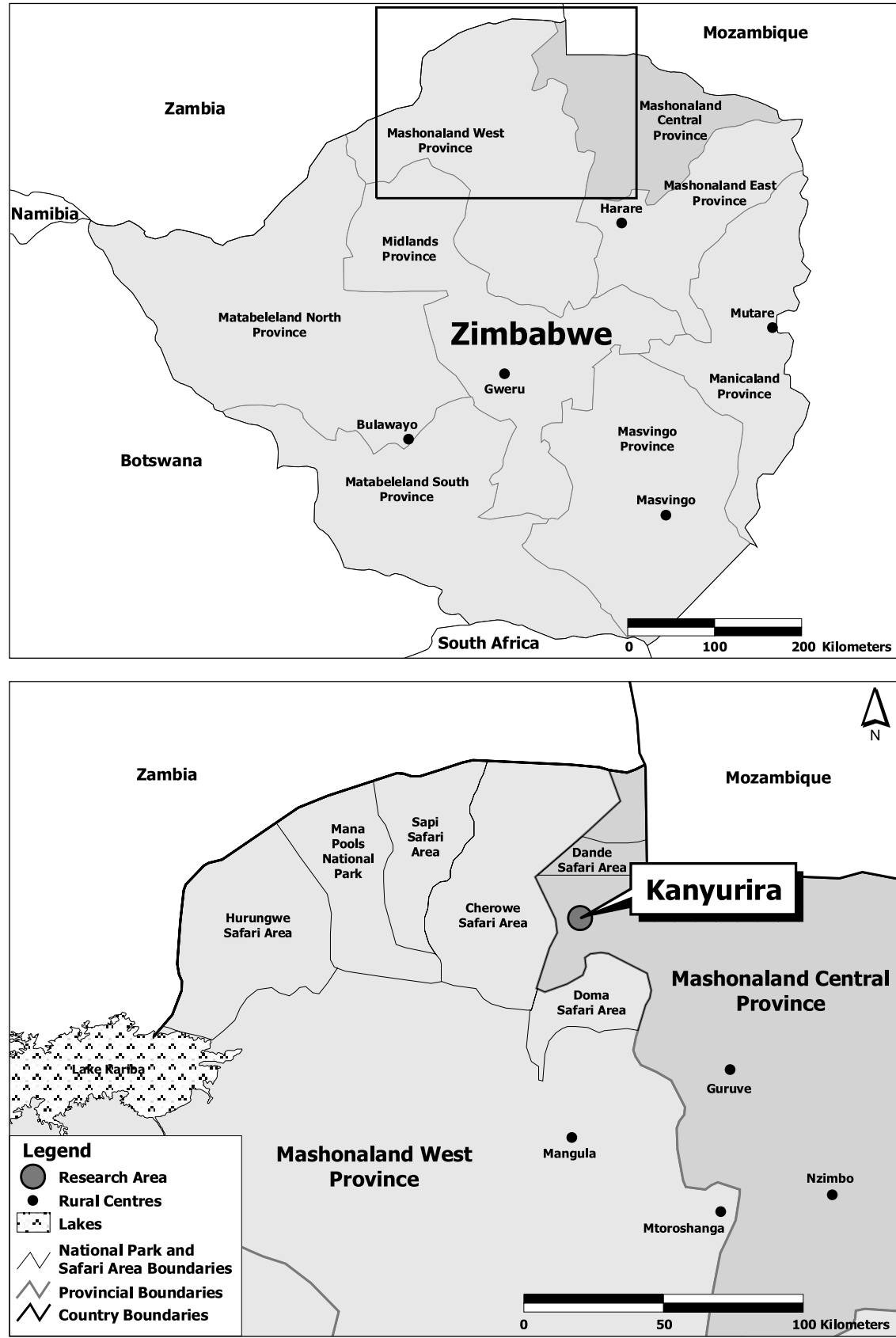

Source: ESRI Data and Maps 2002. 
Area and in the west by Chewore Safari Areas, it covers an area of over 400 $\mathrm{km}^{2}$ (Cutshall 1989). Settlement, consisting of about 250 households, is concentrated along the alluvial soils on the banks of the Angwa River. This area, which is enclosed by a solar-powered electric wildlife fence, consists of a residential area $\left(8 \mathrm{~km}^{2}\right)$ and fields for cropping $\left(10 \mathrm{~km}^{2}\right)$. The remainder of the ward $\left(382 \mathrm{~km}^{2}\right)$ is virgin savannah woodland that is maintained and managed as wildlife habitat (Taylor 1998). Whereas residential stands, gardens and fields are de facto 'owned' by individual households, woodland and wildlife are held in common. (Communal lands are legally held in trust by the president for the people living in them. Although members of the community have the right to change the use of the land, they are not allowed to sell it.)

Residents of Kanyurira have traditionally derived their living from small-scale dryland agriculture, supplemented by foraging and subsistence hunting. Kanyurira experiences a long dry season from April to November and a wet season from December to March. The mean annual rainfall recorded at Angwa bridge, $15 \mathrm{~km}$ north-east of Kanyurira, is $725 \mathrm{~mm}$ ( $\mathrm{n}=15, \mathrm{CV}=34 \%$ ) (Lynam 1993). The low and erratic rainfall patterns make agricultural production precarious and crops often fail. As a result, households remained dependent on government drought relief programmes for food before the inception of CAMPFIRE. Apart from the vagaries of weather, income from agriculture was limited by the distance to markets and the poor condition of roads. Crop damage from elephant and buffalo was significant. Since cattle cannot be kept due to the presence of tsetse fly, some households rear goats and other small livestock.

The vegetation of the wildlife habitat area has been described by Taylor (1993), who grouped 14 different vegetation types into i) riverine and alluvial vegetation, ii) dry deciduous forest, iii) Colophospermum mopane, iv) Terminalia communities, and v) mixed mopane-miombo communities. He suggested a close association between these vegetation types and the soils in the area. As nearly $170 \mathrm{~km}^{2}(40 \%)$ of the total area lies above the Zambezi escarpment, the elevation of the area has a considerable range: from about $400 \mathrm{~m}$ in the Angwa River valley to $1,120 \mathrm{~m}$ at the top of the escarpment (Lynam 1993).

\section{WILDLIFE MANAGEMENT}

\section{Campfire}

In the past, the quest for survival led the people of Kanyurira to hunt and forage collectively. It has been estimated that the annual average harvest of wildlife was more than $40 \mathrm{~kg}$ of dressed meat per person (Murindagomo 1988). Traditional hunting not only had practical connotations, but also spiritual ones. While hunting was necessary to feed families, especially during droughts or the winter when grain reserves fell, the skills of the hunter were also admired. Anecdotal evidence suggests that subsistence hunters usually belonged to a few families that had a tradition of hunting.

Traditional subsistence hunting inevitably brought the people into conflict with the government's wildlife authorities, who harassed and arrested 
suspected offenders. Rather than curtailing poaching, this high-handed approach by officials generated resentment towards the state and a greater determination by the people to rid their area of wildlife. In order to achieve this, Kanyurira residents, secretly acquired guns and snares. They also started fires in order to kill animals as well as destroy the environment upon which wildlife depended. Moreover, Kanyurira residents encouraged immigrants to settle in the area. The additional human presence, they believed, would displace wildlife from the area (Dzingirai 1996).

In 1989, the people of Kanyurira were understandably suspicious when they were invited to participate in CAMPFIRE and benefit from wildlife management. Despite scepticism from within certain groups, members of the community elected a Ward Wildlife Committee, which marked the inception of CAMPFIRE in Guruve district. In 1991 Guruve Rural District Council was vested with the right to benefit from the management of wildlife in the district when it was granted Appropriate Authority status under the Parks and Wild Life Act. Thus, while the council was the legal manager of the wildlife resource, it was obliged, under CAMPFIRE, to devolve some management authority to the Ward Wildlife Committee. This committee, elected by registered households within the community, is governed by a constitution that was adopted by the community in 1992 (see Taylor 1998, Appendix 9.3). By 1998 it consisted of eight elected representatives who were responsible for the wildlife management activities of 15 staff members, including wildlife fence minders and game guards.

With the change from subsistence to sport hunting, and the adoption of a new constitution, new local rules emerged, which have tended to supersede any traditional rules that may have governed hunting. The new wildlife management rules, which make it illegal to hunt wildlife without Appropriate Authority and a licence (quota), appear to be widely respected in the community, as there have been few reports of local hunting by Kanyurira residents (Dzomba 1997). (Anecdotal information suggests, however, that some hunting is still being carried out by certain members of the community.)

The constitution stipulates rules for the conservation and management of trees, fish and wildlife that households are obliged to follow if they wish to benefit from wildlife revenues. Those members of the community who violate rules against poaching are excluded from receiving a reward for managing wildlife. These rules are enforced by a team of game scouts employed by the Ward Wildlife Committee. Although the legal rights of community members have diminished with respect to their individual right to hunt animals for their subsistence needs, they have increased with respect to their right to benefit from their collective management of wildlife under CAMPFIRE. On balance, this benefit appears to outweigh the benefits from subsistence hunting for most households. In terms of elephants, this transfer of rights has been of undoubted benefit to all households.

As the benefits from wildlife clearly outweigh the costs, many migrants have been attracted to Kanyurira. In an effort to forestall the 'free-rider' problem, the Ward Wildlife Committee's constitution specifies that households must have lived in the study area for at least five years to qualify for revenues earned from sport hunting. At the time of the World Wide Fund for Nature 
(WWF) report (Taylor 1998), only 151 out of the 249 households met this residence requirement. Officially, therefore, only $61 \%$ of households were considered to be wildlife managers who qualified for benefits. Since dividends are paid to households, not individuals, a second requirement is that all members must be married. The constitution further excludes from membership those who are divorced, so as not to provide an incentive for households to split up in order to gain two shares instead of one.

\section{Wildlife management activities}

The main wildlife management activities include land use planning, fence maintenance, setting of hunting quotas, and the monitoring of wildlife and safari hunting. These activities are carried out by locally employed personnel on behalf of households in the community.

Land use planning is important for laying the ground rules for activities in particular areas. In Kanyurira's first land use plan, developed in 1989, the ward allocated an area of $18 \mathrm{~km}^{2}$ on the banks of the Angwa River for settlement and agricultural activities, the remainder of the ward being used for wildlife production. The plan was conceived locally and submitted to the council. The high population growth rate (23\%), however, has seen pressure build up within the fenced area, causing the depletion of soil fertility. As a result, 26 households decided to move outside the electric fence; a move that necessitated a revision of the land use plan (Dzomba 1998). The newly settled area is about $8 \mathrm{~km}^{2}$ in extent and is unlikely to substantially affect the ward's income from wildlife, as approximately $95 \%$ of the ward remains as wildlife habitat for sport hunting. Future land use in the ward will be driven both by the capacity of the ward to manage immigration and population growth and by the extent to which the productivity of the available arable land can be maintained.

The role of the game guards is to monitor safari hunting and enforce local level natural resource by-laws relating to wildlife. Game guards also monitor wildlife populations for quota setting purposes. The hunting quota represents an estimate of the number of animals that can be sustainably harvested from a particular wildlife population (Taylor 1998). Because more than $90 \%$ of wildlife revenue is earned from sport hunting, the objective of the quota is to estimate the number of animals that can be safely harvested without diminishing the sustainability of sport hunting in the future. Consequently, the quotas for sport hunting, expressed as an 'off-take' percentage, are usually well below the net growth rate of the population. The off-take of elephant, for example, is between 0.5 and $0.75 \%$ per annum, while the growth rate is about $5 \%$ per annum. Because the number of animals on the quota directly affects the income earned, quota setting has become a pivotal activity under CAMPFIRE (Taylor 2001). A participatory quota setting methodology has been developed, which allows qualitative and quantitative data inputs from all stakeholders.

Since 1996, the Kanyurira Ward game scouts, in conjunction with WWF and the Ward Wildlife Committee, have been developing a systematic, locally based ground-counting programme. Each month pairs of game scouts traverse a set of predefined transects and record the numbers seen per unit of time on patrol (elephants/effective patrol time); the numbers seen per unit of time 
on specific transects set up for the purposes of estimating wildlife numbers;and, in conjunction with the safari operator, the trophy quality. This information is analysed and stored by the scouts in the ward. Currently the information gathered is only sufficient to develop an index of abundance of wildlife populations in the ward. However, these results are used by the Ward Wildlife Committee at the annual quota setting workshop. Table 1 illustrates how, in 1998, this information was used in conjunction with other methodologies to assess the quota requested for elephant for 1999. More importantly, it highlights the need to have locally based information against which other sources of data can be triangulated, such as the aerial wildlife surveys carried out by WWF and the Department of National Parks and Wildlife. These diverse but complementary data sets are analysed in a workshop environment using a participatory quota setting methodology (WWF 1997, 2001; Taylor 1998). The recommendations from this workshop are submitted to the Department of National Parks and Wildlife for verification, which then sets hunting quotas for the council. These procedures and guidelines, as well as the steady growth in elephant numbers, have contributed to Zimbabwe's substantial share of the global market for sport hunting of elephant. The recurrent cost of monitoring activities is approximately $20 \%$ of recurrent expenditure, or $6 \%$ to $10 \%$ of total income.

The Ward Wildlife Committee is also responsible for maintaining the solarpowered electric perimeter fence. For this purpose it employs locally trained fence maintenance staff. Since adopting wildlife as a primary land use in the ward, an electric fence has been erected (with financial assistance from donor agencies) that now protects two of the three villages from wildlife. The installation of the fence has substantially decreased the incidence of human injuries as well as crop and livestock damage. As most residential and cultivated areas are confined by the wildlife fence, practically all sport hunting is carried out in the woodland area that is held in common.

Table 1. The results of the participatory quota setting exercise in Kanyurira Ward 1998

\begin{tabular}{lcccccc}
\hline & 1998 & $\begin{array}{l}\text { Ground } \\
\text { quota }\end{array}$ & $\begin{array}{l}\text { Aerial } \\
\text { count }\end{array}$ & $\begin{array}{c}\text { Trophy } \\
\text { survey }\end{array}$ & $\begin{array}{c}\text { Community } \\
\text { quality }\end{array}$ & $\begin{array}{l}\text { Requested } \\
\text { estimates }\end{array}$ \\
\hline Elephant (male) & 4 & $\uparrow$ & $\downarrow$ & $\uparrow$ & $\uparrow$ & 4 \\
Elephant (female) & 15 & $\uparrow$ & $\downarrow$ & $\mathrm{n} / \mathrm{a}$ & $\uparrow$ & 12 \\
\hline
\end{tabular}

Source: Rigava personal communication.

Key:

$\uparrow \quad$ Increasing population

$\downarrow \quad$ Decreasing population

\section{Support for wildlife management}

In 1992, representatives of government and non-governmental organisations (NGOs) formed an advisory committee, headed by the CAMPFIRE Association, 
known as the CAMPFIRE Collaborative Group. While the CAMPFIRE Association represents the interests of those rural district councils that have been granted Appropriate Authority, the other NGOs in the collaborative group offer technical support and services to councils and wildlife producer communities responsible for implementing CAMPFIRE.

There has been considerable outside support for the Guruve Rural District Council and the Kanyurira Ward Wildlife Committee under CAMPFIRE-mainly by NGOs who have relied heavily on donor assistance (Table 2). Financial support has enabled the erection of wildlife fencing, while training, technical backup, and workshops have been held under the auspices of the CAMPFIRE Association.

Table 2. Technical support and services provided by government representatives and NGOs to councils with Appropriate Authority

\begin{tabular}{|c|c|}
\hline Agency & Technical support and services \\
\hline CAMPFIRE Association & $\begin{array}{l}\text { Lead agency in the CAMPFIRE Collaborative Group; provides } \\
\text { a secretariat for members and represents them regionally, } \\
\text { nationally and internationally }\end{array}$ \\
\hline $\begin{array}{l}\text { Department of National } \\
\text { Parks and Wildlife } \\
\text { Management }\end{array}$ & $\begin{array}{l}\text { Provides an enabling framework for the national wildlife } \\
\text { industry and sets sport hunting quotas }\end{array}$ \\
\hline $\begin{array}{l}\text { Ministry of Local } \\
\text { Government, Rural and } \\
\text { Urban Development }\end{array}$ & $\begin{array}{l}\text { Supports rural district councils that have been granted } \\
\text { Appropriate Authority }\end{array}$ \\
\hline ACTION & $\begin{array}{l}\text { A local NGO that develops and provides educational and } \\
\text { training material for wildlife producer communities }\end{array}$ \\
\hline Africa Resources Trust & $\begin{array}{l}\text { Promotes the sustainable use of natural resources at a } \\
\text { domestic, regional and international level }\end{array}$ \\
\hline $\begin{array}{l}\text { Centre for Applied Social } \\
\text { Studies }\end{array}$ & $\begin{array}{l}\text { Socio-economic research on community-based natural } \\
\text { resource management }\end{array}$ \\
\hline World Wide Fund for Nature & $\begin{array}{l}\text { Ecological and economic support and training of councils } \\
\text { and wildlife producer communities }\end{array}$ \\
\hline Zimbabwe Trust & $\begin{array}{l}\text { Development of community-based organisations and } \\
\text { institutions to manage their own natural resources }\end{array}$ \\
\hline
\end{tabular}

Source: Bond 1999.

Note: The political and economic turmoil in Zimbabwe, since the study was carried out, has seen the withdrawal of international assistance and the demise of the campfire programme.

In 1992, WWF, through the Support to CAMPFIRE Project, initiated a 'participatory technology development' approach in three selected communities in the Zambezi Valley, including Kanyurira. This approach was designed to develop sustainable and rigorous methods of natural resource and project management by the communities themselves. Through the project, Kanyurira benefited from infrastructural development (fencing, workshops, etc.) as well as through intensive training and extension courses for the community. 
These contributions where supplemented by the sustained efforts of Professor Marshall Murphree and his colleagues at the Centre for Applied Social Sciences at the University of Zimbabwe, who carried out a number of studies on the local management of wildlife resources (Cutshall 1989; Nabane and Matzke 1996; Murphree 1997).

The Zimbabwe Trust provided organisational development and institutional support to the Ward Wildlife Committee through its process-oriented monitoring system and by persuading the council to devolve greater powers to the committee. In addition, various donors, most prominently the United States Agency for International Development and the Norwegian International Development Agency, have funded community facilities (grinding mill, store) and projects (ploughing, transport), while Ingwe Safaris have contributed significantly to general community welfare from providing meat and ferrying the sick to buying ploughs and supplying a diesel tank. This support, and the financial benefits that have accrued from wildlife management, has helped effect a complete change in attitude and behaviour of the people of Kanyurira towards wildlife (Dyson 1998). The political and economic turmoil in Zimbabwe, since the study was carried out, has seen the withdrawal of international assistance and the demise of the campfire programme.

\section{SPORT HUNTING OF ELEPHANT}

When CAMPFIRE was first introduced to Guruve, the council decided to involve itself directly in managing the sport hunting lease, an experiment which proved both inefficient and expensive (Jansen 1990). As a result, in 1991, the council put the hunting lease out to tender, which was won by Ingwe Safaris, an experienced private hunting safari company that subsequently had its contract extended in 1997. In 1998, Ingwe Safaris were operating with a staff contingent of 30, all men, including four professional hunters. Under the terms and conditions of the contract, the council granted Ingwe Safaris the exclusive right to hunt wildlife within a prescribed area (Guruve South and East), which includes Kanyurira.

The value of the hunting lease is based on the type, number and value of animals that may be taken in a particular area. This 'hunting quota' is set by the Department of National Parks and Wildlife based on the counting and monitoring of wildlife. Once it is satisfied that a particular number of animals, including elephant, can be hunted on a sustainable basis, the department issues the council with a hunting quota. However, in terms of the council's agreement with the safari operator, this quota is transferred to Ingwe Safaris. Finally, the safari operator, through international marketing, sells a 'hunt' to foreign clients, usually from Europe and America. Each hunt will last from one to three weeks, during which time the hunter (client) will pay to shoot a number of different animals (trophies) listed on the hunting quota. The client pays two fees, the price of the 'trophy' (the animal hunted) and the 'daily rate', or the cost of hunting, which includes transport, accommodation, professional fees, etc. While tuskless female elephants are sometimes shot, mature bull elephants are most highly prized by sport hunters.

Although elephant can be hunted throughout the year, the main hunting season stretches from May to September, when $79 \%$ of elephant are taken 
Figure 2. Total number of hunts and hunting days

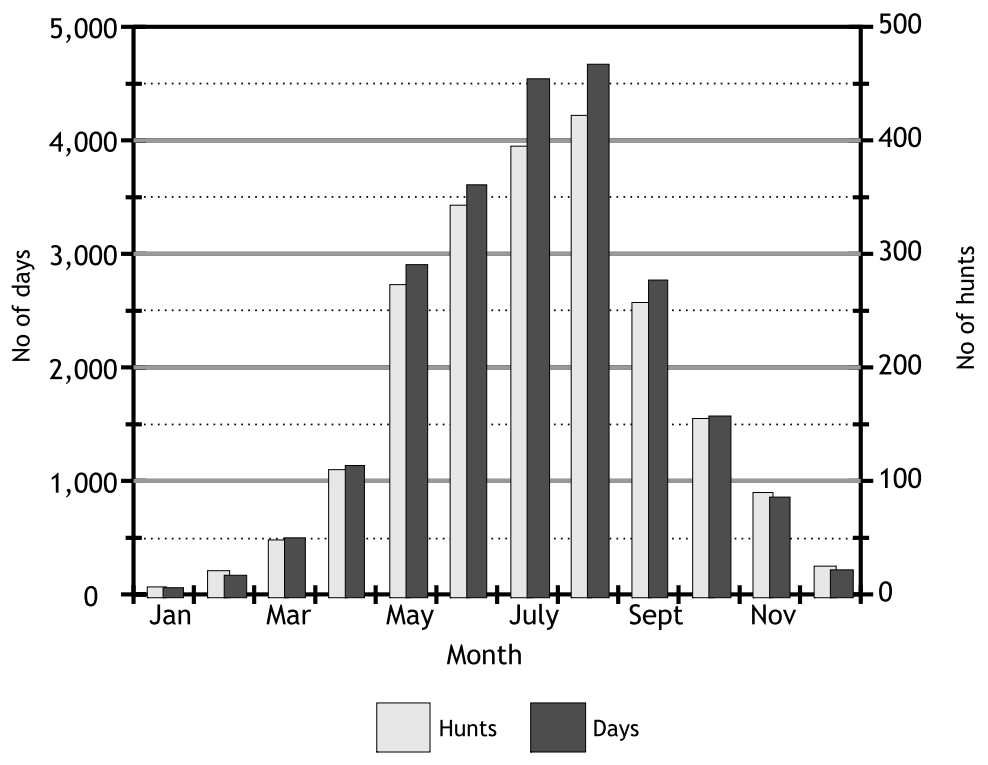

(Figure 2). Only a very small proportion (1.5\%) of the mature elephant population is harvested in any one year. This translates into $10 \%$ of the annual increment in the elephant population (Martin and Thomas 1991). The impact of sport hunting on the overall elephant population within any given area is therefore very low.

Typically, after an elephant has been shot and killed by a hunter, and the requisite photographs have been taken, the elephant's tusks (the trophy) are removed. However, clients often claim the feet and panels of the hide as well. In Kanyurira, the safari operator is obliged, under terms of his contract, to make the meat available to the community. Depending on where the elephant is shot, people are either transported to the carcass or it is butchered and the meat transported to a central distribution point. Members of the Ward Wildlife Committee or their employees ensure that the meat is equitably distributed among households.

In terms of the lease agreement the council receives $40 \%$ of the gross earnings generated from sport hunting by the safari operator. The council, in accordance with the principles of the CAMPFIRE programme, then pays the Ward Wildlife Committee a portion of the hunting revenue received from the safari operator. In Guruve, approximately $70 \%$ of the revenue that accrues to the council is disbursed annually to the producer wards. The ward in which the animal was shot receives the trophy fee for the particular animal, plus a proportion of the daily rates. The major part of the revenue that is retained by the council goes towards the management of wildlife, and a smaller portion (usually about $15 \%$ ) is retained as a management levy. Finally, it is the responsibility of the Ward Wildlife Committee to distribute the revenue equitably (as 'dividends') to all registered households within the Kanyurira 
community. These benefits come either in cash or in the form of development projects, such as a clinic or school, as a reward for managing their wildlife resource and an incentive to continue doing so. They also represent compensation for the opportunity that households forego by not using the wildlife areas for agricultural purposes (mainly cropping and grazing), and as compensation to the 'producer community' for the costs they must bear for losses they suffer to their crops and property as a result of damage by wildlife.

\section{THE MARKET}

\section{Sport hunting in Zimbabwe}

Zimbabwe has been active in the international market for sport hunting since its independence in 1980, and has seen this market expand considerably over the last 10 years. The total annual revenue earned from sport hunting rose from approximately US\$2.4 million in 1986 to over US\$20 million in 1998 (Figure 3 ). During the same period, the annual average trophy fee paid for elephant increased from US\$2,600 to US\$9,600 (Figure 4). Zimbabwe has garnered 48\% of the world market in sport hunting of elephant. Its closest competitors, Botswana and Cameroon, hold $21 \%$ and $10 \%$, respectively. By using the Convention on International Trade in Endangered Species and Wild Fauna and

Using CITES quotas for ivory as a proxy, and given the gross estimated value of an elephant of US\$16,229, the total value of the CITES quota is estimated at US\$13.6 million. (See Appendix 1 for tables of estimations of these values.) However, CITES quotas are seldom fulfilled. In Zimbabwe,

Figure 3. Sport hunting revenue (1984-1998)

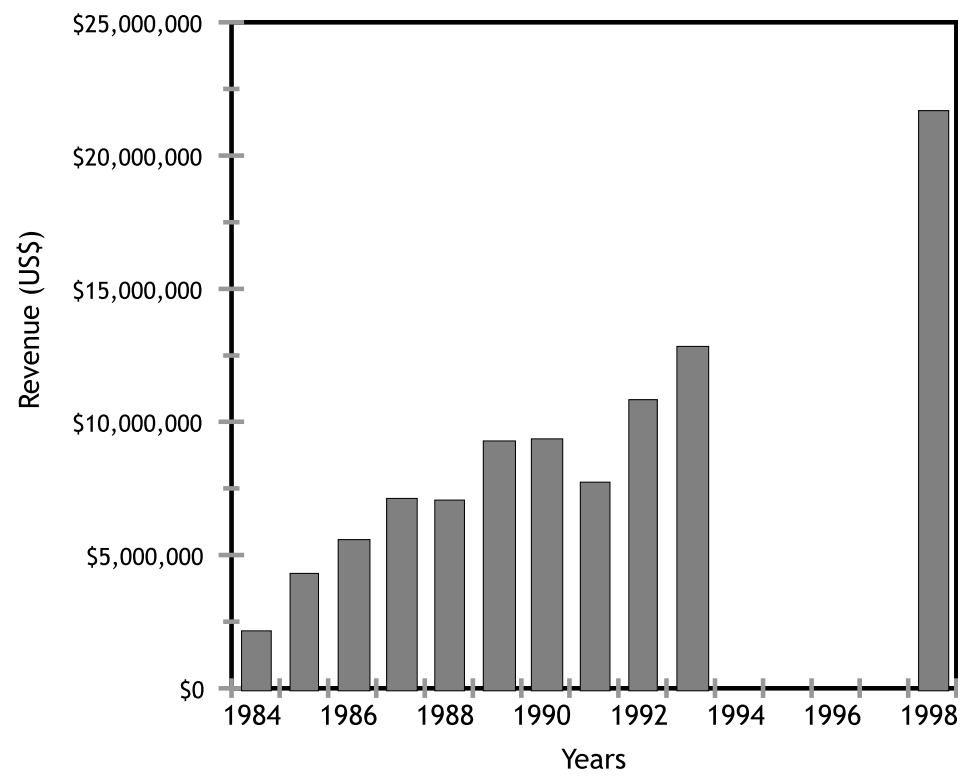


Figure 4. Trophy Fee for Elephant (1986-1998)

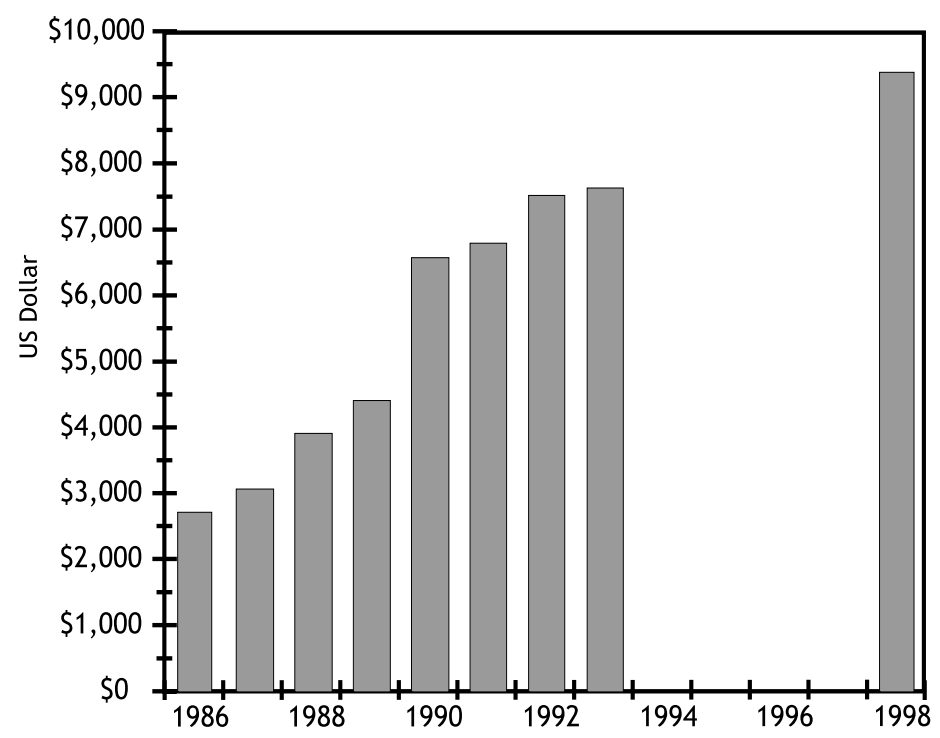

for example, only 270 elephants out of a possible 400 were taken in 1998, and Mozambique has banned elephant hunting altogether. If it is assumed that only $75 \%$ of quotas are used, a figure closer to US\$10 million would represent a more realistic estimate of the world market.

Much of this revenue growth is underpinned by the cultural understanding and marketing strategies of local white safari operators about European and American imaginings of the 'African wildlife experience' and the 'Great White Hunter', romanticised by Earnest Hemmingway and epitomised by films such as Out of Africa and Clint Eastwood's White Hunter, Black Heart. Safari operators of European descent therefore have a sociocultural advantage over their black counterparts in terms of their ability to tap into international marketing channels and compete for clients. Another constraint to entering the sport hunting market is the high capital costs of establishing a business as a safari operator, notably the need for reliable four-wheel-drive vehicles and to pay for hunting quotas.

Sport hunting is supported by the Zimbabwe Association of Tour and Safari Operators (ZATSO), the Zimbabwe Tourism Authority, and by the Department of National Parks and Wild Life. ZATSO promotes the interests of its members, such as Ingwe Safaris, by lobbying government ministers, negotiating with government, and drafting a code of conduct, rules and guidelines members are expected to follow in order to promote professionalism within the hunting subsector. On the marketing front, the association publishes an annual handbook with information on hunting and its members, and it participates in Safari Club International shows on behalf of its members.

Safari operators are required to pay a $2 \%$ tourism levy to the Zimbabwe Tourism Authority, a statutory body. The authority has supported the 
international marketing of sport hunting by sponsoring visits of hunting journalists and by its contributions towards paying for the ZATSO stand at the annual shows of Safari Club International.

The government also provides indirect support through the Ministry of Mines, Environment and Tourism. More specifically, sport hunting is one of the responsibilities of the Department of National Park and Wildlife, which played a key role in establishing CAMPFIRE during the 1980s and, later, in the down-listing of elephants at the CITES convention. This allowed limited trade in ivory and maintained the quota of elephant that could be hunted. Over the last 10 years, however, state involvement in sport hunting has steadily declined. This is partly attributable to economic reform policies and the transformation of the department into a statutory fund. It may also be due to the scarcity of government revenues and because the private sector and NGOs have become increasingly involved in sport hunting. Nonetheless, the Department of National Park and Wildlife still plays a crucial role in setting hunting quotas and controlling hunting activities.

\section{CONCLUDING REMARKS}

If Appropriate Authority had not been devolved to the council, there would not have been the rationale for maintaining a large proportion of Kanyurira as wildlife habitat. As a result of this change, the people of Kanyurira have benefited economically at the district, community and household levels. Thus, while substantial improvements can still be made to CAMPFIRE, the net effect of the policy changes has been positive.

One area that requires resolution is the struggle for proprietorship between the producer community and the council over the management of wildlife. The community's weak proprietorship over wildlife and control over the benefits derived from wildlife is reflected in the high variability in revenue paid to the ward (Bond 1999). For example, the incorporation of additional agricultural land in the Ward Wildlife Committee's 1998 land use plan was contested by the council (Taylor 1998), which then refused to pay the ward its wildlife dividend. As a result, fence minders were not paid and the wildlife fence fell into disrepair.

Other cases of this dependency and lack of proprietorship are illustrated by the selection of the safari operator and the setting of quotas. In 1997, the final selection of operators was done by the council's Finance Committee, without any representation from Kanyurira's wildlife committee. (In 1995 during a participatory evaluation of the agents of change in the ward, the incumbent safari operator was identified as the 'most important agent of change'.) In the case of quota setting, the community had decided not to increase the 1997 quota, despite evidence that elephant populations were increasing, yet the Department of National Parks and Wild Life ignored these recommendations and set the quota at higher levels.

Although these examples illustrate the underlying contradiction between the community's relatively weak proprietary rights compared to its wildlife management responsibilities, there are indications of change. The Secretary for Mines, Environment and Tourism announced in July 2000 that the devolution 
of the CAMPFIRE programme to the subdistrict level should result in communities receiving $80 \%$ of total earnings from wildlife management.

Despite this change, there is a need to recognise the limitations of what programmes such as CAMPFIRE can deliver. Given the low labour and technological intensity of managing wildlife, there is only limited scope for increased production and employment opportunities based on utilising the wildlife resource. Moreover, there is a strong demand for agricultural land in the communal areas that enables households to earn and control incomes on which their livelihoods depend. This demand for agricultural land has fostered a persistent migration into the mid-Zambezi Valley. The subsequent loss of wildlife habitat continues to cast a shadow over the future of sport hunting and those who benefit from it.

\section{ACKNOWLEDGEMENTS}

We would like to thank Brian Belcher, Manuel Ruiz-Pérez and Bruce Campbell for inviting us to participate in the Center for International Forestry Research's international comparison of cases of forest product development. We also appreciated the support provided by Ousseynou Ndoye and Irdez Azhar. Valuable comments on the earlier draft were received from Phosiso Sola, Russell Taylor, Bruce Campbell and Lillian Dimbi-Goredema. We are also grateful to Bill Bedford of Ingwe Safaris, Sally Bown of the Zimbabwe Association of Tour and Safari Operators and members of Kanyurira Ward Wildlife Committee who provided us with essential information

\section{ENDNOTES}

1. Shanduko: Centre for Agrarian and Environmental Research, 195 Fife Avenue, Harare, Zimbabwe. E-mail: daledore@zol.co.zW

2. World Wide Fund for Nature (Southern Africa Region Programme Office), Almond Tree Cottage, Long Wittenham Road, North Moreton, Nr Didcot, Oxon OX11 9AZ, United Kingdom. E-mail: leebee@atcottage.freeserve.co.uk

\section{REFERENCES}

Bond, I. 1994. The importance of sport-hunted African elephants to CAMPFIRE in Zimbabwe. Traffic 14(3): 117-119.

Bond, I. 1996. Immigration and loss of wildland in CAMPFIRE districts: an economic perspective. CAMPFIRE Newsletter 14: 7-8.

Bond, I. 1999. CAMPFIRE as a vehicle for sustainable rural development in the semi-arid communal lands of Zimbabwe: incentives for institutional change. Ph.D. Thesis, University of Zimbabwe. 289p.

Bond, I. 2001. CAMPFIRE and the incentives for institutional change. In: Hulme, D. and Murphree, M. (eds.) African wildlife \& livelihoods: the promise and performance of community conservation, 227-243. James Curry, London.

Cutshall, C.R. 1989. Masoka/Kanyurira Ward: a socio-economic baseline survey of community households. Center for Applied Social Sciences. University of Zimbabwe, Harare. 37p. 
Dyson, J. 1998. From poachers to protectors. Readers Digest, July 1998. p. 5864.

Dzingirai, V. 1996. Every man must settle where he wants: the politics of settlement in the context of CAMPFIRE. Zambezia 23(1): 19-30.

Dzomba, H. 1997. A people's history of the environment. WWF Programme Office, Harare.

Dzomba, T. 1998. Masoka problem analysis. In: Taylor R.D. (ed.) Kanyurira Ward and Guruve Rural District Council, land use planning workshop report. Mushumbi Pools. 2-4 December 1997. Harare, Zimbabwe. 50p. plus appendices.

Jansen, D.J. 1990. Sustainable wildlife utilisation in the Zambezi Valley of Zimbabwe: economic, ecological and political trade-offs. WWF MAPS Project paper No. 10. Harare. 29p.

Lynam, T.J.P. 1993. Agro-ecosystems analysis in a semi-arid small scale farming system of Zimbabwe: a systems approach. D.Phil. Thesis, Michigan State University, Michigan. 274p.

Martin, R.B. 1986. Communal Areas Management Programme for Indigenous Resources [CAMPFIRE]. Working Document No. 1, DNPWLM, Harare, Zimbabwe. 59p.

Martin, R.B. and Thomas, S. 1991. Quotas for sustainable wildlife utilisation in communal lands: a manual for district councils with appropriate authority. Zimbabwe Trust and Dept. of National Parks and Wildlife Management, Harare.

Murindagomo, F. 1988. Preliminary investigations into wildlife utilisation and landuse in Angwa, Mid-Zambezi Valley, Zimbabwe. M.Phil. Thesis, University of Zimbabwe, Harare. 232p.

Murphree, M. 1993. Communities as resource management institutions. Gatekeepers Series 36, IIED, London.

Murphree, W.M. 1997. Congruent objectives, competing interests and strategic compromise: concepts and process in the evolution of Zimbabwe's CAMPFIRE Programme. Paper presented to the Conference on Representing Communities: History and Politics of Community-Based Resource Management. Unicoi Lodge, Helen, Georgia. 50p.

Nabane, N. and Matzke, G. 1996. Outcomes of a community controlled wildlife utilisation programme in a Zambezi Valley community. Human Ecology 24(1).

Taylor, R.D. 1993. Resource survey report on Masoka/Kanyuirira. WWF Multispecies Project. Unpublished report.

Taylor, R.D. (ed.). 1998. Kanyurira Ward and Guruve Rural District Council, land use planning workshop report. Mushumbi Pools. 2-4 December 1997. Harare, Zimbabwe. 50p. plus appendices.

Taylor, R.D. 2001. Participatory natural resource management and monitoring: implications for conservation. In: Hulme, D. and Murphree, M. (eds.) African wildlife \& livelihoods: the promise and performance of community conservation, 267-279. London, James Curry.

World Wide Fund for Nature. 1997. Quota setting manual. Wildlife management series manuals. Harare, WWF (SARPO).

World Wide Fund for Nature. 2001. District quota setting toolbox. Wildlife management series manuals. Harare, WWF (SARPO). 


\section{APPENDIX 1}

Table A1. Estimation of the value of one elephant (Kanyurira)

\begin{tabular}{rccccccc}
\hline $\begin{array}{l}\text { Total } \\
\text { daily } \\
\text { rates } \\
\text { (US\$) }\end{array}$ & $\begin{array}{c}\text { Total } \\
\text { fees } \\
\text { (US\$) }\end{array}$ & $\begin{array}{c}\text { Trophy } \\
\text { fee } \\
\text { for } \\
\text { elephant }\end{array}$ & $\begin{array}{c}\text { Percent } \\
\text { of daily } \\
\text { rate -ex } \\
\text { elephant }\end{array}$ & $\begin{array}{c}\text { Actual } \\
\text { daily rate } \text { ex elephant } \\
\text { (US\$) }\end{array}$ & $\begin{array}{c}\text { Estimated } \\
\text { gross value of } \\
\text { an elephant } \\
\text { (US\$) }\end{array}$ & $\begin{array}{c}\text { Income } \\
\text { to RDC } \\
\text { (40\% of } \\
\text { gross } \\
\text { income) }\end{array}$ & $\begin{array}{c}\text { Income } \\
\text { to producer } \\
\text { ward (70\% of } \\
\text { income } \\
\text { to RDC) }\end{array}$ \\
\hline 3,598 & 12,980 & 10,500 & $81 \%$ & 2,911 & 13,411 & 5,364 & 3,755 \\
13,300 & 20,200 & 10,600 & $52 \%$ & 6,979 & 17,576 & 7,030 & 4,921 \\
14,400 & 21,000 & 10,500 & $50 \%$ & 7,200 & 17,700 & 7,080 & 4,956 \\
\hline
\end{tabular}

Table A2. Estimate of global market for the sport hunting of elephant

\begin{tabular}{lccrrr}
\hline Country & $\begin{array}{c}\text { CITES } \\
\text { quota } \\
\text { (animals) }\end{array}$ & $\begin{array}{c}\text { CITES } \\
\text { markets } \\
\text { share }\end{array}$ & $\begin{array}{c}\text { Calculated } \\
\text { average } \\
\text { value }\end{array}$ & Gross value & $\begin{array}{c}\text { Assuming } 75 \% \\
\text { of quota } \\
\text { hunted }\end{array}$ \\
\hline Botswana & 180 & $21 \%$ & 16,229 & $2,921,220$ & $2,190,915$ \\
Cameroon & 80 & $10 \%$ & 16,229 & $1,298,320$ & 973,740 \\
Mozambique & 10 & $1 \%$ & 16,229 & 162,290 & no hunting \\
Namibia & 75 & $9 \%$ & 16,229 & $1,217,175$ & 912,881 \\
South Africa & 43 & $5 \%$ & 16,229 & 697,847 & 523,385 \\
Tanzania & 50 & $6 \%$ & 16,229 & 811,450 & 608,587 \\
Zimbabwe & 400 & $48 \%$ & 16,229 & $6,491,600$ & $4,868,700$ \\
\hline & 838 & $100 \%$ & & $13,599,902$ & $10,078,209$ \\
\hline
\end{tabular}




\section{Sources used for illustrations}

Chapter 2: $\quad$ Garcinia kola, based on a photo by Paul Latham, from "Photos of Flowers and Plants from Bas-Congo" (http:// club.euronet.be/luc.pauwels/GarcKola.JPG)

Chapter 3: Prunus africana, redrawn from a botanical illustration by Margaret Stone, published in Beentje, H. (ed.) Flora of Tropical East Africa, Royal Botanic Gardens, Kew

Chapter 4: $\quad$ Harpagophytum procumbens, based on photos by Rachel Wynberg

Chapter 5: Cassipourea flanaganii, redrawn from a botanical drawing by Tony Dold

Chapter 6: Vitellaria paradoxa, redrawn from a botanical illustration by Margaret Stone, published in Beentje, H. (ed.) Flora of Tropical East Africa, Royal Botanic Gardens, Kew

Chapter 7: Garcinia kola, based on a photo by Paul Latham. Flowers and Plants from Bas-Congo (http://club.euronet.be/luc.pauwels/ GarcKola.JPG)

Chapter 8: Dacryodes edulis, drawn from a botanical specimen, Bogor Herbarium

Chapter 9: Azadirachta indica, drawn from a botanical specimen, Bogor Herbarium

Chapter 11: Afzelia quanzensis, based on photos by Piet Van Wyk, published in Van Wyk, Braam and Van Wyk, Piet (1997) Field guide to trees of southern Africa. Struik, Cape Town.

Chapter 12: $\quad$ Pterocarpus angolensis, based on photos by Piet Van Wyk. Van Wyk, Braam and Van Wyk, Piet (eds.) 1997. Field guide to trees of southern Africa. Struik, Cape Town.

Chapter 13: Acacia seyal, based on a photo by Ken Cook from Plant Creations Inc. (http://www.plantcreations.com)

Chapter 14: Hyphaene petersiana, based on photos by Phosiso Sola

Chapter 15-17: Laccosperma secundiflorum, drawn from a botanical specimen 


\section{Forest Products, Livelihoods and Conservation}

\section{Case Studies of Non-Timber Forest Product Systems}

\section{VOLUME 2 - AFRICA}

Non-timber forest products (NTFPs) provide important sources of subsistence, income and employment everywhere there are forests (and sometimes even where there are none). With new emphasis on poverty alleviation and livelihood improvement in national and international development agendas, this group of products seems to offer means to increasing welfare in an environmentally sound way. And yet, despite more than a decade of research and targeted development projects, systematic understanding of the economic behaviour of NTFPs, and their role and potential in conservation and development, remains weak.

To help fill this gap, a large group of researchers combined efforts to compare and contrast individual cases of commercial NTFP production, processing and trade from throughout Asia, Africa and Latin America. The cases represent a range of product kinds, geographic, biophysical, social, and economic conditions. As a part of the research process, the cases were described in narrative reports.

This book, along with the companion volumes, presents the full set of 61 cases from Asia (Vol. 1: 21 cases), Africa (Vol. 2: 17 cases) and Latin America (Vol. 3: 23 cases). The reports are organized to present a standard set of information to support comparative analysis, but the authors also included rich detail, idiosyncrasies and analyses of issues and opportunities in their own cases. Individually, the cases provide a wealth of interesting and useful information. Collectively, they offer an invaluable resource for researchers, development practitioners and conservation workers interested in understanding the links between commercialisation, livelihoods and forest conservation.
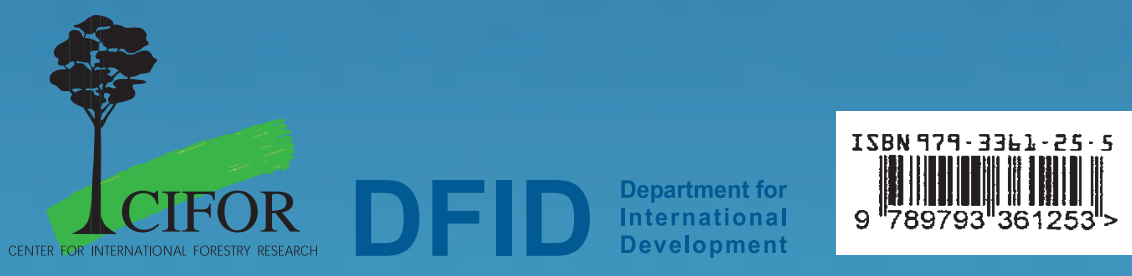